


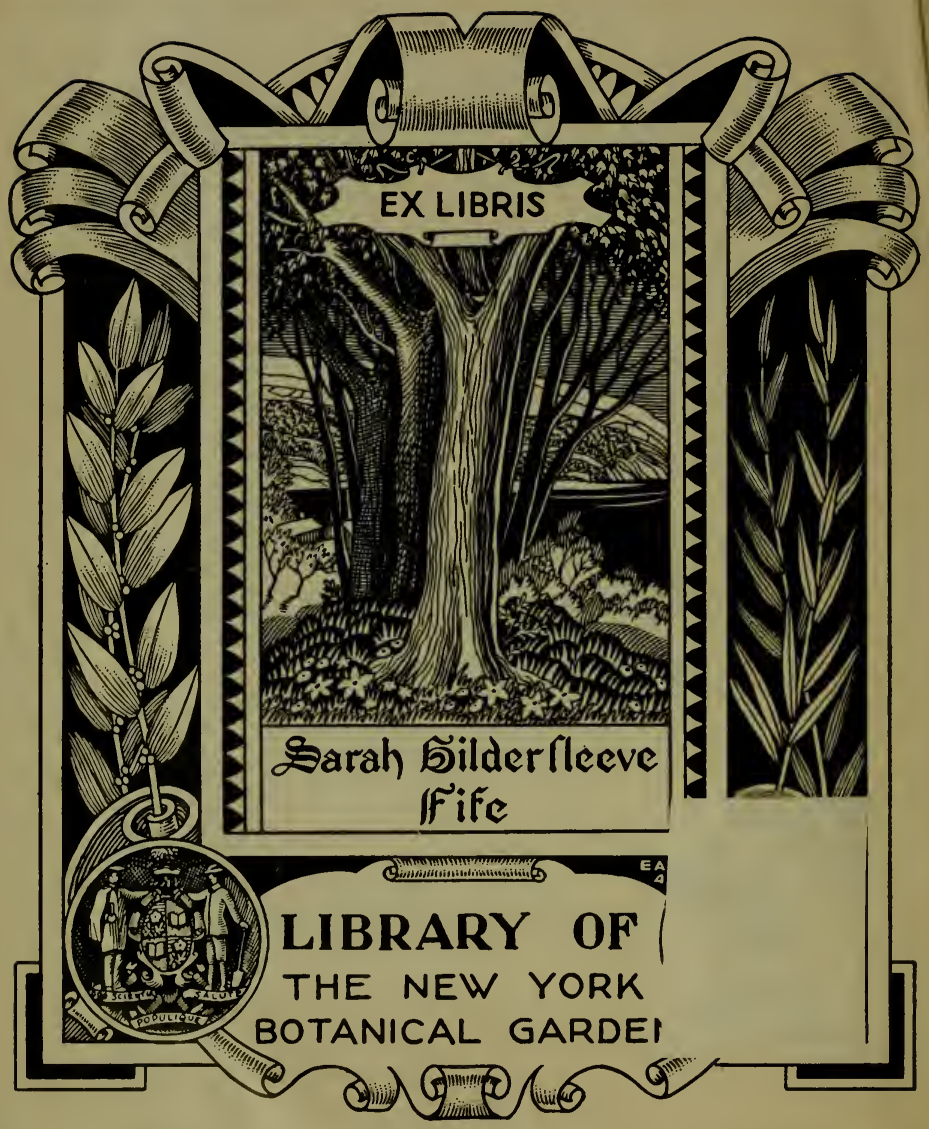


With reyaets

Buth Stouniace

Auguct 29.1931 



\section{PLANTS AND THEIR WAYS IN SOUTH AFRICA}


THE

SOUTH AFRICAN SCIENCE SERIES.

Planned by Dr. Murr, Superintendent

General of Education, Cape Province.

SOUTH AFRICAN FLOWERING PLANTS. For the use of Beginners, Students, and Teachers. By the Rev. Professor G. Henslow, M.A., F.L.S., F.G.S. With II2 Illustrations. Crown 8vo, $5 \mathrm{~s}$.

PLANTS AND THEIR WAYS IN SOUTH AFRICA. By Bertha Stoneman, Huguenot College, Wellington, South Africa. With 354 Illustrations, Diagrams, and Map. New Edition, revised and enlarged. Crown $8 \mathrm{vo}, 5 \mathrm{~s}$.

ELEM EN TARY BOTANY. By H. EDMonus. Adapted for South Africa. By Dr. MARLOTH and J. Bretland Farmer, D.Sc., F.R.S., Professor of Botany in the Royal College of Science, London. With 282 Illustrations. Crown 8vo, 4s. $6 \mathrm{~d}$.

AN INTRODUCTION TO THE GEOLOGY OF CAPE COLONY. By A. W. ROgERs, D.Sc., F.G.S., and A. L. DU TorT, B.A., F.G.S., of the Geological Survey of Cape Province. With a Chapter on the Fossil Reptiles of the Karoo Formation by R. BRоom, M.D., B.Sc., C.M.Z.S., of Victoria College, Stellenbosch. With Illustrations and Coloured Map. Crown 8vo, 9s. net.

PHYSICS FOR SOUTH AFRICAN SCHOOLS. To cover sections $A, B$, and $C$ of the Syllabus in Elementary Physical Science for the Matriculation Examination of the University of the Cape of Good Hope. By Geo. W. Cook, B.Sc., Principal of the Government School, Kronstad. Crown 8vo, 3s. 6 d.

LONGMANS, GREEN AND CO., London, New York, Bombay, Calcutta, and Madras. 


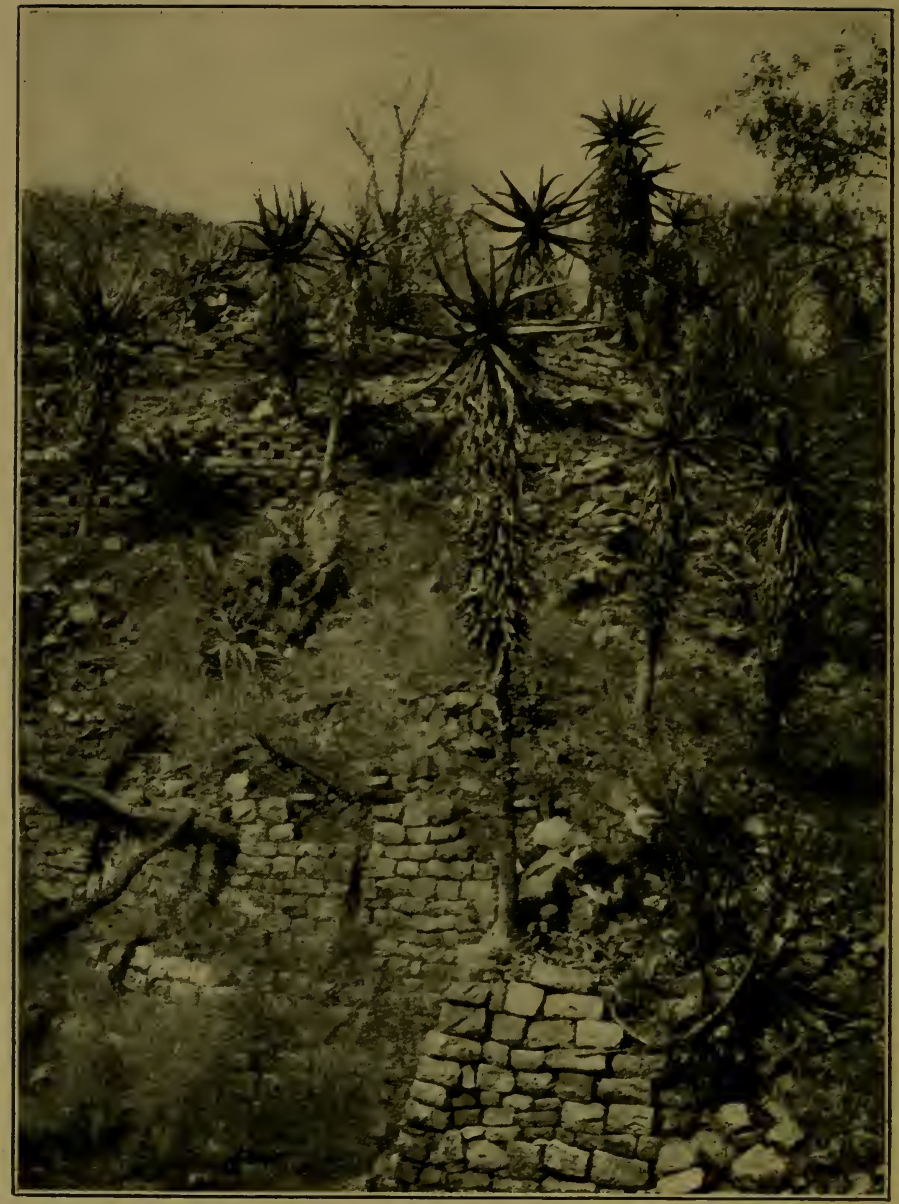

ALOES ON KHAMI RUINS

(Twelve miles from Buluwayo).

Photograf h by the courtesy of F. D. Cartwright, Esq., M.L.A. 


\title{
PLANTS
}

\section{AND THEIR WAYS}

IN SOUTH AFRICA

BY

BERTHA STONEMAN, D.Sc.

FELLOW OF CORNELL UNIVERSITY,

PROFESSOR OF BOTANY, HUGUENOT COLLEGE, WELLINGTON, SOUTH AFRICA

WITH NUMEROUS ILLUSTRATIONS

NEW EDITION, REVISED AND ENLARGED

\author{
LIBRARY \\ NEW YORK \\ BOTANICAL \\ GARDEN
}

LONGMA NS, GREEN AND CO.

39 PATERNOSTER ROW, LONDON

FOURTH AVENUE \& 30TH STREET, NEW YORK

BOMBAY, CALCUTTA, AND MADRAS

I9' 5 


$$
\begin{aligned}
& \text { QK } 403 \\
& .575 \\
& 1915
\end{aligned}
$$




\section{PREFACE TO SECOND EDITION.}

For several reasons it has seemed desirable to extend the first edition of this book into a second, and in doing so additions have been made, in some cases with considerable reluctance. Not that the first edition was by any means regarded as complete. The book was first written with a view of attracting young eyes to objects of interest in the plant world that could be enjoyed without the use of a compound microscope. In a measure the object was attained, at least sufficiently to show that a microscope was by no means indispensable for students beginning to observe plant life. When contemplating revision, suggestions were asked of young teachers, and some of them seemed to find the lack of a lesson on internal anatomy one of the disadvantages of the former edition. In order to meet their needs a short lesson on this subject has been added, together with a more extended synopsis of the Natural Orders of South African plants. While these additions appear somewhat as excrescences to the more elementary chapters of the book, the hope is entertained that their usefulness to those for whom they have been written will justify their insertion.

It is a pleasure to acknowledge gratefully my indebtedness to those who have aided me in the work of revision. Miss Alette Hugo and Miss Avrylle Bottomley have given valued assistance in pen-and-ink drawings. Miss Pegler, F.L.S., and 
E. J. Steer, Esq., have afforded me the use of photographs which are acknowledged in the text. Miss Ethel M. Doidge, to whose assistance as a student I was formerly indebted, and whose admirable research along botanical lines has led to a Doctorate in Science, has kindly looked over the proofs. The subject-matter has also undergone the kindly but no less searching glance of Dr. F. C. Kolbe, whose trenchant criticisms, tempered with keen interest and rendered with genial humour, have, for many years, been an incentive to me in my work.

Whatever of living interest is scattered among the pages is largely due to walks and talks with a keen and loving observer of Nature, J. J. van der Merwe, Esq., of Waterval, Wellington.

My Publishers, Messrs. Longmans, Green \& Co., have extended unfailing assistance and courtesy.

BERTHA STONEMAN.

\author{
Huguenot College, \\ Wellington, South Africa, \\ April, rgr5.
}




\section{N T R O D U C T I O N}

VITH the introduction of microscopes into the secondary schools, the early superficial study of plant "analysis," which aimed at finding the names of plants, gave place to a study of minute anatomy and the lower forms of plant life. The microscopical method is of undoubted educational value, but the student, who confines his attention too exclusively to minute structures and forms of plant-life, is in danger of losing that living interest which a wider outlook into the science alone can afford.

There is yet a third method which considers plants as living things, and the study of their life relations becomes the new standpoint from which they are approached. The influence of light, air, and moisture on the form and position of stems and leaves, and how the conditions of soil affect the development and distribution of plants, are questions not only of interest in themselves, but likely to stimulate the reasoning powers of even young children; and children are most interested when they can be led to think for themselves.

This book has been written with a view to suggesting how some of these conditions are met by plants in South Africa. Some of the chapters as, e.g., IV, VII, and XVIII, are intended as reading lessons. The object of others is to furnish outlines for the study of plant forms, while there is little except, possibly, the names of the parts of the flower in Chapter XIV, which should be committed to memory. 
Plants can be brought to the schoolroom and studied in window-boxes. It is not enough to see the plants through the stage of germination merely; they should be watched until their life story has been told.

With the generous aid of the Education Department, it is possible to add each year some simple, well-constructed apparatus as a means of increasing interest in the work. It is poor economy to use implements so crude as to give inexact and unsatisfactory results, when, for a slight outlay, the correctness and consequent value of an experiment may be insured. Glass jars, flasks with rubber stoppers, retort stands, porous flower-pots of various sizes, wire, thread, scissors, cork-borers, glass and rubber tubing, U-tubes, glass funnels, and thermometers are indispensable.

Valuable suggestions may be obtained from Prof. Atkinson's "First Studies of Plant Life," from the "Elementary Textbook," by Prof. L. H. Bailey, and the accompanying Lessons, the Plant Physiologies of Darwin and Acton, MacDougal, Ganong, and Cavers. "The Teaching Botanist," by Ganong, Miss Johnson's "Text-Book of Botany," and "Plant Geography," by Schimper, are excellent books. "Flowering Plants and Ferns," by J. C. Willis, of the Cambridge Biological Series, is a valuable guide in the study of morphology, geographical and economic botany. To this list may be added Maud Going's charmingly written books, "With the Trees" and "With the Wild Flowers".

My thanks are due to the generous advice and assistance rendered by Dr. Marloth, Dr. MacOwan, Dr. Bolus, and the Rev. Dr. Kolbe.

It is also a pleasure to express nyy deep indebtedness to my present and former students who have kindly assisted me in illustrating the book, in particular to Miss Lucette Creux 
and Miss Hannah Albertyn for the illustrations furnished by them, and to Miss Ethel M. Doidge for those bearing her initials, to Miss A. V. Duthie for numerous drawings, and chiefly to the untiring interest of Mrs. G. A. Bottomley, to whom the greater number of the original pen-and-ink drawings are due.

The author is indebted to the publishers (Messrs. Longmans, Green, and Co.) for the privilege of using from Edmonds and Marloth's "Elementary Botany of South Africa," Rev. Prof. Henslow's "South African Flowering Plants," Thomé and Bennett's "Structural and Physiological Botany," and Farmer's "Practical Introduction to the Study of Plants," the illustrations acknowledged in the text.

This work is the second of "The South African Science Series," the first being Mr. Rogers' "The Geology of Cape Colony," designed by Dr. Muir to promote the study of natural science in South Africa.

Huguenot College, Wellington, South Africa, February, I9o6. 


\section{ON T E N T S}

CHAPTER

1. Plant Life

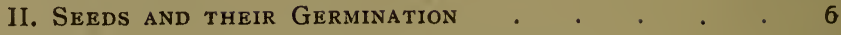

III. Growth of Roots, Stems, and Leaves • • • I8

IV. Further Growth and Duration of Plants • • • 25

V. Growth of Buds and Branches . • . . . 36

VI. A Study of Leaves . • . • . • . • . 45

VII. Waterways in Plants . . . . . . . 57

ViII. Cells and Tissues . . . . . . . . . 63

IX. Stem and Root Structure • • • • • . 7

X. The Respiration of Plants . . . . . . . 83

XI. A Short Lesson on SoIL . . . . . . . 88

XII. The Food Making of Plants . • • • • • . 92

XIII. Dependent Plants . . . . . . . . . 98

XIV. Plant Defences . • . • • . . . . 103

XV. New Plants without Seed . • . . . . . . I

XVi. Climbing Plants and Plant Migrations . . . 124

XVII. Flowers aNd THEIR PARTS . . . . . . I3I

XVIII. Pollination and Fertilization . . . . . 153

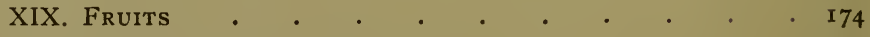

XX. The Seed's Travelling Outfit . . . . . . L 85

XXI. KuKUMakranka . . . . . . . • • IgI

XXII. Classification of Plants . • . . . . . 194

XXIII. The Botanical Regions of South Africa . • . 374

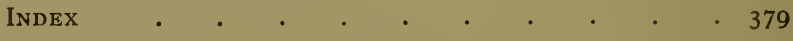




\section{PLANTS AND THEIR WAYS IN SOUTH AFRICA.}

\section{CHAPTER I.}

\section{PLANT LIFE.}

WHO has not watched and enjoyed growing things? The baby is carefully weighed and measured ; the kitten, the garden, and the flowers of the veld in turn absorb our attention.

Growth means life; and every living thing has something of interest to tell if our eyes have been trained to see and we have learned to think about what we see.

In studying plants we find great differences in the plant kingdom, and how as living things they can change their form and habits of growth so as to fit themselves to widely differing conditions of life, for plants cannot choose where they would grow. In doing so, the members of one plant family come to look so unlike one another that it becomes difficult to detect any family resemblance; while members of different families look enough alike sometimes " to be brothers and sisters," for plants that have come from the same parents in past years are grouped together in a family or order. We are surprised to find that dodder, which fastens its threads upon lucerne and chokes it and robs it of its food, belongs to the highly respectable family of the sweet potato.

When lavish Nature sows her seed, some, it is true, "falls upon stony places and withers away," but some lays hold of the rccks and changes them into soil, so that one dainty pink-andwhite Crassula which grows on our hillsides rejoices in the name Saxifraga, the rock-breaker.

It would be difficult to say where plants are not found; on the heights of the Drakensbẹrg, and even higher ranges, flowers 
blossom and die, where none but their Maker beholds their beauty. Plants are found, beautifully white and delicate, deep down in the darkest mines. They are able to withstand the heat of boiling springs, and explorers from the frozen Antarctic return with mosses and lichens. Germs of plants kept in liquid air for six months at a temperature of- $190^{\circ} \mathrm{C}$. have suffered no injury, while others have remained for ten hours in a bath of liquid hydrogen, $60^{\circ}$ colder still, and have then come forth and flourished. ${ }^{1} \quad$ Plants are quite at home on cheese and

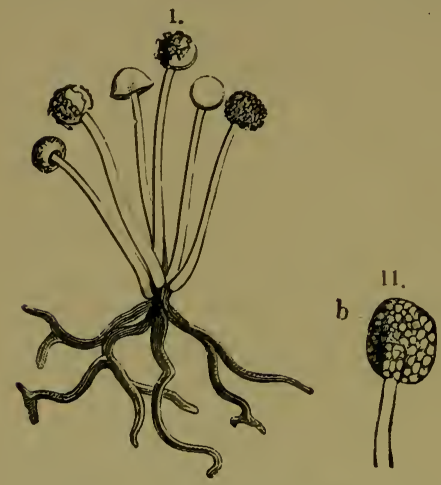

FIG. I.-Common mould (1/ucor mucedo): I. An entire plant with six sporangia in different stages of development (strongly magnified). II. Single sporangium with spores $b(x$ 200). (From Thomé and Bennett's "Structural and Physiological Botany".) canned fruit, and an old shoe cast upon a rubbish-heap may boast its botanic garden. These are the moulds, and against them the housekeeper is waging constant warfare.

Some plants are so small that the sharpest eyes cannot see them without powerful microscopes. Of these, some grow in the human body better than anywhere else. We call them germs. Several kinds grow on the teeth and cause their decay, unless the teeth are carefully brushed. One kind, which passes part of its life in impure milk or water, lodges in the throat and causes diphtheria ; and another produces enteric fever, so that eternal vigilance is the price of health.

1 To liquefy air requires intense cold. The temperature at which a gas liquefies is called its critical temperature. Hydrogen requires the lowest temperature of any gas yet liquefied. The particular pressure under which a gas liquefies when reduced to its critical temperature is known as its critical pressure. Thus, hydrogen gas liquefies at $-238^{\circ} \mathrm{C}$. (the critical temperature) under a pressure of $x_{5} 3$ atmospheres. The critical pressure of oxygen is $5^{8}$ atmospheres at a critical temperature of - Ir $8.8^{\circ}$. At temperatures below the critical temperature a gas liquefies under less pressure. 
Others of these minute plants are as useful as some are harmful. When the housekeeper is mixing "sponge" for bread, she is putting in as she stirs germs known as yeast plants which abound in the air. If the sponge is set in a warm place,

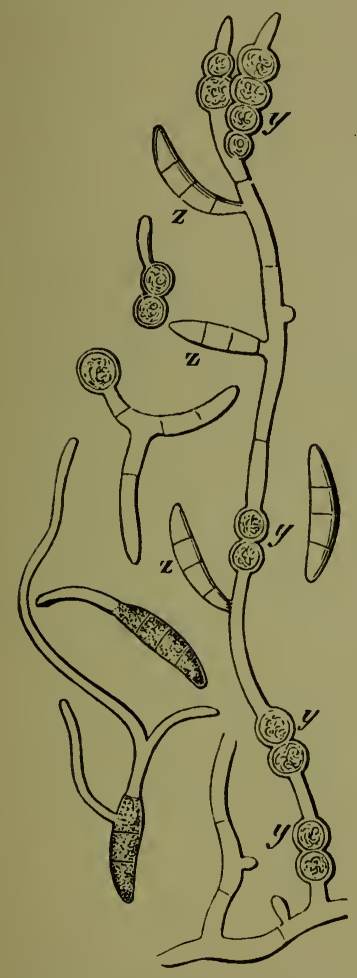

FIG. 2.-Fungus-filaments from a rotten potato. (From Thomé and Bennett's "Structural and Physiological Botany ".) the moisture causes them to grow rapidly. The growth changes a part of the starch of the flour into alcohol and carbonic acid gas, which, rising in bubbles, makes the bread light. A sudden chill prevents their growth, and the bread is heavy. Some germs are necessary to cause milk to become sour.

Flies should be kept from dwelling-houses and their breeding places destroyed, for it has been found that they spread disease by the germs they carry on their feet. Sometimes a germ attacks a fly. It grows and multiplies rapidly, and before the day is over it completely fills the fly and sends out little sticky threads, which fasten it to the wall or window. You may often see them in wet weather.

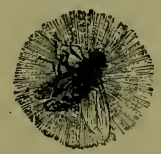

FIG. 3.-Fly killed by mould. (From 'Thomé and Bennett's "Structural and Physiological Botany".)

Upon these threads little bodies-spores-are borne, which blow about and attack other flies. Some serve locusts and grasshoppers in a similar manner. It would be a good way of getting rid of these plagues were it not that, for these spores 
to multiply rapidly, moisture is necessary, and the locusts are not particular to time their visits to our gardens during the wet seasons.

Lichens grow on rocks and trees where they lend splashes

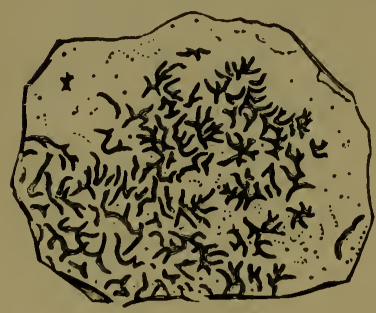

FIG. 4.-Graphis elegans, a pictorial lichen (natural size). (From Thomé and Bennett's "Structural and Physiological Botany".) of colour in many shades of red and brown, grey and green. They, too, have their place in the plant-world, and do their share of the world's work. They can thrive in barren spots where no flowers can beautify. Small as they are, they can dissolve and absorb small portions of the rocks on which they dwell. Gradually these plants crumble to dust, which may be used to nourish some less humble plant.

Mushrooms "that spring up in a night" bear their fruit and die. Contrasted with these small short-lived plants are those that grow to immense size and live through generations. We owe the oaks and the fir trees that beautify the western part of Cape Province to the first European settlers, to whose unselfish foresight they stand as lasting monuments. The historical oak of French Hoek has blossomed and shed its fruit for two hundred years, but no date in history records the planting of the famous "Wonderboom" of Pretoria. Where the spreading branches have taken root, new trunks have grown up until the single tree has become a small forest.

The life histories of the moulds, yeasts, and disease germs have been learned only in recent years, since microscopes have been improved; but the old Hebrew poets, who watched the paths of the stars as they tended their flocks, studied the trees and flowers; and we know our Saviour cared for them, for $\mathrm{He}$ often spoke of them in teaching His beautiful lessons. We, too, may study them without books and without knowing their long Latin names, though these have their uses. How unfortunate it would be if Johannesburg or Springbokfontein had no names when we wished to book our luggage for those places. The 
long names of plants are not so formidable either, when stripped of their Latin endings. Thus, MacOrwaniana pays tribute to one of South Africa's esteemed botanists, Dr. MacOwan; and how better could our world-wide authority on orchids be honoured than by naming a new Disperis, Bolusiana? The paired leaf of Bauhinia reminds us of the twins, Bauhin, who long ago devoted themselves to Botany. When we have

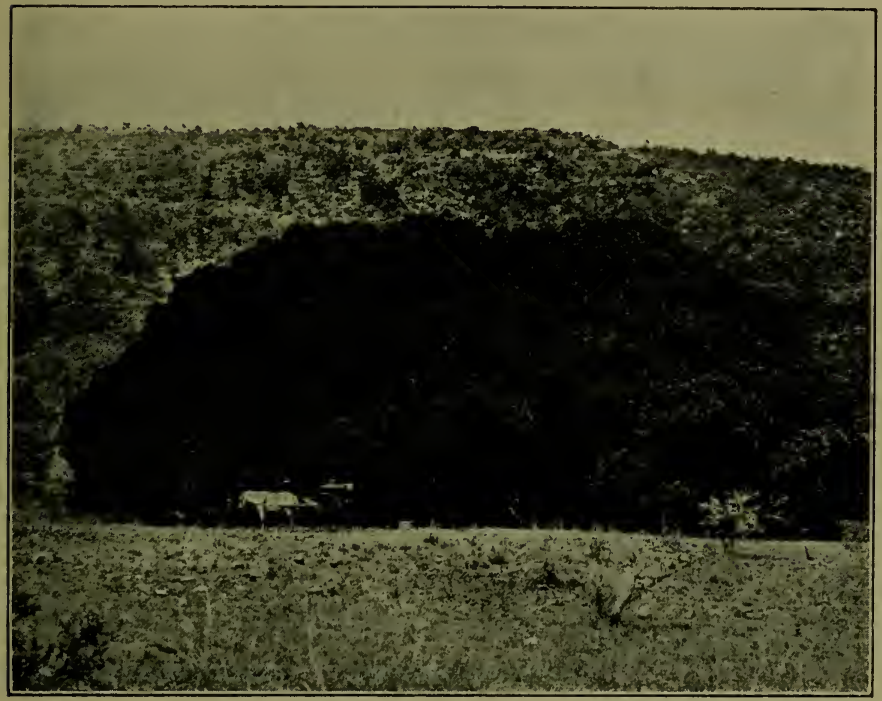

Fig. 5. - "Wonderboom " near Pretoria.

found the two forms of fruit on one head of flowers, Dimorphotheca (two-formed capsule) seems a most appropriate name, and once having seen the little crown of pappus hidden among the long hairs of the ovary, we shall never forget Cryptostemma, which means " hidden crown". If you have not studied Latin or Greek, ask help from your brothers and sisters who are in college. To speak of plants and their parts, we must have names, and the reader may skip any name in this book longer than Hermanuspetrusfontein. 


\section{CHAPTER II.}

\section{SEEDS AND THEIR GERMINATION.}

BESIDES maintaining its own life, a plant's activity is directed toward reproducing its like in the lives of others. One of the most usual means of reproduction with which we are familiar is the seed. Seeds may be very small, like those of orchids, heaths, or Streptocarpus ; or large, like the acorn and coco-nut. In each seed there is a tiny plant. Before the parent plant sends her offspring out into the world to fend for itself, the seeds are well provided with a nicely fitting coat and a generous supply of food, which serves them until they are able to make their own. The pine seed is provided with one thick hard coat, the sunflower with a very thin papery one, but many seeds have two, which fit so closely that when the seeds shed their coats the two come off together.

When seeds are soaked in water, the coats begin to swell. In the bean they become wrinkled. As the water soaks in farther the rest of the seed swells and fills the coat until it bursts, and the embryo begins to make its way out. The seed is said to germinate. This shows that the seed which was so hard and dry is alive. It was alive all the time, but did not grow.

What made it begin to show life?

One of the simplest seeds to understand is the bean. It is an old and useful friend. In order to make out the different parts of seeds, it is well to compare them with some which have just begun germinating, for then the parts separate more easily. For this purpose seeds may be put into a box of clean sand. A biscuit-tin is good, but care should be taken first to make holes in the bottom to insure drainage. 
Plant broad and narrow beans, Indian corn, water-melon, or pumpkin seeds, and any others which you may have gathered.

As soon as the bean plant begins to make its appearance above the soil, an examination will reveal two thick leaves placed opposite to one another. Between them there is a small leaf-bud with one leaf folded within another. They are attached to the stem, which extends below the first pair of fleshy leaves and joins the root. It may be difficult to say where the stem ends and the root begins. Now compare a seed which has been soaked in water a few hours. Before removing the seed-coat notice the scar or hilum where the bean was attached to the pod.

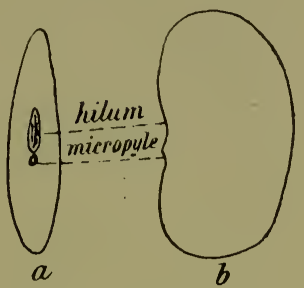

FIG. 6.-Bean seed before removing the coat.

At one end of the hilum is a small hole, the micropyle. The seed-coat comes off easily and the seed splits into two parts, which you will see correspond to the two fleshy leaves. They are called cotyledons. Between these two halves there

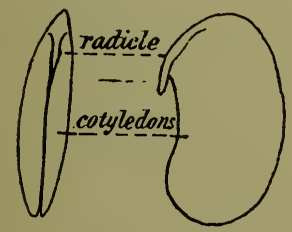

FIG. 7.-Bean seed with coat removed.

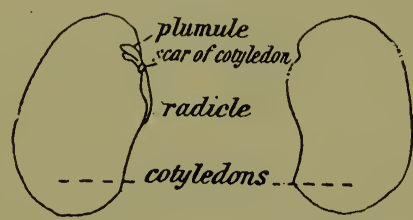

FiG. 8.-Bean seed with one cotyledon removed.

lies a small curved body, at one end of which may be seen the two small leaves the plumule. The other end, which will make the root, is called the radicle. So a seed contains a whole plant, very small and compact, which will germinate when warmth, moisture, and oxygen from the air are supplied. ${ }^{1}$ The small plant folded away in the seed is called the embryo.

${ }^{1}$ Seeds of some South African plants require light in addition to these three conditions, although light is usually unnecessary. 
Instructions for Work. - Make a drawing of the outside

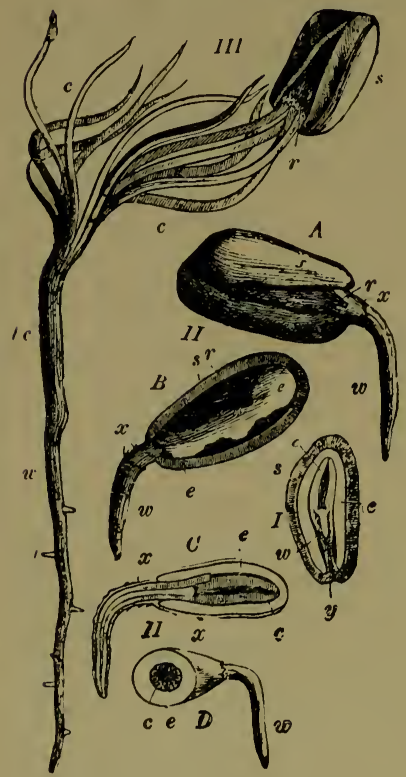

FIG. 9.- - Seeds of Pinus pinea in different stages of germination. I. Ripe seed in longitudinal section : $s$, testa ; $e$, endosperm ; $w$, radicle of embryo; $c$, the cotyledons; $y$, the micropyle end of seed, with the rootlet directed towards it. II. Germination commencing : $A$, Testa ; $s$, ruptured, and rootlet ; $w$, protruding ; $r$, red membrane inside testa ; $x$, ruptured embryo sac: $B$, portion of testa removed; $e$, endosperm : $C$, longitudinal section; $c$, cotyledons: $D$, transverse section. III. Germination complete, the cotyledons, $c$, unfolding, and the hypocotyledonary part of stem, $h c$, elongated, the main root, $w$, developing lateral rootlets, $w$ '. (From Edmonds and Marloth's "Elementary Botany for South Africa ".)

smaller end of the seed. of a bean seed. Carefully look to see how the parts are placed within. At which end of the seed is the plumule with reference to the micropyle? On which side of the seed? Compare the arrangement of the French bean with that of the broad bean. Make drawings of all that you see. Keep these drawings in a book which you will use for plants, or better on separate sheets.

A loquat seed will separate into two parts, the cotyledons ; but the plumule and radicle cannot be so plainly seen.

Now make out the parts in the seeds of a pumpkin, watermelon, or calabash seed.

In all these seeds all the food which the mother plant provided is stored within the two plump cotyledons. But there are seeds in which the food is stored outside the embryo. The pine seed shows this nicely. Remove the thick, hard seed-coat and cut the contents across. A ring containing food will be seen, the endosperm, surrounding a central part. If another is cut lengthwise, this central part will be recognized as the embryo, with the radicle pointing to the Instead of two cotyledons, several 
will be found. The plumule is too small to be seen without a lens.

When drawing a pine seed, draw the seed-coat around the endosperm. A thin papery layer will be found between the two. It once contained food. Draw it by a light line inside the seed-coat.

In the Hottentot fig or T'gaukum (Mesembrianthemum) the embryo is curved around the endosperm.

Examine some seeds of "mealies" or Indian corn ( $\mathrm{Zea}$
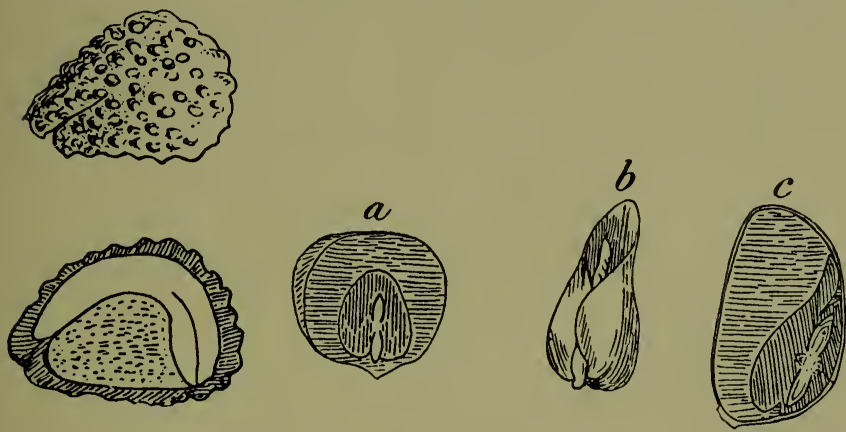

FIG. ro.-Seed of Mes- FIG. Ir.-Seed of Zea mays. $a$, embryo at one side embrianthemum with curved embryo. of endosperm; $b$, embryo removed; $c$, secd cut through, showing plumule, radicle, and side roots.

mays). Notice a small raised place on one side toward the smaller end. By soaking the seed and removing the coat this little body may be removed. It is the embryo. The greater part of the seed is filled with endosperm. The embryo has but one cotyledon, which lies close to the endosperm on one side, and on the other is joined to the plumule and radicle. They are so covered by the folded cotyledon or scutellum that only the tips can be seen.

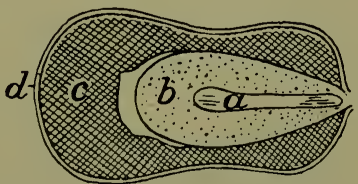

FIG. 12.-Hamanthus seed. $a$, embryo; $b$, endosperm ; $c$, food outside the endosperm partly used ; $d$, seed-coat.

The large seeds of the "April Fool" (Hamanthus) have but one cotyledon. The embryo is a small rod-shaped body lying in the centre of the endosperm. Around the endosperm 
there is another food storing region (perisperm). It can be seen plainly in young seeds, and its position will remind you of the thin layer in the pine seed. ${ }^{1}$

Examine a date and compare the seed with that of Hamanthus.

"Water Uintjes" (Aponogeton) has one large green coty-

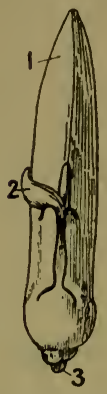
ledon, a thin plumule, and a very small radicle. Its food is all stored in the cotyledon.

Plants which have two cotyledons are called Dicotyledons, those with only one are Monocotyledons. It is an important distinction. Most monocotyledons have endosperm. "Water Uintjes" (Aponogeton) is an exception. The plants in each group have other characters in common which we shall find out later.

In Hamanthus and date the embryos are so very small that the food supply seems unneces-

FIG. I3.-Seed of "Water Uintjes " $(A p$. onogeton). $\mathbf{x}$, large fleshy cotyledon ; 2 , plum ule; 3 , small radicle. sarily generous; but it takes a long while for the date to get a firm footing in the soil, and the "April Fool" is always liable to be overtaken by drought. Nature provides for her children generously, and we all know, when it comes to a question of food, it is better to have too much than not enough.

By this time we have' examined enough seeds to find evidence of provision for the future of the little plants, and as we follow their histories we shall find other conditions admirably fitting them for their struggle in life.

How Seedlings Behave when they Wake Up.

Zea Mays comes up Head Foremost.-You may mistake the little pointed object for a stem, but in a few days you

${ }^{1}$ Perisperm is usually consumed as the seed develops. Strelitzia and Mesembrianthemum may be mentioned as seeds in which it persists in the ripened seeds. In the pine, only a small part of the thin layer inside the seed-coat is perisperm, the remainder is the inner part of the testa which splits away in the ripe seed. 
will find it to be a hollow, pointed body ${ }^{1}$ containing another leaf rolled up within it. This pointed roll easily pushes up through the soil. After it is safely up, watch the outer leaf split open and the next leaf unroll.

The calabash seed has by this time backed out of bed. Here the stem grows faster than the leaves. It makes a loop above ground, and as it gradually lengthens it pulls out the leaves. A little thought will show that this is the better way for the calabash or pumpkin, as the leaves are not rolled, and would have hard work to push up through the soil.

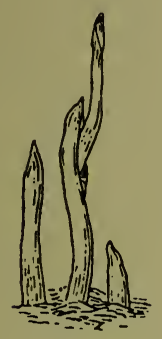

FIG. I4.-Zea mays (Indian corn).

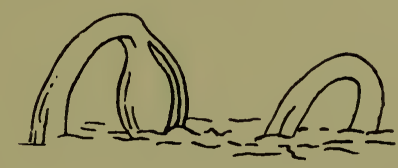

FIG. I5.-The calabash backs out of bed.

Now pull up some of the pumpkin seeds to see what has been happening below. The point at the lower end of the cotyledons has grown out to form a small root. The seed-coat has split open, and there is a little peg where the root is coming out. Plants a day or two older will show that the arching stem is splitting the seed-coat, and that the peg is holding the lower edge firmly in the soil. How did the peg come to be just there? What if the seed had been planted with the other side down?

Let us find out by planting more, taking pains this time to plant them flat. The pointed end, toward which the radicle always points, is a little one-sided. The point is not quite in the centre, and the micropyle is beside it. We can place the seeds in one row with the point at the right, and those in

${ }^{1}$ This pointed sheath is regarded as part of the cotyledon. 
another row with the point at the left. Plant some pointing downward. Remove the seed-coats from others and plant in the same positions. Does the peg form in the same way? Port Jackson seedlings and the Silver Tree have a peg all around the stem. Sometimes the stem below the peg grows too rapidly, or the seed-coat is not held firmly enough by the soil. Then
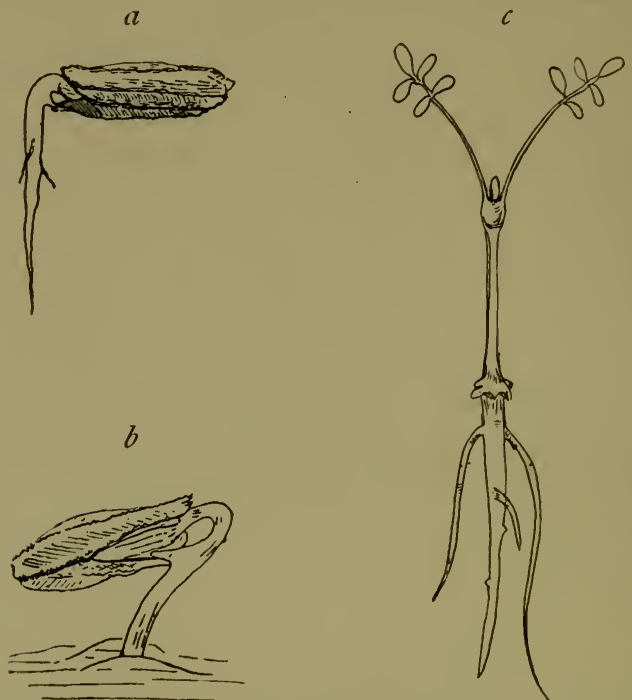

FIG. $16 .-a, b$, the peg is spreading open the seed-coats; $c$, the black wattle seedling has a "peg" quite around the stem.

the peg fails to hold the seed-coat in place and the plant has to get out as best it can. Do such seedlings look as thrifty as others? In Fig. I 7 the peg has done its work, and the coat has been left underground.

The cotyledon (or scutellum) of the mealie has not made its appearance. It remains down where the supply of food was stored, which it has been absorbing and passing on to the plumule and radicle. By the time these parts are green and able to make their own food the seed will feel quite soft. Cut a seed through the centre so as to divide the embryo into right and left halves. By looking at the cotyledon with 
a lens small channels can be seen through which the food passes to the growing parts. The radicle was protected in the

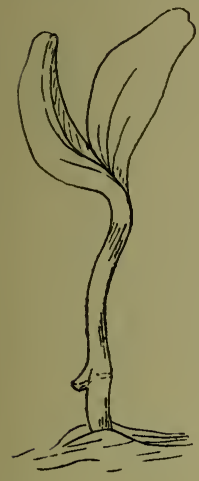

FIG. 17. - Cala. bash. The peg has done its work for the little calabash plant.

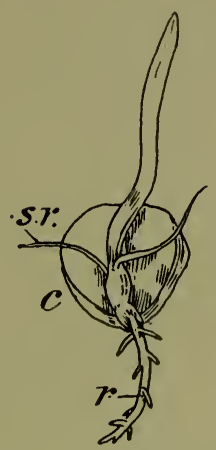

FIG. 18.-Germinating embryo of Zea mays. $c$, cotyledon; $r$, radicle; $s r$, first side shoots growing from stem.
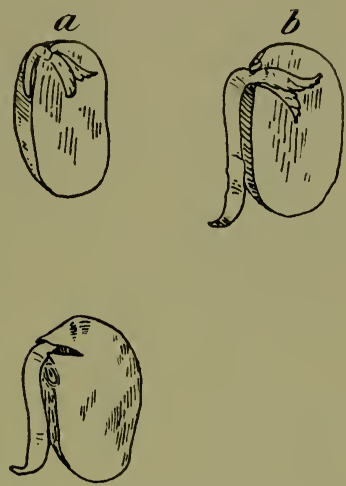

Fig.19.-Germinating bean seeds ; $a$ and $b$ with one cotyledon removed.

seed by a little pocket, as was the leaf. The cap does not grow as much as the leaf-cap does, and the radicle soon pushes through it.

In Zea mays (mealie) the first side roots come from the stem just above the scutellum. They are a part of the embryo. In the pumpkin they come from the radicle which forms the tap root; they are not formed until after the root begins to grow.

Compare the germination of a common bean and that of a broad bean. Both come up with a loop. Does the same part of the stem form the loop? How do the cotyledons behave in the kidney bean and in the broad bean? The cotyledons do not grow as in the calabash or pumpkin. Notice how they wither as the food they contain is given up to the growing parts. When the loop pulled up the cotyledons in the kidney bean, the tender leaves of the plumule folded between them were also safely brought up. The plumule grows out into two green leaves. Notice the little cushions 
near the lower end of their stems. Were these found in the calabash seeds? How is the plumule brought above ground in the broad bean?

"April Fool" seeds (Hemanthus) may not wait to be planted. The juicy berries within which they grow supply moisture, and after sufficient time for ripening they germinate

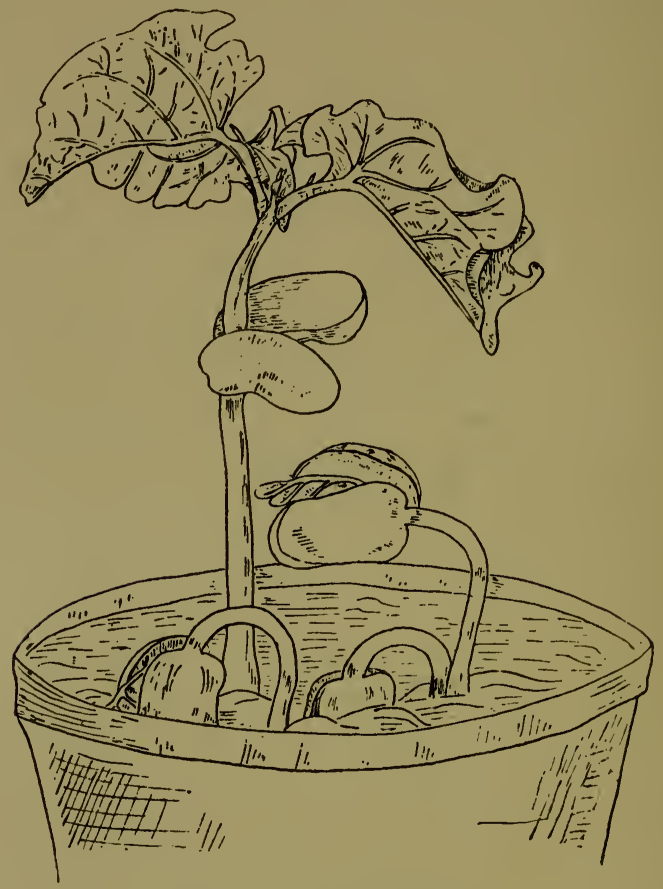

FIG. 20.-Bean seedlings.

of themselves. As growth begins the root is pushed out by the cotyledon, the tip of which, remaining in the seed, absorbs the stored food until the root is old enough to reach the soil and do its work. After a few days the plumule thrusts up its head through a slit in the base of the cotyledon. When planted, does the tip of the cotyledon come above the soil?

While studying the germination of April Fool seeds, com- 
pare them with germinating seeds of onion and date. The latter germinate very slowly. Plant them early in the year.

Watch for acorns that have been left on the ground for

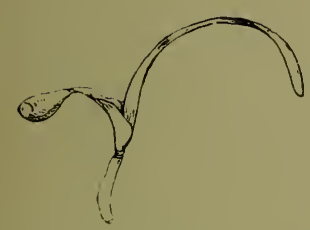

FIG. 21.-Little "April Fool" plants $\left(H_{C E}\right.$ manthus).

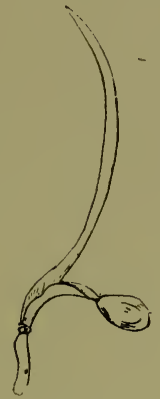

(He-

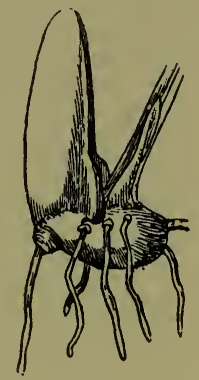

FIG. 22.-Growing seed of Aponogeton (" Water Uintjes").

several weeks after falling. Notice how the plant splits the hard shell, and how the root pushes down and anchors the seed.

Plant other seeds that are about your home. The Silver Tree has large seeds which germinate readily. Arum "lily" seeds may be compared with those of Hamanthus. Aponogeton seeds may be found soon after flowering. Notice how little the radicle develops. A stem soon appears at one side of the cotyledon which bears roots below and leaves above.

Kafir corn may be germinated with Indian corn. In studying germination, take plenty of time to make simple drawings of each plant. Drawings should be made to show the plumule unfolded.

In the seeds we have studied the cotyledons have their special work to do.

The cotyledons of the broad bean simply yield up their food to the growing plant.

In Zea mays the cotyledon not only gives up its own store, but absorbs and passes on the food in the endosperm.

A third form is found in the date seed, where only the tip 
of the cotyledon remains within the seed and absorbs the food, while the lower part pushes the radicle down into the soil, where it is safe from drying up.

The onion does nearly the same as the date. The cotyledon (a) absorbs the endosperm, (b) places the radicle, (c) comes up with a loop and brings the delicate plumule safely above the soil, (d) finally escapes altogether, becomes green, and behaves like a foliage leaf.

The pine and castor-oil seeds have a different habit. Instead of remaining within the seed-coat where the food is stored, the cotyledons pull themselves out, bringing the food with them as little caps, which they consume on the way up, and gradually become good-sized foliage leaves.

Black wattles and the French bean cotyledons come above the ground, yield up their food, then wither and fall off.

The gourd family keeps the cotyledons, which grow and become green.

Here are seven ways, and you may find others. If you live in the East or near a botanic garden, you should study the seeds of Encephalartos (Kafir bread tree). Which type does it resemble?

We have found that cotyledons (I) store food, (2) absorb and pass on food from the endosperm, (3) surround and protect the radicle and plumule, (4) bring them into position, (5) act as foliage leaves.

In no case have the cotyledons looked like the next leaves. Have you found any more showy than the next leaves? Have any borne hairs? Are they ever compound?

In order to watch the growth without injuring the seedlings, seeds may be planted in a frame having glass sides. Ask the tinsmith to cut two pieces of galvanized iron the shape of Fig. 23. Bend them along the dotted lines. Nail the piece $a-b$ to a board for support, and slip in on either side a piece of glass. Discarded photographic plates will do nicely. Several may be used. Fill with moist sand. Thin cloth may be placed between the sand and the glass.

Ex. r. Place the seeds in different positions. Notice how quickly the roots will turn down and the stems bend upward. The work of the roots 
is to be done down in the soil, and that of the stems up in the light; so the sooner they get into these positions the better.

Fine white hairs may be seen on the root and its branches to within a short distance from the tip. As the root pushes

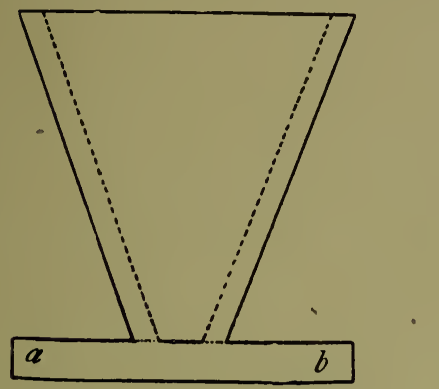

FIG. -23.-Diagram for ends of glass germinator.

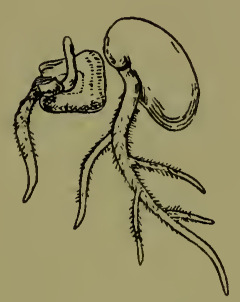

FIG. 24.-Seedlings showing root hairs.

on, the oldest ones are worn off, but new ones are constantly formed towards the tip. They make their way in between the fine particles of soil in search of water, and greatly increase (from five to twelve times) the absorbing surface.

Ex. 2. Fasten some seeds, which have germinated until the roots are about an inch long, to strips of wood. Place them in an inverted flowerpot, in which the water stands to a height of 2 inches. Let the roots in one dip into the water; place the second.lot higher, taking care that they are some distance above, the water. After they have grown an inch or two, note the absence of root hairs in the first lot. The drier the soil, the more numerous are the root hairs. Some water plants, however, have abundant root hairs. 


\section{CHAPTER III.}

\section{GROWTH OF ROOTS, STEMS, AND LEAVES.}

Do all parts of the root continue growing as it pushes down into the soil?

Ex. 3. To answer this we must have the roots where we can examine them. Germinating bean or pumpkin seeds may be placed upon moist

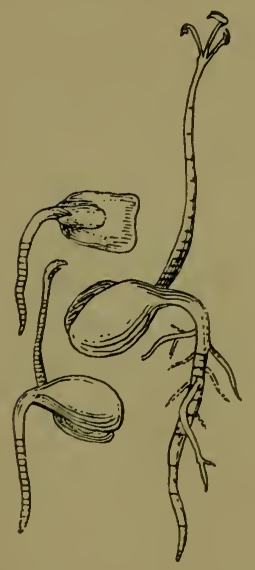

F I G. 25. - Seedlings marked to show the place of greatest growth. cotton wool and held in place by strips of sheet cork fastened together by rubber bands. Suspend in an inverted flower pot over a saucer of water. When the roo:s have grown about an inch and a half, mark off equal distances on them with ink (waterproof ink is better). Place the germinator under cover, and observe the next day. The spaces toward the upper end nearest the seed will be the same distance apart they were the day before. The root has not grown there nor at the tip. Growth in length is greatest just at the back of the tip.

In a similar way examine the growth of stem and leaves. Mark off equal distances as before; they may be a little farther apart on the stem. The place on a stem from which leaves are given off is called a node. The part between two nodes is called an internode. Notice that the stem grows both below and above each internode, but the greatest elongation is in the upper half of an internode. How does a leaf become larger?

Now compare the results with the growth of monocotyledons. 
Ex. 4. Place Zea mays seedlings where they are warm. When the first blade is about 2 inches above ground, or as soon as the leat which it is protecting has burst through, separate carefully with a fine
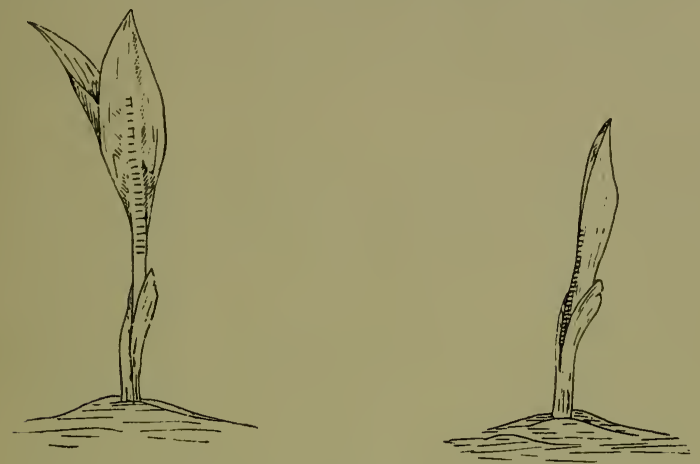

FIG. 26.-Showing basal growth in Zea mays.

needle, and strip from the sheath to expose the base of the leaf within. Mark off lines on the part exposed, carrying them across on to the sheath. When growth has taken place, so that the marks appear above the sheath, it will be seen that the place marked has been pushed up by the growth at the base of the leaf.

Commelina ${ }^{1}$ will be a good plant for studying the growth of a monocotyiedonous stem. Split the shea thing base of the leaf and mark the stem off. Mark other plants -Flagellaria, or any of the species of Asparagus (Wachteen-beetje). Mark the stem in Spring, when they are growing rapidly.

\section{Direction of} Growth of Roots and Stems.-We have

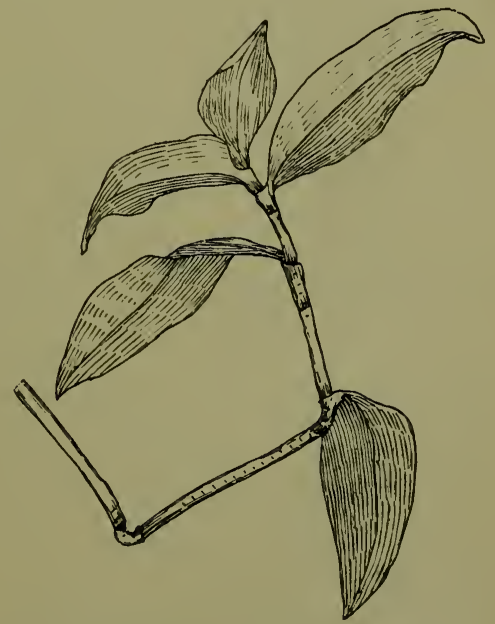

FIG. 27.-Growth of the stem of Commelina.

${ }_{1}^{1}$ Commelina is often cultivated ; it is found wild in the Eastern, Central, and Kalahari Districts. 
seen that the root tends to grow towards the centre of the earth. The side roots extending obliquely in several directions, are well placed for obtaining their food. Pinch off a tip

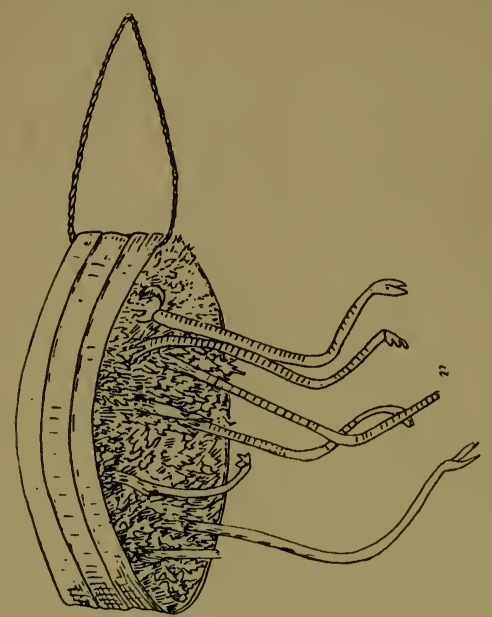

FIG. 28.-Stem curvature induced by gravity. of the main root. One of the side roots now bends down to take its place. Which root does this? Is more than one root affected?

How does the root curve?

Ex. 5. Mark the roots of seedlings in the germinator as before. When the roots are an inch or two in length, suspend the germinator from the side. Now observe where the bend occurs. How does the shortest curve compare with the position of greatest growth?

Mark other roots, and with a sharp knife cut off the extreme tips of some. ${ }^{1}$ Early the next day notice the difference between the cut roots and the uninjured ones. None of the cut roots have bent downward. They have lengthened, so that we know the growing region or motor zone has not been injured. The root grows down because it is stimulated by gravity. But from our experiment we have seen that the tip is the part which is sensitive to this stimulus. It is calied the perceptive zone.

Ex. 6. The Direction of the Stem.-The stem has as strong an upward growth as the root has a downward tendency. Place seedlings that have grown in pots or in the germinator in a horizontal position. In three or four hours a decided change of direction has taken place. In Fig. 28 notice that the one at $a$ is curving, although the end was cut. Observe the stem curvatures of monocotyledons. Where does curvature take place in the jointed stems of grasses? In Commelina?

After the seedlings have become upright, turn the pot hali-way around. Note how soon a change of direction may be observed. It will be made

1 The roots are injured by the shock, but an experiment which may be performed to show this without injury requires an elaborate piece of apparatus. If care is taken, the tip may be slit lengthwise. In spite of the injury the root will still bend down as the root is not injured. 
more apparent by thrusting into the soil two slender wire rods, one on either side of the stem.

Growth Curvature affected by Water.-We have been studying growth curvatures affected by gravity. While the tendency of the main root is downward and that of the

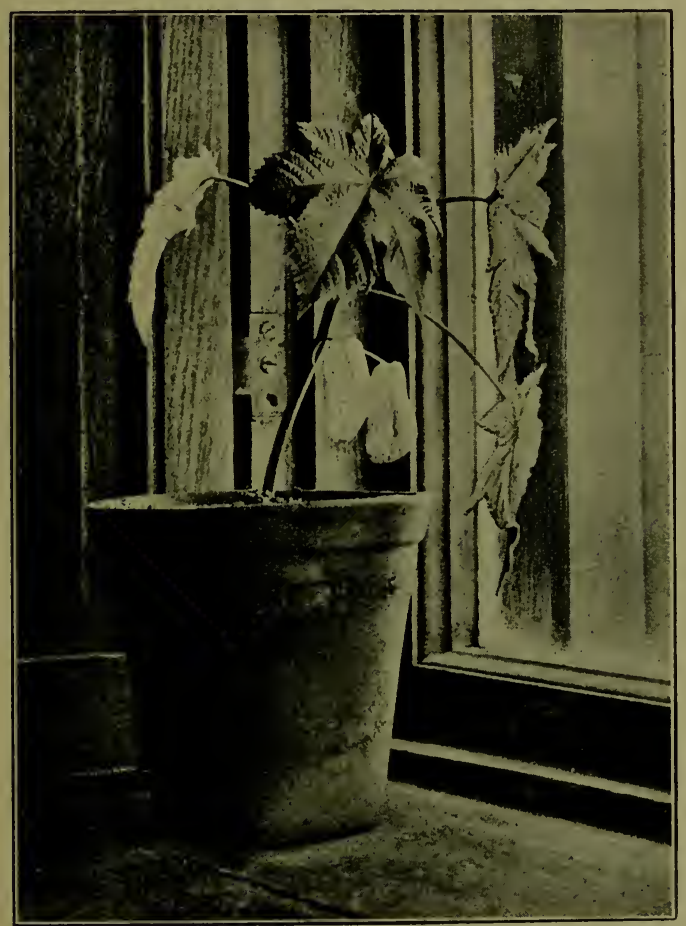

FIG. 29.- - I.eaves of young castor-oil plant looking toward the light.

stem is upward, both are sensitive to other influences. Food material which roots absorb must be dissolved in water, in search of which they often go a long distance. The roots of a tree growing by a stream will reach far out on the side toward the water, Young plants show this curvature, 
Ex. 7. Cover the outside of the glass germinator or of a funnel with several thicknesses of flannel. Fasten seeds which have just germinated by means of a narrow strip of flannel to the upper edge of the glass. Keep the flannel moist, and the roots will follow the inclined face of the germinator instead of growing vertically. The flannel must not be too moist, or the roots will turn from it.

Ex. 8. Growth Curvatures caused by Light.-Place the germinator in a box lighted at one end. Notice the seedlings in a day or so. The stems will bend towards the lighted end. Will the roots show a turning away from the light?

The seedlings of sunflower are very sensitive to light. Place some in a bright light and cover with black paper, leaving an opening at one side. Notice how the cotyledons turn their flat surfaces to the light. As soon as the next pair of leaves appear, reverse the position, so that they turn directly away from the light. Will they turn back? Try the experiment with other seedlings.

Fig. 29 shows a young castor-oil plant. All the leaves, including the cotyledons, have turned toward the window. The

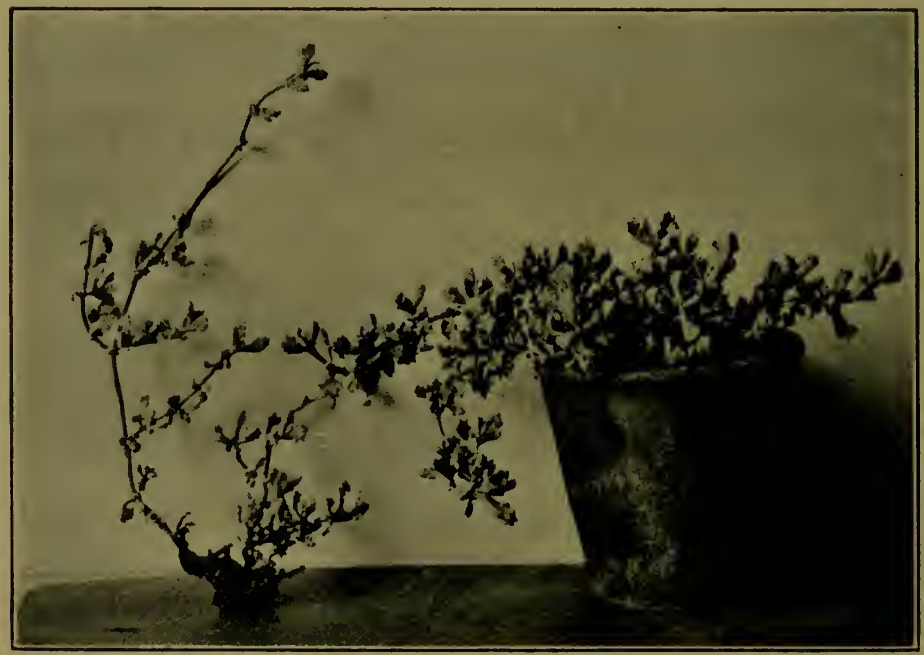

FIG. 30.-The plant in this pot grew on the north side of a large rock. The portion beside the pot grew on the south side in the shade.

stalks (petioles) of the cotyledons have curved so as to bring the surface of the cotyledons into a favourable light position. 
Ex. 9. The cotyledons of the bean have no petioles. On the stem of those which are turned away from the light, below the cotyledons, make a row of ink marks. Place in a lighted window. In a day or so the cotyledons will look toward the light. The row of marks will show that the stem has twisted to bring them into position: When growth in that portion of the stem has stopped, turn the plant halfway around. Will the cotyledons again turn toward the light?

Ex. Io. Remove the tips from sunflower seedlings, cutting off some above and some below the cotyledons. Do the stems still curve toward the light?

Ex. Ir. Plant sunflower seeds and keep them covered so as to exclude all light. At the same time plant others and leave them exposed to light. When the cotyledons of the second lot are well expanded, compare with those which have been covered. The cotyledons are still closely pressed together. Cover those that were left exposed. After a day or two examine them again. Evidently light has an influence in spreading leaves apart ; in darkness they close.

Notice Oxalis plants at night. Leaves and flowers are all closed. In the morning they open. On very bright days the leaves go to sleep, while the flowers remain open. On cold days they remain closed. There is a cushion-like joint at the base of the leaflets made of thin-walled cells. When the cells on the underside lose a portion of their contents the joint bends and the leaf closes down. Look for joints in clover. Are they in the same position? Do clover leaves lie down or stand up when they go to sleep?

If a plant remains in darkness, the leaves remain small and undeveloped, while the internodes lengthen. The plant in Fig. 30 grew under the shelter of a large rock. The part in the pot grew on the sunny northern side, while the piece at the left grew in a more shaded place on the southern side. Fig. $3 \mathbf{I}$ is the picture of a very compact little plant when it is growing at home near Beaufort West; but while lying in the box in which it

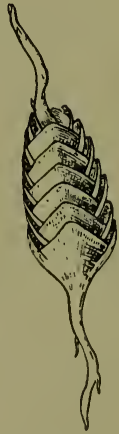

FIG. 3I.-The boxed-up Karroo plant sent forth a shoot in search of light. Observe the difference in position and size of leaves. was posted, the tip of the plant started on a journey of its own. During this growth the leaves formed were very small, but the lengthening stem placed them far apart. It has long been known that a plant grows faster at night and it is a 
matter of common observation that a potato, e.g. which has grown in a dark place, will have a very long stem. It used to be thought that light hindered growth, but dark places are usually damp. It has been found in experiments on bamboos and other plants that light had no effect on their growth, which varied with the humidity of the air and the temperature. Growth is favoured at night when transpiration ${ }^{1}$ decreases and the cells are consequently distended with water. The food supply also has an effect on growth.

1 See p. 30. 


\section{CHAP'TER IV.}

\section{FURTHER GROWTH AND DURATION OF PLANTS.}

By the time the plant has germinated, that is, has unfolded the parts formed in the embryo, and has used up the stored food, the root, by means of the root-hairs, has become closely attached to the soil. New roots are sent out with their roothairs, and the plant is able to get its own food material, partly from the soil through the roots and partly from the air by means of the leaves. While the embryo was unfolding, the plant was not increasing in dry weight, but by the time the first new leaves are forming the plant is beginning to add to its weight ; growth has really begun.

In none of the seeds studied were the cotyledons and plumule similar in appearance. In the bean, after the two plumule leaves, but one leaf unfolds at a time. There appear to be three, but they are all borne on one leaf-stalk. Notice the little cushion at the base of each part.

One pupil kept her bean carefully watered. After a while it bore branches. Each branch appeared in the axil of a leaf. (The axil is the upper angle made by a leaf where it joins the stem.) One day a white blossom was reported; others followed. 'They were short-lived, the pretty white part fell, and she feared the plant would die. But in the centre of each flower a pod came. Seeds appeared in the pods, and in each seed a new bean life was formed. When the pods ripened, they split open, and the seeds fell out. Then care and watching no longer availed. The plant's lifework was done. It had borne fruit; then it turned yellow, withered away, and died. This all happened in less than a year. A plant which completes its life history within a year is called an Annual. Some 

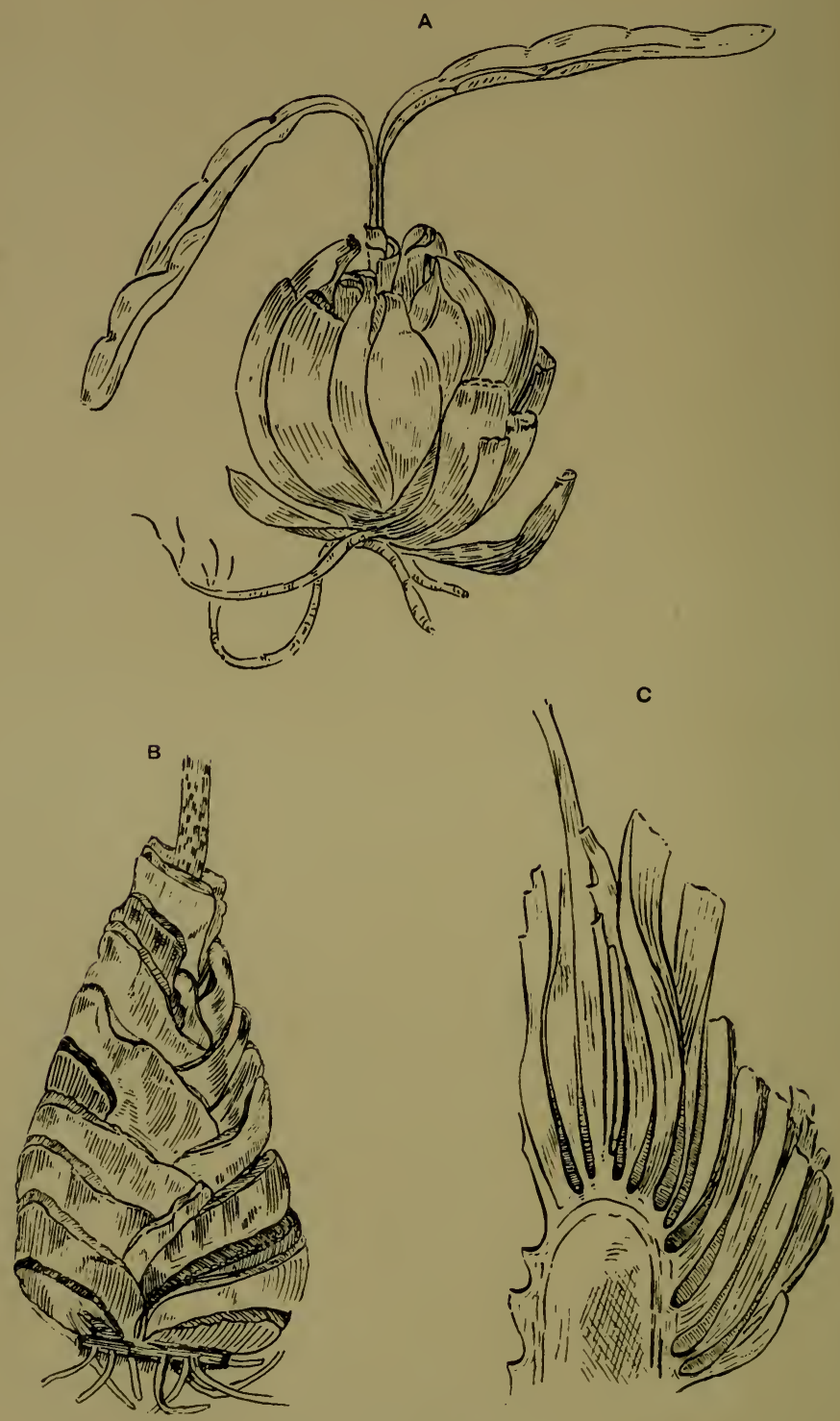

FIG. 32.-Bulbs-A, of a lily ; B, of Hamanthus; C, the same cut in two. 
plants take two years to bear their fruit. The first year is spent in making food, part of which is stored, usually under ground. The second year a flowering shoot is sent up and the food is used to ripen the seed. These are Biennials. In cold countries, or where it is very hot and dry, work has to stop for part of the year; but in a mild climate the work of biennials may continue without interruption, and so the seeds ripen in less than two years. Many are found in vegetable gardens. Members of the carrot family are frequently biennials, though some plants of this family continue their growth under ground year after year, the part above ground dying down each year. This is also the habit of many Pelargoniums ("Geraniums"). If plants or their parts live more than two years they are called Perennials.

The underground part which stores food is sometimes a stem, sometimes a root. "April Fool" (Hemanthus) stores food in a large bulb. A bulb is a short thick stem, surrounded by the fleshy bases of foliage leaves. Gladiolus, Morea, and their family, the Iridaceæ usually store their food in corms. In a corm the swollen stem contains food. The frameworks of foliage leaves often remain attached from year to year, giving a characteristic appearance to corms of different plants. These are called tunics. A corm may be taken for a bulb until cut across. New corms may arise as branches of old ones which are active only one year or the corm may be perennial and give rise each year to a new leafy shoot from the axil of an upper leaf. In Testudinaria and Bowiea they become enormous.

A potato is a tuber. It is the swollen end of an underground branch. That it is a stem may be seen by the "eyes" which are buds, in the axils of reduced scale leaves. The tubers become separated from the main plant and each bud may produce a new plant vegetatively. A sweet potato gives off roots. The lower part is a tuberous root. The upper part has more the habit of a stem, as new shoots for planting are obtained from it.

Stems, more or less swollen, which creep under ground or are partly exposed, are called rhizomes. Plants with rhizomes can spread without being much exposed to the sun. 
Bulbs, corms, tubers, and rhizomes are abundant in South Africa and other dry, warm countries.

Asparagus, Carrots, many Pelargoniums, and others have fleshy roots for storehouses.

Just as stems are found under ground, roots often grow above ground. The Rubber Tree has its large root only partly buried.

The first lateral roots of Zea mays are formed in the

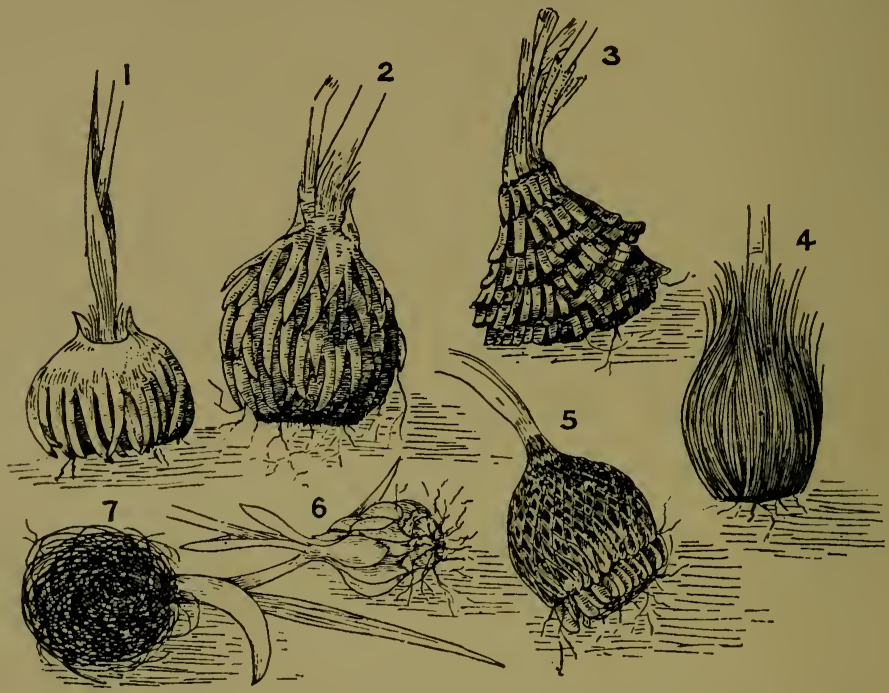

FIG. 33.-Corms with their "tunics". I, Antholyza revoluta, Burm. ; 2, Gladiolus alatus, Linn. ; 3, Lapeyrousia Pappei, Baker ; 4, Babiana ; 5, Synnotia bicolor, Sweet ; 6, Romulea longifolia, Baker ; 7, Hypoxis ovata, Linn. $f i l$.

embryo, in the axil of the cotyledon. A circle of roots is formed in the axil of each leaf of the growing plant for some distance up the stem. Some of these make their way out through the leaves and down to the soil where they absorb moisture and serve to brace the plant.

In the East and about Knysna, many of the orchids are epiphytic. Epiphytes cling to other plants but are not parasitic upon them (see p. 98). They form dense masses 
of roots some of which serve to fix the plant, while others stand out toward the light. They are green and assist the leaves in

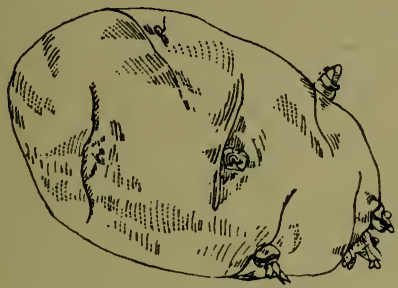

FIG. 34.-White Potato.

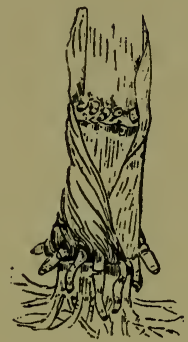

FIG. 35.-The brac ing roots of Indian Corn (Zea mays).

doing their work, while their outer dead cells soak up moisture like a sponge.

Roots borne in the air are called aerial roots. The ivy and climbing cactus use their aerial roots in climbing. They have underground roots which absorb food material.

\section{The Way Trees Grow.}

Some plants continue growth, both above and below the surface of the soil, year after year. If such a plant grows to a height of 20 feet or more, and the lower branches remain undeveloped and fall off, so as to leave a central stem or trunk exposed, it is a tree. If it forks continuously from the base and has no strong central trunk, it is called a shrub.

Roots reach out over a large area or they may extend down to a great depth, so that trees having the two kinds of root systems may be planted close together. Should Oaks and Blue Gums be planted side by side? Shade trees around a garden should have deep growing root systems, so that they will not remove the surface moisture required for the flowers or vegetables.

Plants in the germinator showed root-hairs near the tip. They died away further back where the side roots were forming. 
Of the great root system of trees, only the tips are absorbing food material. As they push forward, the tips are protected by a short-lived cap of tissue, which is constantly being renewed as it is worn off.

Water and solutes (mineral substances dissolved in water) enter the root by osmosis ${ }^{1}$ and diffusion, and pass into the bundles of long slender tubes (vascular bundles), that continue

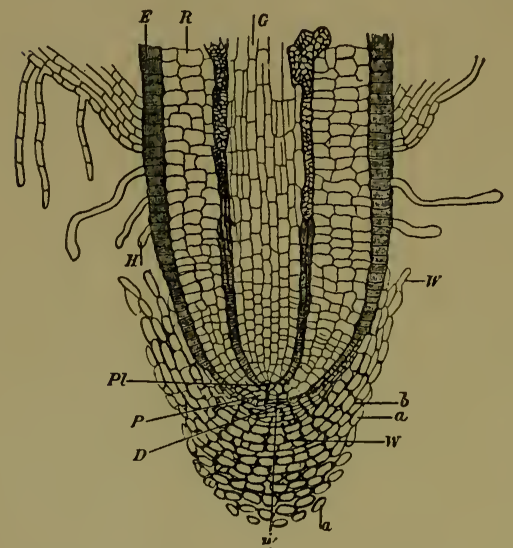

FIG. 36. $-G$, central cylinder, consisting of pith, vascular bundles, and pericycle; $R$, cortex ; $E$, piliferous layer; $W$, root-cap. (From Edmonds and Marloth's " Elementary Botany for South Africa".)

from the root through the stem to the very tips of the leaves. The tubes are not continuous throughout the length of the plant but the contents pass from one tube to another adjacent one. Water is required for food material, some is retained within the cells, the cell walls are permeated with it and part of the water taken in passes out through the leaves and stem into the air. The escape of water is called transpiration.

Cell sap contains sugar and acids. These cause the inflow of water by osmosis. The water constantly passes from cells with less dense to those with more dense osmotic substances. If transpiration hastens the upward ascent of water the solutes are not necessarily hastened since they obey different conditions. $^{2}$ Solutes pass from cells having a greater to those having a less concentration of solutes.

The water, in its long journey, must not be dried up, and to guard against this, under the thin outer dress of stems and

ISee p. 57.

2In a tobacco field Hasselbring ("Bot. Gaz." Jan. 19r4) found that plants which absorbed and transpired the most water contained a smaller percentage and quantity of ash. 
branches an undergarment of cork is found. This garment is made of small cells also, but while the cells beneath have spaces between them which admit air, cork cells fit closely together, and the walls are water-proof; so cork in trees serves the same purpose that it does in bottles. The cork cells are filled with air, and these air spaces, like the loft in a house, assist in modifying the temperature.

To support and provide food for the branches which are added to the tree each year, the stem must increase in thickness. This it does by means of a ring of active cells just outside the woody portion of the stem. These cells, the cambium, are most active in spring when their walls are so delicate that they are easily broken, and the bark may then be readily removed. All the growth outside of this ring of cells is bark. Every boy who makes willow whistles takes advantage of the active season of the cambium, for it is when the cells are young and tender that careful and judicious pounding with the handle of a jack-knife will bring the bark off entire. Later in the season the cambium is not so active (for the whistle-making season is limited, "as every schoolboy knows"), and the cells of the wood are not so large. ${ }^{1}$ The large and small cells alternating make the annual rings in the wood by which the age of a tree may be determined. Rings are formed in the bark, but they are not so well marked as those in the wood.

As the tree grows, the thin green over-dress gets too small ; sap cannot get to it through the cork, so the cells of which it is made starve for lack of food; it cracks and peels off, and the tree henceforth is clothed in more fitting shades of grey or brown as become its years. Young cork cells stretch, but in

${ }^{1}$ The cause of rings is not fully understood. The former explanation of pressure of the old outer cork tissue is no longer held; nor do they seem to be regulated by the food supply. The oak during some seasons puts forth an earlier and a later growth of branches in one season and thus sometimes forms two rings in one year. These, you notice, occur on the upper branches which have the best exposure to light and air. Down below only one period may occur during the season. Phytolacca dioica, L., a shade tree from South America and cultivated in this country (Bellombra or Bella sombra) forms twelve well-defined rings in a year's growth. 
time they lose their elasticity and become too small also. Just underneath lie special cells which keep it renewed. Different trees fashion theiricork after different patterns. In Blue Gums the renewing cells form long narrow plates, and the old tattered garment is shed in long thin strips. In the oak and pine the pieces are small and narrow but thick, while pieces of cork in the wild olive are thin, small, and rough. Cork does not fall off as fast as it cracks apart, but from a tree you can remove layer after layer that have been formed in successive years. This portion of the stem as far in as the cork is formed is known as the outer bark. So long as the renewing cells, or cork cambium, are not destroyed, cork may be removed without causing the death of the tree, and so from the Cork Oak, bottle cork is removed year after year.

In this bark a substance called Tannin preserves the wood from decay. Unfortunately for the tree, tannin is ex-

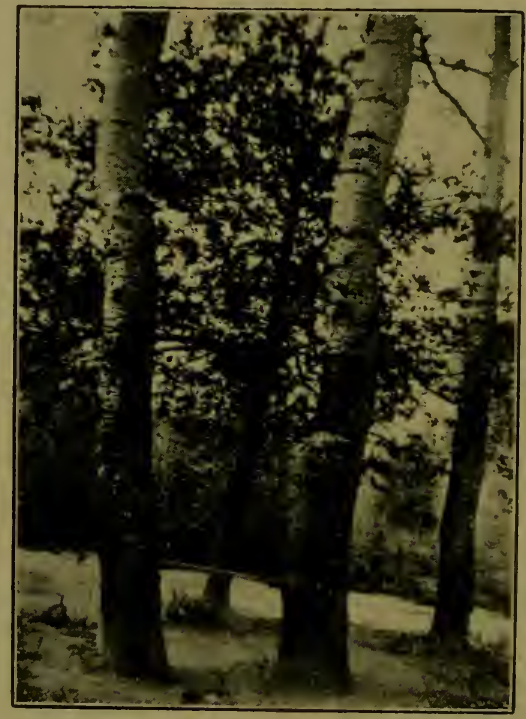

FIG. 37.- Lenticels on the bark of Poplars.

cellent for preserving leather also, and so the beautiful Protea cynaroides, Linn., Leucospermum conocarpum, R. Br. (Kreupel 
boom), and Rhus lucida, Linn. (Taai bosch), are being destroyed to obtain this substance.

In summer there are rifts in the bark which admit air and also allow escape of water. These can be seen on young stems as small light-coloured raised openings. Being lens-shaped, they are called lenticels. In Cassia and the Cape Lilac (Melia Azedarach, L.) they extend horizontally, and in Erythrina they are vertical. They become very conspicuous in poplars as the trunk grows, and give the peculiar marking to the bark. Lenticel cells are also corky, but there are openings between them through which water and air may pass. When trees take their winter rest, a plate of cork seals them, so there is no waste of material. When there is no income there must be no expenditure. In spring, new spongy cells stretch and burst these little seals, and so the lenticels can serve another season. Cork extends down to cover the roots except the growing tip.

Many of the trees introduced to this country from the northern hemisphere are quite bare for a part of the year; but they have come to shed their leaves in July and August at the time when they bear foliage in the north. ${ }^{1}$ Mingled with the northern trees all through South Africa are trees from Australia. Do you know any? Do they shed their leaves so that they are quite bare at some time of the year? Can you tell how long leaves remain on any evergreen tree?

While roots are absorbing food material, leaves are taking in air. In the green cells of the leaves water, with the dissolved earthy matter, is combined with the carbonic acid gas obtained from the air to form the food of the plant.

Air, earth, and water seem at first rather unsustaining diet, but when we consider, we find that people, in common with other animals, since they depend altogether upon plants for food, are nourished by the same materials.

Leaf Fall.- Toward the end of the season when the work of the leaf is nearly finished, preparation begins for cutting it off.

${ }^{1}$ Chestnuts have not changed their time of flowering, so it is too cold for them to bear fruit in the Orange Free State although they come from a much colder country. 
This takes place in various ways. A special separation- or absciss-layer is formed by cells at the base of the petiole with or without their renewed activity. The middle wall plate of the absciss layer becomes mucilaginous, the cells round off and easily separate. The veins which are last to be severed become closed with gum and by pressure of surrounding cells. In the meantime a layer of corky cells has formed just below the

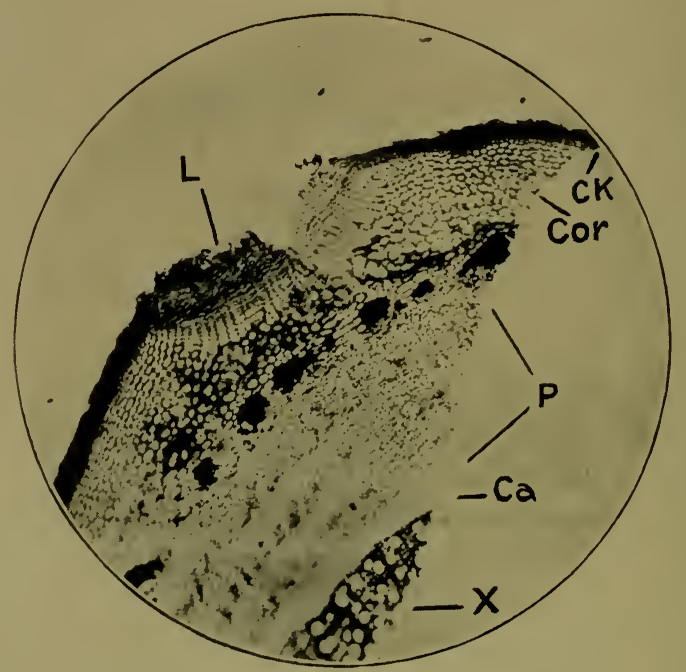

FIG. 38.-Apple stem. Section through (L) a lenticel (winter). X, xylem or wood ; Ca, cainbium ; P, phloem ; Ck, cork ; Cor, cortex ; L, lenticel. (From Farmer's "Practical Introduction to the Study of Botany".) Photo Micro.

absciss layer; these again may be the modified cells already present, or division may take place, the active cells being continuous with the cork cambium of the stem. The cork cambium may remain active for a time after the leaf has fallen, the scar thus becoming well protected.

Pines, Araucaria (Monkey Puzzle), and its relatives cut off dwarf branches which carry a number of leaves with them.

The absciss layer is formed by living cells. If a branch is broken so that it hangs by the bark only, the water supply is 
cut off ; the leaves wither and hang on the branches, for no cutting-off layer can be formed.

When pressing heaths and other small-leaved plants, if they

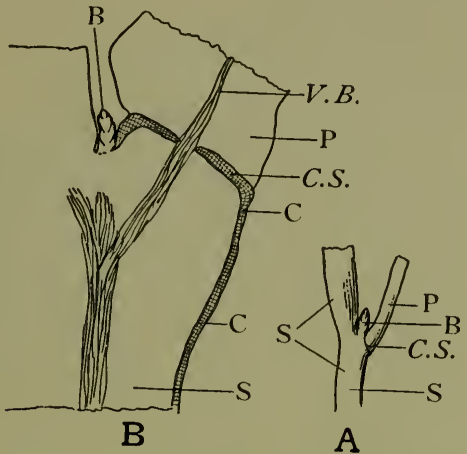

FIG. 39. -A. Longitudinal section through the stem and base of the petiole of a poplar. B. Part of the stem and petiole of $\mathbf{A}$ more highly magnified. S, stem ; P, petiole ; V.B. vascular bundle; C, cork tissue ; C.S. "separation layer". (From Farmer's "Practical Introduction to the Study of Botany".)

are killed by dipping in boiling water, the leaves are less liable to fall off when the specimens become dry. Plants in press are liable to lose their leaves because darkness and a loss of water are conditions that hasten their fall. 


\section{CHAPTER V.}

\section{GROWTH OF BUDS AND BRANCHES.}

PART of the food made by the leaves is used to form the buds for next year's growth. In a dicotyledon a bud is formed in the axil of each leaf, so that if all grew there would be as many branches as there are leaves. Such is not the case ; many buds are crowded out for want of light and air ; others lie dormant low down on the branches as reserves, in case misfortune befall those higher up. The tender tips of branches offer tempting morsels to animals, and even after they are out of reach of grazing animals their dangers are not past. A swarm of locusts may pay an untimely visit, or a strong "south-easter " may scorch and kill leaf and branch in the spring.

Asparagus wraps up its summer buds with little papery coverings, while the evergreen Cunonia capensis, L. ${ }^{1}$ protects its bud by the large stipules of the pair of leaves below. Oaks and poplars have retained the fashion that prevails in their cold native climate of wearing thick coverings which protect from wet and loss of water on sunny winter days when the roots are taking up little water or none.

Some buds contain both leaves and blossoms snugly tucked away together. Others contain only leaves or only blossoms. When the poplars border the streams with a delicate violet tinge, they are just shaking out their fringes of flowers to the breezes. They have been getting ready for the display for many months. Fig. 4 I shows at $a$ the flower-buds of a branch picked in December. They are well along towards next

${ }^{1}$ Cunonia capensis, Linn. (Red Alder, Dutch Roode Els) is a tree with opposite pinnate leaves and dense racemes of greenish-white flowers found by streams throughout the Colony and Natal. 
spring's flowering time. The furry coats on the scales will protect the little flowers from the hot suns and drying winds of
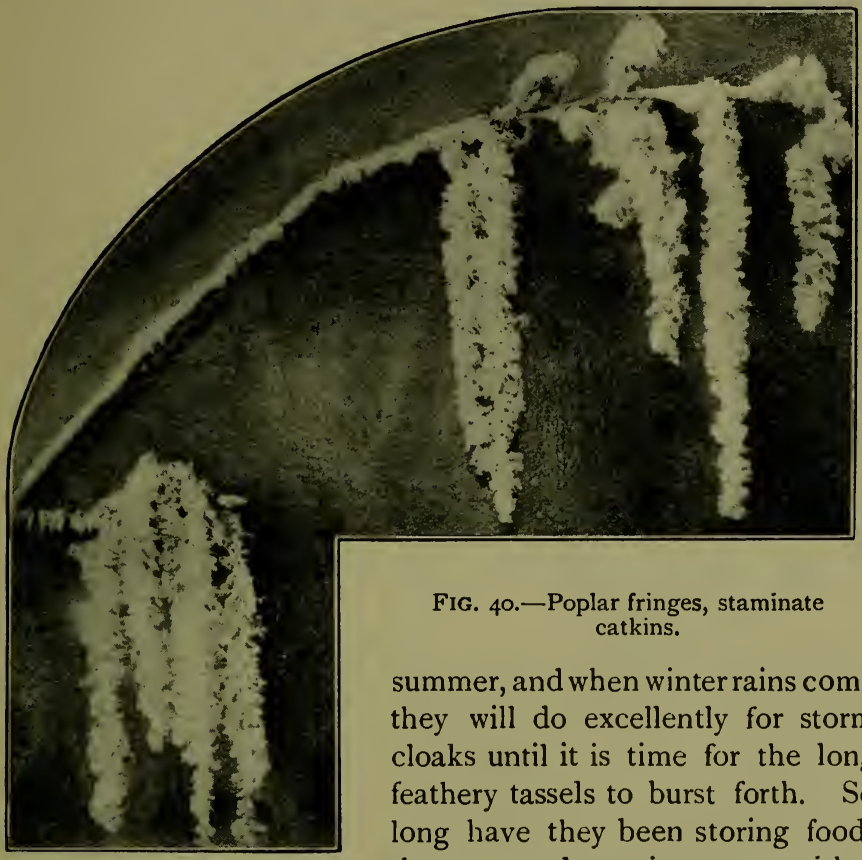

FIG. 40.-Poplar fringes, staminate catkins.

summer, and when winter rains come they will do excellently for storm cloaks until it is time for the long feathery tassels to burst forth. So long have they been storing food, that no wonder spring comes with a "burst". On the main branch, Fig. 4 $\mathrm{I}$, are the scars of last year's leaves, $b$, and just above each one a scar tells where this year's flower-stalks were borne. Just above these scars at the end of the branch $c$ was a bud covered with scales. After the flower-buds burst, this bud began to grow. When the scales fell away they left narrow scars close together. By these scars we may tell how much growth has taken place in a season. The branch at the left has four flower-buds, and a bud at the end to continue the growth. The ring of scars at the base shows that a bud was there last year.

The oak branch in Fig. 42 began its growth this year at $a$. 
The leaves unfolded along the branch above about the same time that the catkins were hanging their pink-and-green tassels of flowers at $c, c$. The branch $a-b$ rested in its growth until the acorns had "set" just below. After they were well formed,

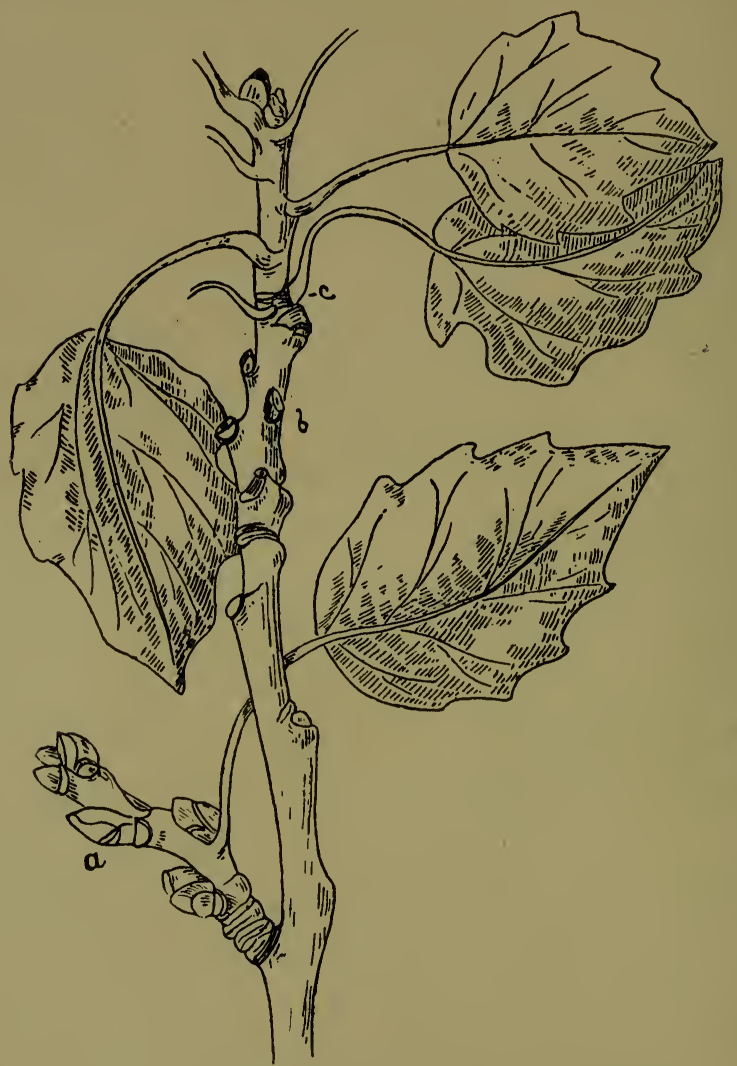

FIG. $4 \mathrm{I}$. - Twig showing leaf scars and buds of poplar.

the resting bud unfolded, and the summer's growth commenced at $b$. If the oak has two periods of growth during the season, in estimating the age of a branch a year's growth will include the distance between three bud-scars. Notice the terminal 
bud of a vigorously growing branch. Determine what part of the leaf protects the tip of the stem.

The terminal bud of a fig and of the magnolia is covered by one pair of large stipules that are formed at the base of each leaf. They fall off quickly and leave their scar encircling the stem. Do any other trees have similar scales? What pro-

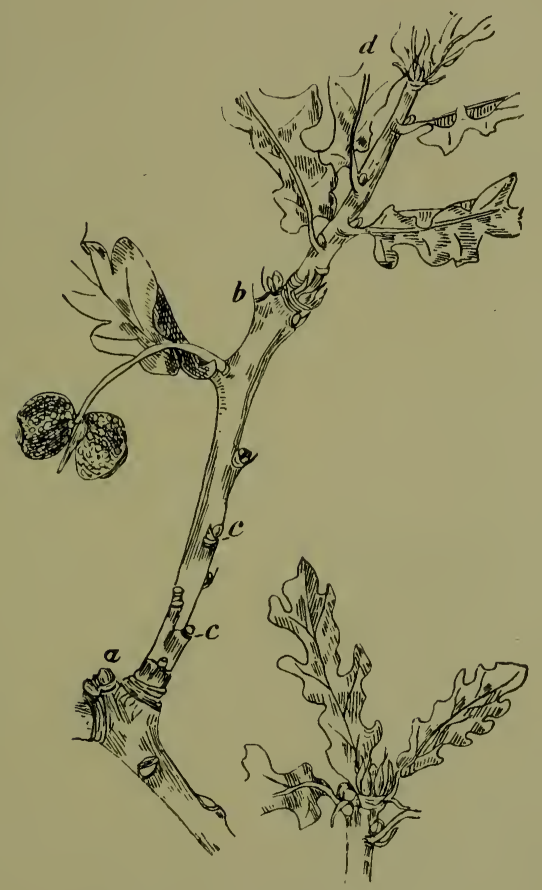

FIG. 42.-Branch of an Oak.

tects the bud in Erythrina (Kaffir-boom)? In the garden pea? The castor-oil plant?

A bud is a shortened stem covered by leaves. Bamboos have very long buds covered by enormous scale leaves. A cabbage is a large bud.

The life of a terminal bud determines the shape and 
character of a tree. In the Blue Gum and Norfolk Pine ${ }^{1}$ the

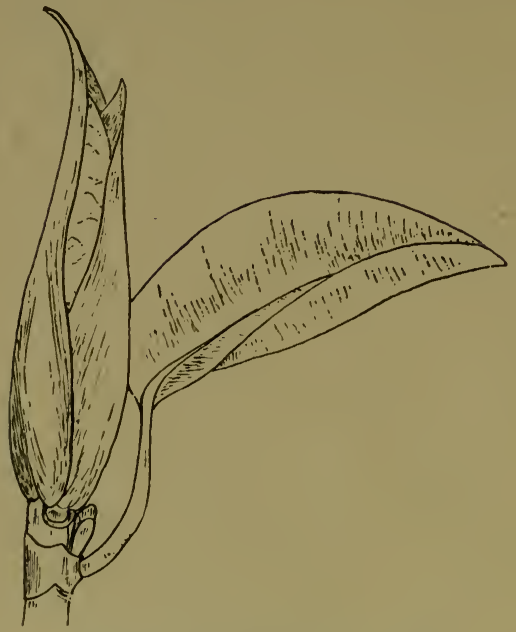

FIG. 43.-Terminal bud of a Fig. terminal bud continues its growth throughout the life of the tree. This gives to the tree a tall, erect habit. In Australia, where the Blue Gums are not cut for firewood, they become the tallest trees in the world.

If the terminal bud continues for a few seasons and then dies, the tree has a broader, bushier habit. A branch of the Weeping Willow (Salix capensis, Thunb.) grows for a season and at the close the terminal

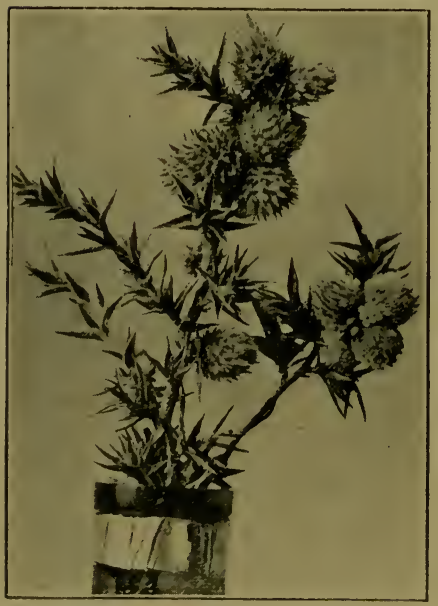

FIG. 44--Galls on Cliffortia.

bud dies. The lateral bud takes the nourishment and continues the growth. This mode of growth gives a drooping habit, the reverse of the Norfolk Pine. A rose also branches in this way, causing the bush to spread.

Galls.-The tips of Clitfortia, Aspalathus, and other shrubs often have peculiar terminal buds. We know they will not produce flowers. Cliffortia has two kinds of flowers, but they are not borne at the tips of branches. These swollen buds are Galls. 
In spring, when the buds were tender and full of sap, insects pierced them with a sharp lance they carry with them, the ovipositor, and placed an egg in the centre of each one. Shortly after, from each egg a small white grub was hatched, which passed all that stage of its life in solitary confinement.

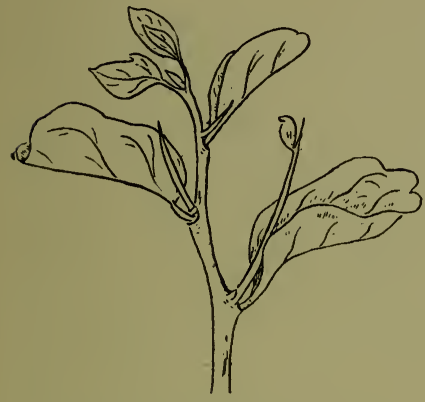

FIG. 45.-Branch thorns of Kei Apple.

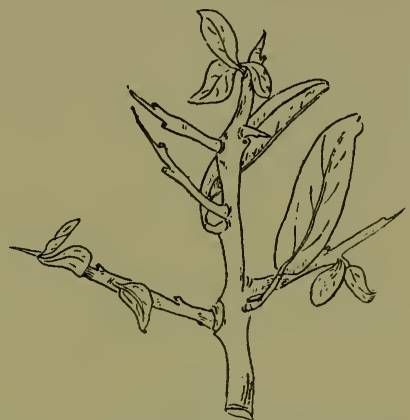

Fig. 46.-Branch thorns of Pomegranate.

Its presence caused the bud to swell so that the few leaves usually formed were not sufficient to protect the mass of tender cells. A great number are stimulated to growth which give the bud the appearance of a small cone. Different combinations of insect and plant give galls of various forms. When they have reached full size (as shown by last year's galls), you can split some through the centre and view the cause of all the disturbance.

Disguised Branches.-Some branches are so altered in appearance that it is not at first evident what they are. In the Kei Apple and Pomegranate it can be seen that the thorns are branches, because they rise from the axils of leaves. In the Pomegranate the end of a branch becomes a thorn. A leaf on a thorn also tells us that it is a branch. Some

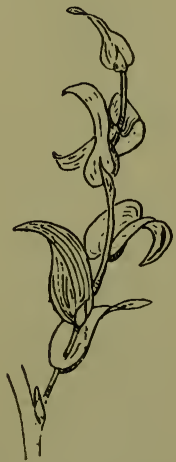

FIG. 47. - Leaflike branches of Asparagus. branches develop into tendrils. Collect as many tendril-bear- 
ing plants as you can find, and tell by their positions whether they are branches or leaves or parts of leaves.

Similarly, by their position we can see that the "leaves" of Asparagus are branches. This will be difficult to understand, especially in the broad "leaved" species, until we see that they grow from the axils of small scale leaves. ${ }^{1}$ Leaves soon attain their full growth while branches grow on indefinitely. There are exceptions to these statements. The Asparagus branches show an exception to the second statement, as do also the dwarf branches that bear the foliage leaves of the pine, the fruit of apple and peach trees, and others will be found.

The Law of Correlation of Growth.-This law has been observed by plants for ages. What does it mean? When a part of a plant is destroyed, the plant's first work is to replace that part. We see how beautifully the law is obeyed when flowers are picked; how many more come to replace them. When leaves are destroyed by locusts or caterpillars, dormant buds which might have remained for ever inactive are given light and air; the food that would have gone to the destroyed part is turned toward these buds, which grow and unfold new leaves. If shoots are destroyed, new shoots are produced; while if roots are destroyed, the first thing needed is new roots. Leaves would not unfold if there were no roots to absorb nourishment. When trees are transplanted, some roots are necessarily injured at the tips. The roots are trimmed off, whereupon a vigorous growth of new roots takes their place.

Fig. 48 shows a young pine seedling which has had its tip cut off. Two buds soon appeared in the axils of the cotyledons. The tip, which was placed in the ground, began to form the lacking roots. This demand upon the plant retarded the growth of the stem, which made no evident growth, while the branches on the seedling increased nearly 3 inches. As a pine tree grows older it loses the power of renewing lost parts. If the tip meets with injury, a side branch will shoot upward rapidly and take its place, leaving only a vacant space to tell

'Asparagus, with broad green branches (Phylloclades), is often miscalled Smilax, which has green leaves-not scale leaves. 
the tale, until the light and air causing the neighbouring branches to put forth extra energy close in the space.

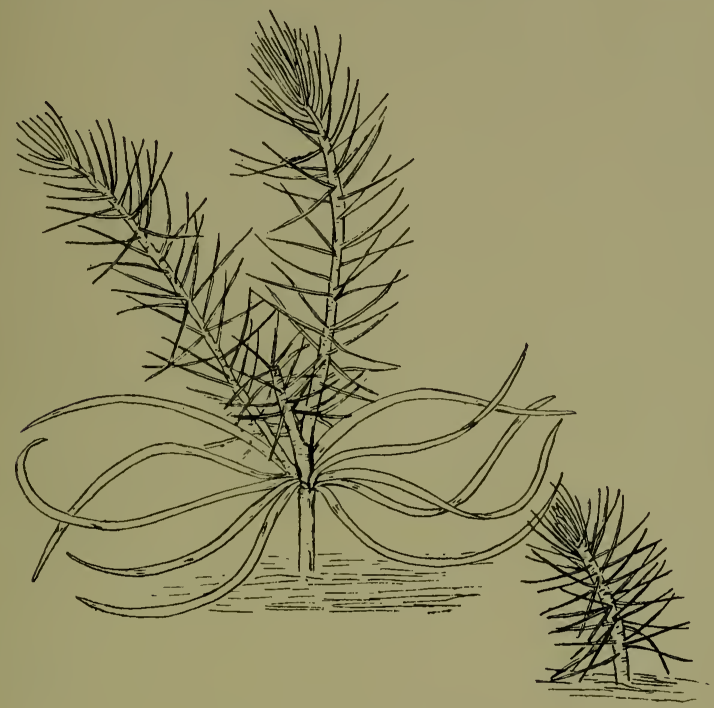

FIG. 48.-Pine seedling.

Cut back the roots and replant a thrifty Acorn seedling. When new shoots have formed repeat the operation several times. Have another seedling growing to compare the growth.

The Japanese have long been famous for their secret of producing dwarf trees. Oaks, over a hundred years old, grow comfortably in a small pot. Maybe if you bear this law in mind you may discover their secret-or a new process.

According to this law, if one part of a plant grows to a large

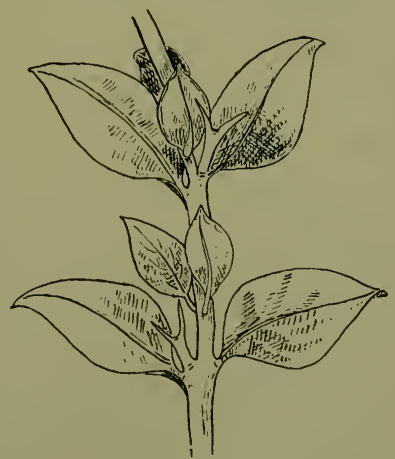

FIG. 49.-Large and small leaves of Carissa ferox, E.M. size it does so at the expense of other parts. The leaves on 
horizontal branches of Carissa ferox, E.M. show this. They are arranged in pairs. The leaves which are exposed to the light are large, while the alternate pairs at right angles to these are not so well placed to receive the light and, perhaps for this reason, or because the pair on either side have developed at their expense, they remain much smaller. Other examples of the same nature may be seen in the study of flowers, where one whorl is often developed at the expense of another. In the ray flowers of Compositæ, where the corolla is conspicuous, the stamens are wanting; this may give a chance for the ovaries to develop or they too may be sacrificed, as in the sunflower. While in the less conspicuous disk flowers where the stamens develop, the ovaries may fail to form fruit as in Othonna, Osteospermum, and Eriocephalus.

On page 17 a correlation was found to exist between the development of root hairs and the supply of moisture. 


\section{CHAPTER VI.}

\section{A STUDY OF LEAVES.}

How many can draw from memory leaf outlines of three different plants? From what plants were the leaves obtained for the drawings on this page? If you have never thought about leaves, you will be surprised to find how many different shapes there are, even on the same plant, and how differently they are arranged on different plants.

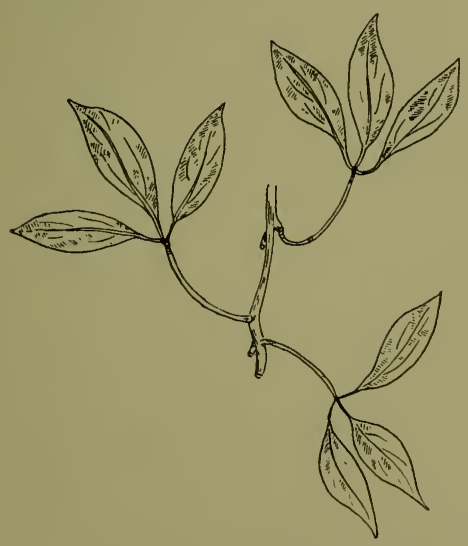

FIG. 50.--Trifoliate leaf.

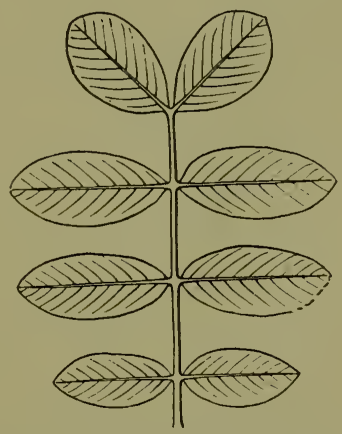

FIG. 5r.-Paripinnate leaf. (From Edm $\supset$ nds and Marloth's " Elementary Botany for South Africa ".)

Most leaves are green, but not every plant has leaves. Mushrooms have none. Do all Mistletoes have leaves?

In studying leaves, we may consider their forms, their parts and positions on the stem, and see how they are all fitted to do their work to the best advantage.

What is a leaf? It is sometimes difficult to know just how 
much to call a leaf. In the bean we called what looked like three leaves a single leaf. How shall we tell that the third leaf in the bean was not three leaves? In studying branches, we found that they were borne in the axil of each leaf. If you examine a branch with leaves like those in Fig. $5 \mathrm{I}$, will you find buds at the base of each part or only where the main stalk joins the stem?

Another test will help us to decide. Leaves remain on a tree for a certain length of time and then fall. When a leaf like that in Fig. $5 \mathrm{I}$ falls, does the stalk that extends through the centre remain or fall off too? A leaf that has several distinct parts or leaflets is a compound leaf.

The Parts of a Leaf.-Fig. $5^{2}$ is the leaf of Hibiscus. It has one large flat upper portion, the blade, a stalk or petiole,

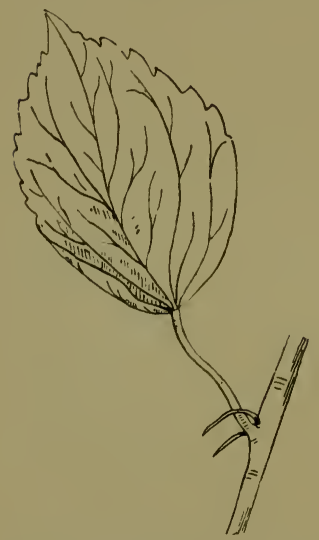

Fig. 52.-Simple leaf of Hibiscus with stipules. and at the base two small leaf-like bodies called stipules. If a leaf has no stipules it is said to be exstipulate. If the leaf-blade joins directly upon the stem and has no stalk, it is sessile. The needle-shaped leaves of pines and heaths have no expanded blades. Sometimes stipules are deciduous; that is, they fall off very quickly, as the Fig and Oak. We must examine young leaves to make sure whether they are stipulate or exstipulate.

The Veins of a Leaf.-Hold a thin leaf up to the light and notice how it is marked with delicate veins. These are made up of the long hollow tubes which carry the food material to its destination. They also serve as a framework to prevent the leaf from tearing. Do they serve like the framework of an umbrella to keep the leaf spread out? You can answer this by looking at pumpkin leaves which have withered in the heat on a sunny day.

The species of Senecio (Fig. 53) has a thick leaf stored with food, which would be wasted if the leaf were torn in the 
wind. It has a firm vein running around the margin which prevents tearing. The thin broad leaves of a Banana have no such border. The wind would bring such a strain on the trees that they would be blown down were it not that the leaves tear down between the veins. The younger leaves are rolled, so that less surface is exposed to the wind. The Date Palm defends itself in the same way, only the leaf splits earlier and has a more tidy appearance. It looks like a compound leaf when it
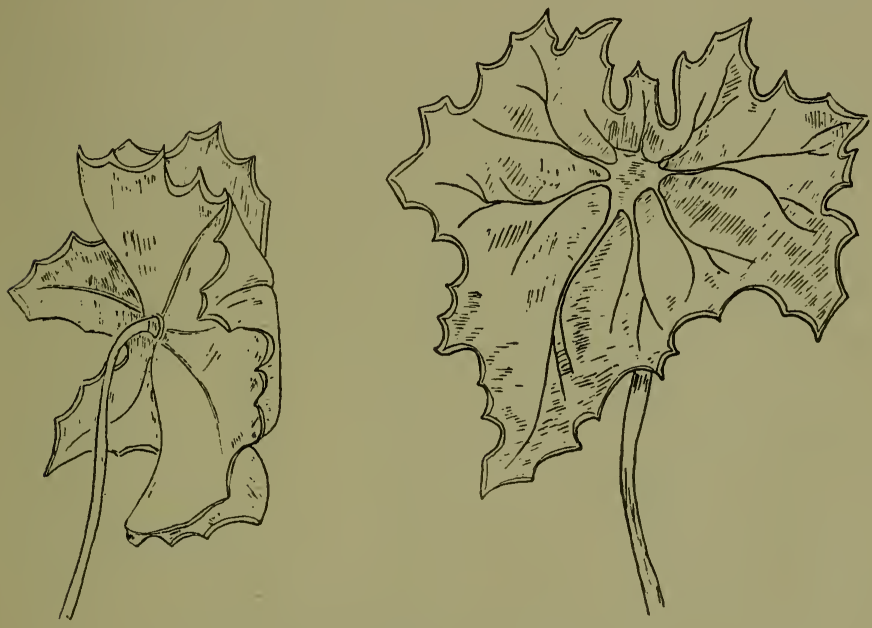

Fig. 53.-Firmly bound leaf of Senecio sp.

is quite unfolded. Examine young date leaves. They are plaited instead of rolled.

When leaves are branched, the branching depends upon the branching of the veins. In some leaves there is a strong central vein, from which other veins branch on either side as the pinnæ branch from the quill of a feather. Such venation is termed pinnate. Or several strong veins may start from the base or lower portion of the leaf, and the venation is said to be palmate (hand-like).

In most dicotyledons the prominent veins join each other so as to form an irregular network ; the veinlets end freely and 
the margins are often notched. In monocotyledons they usually run more or less parallel, the veinlets join near the margin which is usually entire. Simple leaves are sometimes cut. They are called lobed, parted, or divided, according to the depth of the incisions.

The leaflets of a compound leaf are attached by a little hinge or joint. Lebeckia linearifolia, E.M. has but one leaflet.

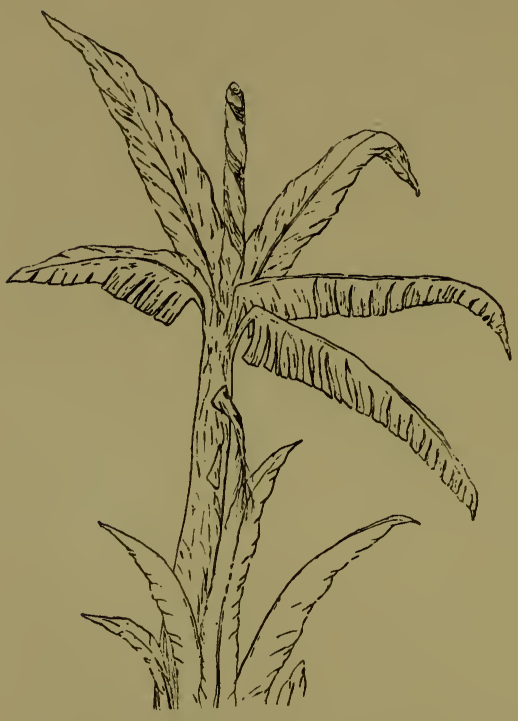

FIG. 54.-Banana leaves torn by the wind.

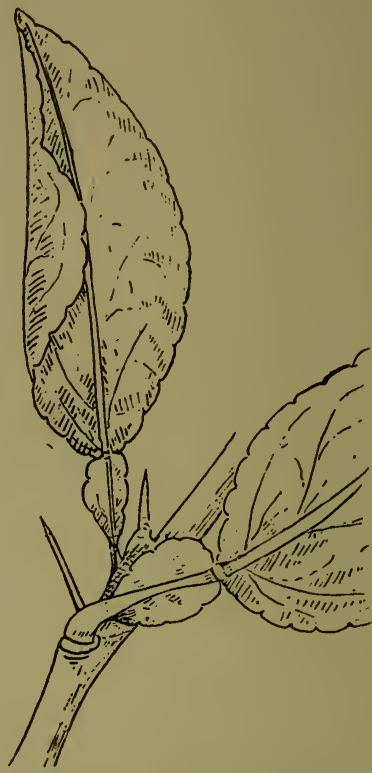

Fig. 55.-Compound leaf of Orange with one leaflet.

The hinge at the base tells that it is a compound leaf which has become reduced to a single leaflet. Other Lebeckias have several leaflets. The same is true of the Orange and Lemon leaf. The trifoliate Orange has three leaflets.

The Arrangement of Leaves on the Stem.-We have seen that leaves are not well developed when covered from the light. Light as well as air is necessary for green leaves to do their work of making food for the plant. Too 
much light, however, is injurious. If we bear in mind these two facts, it will help to explain the meaning of the forms and arrangements.

Leaves also transpire; but the plant must not lose too much water. To be able to meet all these conditions, it is not surprising that we find such a variety of forms and arrangements.

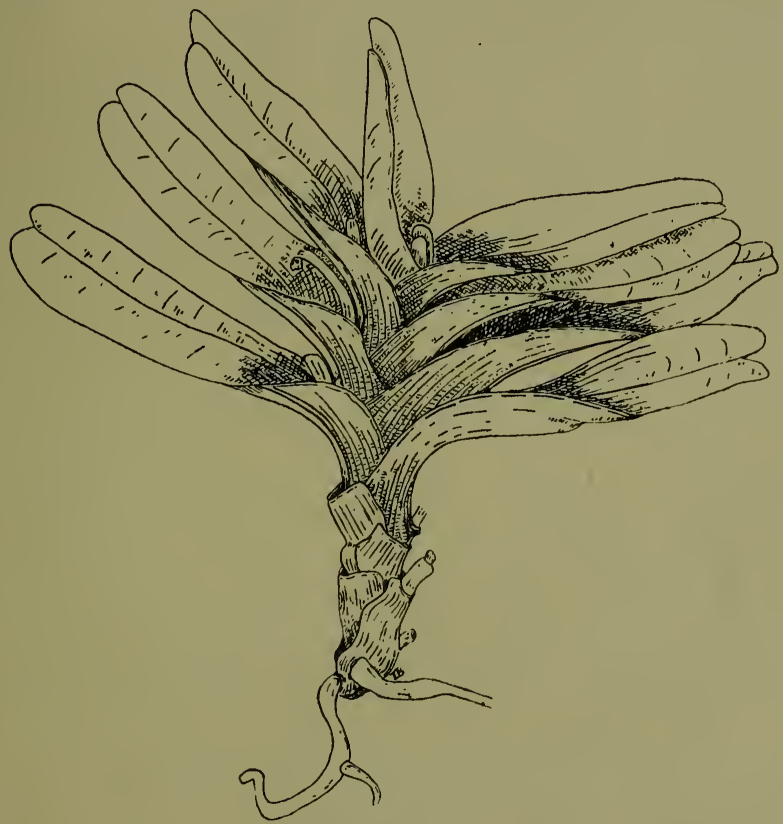

FIG. 56.-Orchid stem with leaves arranged on opposite sides of the stem.

The leaves of the Orchid in Fig. $5^{6}$ have broad bases which encircle the stem. They are arranged in two rows, so that, calling the lowermost leaf No. I, the third and fifth will be directly over it. The distance from one midrib to another is one-half the distance around the stem.

Canna and Kei Apple have broad thin leaves, the fourth is over the first, so that the second and third are exposed to the 
$50 \quad$ Plants and their Ways in South Africa

light. The distance from the midrib of one leaf to that of another is one-third the distance around the stem. What leaf will come over the fourth? This may be found by drawing a
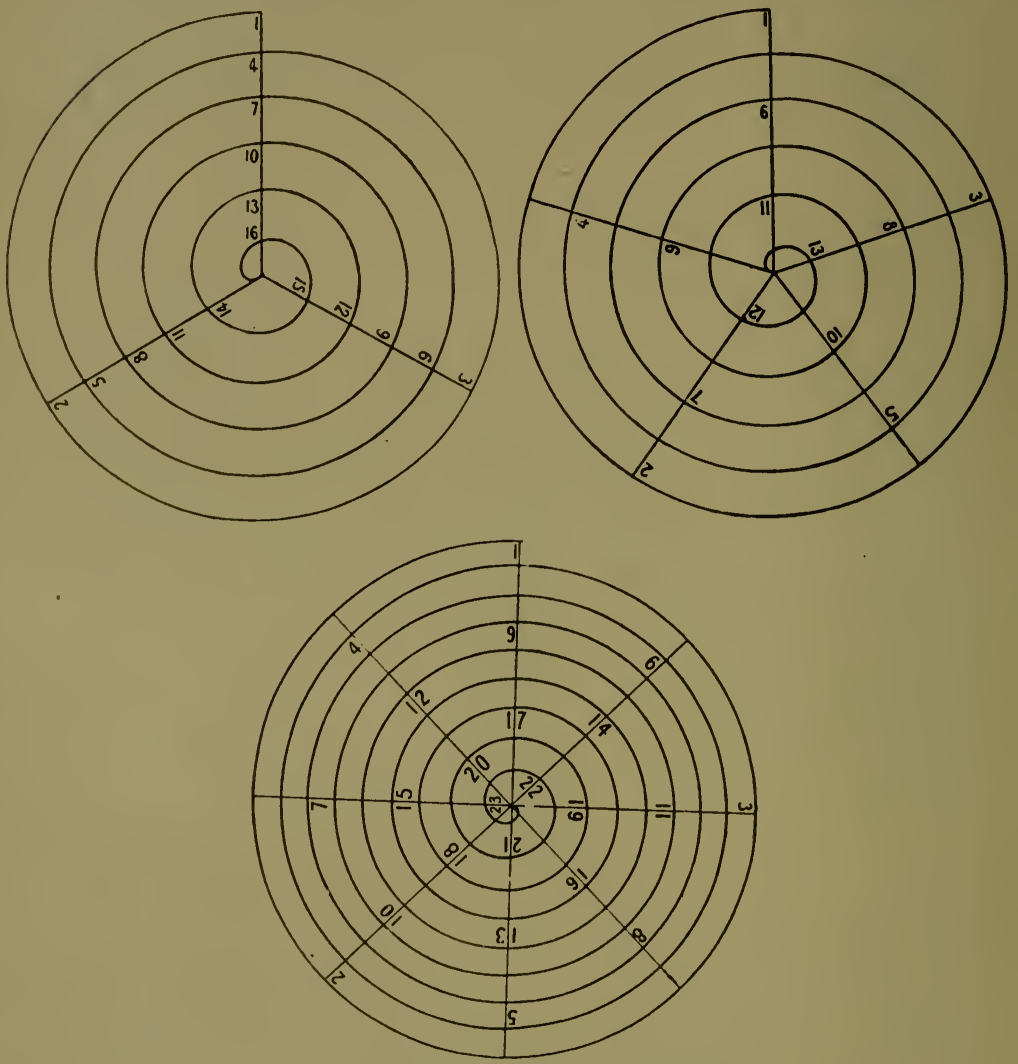

FIG. 57.-Spirals showing $\frac{1}{3}, \frac{2}{5}, \frac{3}{5}$ Phyllotaxy.

spiral and dividing it into three sections. Imagine the centre to be the tip of the stem. Beginning where one of the lines cuts the outer end of the spiral, place leaf number one. Two and three will fall on the other lines. The fourth will be in line with the first. By placing each succeeding leaf one-third 
of the way around the spiral, the seventh will fall on the line with the first and fourth.

Aloe ciliaris bears the sixth leaf over the first. The distance from leaf to leaf is two-fifths of the way around the spiral. What leaf will come over number three? The distance from one leaf to the one next younger is called the angle of divergence. Other Aloes have different angles of divergence. Besides the $\frac{1}{2}, \frac{1}{3}, \frac{2}{5}$ divergence, the fractions $\frac{3}{8}, \frac{5}{13}, \frac{8}{21}$ will represent the arrangement on Proteas and other plants with leaves attached by narrow bases. Still other arrangements may be found.

Besides the spiral arrangement, leaves are frequently placed opposite to one another. When the alternate pairs of leaves are at right angles to each other, as in Carissa and Sage, the leaves are said to be decussate. Not all opposite leaves are decussate. The Crassulas have opposite leaves, but some have the pairs spirally arranged.

Making leaf spirals is excellent work for very warm or rainy days. On pleasant days find as many plants as possible to illustrate these spirals.

Phyllotaxy is the word used meaning leaf arrangement. It is sometimes difficult to make out on branches placed horizontally, as the leaves borne on the lower side turn so as to face the light. Compare them with upright branches.

Instead of drawing spirals, long strips of paper, such as telegraph messages are received on, may be coiled and marked into divisions and then pulled out to represent the stem.

Dr. Kolbe has made an ingenious device for showing phyllotaxy, which he has kindly described and illustrated for us.

\section{Dr. Kolbe's Phyllotaxy Apparatus.}

"Take a strip of corrugated brown paper, about four inches wide and about three yards long. Roll it up closely, but not too tightly, and paste white paper round the cylinder so formed. From the top the coil will look like this (Fig. 58)-

"On the outside of the white paper, divide the circumference into fifths, eighths, etc., as far as you want to show the fractions 
- fifths and eighths alone are enough for me. I mark the

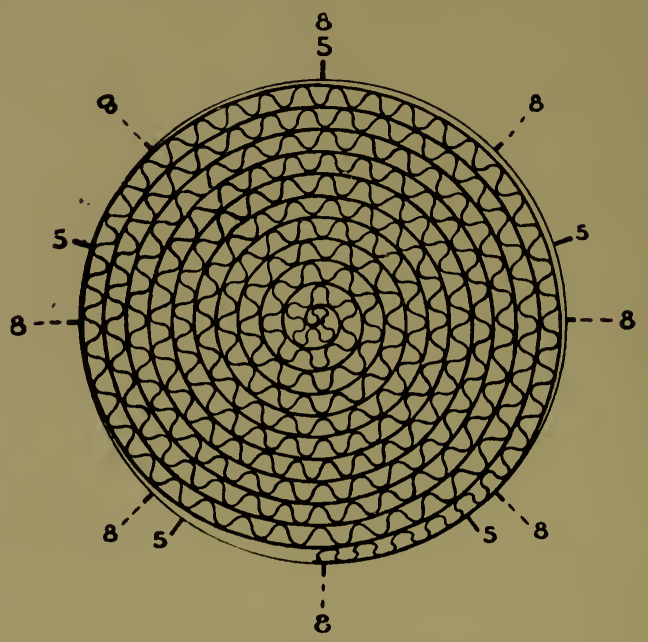

Fig. 58.-Phyllotaxy apparatus.

fifths with blue pencil, and the eighths with red. Side view-

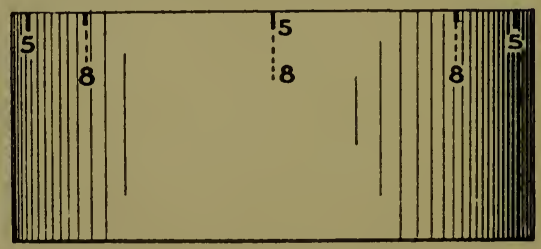

FIG. 59.

"Now cut leaves of various sizes and number them in order,

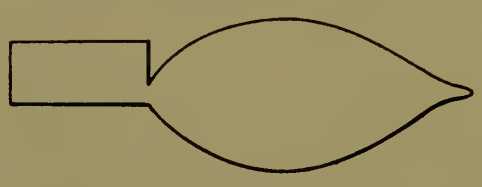

FIG. 60. the smallest being $\mathrm{I}$ for convenience' sake, though, of course, it is the last in growth. Cut the leaf thus-

"Roll up the parallelogram to form a petiole. These petioles will slip into the 


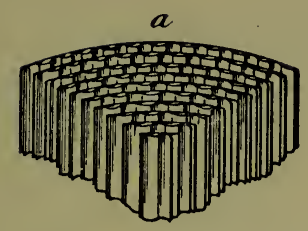

Rosette (section)

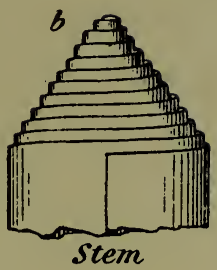

FiG. 6r.

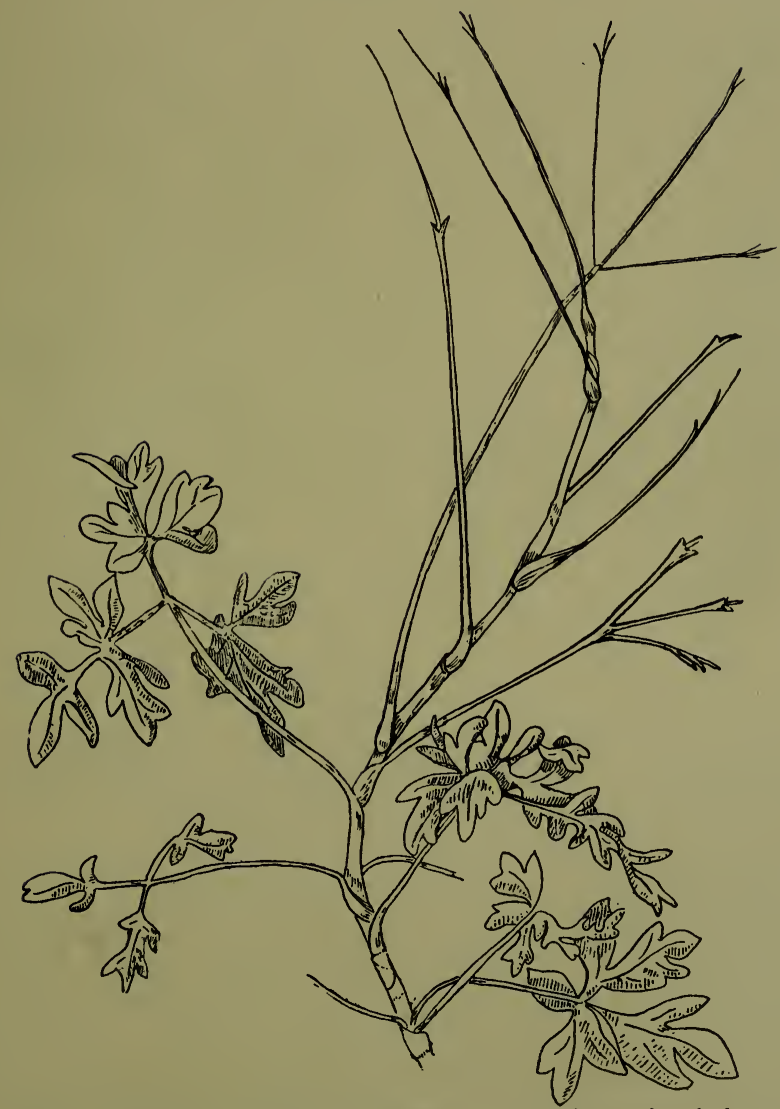

FIG. 62.-Branch of Bupleurum difforme, L., showing variety in leaves, 
grooves of the corrugated paper, and when you let go they expand so as to fit fairly tight.

"Now put leaf I near the middle, pointing to one of the fifths; go round the spiral, and put the next leaf facing the second fifth from the first; and so on, till you have some twenty leaves in position. The phyllotaxy then becomes evident.

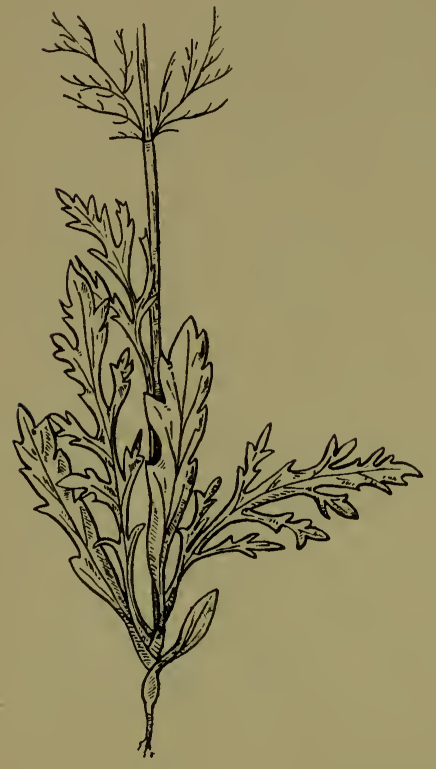

Fig. 63.-Scabiosa. The cut upper leaves allow the light to penetrate below.

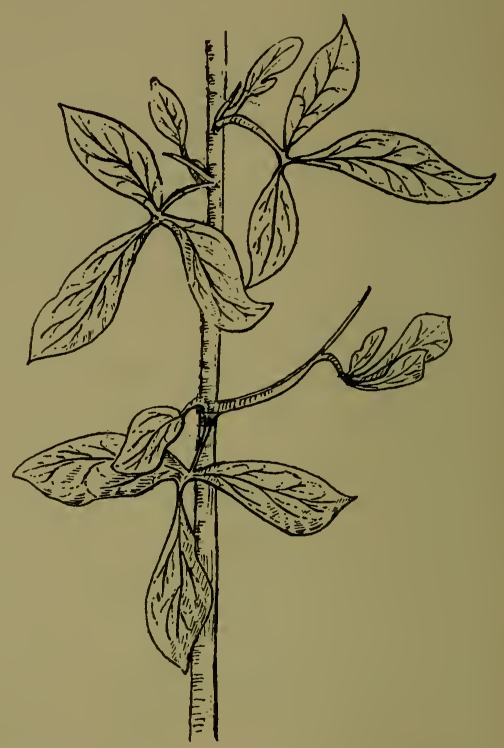

FIG. 64.-Branch of Rhus, showing the simple leaf at the base of each branch.

"If you have not twisted the spiral too tight, the central portion will be found to be moveable. Push it down to show a rosette of radical leaves; push it up to show a stem.

"The stem is very conical, even comical, but the rosette is almost an improvement on Nature.

"By taking coloured leaves for sepals and petals, wax. 
matches for stamens, etc., the same apparatus can be used for making solid diagrams of flowers."

Have you noticed by what other ways leaves manage to get
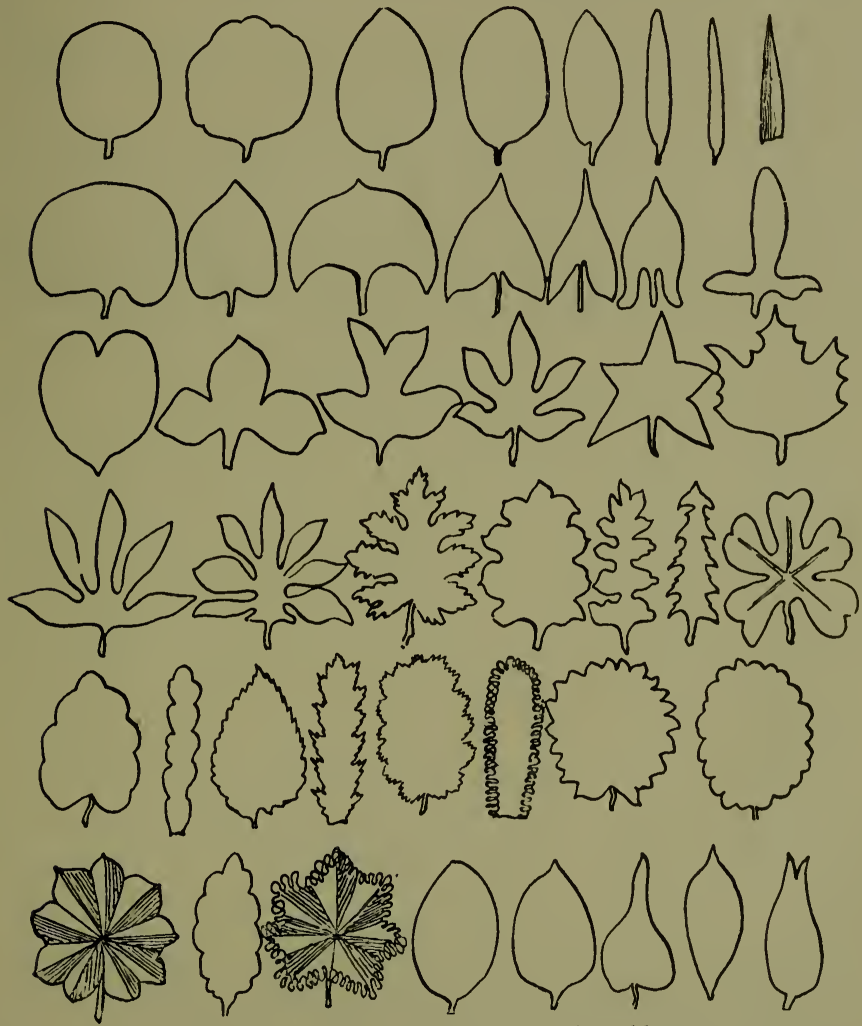

FIG. 65.-Diagram of forms and margins of leaves.

light? Some have much larger leaves below, so that the upper ones cover only a portion. It is more economical for the plant to extend the lower leaves on long petioles. The upper leaves let the light to the lower ones in some cases by being much cut or lobed. In this way the differences in the upper and lower leaves of Bupleurum difforme, L., and Scabiosa come 
to have a new meaning for us. Plants frequently lose all traces of their early leaves, but the first leaf on each branch of the Rhus shown in Fig. 64 serves to remind us of the plant's simple habits in early life.

Attempts have been made to name the different shapes of leaves. To name them all would be a difficult task, as no two leaves are just the same shape.

Aside from the general outline, leaves vary in their margins. They may be entire, or serrate (saw toothed), dentate (toothed), crenate or scalloped, repand, undulate, and so on.

The diagrams of forms and margins of leaves mentioned by Linnæus are shown in Fig. 65. You can find other shapes. 


\section{CHAPTER VII.}

\section{WATERWAYS IN PLANTS.}

How Roots take in Water.-In Chapter IV we read of the water passing from the soil into the roots and thence to the leaves. It is now time to see how this is done.

Each root-hair is a small cell consisting of a jelly-like but living substance called protoplasm surrounded by a thin wall. Each cell absorbs water, which makes it firm. This water holds salts dissolved in it, which are obtained from the soil. When a plant is supplied with water it passes through the walls of the root-hairs and on into other cells; for the whole plant is made up of millions of tiny cells. To see how this is done, let us try an experiment.

Ex. I3. A Bottle Cell.-Take a small wide-necked bottle and fill with syrup made by dissolving a teaspoonful of sugar in half a cup of water. Tie over the mouth a piece of membrane. ${ }^{1}$

Be careful that the solution quite fills the
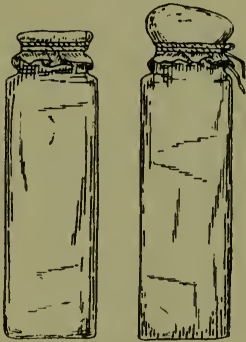

FIG. 66. - A bottle "cell". I. Bottle containing sugar solution; II. the bottle after remaining in the cup of fresh water. bottle before covering. Sink the bottle in a cup of fresh water and set aside until the next day. The membrane now bulges over the mouth. Water has been drawn into the "cell". Into the remainder of the syrup dissolve sugar until no more can be taken. Sink the cell into this thick syrup and set aside for another day. What has happened? The thick syrup has drawn the water out. The water within has passed in the

${ }^{1}$ Obtain a bladder at the butcher's shop. Have the butcher remove the surplus meat and inflate it. When a piece is required, cut it the required size and soak it. It will become thick, but can be separated into layers. Botanical supply companies supply diffusion cells for the purpose, which are neater and more convenient, and should be obtained. 
direction of the stronger solution. Try the same experiment with salt instead of sugar.

Ex. I4. Dissolve out the lime from the shells of two eggs with dilute hydrochloric acid. Place one in fresh water and the other in a salt solution. If the salt solution is of the right strength, diffusion will take place and the egg will shrink, while the other will take up water by endosmosis and will greatly increase in size.

Ex. 15. Remove the shell from one end of an egg, taking care not to injure the thin inner membrane; insert a slender glass tube at the other end, letting it come into contact with the white and seal the join with wax. Place the egg upright in a slender jar which has been nearly filled with water to which a few drops of methyl blue has been added, so that the water comes into contact with the uninjured membrane. In a short time clear water will rise in the tube.

Ex. I6. Place the leaf stalk of a pumpkin in water which has had salt dissolved in it. Leave for a few hours. How does the stalk look? Now wash off the salt and place in fresh water. Notice a few hours later. How has the stalk altered?

Ex. 17. Boil a piece of beet-root or a green bean pod for a few minutes in water. When removed they are quite limp. The water is coloured. When placed in fresh water they do not become firm again. Boiling has killed the living protoplasm. The dead membrane cannot hold the coloured sap. Living cells can retain the sap until a certain amount of pressure is set up within the cell. This keeps the plant firm. Protoplasm acts because it is alive.

Roots not only draw material from the soil, but they send out an acid which dissolves the hard rocks.

Ex. 18. Germinate seeds in a flower-pot into which has been placed an inclined piece of marble having the smooth side up. Keep the roots watered until the pot is well filled with their growth. Remove the marble, and look on it for the etching made by the roots.

Ex. rg. Fasten to a glass slide with a rubber band a piece of blue litmus paper, between the glass and a germinating seed. The glass and paper should be previously moistened well with steam or distilled water. Place within a covered dish. As the radicle lengthens, notice the faint change in colour on the paper. Acid colours blue litmus paper red. It may be the carbonic acid which is formed when roots breathe out carbonic acid gas, as we shall find out they do. Besides carbonic acid, an acid salt is excreted from roots, acid potassium phosphate. ${ }^{1}$

How the Water is Lifted up.-Within the "bottle cell," pressure made the membrane bulge. Cut off growing bean stems below the cotyledons. Drops of water collect at

${ }^{1}$ Not all roots excrete sufficient acid to show these tests. 
the cut end and run down the stem. Pressure from below forces it up. ${ }^{1}$

In order to see how long this continues, we may try another experiment. It will require a vigorous young plant such as a Castor Oil, Pelargonium, or Grape Vine, a piece of glass tubing as large as the stem, also some string and a stake of wood.

Ex. 2o. Cut the stem an inch or two from the soil. Slip one end of the rubber tubing over the glass and the other over the cut stem which was left in the soil. Place a little water in the tube to prevent the stem from drying and tie the glass firmly to the stake. Be sure that the rubber makes a tight joint. It may be tied at each end. The water will rise in the tube. At the close of the day mark the height at which the water stands. Notice how much has passed during the night. Mark the height at each hour of the day. Are the marks the same distance apart ? Does the water constantly rise?

Ex. 21. What becomes of the water? Place the upper part of the plant cut off in the last experiment in a slender jar of water. Pour a layer of oil over the top to prevent evaporation, or thrust the cut end through a stopper and seal with wax. Cover the whole with a bell-jar or a fruit-jar. See that the glass is quite dry before covering. In a short time the jar will be lined with a thin mist, which will collect in drops of water.

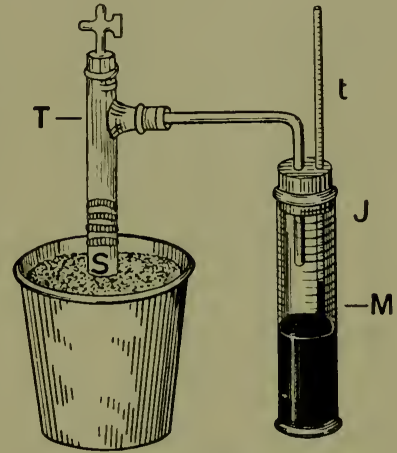

Fig. 67.-Apparatus to demonstrate root-pressure. The cut stem is fastened to a glass tube by means of rubber tubing. The tube leads by an arm into the jar $(J)$. Both are filled with water with mercury in the bottom of the jar. As the cells in the root force the water into the tube the mercury is forced up into the small tube, $t$.

\section{Water passes from the Leaves and Stem of a} Plant in the form of Vapour. As the leaves give off vapour more water is drawn up to take its place.

Ex. 22. Soak strips of paper in cobalt chloride. Dry thoroughly, and notice how they change from red to blue as they dry. Dry the inside of the jar containing the plant. After remaining in the bell-jar for a while the paper changes back to red. This also shows that vapour is passing from the leaves.

${ }^{1}$ This pressure accounts only in part for the upward ascent, which is not fully understood. Evaporation from the leaf surface is doubtless connected with the lifting of water. 
This pretty experiment should not be omitted. Cobalt chloride may be obtained from the chemist. Sixpennyworth will prepare sufficient paper to last some time. It will keep, and the same piece may be used repeatedly.

Ex. 23. Place under the bell-jar fruits of Erodium or Pelargonium and watch them uncoil ; remove, dry in the sun, and repeat the experiment.

Ex. 24. Place a leafy shoot in a glass U-tube (a straight piece of glass may be heated and bent the required shape). Connect the shoot to the tube with rubber tubing so that no air can enter. The tube should be filled from the other end with water. When the water has been nearly drawn out of one arm, pour in mercury. The mercury, which is very heavy, will be raised higher in the arm of the tube containing the plant than in the other, so the leaves can do some heavy lifting.

Does water pass from leaves in any form but vapour? If so, it must be in drops. Place a pot of germinating Indian Corn or Oats under a bell-jar overnight. The next morning notice the tip of each blade where there are small holes through which water can pass in drops.

After a warm night or in shaded places the tips of the young blades in a corn field may be seen beautifully aglisten with drops.

They are not dewdrops, for they are there when no dew is formed on other plants. Other plants show the same nicely. See the drops on Tropaolum (Nasturtium) plants where openings on the leaves are placed at the end of each strong vein.

On a very warm afternoon in summer an entire Rose bush may have the serrate points of every leaf glistening with a drop of water.

\section{Does vapour pass off in equal amount from both} leaf surfaces?

Ex. 25. Place an Apricot leaf between two sheets of filter paper soaked in cobalt chloride. ${ }^{1}$ The leaf should be dried from all surface water; then place between two plates of glass. ${ }^{2}$ On all place a light weight. In half an hour, or less, ex umine. The paper next the under side of the leaf will be red, that on the upper surface will be only slightly changed. Moisture given off by the leaf has changed the colour.

${ }^{1}$ Try the same experiment with a Sunflower leaf; with a leaf from a pepper tree.

${ }^{2}$ Line two pieces of sheet cork with plush and cut holes in the centre of each. Fasten a cover glass over each hole. This may be fastened over the cobalt chloride paper with a rubber band. 
The greater amount of water passes off from the lower surface of the leaf. This is true of many leaves, but not of all. Is the result the same for the lower broad leaves and the upper narrow leaves of the Blue Gum? IVhere does the water escape from the Water - lily leaf? From silver leaves? From "April Fool" leaves?

Why do plants usually lose more water from the under side? How the leaf controls the escape of vapour can be seen with a microscope. A picture will help to make it clear for the present. Scattered over the under surface of the Apricot leaf are very small holes called stomates (singular stoma) or stomata (mouths). Two crescent-shaped cells surround the opening. These lip cells open and close. During the day they are open, and evaporation keeps the leaves cool. If leaves were as hot as the stones around them they would die. In very dry weather the stomata close so that less water escapes. These stomata open into spaces within the leaf into which water passes from surrounding cells. On a summer day leaves lift up and lose tons of water. Leaves
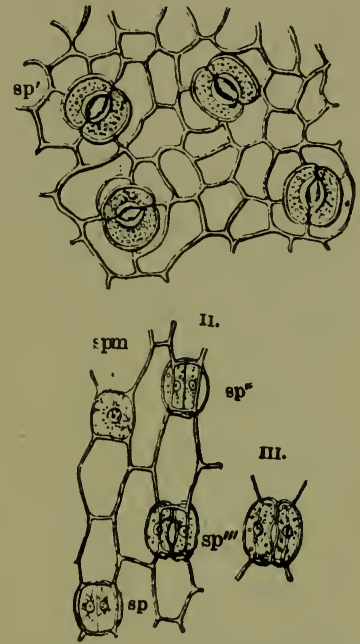

FIG. 68.-I. Horizontal section through the epidermis of the under side of the leaf of $E u$. onymus japonicus looked at from below; $s p$, stomata. II. Course of development of the stoma of Arthropodium cir. rhatum : spm, mother - cell ready for division ; $s p^{\prime}, s p^{\prime \prime}$, $s p^{\prime \prime \prime}$, successive stages of division. III. Mature stoma. (From Edmonds and Marloth's "Elementary Botany for South Africa".) borne on the surface of water or close to the soil have their stomata on the upper surface. ${ }^{1}$

The Water Path from Root to Leaves.-Water does not pass up to the leaves through all parts of the stem. If a Begonia stem is placed in water coloured with red ink, in a few hours the ink will mark the path it has taken. Cut the stem

${ }^{1}$ An area on the under surface which could be covered by the capital $O$ on this page contains over 3000 stomata. 
across and the paths will show as small round dots. They show plainly in Pumpkin stems as strong slender threads. These threads are bundles of still smaller tubes or vessels, and so the strands are known as vascular bundles. Break off a Violet leaf; the vascular bundle may be drawn out from the broken end. The petioles of Plantain or IVild Sago, which grows along

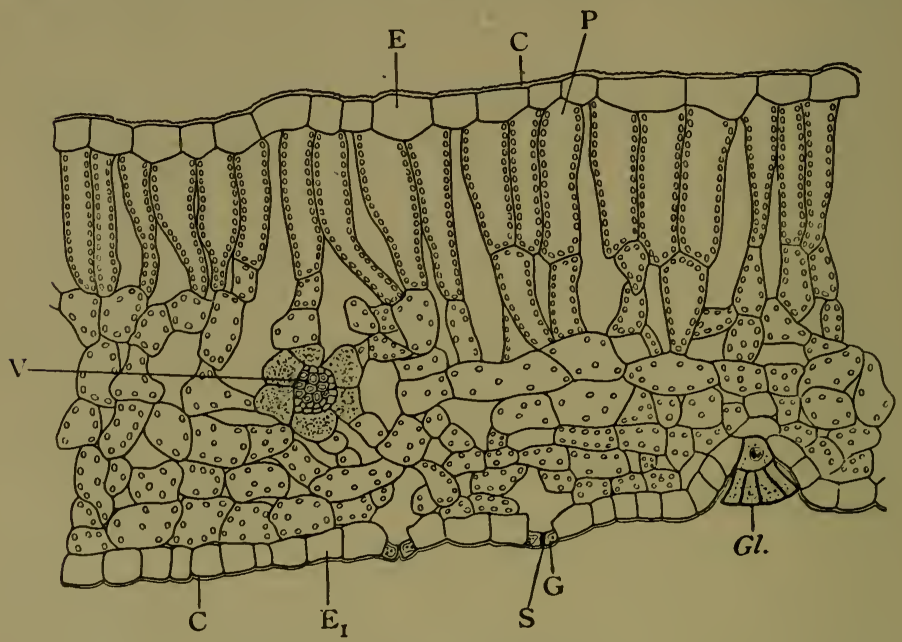

FIG. 69.-Leaf of Privet. $\mathrm{E}$, epidermis of upper; $\mathrm{E}_{1}$, of under surface ; $\mathrm{C}$, cuticle; $\mathrm{P}$, palisade cells; V, vascular bundle enclosed in its sheath ; S, stoma, G, guard cell ; Gl, gland. (From Farmer's "Practical Introduction to the Study of Botany"'.)

sluits, show the vascular bundles nicely. They may be traced to the veins of the leaves in which they end. They even pass to all parts of the flower. In the Strawberry they may be easily seen passing into each "seed" of the fruit. All parts of the plant must be nourished.

Ex. 26. From a woody stem bearing leaves (a willow is good for the purpose), remove a ring of bark down to the wood. Place the lower end in water over which a layer of oil has been poured; cover with a bell-jar. The water will be used up and the leaves will transpire water vapour.

Ex. 27. Carefully separate the bark from the wood at the lower end of the stem; remove the wood and place the stem so that only the bark is in the water. The leaves quickly wither. This shows that water is carried up through the wood. 


\section{CHAPTER VIII.}

\section{CELLS AND TISSUES.}

THE present chapter, which may better be omitted on first reading, is intended to give a more detailed account of cells and their association into tissues which have been mentioned frequently in Chapters IV and VII. For this chapter a micro scope should be used.

The term cell suggests honeycomb; in fact the cells first described were regarded as small cavities surrounded by walls, but the more essential living part of the cell is that which the wall contains.

In a typical cell there may be found (I) the protoplasm, (2) the cell sap, (3) the cell wall.

(I) Protoplasm mentioned in Chapter VII as the living part of the cell, includes:-

(i) The cytoplasm, a gelatinous substance having the appearance of the white of an egg. It is a complex structure and consists of proteids - that is of organic compounds made up of carbon, hydrogen, oxygen, nitrogen, sulphur, and usually phosphorus. ${ }^{1}$ When living it is in constant activity, undergoing continual breaking down and renewal and is besides in ceaseless motion. The rate of movement depends to a large extent upon temperature.

Young hairs of Indian corn leaves reveal this motion if examined under a microscope. The protoplasm here circulates to and fro from the wall to a stationary body, called

(ii) The nucleus. This is a body of the utmost importance. It is complex in composition, complicated in structure, and is

${ }^{1}$ Living and dead protoplasm differ in chemical composition. 
the centre of the cell's life and activity. It appears in its resting state as a denser shining portion of the protoplasm, spherical or lens-shaped. Volumes have been written on its structure and behaviour, the rhythmic dance of its parts in the activity of division which initiates cell division, and the preparation it undergoes when about to fuse with another nucleus in the reproductive process. A larger book must be consulted for these changes.

(iii) The plastids are special little organs embedded with the nucleus in the cytoplasm. Like the nucleus, these are formed from pre-existing plastids. They have their special work to do and are of three kinds :-

(a) Chloroplastids, bodies which contain the green colouring matter by virtue of which the plant is enabled to appropriate the energy of the sun's rays for photosynthesis (see Chapter XII.). In brown and red seaweeds other colouring matter masks the green. By dipping the plants in boiling water these colours will be extracted and the green colour will then become visible. By dipping again in boiling alcohol the green colour will be extracted.

(b) Leucoplastids, which are bodies similar to chloroplastids but are colourless. They are often found in parts concealed from light, as in potato tubers. When these parts are exposed they may develop chlorophyll.

(c) Chromoplastids contain a substance which gives colour to most yellow and red flowers and to carrots. When fruits ripen or leaves take on their autumn tints of yellow, chloroplastids change to chromoplastids.

(2) Cell Sap.-A young cell is filled with protoplasm. In older cells the protoplasm does not increase in proportion to the cell wall. Several vacuoles and in time a large central cavity are formed within it. These are filled with cell sap. It consists of water in which are dissolved food material and prepared foods. Blue and some red flowers owe their hues to colouring substances dissolved in the sap.

(3) Cell Walls.-Not all cells possess walls ; bright orange masses may be found on pine needles in damp places. They are a stage of a low class of plants known as the Myxomycetes. 
Each cell of this mass is without a wall; its protoplasm can reach out in any direction and creep or stream from one place to another. By placing some in a moist chamber this streaming may be watched. Cells of higher plants have walls, except some which are connected with reproduction.

Cell walls are commonly of cellulose. This is a carbohydrate which varies in different plants. Its chemical formula is $\left(\mathrm{C}_{6} \mathrm{H}_{10} \mathrm{O}_{5}\right)_{n}$. It is derived from the cell protoplasm with which it is always in contact in a living cell, and when active it is saturated with water.

As cells mature they undergo a variety of changes. These are alterations in chemical composition, in shape, and in thickness of the wall.

Chemically the walls may become lignified or woody, when they become highly elastic and permeable to water, suberized or corky, as in the outer bark ; such cells are impermeable to water and air and are therefore fitted for protecting. Cutin, occurring in the walls of the epidermis as in cabbage leaves and those of Othonna and Protea, is of the same service as suber. Walls may become mucilaginous. They swell and become gelatinous when soaked in water, they serve to fix the seed to soil in the case of linseed and cress, and while food material is usually stored within the cell cavity, mucilage, e.g. in tubers of Orchids, and the thick cellulose walls in the seed of Coffee and Date, are used as reserve food. In Acacia a further change occurs and the walls change to gum which dissolves in water.

The shape of the cell which constitutes a whole plant in itself may be round or nearly so, but when cells combine to form tissues they become flattened, angular, and sometimes much longer than broad. They may join each other by flat surfaces or they may overlap by long pointed ends. Long pointed cells are commonly found in wood and in the inner bark. Such cells are called prosenchyma to distinguish them from parenchyma where the cells are about equal in length and breadth.

Cells placed end to end may lose their end walls and form long continuous tubes or vessels. Vessels always lose their 
protoplasm; they have markings of different patterns due to successive thickening layers which are laid down on the inner surface of the walls and serve to strengthen them. Vessels convey the transpiration current with its dissolved food material in its upward flow and at length they may serve only as air carriers. Because of the appearance given by their markings vessels are known as trachea.

Fibres may have the same markings as vessels; they are then called tracheids.

Vessels and tracheids are found in the wood of plants. The first vessels to be formed (protoxylem) have the thickening laid down in rings, or spirals. Those formed later on have simple or bordered pits and ladderlike or scalariform markings.

Sieve tubes are found outside the cambium in the phloem. ${ }^{1}$ Their end walls are not wholly absorbed but are perforated in a sieve-like manner. They have not the markings of vessels and retain their protoplasm as long as they perform their function. There is reason to believe that they serve to convey rapidly food containing nitrogen from the place where it is elaborated to parts below.

Besides wood vessels and sieve tubes there are latex vessels or milk tubes. They branch and fuse, forming a network. The walls remain cellulose and are but little if at all thickened. Like the sieve tubes they are without markings. Their contents, latex, are milky, e.g. Asclepias, Euphorbia, Carissa, Sonchus; watery in the poppy family (Papaveraceæ), where coloured latex is also found. Latex contains nutritive substance and possibly waste material.

A variety of other substances are found within cells either as food or as waste products. Of these may be mentioned :-

I. Starch.-This is one of the commonest forms in which reserve carbohydrates may be found. In green parts it is formed as very small grains within chloroplasts. In storage organs, however, as in seeds and tubers, they are formed on lencoplasts and are large and conspicuous. A starch grain shows an inner watery spot, the hilum, with layers around it

${ }^{1}$ See p. 72 . In some stems sieve tubes are also internal to the wood. Some of these are mentioned farther on in the text. 
formed of denser portions alternating with more watery layers. In Rice and Oat seeds they are compound.

2. Sugars, fatty oils, inulin are other forms of non-nitrogenous reserve food. Inulin like sugar is found in solution, but it may be crystallized out by irrigating the tissue with alcohol. It may be found in tubers of certain Compositæ, e.g. Dahlia, Othonna, in Campanulaceæ and other orders.

Starch, sugar, inulin are like cellulose carbohydrates; i.e. they consist of the elements carbon, hydrogen, oxygen, in which $\mathrm{H}$ and $\mathrm{O}$ are combined in the same proportion as in water.

3. Proteids.-Food containing nitrogen may be stored in the form of proteid grains. These are larger and more easily examined in oily than in starchy seeds. In the Castor Oil seed the proteid is especially large. It consists of a proteid body enclosing one or more proteid crystalloids and a mineral granule globoid, made of a double phosphate of calcium and magnesium. While the proteids are distinguished from the oils and carbohydrates as nitrogenous foods they also contain carbon, hydrogen, and oxygen and in addition sulphur and sometimes phosphorus.

4. Amides are simpler forms of nitrogenous foods containing carbon, hydrogen, nitrogen, and oxygen. They occur as reserve food chiefly in roots, bulbs, and tubers as asparagin, tyrosin, and leucin.

5. Minerals. - Crystals of calcium oxalate are frequently found in cells. These are generally regarded as excretions, i.e. when once set apart they no longer function in the plant's activity. Crystals may occur singly or in groups. They are frequently octahedral. In the vine and in many monocotyledons they occur as clusters of raphides or needle-shaped crystals.

Calcium carbonate is more rarely found. It occurs in the form of cystoliths, e.g. Justicia, Ficus, Morus. In the development of cystoliths an ingrowth appears on the wall of an epidermal cell, forming a stalk and an expanded portion, the latter appearing like a cluster of grapes. It diminishes in size, and bubbles of $\mathrm{CO}_{2}$ are given off when the cystolith is treated 
with hydrochloric acid, showing that the cellulose is encrusted with carbonate of lime. At times there is an abundance of lime while again it disappears; it may therefore be an accumulation which is secreted and may be of further use, though it also is commonly regarded as an excretion or waste product.

6. Resins and Ethereal oils, which give odour to many plants, are probably excreted products. They remain in leaves and are cut off at leaf fall.

7. Tannin-containing cells are found in abundance in epidermis and cortex ; tannin is probably a waste product.

8. Enzymes which serve to digest food substances and render them capable of absorption are secreted in special cells in Cruciferæ, Capparidaceæ, and other orders.

To summarize :-

Cells may be-

r. As to chemical composition, of cellulose, lignin, suber, cutin, mucilage.

2. As to growth forms parenchymatous, about as long as broad, not pointed (rounded, oval, tabular, flattened, stellate). Prosenchymatous, long and pointed.

3. As to thickening -

(a) Not forming patterns-

Collenchyma, angles thickened, unlignified with contents.

Parenchyma-

Sclerotic cells, uniformly thickened, lignified without contents.

Thick walled parenchyma, uniformly thickened, retaining contents.

Prosenchyma-

Sclerenchyma, uniformly thickened, lignified, without contents.

(b) Forming patterns-

Parenchyma with simple pits found in wood, phloem, cortex, pith.

Prosenchyma and vessels, forming rings, spirals, simple and bordered pits; found in wood; in tracheæ and tracheids. 
4. As to fusion-

(a) Without protoplasmic contents and with markings-

Vessels, end fusion complete, found in wood, conveying transpiration current and air.

(b) With protoplasmic contents without markings-

Sieve tubes, ends perforated, found in phloem, carrying elaborated food.

Latex vessels, end fusion complete, forming a network, found in various parts, carrying latex.

All of the cells mentioned here except latex tubes may be found in the oak stem (Fig. 72).
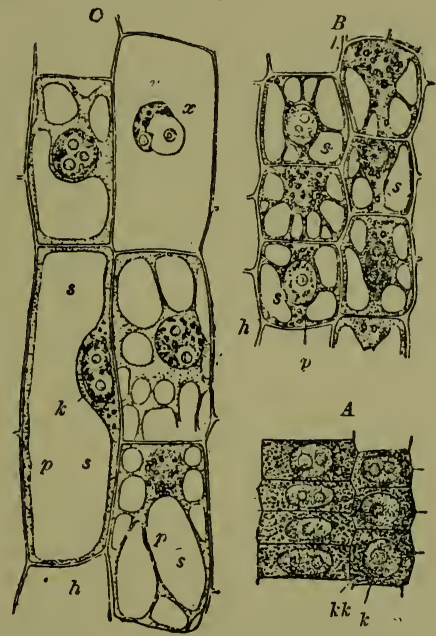

FIG. 70.-Cell structure. $A$, young parenchymatous cells ; $p$, protoplasm ; $k$, nucleus ; $k k$, nucleolus ; $B$, older cells showing vacuoles; $s$ in $C$, the vacuoles have become larger; $y$, the protoplasm has withdrawn from the wall and the cell will become inactive.

5. As to contents-

A typical cell has

(a) Protoplasm consisting of cytoplasm

with outer layer, ectoplasm.

inner layer, endoplasm.

nuclear membrane, kinoplasm.

(b) Nucleus, with nucleolus. 
(c) Plastids $\left\{\begin{array}{l}\text { Chloroplastids. } \\ \text { Leucoplastids. } \\ \text { Chromoplastids. }\end{array}\right.$

(d) Cell sap

Cells may contain

Water and food material.

Air.

Reserve food

Non-nitrogenous Fatty oils.

Nitrogenous

Proteids.

Amides.

Latex which may contain tannin, proteids, fats, and starch.

Excreted, waste or by-products (probably)

Mineral matter.

Ethereal oils and resins.

Tannin.

Enzymes. 


\section{CHAPTER IX.}

STEM AND ROOT STRUCTURES.

A. Dicotyledonous Stem.-For the study of stem structure a Sunflower may first be examined. Cut off a vigorous stem and leave the upper portion in methyl blue. ${ }^{1}$

Cut a portion of a stem across a short distance below the tip and peel off a thin transparent strip, the epidermis ; this takes with it the scabrous hairs with which it is clothed, showing that they are out-growths of this layer. They disappear lower down, leaving the stem rough with their bases.

Within the epidermis lies the cortex. Stain the cut end with iodine and wash off. About a third of the distance from the epidermis to the centre, a ring of small blue dots appears. They are starch grains which iodine stains blue and are stored within the innermost layer of the cortex, the endodermis. In the stem the endodermis may generally be recognized by the starch it contains and is here known as the starch sheath.

Surrounded by the endodermis lies the stele. It consists of a mass of ground tissue or conjunctive tissue within which lies a broken ring of tissue forming elliptical patches. In a fresh stem they appear white toward the centre and greenish without. These are the complex fibro-vascular bundles. Iodine has stained the inner portion a reddish brown. This region, the xylem, contains the wood vessels and fibres. If the stem which was placed in methyl blue be examined it will be seen that these cells have taken up the blue since they serve for the upward path of the transpiration current.

${ }^{1}$ This stain does not injure the stem, a few grains should be dissolved in water until the solution is a clear bright blue. 
To the outside of the xylem other cells of the bundle will take the same stain as did those of the endodermis; they also contain starch and are in the part of the bundle called phloem or bast. In this region sieve tubes occur. With a lens they

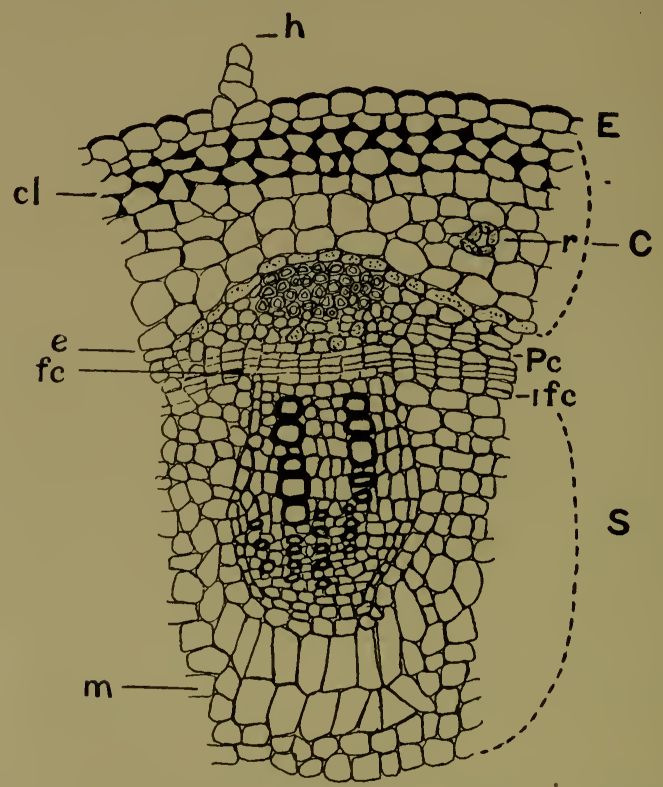

FIG. 71. - Stem of Helianthus (sunflower), cross section. Drawn by Miss Averil Bottomley. E, Epidermis with hair $(h)$, the outer thickened walls form the cuticle. C, Cortex. The outer cells with thickened angles form collenchyma. A resin gland $(r)$ may be seen in the parenchyma. The innermost layer $(e)$, the endodermis or starch sheath, contains starch. S, Stele or central cylinder containing one fibro-vascular bundle. $(P c)$, pericycle: it forms a cluster of sclerenchymatous cells just outside each bundle. Between these cells and the bundle cambium ( $f c$ ) (fascicular cambium) lies the phloem. 'The portion of the bundle inside the cambium is the xylem. It contains rows of large thick-walled wood vessels. $(m)$ Medulla or pith. ( $f c$ ) Interfascicular cambium.

can be made out by their larger size. Iodine stains their contents, and those of neighbouring cells, yellow brown.

IVithin the ring of bundles, the ground tissue making up the greater portion of the stem is known as the medulla or pith, and between the bundles the medullary rays extend out to the cortex. They carry material from the wood out to the cortex 
where it is elaborated and returned to the bundle for distribu-

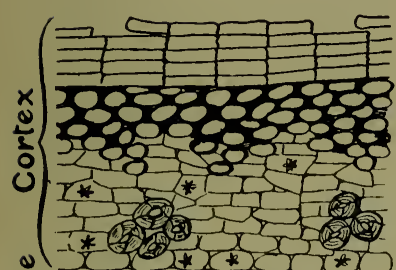

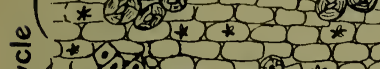

\section{:}
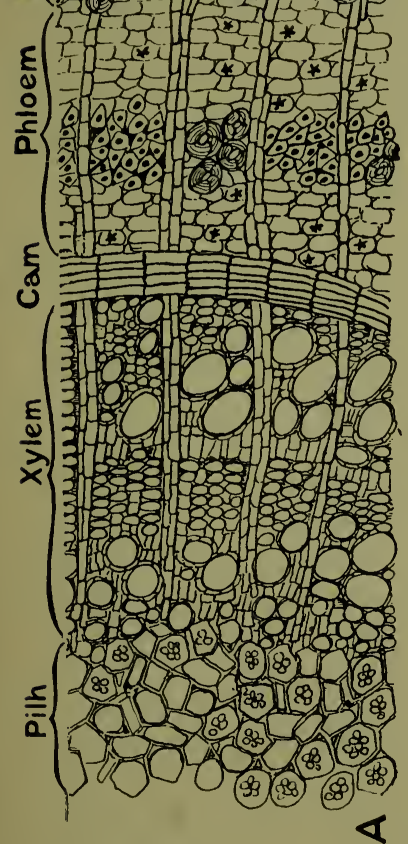

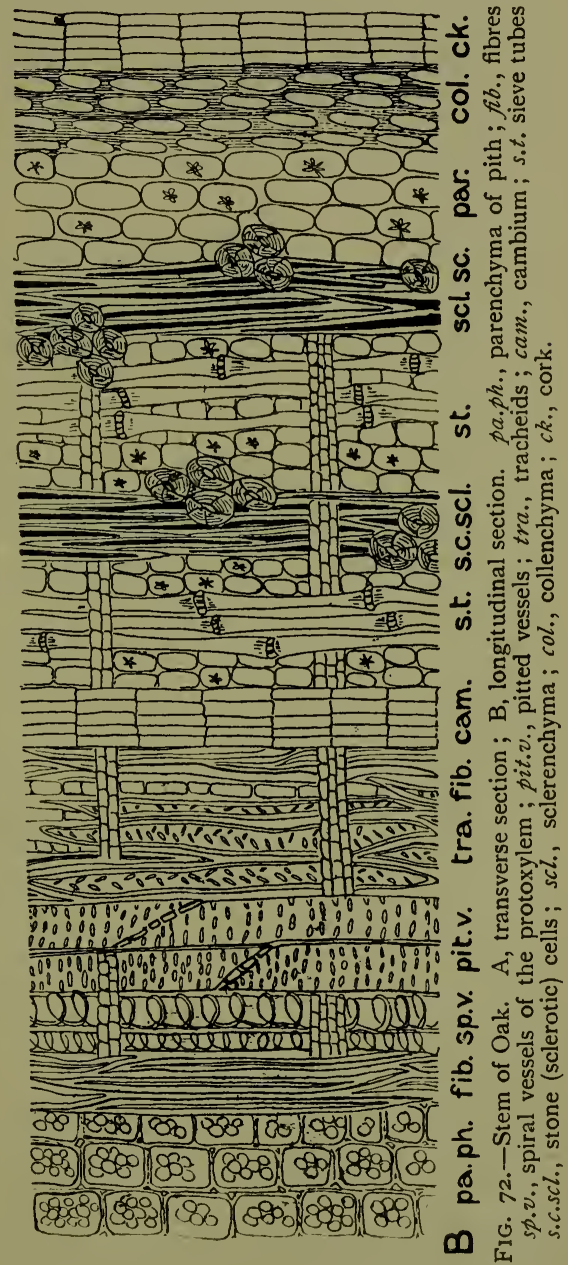

tion; some is carried to the pith where it may be stored. Medullary rays thus serve in horizontal distribution as the 
bundles serve for the vertical distribution of food and food material. Starch is also stored here.

The cells outside of the bundles and within the endodermis comprise the pericycle. This consists of several layers of cells ; those just outside the phloem being developed into thickwalled fibres serving as a protection to the delicate cells of this tissue. The fibres stain with iodine nearly the same colour as the wood. They are sometimes called phloem- or bastfibres, but they are not developed from the same region as the bundles.

Between phloem and xylem the delicate cambium cells are found. Some distance below the tip of the stem, the cells of the medullary ray become active and by their division form cambium (interfascicular cambium) which unites with the cambium of the bundle and forms a complete cambium ring around the stem. This ring, by the constant division of its cells, increases in breadth and circumference; some of its cells, those toward the pith, form new wood; toward the outside phloem is also renewed by them (secondary xylem and phloem); the medullary rays are also extended by the cambium.

Within the cortex and pith are small dots which indicate the position of resin cavities. Where growth is vigorous resin cavities are also found in the secondary phloem.

As the Sunflower is an annual, but little secondary wood and phloem are formed, and correlated with this fact, little if any cork is developed.

Bundles with cambium are known as open as contrasted with those with no cambium which are closed, that is, closed to further development.

The bundles of the Sunflower which have the characteristic structure of dicotyledons are of the type known as collateral ; they have the phloem lying to one side of the xylem and in the same radius. In the Pumpkin family there is phloem to the inside as well as the outside of the bundle, a bi-collateral type. The phloem may surround the xylem; the bundles are then known as concentric.

Before proceeding farther it may be well to define a term which has been frequently used in this chapter, the word tissue. 
A tissue is a group of cells which have had a common origin, have developed in a similar manner so as to have the same appearance, and have the same work to do: for example we speak of the epidermal tissue, ground tissue, vascular tissue, cortical tissue. At the apex of the stem the cells are alike forming one tissue-primordial meristem. Close behind
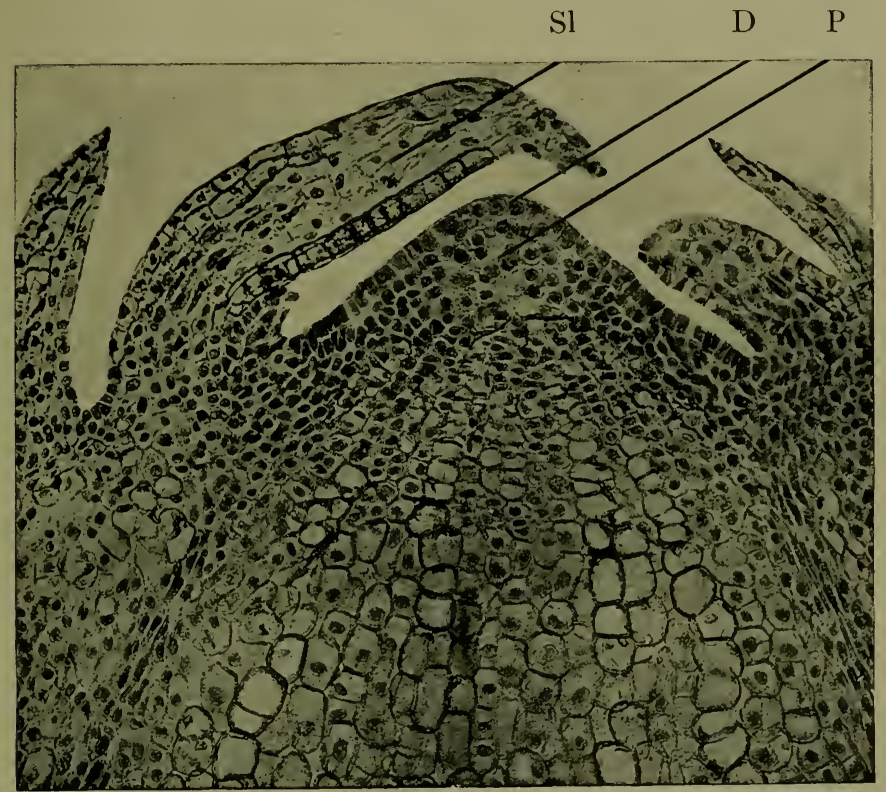

FIG. 73.-The growing point (highly magnified) of the stem of Pinus sylvestris. $\mathrm{D}$, dermatogen; $\mathrm{P}$, periblem and plerome; SI, scale leaf (highly magnified). (Photo-micrograph by Flatters, Milbourne, \& McKechnie.)

the tip, this tissue shows a change: three tissues may be found - (a) the dermatogen ( $\delta e^{\prime} \rho \mu$, skin; $\gamma \epsilon \nu \nu a ́ \omega$, I bring forth) or

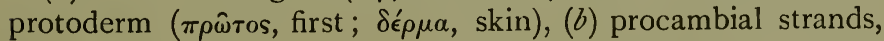
(c) ground meristem.

(a) The dermatogen divides by walls in two directions at right angles to the surface walls, and, as the derivation of the word indicates, forms the epidermis.

(b) Farther down the stem, the procambial strands elongate 
and develop into the three parts of the bundle: its outermost cells form the first phloem (protophloem), the innermost the protoxylem, while between the two regions the procambium remains active and forms the cambium of the bundle.

(c) The cells of the ground tissue divide in all directions and become marked out into the medulla, the medullary rays, the pericycle, and the cortex.

Leaf Formation. - The dermatogen and underlying ground tissue of the stem give rise to the leaf. The cells at a node divide actively and form the leaf protuberance. The vascular bundle supplying the leaf, begins forming at the node; the cells extending up into the leaf and down into the stem gradually elongate until a continuous bundle is formed connecting the leaf with the food supply. In dicotyledons the number of leaf bundles or leaf traces is relatively few ; they run down the stem parallel to one another through one or more internodes and fuse at the nodes. The bundles are common, that is common to leaf and stem. The course they take as they pass down the stem forms the ring which is seen in a cross section of an internode.

B. Monocotyledonous Stem.-A monocoytledonous stem is distinguished from that of a Dicotyledon by the fact that in the former the bundles are closed; that is all the procambium passes over into phloem and xylem so that further increase is prevented.

The bundles appear to be scattered irregularly; as a matter of fact they are arranged in more or less concentric circles. The bundles are common, but in monocotyledons, which as a rule have broad leaf bases, the leaf traces are more numerous, and instead of running down the stem parallel to the surface as in dicotyledons, they curve in the stem; the midribs making the largest curve extend nearly to the centre of the stem, while the lateral veins of the leaf do not penetrate so deeply.

In many monocotyledons it is difficult to distinguish cortex from stele as the bundles extend out from the centre close to the circumference as in Zea mays; in others, Ornithogalum for example, a well-developed ring of fibres in the pericycle makes the distinction evident. In Zea where this ring is wanting, 
each bundle is surrounded by a fibrous sheath developed from the ground tissue.

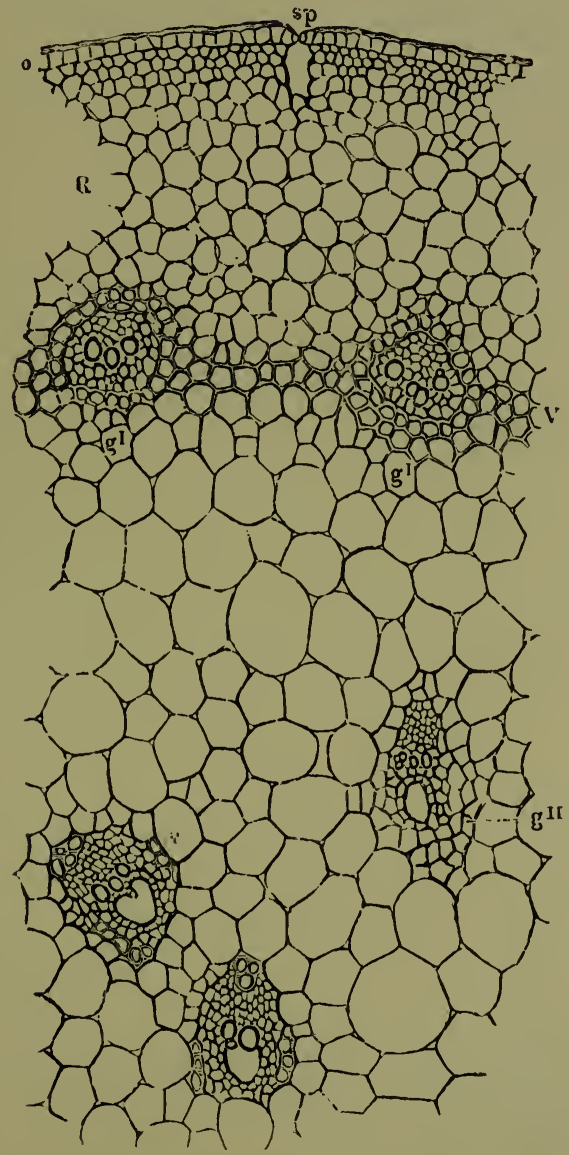

FIG. 74.-Part of a transverse section through the stem of Tradescantia Sellö : $o$, epidermis, with a stoma, $s p ; \mathrm{R}$, cortex; $\mathrm{V}$, thickening ring with the outer vascular bundles, $g^{\prime} ; g^{\prime \prime}$, inner vascular bundles $(\times 75)$.

Secondary Thickening in Monocotyledons.-Since the closed bundles of monocotyledons allow for no secondary thickening, the structure of the mature stem resembles that of 
the younger portions. In a few cases, however, for example Aloe, Yucca, Dracaena, Aristea corymbosa, Benth., the pericycle remains meristematic and continues to lay down bundles and ground tissue by which the bundles are surrounded. These secondary bundles are confined to the stem (cauline) and are without the protoxylem of the common bundles.

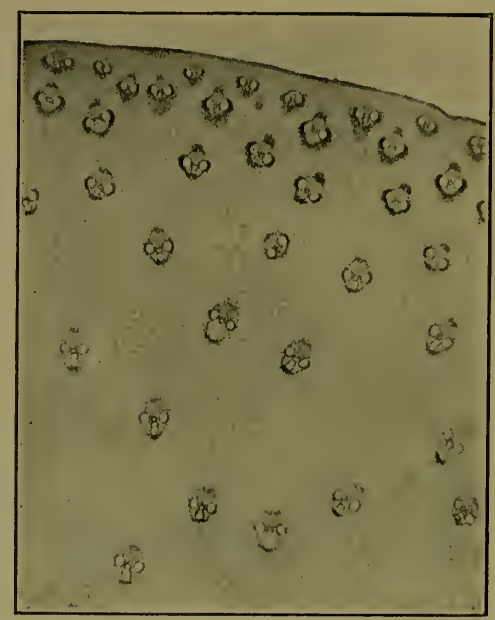

F15. 75.-Transverse section of Zea mays. The cortex and pith are not clearly defined in the ground tissue. Each bundle is surrounded by a bundle sheath and contains two large vessels. An air cavity is formed by the breaking down of cells in the region of the protoxylem.

Phloem in dicotyledons may comprise sieve tubes, with smaller companion cells adjacent to them, phloem parenchyma and sometimes fibres. In monocotyledons only sieve tubes and companion cells are present, while in gymnosperms the sieve tubes have no companion cells. ${ }^{1}$

The secondary wood of gymnosperms with few exceptions consists of tracheids with bordered pits. In angiosperms the wood is marked by conspicuous vessels and wood parenchyma is present. Tracheids on the other hand are more rarely present.

Root Structure.-While a carrot is not a typical root it is easily cut, and something of its structure may be made out with a hand lens or even with the unaided eye. It is a large conical tap root tapering to a slender point with secondary

${ }^{1} \mathrm{~A}$ companion cell is a cell much smaller in diameter and companion to a sieve tube. It is possible that their nuclei assist the activity of the sieve tubes, which, although they act as living cells, strangely enough lose their nuclei. 
roots extending in four rows nearly its entire length. At the base of each root a slender horizontal slit is seen.

A cut across the carrot shows a circle of tissue about mirway between centre and circumference; this region is actively dividing and adding to the thickness of the root. A carrot which has been left for a time in methyl blue will show traces of blue in the

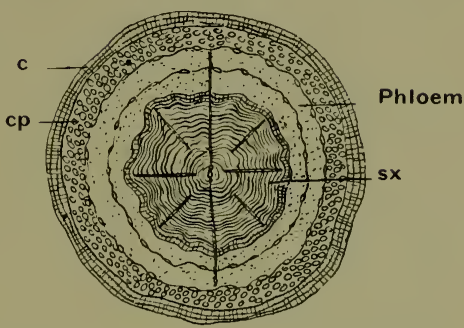

FIG. 76.-Root of carrot, cross section. $c$, Cork; $c p$, secondary parenchyma; $s x$, secondary xylem. part enclosed within this circle which indicates, as in the stem, the region of wood vessels. They are surrounded by an abundance of storage tissue of which the carrot largely consists. Although the carrot has been immersed, a layer of cork prevents the surface of the carrot from absorbing the solution.

If a cross section is stained with iodine, the medullary rays may be traced by the starch they contain. This is most abundant outside of the active ring where the rays extend through the phloem.

Either a cross section or one cut lengthwise shows the lateral roots extending to the central portion of the root. Unlike leaves and branches, they arise in deep seated tissue and make their way through the cortex of the main root.

While points of resemblance may be seen between a stem and a root, they show in their general form essential points of difference.

I. A root is protected by a root cap which is constantly worn away as it pushes its way through the soil. A stem is protected by the young leaves which form the bud.

2. Roots give rise to roots, stems produce stems and also, unlike members, leaves.

3. Lateral roots arise within deep-seated tissue (endogenously); lateral branches and leaves arise from surface tissues (exogenously).

4. The stele in roots is relatively small, that is, the rigid 
part is nearer the centre, which permits bending in the soil over obstacles and enables the root to resist the strain of the parts

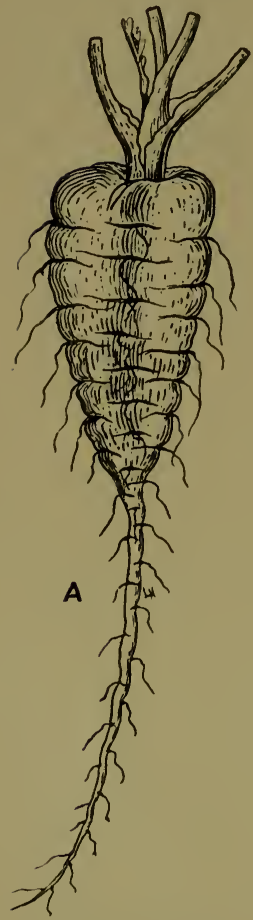

FIG. 77.- Root of carrot. A, showing rifts made by lateral roots; B, longitudinal section.

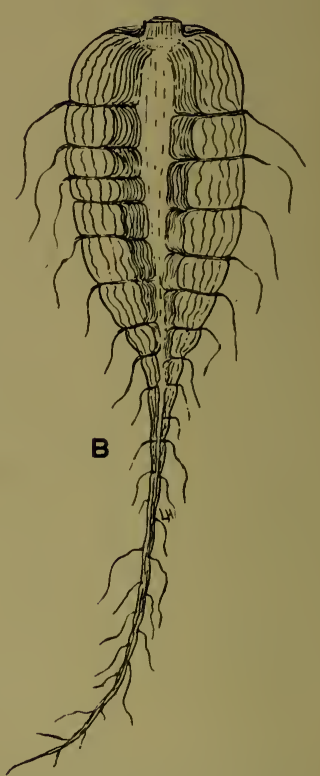

above and so it is fitted to support the plant. The rigid portion of a young stem is nearer the circumference. This enables it to bear a great weight and to resist the wind.

Microscopic Appearance of Roots.-As a root is protected by the root cap, the growing point is just behind the tip. Three more or less distinct regions ${ }^{1}$ may be made out

1 These three regions are more or less evident in the stem. Reference to them is convenient, though less importance is attached to them than formerly. 
although there is considerable variety in the growing point of different roots. In Fig. $36 \mathrm{D}$, the dermatogen (or calyptrogen) produces the root cap which is free from the root except at the growing point. The cells $\mathrm{P}$, the periblem, give rise to cortex and piliferous layer, those marked $\mathrm{Pl}$, plerome, to the central stele. The bean root in Fig. 78 shows a portion of the cortex; it is composed of parenchyma with large air spaces between the cells. Its innermost layer, the endodermis, does not store starch as in the stem; thickenings on its radial walls serve to exclude air and prevent the tissue within from drying.

Around the pith in the centre of the stele, the strands of wood and bast lie separated by conjunctive tissue and in different radii; the arrangement is radial, not collateral, as in the stem. Another contrast to the stem is shown in the position of the small elements of the wood (protoxylem) which lie outside of the large ones (metaxylem).

The outermost layer of the stele, the pericycle lying just within the endodermis, may escape notice. By division of its cells, just outside of the wood strands lateral roots take their rise, so that there are, as a rule, as many rows of lateral roots as there are strands of wood.

In the carrot where a resin gland extends just outside the wood strands which are two in number, roots arise on either side of each gland. This accounts for the four rows of roots seen on the surface.

In the sunflower the endodermis becomes double layered, and resin is stored in large cavities between the cells; these cavities lie outside the bast strands.

Roots are assisted in pushing their way through the cortex by an enzyme secreted by some of the endodermal cells which dissolves the cell walls in the path of the young root. The endodermal cells themselves divide for a time and form a protecting pocket within which the young root is contained.

When growth in thickness takes place in a root (which is seldom in monocotyledons), a wavy ring of cambium is formed. This arises partly from the pericycle outside the wood strands together with the ground tissue just inside of the phloem where 
activity is first evident. Once the ring is formed it lays down wood to the inside, phloem to the outside, with medullary rays at intervals, much as secondary thickening takes place in a stem.

When cork is formed, it also takes its rise in the pericycle,
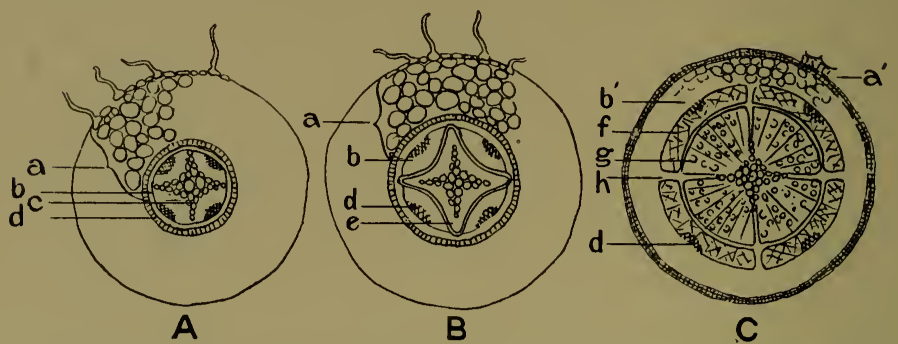

FIG. 78.-Cross section of bean root, diagrammatic. $a$, Primary cortex, with outer piliferous layer, and inner endodermis ; $b$, pericycle ; $c$, primary xylem ; $d$, primary phloem; $e$, a ring of cambium formed of ground tissue between the phloem and xylem, and of pericycle outside the points of protoxylem; $f$, secondary phloem; $g$, secondary xylem; $h$, primary medullary rays ; $b^{\prime}$ pericycle which has formed an outer layer of cork, and secondary cortex within; $a^{\prime}$ remains of primary cortex cut off by the cork.

and in time cuts off the entire cortex; so that a root in which considerable secondary growth has taken place, may show very little actual increase in diameter, as in C, Fig. 78.

The tissues of roots and stems will be understood better by tabulating them:-

The primary meristem $\downarrow$

Dermatogen

Periblem

Plerome gives rise to

Epidermis

Cortical tissue
Epidermal system $\left\{\begin{array}{l}\text { Hypodermis } \\ \text { General cortex } \\ \text { Endodermis }\end{array}\right.$

Sys
System of ground tissue.

Stele 


\section{CHAPTER $\mathrm{X}$.}

\section{THE RESPIRATION OF PLANTS.}

LiviNG things, plants as well as animals, respire both night and day. All parts of a plant must be supplied with air for this process.

If the soil of an orange grove is not well drained or if it is so compact that the roots do not get enough air, the trees look yellow and unhealthy. The farmer restores trees to health by removing the soil and exposing the roots. Plants living in moist places, like the arum or water lily, have large air chambers running through the stem which supply air to the roots. The hollow stems of the Pumpkins admit air to the part underneath the large leaves.

Ex. 28. To show that Air Passages are Continuous Throughout the Plant.-Partly fill a flask with water and provide it with a stopper containing two holes. Into one insert the stem of a leafy plant, into the other a glass tube. The cut end of the stem should dip into the water. By placing your mouth over the end of the tube remove the air from the space above the water. Bubbles of air will rush from the cut end of the stem. The air enters the plant through the stomata. If a water tap is available an aspirator may be used to withdraw the air.

Ex. 29. Insert a woody stem of a Poplar (or some stem on which lenticels can be seen) through the stopper of a flask, seal the lower end with wax, and let the water of the flask cover the stem for an inch or so. Attach an S-shaped tube to the upper end of the stem by means of a piece of rubber tubing. Pour mercury into the S-tube ; the compressed air will find its way out through the lentice's into the water below. ${ }^{1}$

A little over three-fourths of the air (seventy-seven parts) consists of the gas nitrogen $(\mathrm{N})$; about one-fifth is oxygen gas

${ }^{1}$ Prof. Osterhout uses a bicycle pump to compress the air. This experiment must be performed when the leaves are active; in winter when the leaves have fallen the lenticels are closed so that no air is admitted and no water escapes through them. 
(O), and a very small part of carbon-dioxide, $\circ 3$ to 1 oo. Carbon dioxide is a gas compounded of one part of carbon and two of oxygen, which hold on to each other very closely. $\mathrm{CO}_{2}$ is the symbol or short form of writing this gas. Traces of other gases are found. Hydrogen gas $(\mathrm{H})$ is found free in extremely minute quantities. It is combined though with $\mathrm{O}$ to form water vapour. The proportion of nitrogen and oxygen in the air can be shown by the following experiment :-

Ex. 30. Invert a glass jar with straight sides over a pan of water. Notice how high the water stands in the jar. Now lift the jar and place under it a piece of phosphorus fastened to a cork to keep it afloat. (Phosphorus should always be kept and cut under water.) The phosphorus burns, that is, it unites with the oxygen, forming dense white fumes. After a time the fumes disappear. Where have they gone? The water has absorbed them and formed phosphoric acid. What else has happened ? The water has risen and fills about one-fifth of the jar. The acid occupies less space than the gas fumes, so the weight of the air outside the jar forces the water up to take the place of the oxygen. The nitrogen does not burn but fills the remainder of the jar.

Ex. 3r. The amount of oxygen may be more accurately determined by placing the phosphorus in a long specimen tube. The cubic contents may be measured or the outside may be marked off into equal parts. With a lens focus the sun's rays on to the phosphorus, or the tube may be held in hot water until the phosphorus is melted and run down the sides. The entire amount of oxygen will combine with the phosphorus. After cooling, uncork the tube under water, mouth downward, and measure the height of water which ascends in the tube.

Water also absorbs $\mathrm{CO}_{2}$ and holds it in solution or forms carbonic acid; but there is a very small amount of carbonic acid gas in the air.

It is oxygen that we need for respiring. Nitrogen dilutes the oxygen enough for us and for land-plants to breathe. But fish and water-plants require the oxygen diluted still more with water. If oxygen were not diluted with nitrogen we should feel as uncomfortable "as a fish out of water".

Respiration is essentially the same process in plants as in animals. Oxygen is inhaled which enters into chemical combination with the carbon of the complex contents of the cell, breaking them down and forming simpler substances. As a result of this alteration carbonic acid gas and water are ex- 
haled. In plants, as in animals, this process takes place in all living cells, but in plants there are no special organs like the lungs in animals, which assist in the inhalation and exhalation of the gases. Respiration has been regarded as a form of combustion, but it is a more complex and a vital process and so cannot be directly compared to the burning of a piece of wood.

How do we know that plants inhale oxygen and exhale carbon dioxide?

Ex. 32. Respiration or "Breathing" in Germinating Seeds.-Soak a handful of peas in water for twenty-four hours. Remove from the water and put them in a glass jar. Cover tightly and set aside for twenty-four hours. Light a splinter, uncover the jar, and thrust the flame into the jar. It is extinguished. The oxygen which was in the jar has been used by the seeds. They have given off a gas which suffocates the flame. Place a short piece of lighted candle in the bottom of a tumbler. Pour the gas into the tumbler (it is heavier than air). It puts out the flame. What is it?

Ex. 33. To show that Carbonic Acid Gas or Carbon Dioxide is given off when Plants Respire.-Make some baryta-water by dissolving harium hydroxide in water, and allow it to settle. Pour some of the clear water into a test-tube; breathe into it through a glass tube. The water becomes cloudy and a white film of barium carbonate collects on the surface. ${ }^{1}$ Place some baryta-water in a shallow dish. Uncover the jar of peas and pour the gas into the dish. A white film appears on the surface. The peas have exhaled the same gas which you breathed into the jar, carbon dioxide.

Ex. 35. Another pretty experiment shows that carbon dioxide is given off by plants while respiring. Place heads of flowers-daisies just opening are good ones-in a flask. Invert the flask in soda-limewater, which also absorbs carbon dioxide. Pour some mercury into the soda-limewater. In a short time the mercury will be drawn up into the neck of the flask as the carbon dioxide is absorbed. The mercury will continue to rise as long as the carbonic acid gas is absorbed by the solution.

Place the flask in the dark and see if the mercury continues to rise. Mark the height at which the mercury stands at night, and again in the morning. A change in temperature affects the height. When the flask cools, the gas within occupies less space and the mercury rises.

Plants get energy to do work by respiring. Unless our rooms are supplied with plenty of fresh air we become dull and unable to work. Breathing decreases our weight but

${ }^{1}$ Limewater may be used instead. The results are not quite so good. These liquids should be kept corked. 
sets energy free to do work. Ask some one who plays football how much weight the team loses while playing a cup match. The stroke oar in a rowing match will lose six or seven pounds in twenty minutes or during a four-mile race. How hard you breathe when you are playing. Did you ever try to get warm by breathing deeply? A plant loses weight and gives off heat in respiring; it also gets energy to do work.

Ex. 36. Place some peas that have just started germinating in a $U$. tube. Cork tightly. Place the other end in a glass of pyrogallic acid.
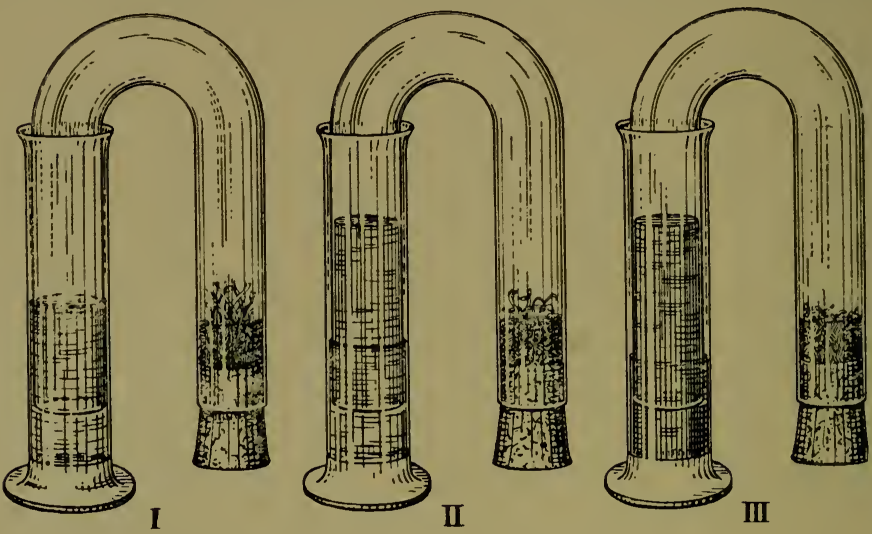

FIG. 79.-Peas germinating, deprived of oxygen.

Since pyrogallic acid absorbs oxygen, the peas are deprived of the gas necessary for respiration. The peas make no further progress in germination. In Fig. 79 the first jar contains water, the second caustic potash, which absorbs $\mathrm{CO}_{2}$, the third pyrogallic acid.

Ex. 37. Dissolve a few grains of methylene blue in a test tube of water, using only sufficient to make a bright but transparent fluid. Place within the solution some germinating seeds and observe on the following day. The fluid has become transparent as the germinating seeds have deprived the dye of its oxygen. Pour off some of the fluid into a flask and shake vigorously. As the fluid mingles with the air in the flask its colour is partially restored.

In a similar manner make a solution using this time methyl blue and taking care as before not to have too deep a colour. Heat this fluid until it becomes colourless and then breathe into it until the colour is restored. Heating the fluid causes carbonic acid gas to expand and escape; breathing the gas into this fluid restores the colour. Now beat the fluid a second 
time untıl it loses its colour, and after cooling place germinating seeds within the tube. Observe after half an hour and tell what gas has been given off by the seeds.

Prof. Farmer uses methylene blue to show gas exchange in photosynthesis (see p. 94). By using the two colours, the exchange of gases in respiration is well shown.

In this exchange, the important thing to remember is that in respiration, the oxygen in uniting with carbon releases energy. This energy is used by the plant in doing work, that is, in the making of food, in growth, and reproduction.

While the terms respiration and breathing are frequently used interchangeably, breathing in animals involves expanding the chest muscles and inflating the lungs, for which there are no corresponding processes in plants. You can see an animal breathe, but you can see neither an animal nor a plant respire. 


\section{CHAPTER XI.}

\section{A SHORT LESSON ON SOIL.}

WHEN the earth's surface cooled in former ages, it probably formed solid rock. This was acted upon by wind, water, heat, and frost and gradually became broken up into small particles which formed inorganic soil. This process is still going on and the results can be seen, for example on hills around Cradock, where the sandstone in weathering, splits apart by concentric coats, into sphere-like pieces. The soil particles are washed or blown down from the mountain tops to the valley where vegetation may appear which then plays its part in the breaking-up of rocks. Fig. I 6 shows the effect of weathering. Soil has been formed on the slopes and at the foot of the mountain range which shows the weathering sandstone above. Inorganic soil is formed of such elements as calcium, magnesium, silicon, sodium, sulphur, phosphorus, potassium and iron combined with oxygen.

In travelling through the country different characters of soils frequently attract attention, chiefly by their difference in colour. There are the light yellow and brick red sandy soils, black and brick coloured clayey loam, light and dark chocolate soil and the rich red volcanic soil, the basaltic lavas of the Drakensberg.

In gardens, wooded kloofs, under old Olive trees and Jakhals-Besjes bushes (Sideroxylon, Melkhout), rich dark soil is found, called humus. This consists largely of organic remains of plants and animals and contains oxygen, hydrogen, nitrogen, and carbon. Humus which is poorly drained and becomes acid is known as Peat.

A fertile soil depends partly upon mechanical structure, and 
it must also possess certain chemical properties. The mechanical properties relate to the soil's capacity to admit air and hold moisture and to allow drainage. If soil has too much clay it becomes water-logged, while an excess of sand renders the soil unable to hold moisture. Correspondingly, although a clay soil may be abundantly supplied with moisture it yields up but a small percentage for the use of plants while sandy soil yields a large percentage of its moisture. A desirable soil contains a mixture of sand, clay, and humus-clay and humus retaining moisture, while sand renders the soil porous so that water in excess may be drained off and a supply of air admitted. Humus may be applied to advantage by ploughing under leguminous crops. To serve as humus they should be used green; they will at the same time increase the nitrogen supply (see p. Iоr). Soil supplied with all the essential inorganic elements will be unproductive in the absence of suitable mechanical conditions.

Food material is obtained from the soil in the form of salts. ${ }^{1}$ Soil bacteria play an important part in forming salts containing nitrogen. Certain bacteria combine nitrogen and hydrogen to form ammonia ; others take up the work and effect a combination of ammonia and limestone or other substances to form nitrites and nitrates. These are soluble in water and may thus be absorbed by plants. Should soil contain so much moisture as to exclude air, another set of bacteria breaks down these salts setting free the valuable nitrogen and rendering the soil unproductive.

Sulphur, which enters into the composition of protoplasm, may be supplied in the form of magnesium sulphate.

Magnesium seems necessary for forming sugars and related substances in the plant although it does not enter into their composition.

Phosphorus is of great importance in forming nuclei and in assisting in the process of nuclear division. Unfortun-

${ }^{1}$ A salt is formed by the chemical action of an acid with a base. E.g. potassium sulphate is a salt formed when sulphuric acid unites with the metallic base potassium oxide, and the action of nitric acid upon the base calcium forms the salt calcic nitrate. Not all bases are metallic. 
ately this element is generally lacking in South African soils and must be supplied by artificial fertilizers.

Some salts, as calcic nitrate, magnesium sulphate, and ammonium sulphate are readily soluble in water and so should be applied at the time of seeding, while calcic phosphate should be applied some time before in order that the acids in the soil may set the phosphorus free and render it in a soluble form for the plants.

Oxygen, as food material, is probably obtained from salts and from water rather than from the free atmospheric oxygen which is the source of that used in respiration.

Water not only serves to dissolve salts for absorption by the plant but it supplies hydrogen, which is in all plant food, and also serves to keep the cells turgid.

The service performed by some of the minerals found in the ash of plants is not clearly understood. Substances which alone in the soil are poisonous to plants, have their poisonous effects neutralized when balanced by other substances. It has been found that the poisonous effects of a sodium salt disappear when calcic chloride is added. Similarly magnesium and potassium salts which are poisonous when found separately lose their poisonous effects when their action is combined. ${ }^{1}$

A great drawback to South African farmers is the large areas of brak or alkaline soil due to sodium or magnesium salts. In times of drought an abundance of white crystals appears by evaporation on the surface. Rain dissolves these salts which are readily re-absorbed by the soil. Much of the underground water brought to the surface by driven wells contains so much of these salts that the soil becomes sterile. Progressive farmers are finding means to remedy this condition. Underdraining or in the case of clay or iron hard pan, dynamiting the soil is effective in carrying away the accumulation of salts. Another method consists in treating the soil with gypsum (calcic sulphate) where sodium carbonate produces the black brak. The calcium of the gypsum replaces sodium and forms calcium carbonate, the sodium combines with the sulphur to form sodium sulphate. The calcium compound thus formed

"Osterhout, “ Bot. Gazette," August, I906, August, Igog. 
is useful in rendering soil porous, but sodium sulphate becomes detrimental if an excess accumulates. Evaporation is checked in dry farming by keeping the surface soil pulverized, so that the crystals accumulate on the surface less rapidly, or the soil may be shaded by shallow rooted plants. Plants belonging to the Beetroot family have been found useful for this purpose as they are halophytes and can take up brak-forming salts to a considerable extent. None of these methods seems to be as effective as under-draining.

Even in dry countries, soil drainage is as important as soil irrigation. In the rainless districts of the Nile nearly as much effort has been expended on drainage as has been in constructing the immense dam at Assuan and the irrigating ditches.

Calcium is of further use as a vehicle for supplying nitrogen in a soluble form as calcic nitrate. It also serves to neutralize acid soils and oxalic acid which accumulates in plant tissues as waste matter. Seedlings, in water cultures, without calcium, seem less able to respond to the influence of light and gravity.

Silica is usually mentioned as valuable in giving rigidity to stems such as the grasses where it is found in abundance. It has been found, however, more abundant in leaves than in the stems where it would be of advantage in supporting the heads of grain. An interesting series of water cultures carried on in Dr. Hahn's laboratory by Mr. Lundie showed that grains flourished and came to perfection in the absence of any trace of silica in the solutions. But the experiments suggested that its presence might defend the plants against the entrance of the rust fungus.

Plants may be grown in the laboratory in the following nutrient solution :-

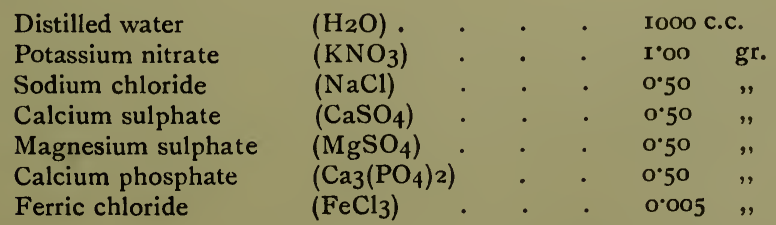

Ferric chloride should be added when the seedlings are put into the solution, which should be diluted with distilled water to one-sixth the strength of the stock solution. 


\section{CHAPTER XII.}

\section{THE FOOD MAKING OF PLANTS.}

BESIDES manufacturing their own food, many plants entertain a gay society of flies, bees, butterflies, and their relatives. Moreover a plant must provide for its large family of growing seeds. In Chapter IV we found that air, water, and soil were the sources of food, and in Chapters X and XI the composition of air and soil were studied.

Carbonic acid gas, which is exhaled by animals and plants and which occurs in such minute quantities in the air, is a waste product to animals when exhaled but it can be appropriated by green plants and made into living substance. This process is known as assimilation. In leafy plants this process takes place chiefly in the leaves. As protoplasm is formed in the leaves it is broken down into simpler forms of food and carried away by the phloem to build up growing parts. Part of it is accumulated as reserve food in the day and used up at night when most rapid growth takes place. Starch is a convenient form of storing food until it is needed for daily use and biennials and perennials store enough one year to give the plant a good start the following year. Potatoes are almost entirely filled with starch. Some plants store food in the form of sugar as the beet, while many composites store inulin.

We can tell where starch is found by staining with iodine, as we did in case of the Sunflower stem. A tincture of iodine may be obtained or the crystals dissolved in water. Scrape a small portion of potato and place it in a tube of water. Add a few drops of iodine. The liquid at once turns blue. Place some maizena or laundry starch in slightly warm water. Allow it to cool and add iodine. The same blue colour appears. The particles of starch are coloured blue by iodine. 
Treat a castor-oil bean or a piece of onion in the same manner. No blue appears, because their food is not stored as starch.

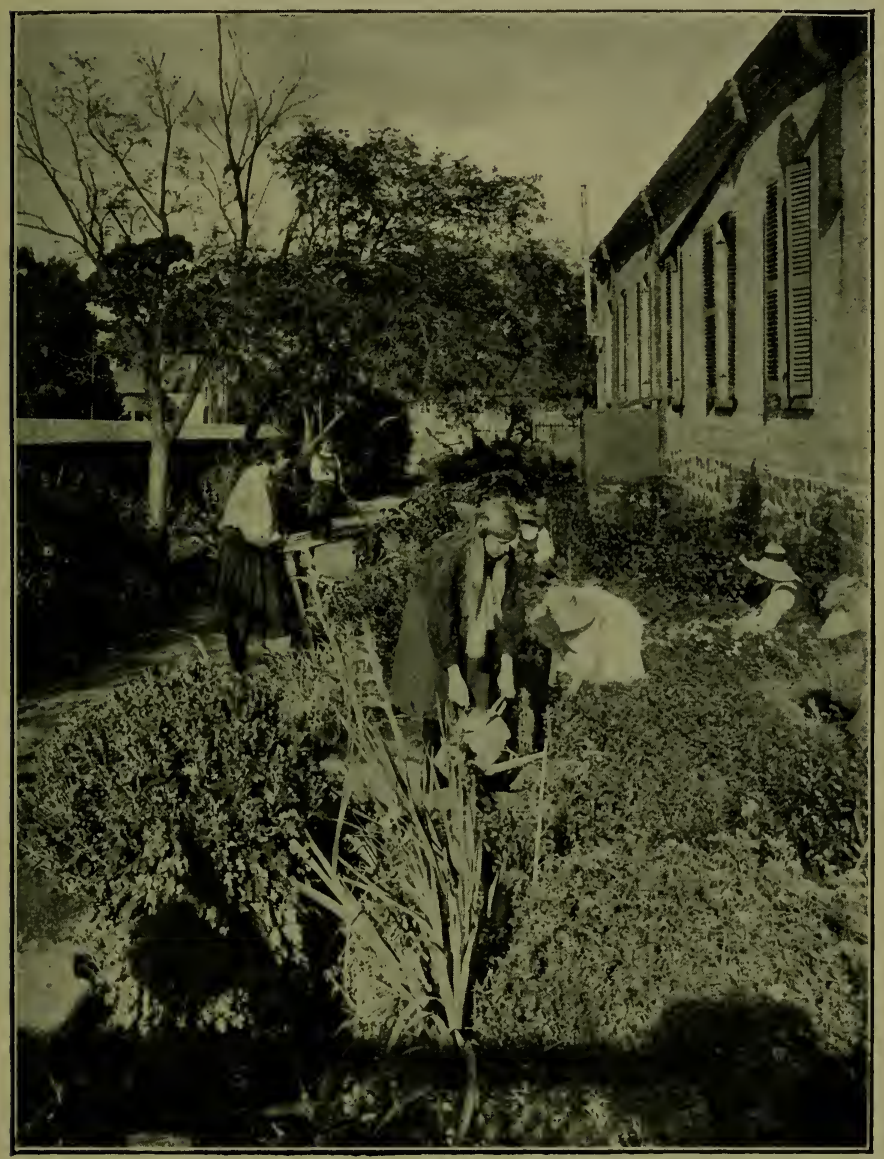

FIG. 80.-Learning plant ways in Eunice High School, Bloemfontein.

Ex. 38. Starch formed in Green Leaves.-In the afternoon of a bright day, place a few green leaves in a strong solution of chloral 
hydrate, which will dissolve out the green colour. Leave them overnight or until the green has dissolved. Boiling hastens the process. Place them in a porcelain or other dish with a white bottom, and pour over them a solution of iodine. The starch in the leaf will become a dark blue.

Perform the same experiment with variegated leaves of Coleus. Thin leaves should be used, as the colour is dissolved more readily. Starch will be found only in the green portions. In higher plants chlorophyll is necessary for assimilation.

Ex. 39. Place a potted plant (Medicago, Oxalis, and Lucerne are good for the purpose) in a perfectly dark place and leave for forty-eight hours. Dissolve out the chlorophyll from the leaves and stain with iodine. They remain uncoloured. The accumulated starch has been used and none has been formed in darkness because the chlorophyll grains cannot appropriate the carbon contained in starch, without the energy obtained by the action of the sun's rays, and so the appropriation of carbon by the plant is known as photosynthesis or carbon assimilation. ${ }^{1}$

The photosynthetic process may take place in the following manner : carbonic acid gas $\left(\mathrm{CO}_{2}\right)$ taken into the plant may form a solution with the water $\left(\mathrm{H}_{2} \mathrm{O}\right)$ which is brought up to the green cells and a portion of the oxygen $(\mathrm{O})$ then passes off into the air, the solution deprived of its oxygen becoming formaldehyde $\left(\mathrm{CH}_{2} \mathrm{O}\right.$ or $\left.\mathrm{HCOH}\right)$. Just what part the sun's rays perform is not certain; it may serve to disassociate the oxygen from the carbon and hydrogen atoms. Formaldehyde may be produced chemically by subjecting a solution of $\mathrm{CO}_{2}$ in water to a weak electrical current. The sun's energy may be changed in the plant to electrical energy and effect the same change.

The molecules of formaldehyde, which is found in plants in small quantities, seem to be quickly grouped together in the cells where it is formed. Six molecules thus grouped could form grape sugar (glucose, $\mathrm{C}_{6} \mathrm{H}_{12} \mathrm{O}_{6}$ ). These stages may be represented by the following formula :-

$$
\begin{aligned}
& \mathrm{CO}_{2}+\mathrm{H}_{2} \mathrm{O}=\mathrm{H}_{2} \mathrm{CO}_{3}=\mathrm{H}_{2} \mathrm{CO}+\mathrm{O}_{2} \\
& 6 \mathrm{H}_{2} \mathrm{CO}=\mathrm{C}_{6} \mathrm{H}_{12} \mathrm{O}_{6} .
\end{aligned}
$$

${ }^{1}$ The old method of covering a portion of leaf with cork or tinfoil is unsatisfactory. Carbon dioxide is excluded as well as light. Prof. Ganong has invented an ingenious frame which will admit air to the leaf while excluding light. 
Besides glucose, fructose, also consisting of $\mathrm{C}_{6} \mathrm{H}_{12} \mathrm{O}_{6}$ but having a different arrangement of atoms in the molecule, and cane sugar $\mathrm{C}_{12} \mathrm{H}_{22} \mathrm{O}_{11}$ are of frequent occurrence in plants.

After the action of light has brought about the formation of sugar (or if a sugar solution is supplied to a plant) the further steps in assimilation by which nitrogen, sulphur, and phosphorus are combined with carbon, hydrogen, and oxygen to form protoplasm, can take place in darkness. The process is a complex one and by no means fully understood.

The accumulation of starch is a sign that carbon assimilation is going on, although in many monocotyledons the food is carried away so rapidly that no starch is accumulated in the leaves.

Much of the food stored in seeds is starch. Remove a mealie seedling from the soil. Cut the seed in two. Cut off a portion of the stem about half an inch long just above the seed. Cut this piece in two lengthwise. Place in a test-tube containing an inch or two of water. Gradually add iodine. Portions of the seed will show blue where some starch is still left. The stem does not stain blue. The food cannot pass to the growing parts as starch; it has been changed to sugar. The bundles through which the sap is passing up into the leaves are stained a yellowish brown. In the North American Maple, the sap is so filled with sugar when it is passing up into the buds in spring, that it is drawn away through little troughs placed in holes bored into the trunk as far as the new wood. On a bright day a drop falls about once a second. Drop by drop about twenty-five gallons of sap may flow from one tree in a season, until the buds begin to unfold, and this will boil down to about five pounds of sugar.

Ex. 40. How can we tell when a plant is making starch? Place in a jar of water a plant which grows in water. The green silky threadlike plants in ponds are suitable. In spring, leaf-bearing plants may be obtained in some ponds which should be used when possible. Place the jar in the sun. In a few minutes bubbles will rise from the plant. Place the plants in water which has been boiled. No bubbles are given off. Boiling the water has driven off a gas which the plants need in making starch. Breathe through a glass tube into some boiled water, and place the plants in this water. Bubbles will soon begin to come off. Carbon 
dioxide, the gas that was breathed from the lungs, is required by the plant to combine with water to make starch.

Ex. $4 \mathrm{r}$. What gas is given off when starch is made? Place a glass funnel over the plants in the jar, with the small end under water.

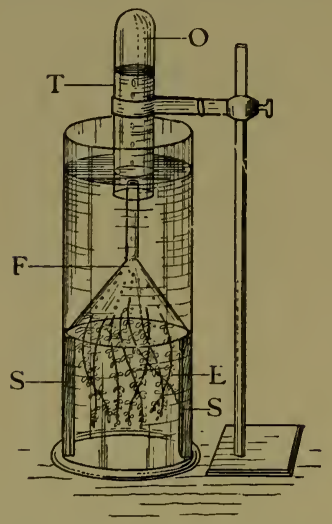

FIG. 81.-E, Elodea plants in water, with the cut ends of the stalks directed into the glass funnel, F; S, supports on which the funnel rests ; $T$, test - tube ; $\mathrm{O}$, oxygen which has collected in the test-tube. (From Farmer's "Practical Introduction to the Study of Botany ".)

Sink a test-tube into the water obliquely, so that all the air may escape and the tube fill with water. Without letting the open end come above water, place it over the small end of the funnel. As the gas rises it drives out the water. When the tube is full, light a long splinter, and blow out the flame, leaving the end glowing. Quickly lift the tube from the water and thrust in the glowing splinter, which again bursts into flame. We know from the last chapter that oxygen is the gas necessary to light a fire.

Ex. 42. To show that no Starch is made without Carbon Dioxide. - Cut under water two small shoots and place in small vials of water. Lower the vials into wide-necked jars and tie over the mouths of each some cloth net. Sprinkle over one net a thick layer of soda-lime; over the other a layer of sand. In a day or two the plant under the soda-lime withers and droops. A test for starch shows that none has been made. The covering of sodalime absorbs the $\mathrm{CO}_{2}$ and prevents any from entering. Carbon dioxide was admitted into the one covered simply with sand, and starch-making was unhindered.

In making starch, plants give off the gas we require in breathing.

In respiring, plants and animals exhale the gas which plants require for starch-making, carbon dioxide.

Assimilation requires light. Respiration takes place in darkness as well as in the light.

Assimilation takes place in green parts. Respiration in all parts of the plant.

Assimilation builds up material and increases the weight of the plant. Respiration breaks down material and the plant loses in weight. 


\section{The Food Making of Plants}

All rules have their exceptions, e.g. some fungi and some bacteria appropriate carbon though they have no chlorophyll. Green leaves or even white petals when removed from light can assimilate if they are provided with carbon compounds as sugar or glycerine in solution. 


\section{CHAPTER XIII.}

\section{DEPENDENT PLANTS.}

Some plants, like animals, cannot make their own food, but depend upon other plants for their food supply.

Parasites and Saprophytes.-A plant which depends upon another living plant is a parasite. Red rust is a parasitic plant which attacks corn-fields and gives the grain a sickly yellow look. It may have been on the seed when it was sown where the spores could attack the young plants as soon as they germinated.

When it fruits, short threads break through the surface of the straw or leaves of the grain, and on their tips small spores are borne. Spores formed in the early part of the season are red. Later, black spores are formed. The spores make red or black patches on the plant. When ripe they are blown by the wind on to other plants, where they grow and send small threads down into the grain again through the stomata. Since they are taking the food, or some part of it, which the grain-plant is making, the heads of grain do not fill out properly. For this reason, farmers try to get seed from grain which is rust proof, for it has been found that certain varieties of grain are resistant to the rust fungus, the fungus threads (hyphæ) are checked after entering the stomata of the resistant grains. This remarkable discovery is of great importance to farmers (Biffen, 1 905-7).

Dodder (Cuscuta) and Cassytha are parasites which have lost their leaves, roots, and most of their chlorophyll. At some season of the year, however, Cassytha stems are quite green. Try to loosen the hold of these plants from the plants around which they are twining and they betray their means of living. 
They send out root-like bodies which penetrate their host (as the plant is called which supplies another with food) and appropriate all the food they require.

Mistletoe and its relative Loranthus penetrate their host in a similar manner. They cannot obtain food from the soil of themselves, but there is chlorophyll in their stems and leaves so that they can manufacture the food from the raw material

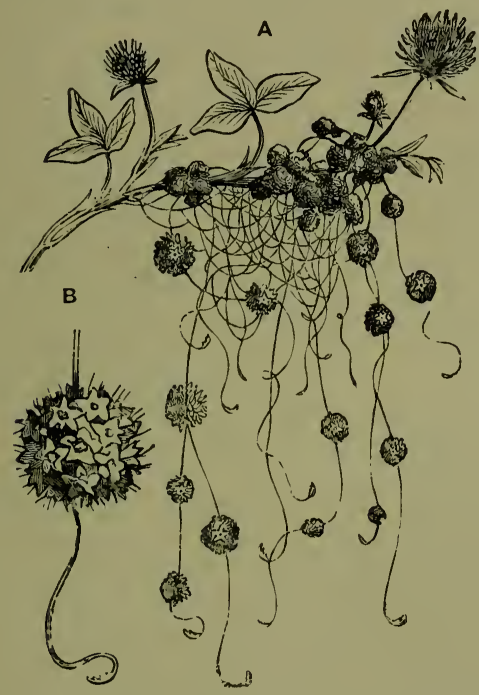

Fig. 82.-Cuscuta Trifolii: A, parasitic upon clover (reduced) ; B, a separate inflorescence (natural size). (From Thomé and Bennett's "Structural and Physiological Botany".)

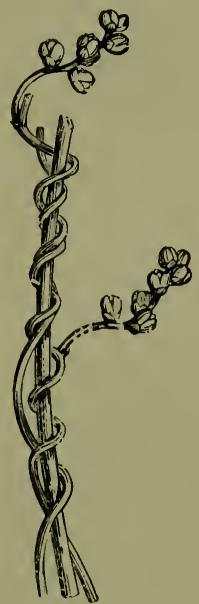

FIG. 83.-Cassytha, twining and parasitic flowering shoot. (From Henslow's "South African Flowering Plants".)

they obtain from the host and the carbon dioxide which they can take from the air. These are called partial parasites. Those which derive all their nourishment from their host are called total parasites.

Some plants which come up from the ground are parasitic on the roots of other plants. The beautiful pink-and-white and crimson Harveya, the flaming Hyobanche, and Sarcophyte, and curious Hydnora are root parasites. The leaves are re. duced to mere scales. 
A saprophyte is a plant which lives on dead or decaying

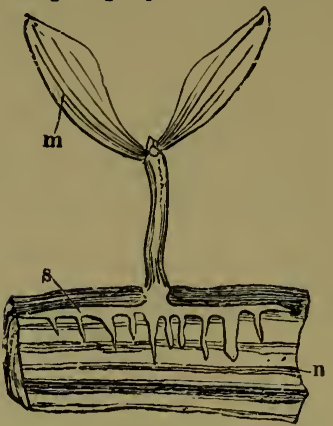

matter. Mushrooms, yeast plants, the mould on bread and cheese, and some bacteria are examples. Saprophytes are very useful members of plant society. Mushrooms change decaying vegetable matter into wholesome food. When insects or

FIG. 84.-A piece of a branch of an apple tree cut through lengthwise, into which a young mistletoe-plant has driven its sucking roots (reduced). (From Thomé and Bennett's "Structural and Physiological Botany".)

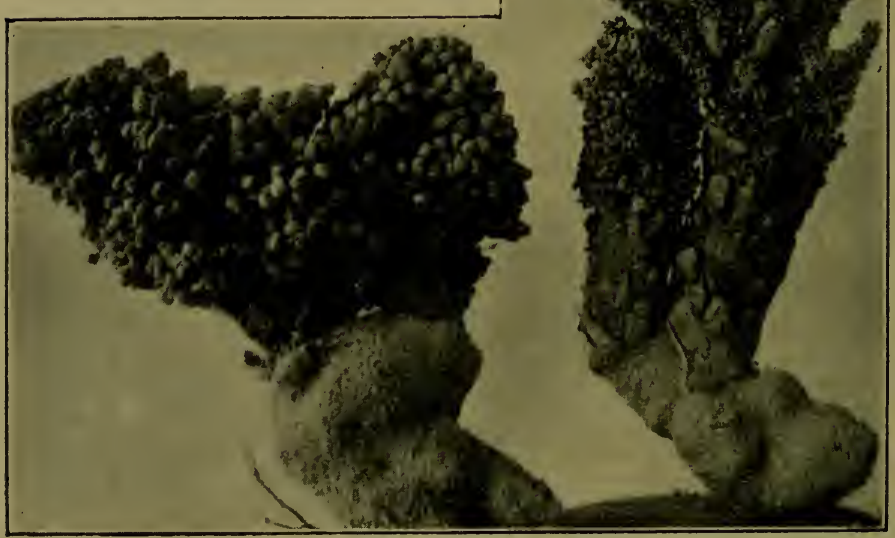

FIG. 85.- Sarcophyte sanguinea (order Balanophoraceæ), a parasite grow ing on the roots of Ekebergia and Acacia in the Eastern Province. I. Pistillate. II. Staminate flower.

animals die, or leaves fall, there would be a great accumulation of useless matter were it not for the saprophytes, which seize upon this decaying matter and make it ready to be used 
by living plants again. So the large trees and beautiful flowering plants are quite as dependent upon saprophytes as the parasites and saprophytes are upon green plants.

On roots of legumes or the pea family swellings or tubercles are formed. They are swollen lateral roots containing minute bacteria which make their way from the soil through the root hairs into the roots. They are plants which obtain nourishment from their host, but they enable the host to use the free nitrogen which is abundant in the air. Nitrogen is a valuable and expensive food material, and can be obtained by most plants only from compounds in the soil. Legumes can not only obtain it for themselves, by the help of these little bodies, but they leave nitrogen compounds in the soil, to be used by other plants. Just think of all the plants in this country which have pods and belong to the pea family! How they are enriching the soil! 1 Yellowwoods (Podocarpus) have little plants living in their roots which perform the same service.

A lichen (see page 4), is made up of two plants, a green alga which manufactures the food, and a colourless plant, a fungus which provides the alga with the necessary salts and water. The threads of the fungus grow around and cunningly enclose the alga, which is thus prevented from drying up in the exposed situations which lichens frequent.

Plants which live together in this way and are helpful to each other are called Symbionts. Plants are sometimes symbiotic with animals. There is a kind of Acacia with little holes in the base of the large hollow thorns. Within these thorns ants make their nests. Other insects eat and injure the leaves of the Acacia. The leaves manufacture a nectar which

${ }^{1}$ It is for this reason that farmers in winter sow peas in their vineyards and orchards and plough them under in spring. They should be ploughed under before the seeds have ripened. That leguminous plants enriched the soil was known in the time of Pliny, but the mystery was not solved until 1886 , by the scientists Hellriegel and Wilfarth. The group of plants thus indebted to bacteria is larger than was at first supposed. Bacteria for inoculating soils or seeds for different crops can now be bought and the yield of grains and tomatoes as well as of legumes has been much increased by bacterial inoculation. 
is poured out at the very tips of the leaflets. The ants sally forth in quest of the sweets, but on the way they make the first course of their feast off the marauding leaf-eating insects.

Insect-eating Plants.-The Sundew (Drosera) obtains its nitrogen from insects which the plant catches and digests

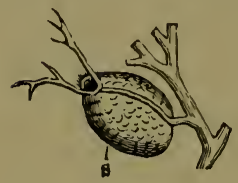

FIG. 86. $-s$, Bladder from a leaf of Utricularia vulgaris ( $x$ 4). (Fron Thomé and Bennett's "Structural and Physiological Botany ".)

never come out again, as pushing the door from the inside closes it. Several small animals may be found imprisoned in a bladder at the same time. Why not call Utricularia an insect-harbouring plant? It has never been ascertained that these small creatures are restive in this confinement. It may be that they live out the few days of their years in quiet contentment, by no means unwilling to yield up their substance eventually to the plants which have harboured them. 


\section{CHAPTER XIV.}

\section{PLANT DEFENCES.}

SiLver leaves are favourite souvenirs for strangers who visit our shores. The stranger finds that the Silver Trees which wave their welcome from Table Mountain are but the harbingers of many surprises that await him in the plant world. The climate of South Africa is different from that of any other countries, and so plants look and behave differently.

In many parts of this country plants have to do their work principally in winter, as the summers are too hot and dry. In the east and north winters are cool and dry, and plants have a warm summer with rains in which to do their work. In other parts it rains neither summer nor winter for months-even years; and to tide plants over these seasons of drought innumerable devices are found.

In cold countries of the northern hemisphere, winter is the sleeping-time of plants. When the leaves are cut off in the "fall" of the year, they lie in sodden heaps beneath the trees during the autumn rains and winter snows. In the spring these leaves hold moisture and give it up slowly to the roots. In this country very little decaying vegetation is left on the ground. The ants could partly explain the reason if you asked them. Have you ever watched them before a rain busily sawing off twigs and carrying them underground? Even burnt matches are regarded valuable timber by them. The ants change the conditions for plants both above and below the soil surface. ${ }^{1}$

${ }^{1}$ It has been found that upon this material, some ants and termites (so called white ants), cultivate vegetable gardens of fungi. These gardens they tend so carefully that only one kind of a crop is grown in a nest. 
I04 Plants and their Ways in South Africa

Plants that work in winter must be suitably clothed for their work. Even when no rain falls, the Silver Trees on Table

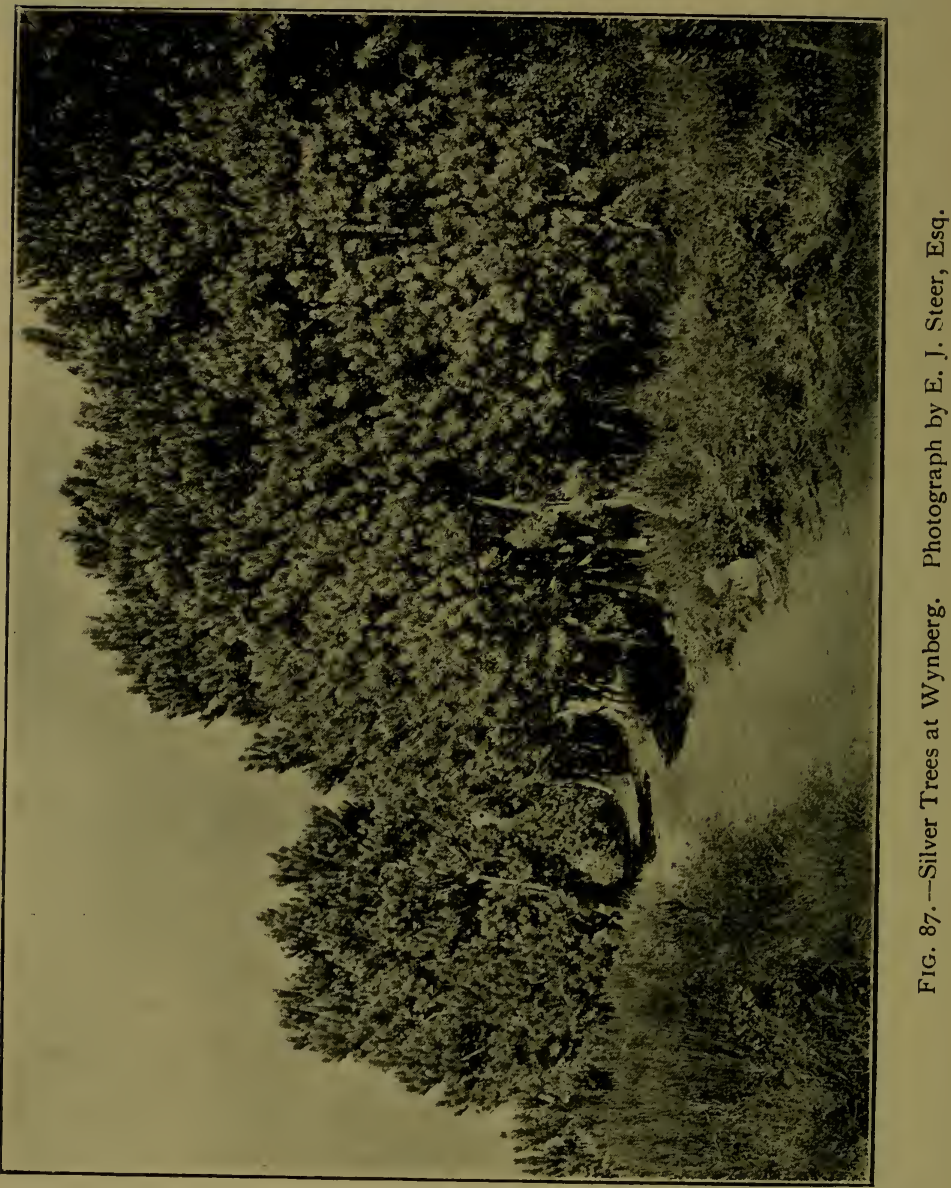

Mountain are frequently enfolded by the fringes of the "Table cloth". We have seen that a great amount of water passes off in the form of vapour. Vapour cannot pass off if the leaves are water soaked and the exchange of gases, $\mathrm{O}$ and $\mathrm{CO}_{2}$ is 
also hindered. Place a silver leaf in water and notice how the silvery sheen is brightened. The thick coat of hairs retains a layer of air which the rain cannot replace. It is because of this that vapour can pass off without interruption. A bamboo leaf under water glistens on the lower surface quite as brilliantly, but the upper surface comes out wet. The stomata which are most numerous on the under surface are sunken, and protected by projecting rods of wax. On the upper surface wax is wanting but the few stomata are protected in another manner.

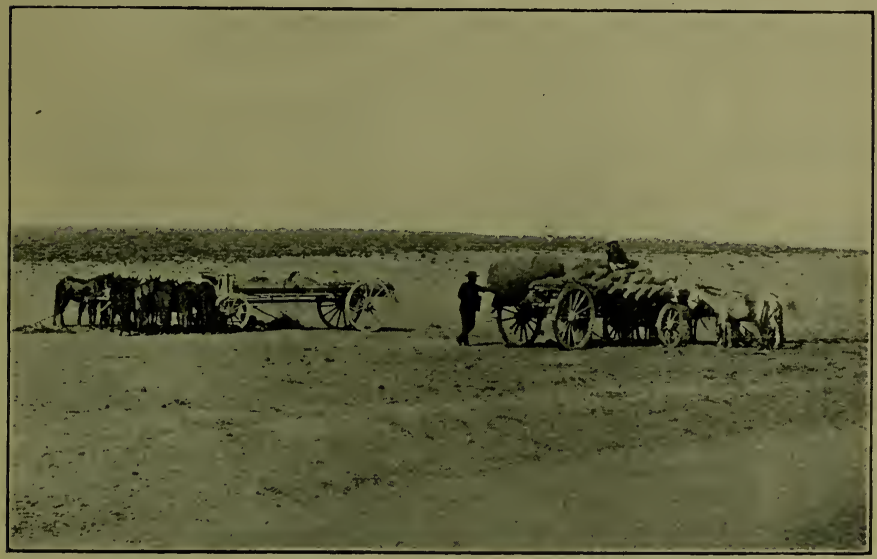

FIG. 88.-Vegetation in the Karroo where there are long droughts. The soil is alkaline.

Peculiar colourless cells of the epidermis lie in rows midway between the veins. When there is sufficient moisture these project above the surface. As moisture is withdrawn, they collapse without injury, allowing the leaves to roll; the stomata lying on either side of these cells are thus covered.

A bamboo leaf which has withered for several days will revive if a stream of water is allowed to flow over the upper surface. While the wax rods make it impossible to wet the under surface, thin walled cells on the upper surface actually absorb moisture.

The sugar bush has another cunningly devised method of 
protecting its stomata. The cells bordering the stomata overarch, forming a little hut with an opening at the top (Fig. 89),

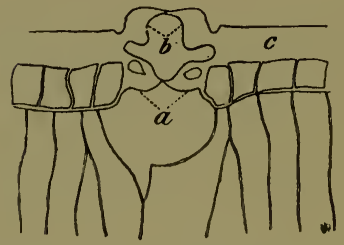

FIG. 89.--Section of sugar-bush leaf through a stoma: $a$, the guard-cell; $b$, projecting dome; $c$, thick cuticle. so small that the vapour can pass out but a drop of rain will not run in.

The heaths have small needleshaped leaves ; their edges are rolled back so as to form partially enclosed channels on the under side where the stomata are placed. These channels are protected by a lining of hairs, making sometimes a close white mat. Many plants have strongly ribbed stems ; between which the stomata are placed, so that transpiration is lessened.

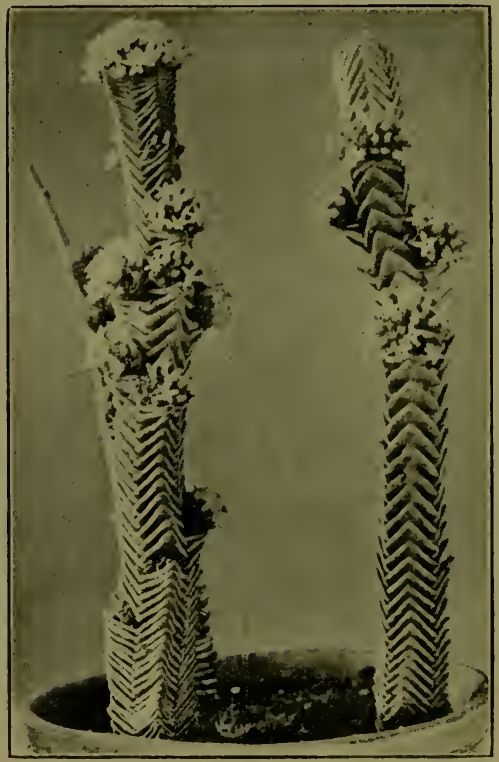

FIG. 90.-Crassula pyramidalis, L.

Our finest heaths are found in the Caledon and Riversdale 
districts. Compare the rainfall of these regions with that of neighbouring districts.

Fortunately for the plants, these waterproof garments are also useful summer styles. The hairs reflect the bright light from the plant, and keep a cool layer of air next the leaf, while preventing too rapid evaporation, although transpiration helps to keep the plant cool, just as it makes us cooler to perspire in summer.

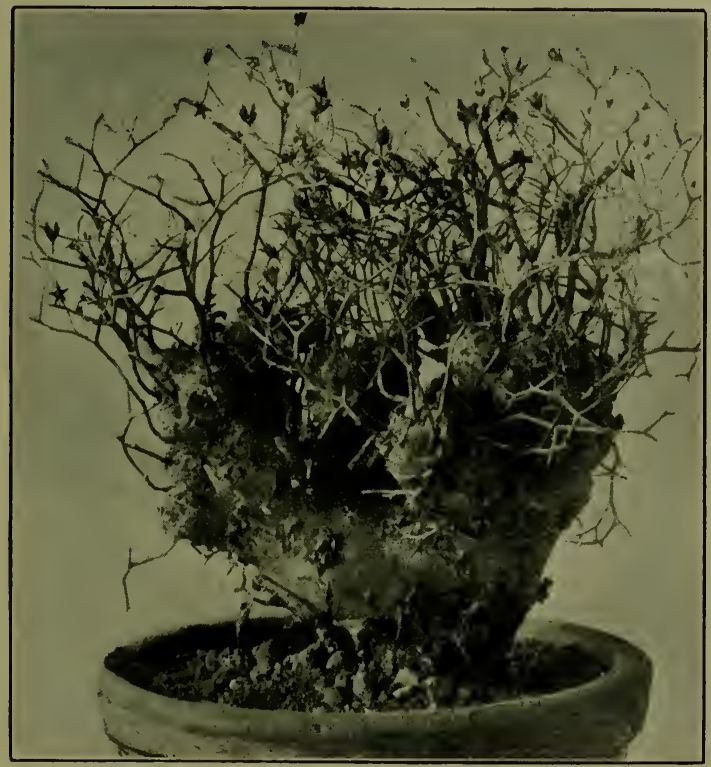

FIG. 9r.-Cotyledon reticulata, Th.

The thick waxy coverings on the leaves of Senecios, Crassulas, and Aloes, which shed rain, also prevent the escape of water in summer. Low-growing plants are often protected by incrustations of lime, which also absorbs and retains moisture.

Besides especial coverings of leaves, many Karroo plants have their leaves packed as closely as possible. In Crassula 
pyramidalis, L., Fig. 90, the leaves shade one another, and no unnecessary growth is expended in stem and branches.

A plant's success in life is estimated by its ability to produce fruit so that its kind may be perpetuated. Judging by that standard, we cannot attribute failure to Cotyledon reti-

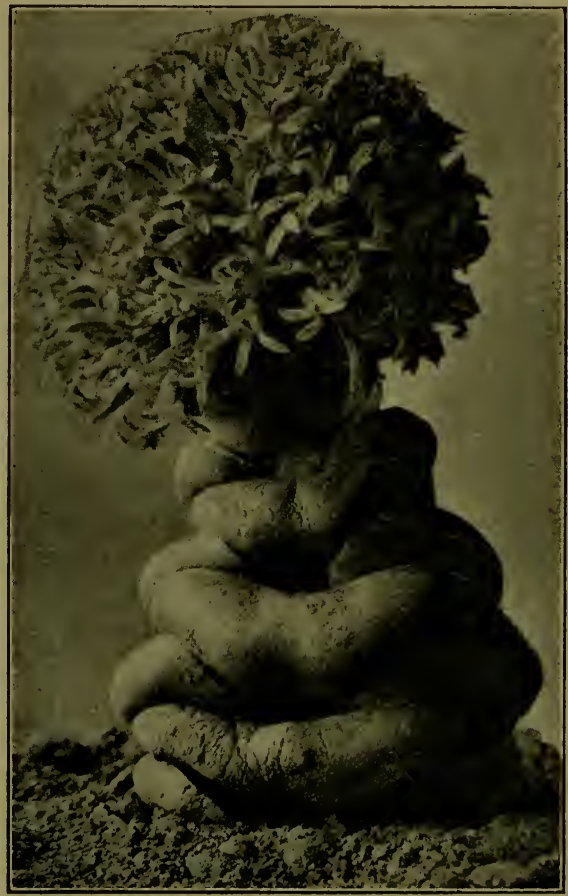

FiG. 92.-Crassula columnaris, L., in cultivation. On the veld it is still more compact with densely packed leaves.

culata, Th., in Fig. 9I, although the plant looks as though it had grown on the principle that the end justified the means. A large supply of food is stored in the ungainly trunk faster than the slender leafless twigs give it out. 'There is little waste, and so the plant does not come to want during the long droughts that occur where this plant loves to dwell. As an example of untidiness it is perfect. 


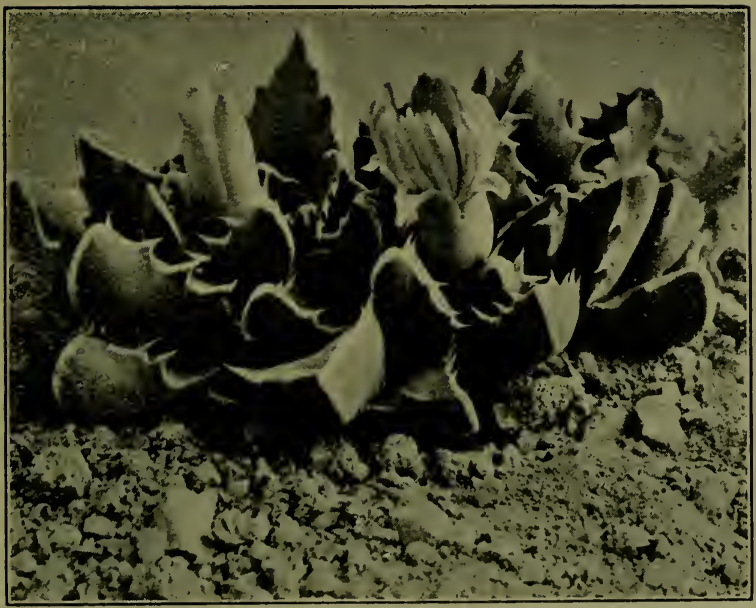

FIG. 93--Mesembrianthemum felinum, Haw.

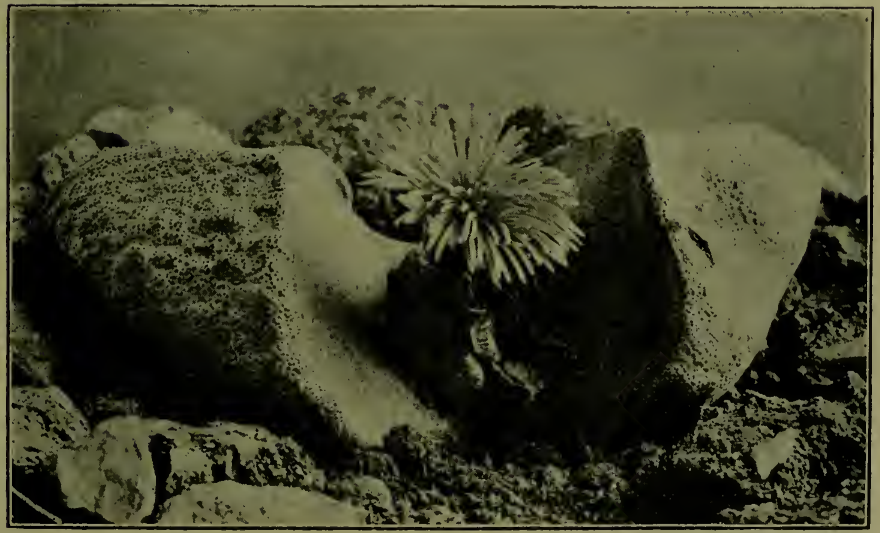

FIG. 94.-Mesembrianthemum Bolusii, Hook. A native of the driest part of the Karroo coming from the neighbourhood of Prince Albert. The waterstoring leaves enable the plant to live through long droughts. Photographs 93 and 94 obtained by courtesy of Dr. Marloth. 
Crassula columnaris, L., and the Mesembrianthemums shown in Figs. 93 and 94, testify that the heat is no excuse for untidiness. They can lay little claim to grace, unless on the ground that the most graceful is that which is best adapted to its use. They are painfully neat in their housekeeping arrangements, and instend of reducing their leaf surface after

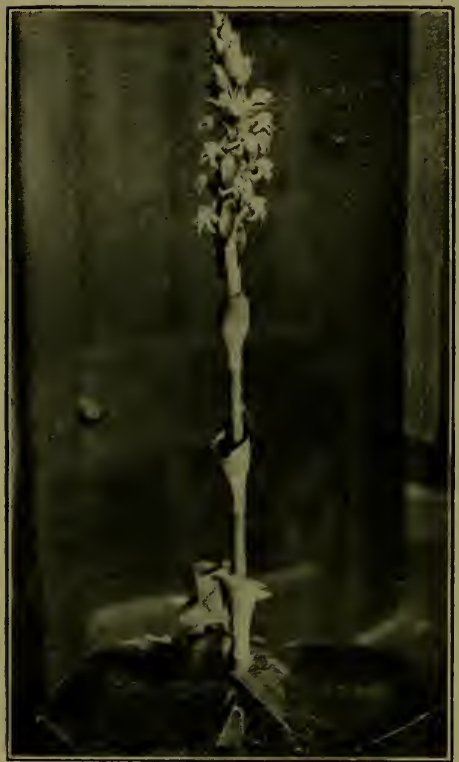

FIG. 95.-Satyrium candidum, Lindl.

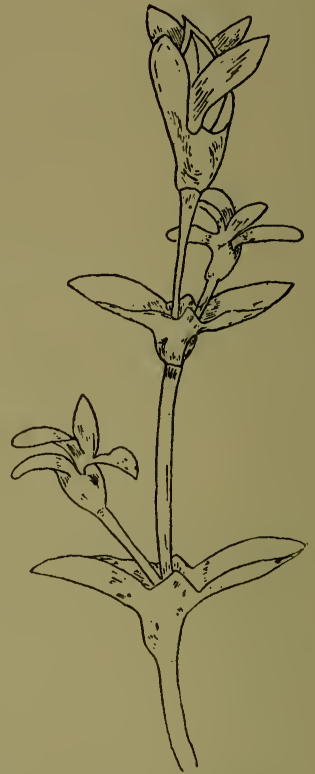

FIG. 96. - Hydrophylax. The leaves and stipules form a cup which catches and holds rain.

the fashion of their neighbours in the western part of the Province, their leaves are much in evidence. The plants of the Karroo defend themselves against the lack of rain by storing water in their swollen roots or stems and leaves. The leaves have thick cuticles, which are often encrusted with lime or covered with wax. In the leaf depressions rain and dew may be caught and retained, and the delicately tinted blossoms 
that crown the labour of these plants declare that Nature need seek no further devices for her Karroo garden. A drink of water from a well driven in the Karroo shows the salty or alkaline condition of the soil, and the fleshy leaves of the Karroo plants remind us of the plants along the salt marshes and sand dunes by the sea. ${ }^{1}$ It was once thought that roots absorbed all the water required by flowering plants. The water caught by the leaves of these plants suggests that they also absorb moisture. Notice how the pitcher-like leaves of

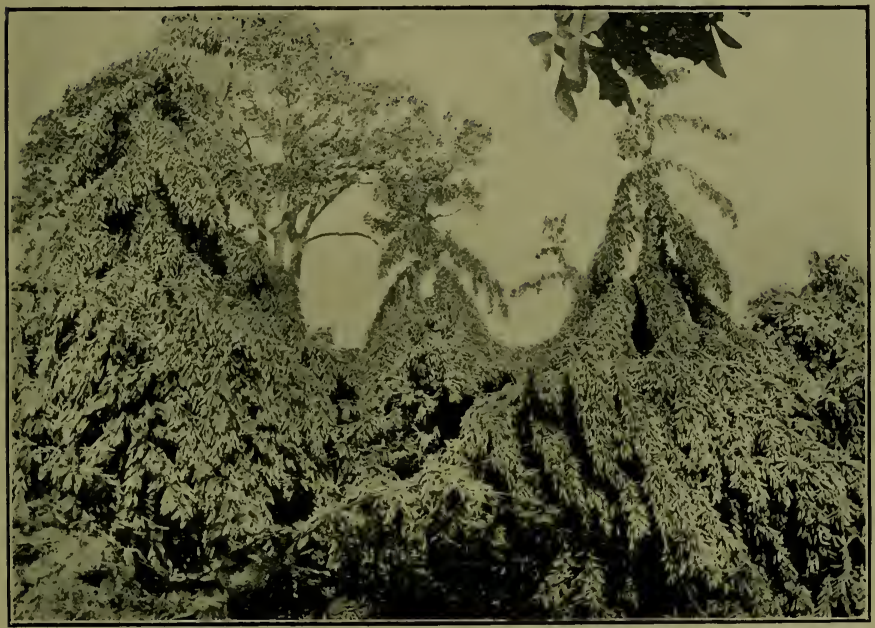

Fig. 97.-A swarm of locusts leaves little green in its path.

Satyrium and the cups formed by the stipules and leaf bases of Hydrophylax catch water.

A swarm of locusts leaves little green in its path, and in times of drought animals are not fastidious in their tastes for herbage; the juices of bitter or poisonous plants act as a guard against destruction from browsing animals.

Plants are also protected by spines or a felt of hair. Hermas

${ }^{1}$ Plants living in dry situations are called xerophytes; while those growing by the sea or by salt pans are known as halophytes. 
gigantea, L. $f$., the "Tondelbloem," has the lower leaves well protected by a dense hairy covering on both sides; as they get

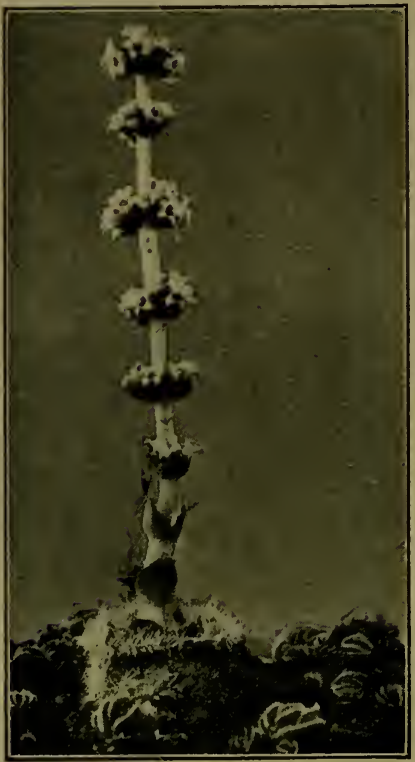

FIG. 98.-Crassula barbata, Th., with spine-protected leaves and bracts.

older, the hair is easily brushed off. The fragrant oil in some plants is distasteful to animals.

Instead of exposing the precious store of water above ground, it is stored by underground reservoirs of bulbs, corms, or root tubers which abound in the Karroo. These have often to give up their stores to thirsty natives and travellers.

Some plants have large bulbs near the surface, or, as in Bowiea, above ground, while others send a long neck deep down into the earth; at the end, patient digging reveals a small bulb or corm.

Much of the gardener's labour is in vain which is spent in carefully hoeing up the soil around his onions. Compare the size of onions which have had the earth heaped around them with those which have been cultivated leaving their bulbs partially exposed.

Plants growing in dry places frequently bear their leaves all in one plane, so that one leaf covers the leaf beneath it. Some bulbous plants have the edges of the leaves, instead of their flat surfaces, turned toward the stem, their bases, partly sheathing the bulbs, lead the water down to the roots. Such leaves are called ensiform.

Every one has noticed the two kinds of leaves borne on the Eucalyptus (Blue Gum). The upper leaves are placed with edges toward the noonday sun. The broad surfaces of the lower leaves receive less light. At sunset, when the light is not so strong, the upper leaves receive it on their broad sur- 
faces, and so are prevented from cooling too rapidly. It is the
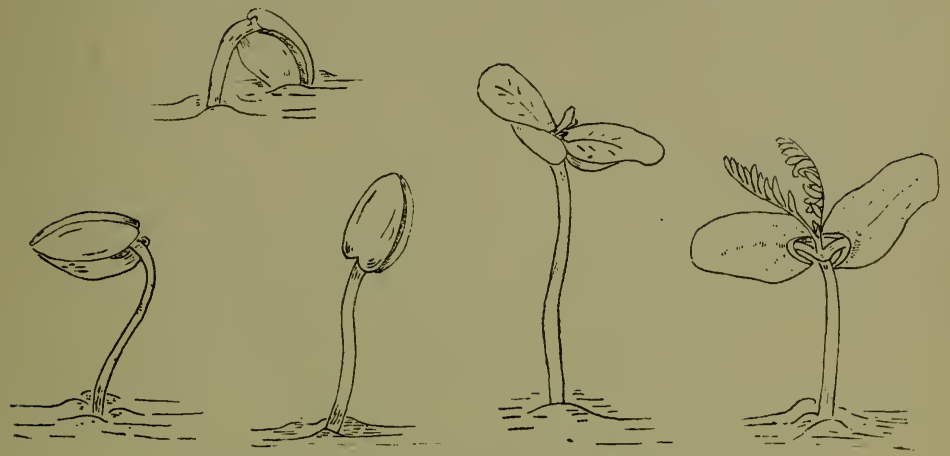

FIG. 99.-Seedlings of Black Wattles (Acacia melanoxylon, R. Br.).

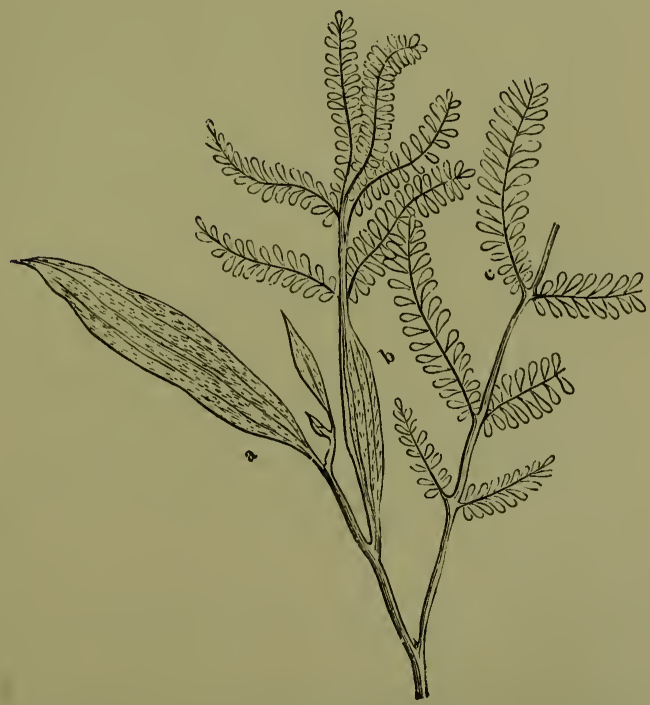

FIG. Ioo.-Branch of Acacia melanoxylon, R. Br., showing phyllodes $(a, b)$. (From Thomé and Bennett's "Structural and Physiological Botany".)

position of the upper leaves which gives such a delicate tracery against the sky. 
Sow Mimosa seeds, those of the Karroothorn and Blackwood, or the Port Jackson "Willow". Watch the seeds of both come up "with a loop," bringing their cotyledons with them. On the first leaves note the little bristle-like stipules. Can you see them on both kinds of seedlings? Are the next

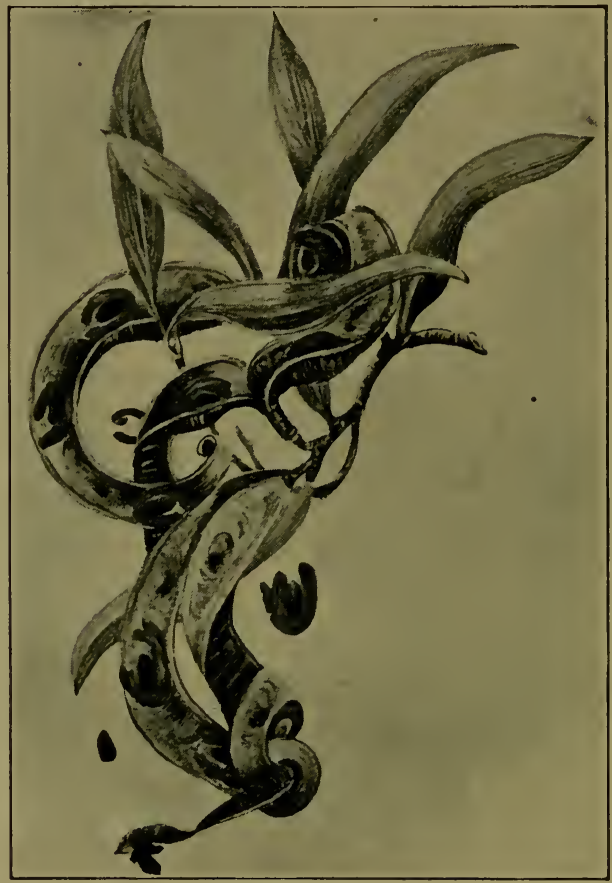

Fig. Ior.- The Black-wood trees lose all trace of the compound leaves they had as seedlings.

leaves the same in each. Watch the seedlings until you find how the Port Jacksons get their long narrow leaves and the Mimosas get their thorns.

When petioles flatten and take the place of the usually expanded portion of the leaves, they are called phyllodes (having the form of leaves). The Mimosa and the Port Jackson look very unlike as trees. But their early history shows that 
they are really closely related. Their flowers and fruit shows the relationship also, so their book name is the same, Acacia. The thorn tree of the Karroo is Acacia horrida, Willd. ; Acacia melanoxylon, R. Br., is an Australian cousin (black-wood).

Notice the bushes and trees about your district. Are their edges or their flat surfaces turned toward the sun? The slender green branches of the beef-wood tree (Casuarina) take the

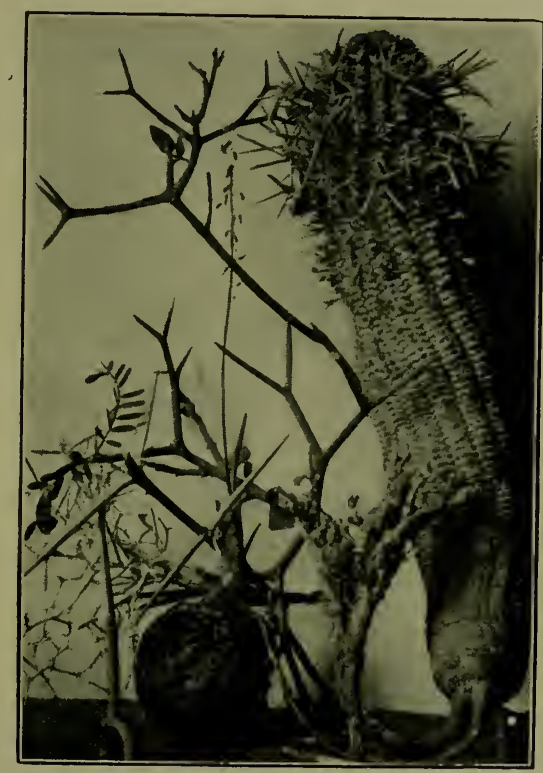

FIG. I02.-A nosegay from the Karroo.

place of leaves. This tree also comes from the "land of shadowless forests".

At noon we spread rugs over the Karroo thorn trees when we sit under them for shade. Place the tin of little Karroo trees in bright sunlight. How do they protect themselves?

Anacampseros papyracea, E. M., known in the Karroo as the "yeast plant," has large papery stipules which completely cover small fleshy green leaves. Their cells absorb rain and 
dew and open out as water runs down their inner surfaces. As this water is absorbed the stipules close over the leaves again. ${ }^{1}$

It would take a much longer chapter than this to tell of all the curious devices by which plants are protected against insolation or exposure to the direct rays of the sun. One of

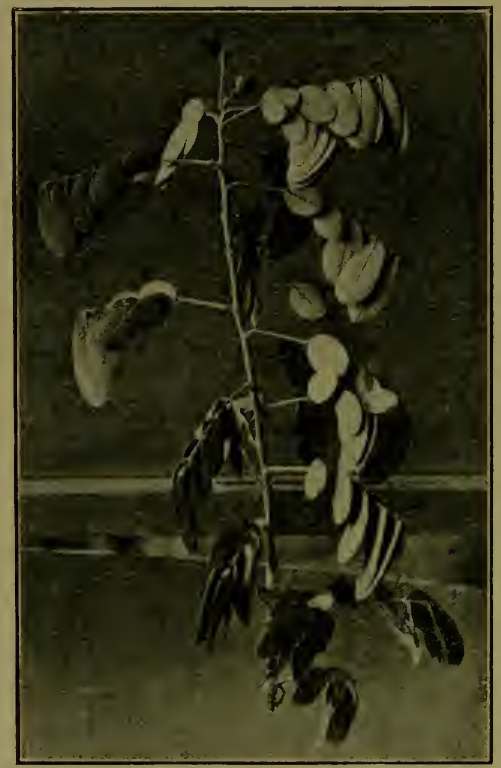

FIG. I03-Leaves of Cassia in sleep position.

the most remarkable methods is shown by a group of plants described by Dr. Marloth as possessing "window leaves" (Fenster-Blätter). These plants have the green portion of their leaves underground, only the colourless tips being exposed; here the light enters and is diffused to the chlorophyll below. Beneath these "windows" in some plants, for example Mesembrianthemum rhopalophyllum, S. and D., are found

${ }_{1}$ This plant supplies a ferment which the natives in some curious way have learned to use in raising bread. 
"curtains" of cells filled with red sap which further protects

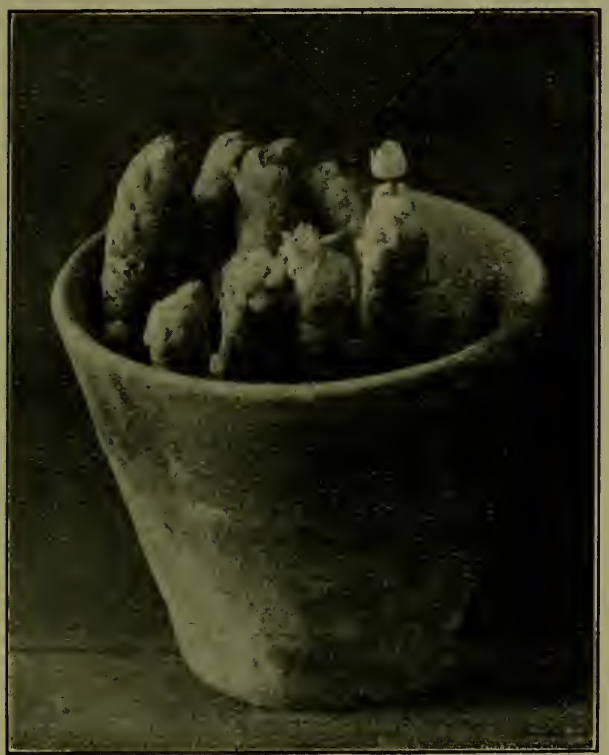

FIG. 104.-Anucampseros papyracea, E. M. Papery stipules cover the small green fleshy leaves.

the chlorophyll from the chemical rays of the sun.

This chapter has dealt with the way some plants have become adapted to certain regions in South Africa so that they have survived in the "struggle for existence". Plants growing in shaded forests or floating in ponds have quite different habits from these we have been describing.

The study of plants in relation to their surroundings is known as Ecology. It seeks to explain the origin of 
plant structures and how they have come to vary. If plants become fitted to their surroundings they thrive and multiply,
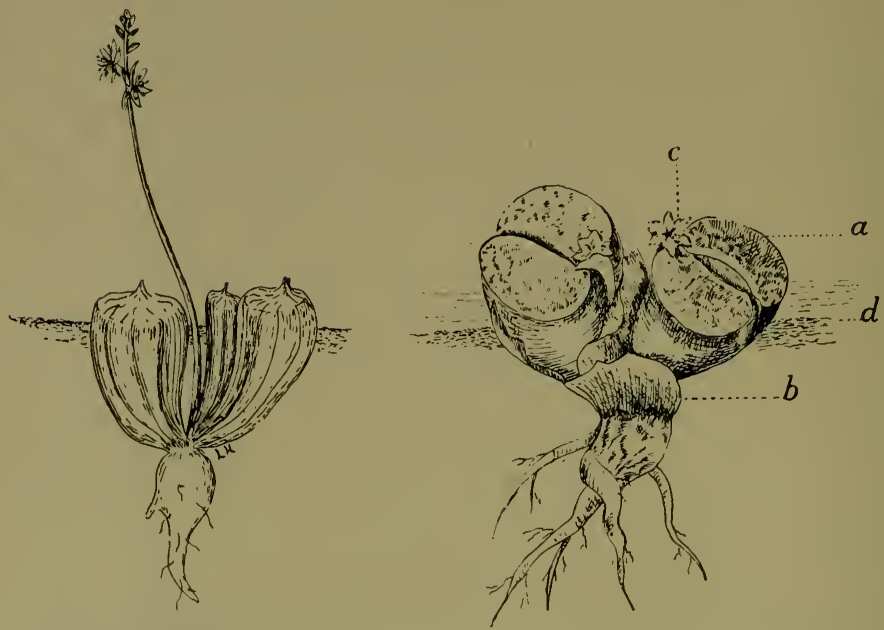

FIG. 106.-One of the plants described by Dr. Marloth as "Pflanzen mit Fenster-Blättern" (Plants with window leaves). A. Bulbine mesembrianthemoides, Haw., showing ground line. The tips of the leaf wither. The light passes through the transparent flat surfaces above ground and is diffused to the chlorophyll situated below in a narrow marginal row of cells. The central cells are water storing. B. Mesembrianthemum truncatum, Th. (collected by Miss Taylor near Kimberley), $a$, opposite truncate leaves; $b$, withered remains of last year's leaves ; $c$, capsule of last year's fruit. The leaves beneath the ground line $d$ are green; the portion of the leaves above the soil form a red sap in the cells which protects the chlorophyll below.

if not they die out, and so the study is also connected with that of geographical distribution and with the origin of plant associations. 


\section{CHAPTER XV.}

\section{NEW PLANTS WITHOUT SEED.}

FLOWERING plants usually reproduce by seeds, but reproduction may take place by other methods.

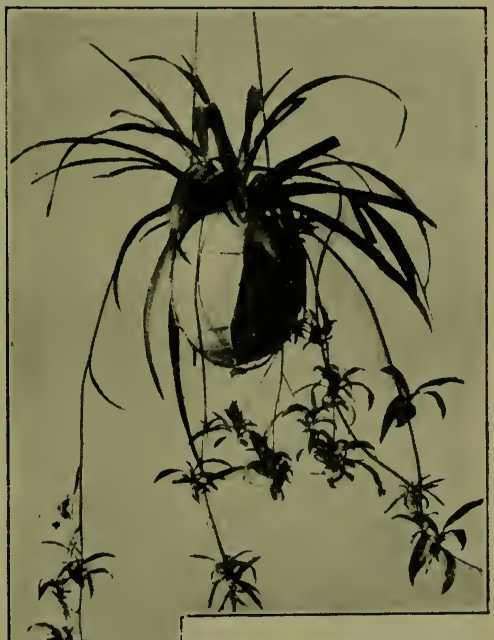

FIG. 107.-Lily growing in ostrich egg.

Some species of Oxalis have a vigorous underground stem system, upon which bulbs in great number are formed. ${ }^{1}$

${ }^{1}$ In these species long roots filled with sap may be found in early winter, As these give up their sap to the brood of young plants they 
Within these bulbs, on the tips of slender coiled stems, other bulbs are formed, which send up new plants year after year. Creeping underground stems are called rhizomes. In some rhizomes (e.g. Pteris and Aspidium) the stem remains below and sends the leaves above ground; more frequently the end appears above ground, while a branch continues below to come above the following year. As the old parts die, branches are set free, and so plants are multiplied.

The Lily growing in the ostrich egg (Fig. I07) had blossoms,

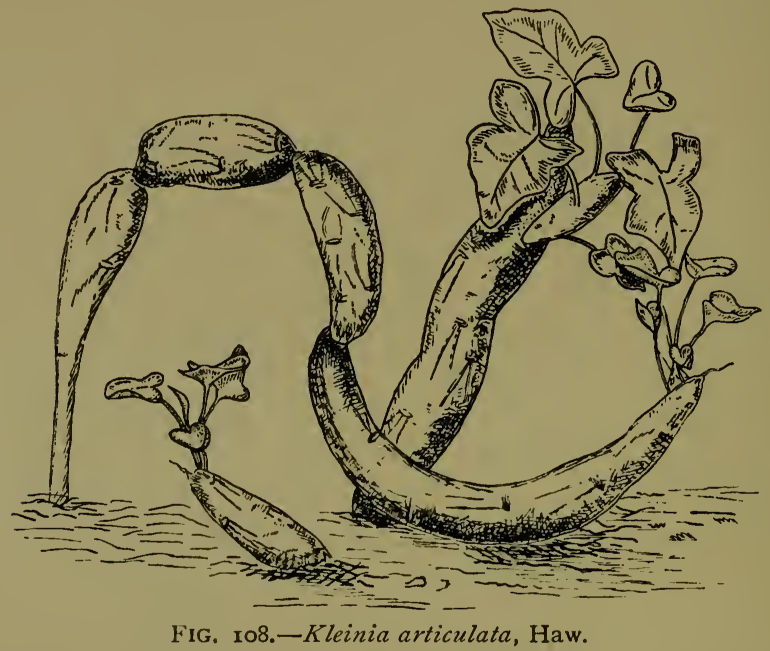

but the seeds did not set; possibly for lack of food which passed on to form little plants on the tip of each flowering stalk. The little plants send out roots in search of food. If they had been left in the mountain they would have been more successful in their search. They are given a good start in the world, for the wiry stems throw out each plant a long

become wrinkled and much shorter. This shortening pulls the adventurous plants down and keeps them sufficiently covered with soil. It is by the pull of drying roots that bulbs with long "necks" are also pulled further down into the soil year by year. Let a bulb dry and see if the roots all wrinkle in the same manner. 
distance from the parent, and in a few years they will travel far up or down the mountain.

A great many of the Cape plants reproduce by bulbs. They may lie dormant in the ground for years. After the vegetation has been burned off these bulbs have a chance, and then send up flowering stalks which turn the blackened veld into a garden.

New plants are obtained by cuttings from old ones. Sometimes the stock is cut back so as to obtain a supply of shoots for this purpose. It is in this way that sweet potatoes are propagated. Kleinia articulata, Haw., Fig. 108 , which grows about Uitenhage, propagates naturally by cuttings. The fleshy stems

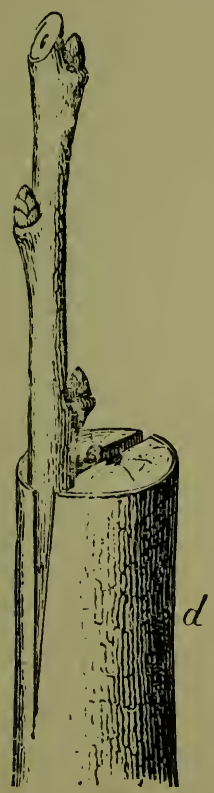
are jointed or constricted at intervals. A strong wind breaks the plant at these joints, and new shoots start from the axils of theleaves

In a seed the first root is formed ready to push down into the soil. In reproduction without seed (vegetative reproduction), new roots have to be formed from the stem; these roots are called adventitious roots.

Vegetative reproduction occurs when plants grow in the shade or in rich soil. When the soil becomes exhausted, seed will be formed.
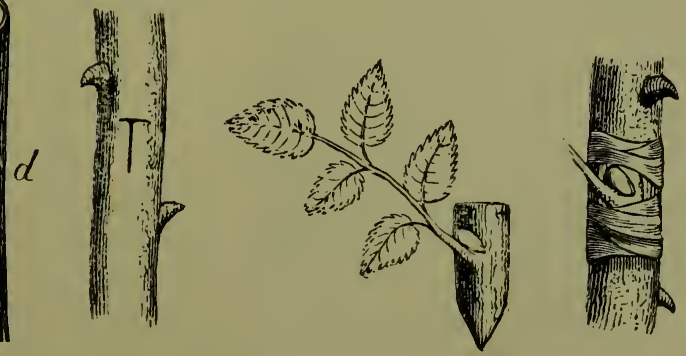

FIG. Iog.-Grafting; $d$, the stock to which the graft is attached. The various elements in the process of budding. (From Thomé and Bennett's "Structural and Physiological Botany".)

Vegetative reproduction is sure and economical, a disadvantage arises from the close crowding of new plants. 
Grafting and Budding.-When plants are grown from seeds they often differ from the parent plant, owing to the fact that the ovules have been cross fertilized, i.e. pollen has been brought from another variety or species. Grafting is resorted to in order to ensure retaining a desirable fru t. By this method, new and delicate varieties may be introduced into the country by grafting on to hardy plants, as in grafting varieties of grape on to the American vines.

Grafting has another advantage, as trees grown from seed take several years to bear fruit. Buds of the first or second order, that is, the bud at the tip of the main stem and those that are borne in the axils of its leaves, do not develop fruitbuds, but leaf-spurs. By using grafting scions of a higher order, fruit will be borne much sooner.

To graft in a simple form, select two branches of the same

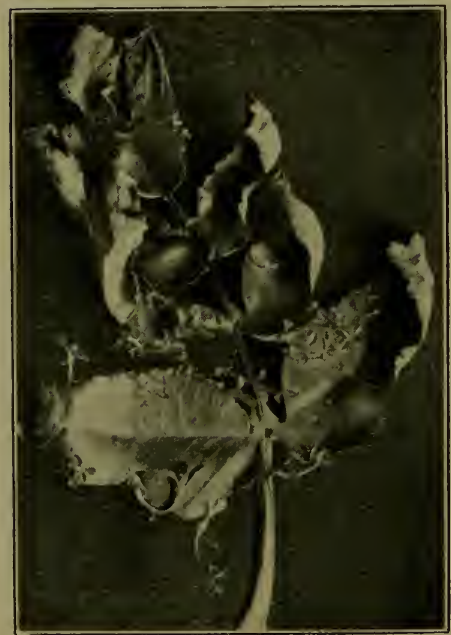

Fig. IIo.-Leaf of Bryophyllum. Little plants are borne all along the edges of the fleshy leaf. They send out roots, fall off, and start new plants, species ; cut from each a portion of the bark and a little wood, which will be bordered by a ring of cambium. Bring the two cut surfaces together and bind them firmly. When the two have united, one may be cut from the parent stock. Sometimes it is desirable to graft a small scion on to a larger stock. The stock is cut off, the scion is pointed at the lower end and thrust in between the wood and the bark. The stock is prevented from drying by a covering of clay or grafting wax. Drying would kill the cambium.

Budding is a form of grafting. A single bud with a portion of wood is inserted into a T-shaped opening of the stock. This method is used with especial'-success with Oranges, Apricots, and Roses, 
An Apple will graft on to a Quince, but a Quince does not take well to a Pear. A Pear will not grow well on an Apple. Prof. Bailey tells us that Tomato plants will grow on Potato stocks, the combination forming Potatoes underground and Tomatoes above. When Tomato plants are the stocks, what will happen? If you own a Rose bush, it will be interesting to see how many kinds of roses you can bud on to one stock. Try it.

Budding and grafting should be done when the sap is active in the spring.

Pineapples and Bananas have lost the power of forming seeds. The leafy stem above the Pineapple fruit readily sends out roots when placed in the soil, and a new plant is grown. How are Banana plants propagated?

The mother fern, Bryophyllum, and Begonias are propagated by means of buds formed on the leaves. The stem or axis of the bud lengthens, and the leaves unfold; roots are sent out from the lower portions of the stems, and the little plants fall off, forming new plants.

Mosses and Mushrooms do not form seeds, but are reproduced by spores. The fern spores are borne in spore cases (sporangia) usually on the under side of the leaves. 


\section{CHAPTER XVI.}

\section{CLIMBING PLANTS AND PLANT MIGRATIONS.}

IT is interesting to notice along waysides and waterways how different varieties of plants dwell in congenial plant societies. Many a delicate plant owes its start in life to the protecting branches of some overhanging shrub or forest tree which it afterwards uses to "rise in the world".

We could not make a satisfactory classification of climbing plants, because almost any family of plants might have climbing members if their surroundings were such as to induce climbing or made the habit an advantage. In fact, a plant which may have quite an erect habit out in the open will become tall and slender and in need of support if growing among bushes.

Stem Twiners. - Microloma and Cyphia show a common method of climbing by twining. The stems twine from left to right, or counter clock-wise. ${ }^{1}$ Growing on the open veld as they do, their support is seldom long enough for their entire length, but the stems often twine several together in a strand firm enough to bear their weight of pretty blossoms up into the sunlight. You may watch them in the schoolroom, if you place them in water, and see how at different hours of the day the stems point in different directions The tips of the stems make wide sweeps, but as they extend in length the coil tightens around the support. One keen-eyed student says she can tell from what hillside Microloma has been gathered by the plant it entwines. On one hillside she seeks it on Restiacea ; in another locality it twines about the rigid branches of Montinia acris ; while elsewhere it mingles its scarlet waxy flowers with the hoary heads of Eriocephalus.

${ }^{1}$ With the sun in the southern hemisphere. 
Tendril Climbers.-The Pea family, Grenadilla and other plants, climb by tendrils. The pumpkin, cucumber, and calabash seldom make use of their tendrils. Their heavy fruits would be a great strain on the plants ; but several native relatives, Luffa and Lagenaria, with their lighter fibrous fruits, are climbers, and Gerrardanthus megarhiza, T. and H., of Natal climbs to the tops of highest trees.

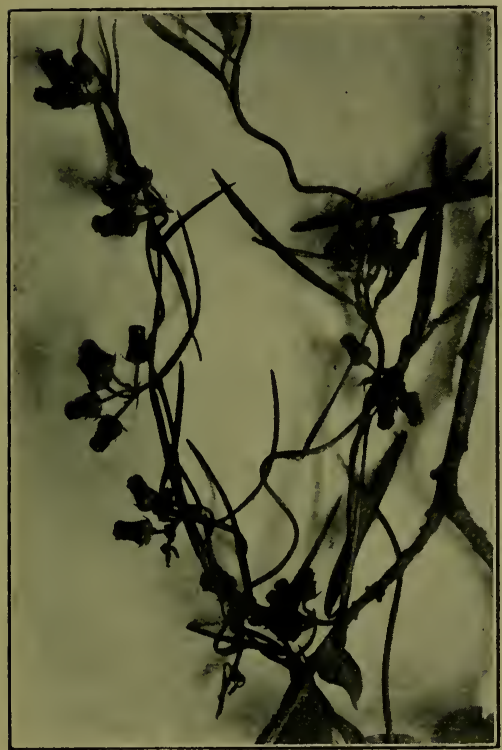

FIG. II1.-Microloma gets up in the world by twining on stems of other plants.

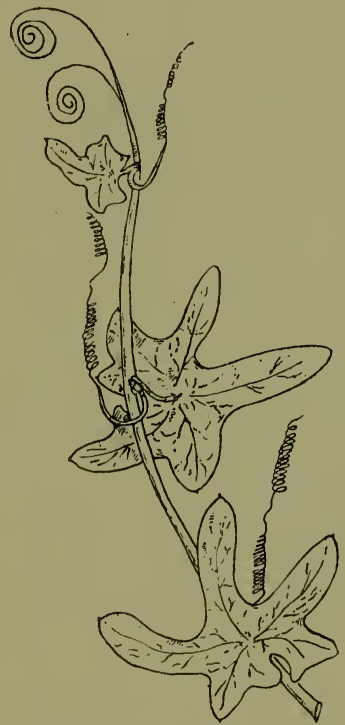

FIG. 112.-The first leaf of the branch in the pumpkin family changes into a tendril.

The tendrils of the Pea are formed from the upper leaflets of a compound leaf. This use of the leaf throws the responsibility of making food upon the stipules or upon the broadwinged stem. In the grape vine the main stem turns aside to form the tendril and to bear the fruit, while the tendrils of Clematis are formed from the petioles. What is the tendril of the Grenadilla?

The beautiful scarlet and orange blossoms of Gloriosa 
are borne up against their glossy background of trees by the coiled tips of their leaves. Littonia and Flagellaria (Fig. I I 4) have a similar habit. No tendrils are borne on the tips of the lower leaves. They can grow erect for some time without a support.

Hook Climbers.-Some plants like Asparagus and Dog Roses lean against others for support. The recurved thorns or prickles which ward off animals serve to fix and support the plant. The Ivy climbs by means of roots (haustoria) which grow out along the stem.

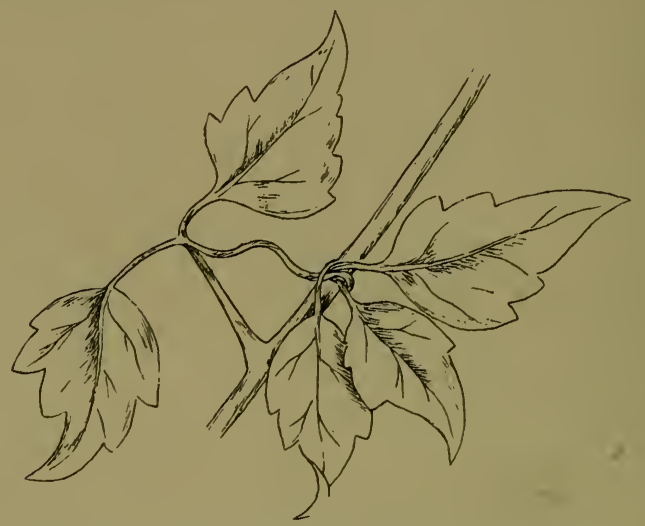

FIG. II3.-The petioles of Clematis act as tendrils.

Plants in dry open places, on the other hand, are less congenial. It is to their advantage to appropriate as much soil as possible to the exclusion of others of their own or of different kinds. Some species of Brunsvigia and Hamanthus spread their flat leaves closely upon the ground, preventing others from gaining a foothold, and smothering any weaker plant which may have taken root in the soil which their leaves can cover. So the plants appropriate water and food material from a wide area.

Foreign Immigration.-Have you ever thought how much or how little South Africa owes to other countries for its flora? Dr. Bolus, in his "Sketch of South African Flora," mentions as une of its peculiarities "its power to resist the 
aggression of foreign invaders". The bulbous plants offer a most determined resistance to other plants. Even South African plants seldom spread when removed from their restricted locality. A Mimosa (Acacia horrida, Willd.) was planted in Wellington as a thank-offering for a difficult journey

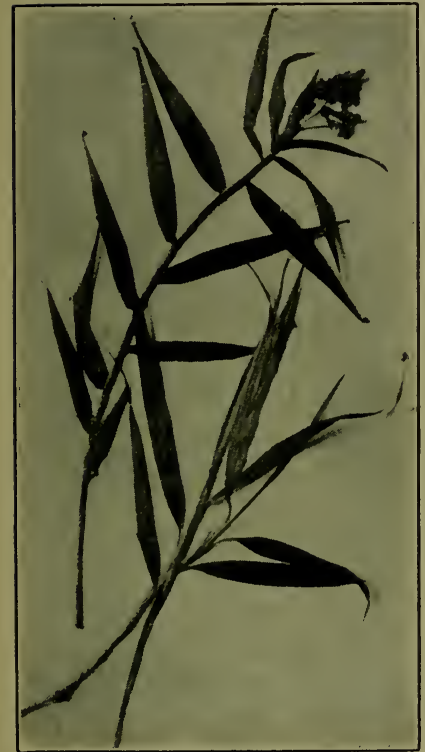

Fig. Ir4.-The leaf tips of Flagellaria serve as a means of support.

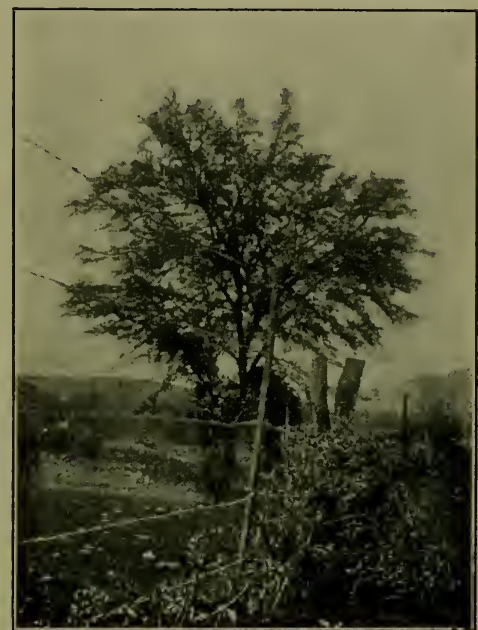

FIG. I15.-A Mimosa tree in Wellington. Out of its natural habitat it thrives, but does not spread as does its relative the "Port Jackson" from Australia. (Photograph by Mrs. Aiken.)

successfully completed before the railway extended to Worcester, more than thirty years ago. Beautifully green in winter, in summer it is a fragrant mass of golden flowers. Fruit and seeds are produced in abundance, but still it stands the only Mimosa tree in the vicinity. However, it is much the same with plants as with people who come to our shores. If they adapt themselves to the conditions as they are, and make the most of them, they are apt to thrive and find hospitable soil.

Have you ever thought how different Johannesburg would look without the Australian Blue Gums? How we should miss 
the oaks which make French Hoek and Stellenbosch so delightfully shady, and how different the suburbs of Cape Town would look without the European Pines!

For draining the fever district what tree could serve better than the Blue Gums? Their thirsty roots make enormous demands on the water supply, while their vertically placed leaves and slender erect habit allow the sun to penetrate to the soil. The Pines or "Firs" and the Blue Gum, which belongs to the

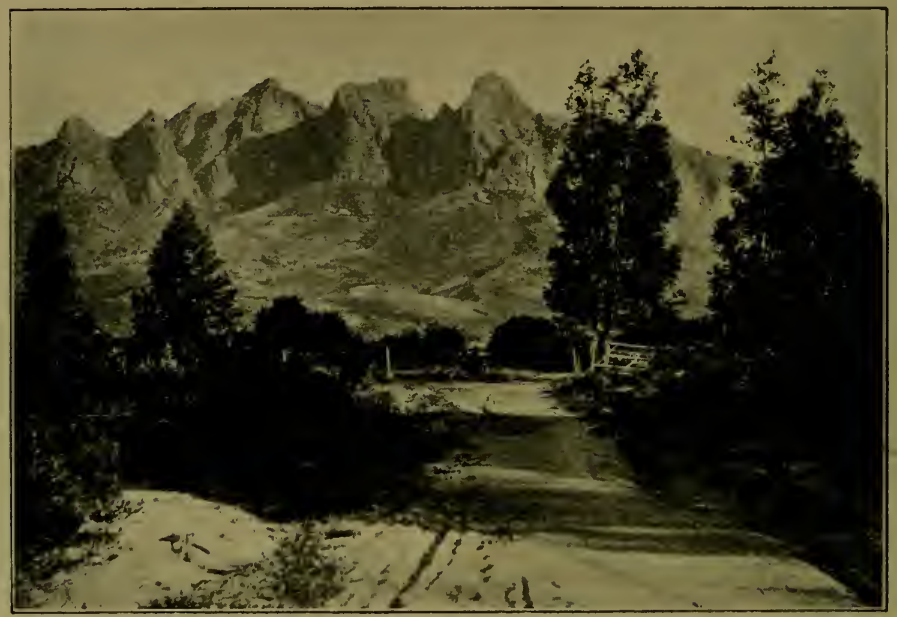

Fig. Ir6.-Moun: Hawakwa, near Wellington. The Australian Eucalyptus softens the treeless landscapes of the Colony. (Photograph by L. Grant.)

Myrtle family, remind us of the prophecy in Isaiah LV. I I-I3 : So shall my word be that goeth forth out of my mouth; it shall not return unto me void, but shall accomplish that zohich I please. . . Instead of the thorn shall come up the fir tree, and instead of the brier shall come up the myrtle tree: and it shall be to the Lord for a name, for an everlasting sign that shall not be cut off.

Along the coast the sands are ever shifting and piling up new dunes. The native plants do their share in staying the sands; the succulent creeping Mesembrianthemum (T gaukum and Paarde Vijgen), and Myrica, with its spreading trunk half hidden in the sand, all help to render the sands more stable. 
The "Port Jackson Willow," from Australia, is admirably adapted to aid in this work. Besides spreading by the countless seeds which it produces, the plant multiplies by tough suckers, that run underground in all directions, forming a firm foundation upon which their humus or decaying leaves mingle with the verdureless sand. Moreover, these plants belong to the great group of leguminous plants, the nitrogen gatherers. Their innumerable roots are claiming quantities of the valuable

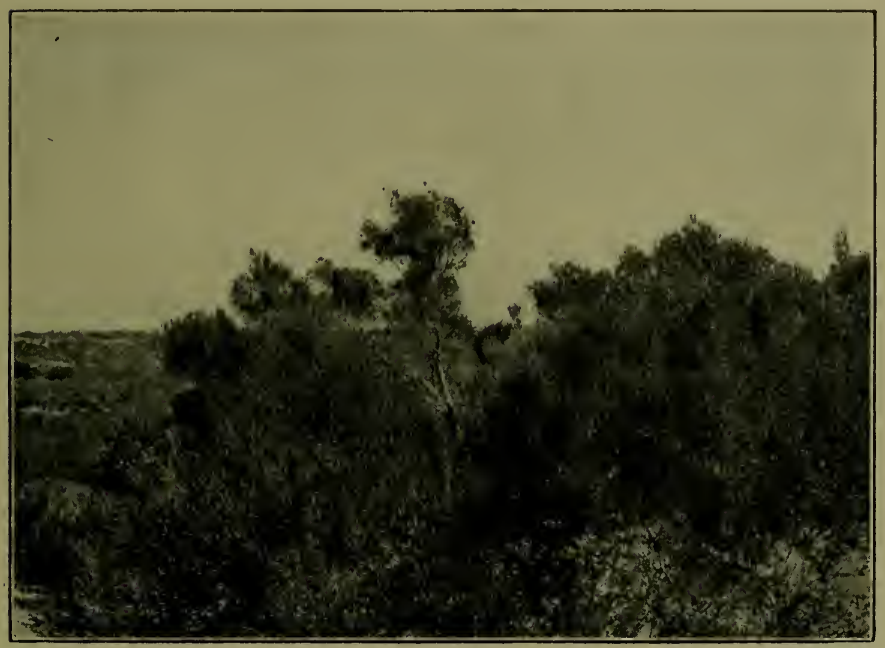

FIG. I17.-Myrica cordifolia, L. (Photograph by Dr. Marloth.)

nitrogen of the air, and are giving wealth to the soil as fast as it is being removed from the Kimberley and Johannesburg mines (See p. гог.)

Plants introduced into America have spread until they have become pests. The same plants brought to this country for their beauty of flower may grow, but seldom become noxious. South Africa, with its wealth of beautiful flowers, can well dispense with introduced flowers, except the Roses and Violets, which are lacking in this country-and how they do thrive!

The lack of fuel and building timber in South Africa is not 
a natural condition but one largely brought about by the agency of man. When Vasco da Gama came to South Africa he named it "Terra de fume" from the fires. From the time when the Hottentot and Bushman were the sole inhabitants of South Africa, grass fires have gradually destroyed the forests. Trees that once occupied large areas now survive only along mountain streams. Cunonia capensis, L., a handsome evergreen tree growing by the borders of streams throughout Cape Province and Natal, is one of these survivors.

Farmers point out barren areas which in their childhood days were well covered with large trees.

"One of the early Dutch Governors made a rule that in thinly wooded districts, every farmer in felling a tree should plant two saplings in its place." 1

Fortunately the Forest Department is doing valuable work in restoring and producing forests.

${ }^{1}$ Quoted from Dr. J. Brown by F. R. Sim, F.L.S., F.R.H.S., in "The Forests and Forest Flora of the Colony of the Cape of Good Hope". 


\section{CHAPTER XVII.}

\section{FLOWERS AND THEIR PARTS.}

Note.-This chapter will contain many new names. We must have them when we study flowers. Do not try to learn them all at once, but find as many flowers as you can and make out each part named in this chapter. You will have the names in mind before you know it.

To understand the parts of a flower, it is better to take those of the veld. Roses, Carnations, Chrysanthemums, and Dahlias of our gardens delight us with their glorious masses of colour, but by long cultivation they have lost some of the characters which Nature originally gave them. Chrysanthemums (the gold flowers), it is said, have been in cultivation for over 2000 years. Enthusiastic cultivators have so put their hearts into showing what a range of colour and size is possible in these old garden favourites, that the flowers themselves have yielded up their own golden hearts to the cause. The centres have grown out into flattened petals, which gradually reveal all the colours they have caught from the sun.

"The lovely wild flowers are the flowers which God has made." We repeat Jean Ingelow's thought when we come upon Heaths, Nerine, and Orchids in some hidden inaccessible place. But garden flowers have their beauty too-beauty obtained by care and skill of those who love them. The wild flowers were so made they can change most wonderfully under cultivation, and lend added cheer and colour and interest to the lives of those far from heath-covered hills or Disa-bordered streams.

If you examine the flower of Crassula, you will find on the outside a circle or whorl of green leaves-the calyx ; each leaf is a sepal. The calyx is the cover of the flower. In 
Dianthus (Carnation), Datura, and Hibiscus the sepals have grown together, forming a cup.

Within the calyx, the second row of flower leaves is the

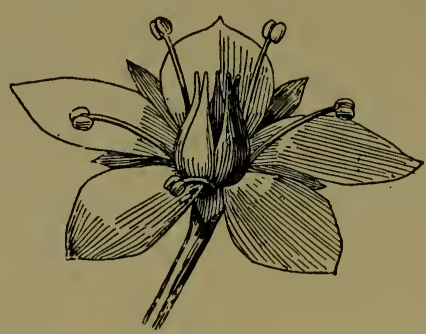

FIG. II8. - Crassula centauroides,

Thunb. (From Edmonds and Marloth's " Elementary Botany for South Africa ".) corolla, or little crown. It is usually the showy part of the flower. Sometimes the calyx is brightly coloured, and may at first be mistaken for the corolla. Calyx and corolla taken together make the perianth.

The third whorl bears little resemblance to leaves. It consists of as many slender threads as there are petals; each thread ends in a yellow knob. They are the stamens. The thread of the stamen is the filament (thread), and the knob the anther. The anther contains the powder-box, and each box contains very valuable powder, called pollen (microspores). In the centre of the flower are several boat-shaped bodies, tapering to a point. 'They are the pistils or carpels. The lower part of the pistil is the ovary. It contains small rounded bodies, the ovules, which are destined to form seeds.

Structure and Forms of Ovules.-The ovule consists of a mass of cells, the nucellus, surrounded by one or two seed-coats; two integuments (or coats) are found as a rule in Monocotyledons and Archichlamydeæ ${ }^{1}$ (Umbelliferæ and Leguminosæ may be noted as exceptions) and one in Sympetalæ. The place of attachment of nucellus and seed-coat is called the chalaza. The stalk is known as the funicle, and the scar formed on the seed at its place of attachment to the ovary, the hilum.

The simplest form is the straight or orthotropous ovule. The funicle, chalaza, and micropyle lie in a straight line. It may be found in the orders Commelinacer, Xyridacee, Polygonacere, Restiacea. A second form found in Mulberry and Fig is known as amphitropous. The nucellus is straight but

${ }^{1}$ A subdivision of Dicotyledons. See Engler's "System of Classification," p. 209. 
the whole ovule is so bent that a line drawn through the funicle would cut at right angles, nearly at the centre, a line drawn through the chalaza and the micropyle. The funicle is partially fused with the seed-coat forming the raphe. The anatropous ovule which occurs most frequently, is still further bent so as to bring the micropyle down to the funicle, the chalaza lying at the opposite end. The raphe extends the whole length of the ovule. The campylotropous ovule,
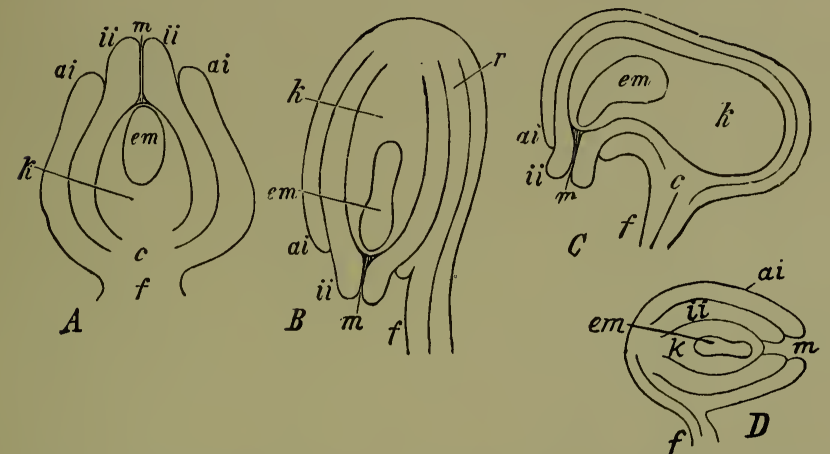

FIG. Ir9.-Sections of ovules (diagrammatic). A, orthotropous; B, anatropous ; C, campylotropous ; D, amphitropous. $f$, funiculus ; ai, outer integument ; $i i$, inner integument ; $k$, nucellus ; $m$, micropyle ; em, embryosac; $r$, the point of union between the side of ovule and funiculus; $c$, the chalaza. (After Prantl.)

found in the narrow bean, is curved so as to lie at right angles to the funicle which is not fused with the integument.

Now find the flower parts in Hibiscus. The stamens here are joined by their filaments into a tube. Above the stamens are five crimson velvety cushions, the stigmas. Carefully split down the stamen tube, and see how these five cushions are borne at the top of a long slender stalk, the style. By following the style down its entire length, we come to the ovary. A cut across the ovary shows as many parts or carpels as there are stigmas. Within the cavities or locules are the ovules. Remember that the ovules are not at first seeds, any more than a new-laid fowl's egg is a chicken. 
When carpels are separate as they are in Crassula, they are said to be apocarpous. When they are joined as in

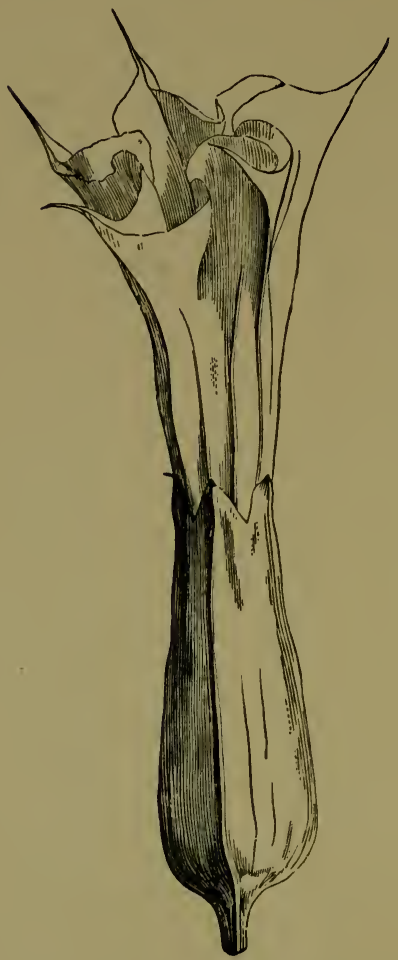

FIG. 120.-Flower of Thorn-apple (Datura Stramonium, L.) (natural size), showing gamosepalous calyx. (From Thomé and Bennett's "Structural and Physiological Botany".)

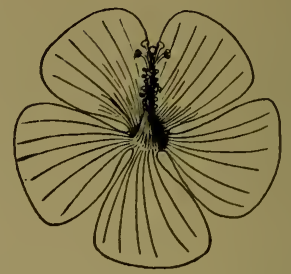

FIG. 121. - Hibiscus athiopicus, L. (From Edmonds and Marloth's " Elementary Botany for South Africa ".)

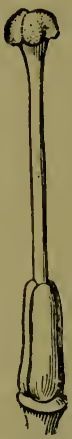

FIG. 122.-Pistil of Lily, with ovary, style, and stigma. (From Thomé and Bennett's "Structural and Physiological Botany ".)

Hibiscus, they are syncarpous. The parts of a pistil areovary, style, and stigma.

Crassula, Hibiscus, Ornithogalum ("Chinkerinchees"), and other flowers have four whorls. Their flowers are complete. Clematis (Traveller's Joy), Protea, and others have but 
one whorl of floral leaves. Although it may be showy, the one whorl is usually called the calyx. If any one or more whorls of the perianth are wanting, the flower is incomplete.

After a few weeks the Clematis loses its sepals, and only the seed-forming portion remains. The ovules within the ovary cannot become seeds without the pollen from the stamens; so the stamens and pistils are called the essential organs.

If the anthers are removed from any flower before they shed their pollen, and the flower is then covered or removed from any similar flower, the ovaries will wither away and form no seed. If, after the stamens were removed, pollen were

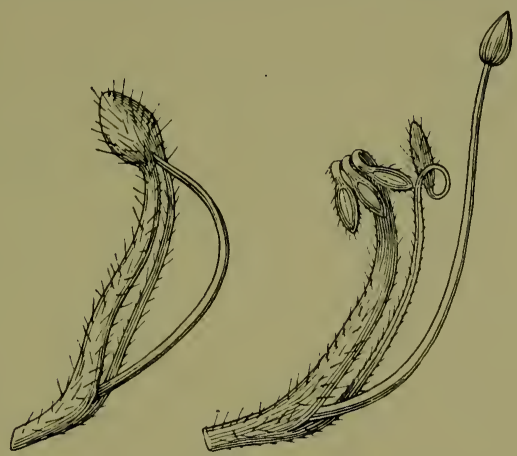

FIG. 123. - Leucospermum ellipticum, L., has no corolla. The flower is incomplete. (From Edmonds and Marloth's "Elementary Botany for South Africa".)

brought from a similar flower and placed at the right time on the stigma, the pistil would continue growing, and seeds would be formed as though there had been no disturbance, even though the petals and sepals were removed. A perfect flower has both stamens and pistils. In the flowers which bear the seed in the Silver Tree, mealie, or Montinia stamens are wanting, while those that have stamens produce no seed. Flowers in which either set of essential organs is wanting are imperfect. If the pistils are wanting, the flowers are staminate. If the stamens are absent, the flowers are pistillate or fertile. A perfect flower is sometimes called bisexual or 
hermaphrodite. The willows and arums have neither calyx nor corolla. A flower may be reduced to a single stamen or a single pistil, as in Euphorbia.

A complete flower has-

(I) Calyx, made up of sepals.

(2) Corolla ", " petals.

(3) Stamens ", ", filaments and anther.

(4) Pistil " ", ovary, style, and stigma.

A perfect flower has-

(I) Stamens.

(2) Pistil.

Practise making out these whorls in flowers. Find other flowers which are pistillate or staminate.
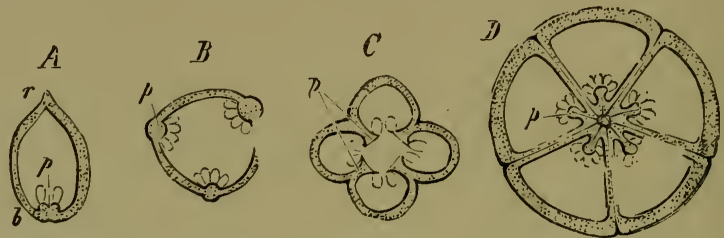

FIG.. I24.-Diagrammatic sections of ovaries : $p$; the placenta, to which the seeds are attached. A, apocarpous; B, C, D, syncarpous. (From Edmonds and Marloth's "Elementary Botany".) A, B, with parietal ; C, D, with axile placentation.

Do not try to remember any of these names until you have seen the parts themselves.

Different Kinds of Pistils. - The long style of Hibiscus
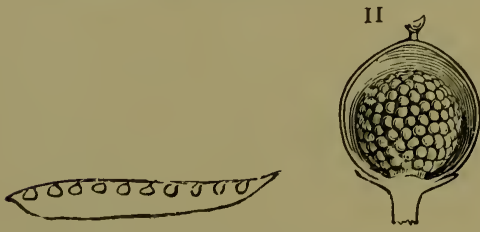

FIG. I25.-I. Marginal placentation.

Unilocular ovary, with free central placenta. (From Edmonds' "Elementary Botany ".) is necessary to bring the stigma out beyond the stamens. In some Or. nithogalums and in $\mathrm{Al}$ buca the stigma sits directly on the ovary. The style is not in all

II.

cases necessary to the pistil. It depends upon the share of the flower.

If a flower has two or more carpels, they generally grow together. A syncarpous ovary may be one-, two-, three-, four-, or many-celled (or uni-, bi-, tri-, quadri-, or plurilocular). 
As the ovaries are variously formed, the ovules are placed
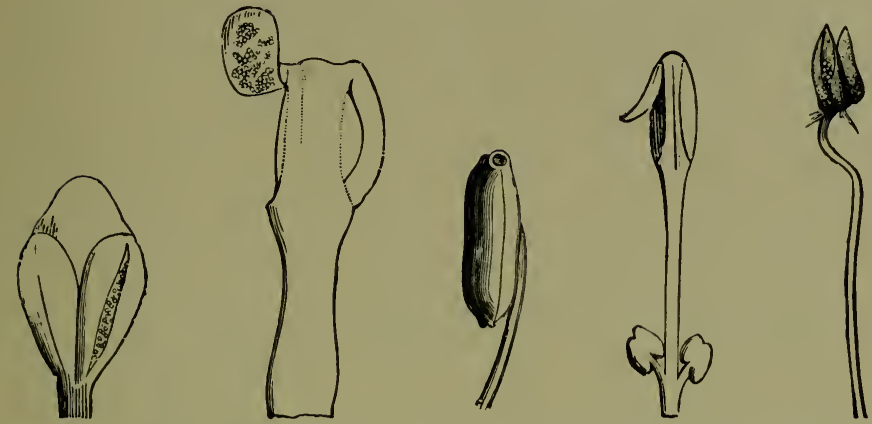

FIG. 126.-I. Stamen of Pinus sylvestris, L., with longitudinal dehiscence (magnified). II. Stamen of barberry, the anther opening by recurved valves (magnified). III. Stamen of Rhododendron, each anther lobe opening by a pore. IV. Stamen of bay, Laurus nobilis, L., with two glands at the base of the tilament, the anther opening by recurved valves. V. Stamen of Erica, the anther opening by pores and bearing two appendages at its base (magnified). (From Thomé and Bennett's "Structural and Physiological Botany".)

in different positions. In the bean they are placed on the upper edge of the ovary; in Orchids, Violets, and Drosera the ovary is made up of three or five carpels which just meet at the edges. The joinings make three thick ridges the length of the ovary. The part upon which the seeds are placed is called a placenta. In Ornithogalum and Gladiolus the three carpels curve in until they meet at the centre or axis of the ovary. In Carnations, "Poor Man's Weather-glass" (Anagallis), and Portulacaria (Spekboom), the ovules are borne on a column, the end of the flower-stalk or receptacle; they are free from the wall of the

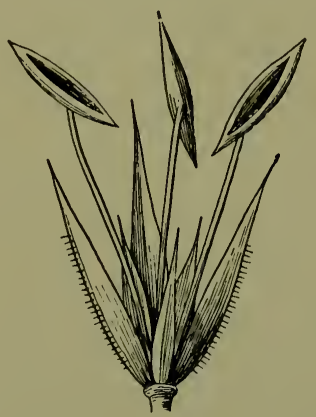

FIG. 127.-One-celled swinging anthers of Restio. (From Edmonds and Marloth's "Elementary Botany for South Africa ".) ovary.

These three kinds of arrangement or placentation are marginal, which includes the parietal and axile, and "free 
central placentation," including basal, where the axis is not prolonged.

Different Kinds of Stamens.-Stamens may have long filaments, but in some flowers they are very short. Like the style and the petiole of a leaf, the length is adapted to place the essential part of the organ in a favourable position. When filaments are wanting the anthers are said to be sessile. In S.A. Proteacea, where they seem to be wanting, they have fused with (are adnate to) the perianth lobes.

Anthers are differently attached to the filaments. In Gladiolus, Lobelia, and some Heaths the filament is joined to the

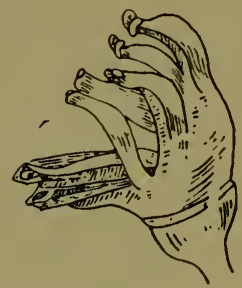

Fig. 128.--Stamens of Cyanella capensis, L.

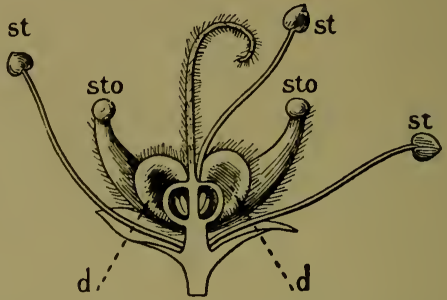

FIG. 129. - Section through flower of Barosma crenulata, Hook., after the removal of the petals (magnified): st, fertile stamens; sto, barren stamens (staminodes) ; $d$, lobes of disk. (From Edmonds and Marloth's "Elementary Botany for South Africa".)

base of the anthers (basifixed). In Jasmine the filaments extend between the anthers (adnate) In grasses and in Bulbinella the filaments are so joined to the centre of the anther at the back that they easily swing (versatile). Versatile anthers are frequently found where pollen is conveyed from them to the stigmas by wind. The continuation of the filament to which the anther is attached is called the connective.

Examine anthers in buds. Usually the anther consists of two lobes. On cutting across the anther, each lobe will be seen to contain two pollen sacs or microsporangia. When the pollen grains or microspores are ready to be discharged, the tissue separating the two pollen sacs of each lobe is broken down and the two cavities merge into one. Such anthers are 
frequently called two celled, although they were originally four chambered. Restio and Hibiscus have two microsporangia, but in older botanies are called "one celled". A split occurs in the ridge of each lobe and the anthers are said to dehisce.

Dehiscence takes place in different ways. The anthers of Watsonia, Antholyza, and Protea open the entire length. Cyanella and many Heaths open by little pores at the tips. Do you know of any other that open in this way? Cassytha and Ocotea (Stinkwood) open by little lids upon which the pollen adheres.

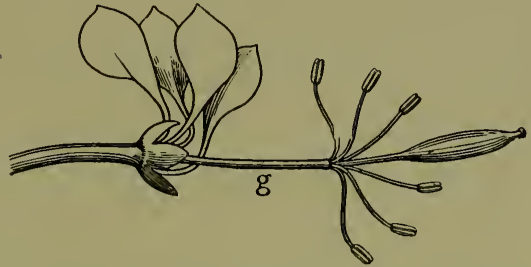

FIG. 130.-Gynandropsispentaphylla,DC. Flower with large gynophore, $g$. (From Edmonds and Marloth's "Elementary Botany for South Africa".)

In Adenandra, Barosma, and in some species of Albuca, what appears to be every other stamen bears no. anther. In Adenandra they bear honey glands at the tip. Bodies which are in the position of stamens, but which do not form pollen, are called staminodia.

Stamens may cohere by their anthers (monadelphous), or by their filaments (synandrous or syngenesious); they may adhere by their filaments to the petals (epipetalous), or to the sepals (episepalous).

The following terms refer to the number of stamens and to their position :-

Pleiostemonous stamens many or indefinite, twenty or more.

Diplostemonous, two whorls, each of equal number to the petals, the outer whorl alternating with them.

Obdiplostemonous, as in diplostemonous, but the outer whorl is opposite or anteposed to the petals.

The Insertion of the Flower.-The end of the flowerstalk, the receptacle or thalamus, is usually a shortened cone, so that the four whorls of the flower are borne closely together. 
Sometimes the part between any two whorls may be lengthened. In the Capparis family, which is found chiefly in the East, the thalamus is lengthened between the petals and stamens,

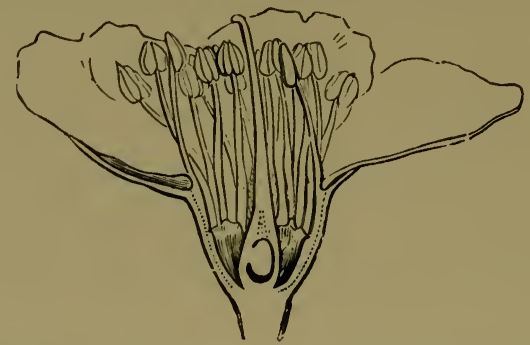

FIG. I3I.-Peach. Vertical section of flower. (From Henslow's "South African Flowering Plants".)

and again beyond the stamens, so that they are separated from the pistil. The thalamus may be swollen into a disk, as in Adenandra, Tecomaria, and Plumbago. Where there are many ovaries, as in the strawberry, it is much enlarged.

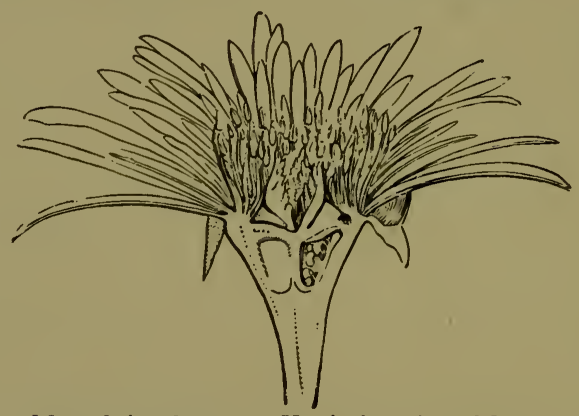

FIG. 132.-Mesembrianthemum. Vertical section of flower. (From Henslow's "South African Flowering Plants".)

In some flowers the receptacle grows up in a tube around the ovary and bears the perianth and stamens on the rim of the tube. If the tube is free from the ovary, the stamens and petals are perigynous. ${ }^{1}$

If the tube is joined to the ovary as it is in the Hottentot Fig

${ }^{1}$ Perigynous means around the ovary. Gynœcium is the term applied to all the ovaries of the flower. The corresponding term for the stamens is Andrœcium. 
(Mesembrianthemum), the stamens and petals are epigynous. These two conditions come late in plant life. In early flower forms the three outer whorls are situated below the ovary. The stamens and perianth are hypogynous, the ovary is superior. All these forms are found in different members of the Rose family. Which kind is found in the Pumpkin?

The Duration of the Parts of the Flower.-The corolla usually has the briefest life, and in some flowers it lives but a day. If the perianth remains until the fruit is ripe, it is persistent. The strawberry has.a persistent calyx. If it falls off after the pollen has reached the stigma, it is deciduous, as in members of the Lily family. If the calyx falls off before the corolla opens, it is caducous. What do farmers mean by Vines "shedding their caps"? When is this done?

Different Forms of Calyx and Corolla.-In describing the calyx and corolla it is necessary to have names for the different shapes. They get their names from something more familiar to us. Kalkoentjes and patrijsjes are good names for some flowers if one understands Dutch. Some flowers have Zulu names. Wheelshaped answers for a flower the shape of the one in Fig. I 33. It is also called rotate, from the Latin word for wheel, rota.

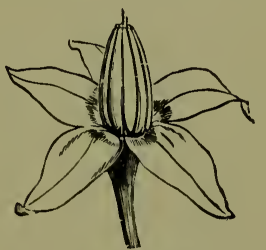

FiG. I33.-Rotate flower of Solanum. (Fronı Thomé and Bennett's "Structural and Physiological Botany ".)

When petals are distinct from each other, the corolla is said to be polypetalous or choripetalous. While the former term is older and more familiar, on comparing the derivation of the two terms the latter will be found better to express the meaning. In Roella and Tecomaria the corolla consists of a single piece ; it is gamopetalous, monopetalous or sympetalous. To these terms there are corresponding ones referring to the sepals. The lower sympetalous part of the united corolla is the tube, and the upper spreading part the limb. The upper boundary of the tube is the throat.

Flowers, especially those with sympetalous corollas, often 
have very curious shapes. We liken them to butterflies, spiders, bells, trumpets, lips, kalkoentjes, patrijsjes, kapjes; but since Latin names have been longest in books, we still use them. The most important thing is to know the flowers and

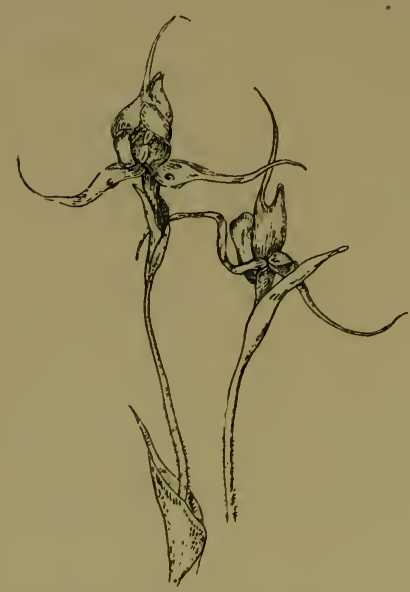

FIG. 134.-Disperis capensis, Swtz. (Moeder capjes or Hottentot bonnets). to find out, if possible, how they came by their different forms. When the parts of the corolla and calyx are all the same shape, the flowers are regular or actinomorphic. When they are two-lipped, like Lobelia, or butterfly-

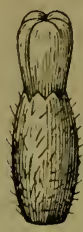

FIG. I35.-Valvate æstivation of $A c a$ cia horrida, Willd. (From Edmonds and Marloth's "Elementary Botany for South A frica".)

shaped, like the Pea, they are irregular or zygomorphic. ${ }^{1}$ Bright-coloured flowers are often zygomorphic.

Flowers built on the plan of three often have sepals and petals of similar shape and colour. By this time you have observed that certain flowers have three sepals, three petals, and that the stamens and carpels are also three or some multiple of three, while others are built on the plan of five. Four is less commonly the number found.

Estivation. - Like the leaf buds, flower buds have their parts neatly folded. The stamens are curved inward to bring the anthers as near the centre as possible, and sepals and petals are wrapped around them. Sometimes petals and sepals are

${ }^{1}$ Of these terms zygomorphic, though a more difficult word to use at first, is preferable, as the term irregular suggests that the flower is not symmetrical, as it generally is. 
valvate, that is, they just meet by their edges. If they overlap, the æstivation is imbricate. In Hibiscus and Oxalis the petals so overlap that one edge of each is without and one
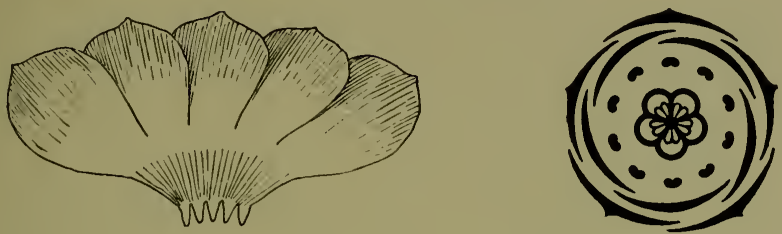

Fig. 136.-Convolute æstivation of Oxalis (the sepals are imbricate). (From Edmonds and Marloth's "Elementary Botany for South Africa.")

within another. They are twisted or convolute. In Crassula and Adenandra one is quite within the others and one overlaps by both its edges. Which æstivation is more common?

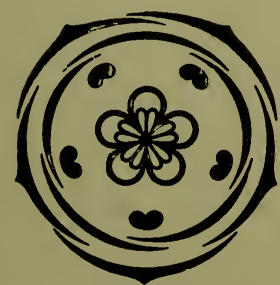

FIG. r37.-Imbricate æstivation of both sepals and petals. (From Edmonds and Marloth's "Elementary Botany for South Africa.")

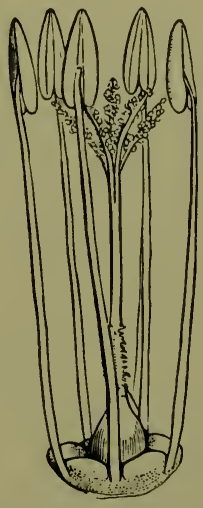

F I G. I 38 . - Plumbago. Stamens, honey glands, and pistil. (From Henslow's "South African Flowering Plants".)

Honey glands are the parts of flowers which secrete nectar. In the Buttercup (Ranunculus) and Grewia a gland is placed at the base of each petal. Geranium has a gland at the base of each long stamen. These flowers are regular and 
the glands are evenly distributed around the flower. In zygomorphic flowers, where insects alight in one particular place, the gland is situated where the beneficial insects can most easily help themselves. Pelargonium (commonly called Geranium) holds its honey in the long spurred sepal at the

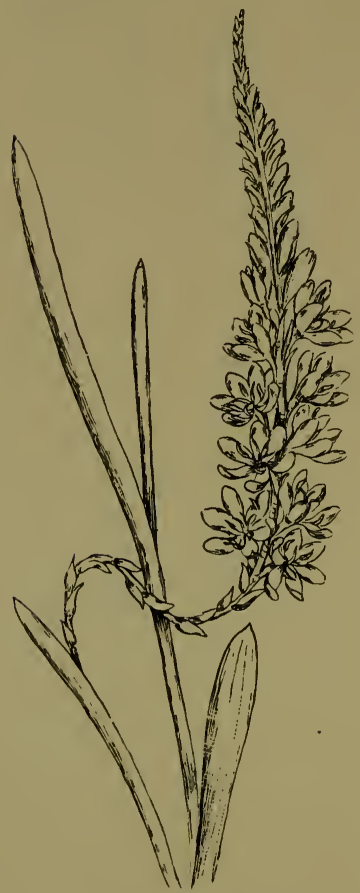

FIG. 139.-Micranthus fistulosus Eckl. A scape bearing a spike of flowers.

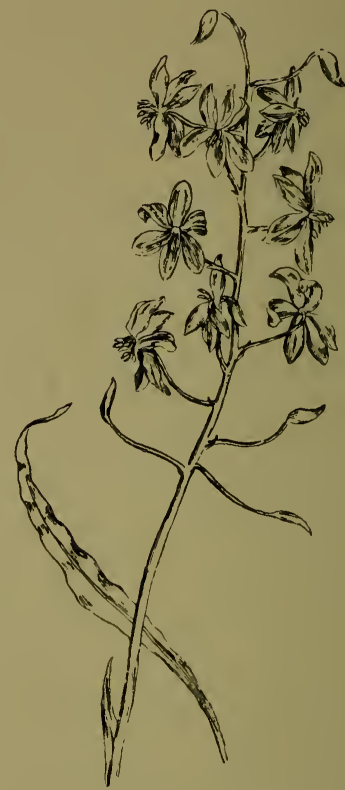

FIG. I40.-Raceme of Cyanella capensis $\mathrm{L}$.

back of the flower. The spur is joined to the stalk. It can be located by cutting the stalk just below the flower.

The calyx tube catches honey. If the calyx tube is attached to the ovary, the gland is borne at the top of the ovary, as in the Carrot family and Mesembrianthemum.

There are many devices which conceal honey, e.g. the wide bases of the filament of Roella roof over the honey in 
the base of the corolla tube so that it can be obtained only through narrow slits. The downward hanging hairs in Microloma are said to guard against flies.

Arrangement of Flowers on the Stalk.-Anthotaxy (or inflorescence) is a term applied to the arrangement of flowers as phyllotaxy applies to leaf arrangement. Some of our large flowers, as Hypoxis stellata Linn. (Peacock's Eyes) are borne singly on the end of the flower stalk. Others, as Malvastrum and Hermannia, are borne singly in the axils of the leaves ; the main stem can then continue to lengthen. If the peduncle or flower stalk arises from the ground and bears hardly any or no leaves it is termed a scape. Fig. 139 shows a scape bearing a cluster of flowers. The ovary of each flower is sessile, or borne close upon the stem. The anthotaxy is a spike.

A raceme has the flowers attached to the main

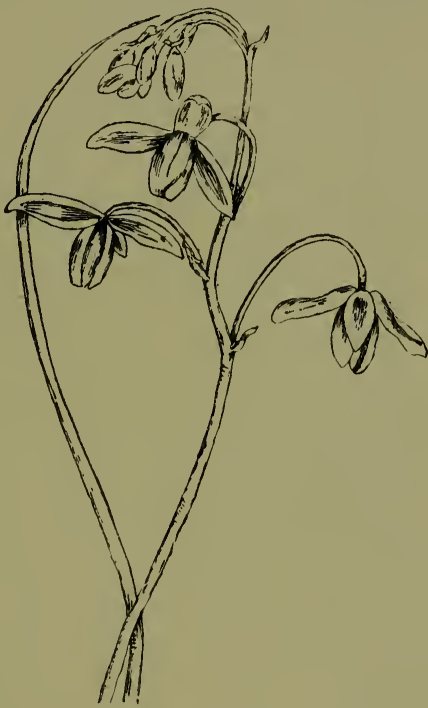

FIG. I4I.-Corymbose raceme of Albuca minor Linn. stalk or axis by a short stalk. If the lower stalks are lengthened and the upper ones shortened, the raceme is a corymb. If the stalks themselves are branched, the inflorescence is a panicle. This is common in the grasses, the Vine, and the Olive. In grasses it is a panicle of spikelets instead of single flowers.

The spike and raceme have a lengthened axis. A capitulum or flower head has a shortened axis and sessile flowers, as in the Everlasting family and Protea; for here what looks like a single flower is really a cluster of many flowers. If the flowers are borne on pedicels which spring from the same height on the axis, we have an umbel. The Carrot family 
takes its name from the umbel or umbrella-like arrangement of the flowers. Widely different families have this floral arrangement - as the Pelargoniums and Erodiums of the family Geraniacee, many of the Amaryllidaceæ or Belladonna family, Microloma and Asclepias.

In what is regarded as the true spike, raceme, capitulum, and umbel, the younger flowers continue to open toward the

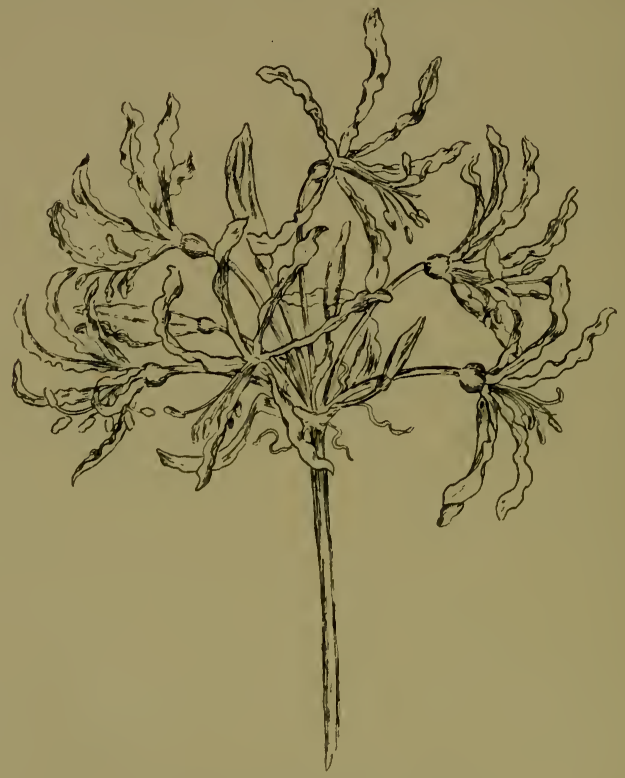

Fig. 142.-Simple umbel of Nerine.

top or centre, which in the umbel corresponds to the top. The arrangement is indefinite or racemose.

In Dianthus and other members of the Carnation family, in Crassula and Datura, the central or terminal bud opens first, and later buds come from side branches below. This type of flower cluster is known as a cyme, and the flower arrangement is definite or determined; that is, the first flower determines that the stem shall extend no farther. It has a definite length. It happens that flowers do not always follow 
strictly one or the other arrangement, but the definite and indefinite are often mixed. The flower cluster of the Olive is a panicle, but the separate branches have the flowers arranged in cymose clusters. In Leonotis each separate flower cluster is definite, but the younger clusters are at the top. The terminal umbels of IVild Carrot, which are the first to open, are indefinite. Younger umbels tip the branches which come from the axils of lower leaves, the youngest being lowermost

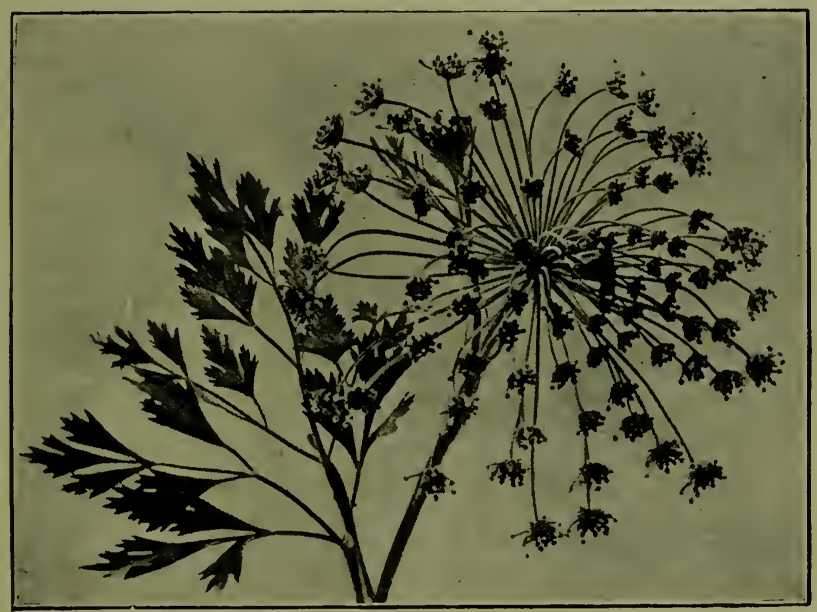

FIG. 143.-Compound umbel of Bubon. (From Ednonds and Marloth's "Elementary Botany for South Africa".)

on the stem. In other umbels of this order the central flowers open first.

The simple umbel of Nerine (Fig. I42) is definite, as they are in Asclepias, Hydrocotyle, Sparmannia. IThe youngest flowers in the Sunflower family are always at the centre but in Scabiosa the heads are cymose. These definite umbels may consist of condensed clusters of cymes as in Agapanthus.

The garden Foxglove sometimes, instead of rearing stately racemes of flowers, has a large terminal flower which looks like several joined into one (peloria). This stops the growth of 
the main shoot which then sends out late all shoots with cymose racemes.

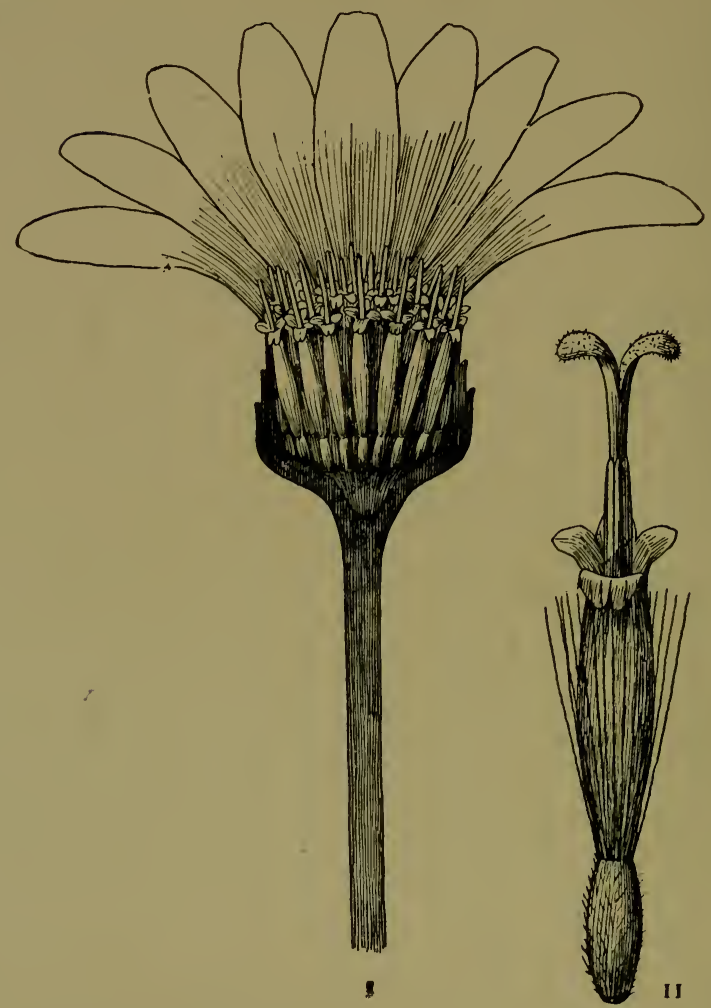

FIG. 144.-Gerbera asplenifolia, Spr. I. Section through head. II. Disk floret. (From Edmonds and Marloth's "Elementary Botany for South Africa ".)

Flower Arrangements.

General Method. Indefinite
Kinds of Clusters.

SPIKE-Catkin : deciduous, pistillate and staminate flowers; Oak.

Spadix: fleshy spike; Arum.

Cone: parts hard and woody; Fir, Leucadendron. 
General Method.

Usually indefinite.

Kinds of Clusters.

RACEME-Corymb: more or less flattopped; Ornithogalum.

Panicle: branched stalks; Grasses.

UMBEL-Simple: Hydrocotyle (definite.)

Compound: Daucus.

Capitulum (or head)-Composita, Protea.

Definite . . . Суме-2-sided : dichasium, Spergula, Crassula.

I-sided : cincinnus, Lobostemon,

Heliotrope.

Mixed . . . . Cymose-(Heads and panicles)-Leonotis, Olive.

Bracts.-In examining flower arrangements, the flowers are usually found protected by one or more leaf-like bodies, green or coloured, which may have been mistaken for the calyx. In Gladiolus, Antholyza, and their relatives, this mistake is often made, but you will find that in these flowers the sepals are like petals, and are borne at the top of the ovary.

Leaves in whose axils flower-buds instead of leaf-buds arise, are termed bracts. They are generally smaller than leaves, but sometimes much larger and more showy than the flowers, as in

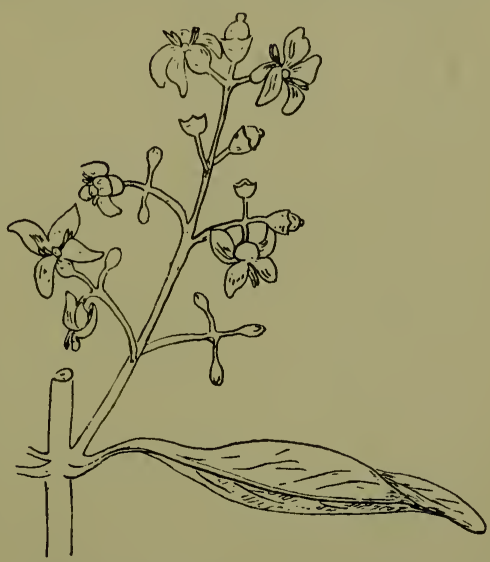

Fig. 145.-Flower and fruit of the Olive, showing a definite or cymose panicle (see p. 147).

Protea, Poinsettia, and Hamanthus. When several bracts surround a head of flowers, as in Protea, the Barberton Daisy, and others of their tribe, they form an involucre.

When a bract is large and sheaths the inflorescence, as in Arum, it is called a spathe. Bracts which enclose the flowers of grasses and sedges are called pales and glumes. 

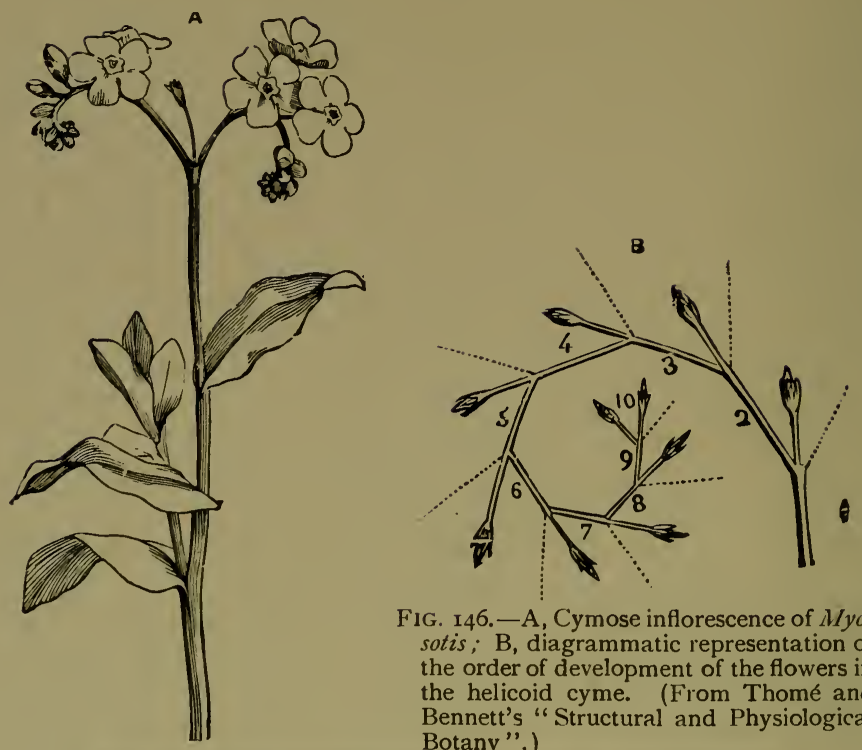

FIG. 146. - A, Cymose inflorescence of $M y o$ sotis; $\mathrm{B}$, diagrammatic representation of the order of development of the flowers in the helicoid cyme. (From Thome and Bennett's "Structural and Physiological Botany ".)

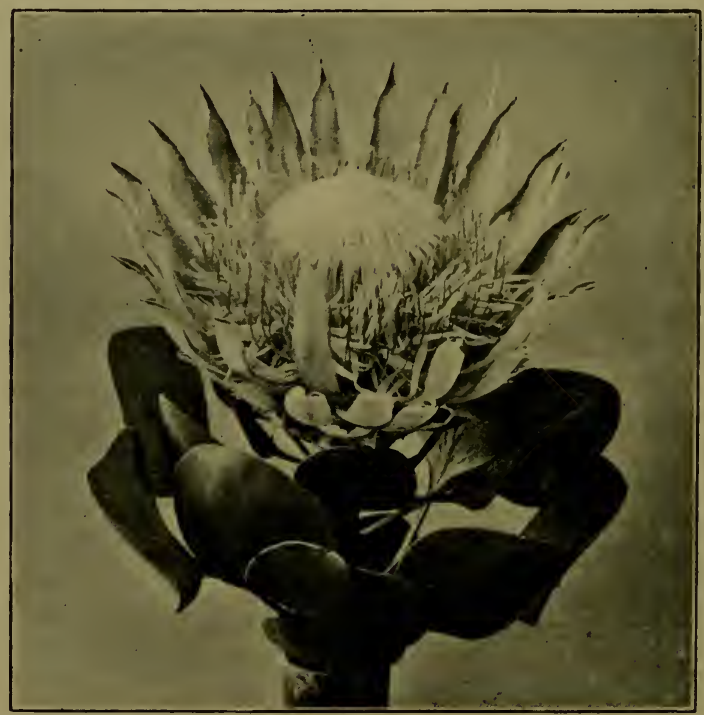

Fig. 147.-Capitulum, or head of Protea, surrounded by'-bracts forming an involucre. 
In Satyrium the bracts become more and more like the foliage leaves farther down on the stem. Bracts are modified leaves. Are all flowers subtended by bracts?

Relation of Flower Parts.-Just as bracts merge into leaves, so the sepals may become quite leaf-like, and there are green Roses and Dahlias in which the petals have taken on the appearance of leaves. Usually stamens and pistils look very unlike leaves, but here the garden flowers come in as teachers.

A canna flower is interesting. Above the ovary are three small sepals; then three narrow-pointed petals. The showy parts come next, and on one of them an anther locule is formed; the other locule is replaced by a petal-like part. It

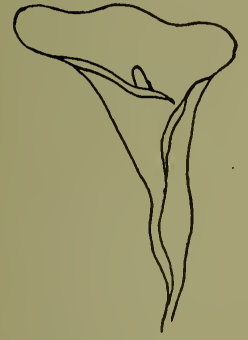

FIG. 148.-Spathe of Zantedeschia athiopica, Spreng (Richardia africana, Kunth), surrounding spadix.

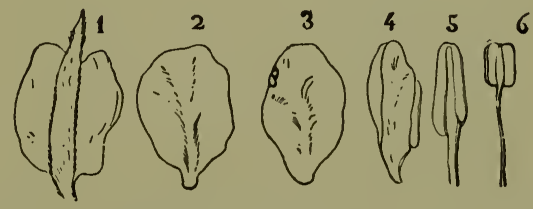

FIG. 149. - Stages of transition between the petals and stamens of Rosa centifolia. 1 (From Thomé and Bennett's "Structural and Physiological Botany".)

must be a stamen. It is the only one which bears an anther, but from the position of the others we call them sterile stamens, or staminodia.

Water-lilies and garden flowers which double, show all gradations of stamens that have become transformed into petallike bodies.

The pistil at the very centre of the flower has been so protected and has its one special work to perform, the bearing of seeds, that it is seldom altered so as to make evident its kinship to the leaves. The carpels of Sterculia appear like

${ }^{1}$ It would probably be more in accordance with the order of development were the ordẹr of the numerals- $-6-$ - reversed, 
five leaves with petioles. Before they are ripe they spread open, and the seeds ripen along

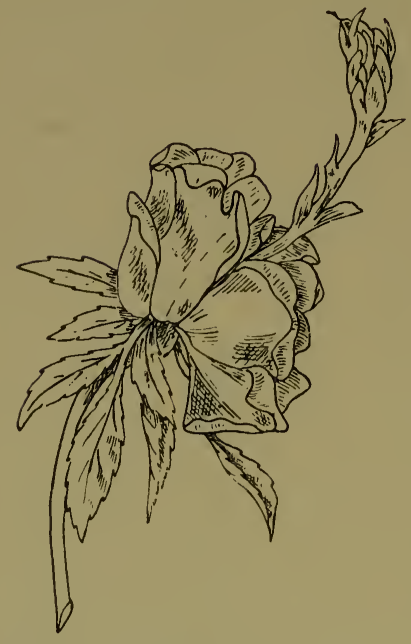

FIG. I50.-The centre of the Rose has grown out into a leafy branch. their edges. In the "Christmas Rose," leaves and leaflets take the place of ovaries and ovules. The centre of the flower is a mass of crumpled leaves. In Fig. 150 the centre of the Rose has lengthened and become a leafy branch. As plants come to be propagated by other means than seeds, the seeds and seed vessels turn their energies toward the work of foliage leaves.

The frequent similarity between the different whorls suggests that in their past history there has been less difference between the whorls than now exists. It may be that perianth and stamens, for example, are modified forms of foliage leaves, or what is more probable, stamens may have given up forming pollen in the outer whorls and so have become larger and petal-like owing to the abundance of food material at hand. 


\section{CHAPTER XVIII.}

\section{POLLINATION AND FERTILIZATION.}

Throvghout the Colony a bush two or three feet high with smooth linear leaves grows on dry hillsides. The whole plant

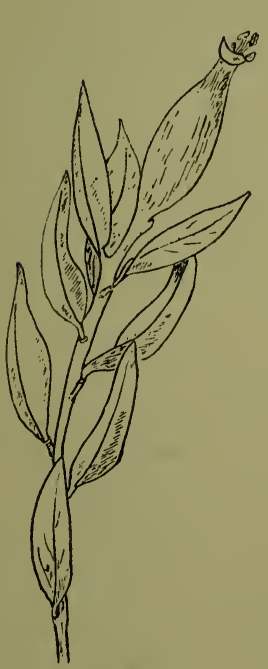

I.

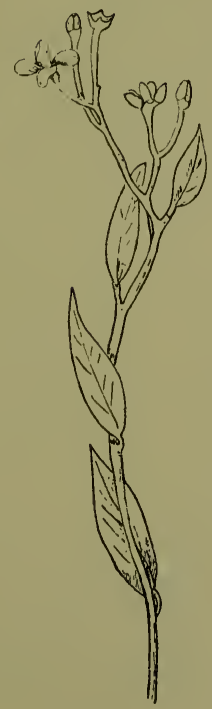

II.

FIG. I5r.-Montinia acris, L. I. Branch tipped by an ovary. II. Branch bearing staminate flowers.
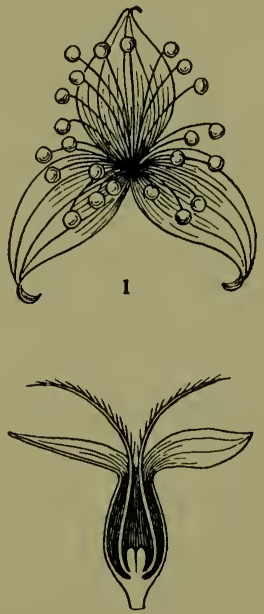

II

FIG. I52. - Cliffortia ruscifolia, L. I. staminate flower. II. Section through female flower. (From Edmonds and Marloth's "Elementary Botany for South Africa".)

has a sharp taste, from which it gets its last name. The flowers of this bush, Montinia acris, L., are not so very pretty, but the 


\section{54 Plants and their Ways in South Africa}

dry rattle of last year's pods bids us examine the flowers of this season. We find a small white flower with four petals

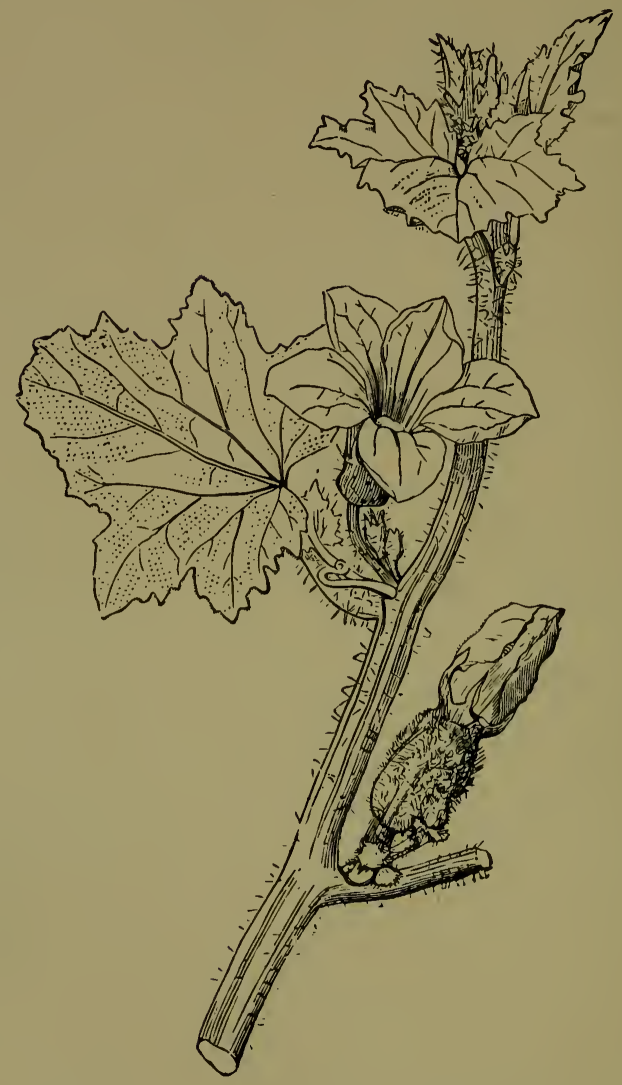

Fig. 153.-Melon. Flowering branch, with male and female flower. (From Henslow's "South African Flowering Plants".)

terminating a branch. The calyx is small, even in the bud hardly covering the flower. The large ovary below is surmounted by a four-angled honey gland and two short stigmas. Opposite the sepals are four small bodies that look like the 
unfulfilled promise of stamens. What is the flower to do without pollen?

A little farther on we come to another similar bush, but the flowers are borne in cymose corymbs. Below the flower is no sign of an ovary, but between the petals are four perfect stamens. Here is indeed a division of labour! You will seldom find one bush without coming to another close by.

Cliffortia is another common bush often with sharppointed leaves. It has two kinds of flowers. Dr. Kolbe tells

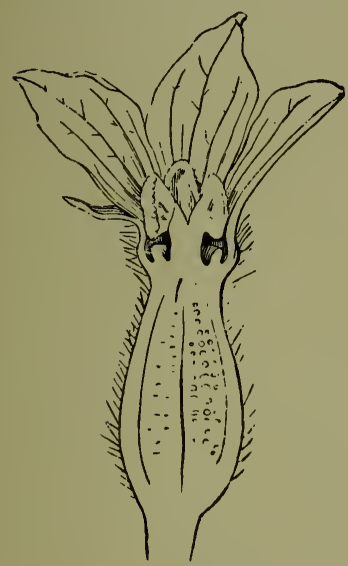

FIG. 154.-Melon. I. Pistillate "South African Flowering Plants".)

us to look for the staminate flowers in the direction of the prevailing winds. You may have to go far afield before finding them. They have long slender stamens. The stigmas are long and feathery, and you can find no honey glands.

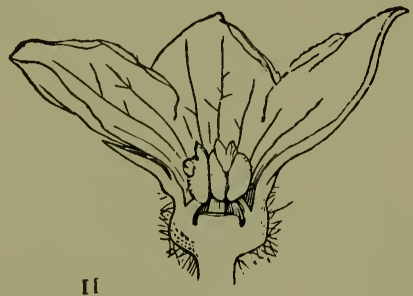

II

The Silver Tree (Leucadendron argenteum, $\mathrm{R}$. Br.) and its more humble relatives, which make the veld bright in spring with their pale yellow leaves and bracts, have also their flowers of two kinds on separate trees or shrubs. Sometimes the different species grow so sociably that it is difficult to decide which pistillate and staminate flowers grow together, as is true also of the Restiacea.

The Pumpkin family has large yellow flowers. Some of them open for a day and their glory is departed. They contain stamens. Hidden sometimes beneath the foliage are flowers, with large ovaries below, which were wanting in the 


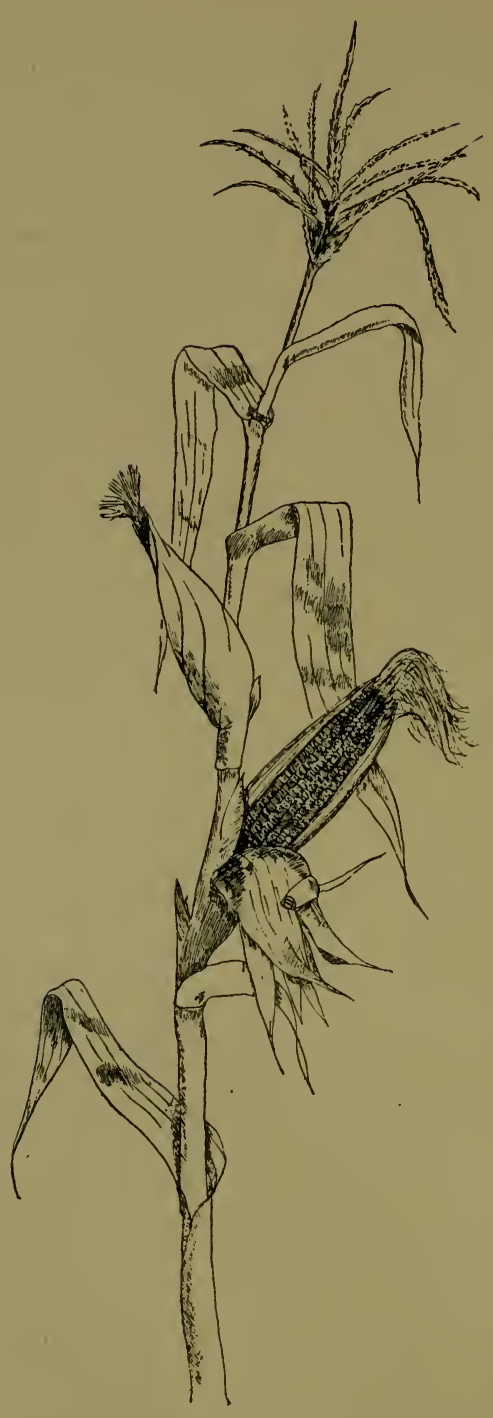

FIG. 155.-Zea mays is monœecious, i.e. the staminate and pistillate flowers are on the same plant. The staminate flowers form the "tassel" at the top, the pistillate form the "ears". other flowers; these give promise of becoming pumpkins, or Kafir watermelons or calabashes, according to the plant.

Are the two kinds of flowers on the same or on different plants? Do they open again after closing? What time of day do they open?

Zea mays, or Maize, is shown in Fig. 155. At the top of the stalk the "tassel" is composed of staminate flowers. Two flowers are in each cluster protected by two glumes each. When ripe, the long slender filaments hang out and dangle their anthers in the wind. Where large fields of Indian Corn are growing the air is heavy with pollen which they shed. You will find no pistil in these flowers. Pistils produce the seed, and we do not look for seed in the tassels. Down below, if all goes well, seeds will ripen in the "ears". Notice the long silks at the top of the ears. Turn back the large bracts (husks), and trace some of the silks to the kernel of grain. Each grain is an ovary containing a single seed, and partly 
enclosed by two bracts. The silk is the long style, the upper portion of which is stigmatic.

Examine Kafir Corn. Where are stamens and grains borne?

The white spathe of Zantedeschia ("Arum ") surrounds a central column, on the lower part of which ovaries are borne. The upper portion is not ripe until a few days after the stigmas are. It consists of stamens closely crowded, which will in time discharge quantities of white pollen. The spathe or bract

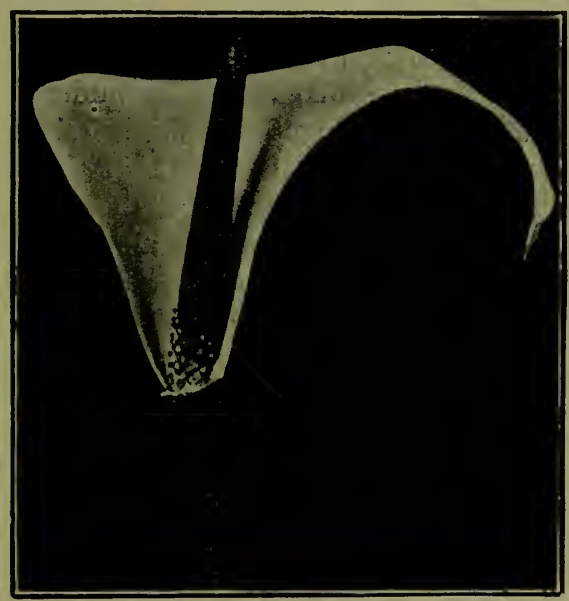

FIG. 156.-Spadix of Zantedeschia athiopica, Spreng, with one half of spathe. The pistillate flowers are below, the staminate flowers above. (From Edmonds and Marloth's "Elementary Botany for South Africa ".)

surrounds a spadix of flowers, the pistillate below and staminate at the top.

These are only a few examples of imperfect or diclinous flowers. Why should stamens and pistils be separated in different flowers? Often on different plants?

We are beginning to feel sufficiently acquainted with flowers to ask for confidences not revealed to chance acquaintances. If we find a new acquaintance on the veld, let us know all we can about it before it is pressed. Some of them 
have not wholly revealed themselves until they are past pressing.

The pleasure in knowing a flower's structure and plan is increased when we learn a meaning of the endless variety of forms and markings from patient watching or from reading what others have found. Long after flowers had been studied and their parts described the use of pollen remained a mystery. At last, in I682, an English botanist, Nehemiah Grew, discovered that before seeds were produced pollen must be transferred to the stigma. No one believed him, nor did he know just why it was so. Fifty years later Linnæus, the Swedish botanist, said it was true, and then people began to think it must be so. It is hard to believe what we do not understand. Even the great Linnæus had not found out all, and it was thought that pollen was necessary for the ovules of the same flower, since, in the Roella family, for instance, the pollen from the anthers is all caught upon the bristles along the style of the same flower. But even here the pollen has been brushed off before the clapper-like stigmas have split open at the end and exposed the part which receives the pollen if it is to be of service to that flower. One man declared even that when a pollen grain had been caught on a bristle it drew back and pulled the pollen grain into the style. It does not, but when we have wrong ideas they make us think a great many things are true that are not. He thought he saw what he was so sure must happen.

Another fifty years went by. People were carefully and patiently watching, and the truth is bound to be known when people are eager to know it. A German botanist, Sprengel, found that in most flowers the pollen cannot reach the stigma of its own flower; even if it is caught on the style it seldom reaches the tip or sensitive part of the stigma. What he saw puzzled him and others, until Darwin, seventy years later, showed that nearly all flowers are so constructed that they receive pollen from another flower, and so ovules are usually cross fertilized.

When pollen has been transferred from the stamens to a pistil, the pistil has been pollinated. But that is not all, for 
to enable the ovule to become a seed, or to form an embryo within it, the pollen grain has to send out a little tube which carries a marvellous body, the sperm cell or sperm nucleus. Within the ovule there is another similar nucleus with which the first must meet and unite. When this has been effected the ovule has been fertilized. You do not understand how it is done? Neither does any one else fully, but the process can be seen by using a microscope, which you all may do some day.

It takes some time after pollination for fertilization to take place. It may be completed within a few hours. In the Arum it takes several day; for the pollen tube to reach the ovule nucleus with its own, though the distance is so short. In Pines the tube grows about half the length one year; then it rests through the summer and until about August of the following winter and completes the journey by the beginning of November, so that it takes a Pine cone two years to ripen.

There are many devices used by flowers to prevent pollen from coming in contact with the stigmas of the same flower, to attract insects, and to ensure the pollen's delivery to its proper destination-another flower of the same species. ${ }^{1}$

In early spring, Nature carpets the veld with Oxalis. Large centre-pieces of brightest yellow are bordered with pink and buff and white. The brighter the sun, the brighter will be the carpet. Upon first sight the flowers appear to have fifteen stamens. A second look will show five greener than the others, tipped with round cushions that look as though they were stuck full of pins. The cushions are stigmas. In some flowers they stand higher than the stamens, in others shorter. Examine a handful until you find some stigmas standing between the two lengths of stamens.

The Oxalis has a meaning when we know that bees which visit it have long tongues, which are neatly rolled up when not

1 By prepotency of pollen is meant the power or quality by which certain pollen fertilizes a given pistil in preference to other pollen. E.g. the pollen of the same species is dominant or prepotent over the pollen of another species. The pollen of another flower is prepotent over the pollen of the same flower in Roella. 
in use. When a flower is visited, the tongue is uncoiled and thrust down the flower after

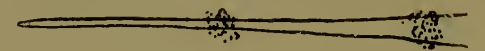

Fig. I57.-Diagram of bee's tongue after visiting Oxalis with long and short stamens.

its tongue, as shown in Fig. I57. When it visits another flower with long stigmas the pollen will be brushed off on the upper part of the tongue, and short stigmas of a flower will brush it off below.

In Gazania and Cryptostemma the stamens are joined by their anthers, making a collar around the stigma. Watch the

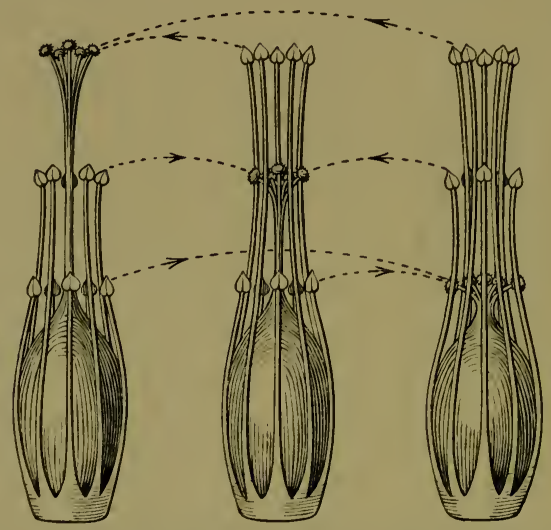

FIG. 158.-Trimorphic flowers of Oxalis cernua, Thunb. The arrows indicate the legitimate combinations. (From Edmonds and Marloth's "Elementary Botany for South Africa".)

flowers of the disk in the centre. The outer flowers of the disk open before the inner ones on successive days. On a bright morning their long club-shaped stigmas push up through the collar, well covered with pollen. On the following day the elastic style has shortened, the five teeth made by points of the stamens brush off the pollen in rings in each flower which soon disappears. These stigmas open later at the top and receive pollen, while closed stigmas of an inner whorl brush out rings of pollen from their flowers. When they in turn are ready to 
receive they also split down the centre and spread apart. The fruits formed in these flowers give evidence that the insects have unconsciously brushed off the pollen from the stamens of the outer flowers and delivered it to the inner stigmas.

Senecios also spread apart the stigmas in the disk flowers. They have a little brush just at the tip. They can curl back far enough to help themselves from neighbouring flowers, and even from the pollen that has adhered to their own styles if no insect pays them a visit.

Take any Indigofera. They are usually creeping plants with blue or purplish flowers, belonging to the Pea family.

Botanists state in a matter-offact way that the keel, or two boat-shaped petals in front, is provided with a spur or prominence at each side near the base. The bees have never had their attention called to this, and are unaware that these prominences are hidden springs, and that this keel contains concealed and loaded weapons. The unsuspecting bee poises on the two side

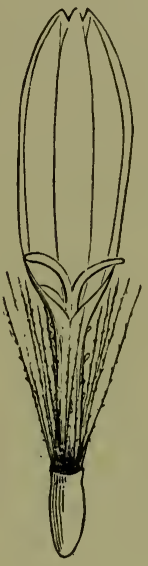

I.

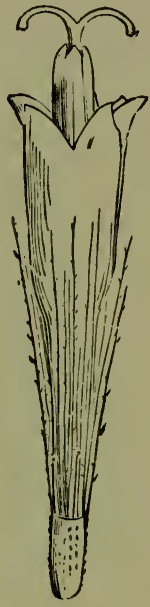

II.

FIG. $159 .-$ The disk flowers of Senecio have stigmas that can coil back and help themselves to pollen. The ray flowers (I.) have no stamens. (From Thomé and Bennett's " Structural and Physiological Botany".)

petals invitingly offering a resting-place, when, presto! the springs are set off, the side petals spread apart; the keel drops, releasing the stamens charged with powder, and up they fly. The range is just right, and the bee is well dusted for the next flower which has its pistil ready to receive it.

Every one who lives in the Eastern Province knows what is meant by "lighting matches". The " matches " of Loranthus oleafolius are borne in umbels of three to five flowers, bright red at base, and orange in the upper portion with green tips. The plant, which is parasitic on Acacia trees, pays for its 
support by brilliantly illuminating the tree at Christmas time with its flowers. When ready for "lighting," the tips which hold the ends of the stamens become black. When this sensitive

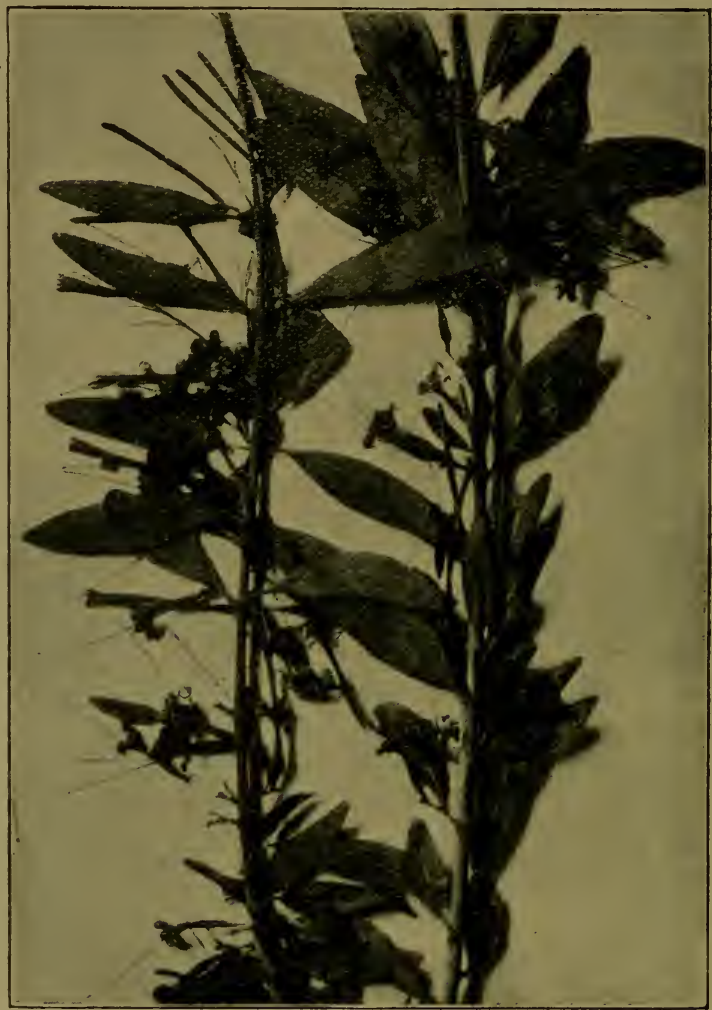

FIG. r60.-Loranthus olecetolius, Ch. and Sch. The sensitive tips of the corolla fly back and scatter the pollen as the stamens are released.

point is struck by birds, back fly the petals, and the pollen is thrown some distance as the stamens are freed from confinement. In Natal another species (L. Natalitius, Meisn.), which the children know as "lighted candles," has waxy white flowers 
tipped with yellow. The sugar bird sets free the arched style of Protea, which scatters the pollen before the stigma is ripe.

When other flowers are closed for the season, the blue sage (Salvia) may be depended upon to offer refreshments to visiting bees. Down by the four-parted ovary there is a little yellow gland where honey is made. At the entrance of the flower a "rocking chair" is invitingly placed, made of the two swinging stamens. One pollen chamber of each stamen has been sacrificed to make the "seat" of the chair. As soon as the bee touches this, the upper locules bend down and dust the bee's back with pollen just along its hairy belt. The bee then passes on to other sage blossoms. In some of these, stigmas

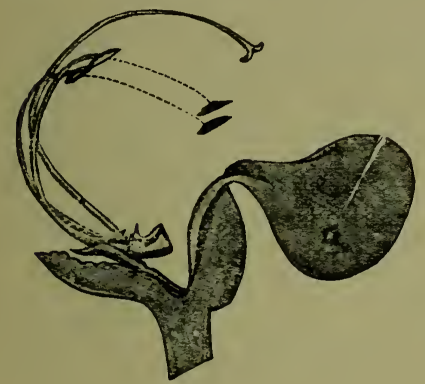

I.

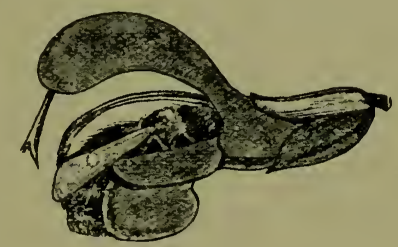

II.

Fig. 16I.-Salvia. I. Corolla, the hood removed. II. Ditto with bee. (From Henslow's "South African Flowering Plants".)

which are ready to be pollinated arch down far enough to be dusted with the precious load.

Holes cut in the tube; of flowers are evidence that a robbery has been committed. The flower has been broken into and pilfered of its honey without the insect performing any assistance in conveying pollen. You can watch bumble-bees bite holes in flowers which have tubes too long and narrow for the bee to enter. Darwin tells us that honey-bees, which usually pay down for each meal, are not above using the holes made by bumble-bees the previous day.

Orchids have gone to such an expense in making their perianth attractive to insects, and in filling their long cornu- 
copias with honey, that they make up arrears by economizing in pollen. ${ }^{1}$

However nicely flowers are adapted for scattering their pollen as dust, some of it is sure to be wasted. The pollen of the Orchid is bound up in neat parcels (Pollinia), each provided with a gummed label attached to an elastic cord, or the two parcels may be attached to one label. At meal times butterflies or moths collect these parcels, which become firmly gummed on to some part of their bodies, and as they go from flower to flower they deliver directly to the stigmas some of the quickening grains. You can see how it is done by applying a pencil point to the two white labels at the entrance of a Satyrium or a Disa flower.

The moth or butterfly sometimes gets so many of these parcels on to various parts of its body as to seriously inconvenience it. Sometimes their tongues become so covered that they starve to death. Professor Gray illustrates a moth flying with a pollen mass on each eye. Fortunately each eye is

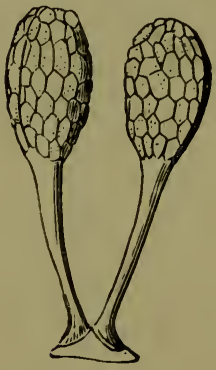

FIG. 162.-Pollinia of an Orchid, with their pedicels united by the rostellum. (From Thomé and Bennett's "Structural and Physiological Botany".) made up of hundreds of smaller ones, so the moth has enough left to guide him to another flower.

Microloma, Secamone (Baviaan's touw), Asclepias (the milk bush), which is so plentiful on the Karroo, and all their family have their pollen in masses also. One of this family cultivated in gardens is known as the Fly-catcher. Toward evening all kinds of moths are caught by their feet between the edges of two stamens just where two parcels are joined together by a black gland. Most of the prisoners have a short sentence, as will be found by looking for them the next morning. One beautiful moth imprisoned overnight was seen to escape next day, but it carried a pollinium with it, as it escaped with a jerk, from the little slot where the gland is situated.

${ }^{1}$ To know what Orchids mean by masquerading as they do, Darwin's book on "The Fertilization of Orchids" should be read. The beautifully 
Flowers are not at home to all visitors. The sticky juice covering the upper portion of the stems of Heaths and of other flowers prevents ants from scaling the heights to rob the honey within the flower. Flowers are often closed when unwelcome guests are flying about. The opening and closing of flowers at certain times of the day led Linnæus to arrange a floral clock, but the movements of flowers, like those of leaves, are regulated by varying conditions of temperature and sunshine, so it would not do to depend upon such a timepiece for getting to school in time.

IVhen moths and beetles are flying about our lamps, have you ever wondered what they are about so late at night? It will be worth while to visit flowers with a lantern to find out.

The story of the Yucca and its moth has been often told since it was found by Mr. Riley and Dr. Engelmann, ${ }^{1}$ but it is so interesting that it will bear repeating. The Yucca, which bears its majestic panicles in many of our gardens from November till January, has come from Mexico. The flowers are scentless during the day, but give forth their fragrance, as do so many of our flowers, only to attract night visitors. Have you ever seen the seeds after flowering? For sixteen years the flowers of one plant have been watched, and sixteen times they have withered and are cut off,

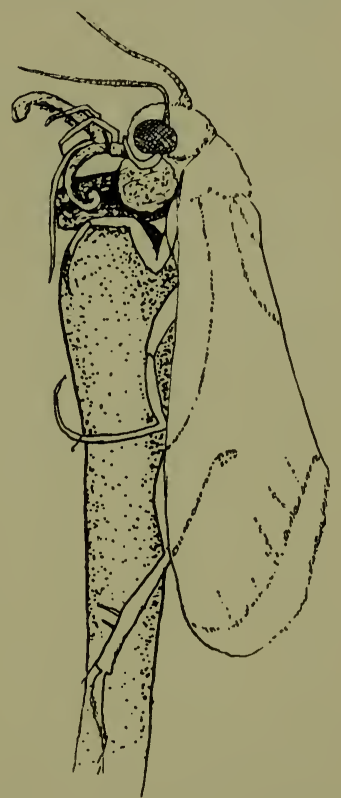

FiG. I63.-The Pronuba moth gathering pollen from the stamen of Yucca to carry to the stigma. (From the "Popular Science Monthly".)

for Nature retains no useless burdens. The moth which can aid in quickening the seeds has been left behind in Mexico.

illustrated books of Dr. Bolus on South African Orchids will help you to understand the flowers.

${ }^{1}$ C. V. Riley, Missouri Experiment Station Report, 1892. 
There in the daytime it rests, hidden in the half-closed flowers, matching them so nearly in colour with the front wings that it is difficult to detect. Like other night flowers, they are white, so that they can be seen from a distance. At night the flowers expand like large six-pointed stars, and the mother moth begins her rounds. First she goes from one stamen to another, until she has obtained a ball of pollen nearly as large as her head, which is held by her front legs against her body. She is not intent on nectar, nor does she gather pollen as bees do for making beebread. Why, then, does she carry her precious load? She now lays her eggs in a pistil. They pass from her body through a long tube furnished with a saw. With this she pierces the ovary and deftly places an egg just beside a tiny ovule. When the eggs hatch out, the little larvæ have the growing seeds for food. Now we know that the ovules will not develop into seeds unless they receive the power from the pollen. It looks as though the moth knew this long before we did, for when she lays an egg up she runs with her ball of pollen, thrusts it into the cleft stigma, and works her head up and down vigorously to ensure that some pollen has been driven home; then she runs back, lays another egg, and repeats the operation.

One year a Yucca in a neighbouring garden surprised us by bearing fruit. The fruits did not show the spots which result from the injury when the eggs are placed, and no larvæ were found among the seeds. Had our own large grey moths performed the service? This year a few bees were seen among the other Yucca flowers, but hopes for fruit were in vain, for the bare withered stalks a few weeks later told that once more the flowers exiled from home had wasted their sweetness. ${ }^{1}$

The scarlet bells of Antholyza revoluta, Burm., are often found in fields of corn. Their long curved tubes are narrowed at the base and suddenly enlarge about the middle, where honey is made which fills the lower part of the tube. The stamen attached to the front sepal is arched backward and brought into line with the two at the back, which by a twist of the filaments turn the anthers so that they all discharge their pollen toward the centre of the flower. In the younger flowers at the top of

${ }^{1}$ In some parts of South Africa the Yucca sets seeds regularly. 
the stalk the stamens ready to discharge their pollen hang forward below the style, whose three branches are closed like the pages of a book. In the older flowers below, the anthers which have discharged their pollen are drawn back by the drying of their filaments. The lobes of the stigma are unfolded and hang down below the stamens. An insect in search of honey sips and flies away, unconscious of the dust on its back, or that this dust is brushed off on to the stigmas of other

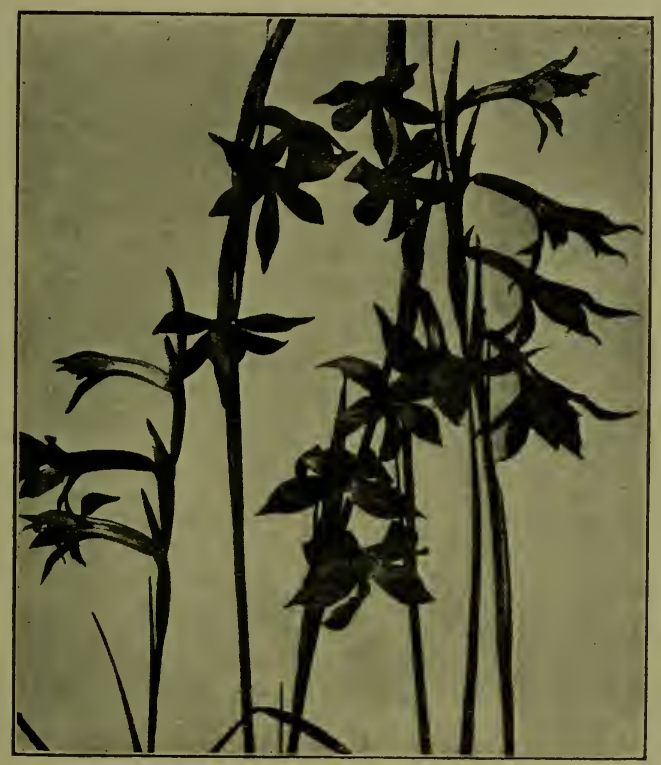

FIG. 164.-Antholyza revoluta, Burm.

flowers. When a stigma is well dusted the perianth withers and closes, which prevents the pollen from getting brushed off. This is a sign that the honey season is over, and no more insects need apply.

Antholyza has no noticeable markings on the brilliant coloured perianth, as irregular flowers usuallyhave, advertising their sweets. The upper petals are transparent, and the light shining through brings into prominence the veining which may 
indicate the way to refreshments. A transparency is of little value unless a light shines through it. Flowers that open in a shaded room have a much lighter colour. The pigment that gives the flowers their brilliancy is often concentrated in bright patches on the three lower parts of the perianth, where irregular flowers of this order are usually marked.

Are the flowers all turned in the same direction on the stem? If they turn toward the light the transparency would lose its effect. Do you find them turned toward the light or away from it? At which end of the flower-stalk does the visiting insect begin when in quest of honey? Do different insects have the same habit? Maybe you can already answer

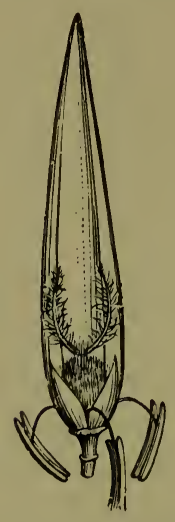

FIG. 165.-The swinging anthers of grasses scatter their pollen in the wind, which the feat hery stigma c a tches. (From Thomé and Bennett's "Structural and Physiological Botany".) some of the questions. If you cannot, it will pay you to watch with us.

Although so many attract insects by colour or odour, some flowers are selffertilized. The violet has inconspicuous flowers late in the season. They never open, and so have to be self-fertilized. Branches bearing self-fertilized (cleistogamous) flowers of the blue Commelina (C. Benghalensis, Linn.) bore underground where the seeds ripen. Some species of Oxalis and Stapelia also have closed flowers after the others have withered. In early times such extravagance as brilliant colour, ${ }^{1}$ honey, and choice perfume was not indulged in by plants ages ago when the wind was the only method of transporting pollen. An abundance of pollen had to be provided in those days, as the wind is a wasteful messenger. The conifers doubtless shed their pollen to the breeze before the hum of flies and bees had been heard. Grasses have kept the old-time habit. Or may it be one they have acquired? Their long filaments hang out the swinging anthers to

${ }^{1}$ While we associate colour of flowers with insects' visits, colour may be due to chemical changes in the plant without reference to insects. 
the breeze and the feathery stigmas catch the pollen as it passes. ${ }^{1}$ Willows, Poplars, and Oaks have a very ancient history. Their flowers are not showy. Do you find bees visiting them? Does a bee pass from the Catkins of an Oak to the Acorns, or is it simply in quest of pollen? From what flowers is honey made in your district? Bees are partial to blue flowers. Did you ever see a butterfly visit a flower of this colour? If so it should be noted carefully. Do butterflies have their favourite colours? Do you know any regular flowers with guiding lines on their petals? Recall Montinia and Cliffortia. Are they pollinated by the same agency?

While irregular flowers suggest insect visitors, insects and birds frequent regular flowers. Garden Canterbury Bells are so blue that we should hardly expect a bee to pass them by. Here the bee poises on the stigmas and from that coign of vantage gathers the pollen, never once touching the symmetrical corolla. Sugar birds sip honey on the wing from wild tobacco and Hibiscus flowers, and when they do alight on the latter the style, strengthened by the stamen tube, offers a firm landing place. Some of the Antholyzas have narrow tubular perianths. On these butterflies hang suspended, clasping the tube with their six legs.

The Sweet Pea, while irregular, fragrant, and attractively varied in colour, is habitually self-fertilized.

A beautiful red Lily grew in a conservatory beside a white one. Bees seldom find their way into a greenhouse, and so the plants seldom set seed. But the gardener carefully removed the pollen from the red Lily and placed it on the stigma of the white one. In due time seeds were formed. When they were planted and a flower came they were white beautifully marked with red.

The nuclei convey characters which become associated in the fertilized egg. The combined characters are carried in the nuclei which result from the fertilized egg in all the cells until microspores and megaspores (pollen grains and embryo sacs in seed-bearing plants) are formed. There the characters separate

${ }^{1}$ Wind pollinated flowers are usually imperfect. 
out so that half the spores convey paternal and half maternal characters.

If the characters are contrasting ones as short and tall, smooth and hairy, one will be suppressed by or recessive to the other and will not appear in the hybrid of the next generation but in the generation following unexpected combinations may occur.

If the characters are not contrasted so that one suppresses the other, a blend of characters may occur. For example, if two white sweet peas be crossed, one with long pollen and a flat standard (back petal), the other with round pollen grains and a hooded or incurved standard, all the flowers of the next generation $\left(\mathrm{F}_{1}\right)$ will be of two shades of purple with flat standard and long pollen.

The characters determining the flat standard are said to be dominant to the hooded characters and long pollen is dominant to round. These characters separate out in the pollen and ovule of this generation, and in recombining, produce in the next gen $\epsilon$ ration $\left(\mathrm{F}_{2}\right)$ a great variety of colours, combined with either long or round pollen and flat or hooded standards. Look in your garden of sweet peas and see if the hooded standard is found with all colours.

The combinations will not be haphazard as may at first appear ; the world is indebted to Mendel, ${ }^{1}$ who experimented in his convent garden fifty years ago, for showing that the combinations occur according to definite mathematical laws. It is not known that all hybrids behave according to the Mendelian law, but the clue which Mendel gave is being used to-day in scientific plant breeding.

The law in its simplest form for simple hybrids may be expressed in the accompanying diagram.

Let $A$ and $B$ represent two unit characters, $A$ being dominant to $\mathrm{B}$. In the first generation $\mathrm{A} b$ in which these two characters are crossed only A will appear. In the spores of this generation the unit characters will separate out, and in the next generation, fertilization may effect a

${ }^{1}$ Since Mendel experimented with his peas, de Vries Correns and others have revived and greatly extended this work. 
combination of $\mathrm{A}$ with $\mathrm{A}, \mathrm{A}$ with $\mathrm{B}$, or $\mathrm{B}$ with $\mathrm{B}$ so that $\mathrm{A}$ will appear on an average three times as often as $\mathrm{B}$. In succeeding generations $A$ crossed with $\mathrm{A}$, or $\mathrm{B}$ crossed with $B$, will "breed-true" to $\mathrm{A}$ or $\mathrm{B}$, but $\mathrm{AB}$ plants, or hybrids, will continue to separate out in the same proportion as before.

Since so much has been learned about flowers and their insect guests, it has been asked whether flowers were designed to attract insects or whether insects, by visiting flowers, have given them their markings
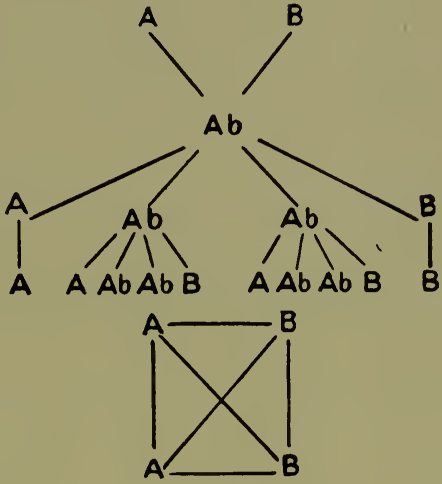

FIG. 166.

where they have come in contact with them, and so have made them irregular by always lighting on the same spot. ${ }^{1}$ We can tell what was in the past only by thinking about what we see now. At least, we feel sure, from fossil plants and insects, that there were no showy flowers until bees and butterflies had been created to gather honey. .

Dr. Kolbe was one morning the uninvited guest at a sugarbird's breakfast. We will "let him tell in his own words" his thoughts on that occasion.

\section{"The Gladiolus and the Sugar-bird.}

"Some time ago I was reading 'The Making of Flowers,' by the Rev. Prof. G. Henslow ("Romance of Science Series," S.P.C.K.), in which he explains the forms and markings of flowers as a result of plant responsiveness to the mechanical stimulus of insects in search of honey. The theory was particularly attractive to me: it seemed to explain so much. Thus thinking, I noted one day how a lot of Gladioli in a garden

${ }^{1}$ That flowers and insects have developed independently of one another is a third possibility. 
had deep markings at the back, just where the perianth lobes begin to separate, but where they still overlap one another. No insect, I said, would be such a fool as to go prodding at the back when so wide a front door was provided. I had plenty of time to theorize. It was holiday time in a region where our next-door neighbours were over the hill two miles away. So I sat on the stoep and lazily condemned Prof. Henslow's theory. A single fact, I severely reminded my reluctant fancy, was enough to upset any hypothesis. While I sat, mentally active but bodily motionless, there flashed quite close to me one of those animated streaks of God's brightest colours that we call sugar-birds-as brilliant as America's intensest humming-bird, only more of it. 'I was delighted, for my nearness of sight prevents much acquaintance with wild birds. This little thing evidently took me to be part of the stoep furniture, and by absolute stillness I encouraged the delusion. From his coign of vantage he made a brief survey of the garden, with a determination of breakfast written on every feather of him. But breakfast on what? In the West, Nature supplies them abundantly with Proteas, but of this order I think there is only a little Leucospermum growing in the Transkei. What was it to be? Honeysuckle, or Tecomaria capensis? Habemus utrumque as Horace said of certain human nectars. Birdie did not leave me long in doubt. Down he swooped on the spikes of Gladiolus-there were some twenty of them-and he sampled every open flower on every spike. And he attacked them at the back, clinging to the column of the spike and working his way downwards from side to side so as to miss nothing. His curved beak entered the flower just where the lobes part, and scraped down the tube till it found the honey. Now, if you look at the inside of the Gladiolus, you will find that the purple mark yoes all the way down the path of the beak; and in some of the flowers this purple path is not visible from without, but only the spot at the lobe-parting. How about the theory now? Shall we say the flower spontaneously advertises in front for insects and at the back for birds? Or did it just blush at being so tickled? 
"Nay, more, why are all the blooms on only one side of that spike? Don't tell me they want to face the light. In my garden they face to all points of the compass. Can it be that, just as the weight of insects enlarges the lip of Labiate and Acanthacee, so the push of the sugar-bird has driven all the flowers to one side and left the gay robber a clear vertical perch?

"My little friend took a considerable time over his breakfast. You can't conscientiously rob a hundred flowers of all their honey on both sides just in a couple of minutes. But I was so grateful to him for enlarging my knowledge and for bringing his loveliness so near to my eyes, that by no movement did I spoil his meal with any nervous tremor. If he had known how I wanted to stretch my limbs in the middle of it, he would have been grateful too." 


\section{CHAPTER XIX.}

FRUITS.

IF a flower has been fertilized, changes will take place in the ovule and other parts of the plant, and fruit will be formed. Sometimes, after wind and insects have done their share in pollination, a prolonged rain will wash off the pollen before fertilization has taken place. In that case the flowers are of no more use. An absciss layer is formed, and they fall to the ground. If a hard storm comes when Apricots are flowering, "it will be a poor year for fruit," the farmers say. But, as compensation, a few flowers which were protected will form fine large fruit. The storm may be fortunate, as it gives the trees a rest. It is exhaustive work to form fruit. Food must be made for the embryo which begins to grow, and the seedcoats must be strengthened. Sometimes an outer coat, an aril, is formed after fertilization. When the ovule is ripe it is called a seed.

In the second place the ovary undergoes changes which aid the seed-coats in protecting the embryos, but their chief use is to scatter the seed. We speak of the ripened ovary as the fruit. The ripening ovules derive their nourishment from the mother plant through their attachment to the ovary.

Some fruits are dry and hard; others are juicy. A dry fruit is frequently miscalled a seed. On the other hand, any part of the plant that is good to eat is apt to be called a fruit, even to a Potato! Have you ever seen the fruit of Potato? You have never eaten it.

A. Fruits formed from a Single Flower.-Osteosper- 
mum forms a circle of seed-like fruits. Each one contains a hard white shining seed. The fruit is borne below the flower and is indehiscent; that is, it does not open to let out the seed. The fruit of the Composite family, to which Osteospermum belongs, all have their fruit formed in this way, although, instead of being smooth and shining, it may he woolly or differently marked.

A dry one-seeded inferior fruit is called a cypsella.

Protea and Clematis have also dry -indehiscent fruits. The styles of the ovaries remain on the ripe fruit, and the enclosed seed is attached at one place, the placenta. A Protea flower has but one ovary, but Clematis has a

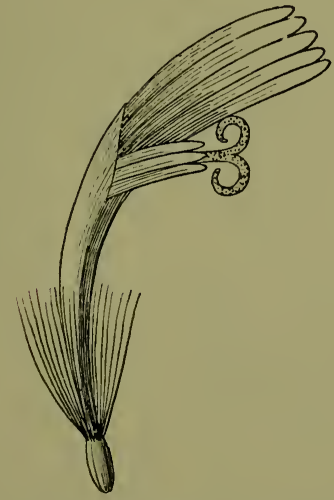

FIG. 167.-Floret of Sow-thistle. (From Edmonds and Marloth's "Elementary Botany for South Africa".)

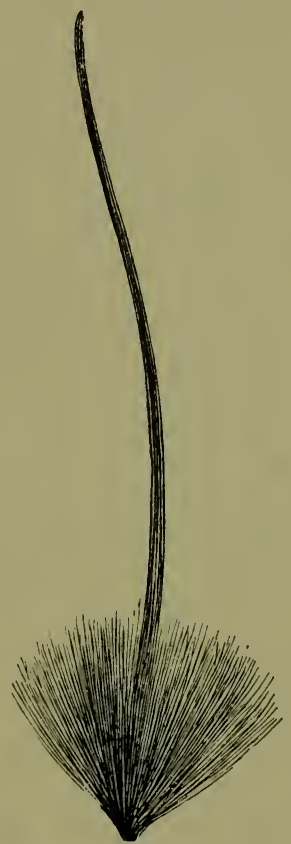

FIG. I68.-Tailed achene of Protea mellifera, Ihunb. (From Edmonds and Marloth's "Elementary Botany for South Africa".)

cluster or an etærio of fruits. In these flowers the ovary is borne above the perianth.

A dry one-seeded superior fruit is an achene.

In the Strawberry the receptacle which bears the achenes is convex and fleshy; in the rose it is hollow, and:conceals the hairy ovaries. 
Tripteris, Triaspis, Dodonaea, Combretum (Roodeblad), and Portulacaria (Spekboom) have winged fruits.

A winged truit is a samara.

In the fruit of the grasses the ovary wall and the seed-coat become attached to each other. On the grain of Maize a little point on one side indicates the place where the style, the silk, was borne.

A dry one-seeded fruit in which the ovary wall and seedcoat are attached is called a caryopsis.

A dry fruit which splits into several portions each contain-

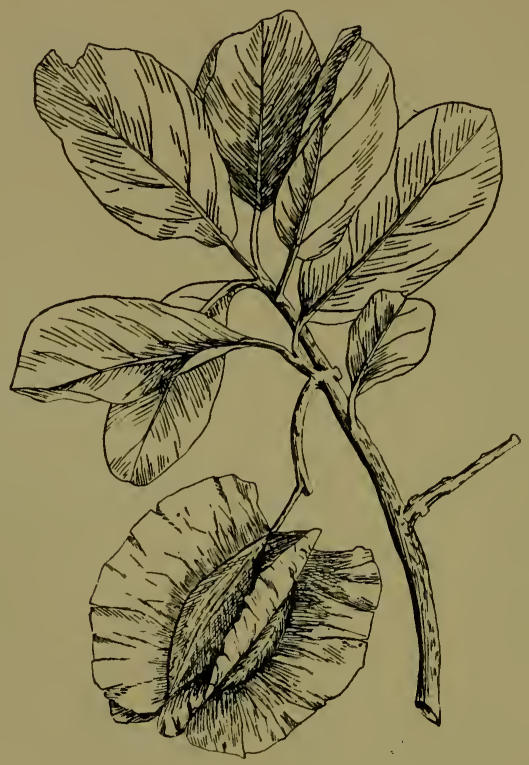

FIG. 169.-Samara of Combretum.

ing a seed is a schizocarp. Some of the Malvacea have this fruit. It is found in the fruit of the Geranium family, the Euphorbias, the Umbelliferce, Labiate, and others.

Schizocarps are of various kinds. They may be two, three, or many parted. They may retain the seed or let it escape. 
If a fruit remains closed or indehiscent it is usually one seeded. It would be a disadvantage to have many seeds germinating together. Fleshy fruits rarely dehisce.

Dehiscing fruits are called pods or capsules. The bean, Port Jackson, and Erthrina have a pod which has only one carpel, and which splits along both edges. It is called a legume.

Asclepias (Pachypodium) and Crassula have similarly formed fruits which split on one side only. Such a fruit is a follicle.

The siliqua and silicula are found in the Cruciferæ or mus-

I.
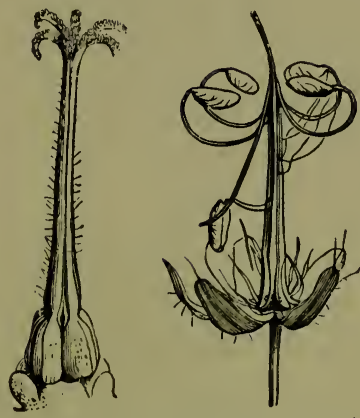

FIG. I70.-Quinquepartite schizo. carp of Geranium Robertianum, L. I. The immature pistil. II. The mature fruit. (From Thomé and Bennett's "Structural and Physiological Botany".) tard family. They are made of two carpels joined by their edges where the seeds are borne. A partition, or replum,

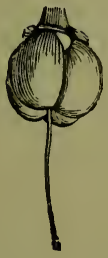

FIG. I71.-A schizocarp consisting of four nucules.

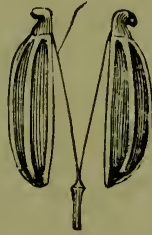

FIG. 172.-Fruit of the

Fennel : $a$, carpophore.

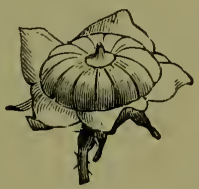

FIG. I73.-Multipartite schizocarp of Malva. (From Thome and Bennett's "Structural and Physiological Botany.")

grows up from below and divides the fruit into two chambers. When ripe the two carpels split apart from the bottom upward, leaving their edges with the seeds surrounding the replum. If the fruit is several times longer than broad it is a siliqua ; if it is about as long as broad it is a silicula. In some of the Heliophilas the siliquas are prettily constricted so that they look like a string of beads. If the fruit splits across at each 


\section{8 Plants and their Ways in South Africa}

narrow place, as it does in some fruits of this family and in Hedysarum of the bean family, it is called a lomentum.

Some fruits have more than one chamber when made of several carpels that have grown together. They are then said to be syncarpous. If carpels are separate from each other they are apocarpous.

Dehiscence takes place in various ways. The ovaries of

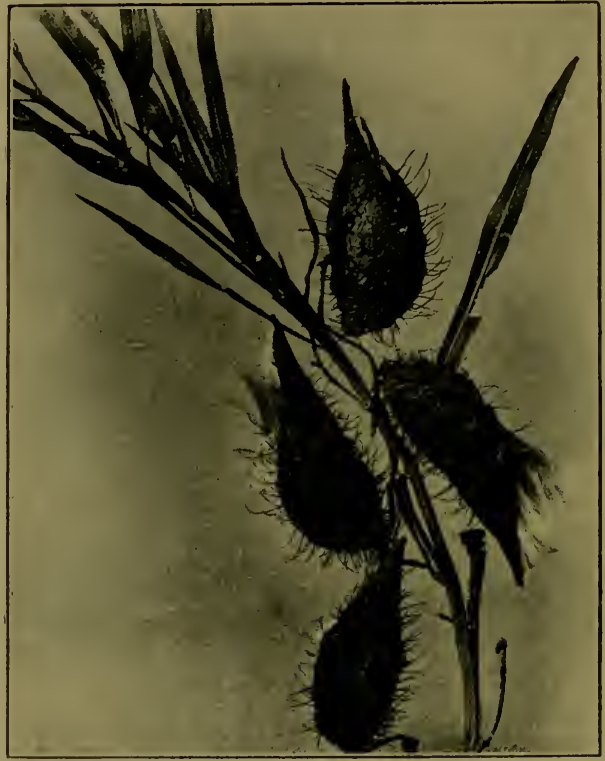

FIG. 174.-Follicles of Asclepias.

Albuca hang downward in flower so that the stigmas are protected from rain. When the fruit ripens it straightens up and splits from the top down the centre of each carpel (loculicidal dehiscence). When the split occurs between the carpels the dehiscence is septicidal.

The "Poor Man's Weather-glass" (Anagallis) and usually Hypoxis split around the centre of the ovary so that the upper half falls off. In Wahlenbergia a small triangular lid lifts up 
at the top of each carpel. Mesembrianthemum has a curious

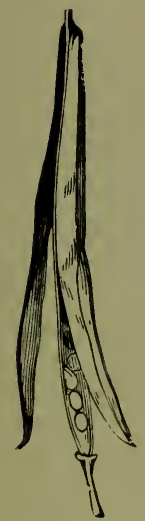

I.

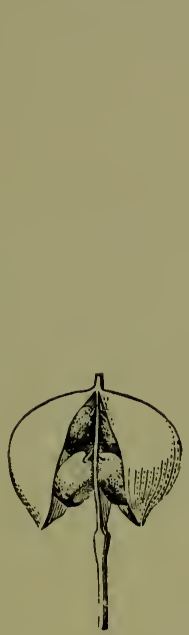

II.

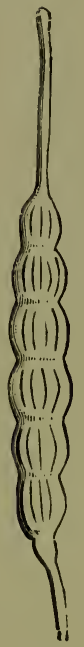

III.

FIG. 175.-I. Wallflower (Cheiranthus Cheiri). Siliqua. II. Silicula of Cochlearia open and showing the seeds attached to the replum. III. Lomentum of Raphanus. (From 'I homé and Bennett's "Structural and Physiological Botany ".)

fruit. The capsule is below the flower, and has from five to

I.

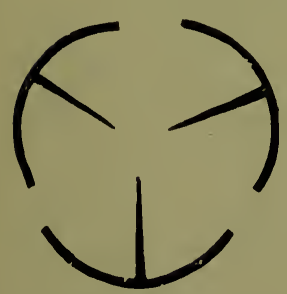

II.

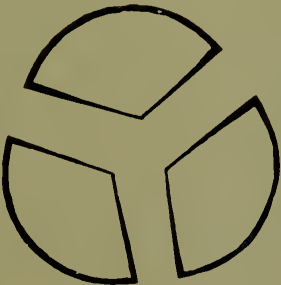

III.
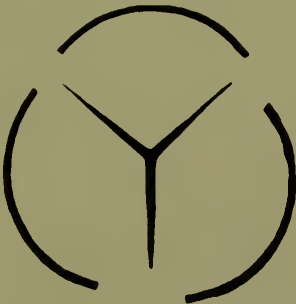

FIG. 176.-I. Diagram of a loculicidal capsule. II. Diagram of a septicidal capsule. III. Diagram of a septifragal capsule. (From Thomé and Bennett's "Structural and Physiological Botany".)

twenty carpels. The seeds are borne near the base of the carpels on long cords or funicles. The flowers open in the sun- 
shine. Do the fruits? Place some ripe fruits in a glass of

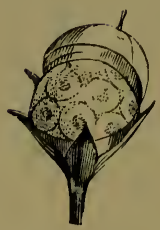

FIG. I77.-Capsule or pyxis of Anagallis, with circumscissile dehiscence. (From Thomé and Be nne t $t$ 's "Structural and Physiological Botany".) water. In a few minutes the roofs of the chambers will lift up and expose the seeds. Remove the fruits and watch them close as they dry. Try the same experiment with the fruits of Wahlenbergia. Do the fruits act in the same way? Mesembrianthemum thrives in the sun and the sand; but the seeds are kept within the closed fruit until the rain comes, when they are released to germinate.

The Apricot, Grape, Date, and Water-melon are fleshy or succulent fruits. Since succulent fruits are formed in different ways, different names are given them. In these fruits the three parts of which the wall of the ovary is made is more easily distinguished than in dry ones. In the Apricot the outer wall, or epicarp, is the downy skin. The juicy middle layer is the mesocarp, and the inner
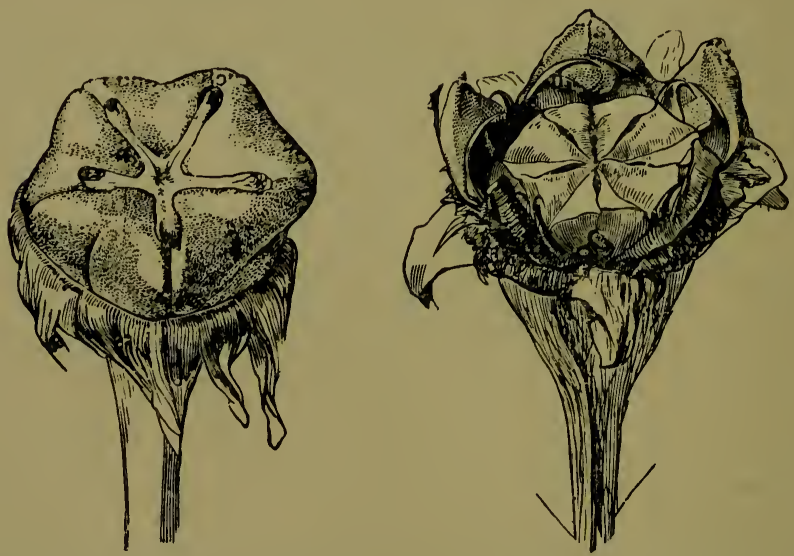

FIG. 178. - The fruit of Mesembrianthemum dehisces by triangular valves. (From Henslow's " South African Flowering Plants"..)

layer, or endocarp, is the hard stone or pit which contains the seed. Such a fruit is a drupe. An Almond is formed 
in the same way. Since the inner wall of the ovary is so hard, there is no need for the seed-coat to harden. Make out the parts of a Date. A Date is not a drupe.

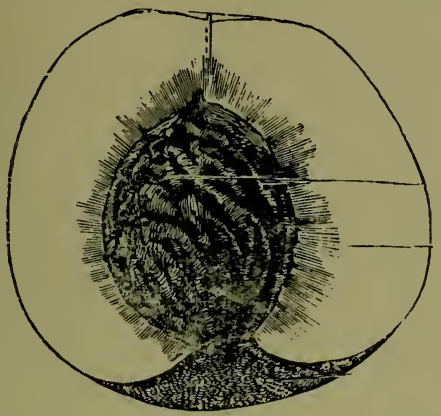

FIG. 179.- - Longitudinal section through the unilocular drupe of the Peach. (From Thomé and Bennett's "Structural and Physiological Botany ".)

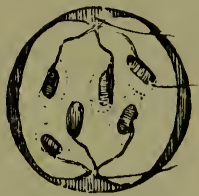

FIG. I80.-Transverse section through a Gooseberry; the firmer outer layer of the pericarp encloses the succulent flesh ; the seeds lie embedded in the latter, and are attached by long funiculi to two opposite parietal placentæ. (From Thomé and Bennett's "Structural and Physiological Botany".)

A berry is a fruit with a firm outer covering; the rest of the fruit is juicy. Did you ever look at a young orange? The inner walls of the fruit are covered with tiny hairs. These grow and fill the cavities as the fruit ripens. They make the juicy part of the fruit.

A young Apple shows five carpels surrounded by a green cup. This cup grows and ripens with the ovaries. A Rose Hip has a fruit built on a similar plan, only there are more carpels.

The part outside the outer double line, in Fig. I $8 \mathrm{I}$, is the receptacle which bears the calyx

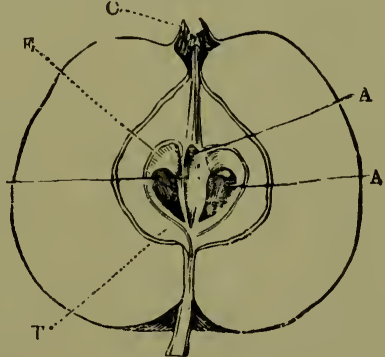

FIG. 181. - Longitudinal section through an Apple : C, dry persistent calyx limb ; E, loculi with cartilaginous endocarp ; $\mathrm{T}$, mesocarp. (From Thomé and Bennett's "Structural and Physiological Botany ".) at the top. It encloses and is united with the five carpels, the core. The mesocarp lies between the outer and inner double lines of the diagram. The inner hard shining layer surrounding the seeds is the endocarp. 
A fruit like an Apple is called a pome.

The Pomegranate has a two-storied fruit. If you cut across the fruit very low down you will find three chambers with
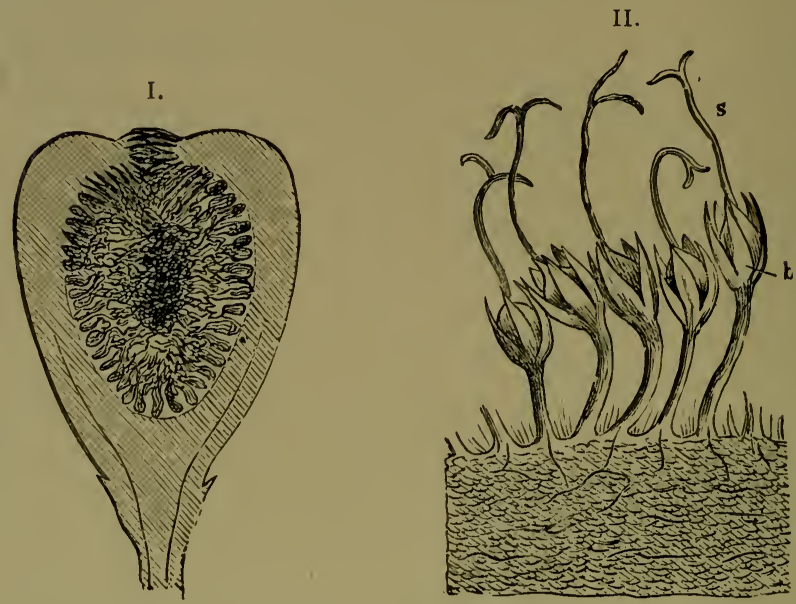

FIG. 182.--I. Longitudinal section through the hypanthodium of a Fig, exposing the flowers in its interior ; II. a piece greatly magnified, with five female flowers ; s, pistil ; $b$, perianth. (From Thomé and Bennett's " Structural and Physiological Botany".)

seeds borne at the centre; higher up a cross section will show five or more chambers where the seeds are borne in the outer edge. When the fruit ripens the bright red tubular axis takes part in its formation.

B. Fruits Formed from a Collection of Flowers.-All fruits thus far described have grown from the centre of a single flower. In the fig the hollowed receptacle bears within its cavity a great number of flowers. In some figs the flowers bear only ovaries; in others the staminate flowers are borne. It is the work of one very small insect to convey the pollen from one kind of Fig to the stigmas in the other.

In many species, all or most of the ovulate flowers below the staminate ones are transformed into gall flowers. This is the case for instance in Ficus carica which has three kinds of flowers -staminate flowers and those with short and with long styles. 
The insect enters the orifice of a fig and lays eggs in the ovaries with short styles which lie below the staminate flowers. The inflorescence is protogynous. When the eggs hatch, the females emerge to lay eggs in another flower. By this time the stamens are ripe and as the female passes out she takes some of the pollen with her. The insect ovipositor is not long enough to reach the ovaries with the long styles. They therefore develop seed.

The insect, which is a wasp, Blastophaga glossorum, loses its wings in making its way through the sinall opening and dies within after laying her eggs. The male wasps die after mating and do not escape from the figs within which they hatch. No wasps hatch in the edible figs as no eggs were able to be deposited there, the edible fig having the long styled flowers.

The pistillate flowers mature two months before the staminate, but by this time the second crop of fruits are borne with stigmás ready for pollination, by the stamens of the preceding generation.

The Agricultural Department introduced trees, with staminate flowers (caprifigs), into this country in 1903 . In 1908 , after the trees were old enough to bear fruit regularly, the Blastophaga was introduced. Figs will ripen without the wasp and the caprifigs, but the fruit is not so fine as the Smyrna Fig, which requires caprification. The Government Entomologist of Cape Town kindly supplied information that in December, I9I0, the wasp was emerging from the caprifigs and seeking fruit to enter. Figs not requiring caprification are benefited inasmuch as it causes the trees to mature an additional crop of fruit. The Castle Kennedy Fig, which normally develops its early crop and sets its second, will mature its second crop if the flowers are pollinated.

In the Mulberry several female flowers grow in a head. The Blackberry looks something like this fruit, but if the two fruits grow in your district you can see that the Blackberry is formed from a single flower, and that the Mulberry is a head of imperfect flowers.

The Pineapple is a head of perfect flowers crowded together 
in a spike. The flowers, with their bracts and the central axis, become juicy. By cultivation the Pineapple has lost its seeds.

By our definition of a berry, a Tomato, a Calabash, a Grape, and an Orange are berries, but a Strawberry, a Blackberry, and a Mulberry are not. This seems like a study of plants "through a looking-glass".

Our definition of a fruit will have to be modified for such fruits as that of the Apple, Strawberry, and Pineapple. It may be defined as that part of the plant which is stimulated to growth as the result of fertilization. 


\section{CHAPTER XX.}

\section{THE SEED'S TRAVELLING OUTFIT.}

SEeDs are not only well supplied with food before beginning their independent life, but every means is taken to arm and equip them in such a way that they may travel far afield, to find congenial soil. If they were to drop down under the

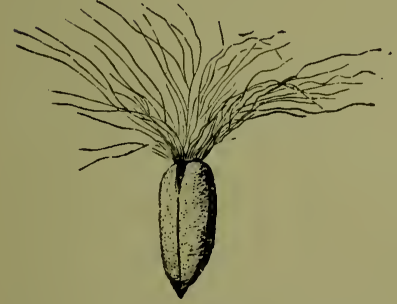

FIG. I83.-Ripe seed of Epilobium, with coronet of hairs (magnified). (From Thomé and Bennett's "Structural and Physiological Botany".)

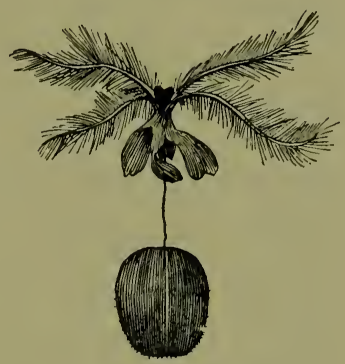

FIG. 184.-Leucadendron argenteum, R. Br. Nut with persistent style and calyx, the latter split at its base and prevented from slipping off by the knobby stigma. (From Edmonds and Marloth's "Elementary Botany for South Africa".)

plant and remain there they would have a hard struggle for existence in soil already exhausted.

The flowers of Albuca hang downward and protect the stamens and stigmas from rain. When the fruit ripens it straightens up and splits lengthwise. The wind blows through these slits and the seeds fly out and away. Had the fruit remained hanging the seeds would be in danger of falling in a heap beneath the plant. 
186 Plants and their Ways in South Africa

The Asclepias and Stapelia family provides its seeds with a long tuft of silky hairs. The seeds are packed away in the

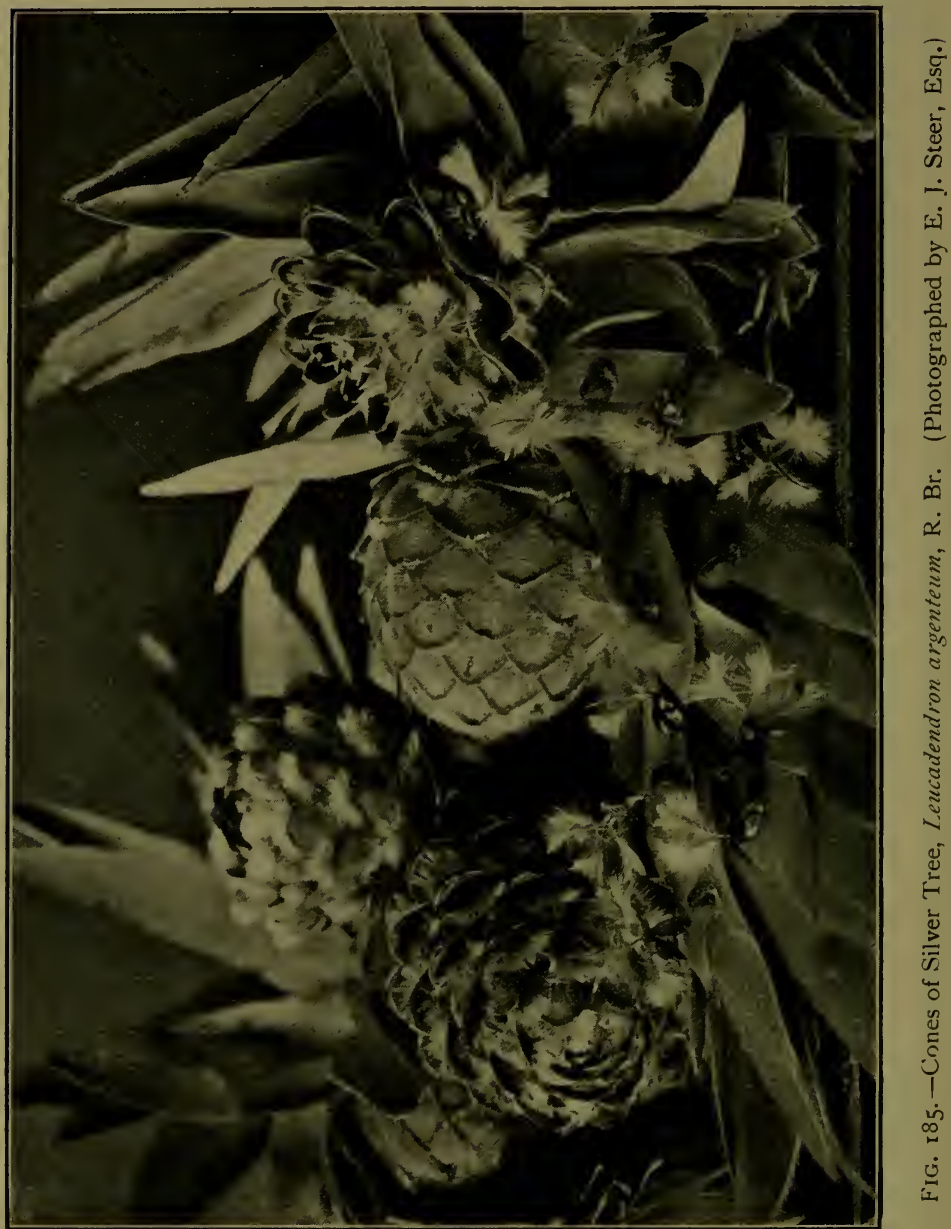

ovary with a marvellous economy of space. When ready for their journey the ripe pods split open, the tufts of hairs 
push out the seeds, and they go sailing, sometimes miles away.

Epilobium of the Evening Primrose family has seeds similarly provided.

The seeds of the South African Proteaceæ do not escape from the ovaries, which are variously fitted for aerial navigation. Protea ovaries have at the base long tufts of silky hairs

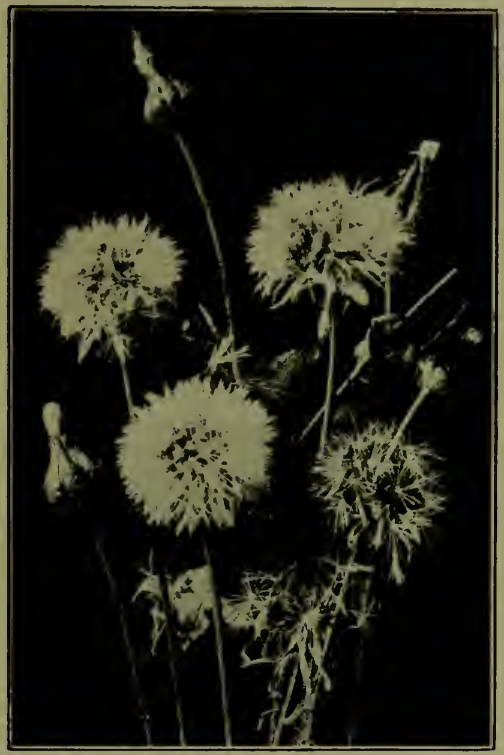

FIG. 186.-Urospermum. The fruits travel in dry weather.

which are caught by the wind. The seeds of the Silver Tree appropriate the whole perianth for a sail, which is prettily fringed along the edges. As the fruit enlarges the lower part of the perianth is split open and run up on the style for a mast, where the little knob of a stigma keeps it from slipping off. It must be that many a craft is wrecked for, besides the trees on Table Mountain and Devil's Peak, few have found anchor. Some have found a haven beneath the shelter of 
Paarl Rock, and a few have grown on the mountains about Wellington.

Some species of Leucadendron have winged fruits. The Australian Hakea and Grevillea of this order have dehiscent fruits. The fruit of Hakea is hard and woody, and contains two seeds with broad membranous wings. The face of the seed which fits into the woody cavity is rough. The seeds are so weighted that they fall rough side down. Hold them under water and the rough side glistens with air that is held

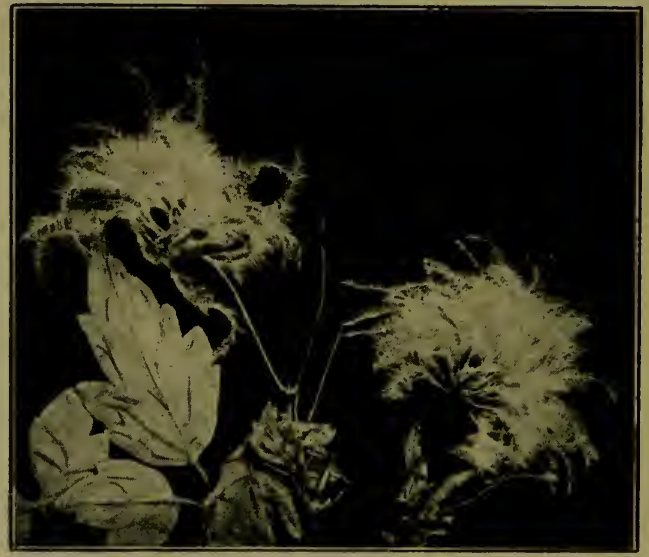

FiG. 187.-Clematis fruits with their feathery styles ready for a journey.

in the crevices. The projections help secure a foothold and carry air for the young plant's needs.

Many of the Compositæ fruits are scattered by a tuft of hairs. This is the calyx, and is known as pappus. (See Fig. r86.) The order Valerianaceæ also employs this method.

Clematis, or Traveller's Joy, seeks fresh fields by means of the long hairy styles, which bear the ovaries away. The fruits of Pelargonium are carried in a similar manner.

When a farmer sows his seed it falls any side down, but Nature is more careful in her ways. The long styles of Protea, the winged seeds of $H x$ kea, the parachutes of the Milk Weeds 
and of Urospermum, so nicely balance the fruits that they come to rest with the radicle pointing downward. The styles of Erodium and other members of the Geranium family coil tightly and catch upon some object. In rainy weather they untwist and screw the seed down into the soil.

When walking through the veld, we come home with our clothing covered with "burrs". As we pick them off the seeds are scattered far from home. Take a little time before throwing them away to see by what ingenious methods they have attached themselves. The spirally twisted legumes of Medicago are furnished with a border of firm little grappling hooks. The two sharppointed awns of Bidens pierce our clothing, and the reflexed bristles prevent them from brushing off again. Fruits of Burr Weed (Xanthium) and Klis Grass (Setaria verticillata, Beauv.) become very troublesome when the fruits become fastened into the wool of sheep or goats. Fig. 188 shows the "wool spiders" of the "Grappling Plant" (Har-

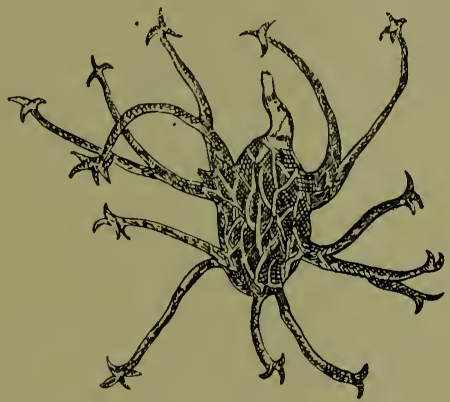

FIG. 188. -Seed of Harpagophytum procumbens, D.C. ("Grapple Plant" or "Wool Spider".) pagophytum procumbens, D.C.).

Seeds of orchids and Streptocarpus are so light that a breath of wind will blow them away.

The whole plant of Brunsvigia breaks off close to the ground, goes rolling over the veld, scattering the hard smooth seeds as it tumbles along.

Many seeds are covered with an edible pulp, and so are scattered by birds or other animals.

One species of Mistletoe, Viscum minimum, Haw., a parasite on Euphorbia, is independent of outside aid. It grows profusely within its host, but projects beyond the surface less than half an inch and bears three flowers. When their large berries ripen, without falling from the stem, they each 
send out a long radicle, which turns around and plants itself upon the same Euphorbia.

Some fruits explode and send their seeds forcibly away. A choice legume was ready to be mounted on a herbarium sheet; suddenly it exploded, twisted back, and all but one seed disappeared. Euphorbia fruits similarly set up quite a bombardment when they are ripe. Some fruits of the order

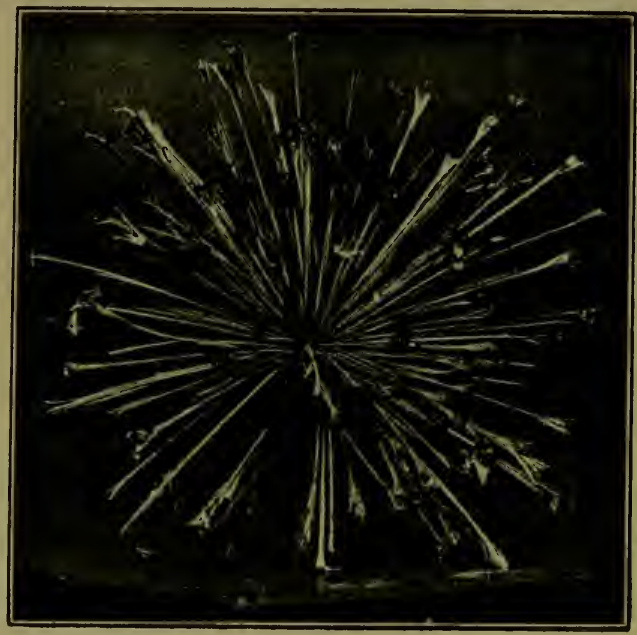

FIG. 189.-Buphane scatters its seeds by breaking from its moorings and rolling over the veld. (Photograph by L. Grant.)

Acanthaceæ are mucilaginous and explode when wet instead of dry.

An Oxalis seed has a fleshy cup-shaped aril. When this dries it curls inside out instantaneously and the seeds are scattered some distance.

New plants sometimes enter a country in coffee or in forage. Along railways we sometimes see flower faces that seem to have lost their way. The little white clover clinging close to the sod by the grassy borders of sloots lifts up its head, and its delicate breath reaches us freighted with a message from distant lands. 


\section{CHAPTER XXI.}

\section{KUKUMAKRANKA.}

"DiD you ever hunt for Kukumakrankas? Here is one."

From a respectful distance it looked loaded, but the bearer disarmed me of suspicion.

"We do go hunting for them sometimes. You find them sticking out of the ground."

By this time information was coming from other sources.

"You keep them to enjoy their perfume." "You wear them in your hat." "Or press them in a book!"

The specimen shown was soft, light brown, and tapered at one end. It was loaded with FIG. 190.-Kukumakranka fruit. seeds which showed through the thin covering, and was evidently the ovary of some plant.

"What kind of a flower has it?"

"It never flowers," replied a chorus of voices; "that is all there is of it."

Here was a puzzle. It was then in May, and since the seeds were quite ripe the flowers could probably not be found that season. Nor were they the next, nor the next. At last, at Stellenbosch, one Christmas holiday, my hostess brought in a flower-a beautiful, cream-white, six-pointed star, borne at the top of a long tube.

"That is surely a Kukumakranka," I exclaimed. "You have left part of it in the ground-the Kukumakranka-the part we hunt to wear in our hats and enjoy the scent, and press in books." 
No time was lost in seeking out the place where it was found, and there, in the rich brown carpet under the pines, the stars were glowing in profusion. Several inches below the pine-needles a slender ovary was unearthed, concealed in the dry brown scale-leaves of a bulb, from which were extended some long, dried-up, brown remnants of last winter's green leaves.

The flower had a long slender style, leading down through

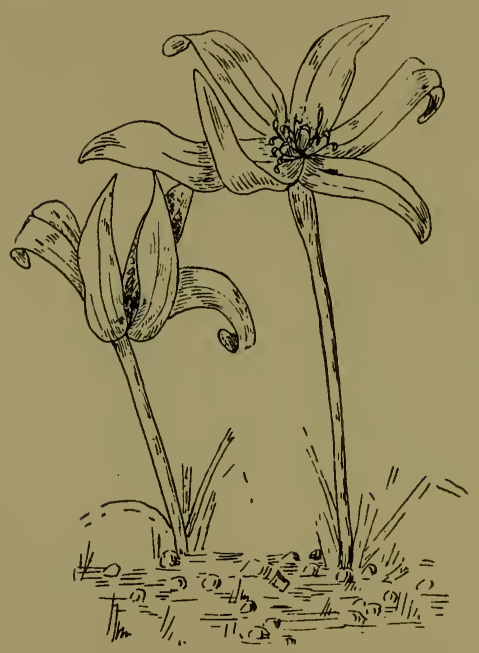

FIG. I9I.-Flower of Gethyllis (Kukumakranka).

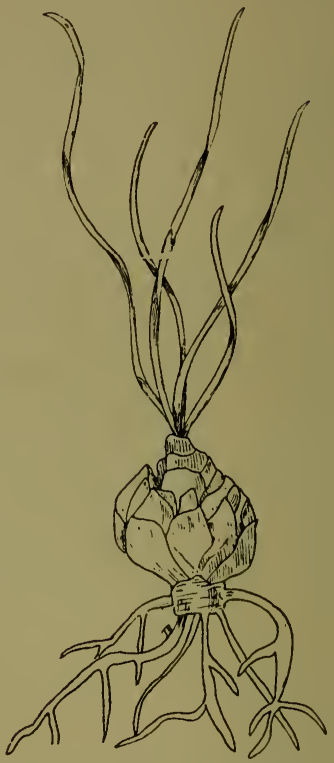

FIG. 192.-Bulb and leaves of Gethyllis.

the tube to the ovary. It was crowned with a cushion-shaped stigma. There were six filaments borne at the throat of the tube, divided near the middle into two branches, each bearing an anther.

On looking for it in FLORA CAPENSIS among the Amaryllideæ, its book name was found to be Gethyllis. There are nine different species bearing the name, the number of stamens 
varying from six to twenty. The leaves of some are spirally twisted, others are rolled back spirally from the tip like a watch spring. By degrees the beautiful curious plant revealed the secret of its success in making the most of a warm, sunny climate. When the winter rains provide sufficient moisture, the full-grown leaves, like those of "April Fool," appropriate it for preparing the year's food supply, which is stored in the bulb for future use in forming and ripening the seed. Christmas is its coronation time, when there is little else to lure us on to the parched veld. All through the summer months, in the centre of its protecting leaves, the fruit can ripen underground, and with the May or June rains it grows longer and longer, till it projects above ground with all its seeds ready to scatter and germinate. Sheep eat the fruit, and so possibly help to scatter the seeds. How does the pollen get from the anthers to the style? Does some night moth, poising for a sip of nectar, carry the golden Christmas gift from flower to flower?

It is a widespread family, extending from the Cape to Graaff Reinet, and from Mossel Bay up through the Karroo to Little Namaqualand.

One is almost inclined to wonder just wherein lies the delight in hunting for the odd fruits. Maybe the enjoyment has been inherited but, at any rate, there would be a sense of something lacking if, in their season, a few were not brought in from the veld. 


\section{CHAPTER XXII.}

\section{CLASSIFICATION OF PLANTS.}

WE have seen in earlier lessons how plants change their forms and habits of growth to suit different conditions of life. Probably none of the familiar plants of the veld look to-day just as they did when they were first created. More than 125,000 species or kinds of plants have been described or named, but since differences in soil, the amount of water, or sunlight available and cross fertilization bring about a change in the plants, it is often difficult to say just how many species there are in a district.

It is impossible to define the term species although it is a word which is in constant use. Species are not fixed by absolute characters. For purposes of classification any kind of plant which breeds true, that is, which can reproduce its like (within limits) by seed, which is fairly constant over a considerable territory and can be described so that it may be distinguished from other kinds, may be called a species.

A group of species which are more like each other than they are to other species is called a Genus, or a genus may comprise but a single species if it has a combination of characters not found in any recognized species.

Just as species are grouped into genera, so genera are grouped into Orders. The many kinds or species of heaths are grouped into the genus Erica. The genus Philippia is similar to Erica, but whereas Erica has three bracts "as a rule," beneath the flower, Philippia has none. If we find an Erica with none we may still distinguish it from Philippia which has a calyx of unequal lobes. Other genera may have but four stamens instead of eight, as found in Erica and 
Philippia, or the number of seeds may differ. Yet these genera have enough conspicuous characters in common to place them all under the one order Ericaceæ.

As a matter of fact there are no hard and fast lines to be drawn in nature. These groupings into orders, genera, and species have been made so that we may think and speak of them more easily.

Individuals of a species in which the difference is slight but constant are spoken of as varieties. When two species are crossed, their offspring (liybrids) are as a rule sterile, they will not form seeds. The common offspring of two varieties are usually fertile.

Of late years the collecting and naming of plants in schools has gone out of fashion. This is unfortunate. To know the name is not enough, but it helps us to know the plant. One who has made a collection has found how and where the plants grow, when they blossom and fruit, and it is to be hoped has gained some general ideas as to how their forms and markings, colours, and odours are related to their benefactors of the animal world. Not only the flower, but the whole aspect of the plant, tells how it has survived the wind and weather, how it has battled with unfavourable conditions of soil and drought and its sturdier neighbours in the struggle through the ages toward self-expression and perfection. It is hardly worth while knowing that the stamens of some flowers are declinate while others ascend and arch downward, unless we see how they are adapted to visiting insects in relation to pollination.

The first attempt at classifying plants came about through their real or supposed medicinal values. For this purpose they were classified as trees, shrubs, and herbs. From the time of Aristotle until the sixteenth century students began to arrange plants into groups which were very artificial. The most famous of these groups was that of the Swedish botanist, Linnæus. This system was used until the middle of the seventeenth century. In constructing these keys, plants were grouped according to a few evident characters as the number of parts of the flower, which enabled students to refer plants readily to their proper orders. Since then efforts have been made to so classify plants that those plants shall be brought 
together which are naturally related. A study of plant groups shows a gradually increasing complexity from the simpler water plants, the algæ, to those which live in damp places but bear their spores in the air, on to the seed-bearing plants. That there has been a continuous line of ascent is far from probable. But the laws of growth and development which are observed in common by different plant families leads to an interesting study of plant relationships.

The most highly developed plants are the Spermaphytes or seed-bearing plants. They were formerly known as Phanerogams (this term means sexual organs exposed), and were distinguished from all the lower groups or Cryptogams or plants with "sexual organs concealed". At the time these words were coined, it was thought that stamens and pistils were sexual organs and these are found only among seed-bearing plants. When microscopes and methods were improved it was found that the sexual organs were much more in evidence in the Cryptogams than in the seed-bearing plants.

Two groups of seed-bearing plants are recognized: the Gymnosperms and Angiosperms. While these divisions are based on many distinct characters, the groups may be readily distinguished by the fact that in Gymnosperms the seeds are exposed on a scale as in the pines and yellow woods, while in Angiosperms they are enclosed within the ovary. In the former group the pollen grains (microspores) are lodged directly within the micropyle, while in the angiosperms they are carried to the stigma and the pollen tube has farther to travel before they convey the sperm cells to their destination within the ovule. Of the Spermaphytes the Gymnosperms are a very ancient group as their imprints in the older rocks show. To go into details of their subdivisions would be perplexing to those for whom this book is written. The classes represented in South Africa will be mentioned later.

The Angiosperms are subdivided into two main groups, Dicotyledons and Monocotyledons, which have been mentioned in previous chapters. It will be well here to review some of the more prominent characters by which they are distinguished. 
I. The embryo of a Monocotyledon has one terminal cotyledon with the plumule at one side, while that of a Dicotyledon has usually two cotyledons on opposite sides of a terminal plumule. Endosperm is usually present in Monocotyledons while it is usually absent in Dicotyledons.

2. In a Monocotyledon, the prophyll or first leaf on a branch is placed on the side toward the main axis. In Dicotyledons there are two prophylls placed opposite to one another on the sides of the branch.

3. The stem of a Monocotyledon has numerous bundles which though arranged more or less in concentric circles appear to be scattered, while the primary bundles or leaf traces in a Dicotyledon are few and lie in a ring. In the former the bundles are closed, i.e. the cambium all passes over into permanent tissue while in Dicotyledons cambium between the wood and bast remains active and the bundles are open.

4. Leaves of a Monocotyledon are as a rule simple and exstipulate with large sheathing bases. The main veins which are usually parallel are united by small cross veins and the margins are entire. In Dicotyledons the leaves which are often compound, generally have a petiole; they may also have stipules; the veinlets end freely and the margins are often notched.

5. The floral structure of a Monocotyledon usually consists of five whorls of three parts each and the floral diagram may be represented thus : $\mathrm{K} n, \mathrm{C} n, \mathrm{~A} n+n, \mathrm{G} n$ where $n$ equals three. ${ }^{1}$

That of Dicotyledons may have five or four (or fewer) members in a whorl and the floral formula may be represented thus : $\mathrm{K} n, \mathrm{C} n, \mathrm{~A} n+n$ (or $n$ ) $\mathrm{G} n$ (or fewer) where $n$ equals five, four, or fewer.

In learning to distinguish plants it greatly simplifies matters to be able to group those which seem to be related; but we must remember that outward appearance is often deceitful, and that plants, like people living under the same

${ }^{1}$ These letters are used to designate calyx $(\mathrm{K})$, corolla $(\mathrm{C})$, anthers (A), Gynœcium (G). 
conditions, come to resemble one another in habits and appearance.

A Euphorbia is mistaken for a Cactus by many, but it would be hard to find a common ancestor for these two families. To be frank, however, it must be confessed that authorities in botany find much to puzzle them in making out the ancestral tree for the plant family where difficulties meet them at every turn.

It was formerly thought that Monocotyledons were more primitive than Dicotyledons but largely from evidence afforded by the vascular tissue of Monocotyledon seedlings it is now quite generally held that they have been derived from early Dicotyledons. However, both groups may have branched off from some ancestry common to both. Other problems deal with the nature of the flower. Were the first flowers provided with well-developed perianths or were they inconspicuous and without a perianth? There is evidence among the fossils in support of both views. Has the perianth been derived from modified bracts or from modified stamens? Were the first flowers perfect or unisexual and were flowers first pollinated by wind or were wind-pollinated flowers derived from those formerly pollinated by insects?

Probably some of the flowers which are without a perianth are primitive and some are reduced. An apetalous flower occurring in an order where the greater number of genera have petals may have lost the habit of forming petals which its ancestors possessed. The same may be surmised of windpollinated flowers.

In the systems of classification, the natural order Ranunculaceæ will be seen to stand first in the well-known English system of Bentham and Hooker. Primitive (unspecialized) characters of this order are seen $(\mathbf{r})$ in the indefinite number of perianth segments and sporophylls (stamens and carpels). (2) These are separate from one another, and (3) arranged in spirals (instead of cycles or whorls); (4) a convex axis (thalamus or receptacle). These characters, which are not found throughout this order, are more clearly seen in Magnoliaceæ. 
In the German system of Engler, flowers with inconspicuous or no perianth occupy the lowest rank. ${ }^{1}$ These together with flowers with separate petals are united under Archichlamydea. In both systems there is a tendency, as development proceeds, for the axis to become shortened and finally concave. Parts become definite or reduced in number and arranged in cycles (whorls). After the perianth has become cyclic, sporophylls may still occur spirally. Such flowers are known as spirocyclic.

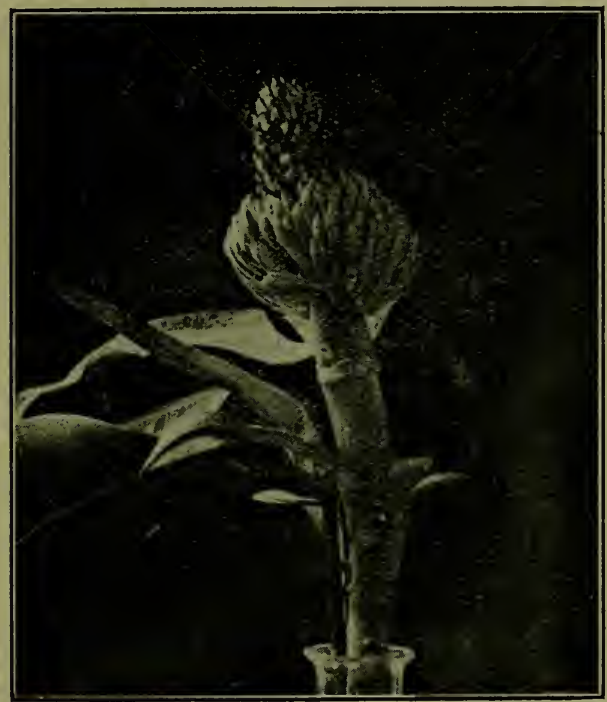

FIG. 193.-Spirocyclic flower of Magnolia. The perianth is in whorls, the stamens and ovaries in spirals.

With these changes coming into vogue, another tendency appears. Parts of a cycle "fuse" with one another. The term leads one to suppose that parts which were at first separate, join. As a matter of fact, after the rudiments of a cycle are laid down, the floral axis beneath develops in a ring or zone instead of in separate portions (zonal development). The

1 In this system incomplete flowers do not form a distinct group as in the former but are regarded, in many instances, rather as a primitive condition than as incomplete by reduction. 
name Sympetaly (Gamopetaly, Monopetaly) refers to zonal development of the corolla, and corresponding terms to that of sepals, stamen, and carpels (see p. I4 I).

The natural order Compositæ, in which cohesion and adhesion is greatest among Dicotyledons, gives evidence to the advantage attending the union of floral parts, if we may judge by numbers. This widely distributed order literally inherits the earth and is the largest among flowering plants, numbering over I I, 000 species.

Combined carpels economize in pollen. A sympetalous corolla offers a firm support for insects and catches the overflow from nectaries which it helps to conceal. As development advances the hollow receptacle "fuses" with the ovary which becomes inferior.

Grouping of flowers to form heads and umbels seems also to further success. It is not only an economy of insect labour but the flowers, sharing the protection afforded by a common involucre, may have the calyx developed as a special mechanism in the dispersion of seeds. Each seed in Compositæ is provided with its own aeroplane.

Two-sided symmetry (zygomorphy) is frequent among more highly specialized flowers. The cause of this development is far from clear. In heads and umbels it may be connected with one-sided contact with other flowers. Nutrition, air, and light relations have been suggested as "explanations". In flowers borne laterally on the stem, it may have been induced by insects' visits. Each flower is zygomorphic before it is visited, so this theory requires us to believe that the effect of the insects' alighting upon it is transmitted through succeeding generations. Gravity and other causes may have some part in bringing it about.

The tendencies shown in the evolution of flowers have been related to economy in pollen, efficiency in pollination, and in seed distribution. Thus far fossil records show Archichlamydeæ before Sympetalæ, and flowers with radial symmetry before zygomorphic ones.

"The less an organ is concerned with special habits, the more important it is for classitication." Groups of higher rank 
are separated by differences in parts which alter little or slowly. A plant's immediate needs are met by its vegetative organs (root, stem, leaves). These change remarkably under varying condi. tions of climate and soil. The reproductive parts, concerned with the future needs of the race, are less affected by these outward conditions. Consequently the flower is of more importance in distinguishing main groups. Besides cohesion of the floral parts, and the position of the ovary, the seeds, their number and position, the number of coats, and the presence or absence of endosperm, are important factors. The composition and shape of the leaves are less valuable; but their position, venation, and presence or absence of stipules are of importance in distinguishing lower groups.
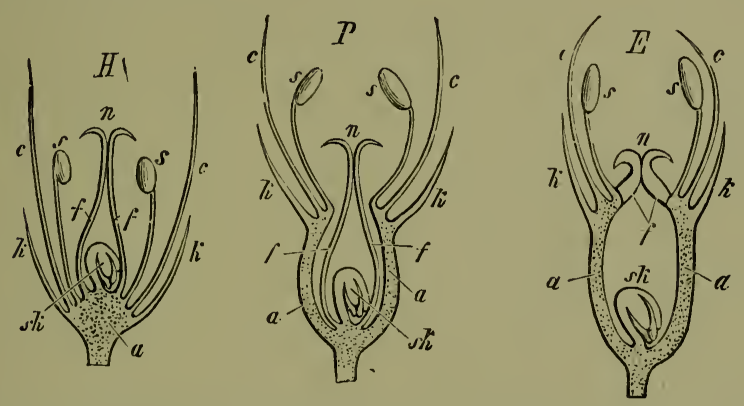

FIG. 194.-Diagram; to illustrate the morphology of flowers. A, hypogynous ; B, perigynous; C, epigynous.

It is upon the degree of cohesion and adhesion that Bentham and Hooker make their main divisions in the classification of Angiosperms. In Thalamiflure and Disciflorce the sepals are usually distinct and separate; the ovary is always superior, that is the other floral parts are situated below the ovary (hypogynous). In Discifloræ the receptacle is expanded into a disk. In Calyciflorce the receptacle is more or less expanded and hollowed, gradually becoming tubular and surrounding the ovary. If this tube is free from the ovary, the floral cycles are perigynous; if it is joined with the ovary the perianth and stamens are epigynous.

In classifying a plant, a synopsis is useful for identifying 
the order to which it belongs. After a little practice the characters of the order or family will be recognized at a glance without the synopsis.

Condensed Synopsis of Bentham and Hooker (I862).

This system is used in "The Genera of South African Plants" and in "Flora Capensis". For a fuller outline the student should consult the Synopsis of Engler (p. 206)

\section{PHANEROGAM $Æ$.}

\section{Angiospermæ.}

\section{Class I.-Dicotyledons.}

Group r.-Polypetala.

Series I.-Thalamifloræ.

A. Pistil apocarpous; stamens many . . . Ranunculacere.

AA. Pistil syncarpous.

B. Stamens free; flowers regular.

C. Leaves alternate.

D. Ovary I-celled; placentation parietal

E. Carpels 2.

Petals 4 ; stamens 6 , tetradynamous; replum present .

Petals 4 ; stamens 4-many; replum absent .

EE. Carpels 5.

Stamens 5 ; insectivorous herbs Droseracee.

DD. Ovary 3-celled; placentation axile.

Stamens 5 ; insectivorous shrubs

CC. Leaves opposite; placentation basal or on extended axis .

BB. Stamens monadelphous; flowers zygomorphic; leaves exstipulate.

Carpels 2, I-seeded . . . . . Polygalacere.

BBB. Stamens monadelphous, variously united

Crucifere.

Capparidaces.

Droserace $e$.

Caryophyllaces. or in TILIACEe sometimes free; petals twisted in bud; leaves stipulate.

Stamens united with petals; anthers Icelled

Stamens united with petals or free; anthers 2-celled . $\cdot . \cdot \cdot$ Sterculiace

Stamens united in groups or free; introrse

- Tiliacee. 


\section{Series II.-Discifloræ.}

A. Stamens beneath the disk forming a ring or broken up into glands.

Flowers often zygomorphic; leaves not gland-dotted; disk extended between the I-seeded carpels

Flowers mostly regular; leaves gland-

dotted . . . . . . Rutaces.

AA. Stamens within or on the margin of the disk; sometimes beneath.

Trees or shrubs often spinous; leaves simple, opp. or alt. . . . . .

Trees or shrubs often spinous; leaves alternate, mostly pinnate; disk often at one side.

Celastrines.

Geraniacee. ${ }^{1}$

- Sapindacee.

\section{Series III.-Calycitoræ.}

A. Pistil apocarpous, superior (except in some

Rosaceæ); stamens perigynous.

B. Carpel I ; fruit a legume . . . Leguminosæ.

BB. Carpels two or more (South African genera).

Stamens numerous; leaves stipulate . Rosaceæ.

Stamens 4-Io (S. A.); carpels 4-7 . Crassulace 2.

AA. Pistil syncarpous, ovary inferior (except in some Ficoideæ).

Petals (staminodia) numerous; embryo curved; plants with fleshy leaves . .

Petals 4 ; calyx (receptacle) with a long tube extending beyond the ovary, many seeded

Petals 5; 2-celled, 2-seeded flowers in umbels

FICOIDE ${ }^{2}{ }^{2}$

ONAGRARIEA. ${ }^{3}$ UMBELLIFERE.

\section{Group 2.-Gamopetala.}

A. Ovary inferior.

B. Stamens inserted on the corolla tube.

C. Ovary r-celled, I-ovuled; flowers in heads, leaves, ex-stipulate.

Stamens 4, free; ovule pendulous.

Heads definite, leaves opposite . . Dipsacke.

Stamens 5, anthers united; ovule erect;

heads indefinite . . . . Compositæ.

\footnotetext{
${ }^{1}$ Including Oxalidace

${ }^{3}$ Oenotheraceæ, Engler.
} 
CC. Ovary 2- or more celled; leaves opposite, stipulate. $\cdot \cdot \cdot \cdot \cdot \cdot$ Rubiace在.

BB. Stamens epigynous, free from the corolla: ovary 2-ro-celled; half inferior; fruit a capsule

AA. Ovary superior.

B. Flowers regular.

C. Leaves alternate (also opposite and whorled in Ericaceæ).

D. Flower parts usually in fours; rigid shrubs with reduced needleshaped leaves; stamens frequently opening by pores.

ERICAcee.

DD. Perianth 5-parted; habit various; leaves expanded.

Fruit a berry or capsule, obliquely inclined

Fruit an achene . . . . Plumbaginace

CC. Leaves opposite; alt. in Pachypodumm, and in some Gentianaceæ.

D. Pollen grains collected in masses.

Herbs often with milky juice; seeds hairy .

DD. Pollen grains separate.

Shrubs with milky juice; seeds usually hairy; fruit a berry or follicles; leaves alternate and stipulate in Pachypodium

Apocynacex.

Herbs with bitter juice; corolla withering on; fruit a berry or follicles; seeds not hairy .

Asclepiadace

BB. Flowers zygomorphic or rarely regular; corolla 2-lipped.

C. Ovary 2-celled; fruit a many-seeded capsule, rarely a berry.

Leaves simple, seeds small, endospermous

Scrophulariaceæ.

Leaves compound; seeds flat with large membranous wings, except in $K i$ gelia; ex-endospermous

Gentianacee.
Solanace e.
PLUMbaginacea.

Ovary 4 -lobed or 4 -celled, separating in fruit; four seeded.

Leaves opposite; stem square; strong odour

\author{
Labiatæ.
}

Leaves alternate; stem round; flowers nearly regular. . . .

Boraginacee. 


\section{Group 3.-Incompleta.}

A. Perianth present; flowers perfect or imperfect.

B. Ovary superior.

Flowers regular. Perianth tubular, its lobes imbricate in bud. Shrubs .

Perianth more or less irregular, 4 -cleft or 4-parted, valvate in bud; trees or shrubs

Thymeleace

BB. Ovary inferior.

Perianth 4-8-parted; fruit a berry; parasites on trees

Perianth 3-parted, becoming woody; root parasites . . . . .

AA. Perianth absent; sometimes with sepals, flowers imperfect.

Fruit a 3-celled schizocarp; plants usually milky; herbs, shrubs or trees.

Fruit usually I-celled; staminate flowers in Catkins; trees . . . Amentace£.

LoRANTHACEæ.

HydNoRACEÆ.

\section{Class II.-Monocotyledons.}

\section{Group r.-Petaloida.}

A. Ovary inferior.

Stamens I, joined to the style ; ovary Icelled

Stamens 3 ; ovary 3 -celled . . . . IRIDEA.

" 5; " . . . . . Musace天.

AA. Ovary superior.

EUPHORBIACE

B. Flowers perfect.

Perianth coloured; stamens 6 . . Liliace $e$.

Calyx green; corolla coloured; anthers differently formed

Commelynacee.

Perianth coloured; ovary inferior or superior, stamens $3-6$. . . . HÆMOdORACEÆ.

BB. Flowers imperfect.

Flowers diœcious. Perianth of 6 , rarely 4 glumes

$$
\text { Group 2.-Glumacea. }
$$

Stem solid; sheath of leaf not split, without a ligule

- Cyperaces. 
Stem hollow; leaf-sheath split; ligule present . . . . . . Graminace

\section{Gymnospermæ}

(For Classification see System of Engler).

\section{System OF ENGLeR, I 897 .}

Adapted and limited (in the Angiospermæ) to the orders found in South Africa.

Groups of related orders in this system are combined in cohorts. The earlier cohorts are ill defined and characters of different cohorts overlap. As the characters of the orders become more specialized the cohorts become better defined.

\section{SPERMAPHYTA.}

\section{Gymnospermæ.}

Ovules not enclosed in an ovary. Endosperm formed, without nuclear fusion, before fertilization.

Class I. Cycadales-stem unbranched or with

little branching; leaves pinnate;

perianth wanting; diœcious . CyCADACE $x$.

Class II. Ginkgoales-stem branched, with

long and short shoots; leaves

fan-shaped; diœcious . . GINKGOACEÆ.

Class III. Coniferc-stem branched, with or without long and short shoots; leaves usually narrow; flowers unisexual; perianth wanting.

Cones imperfect, seeds projecting beyond the carpels, with fleshy aril

Cones fully formed; seeds concealed between the scales. . Araucariacr $F$.

Class IV. Gnetales-stem simple or branched, habit various; leaves in pairs, simple; perianth present . . Gnetacex.

\section{Angiospermæ.}

Ovules borne within an ovary of carpels with cohering margins. Endosperm produced by nuclear fusion, formed after fertilization. 


\section{Class I.-Monocotyledons.}

A. Flowers with marked indefiniteness in the number of flower parts.

B. Perianth as a rule absent (Achlamydeous), either as a primitive condition or by loss of perianth formerly present in earlier related types; when present illdefined and consisting of bristles or scales. Wind pollinated.

C. Stamens and carpels showing great variation in number; apocarpous, or carpels more or less joined and at length separating ; I-4, each I-ovuled; spathe wanting, aquatic or marsh plants.

Perianth of bristles, flower spikes on long scapes, staminate above, pistillate below .

- Typhacee.

Perianth none, or tubular, or of three or six valvate segments; habit various .

CC. Stamens usually definite, carpels syncarpous.

Seed-coat fused with ovary ; leaf sheath

split, ligule present .
Seed-coat free from ovary; leaf sheath not split, ligule absent

Graminace£.

NaIADace e.

CyPeRAces.

BB. Perianth as a rule present, or absent through reduction; inflorescence subtended by bracts; stamens and carpels as a rule definite; usually insect pollinated.

Plants with root stock, spathe conspicuous Minute floating plants, spathe inconspicuous

AA. Flowers of five whorls prevailing, each whorl usually 3-parted.

B. Perianth with sepals and petals similar (Homochlamydeous).

C. Perianth bracteoid or sepaloid, hypogynous.

D. Carpels a pocarpous, I-seeded, endosperm cartilaginous, horny or oily.

Diœecious trees with unbranched stems and pinnate leaves . . Palme.

DD. Carpels syncarpous.

ARACE

Lemnacee. 
E. Flowers monœcious; ovules solitary, endosperm mealy.

Flowers in dense involucred heads with staminate flowers central . ERIOcaulace

EE. Flowers diccious, seeds solitary.

Trees with unbranched stems, flabellate leaves . . . PALme.

Herbs; stamens 3, anthers Icelled (S.A.), endosperm mealy Restiacese.

EEE. Flowers perfect.

Herbs climbing by leaf tips; stamens 6 .

Flagellariace $x$.

Rush like herbs or under shrubs; stamens 6-3 . . . . JUNCACE

CC. Perianth corolloid.

D. Perianth hypogynous.

E. Placentation parietal; marsh herbs

EE. Placentation axile.

Fruit a capsule or berry, stamens 6 ; many-seeded.

Fruit a capsule, seeds solitary; stamens 6-3

LILIACEE.

Pontederiaces.

DD. Perianth epigynous.
E. Flowers imperfect,

E. Flowers imperfect, mostly diœcious.

Stem twining, arising from enormous cork covered tuber .

Dioscoreacee.

EE. Flowers perfect.

F. Placentation axile.

Stamens 6; root stock a corm or bulb

Amaryllidaceæ.

Stamens 3; opposite sepals, root stock a corm or rhizome . • $\cdot$.

HEMODORACEE.

Stamens 6.3; root stock with red juice, never bulbous, seeds solitary . $\cdot$.

Stamens 5 ; flowers in axils of large coloured bracts, seeds arillate

FF. Placentation parietal or axile. Stamens 3, opposite petals. FFF. Placentation parietal.

Stamen I; gynandrous: seeds many, small

IRIDACE

HÆMODORACEE.

Musace

Burmanniacee.

Orchidaces.

BB. Perianth with green sepals and coloured petals (HETEROCHLAMYDEOUS). 
C. Perianth hypogynous.

Ovary I-celled, placentas parietal, ovules many . . . . . XYridace..

Ovary 3-2-celled, placentas axile, ovules few . . . . . Commelinacee.

CC. Perianth epigynous.

Flowers unisexual, stamens 3 ; floating herbs

Flowers perfect, stamens $\mathrm{r}$, gynan-

HYDROCHARITACE .

drous . . . . . ORCHIDACE

\section{Class II.-Dicotyledons.}

\section{Series I.-Archichlamydeæ.}

Perianth either (I) absent; (2) in one whorl, simple, petaloid or sepaloid; (3) in two whorls, the inner polypetalous; (4) in two whorls, the inner sympetalous (rare, where nearest relatives are polypetalou), or (5) in one whorl by the abortion of the inner whorl (apetalous). Ovules usually with two integuments.

A. Perianth wanting (ACHLAmydeous).

B. Carpels apocarpous or syncarpous; flowers perfect or diœcious.

Fruit a berry; seed I basal, orthotropous; jointed shrubs or herbs ; frequently root climbers or epiphytes . . . PIPERACEæ.

BB. Carpels syncarpous, flowers diœcious. Fruit a capsule, seeds many, hairy; trees. . . . . . .

Fruit a waxy berry, seed I, shrubs . MYRICACEe.

AA. Perianth simple (Homochlamydeous).

B. Calyx bract-like, usually green.

C. Perianth hypogynous.

D. Carpels a pocarpous or syncarpous.

Fruit of many I-seeded carpels .

- Phytolaccaces.

DD. Carpels syncarpous.

E. Ovules basal; erect herbs or shrubs, fruit an achene or nut; partial inflorescences at least, cymose.

F. Leaves exstipulate; ovules campylotropous.

Ovule I; calyx herbaceous; halophytic herbs

Ovule I-many; calyx membranous; not halophytes

Chenopodiace⿸⿻ 丿亅.

AMARANTACE $A$. 
FF. Leaves stipulate; ovule I, basal, erect, orthotropous.

Herbs with sheathing (ochraceous) stipules . .

Herbs or shrubs, stipules not ochraceous .

EE. Ovule pendulous, trees or shrubs, milky, leaves stipulate.

Flowers clustered in fig-like receptacles . . . . .

EEE. Ovules basal becoming parietal,

Polygonace

URTICACE e. or axillary.

Fruit a capsule or of separable nuts, leaves exstipulate, xerophytic herbs

MoRace原.

CC. Perianth perigynous.

DD. Carpels syncarpous.

Fruit fleshy or dry, trees with alternate exstipulate leaves, or cordlike parasites

Lauracee.

Fruit a capsule, placentation parietal,

Aizoace

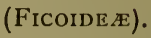
stamens many, with petaloid staminodia; fleshy herbs, leaves usually opposite

Aizoacex.

CCC. Perianth epigynous.

Fruit a nut ; monœcious, trees, leaves alternate with scaly stipules . . FAGACEA.

BB. Calyx corolloid.

C. Perianth hypogynous.

D. Carpels apocarpous ; leaves exstipulate.

E. Achenes few or many, bracts not showy; stamens many, herbs or climbing shrubs . .

EE. Achenes r, bracts often showy. Stamens 4 opposite and adnate to calyx lobe; leaves alternate, shrubs or trees... Stamens I- 5 or more by branching, alternate to calyx lobes, hypogynous; leaves opposite, herbs or climbing shrubs

Ranunculacee.

Proteacee.

DD. Carpels syncarpous; leaves stipulate.

Fruit a three winged or angled nut; herbs.

Fruit a capsule, fleshy herbs, stipules not shea thing

- Polygonacee.

Nyctaginace.e.

Portulacace 
CC. Perianth epigynous.

Fruit a fleshy berry, green parasites

on trees.

Loranthace.e.

Fruit a woody berry, fleshy root parasites

Fruit I-seeded, root parasites, imperfect . . . . . .

AAA. Perianth double, except Section $C$, under

BBB; sepals forming calyx, corolla petaloid (Heterochlamydeous).

B. Perianth hypogynous or slightly perigynous; receptacle not concave or tubular.

C. Carpels apocarpous; flowers spiral, spirocyclic or cyclic (Cohort Ranales).

D. Carpels many; stamens many; flowers perfect.

Ovules many-I ; fruit usually multiple, trees or shrubs .

Ovules I, fruit achenes, herbs, or climbing shrubs

DD. Carpels few, stamens few, flowers diœcious.

Fruit a drupe, stamens monadelphous, climbing shrubs . . Menispermace

CC. Carpels syncarpous.

D. Placentation parietal, sepals free. (Cohort Rhoeadales, excluding Nymphæaceæ, Bixaceæ, and Droseraceæ).

E. Stamens many, rarely few.

Fruit a large berry, water plants Fruit a capsule, dehiscing by

pores, herbs with latex
Fruit a capsule or berry, trees or shrubs

Anonaces.

Ranunculace

HYDNORACEÆ.

Balanophoracee.

EE. Stamens few; leaves alternate

NYMPHÆACE⿸.

Papaveraces.

BiXacee. ex-stipulate.

F. Herbs.

Stamens $6,{ }^{1}$ capsule inflated; climbing . . . Fumariaces.

Stamens 6 , tetradynamous; fruit a siliqua $\cdot \cdot \cdot$

Stamens $3-8$; fruit a gaping capsule . . . REsedace .

${ }^{1}$ Or two, each branched into three. 
FF. Trees, shrubs, or herbs.

Stamens 4-many, with ovary borne on prolonged axis; fruit a capsule or berry . . . . . .

Stamens 5 ; herbs or shrubs, with insect-catching leaves . . .

DD. Placentation free, central. Inflorescence

Capparidace.e.

Droseracee.

cymose.

Fruit a capsule, leaves opposite .

DDD. Placentation axile, or frequently parietal, sepals free or connate. Cymose inflorescence prevailing except in Malpighiaceæ and Polygalaceæ.

E. Sepals usually imbricated, and free.

F. Disk within stamens, carpels (5-2), ovules usually few, stamens obdiplostemonous, or outer whorl absent, more or less joined at base. (Cohort Geraniales.)

G. Flowers perfect.

H. Flowers regular, sometimes irregular; stamens opening by slits.

I. Leaves not gland-dotted; herbs or shrubs; styles usually free.

Stamens obdiplostemonous when more than two whorls.

J. Leaves alternate.

Fruit a schizocarp; leaves simple or pinnate, stipulate .

Fruit a loculicidal capsule, leaves palmately compound, exstipulate .

Fruit a septicidal capsule, leaves simple, stipulate or exstipulate

JJ. Leaves opposite, stipulate.

Fruit a capsule, schizocarp or berry; seeds few .

Geraniace

Caryophyllaces.

OXALIDACE

- Linaceæ.

II. Leaves gland-dotted; shrubs or
trees; styles united.

Zygophyllace

J. Stamens free, leaves exstipulate.

Fruit a capsule or berry; leaves heath-like, trifoliate, or pinnate . . .

Fruit drupaceous; leaves imparipinnate. . . .

Rutaces.

- Burserace 
JJ. Stamens connate.

Fruit a capsule, drupe or berry, leaves simple or pinnate, exstipulate . . . . . .

Fruit a samara, leaves alternate or opposite, simple, stipulate.

HH. Flowers zygomorphic; stamens open-

Meliace $e$.

Malpighiacee. ing by pores.

Fruit 2-celled, 2-ovuled, capsule or berry, stamens 8 , monadelphous .

GG. Flowers imperfect, often much reduced. Fruit a schizocarp, 3-celled, plants usually milky . . . . . .

FF. Stamens within or on the margin of the disk; disk cushion-like adnate to base of calyx; ovary free or immersed in disk; ovules one or two; trees or shrubs. Perianth, andrœcium and gynœcium often reduced. Perigyny and epigyny occur. (Cohort Sapindales excluding Guttiferæ.)

G. Leaves simple; flowers usually perfect.

H. Ovules erect, micropyle facing downward.

I. Fruit more or less immersed; trees or shrubs often spinous.

Stamens alternate petals, seeds usually arillate

Stamens opposite petals

II. Fruit not immersed; plants not spinous; leaves stipulate.

Fruit a berry; stamens $4-5$, opposite petals; climbing . . . .

Fruit of I-Io drupes; stamens many, anthers dehiscing by pores

$\mathrm{HH}$. Ovules pendulous; leaves usually stipu-

\section{Polygalaceæ.}

EUPhorbiaceæ. late; flowers perfect.

Fruit a drupe . . . . . Olacaces.

Fruit a drupe; flowers diœcious . . ILICACE $Æ$.

GG. Leaves pinnate, rarely simple; flowers frequently imperfect.

Fruit leathery or membranous, inflated capsule

Fruit a drupe, often winged; resinous.

Vitacee.

OCHNACE⿸.

Sapindacek.

Anacardiacee.

EE. Sepals usually valvate, more or less connate and petals convolute; stamens usually many; disk inconspicuous or none. 
F. Stamens in several sets, opposite the petals; anthers 2-celled; placentation parietal or axile.

Calyx imbricate; leaves opposite, exstipulate; oil glands present

Calyx valvate; leaves alternate, stipulate; oil glands absent .

FF. Stamens monadelphous; leaves al-

Guttifere.

TILIACEe. ternate stipulate; placentation axile.

Anthers I-celled . . . Anthers 2-celled . . . .

BB. Perianth and stamens slightly perigynous; receptacle usually hollow or tubular.

C. Carpels apocarpous. (Cohort Rosales.)

D. Seeds endospermous; leaves ex-stipulate except Connaracea, opposite or alternate.

Carpels isocarpic; stamens iso or diplo-stemonous, fleshy plants. .

DD. Seeds ex-endospermous; leaves mostly stipulate; usually alternate.

E. Stamens many; flowers regular.

Fruit a pome, drupe, or achene . Rosace e.

Fruit a legume . . . . Leguminose.

EE. Stamens few.

Carpels 5 , fruit a follicle; stamens 5-ro; stipules absent . $\cdot$.

Fruit a legume or loment; stamens

Io; stipules present . . . LEGUMinose.

CC. Carpels syncarpous.

D. Placentation axile. (Cohort Rosales excluding Elatinaceæ.)

E. Fruit a many-seeded capsule (few seeded Cunonia, Saxifragacea).

F. Plants in swift streams, forming a thallus

Crassulacee.

Malvaceæ.

Sterculiacee.

Connaracee.

FF. Trees or shrubs; capsules $2-5$ celled.

Styles separate; leaves simple, exstipulate, or compound, stipulate, alternate, or opposite. . Styles united; leaves simple, stipulate opposite . . . . Saxifragace .

Podostemacee.

Styles united; leaves alternate, simple, exstipulate, shrubs with conspicuous flowers . .

Elatinacee.

Pittosporace 
EE. Fruit few seeded.

As in Saxifragacea but seeds solitary ; leaves simple, alternate, exstipulate, expanded

Capsule 2-, or nut I-seeded, heathlike shrubs

DD. Placentation parietal or basal. (Co-

hort Parietales including Guttiferæ and Elatinaceæ, Loasaceæ, Begoniaceæ, Bixaceæ.)

E. Leaves exstipulate; fruit a manyseeded capsule, salt-loving or desert plants with reduced leaves.

Style I, seeds smooth, calyx persistent

Styles 3 , seeds hairy . . .

EE. Leaves stipulate.

F. Fruit a berry or pulpy capsule, trees or shrubs.

Flowers usually imperfect, stamens many or ro . . .

Flowers perfect; stamens 3-5 within a fringed corona ; climbing .

Flowers perfect; stamens 5 ; corona wanting, petals convolute

FF. Fruit a dry capsule; herbs or shrubs.

Flowers regular; or zygomorphic ; anterior petal often spurred .

BBB. Perianth perigynous, occasionally epigynous, ovary mostly syncarpous, free from or rarely united with the tubular axis, mostly woody plants.

C. Calyx coloured; petals absent by abortion or represented by glands; leaves exstipulate, ovary free from tubular axis (Thymelæales).

D. Fruit a capsule, four parted; sepals 4 ; leaves opposite.

Endosperm present, sepals imbricate, stamens 8, internal phloem absent.

Endosperm absent, sepals valvate, stamens 4 , internal phloem present

DD. Fruit an achene; leaves alternate or opposite.

Sepals 4-5; corona often present; stamens haplo- or diplo-stemonous

Hamamelidace

BRuniace⿸⿻.
Frankeniace

TAMARICACE 2 .
Bixacex.

Passifloracee.

TURNERACEA.

Geissolonaceæ.

Penæacex.

THYMEL 
CC. Calyx herbaceous, petals present ; ovary free or partially united to tubular axis, leaves opposite. (Cohort Myrtifloræ.)

Ovary free, capsule many seeded

Ovary free, or adhering to the axis, fruit a one or two-seeded berry .

Fruit a drupe, capsule, or berry; stamen knee bent opening by pores

Lythrace.

RHIZOPHORACEÆ.

Melastomace $Æ$.

BBBB. Perianth epigynous.

C. Inflorescence cymose, usually solitary, rarely racemose.

D. Placentation parietal; stamens many.

Flowers spirocyclic; fruit a manyseeded berry

Flowers cyclic; fruit 3-celled, seeds solitary under shrubs . . .

DD. Placentation axile, stamens many or few. (Myrtifloræ, excluding Begoniaceæ and Rosaceæ.)

E. Leaves stipulate.

F. Fruit a capsule ; stipules persistent; leaves alternate.

Flowers monœcious; fruit winged, many seeded, succulent, perennial herbs. Flowers perfect, fruit not winged, cells r-seeded.

FF. Fruit a berry, stipules deciduous; leaves opposite.

Trees or shrubs, growing by the sea

EE. Leaves exstipulate.

Cactacee.

LOASACEÆ.

\section{Begoniacex.}

Rosaceæ.

F. Stamens indefinite.

Trees or shrubs, leaves mostly opposite entire; placentation axile

Myrtacee.

Under shrubs, leaves alternate, lobed; placentation parietal. LOASACEe.

FF. Stamens definite.

G. Fruit many seeded.

Stamens knee bent, dehiscing by terminal pores; leaves opposite

- Rhizophoracee. 
GG. Fruit I- or few seeded.

Fruit winged or ribbed; trees or shrubs. . . . . .

Fruit not winged; flowers uni- rarely bisexual, herbs, in wet places .

CC. Inflorescence usually an umbel, either Combretace灰.

Haloragidace racemose or cymose; ovules solitary, pendulous; seeds endospermous. (Cohort Umbellifloræ.) .

D. Fruit a drupe or berry, 2-4 celled; trees or shrubs.

Leaves alternate, palmate with small stipules $\cdot \cdot \cdot \cdot \cdot \cdot \cdot \cdot \cdot \cdot$

pulate . . . . . Cornaces.

DD. Fruit a schizocarp, 2-celled.

Herbs or shrubs with simple or com-

pound leaves, petioles sheathing . UMBELLIFERÆ.

\section{Series II.-Sympetalæ.}

Calyx and corolla present, the petals united, rarely free or nearly so. Ovules with a single integument.

A. Flowers as a rule pentacyclic and isocarpic, i.e. with five floral cycles and number of carpels equal to parts in the other cycles. Floral formula $\mathrm{K}_{5}, \mathrm{C}_{5}, \mathrm{~S}_{5}+5$ (in which either whorl may be wanting in some forms), G (5).

B. Stamens diplostemonous (twice as many as petals) the outer whorl alternating with the petals or by the suppression of the outer whorl equal to and opposite to the petals, rarely, by branching of the filaments, stamens many; epipetalous.

C. Outer whorl of stamens fertile or represented by petaloid staminodia; placentation axile, woody plants with simple leaves. (Cohort Ebenales.)

Plants milky, fruit a drupe or berry, seeds erect .

Araliacele.

Plants not milky, seeds hanging, fruit a berry

CC. Outer stamens absent, inner opposite Sapotace to petals; placentation basal or free central. (Cohort Primulales.) 
D. Fruit indehiscent; leaves alternate exstipulate.

Fruit a drupe or berry, shrubs or herbs

Fruit an achene, calyx persistent, shrubs or herbs. . . .

DD. Fruit a many-seeded capsule; leaves alternate or opposite, exstipulate. Herbs

BB. Stamens obdiplostemonous, the outer whorl opposite to petals (or sometimes wanting), hypogynous or slightly epipetalous. (Cohort Ericales.)

Shrubs or trees with needle shaped usually grooved leaves. Stamens usually dehiscing by terminal pores.

AA. Flowers tetracyclic, usually of four whorls and anisocarpic, i.e. carpels fewer than parts of the other cycles; stamens alternating with and equal to the petals or rarely fewer when zygomorphic, epipetalous or hypogynous. Carpels usually two, in Convolvulacea, rarely three to five.

B. Perianth hypogynous.

C. Flowers mostly actinomorphic (regular), inflorescence mostly cymose. (Cohort Contortæ.)

D. Leaves entire mostly opposite, carpels apocarpous or syncarpous.

E. Stamens equalling the petals; internal phloem frequent.

F. Latex present; leaves exstipulate, rarely stipulate; stamens applied to the stigma.

Pollen powdery; styles united; fruit a capsule, drupe or berry Pollen sticky in masses (pollinia) ; fruit a follicle
atex absent, leaves opposite.

FF. Latex absent, leaves opposite.
G. Placentation axile; leaves stipulate.

Diœcious; shrubs; leaves with axillary spines . . .

Perfect; herbs shrubs or trees Apocynacee.

Asclepiadacese.

ERICACEe.

MyrSinaCE $x$.

Plumbaginace.e.

Primulacea. 
EE. Stamens 2.

Shrubs or trees, fruit a berry or capsule

DD. Leaves mostly alternate (opposite in some

$H_{y}$ drophyllacea); carpels 2 (rarely three to five) syncarpous; inflorescence mostly cymose.

E. Seeds usually few, 2-I in each carpel ; fruit frequently separated into $3-4-5$, I-seeded compartments.

Seeds erect, climbing or trailing. " " perennial herbs with radical leaves par.

Seeds hanging; habit various, erect, roughly hairy . . . .

EE. Seeds many (few in Retzia, Solanacea); calyx usually persistent.

Placentation parietal; bundles collateral . . . . .

Placentation axile; bundles bicollateral; carpels obliquely inclined .

CC. Flowers mostly zygomorphic and then stamens frequently one fewer than petals ; inflorescence cymose or racemose; leaves mostly opposite (sometimes alternate in Scrophulariacea and Verbenacea); herbs or shrubs. (Cohort Tubifloræ.)

D. Fruit a schizocarp, rarely a drupe.

Fruit usually a drupe, leaves sometimes alternate. . . . . Fruit of four one-seeded nuts . . . Labiate.

DD. Fruit a capsule, rarely a berry.

E. Seeds many.

F. Capsule 2-celled; placentation axile.

Seeds small, endospermous; leaves opposite or alternate . . .

Seeds large,winged exendospermous; leaves opposite, usually compound

HydrophyllaceE.

Solanacee.

Convolvulacee.

Plantaginacee.

BoraginaCE $x$.

Scrophulariace $e$.

Bignoniacele.

FF. Capsule I-celled; placentation parietal, seeds very small.

G. Parasites; inflorescence racemose Orobanchace£.

GG. Not parasites.

Inflorescence cymose, carpels Icelled . . . . Inflorescence racemose, carpels becoming 4-celled; usually horned MARTYNIACEÆ. 
FFF. Capsule I-celled; placentation "free central".

Insectivorous plants; stamens two, anthers I-celled . .

LentibulariaceÆ.

EE. Seeds few, at least South African species.

Capsule often explosive, bracts usually conspicuous . . . .

BB. Perianth epigynous (half inferior in CamAcavthacee. panulacea and Goodeniacea).

C. Leaves opposite; stamens free; flowers cymose. (Cohort Rubiales.)

D. Leaves stipulate.

Stamens as many as petals; seeds many or solitary . . . .

Rubiace

DD. Leaves exstipulate, stamens as many as petals or fewer; seeds pendulous. Carpels three, ovary I-3-celled; calyx a pappus; inflorescence, panicled . Carpels two, ovary I-celled, inflorescence capitate .

Valerianaces.

DiPSACE⿸⿻ 丿.

CC. Leaves usually (except some Composita) alternate exstipulate; stamens approaching or partly united, flowers racemose. (Cohort Campanulatæ.)

D. Seeds many; placentation axile.

Flowers imperfect, regular . .

Flowers perfect, regular or zygomorphic; latex usually present . CAMPANUlaCEe.

DD. Seeds few ( $\mathrm{I}$ in Composita) erect.

Anthers free or cohering; calyx herbaceous; latex absent . . . GOODENIACEÆ.

Anthers united; calyx a pappus ; with latex or resin . . . . Compositæ.

The plants ranked below those that bear seed are divided into three groups, making in all five divisions of the Vegetable Kingdom :-

I. Thallophyta.

II. Bryophyta.

III. Pteridophyta.

IV. Gymnospermæ.

V. Angiospermæ.

While the lower forms are of great interest and importance, they are in so many cases known only by the aid of the micro- 
scope, and are consequently so unfamiliar to those for whom this book is intended that they can be but briefly mentioned.

\section{Division I.-Thallophyta.}

This division includes a great variety of plants, some very simple and others quite elaborate, but they are grouped together
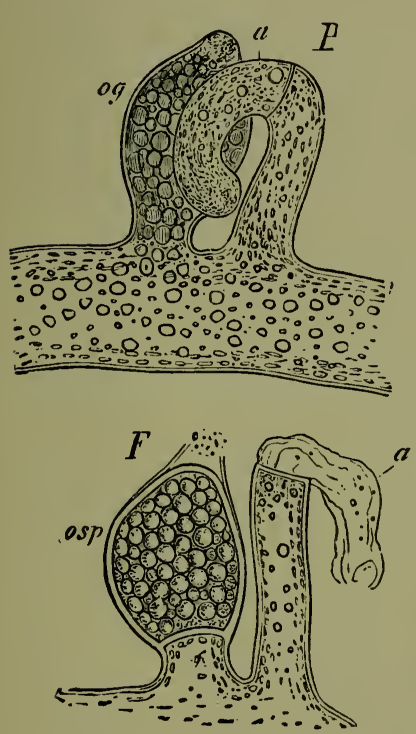
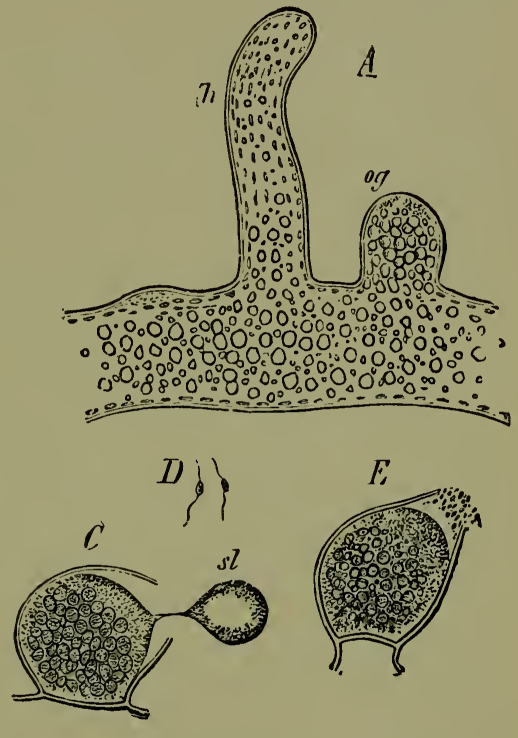

FIG. 195.-Vaucheria. A, B, formation of antheridia and oogonia ; $h$, male branch; $a$, antheridium; $o g$, oogonium ; $C$, oogonium opening to exude the drop of mucilage, $s l ; \mathrm{D}$, spermatozoids ; $\mathrm{E}$, spermatozoids entering oogonium ; $\mathrm{F}, a$, an empty antheridium ; osp, oogonium with oospore or fertilized oosphere (magnified). (After Goebel and Pringshein.)

as having no root, stem or leaves, and in having one-celled fruiting organs. It may be divided into three subdivisions.

A. AlGF.-Most of the plants composing the green floating scum on ponds, which is sometimes called "frog spittle," are algæ. Others are found on damp walls, on stones, or moist earth. All the seaweeds are algæ. These plants may be but single cells, long threads or filaments of cells, or masses of cells. The filaments may break apart, and so form new plants, or the cell 
contents may round off and form spores. The spores of pond scums are preserved in the dried mud during the dry months, and when the rains come they grow into new plants.

In most algæ a fusion of two cells forms a stage in their life history. These may be like one another or an egg- and sperm-cell may fuse which may be compared to the fusion in higher plants.

By means of chlorophyll, algæ appropriate the $\mathrm{CO}_{2}$ dissolved in the water and so assimilate their own food.

B. Fungi.-The fungi, which comprise the second class of Thallophyta, differ from algæ by the absence of chlorophyll. This in itself would not justify a separate grouping of the fungi, as this is not recognized as a basis for division in the higher plants. The fungi, though they may be degenerate forms of algæ, are distinguished by their mode of developing and their life history.

Although as parasites the fungi are destructive to higher plants their importance in the economy of Nature as saprophytes and symbionts is only beginning to be understood. Fungi grow symbiotically on the roots of many plants. By removing the soil from the roots of a young oak plant the threads (mycelium) of a fungus may be seen near their tips. Reference is made on p. 342 to the fact that those growing as mycorhiza on heath roots appropriate free nitrogen and are thus of great importance to the soil. Some of the commonest moulds as Penicillium (the blue mould) also appropriate free nitrogen, as Miss Ternetz has found.

The yeast plant Saccharomyces is of interest as being one of the chief organisms concerned in alcoholic fermentation of carbohydrates. When yeast cells are placed in starch paste or in a solution of cane sugar an enzyme excreted by the yeast sets up a digestive process. Starch uniting chemically with water (by hydrolysis) becomes changed into maltose $\left(\mathrm{C}_{12} \mathrm{H}_{22} \mathrm{O}_{11}\right)$ which by union with another molecule of water breaks up into two molecules of glucose thus :-

$$
\underset{\text { Maltose }}{\mathrm{C}_{12} \mathrm{H}_{22} \mathrm{O}_{11}}+\mathrm{H}_{2} \mathrm{O}=\underset{2}{2\left(\mathrm{C}_{6} \mathrm{H}_{12} \mathrm{O}_{6}\right) .} \text { Glucose }
$$


Cane sugar by taking up a molecule of water breaks up into a molecule of grape sugar (glucose) and fructose :-

$$
\mathrm{C}_{12} \mathrm{H}_{22} \mathrm{O}_{11}+\mathrm{H}_{2} \mathrm{O}=\mathrm{C}_{6} \mathrm{H}_{12} \mathrm{O}_{6}+\mathrm{C}_{6} \mathrm{H}_{12} \mathrm{O}_{6} \text {. }
$$

After this change outside the yeast cells has taken place (extracellular digestion), the simple sugars are taken into the yeast cell. Here it meets with an enzyme which cannot pass out of the cell. This enzyme disorganizes these sugars, whereupon oxygen which was driven away from the carbon when it was first formed, now recombines with it forming $\mathrm{CO}_{2}$. Not all the carbon is oxydized, but the sugar is broken down into carbonic acid gas and alcohol :-

$$
\mathrm{C}_{6} \mathrm{H}_{12} \mathrm{O}_{6}={ }_{2} \mathrm{C}_{2} \mathrm{H}_{6} \mathrm{O}+{ }_{2} \mathrm{CO}_{2} \text {. }
$$

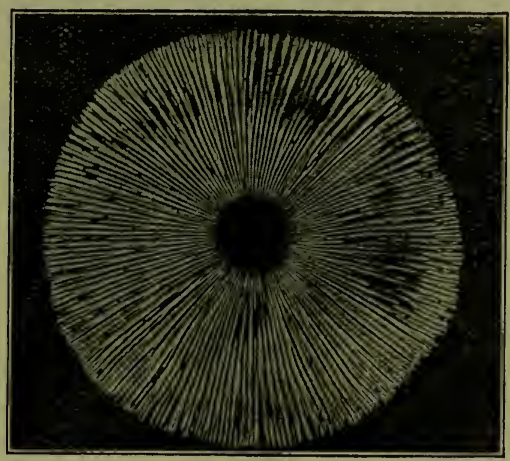

FIG. 196.-Spore print of a Mushroom. (Printed and photographed by Miss Ethel M. Doidge.)

In preparation of the Kaffir beer Leting, Miss Doidge has found that a mould (Mucor) effects the change from starch to sugar and can also ferment some of the sugar, forming some alcohol. When the Leting is fresh a bacterium causes an acid fermentation of the starch of the Kaffir corn thus producing a very wholesome drink which is not intoxicating.

Many of the rusts live part of their life as parasites on one host while to complete their life-history quite another host is necessary. 
Where do Mushrooms Bear their Spores?-Cut off the stem of a common Mushroom. Lay the cap carefully on a sheet of paper, gills downwards. After several hours there will be a pretty spore print on the paper. The fine powder is the spores. When the spores lodge in a place with sufficient moisture, they send out delicate white threads, which grow mostly underground, but you can see them on the surface under trees during the rainy season. They look like masses of wet cotton-wool. This is what Mushroom gardeners

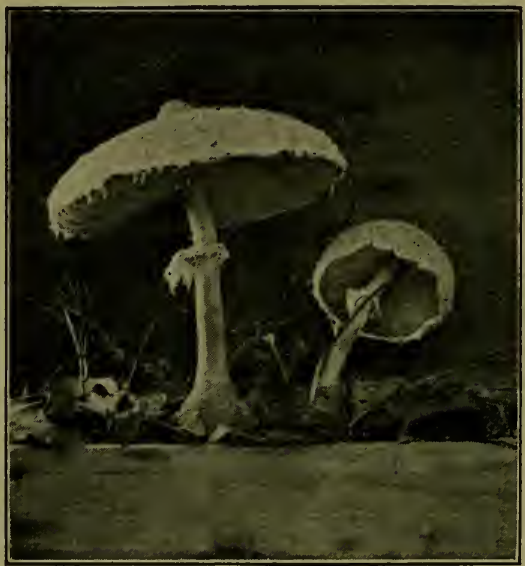

FIG. 197.-Photograph of a Mushroom (Amanita), showing the ring (annulus) and cup (volvit).

call spawn. It takes up moisture and food from the soil, and as it may grow underground for months, it is no wonder that when Mushrooms come they seem to "spring up in a night". They start as buttons on the spawn, and may get quite large before we notice them.

One common Mushroom, Psalliota campestris, which is often cultivated for the table, has pink gills (the spores are at first pink) which after a time turn brown. It has a white or brownish cap and a ring around the stem.

The Mushroom in Fig. 197 has a ring which shows on the upper portion of the stalks. This ring is the remainder of a 
veil of interwoven mycelium which was attached to the edge of the umbrella (pileus) and protected the gills. The stalk of this one stands in a cup which, like the ring, is the remains of a protecting veil. But this one extended over the cap. When the cap pushed through, parts of the veil made the rough patches on the cap. Do not eat this kind. The rough cap tells of the cup below, and a Mushroom is quite apt to be poisonous if it has a cup at the base.

Puff balls are a kind of Mushroom. When you

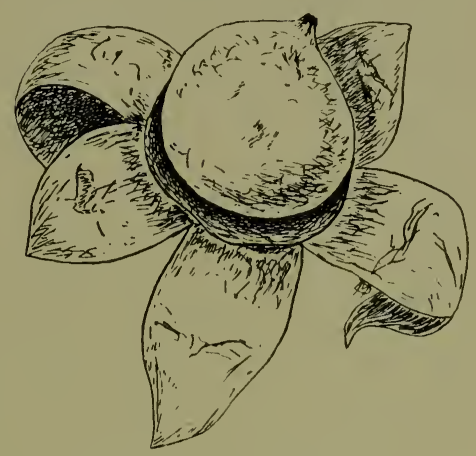

FIG. 198.-Geaster (earth-star). pinch them the spores come out in a cloud. The earth star is a pretty little puff ball, which looks like a star, and grows close on the earth in the spring. An outer cover or peridium splits back when the spores are ripe and forms the star.

C. BACTERIA.-These are minute organisms frequently known as "germs". They each have a distinct life history; and while they are generally under a ban as disease-producing, many are necessary in the economy of Nature. They are, like fungi, destitute of chlorophyll, yet they can live under a great variety of conditions, in either the presence or absence of light, air and organic matter.

\section{Division II.-BRYOPHYTA.}

'Two well-defined stages characterize this group, each one bearing reproductive bodies from which the other is derived. In this alternation of generations the stage which arises from the union of the sexual cells, the sperm- and the egg-cell, and bears the spores, remains dependent upon the stage which bears the sexual cells. It contains the liverworts and mosses.

LIVERWORTS are often flattened green plants, growing in 
moist kloofs and other damp, shady spots. One of the most familiar liverworts is Marchantia. It has a flat, leaf-like, forked thallus growing close to the soil. On the under side are thread-like rhizoids, which serve the purpose of roots. On the thallus are little cups, containing small green bodies. They are buds which grow from the bottom of the cups. They become loosened, and are washed out to other places, where they form new plants. Umbrella-like bodies are often to be found growing up from the thallus. These stalks are of two kinds. At the top of some are stars of nine or more rays. Others have round, scalloped tops. Sunken in them are clubshaped bodies called antheridia (anther-like). They contain many small nucleated cells (sperm-cells),
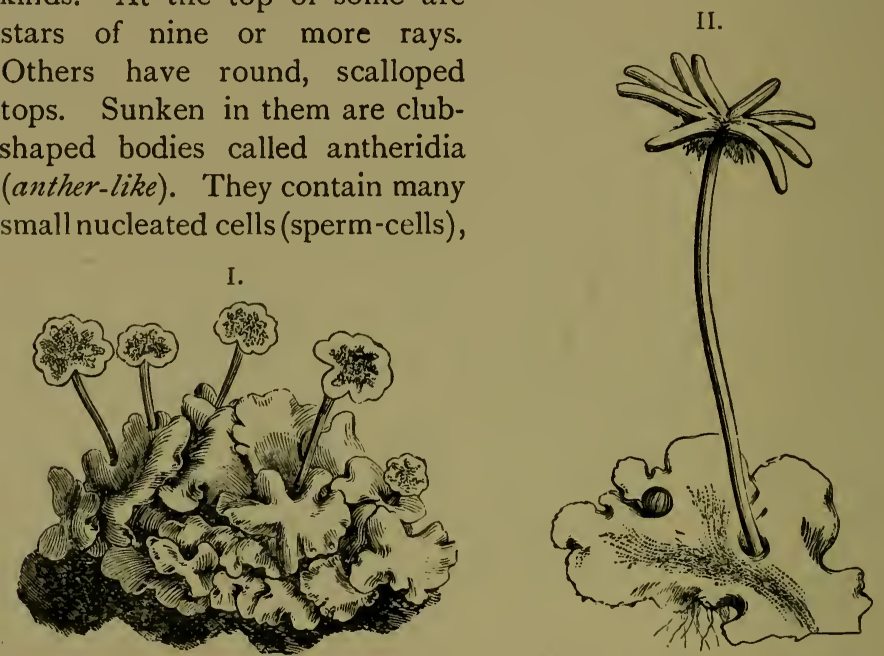

FIG. 199.-Marchantia polymorpha. I. Thallus with five anther-bearing umbrellas. II. Thallus with an umbrella bearing the egg pockets beneath. (From Thomé and Bennett's "Structural and Physiological Botany".)

which escape when the antheridia are ripe, and swim about by means of tiny lashes, cilia, attached to them. They are extremely small, and can only be seen by means of a microscope. Underneath the stars on the other stalks, protected by delicately fringed curtains, are bottle-shaped bodies, each containing an egg-cell. These are sought out by the sperm-cells, which unite with them just as the nucleus in pollen grains unites with the egg-cell in an ovule of higher plants. As a result of this union, 
the egg divides rapidly and forms a sporogonium, consisting of a sporangium borne on a short stalk which is attached by means of a foot to the umbrella from which it derives its nourishment. When ripe, the sporangium bursts and discharges a golden dust of spores. These are scattered by wind and grow to form new plants like those formed by the gemmæ, the gametophytic or sex-bearing stage.

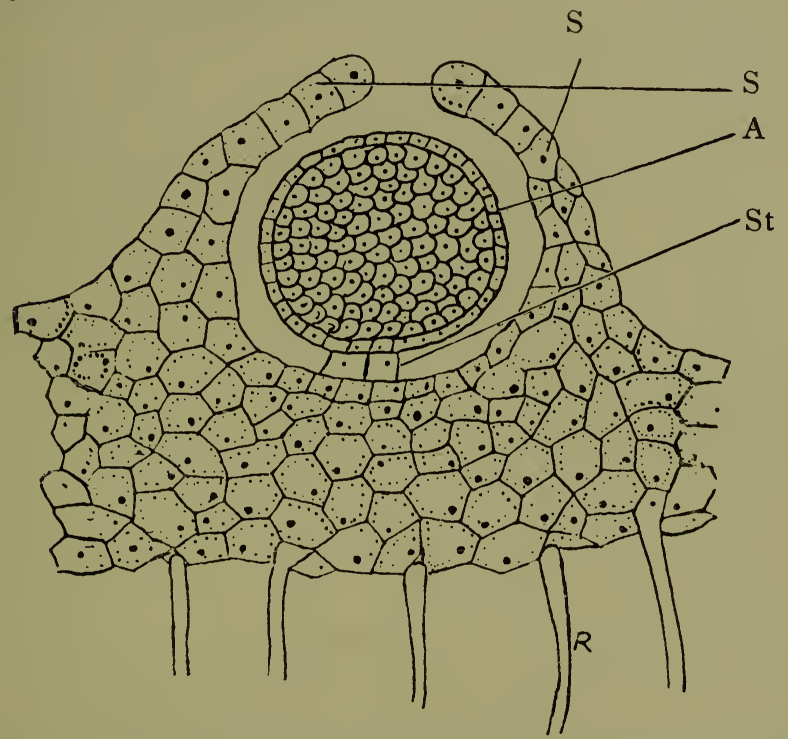

FIG. 200.- Transverse section through the middle portion of thallus of Pellia epiphylla. R, rhizoids; S, S, sheath; St, stalk of antheridium; A, capsule or head of antheridium (magnified). (From Evans' "Intermediate Text Book of Botany".)

Mosses, like liverworts, usually grow best in moist, shady places. We can find mosses on the ground under the shade of bushes and trees, or on the trunks of trees, but they grow best in moist woods or ravines. If no woods are near, look on thatched roofs, which are often beautifully green with moss on the shaded southern slope.

Mosses have leafy stems, and by examining the tips of these stems in early spring, sharp eyes, with a hand lens, can 
just detect in the tops of some of the stalks little bodies, sur-

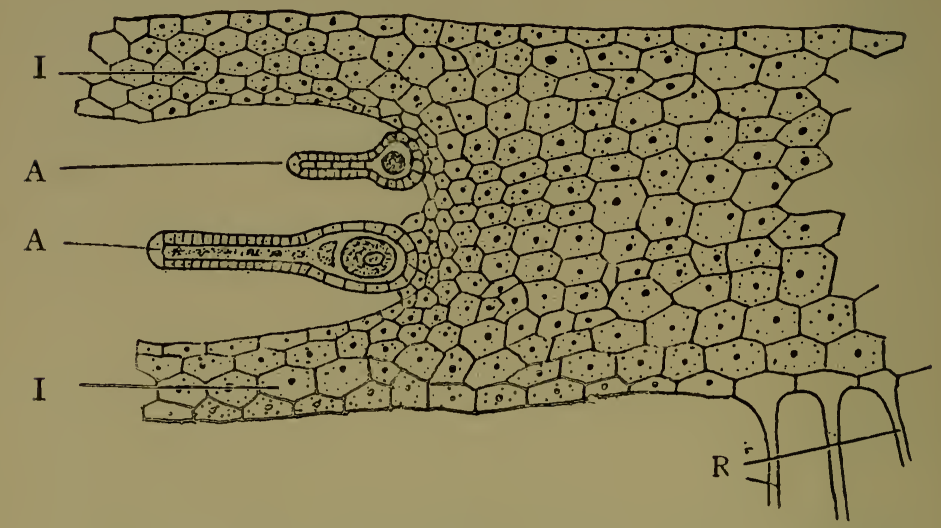

FIG. 20r.-Section of Pellia epiphvlla through an involucre. R, rhizoids ; I, I, involucre ; AA, developing archegonia (magnified). (From Evans' 'Intermedi ate Text Book of Botany".)

rounded by a rosette of leaves. These correspond to the antheridia of the liverwort.

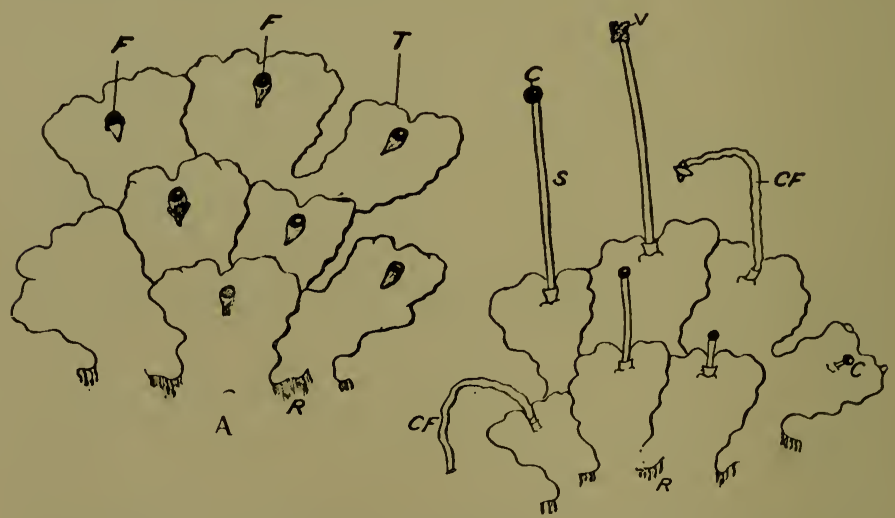

FIG. 202.- Pellia epiphylla. A liverwort with impergate sporangia. T, lobe ; $\mathrm{R}$, rhizoids ; F, fruits enclosed in calyptra ; $\mathrm{C}$, central slightly thicker layer; $C, C$, capsules; $V$, capsule open ; $C F$, collapse of seta after dispersal of spores. (Evans' "Intermediate Botany".)

The egg-cell pockets, archegonia, usually borne on 
separate stems, are more difficult to find. They are not surrounded by so conspicuous a rosette.

The sperm-cells escape, and swim to the egg-cells in much the same way as they do in Marchantia. When the egg-cells have become fertilized, they send up stalks, which are tipped by little capsules. You can find them in great numbers when the mosses are fruiting. Some of the capsules will have little hoods, the remains of the archegonia which have been carried up. Remove one. On the capsule is a small lid. Take it off with a needle. Under the lid is a mouth with a row of teeth. Breathe on them several times. What happens? They open and close. When ripe the capsule is filled with spores. They sift through the teeth during the summer, and when rain comes, or when they lodge in a moist place, they send out thread-like plants very much like an alga; it is from these threads that the leafy stems grow. ${ }^{1}$

\section{Division III.-PTERIDOPHYTA.}

Here too there is a distinct alternation of generations but in this division the sporebearing generation is the more conspicuous. It acquires stem leaves and roots and becomes quite independent of the gametophyte. The Pteridophyta include the ferns, the club mosses, and the horse tail or Equisetum, which is found in Eastern districts.

${ }^{1}$ The capsule with its stalk is the sporophyte. At the base of the stalk, the foot draws nourishment from the leafy part, the gametophyte. The two
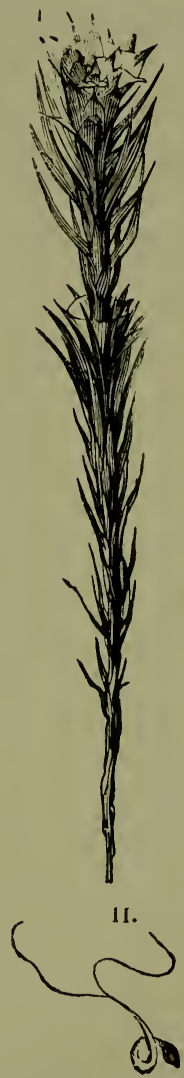

FIG. 203.-1. Moss plant. II. Swimming sperm-cell (m a g n i fi e d). (From Thomé and Bennett's " Structural and Physiological Botany".) generations, the one bearing the sexual cells and the other the spores, alternate with one another and exhibit what is known as Alternation of Generation in plants. 
Maiden Hair and most of the South African ferns have short creeping stems, but Cyathea of Natal, and the beautiful Hemitelia, of Knysna and the West, have woody stems which grow to quite a height.

On the under side of most fern leaves you will find brown spots. Some people cut their ferns down and burn them when they find them there, thinking that they are scale insects. When the spots get quite brown, gently shake a leaf over white paper. A brown dust will appear on the paper. These

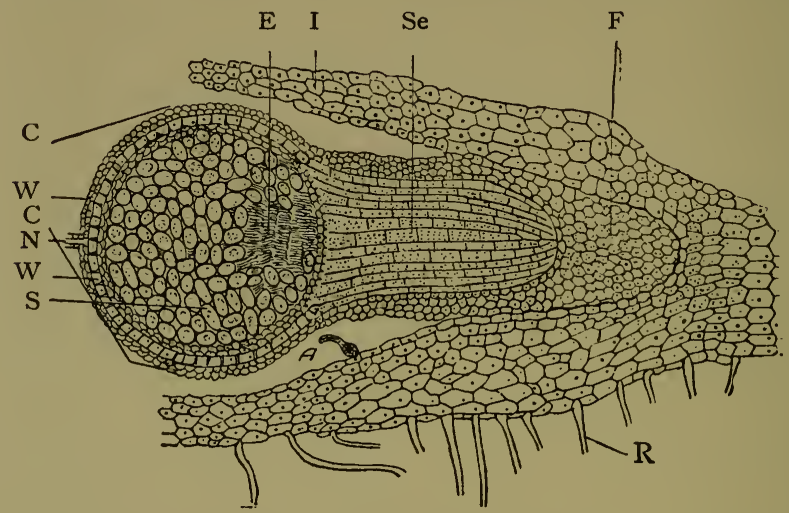

FIG. 204.-Longitudinal section through the sporophyte of Pellia epiphylla, $R$, rhizoids ; I, involucre ; F, foot of sporophyte ; Se, seta ; C, capsule ; W. wall of capsule; Wa, wall of archegonium ; $S$, spores; $N$, remains of neck of archegonium ; A, unfertilized archegonium (highly magnified). (From Evan's "Intermediate Text Book of Botany".)

are the fern spores, contained within clusters of spore-cases forming the dots. A dot is called a sorus (plural, sori). When the spores are ripe and have fallen in moist places, they burst their brown walls and begin to grow. In a few weeks a spore will grow into a filmy, green, heart-shaped plant. Look under the shelves of greenhouses or on the outside of pots in which ferns are growing. They are often abundant there. People call them "Moss," but we know that moss leaves are borne on stems. Each one of these plants grows by itself.

How Does the Fern Plant Come?-On the under side of the plants which are called prothallia are rhizoids and 


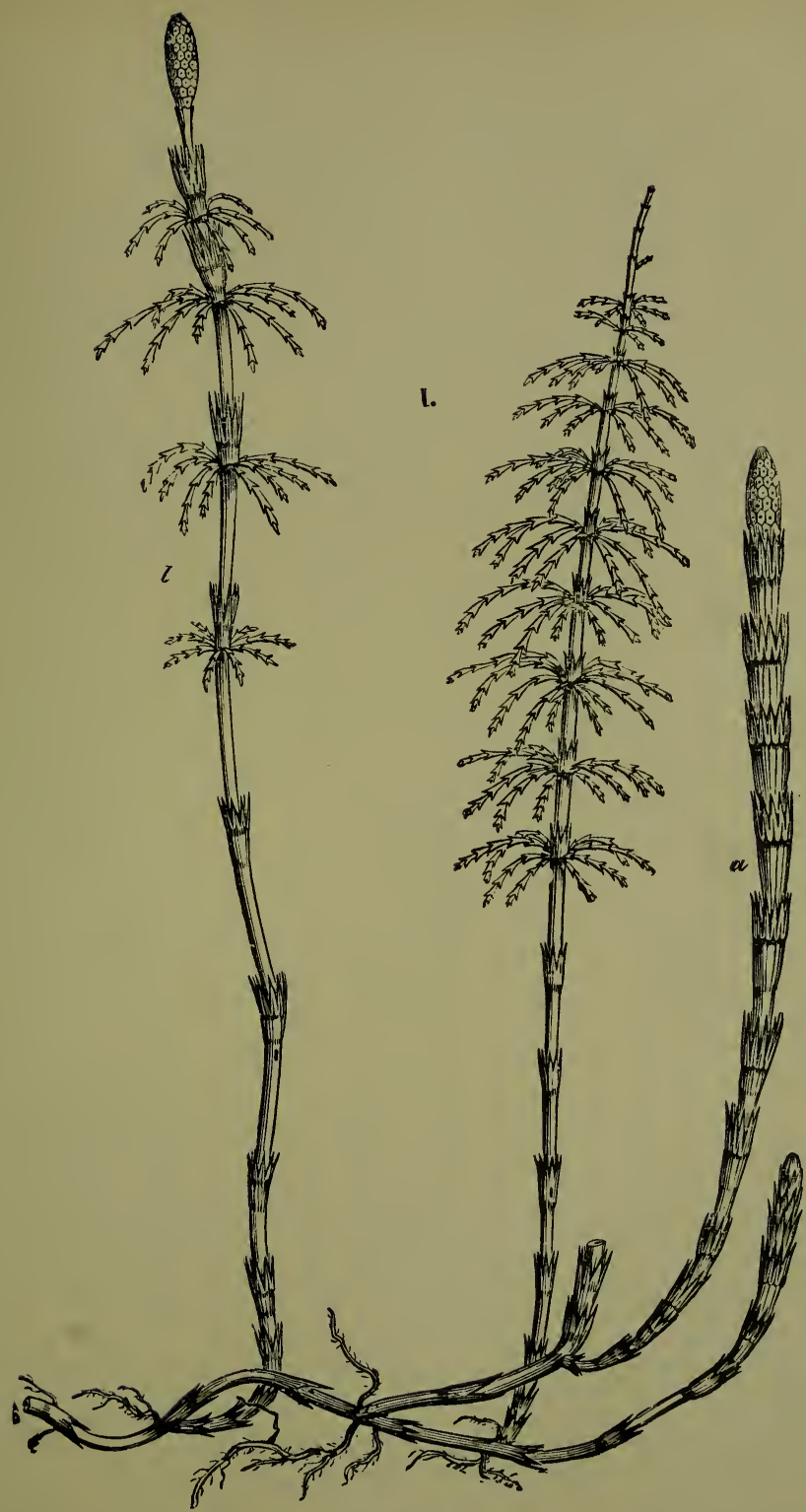

FIG. 205, I. - Equisetum sylvaticum ; a , a fertile shoot, not containing chlorophyll, bearing the sporangia at its summit; $b$, a fertile green shoot; between these a sterile green shoot (reduced); these three kinds of shoots do not always occur. 
two kinds of sexual organs, resembling those in the liverwort and the moss. Archegonia containing the germ-or egg-cells are near the notch in the prothallium; antheridia containing the sperm-cells are down near the point among the rhizoids. A sperm-cell swims into the archegonium, unites with the germ-cell, and then the germ-cell grows into a leafy fern plant, just as the stalked capsule of the moss grew out of the pockets hidden among the leaves. The fern plant, though,

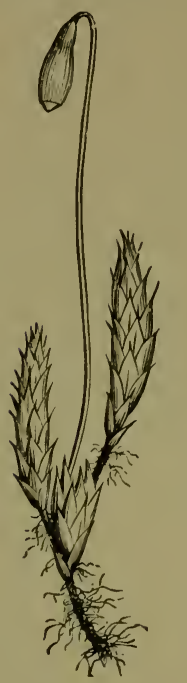

I. forms roots and can soon take care of itself, while the moss capsule always depends upon the leafy part for its food. In the liverworts, mosses, and ferns, the germ-cell has to swim to reach its sperm-cell, but the spores are borne up into the air, and are scattered by the wind.

In the ferns and all more highly developed plants, the sporophyte is the conspicuous leafy generation.

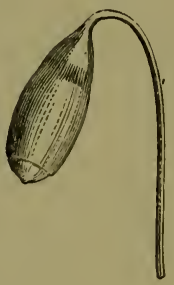

II.

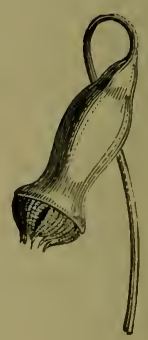

III.

FIG. 206.-I. A moss plant (Bryum argenteum). II. Capsule enlarged. III. Capsule open for the spores to escape. (From Thomé and Bennett's "Structural and Physiological Botany ".)

The higher plants also have two generations, but the generation corresponding to the prothallium of the fern is hidden away, partly within the seed and partly within the pollen grains. The sperm-cells are contained in the pollen, and are carried down in the pollen-tube. By this time they have lost the power of swimming.

Osmunda regalis, L. is a stately fern also extending across South Africa. The fruit-bearing part is quite distinct from the leafy part, forming a plume-like panicle.

Schizea pectinata, Sm. is a curious fern, which might 
easily be mistaken for a grass. The frond or leaf is just a wiry stalk with very small comb-shaped lobes at the top.

Unlike so many ferns which thrive best in shady ravines, it can grow in very dry, hot situations. It is found on mountain tops and down nearly to the sea level.

Gleichenia may be distinguished from all other South Africa ferns by the dichotomous branching of the fronds. In the Knysna forests it climbs gracefully up the banks, ten or twelve feet high.

Hemitelia capensis, Br., the tree fern, the most beautiful fern in South Africa, extends from Table Mountain to Natal.

Pteris aquilina, L. grows commonly on hills.

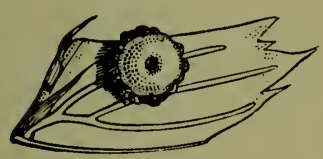

I.

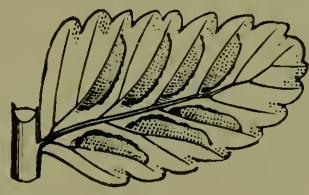

II.

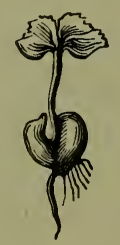

III.

Fig. 207.-Pinnæ of fern leaves. I. Aspidium with a single sorus; the spore cases may be seen around the edge of the indusium. II. Asplenium with several sori. III. A young fern plant growing from the heart-shaped prothallium. (From Thomé and Bennett's "Structural and Physiological Botany ".)

The spore cases of Pteris are continuous along the margin of the leaf, which is folded over to protect them.

Lomaria capensis, Willd., a large coarse fern with ropelike spreading stems, may be known by the whole under surface of the fertile fronds being covered with fruit-dots.

Hymenophyllum and Trichomanes are found in deep ravines, washed by the spray of waterfalls. The beautiful little fronds are almost transparent, and the delicate creeping stems are like threads. The spore-cases are clustered on a stalk, enclosed in a tubular or cup-shaped indusium. The indusium of Hymenophyllum is deeply two-loped. That of Trichomanes is not slit, and the fronds are less divided. 
Adiantum, the Maiden Hair, may be known by the slender, black leaf stalks and the fan-like veining. The sori are on the margins of the fronds, and the recurved edge of the frond forms an indusium. The sori are not continuous, as in Pteris.

Selaginella belonging to the group Lycopodinea (Club mosses) is frequently seen in greenhouses. Several species are native to South Africa. At

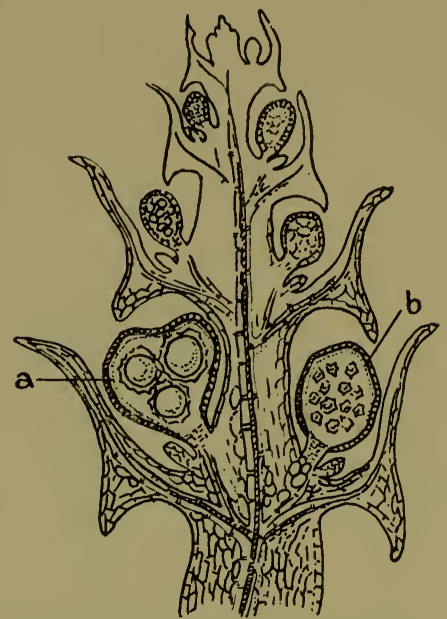

FIG. 208.-Longitudinal section through a cone of Selaginella. a, macrosporangium ; $b$, microsporangium. the tips of the branches sporangia are clustered to form a cone. In some sporangia only one of the many spore mother-cells develops, so that when ripe they contain only four large spores each (megaspores). Those in which all the spore mothercells develop contain a large number of small spores (microspores). The megaspores germinate within the sporangium each forming a prothallium much more reduced than that of the fern, in fact the cells barely emerge from the ruptured spore wall, where a few archegonia are formed. The prothallium formed from the microspore is still more reduced and consists of a single cell. But one antheridium is formed which produces several sperm-cells.

After fertilization, an embryo is developed from the eggcell which for a time derives its nourishment from the small prothallium. Later, like the fern, it forms roots and becomes an independent plant.

The life history of the fern may be shown by the diagram below :- 
Prothallium
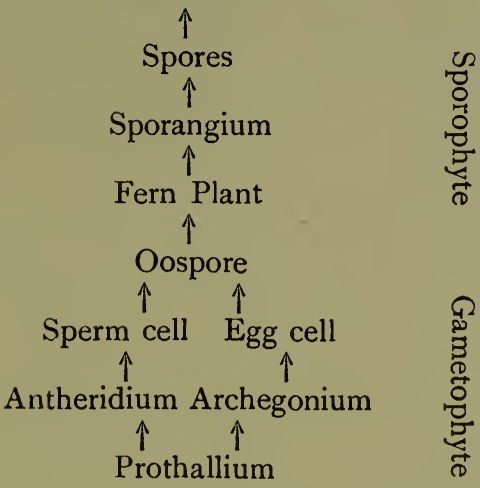

Spermaphyta or Seed-Bearing Plants.

Although seed formation was given as a distinguishing character of Spermaphyta, the nucellus of the ovule may be compared to the megasporangium of Selaginella, where how-

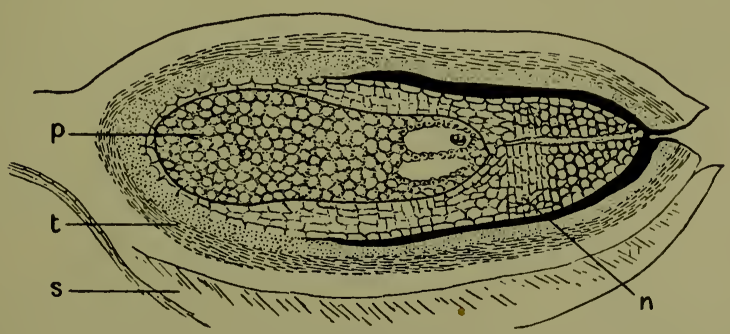

FIG. 209.-Longitudinal section through an ovule of Pinus ready for fertilization. $t$, testa showing middle hard layer; $n$, nucellus. A microspore has lodged within the micropyle and the pollen tube has nearly reached the prothallium; $p$, prothallium (endosperm) filling the macrospore (embryo sac). Two archegonia are seen at the micropylar end, one containing an egg cell ; $s$, scale bearing the ovule.

ever the spore output is still more reduced, as a rule.in Spermaphyta only one megaspore of one spore mother-cell develops. This was named the embryo sac before comparison revealed the homology with the lower forms. 
In Gymnosperms, of which Pinus may be taken as a type, the nucleus of the megaspore divides to form a mass of cells, the prothallus or endosperm. This forms several (three or four commonly in Pinus pinea) arche-

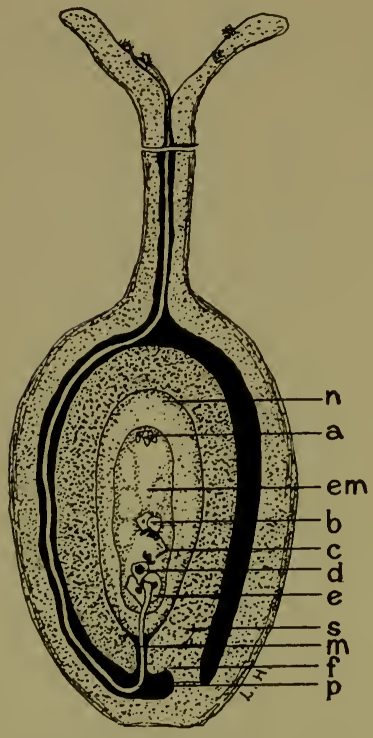

FIG. 210.-Diagrammatic view of ovary of a Dicotyledon containing one erect, tasal, anatropous ovule. The pollen tube has discharged its two nuclei. n, nucellus ; em, embryo sac ; $a$, antipodal cells; $b$, two polar nuclei which unite to form the central or definitive nucleus ; $e$, egg apparatus with sperm cell applied to the egg cell, $d ; s$, seed coat ; $c$, nuclei discharged by the pollen tube; $f$, funicle ; $p$, pollen tube which has entered through the micropyle. gonia at the end toward the micropyle.

In Angiosperms the nucleus of the megaspore typically divides into two, which pass to opposite ends of the spore. These each divide twice, forming four nuclei at each end. Of these, three at the micropylar end form the egg apparatus, the largest of the three becoming the egg. Of the four at the opposite end, three surround themselves with walls. They are regarded by some as constituting a rudimentary prothallus and by others as a second egg apparatus which no longer functions as such. One of the four nuclei at each end passes to the centre of the megaspore. These fuse and after fertilization, this, the secondary nucleus develops the endosperm.

It is an advantage for the megaspore to remain enclosed by the food-storing cells of the nucellus, but a serious problem now presents itself : How is the spermcell to reach the egg ? In the lower types they did so by swimming. But obviously swimming would avail little under present conditions, and it has become practically a lost accomplishment of the sperm-cells of Spermaphytes. The difficulty has been surmounted by the microspores (pollen grains). These have 
developed the pollen tube mentioned on p. I59. When the pollen tube reaches its destination in an angiospermous ovule (Fig. 2ro) it discharges two nuclei which it has brought the entire journey. One serves as a sperm nucleus. For a long time the fate of the other was a mystery. It was finally found in many angiosperms to fuse with the secondary nucleus, thus taking part in the formation of the endosperm.

Another remarkable discovery revealed the fact that in some Gymnosperms of the Cycadales and in Ginkgo (the Maiden-hair tree) the sperm cells have not quite lost the feat of swimming, but after the pollen tube has discharged them in a depression, the archegonial chamber, the sperm cells

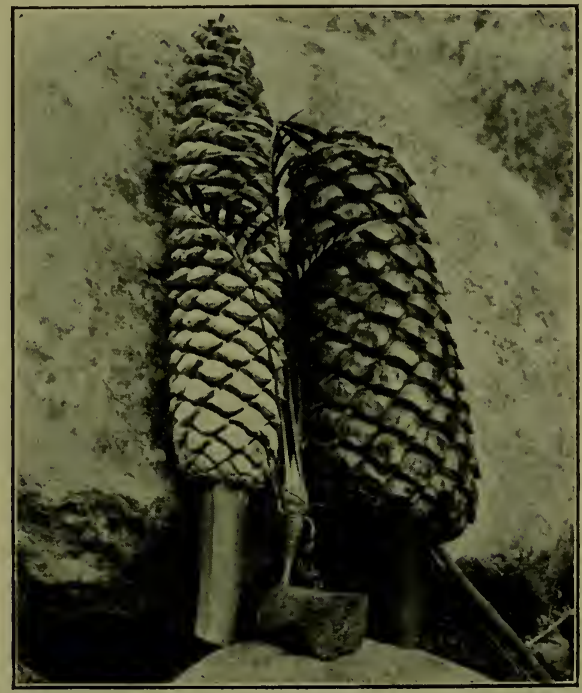

FIG. 2II.-Encephalartos villosus, Lehm. Staminate cone, left side. Ovulate cone, right side. "Seedling perhaps two years old" (Miss Pegler).

swin in a liquid discharged from the pollen tube and enter the archegonial necks by their own activity. This fact is of especial interest in showing the relationship between the higher and the lower plants. 
Division IV.-Gymnosperms.

Gymnosperms are woody plants storing resin or mucilage. The flowers are diclinous (male and female separate), and the plants are either monœcious or diœcious. ${ }^{1}$

Three orders of Gymnosperms are found in South AfricaCycadaceæ, Coniferæ, and Gnetaceæ. These orders include five genera.

CycadaceÆ.-The two South African genera of this order are often mistaken for tree ferns or palms, until the large cones a foot or more long are seen among the crowns of pinnate leaves. Spirals of rigid scale leaves alternating with foliage leaves also serve to distinguish Cycadaceæ.

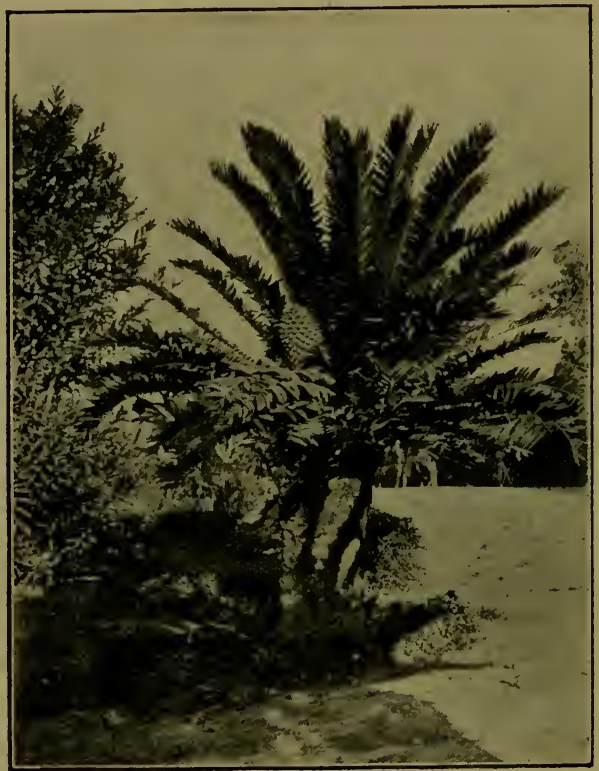

FiG. 212.-Encephalartos villosus, Lehm. (Photograph by P. S. Laney, Esq.)

Encephalartos.-Stem cylindrical; pinnæ of the leaves without midrib, finely parallel veined.

Santgeria.-Stem short, swollen; pinnæ midribbed with forked veins.

1 Staminate and pistillate flowers on the same plant or on different plants. 
Encephalartos (Zamia).-The stamen-bearing cones are long and slender, and the scales are covered on the under surface with microsporangia. These are arranged in sori, reminding us of the ferns. The ovule-bearing cones are shorter and thicker, each scale bearing a pair of ovules. The thick unbranched trunk, rough with the bases of fallen leaves, has a palm-like appearance.

There are twelve species found in the Eastern Province and Natal. They are found along ledges in ravines, and extend as far west as the Kroome River. They form quite a special feature of the Fish River Bush, and extend from near the sea-level to an altitude of 5000 feet.

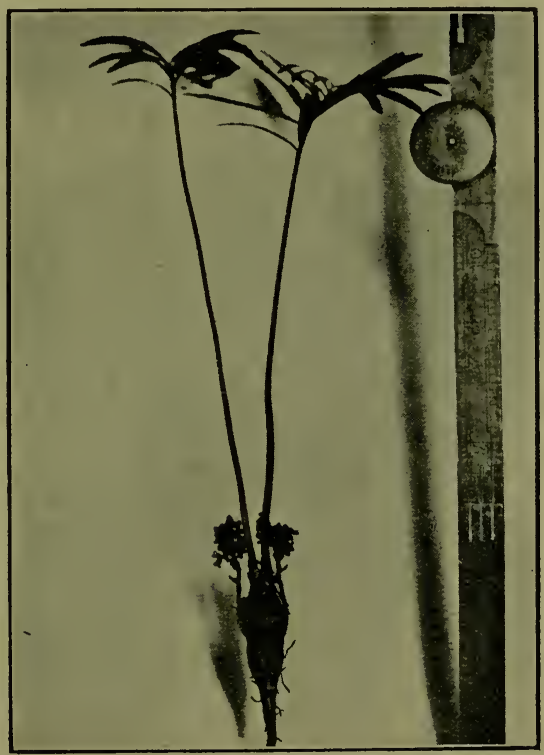

FIG. 213.- Young plant of Encephalartos villosus, Lehm. Showing apogeotropic breathing roots. By kindness of Miss Pegler. (Photograph by P.S. Laney, Esq.)

Stangeria is a curious plant, with a few leaves crowning its turnip-shaped trunk. The feathered venation of the leaves distinguishes them from those of Encephalartos. It dwells in Natal, and comes as far south as Lower Albany. 
The Cycadaceæ come of a very ancient lineage, for their fossil forms are found in older rock formations than those of any of their living Gymnosperm relatives.

A xerophytic character of these plants is the well-developed underground stem system by which vegetative reproduction

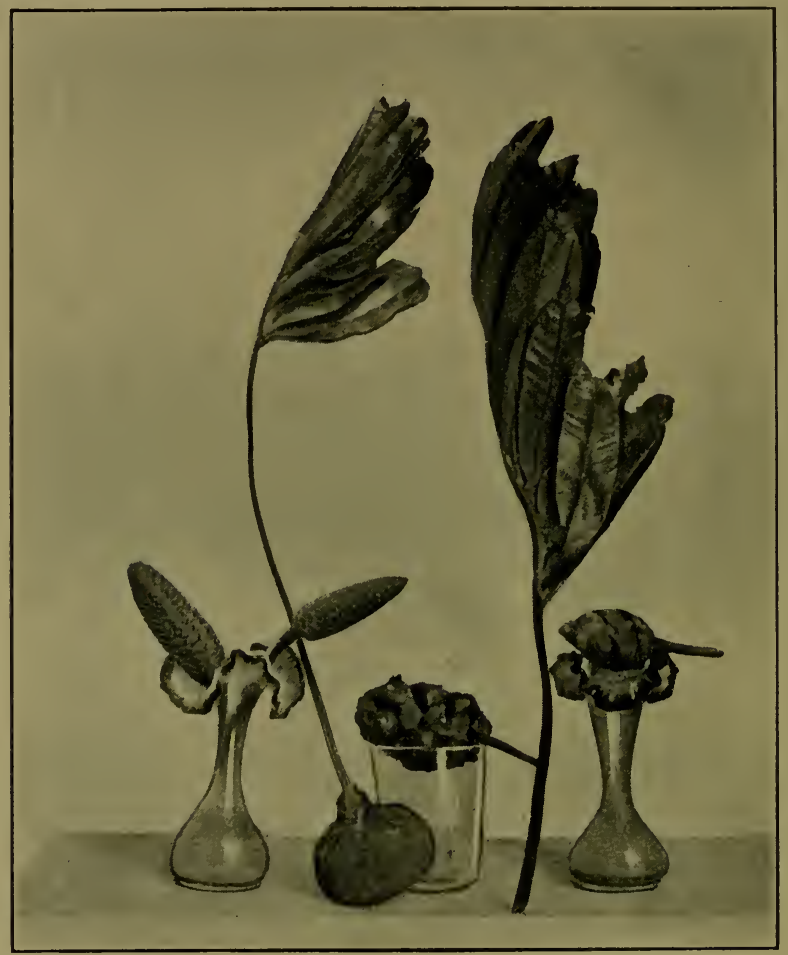

FIG. 214.-Stangeria zeyheri. Showing the feathered venation.

is secured. A curious feature is shown in Fig. 2I3. From the upper portion of the tap root, roots are given off which grow directly upward (apogeotropic). These contain within their cortex small blue-green algæ which may assist in the respiration of the roots.

The cones of $E$. Friderici Guilielmi, Lehm., which grows 
near the Thomas River, are thickly covered with wool. A beetle belonging to a very ancient family, Phlæophagus by name, frequents the cones and may assist in distributing pollen.

ConifERæ.-Unlike the Cycadaceæ, the Coniferæ have much-branched trunks and small simple leaves.

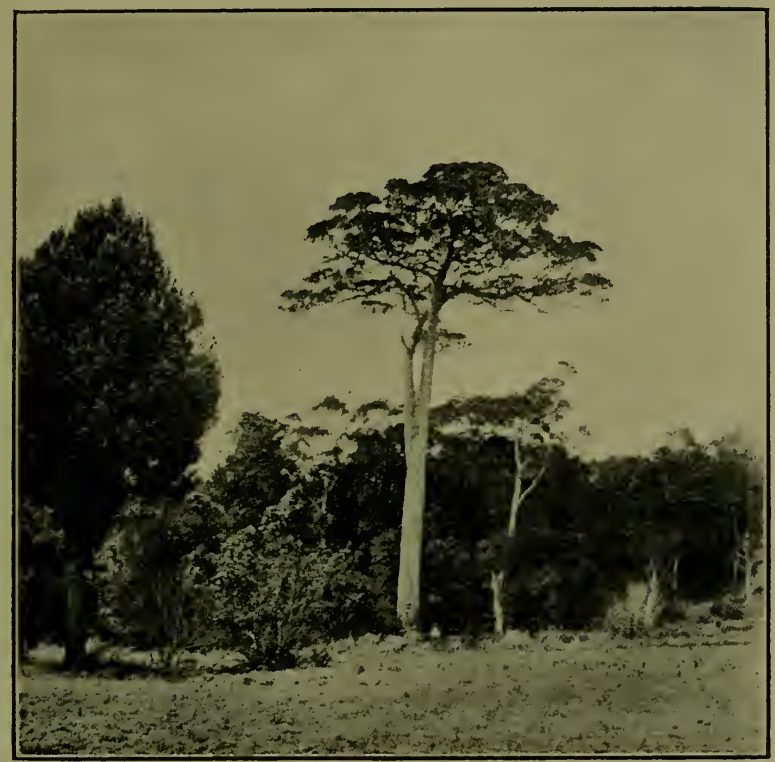

FIG. 215.-Podocarpus elongata, L'Her. Outeniqua Yellow Wood. (Photograph by Mr. Zahn Knysa.)

Podocarpus, or Yellow Wood, is the monarch of the eastern forests, attaining a height of 50 to 80 feet.

The stamen-bearing catkins are about an inch in length. The ovule flower is reduced to a single ovule borne upon a scale. (There is a scale facing this one which sometimes bears an ovule.) The cones are reduced to their lowest terms. These fleshy scales form the receptacle for the drupe-like fruit with its fleshy covering and hard middle layer of the coat.

P. thunbergii, Hook. (true Yellow Wood) has lanceolate, shining leaves and dark blue receptacles. 
P. elongata, L'Her. (Outeniqua Yellow Wood) has narrow leaves and a small crimson receptacle. These monarchs of the East attain a girth of 30 feet and some are estimated to be a thousand years old.

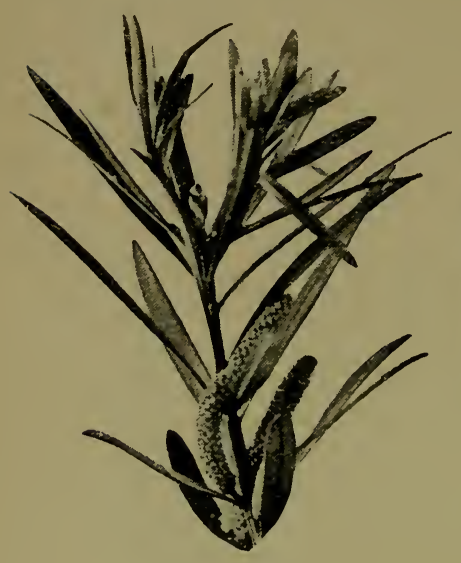

I.

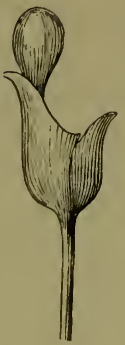

II

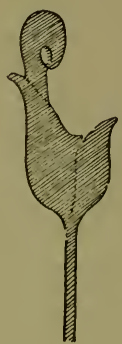

III

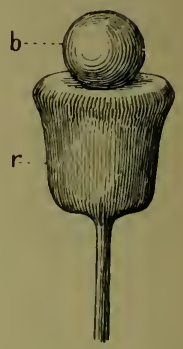

IV

FIG. 216.-Podocarpus econgata, L'Her. I. Branch $\left(\frac{1}{2}\right)$ with three stamenbearing spikes. II. Ovule-bearing scale. III. Section through the latter, showing one ovule. IV. Ripe pseudocarp : $r$, fleshy receptacle; $b$, seed enclosed in green resinous scale. (From Edmonds and Marloth's "Elementary Botany for South Africa ".)

Widdringtonia is the other genus of this order in South Africa. It extends from Natal to the mountains of Clanwilliam, where it is found at its best. In the East it grows five or six feet high. The leaves are needle-shaped, becoming scale-like in the older plants. The cones are large and hard, formed of a few woody scales. The winged seeds of the tree may account for its wide distribution, although its range of altitude is limited, as it is generally found growing on mountain heights.

The "Firs" which belong to the order Coniferæ are native to the Northern hemisphere. The extensive fir plantations on the slopes of Table Mountain show that the soil is no less congenial to them than that of their ancestral homes in Southern Europe. Pinus pinea, the Stone Pine, and $P$. pinaster, the Cluster Pine, are the species usually found in plantations. The annual rings of some trees cut on the market-place at Cape Town indicated an age of 209 years. ${ }^{1}$

${ }^{1}$ Dr. F. C. Kolbe. 
The order Gnetaceæ is represented by Gnetum and Welwitschia. Welwitschia is well adapted for its life in the Damaraland desert, to which it lends an additional weirdness. The trunk is very short, sometimes two or three feet thick, and grows mostly under the soil. The large tap-root extends deep down in the sand. It has but two leaves besides the cotyledons six feet or more in length, which become split into narrow shreds as they are lashed by the wind. Like other leaves found in deserts, they have a very thick cuticle. The large two-lobed summit of the trunk bears the crimson cones. The fruiting cones are about 2 inches long.

The staminate flowers have a four-parted perianth and six stamens surrounding a reduced ovule. The pistillate flower has a tubular perianth and contains an exposed ovule.

\section{Division V.-ANGIOSPERMS.}

\section{Sub-class I.-Monocotyledons.}

\section{Order TyPнace $Æ$.}

This order which contains the single genus Typha (Cat's tail Bulrush) is placed, in the Engler system, among the most primitive of the Monocotyledons. The erect stem arises from a thick rhizome and bears a dense velvety inflorescence of pistillate flowers with staminate flowers above. Each flower is surrounded with a number of hairs. Stamens 2-5; carpels with one pendulous ovule. Fruit an achene covered with hairs which aid in its distribution. The flowers are wind pollinated.

The incomplete and imperfect flowers, the single genus and the few species (I2) attest to the ancient lineage of this order. It is found in fossil form in Tertiary times. Fossils of dicotyledons are, however, found before this.

Order Cyperace 2 , the Sedges or Nut Grass Family.

This family consists of tufted wiry grass-like plants with creeping grass-like sympodial rhizomes. Stem 3-angled and 
244 Plants and their Ways in South Africa

solid. Leaves all 3-ranked with an entire sheath. Flowers
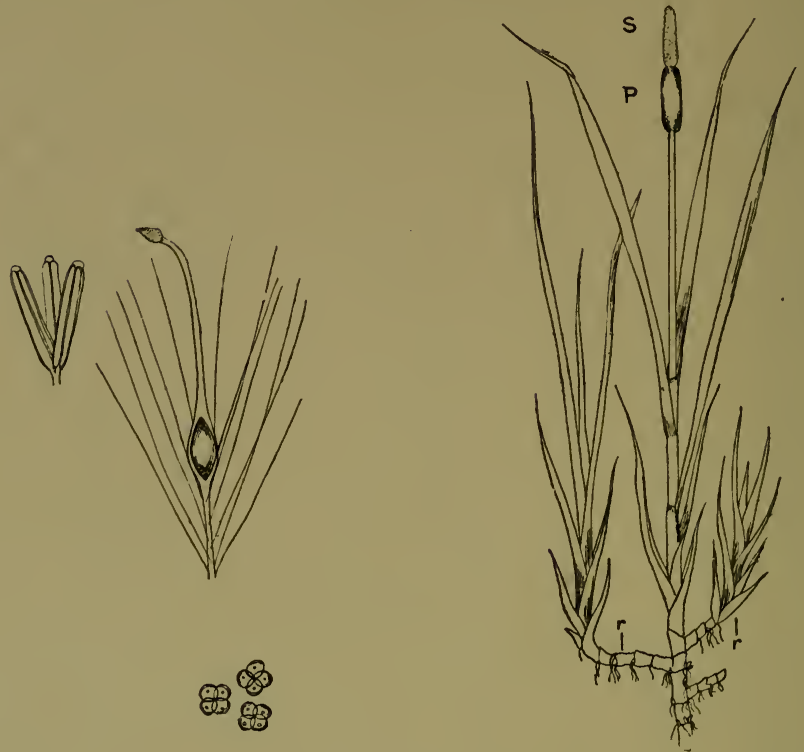

FIG. 217. - Typha (reed-mace, cat's tail, bulrush). I. showing habit of plant ; $r$, rhizoids; $s$, staminate; $p$, pistillate portion of inflorescence. II. staminate. III. pistillate flower. IV. pollen grains cohering in tetrads.

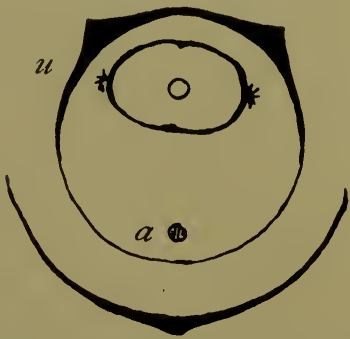

FIG. 218.-Unisexual flower of Carex (after Eichler); $u$, utricle ; $a$, axis.

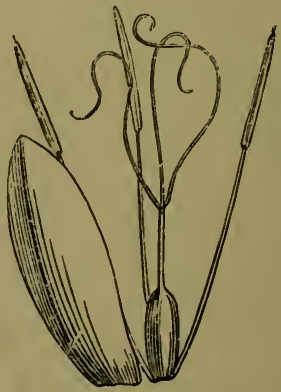

FIG. 219.-Flower of Cyperus, with the parts separated.

in the axils of glumes; perianth of bristles, hairs, or none, 
in spikelets. Stamens 3 ; anthers basifixed, 2-celled; ovary I-celled; fruit an achene.

Cyperus.-Glumes in two ranks. C. textilis, Thunb. (Matjesgoed), is used for thatching and baskets. The tubers of $C$. esculentus, Drege., are eaten by natives of the north.

I.

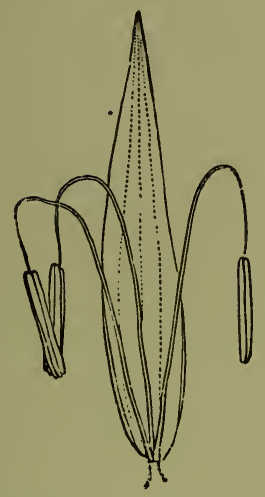

II.

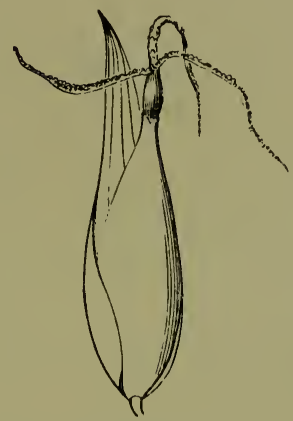

FIG. 220.-I. Staminate flower. II. Pistillate flower of Carex. (From Thomé and Bennett's "Structural and Physiological Botany.")

Carex.-Glumes overlapping, placed all around the stem. The flowers are usually imperfect.

Order Graminace

Stem cylindrical or compressed (not 3 -angled), hollow (not in Indian corn or sugar cane), with solid nodes. Leaves 2 ranked, sheath split, ligule present. Flowers in the axils of glumes; perianth of two minute lodicules; stamens 3 (sometimes 6); anthers versatile. Fruit an achene (caryopsis).

The number of genera of this large order found in South Africa is not great. In temperate regions grasses are low and spreading; in tropical countries the canes and bamboos form tall forests; while in dry regions grasses usually grow in tufts, which allow the bare ground to be seen between them.

This order is one of the most important groups of plants. To it belong all the grains-wheat, rye, barley, oats, rice, and 
millet. The sugar obtained from sugar-cane and the pasturage afforded to stock are among the benefits conferred on mankind by this order.

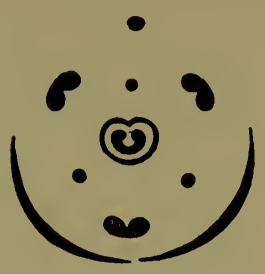

FIG. 221.-Floral diagram of meadow grass, Poa annua.

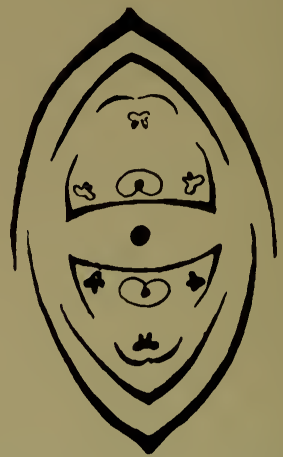

FIG. 222.-Floral diagram showing two flowers of Avena.

These plants are of world-wide distribution, and are well fitted for their battle in life. The bracing roots and hollow stems help to support the weight of grain, which becomes heavier by careful selection of seed in cultivation. When beaten down by heavy rains, the lodged grain is brought up

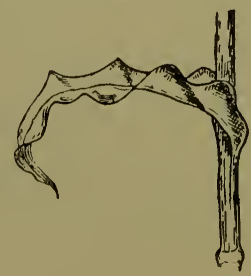

I.

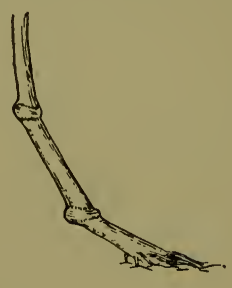

II.

FIG. 223.-I. Fluted leaf of Zea mays, L. II. Stem, straightening up after a storm.

from the ground by means of an unequal growth of the stem at the nodes. Just as the hollow stem gives strength, so the hollow leaf-sheath is able to withstand great force brought to bear upon the leaves by the wind. The split sheath and fluted edges of the lower part of the blade allow the leaves to wave 
in the wind without danger of breaking. The out-growth called the ligule at the union of the sheath and blade turns off the water caught by the leaves, which is led down to the fibrous roots. The stomata are protected in the creases of the stems and leaves, and by the leaves rolling up in dry weather.

Briza maxima, L., the pretty quaking grass, will be good for studying the flowers, as it is found so generally distributed. The oval spikelets are borne in racemes or panicles. They nod gracefully on slender pedicels, whence the name, meaning, in Greek, to slumber. At the lower end of the spikelet are two short green glumes of unequal size, with 5-7 nerves. They are keeled, that is, like the bottom of a boat. They have no flowers in their axils, but protect the whole spikelet. The glumes above them all contain flowers. For each flower there is one outer heart-shaped rounded glume, also keeled, and an inner, much smaller, flat, and two-nerved glume or palea (the flowering glumes are called paleæ to distinguish them from the

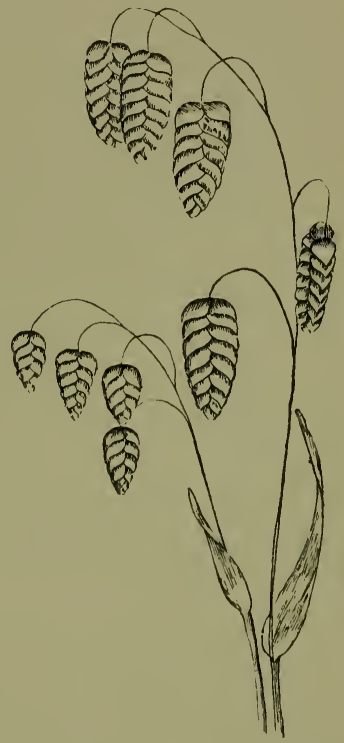

FIG. 224.-Hanicle of Briza maxima, L. (After "Botanical Magazine".) empty glumes), which clings closely to the grain. When the three stamens are ready to shed their pollen, the glumes open, and the slender filaments hang out the swinging anthers. The ovary has two feathery stigmas. Between the ovary and the outer glume there are two very small bodies called lodicules.

In the bamboos there are three lodicules longer than the ovary, which suggests that the grasses may once have had a perianth.

Large as the order is, the flowers are very similar in the different genera. The outer glume is awned in the Oat (Avena); that is, it has a long twisted spike extending from the midrib. The awn is common to other genera. Rice has 6 stamens. In Coix, "Job's Tears," and Maize the flowers are monocious, The stamens here are toward the top of the 
panicle, and the pistillate flowers below. In Maize the stigma is neither branched nor feathery nor is the stem hollow. When the seed is shed,

I.

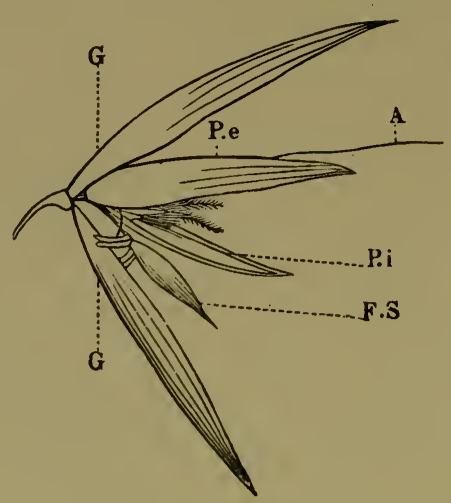

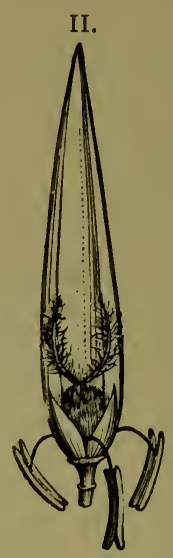

FIG. 225.-I. Expanded spikelet of the Oat, with a fertile and barren flower, FS ; G, glumes ; Pe, outer pale, with awn, A ; Pi, inner pale ; within are the feathery stigmas. II. Fertile flower with outer pale removed. (From Thomé and Bennett's "Structural and Physiological Botany".)

the spikelets in some genera break off just above the empty glumes, sometimes below them.

Tricholæna is a beautiful grass with soft silky glumes. In Tricholana rosea, Nees, the glumes are rose-coloured.

Phragmites communis, Trim., is a common reed used for thatching.

Coix lachryma is a curious but pretty grass. The pistillate flowers are enclosed in a hard bony involucre; the flowers containing stamens are borne on a stalk up through an opening in the top of this bead-like involucre. The popular name of this grass is "Job's Tears".

\section{Order Restiace龙.}

This order is frequently confused with the grasses, A comparison of the two will show how they differ, 
Restiacea.

Flowers diœcious.

Perianth of 6 glumes in two whorls.

Anthers I-celled. (In S. A. genera.)

Ovary 1 to 3 -celled, dehiscent or indehiscent.

Ovule pendulous orthotropous.
Graminacea.

Flowers perfect or monœcious.

Perianth (?) of two or three lodicules.

Anthers 2-celled.

Ovary I-celled, indehiscent.

Ovule, erect anatropous.

Both grasses and Restiaceæ have leaves with split sheathes. The blade of the leaf in Restiaceæ usually falls, leaving the sheath.

The Restiaceæ are much more difficult to determine than the grasses or sedges, as the different species grow intermingled on the veld, and it is difficult to determine which staminate plants fertilize a given pistillate form. To add to the difficulty, the inflorescences are different in the pistillate and staminate flowers of the same species.

Like the rushes, ${ }^{1}$ they grow most luxuriantly in moist places, especially along the rivers' edge, where they reach a height of 6 to ro feet. The Restiaceæ are found in Australia and South Africa, where they are most abundant in the western portion. A few are found in New $Z$ ealand and Cochin China. One species is found in Chili. The order contains eleven genera, of which the following six are the most familiar:-

Fruit dehiscent.

Restio . . . . . Sheaths persistent.

Dovea . . . . . Sheaths deciduous.

Fruit indehiscent. Flowers in dense spikes.

LEPTOCARPUS . . . Fruit angular.

THAMNOCHORTUS . . . Fruit flattened.

Pistillate flowers solitary.

Hypodiscus . . . . Flowers on a fleshy stalk.

Elegia . . . . . Flowers in panicles.

${ }^{1}$ They differ from the true rushes, Order Juncaceæ, to which Palmiet belongs (Prionum palmita, E. Mey). This plant is the large rush with the thick black spongy stems and leaves something like a pineapple. It sometimes nearly fills rivers, 
250 Plants and their Ways in South Africa

I.

II.

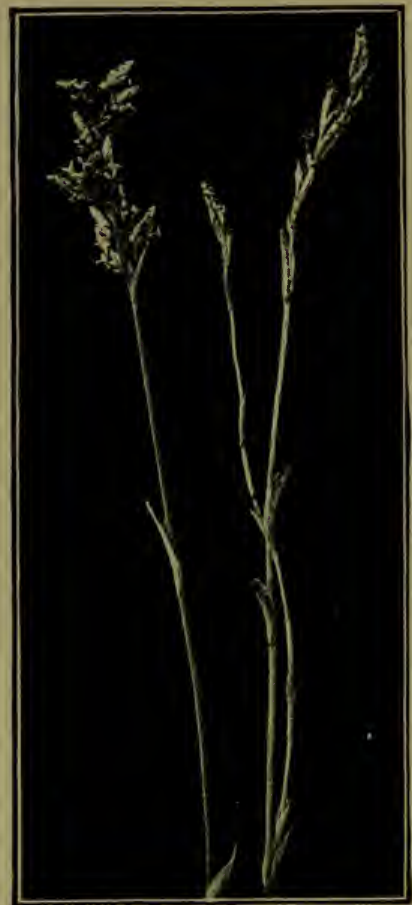

III
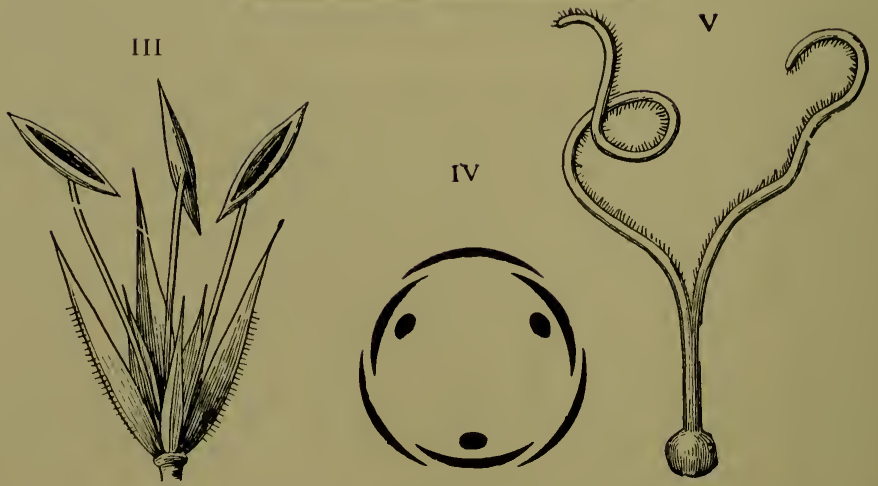

FIG. 226. - Restio cuspidatus, 'Thunb. I. Stamen-bearing plant (I12). II. P istil-bearing plant $\left(I_{12}\right)$. III. Staminate flower $(\times 4)$. IV. Diagram of staminate flower. V. Pistil $(\times 4)$. (From Edmonds and Marloth's "Elementary Botany for South Africa ".) 


\section{Order Commelinace $Æ$.}

This order consists of a few genera of creeping or spreading herbs with sheathing leaves and jointed stems. The flowers wither quickly, and, unlike most monocotyledons, the calyx is green and the corolla only is coloured. Anthers of some filaments are either wanting or some are differently formed from the others. Fruit a 3-celled capsule or indehiscent. Ovules few, orthotropous. Seeds endospermous, often arillate.

Fertile stamens 3-2; sterile o-4. Flowers zygomorphic.

CoMmELINA.-Inflorescence of 2-I cymes included within a funnelshaped bract.

AnEILEMA.-Inflorescence panicled, not included within a spathe.

Fertile stamens 6-5. Flowers actinomorphic.

Capsule 3-celled. Flowers axillary clustered.

CoLEOTRYPE.-Stamens inserted high on corolla tube. Blue or white with beaded hairs.

Cyanotis.-Stamens hypogynous. Blue or purple.

Capsule 2-celled. Racemes panicled.

FLoscopa.-Flowers rufous, hairy. Stamens without beaded hairs.

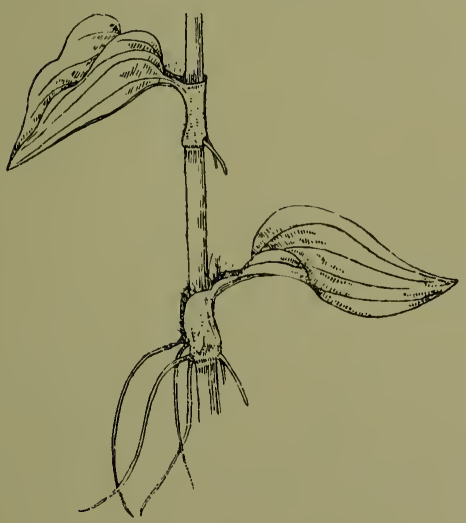

FIG. 227.-Sheathing leaves and adventitious roots of Commelina.

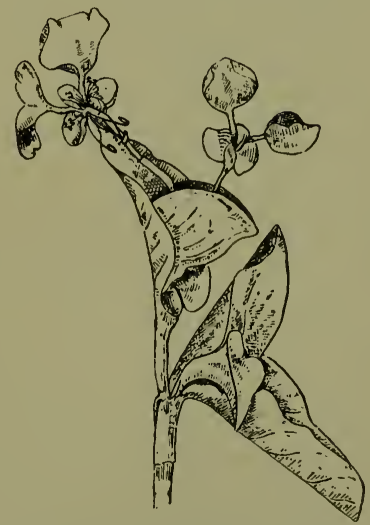

FIG. 228.-Flowering shoot of Commelina, showing two stalked petals and different kinds of stamens.

Linnæus, with all his love for study of plants, enjoyed a joke. He tells us that he named this genus after three Dutch botanists, the brothers Commelyn, because two of them, 
likened to the two showy blue or yellow petals, were industrious, and published their works on Botany. The third,

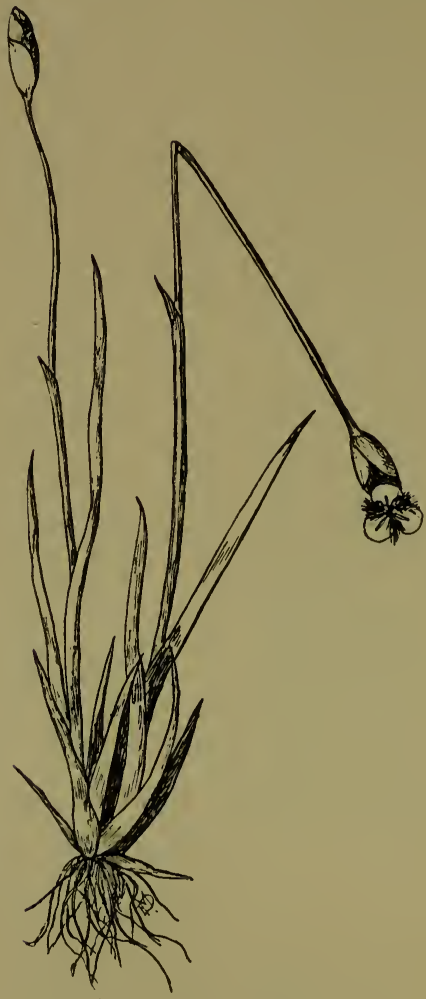

FIG. 229.-Xyris anceps, Lam. Kaspar, lacking in ambition, amounted to nothing, like the third insignificant white petal. Fortunately, poor brother Kaspar was dead before the birth of the joke.

Commelina.-There is an interesting division of labour between the stamens. The upper three stamens furnish little or no pollen, but the anthers contain honey. The lower middle stamen bends up opposite the centre of the flower. Bees collect pollen from this stamen for their bread, are dusted with pollen from the side stamens, which they carry to other flowers, and then climb up and pierce the upper anthers for honey.

In the morning the bright little flowers open; in the afternoon, or as soon as the bees have visited them (female bees are said to be their chief benefactors), the flowers quickly roll up and wither into a moist shapeless mass. $C$. benghalensis, L., has been mentioned as having cleistogamous flowers (p. I68).

Cyanotis (Tradescantia) also blossoms for a day and then perishes or "dissolves in tears," whence it also is known as "Job's Tears". The hairy filaments serve as a foothold for bees. The anthers are similar.

The species are chiefly eastern, though Commelina and Cyanotis are found throughout the Cape Province. 


\section{Order XYRIDACE $Æ$.}

Flowers perfect; calyx inferior, herbaceous, sepals 3, rarely 2 ; side sepals small, anterior one large, enveloping the flower. Corolla coloured, tubular, splitting with the growth of the ovary; lobes withering and persisting on (marcescent). Stamens 3, opposite the petals and joined to them, sometimes with three hairy staminodia alternating, ovary superior, I-chambered or imperfectly 3 -chambered. Placentas 3, parietal or shortly united at base, with many orthotropous ovules. Capsules dividing between the placentas (loculicidal). Two genera, one of which, Xyris, is South African, scattered over the warmer regions of the earth.

A.

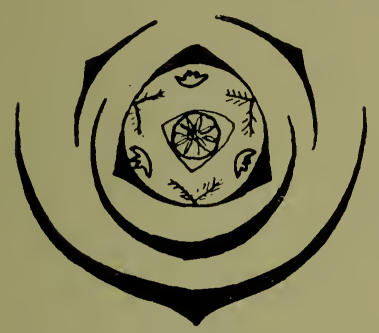

B.

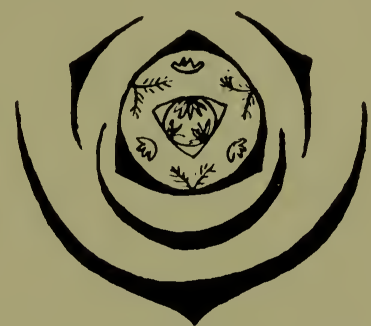

FIG. 230.-Floral diagram. Xyris, A, Sect. Nematopus; B, Sect. Euxyris.

The plants are tufted with grass-like radical leaves. Scapes single, terminated by a head or spike of flowers.

They are found in damp places. Chiefly Eastern.

\section{Order Liliace..}

Flowers perfect; calyx and corolla similarly coloured, usually regular. Perianth lobes separate or united in a tube. Stamens $3+3$. Ovary superior. Fruit a 3 -celled septicidal or loculicidal capsule or berry. The flower-stalks are usually jointed, just under the flower, at the middle or near the base. The stalk separates here when the seeds are ripe, or if the ovules are not fertilized.

This large order includes trees, shrubs, or bulbous or fibrous rooted herbs. The flowers may be large and showy or small 
and greenish. Honey glands in the flowers attract insects. The flowers may be arranged in umbels, ${ }^{1}$ spikes, racemes, or panicles. One of the largest orders of flowering plants; 200 genera, 2500 species. Cosmopolitan.

Series I.-Fruit a berry. Anthers opening toward the pistil. (Introrse.) Smilax.-Stems woody, climbing. Leaves normal, net-veined. Flowers diœcious.

Asparagus.-Stems generally woody, climbing or erect. Leaves small, bract-like, with one or several leaf-like branches in their axils.

Series II.-Fruit a capsule. Anthers versatile, opening toward the pistil. (Introrse.)

A. Rootstock not bulbous. Perianth lobes united.

B. Flowers in racemes.

Kniphofia.-Leaves not fleshy. Perianth tube long.

Aloe.-Leaves fleshy. Perianth tube short, with conniving segments.

BB. Flowers in umbels.

Agapanthus. - Flowers blue or white ; corona wanting.

Tulbaghia.-Flowers greenish- or purple-brown; corona present.

AA. Rootstock not bulbous. Perianth tube cut down to the base. Anthers swinging (versatile).

Bulbinella.-Flowers yellow or white. Filaments smooth.

Bulbine. - Flowers yellow. Filaments bearded. Ovules more than two in a cell.

AAA. Rootstock bulbous or tuberous. Flowers in racemes or spikes.

B. Perianth cut down to the base.

Bowiea.--Rootstock a partly underground corm. Stem climbing. Leaves small, soon falling.

Eriospermum.-Rootstock tuberous. Stem erect, usually with solitary leaf, after flowering. Seeds woolly.

Albuca.-Rootstock bulbous. Petals conniving but not united. Seeds flattened, crowded.

Eucomis. - Seeds not crowded. Raceme crowned by a rosette of leafy bracts.

Ornithogalum.-Perianth lobes spreading. Raceme not crowned with bracts. Flowers never blue.

BB. Perianth lobes slightly united at base. The outer sometimes free.

Lachenalia._-Perianth cylindrical. Outer segments usually shorter.

${ }^{1}$ The apparent umbels are really cymose. When the inflorescence is racemose the flowers have no bracteoles. 
Series III.-Fruit a capsule. Anthers opening outward. (Extrorse.)

A. Rootstock a bulb or corm. Perianth segments narrowed into a distinct claw. Capsule dehiscing septicidally.

Wurmbea.-Flowers spicate. Perianth segments joined at the base.

Androcymbium. - Flowers in a head, overtopped by bracts; stem short; perianth lobes separate.

AA. Rootstock not bulbous. Capsule dehiscing loculicidally.

Gloriosa.-Stem climbing by leaf tips. Perianth segments clawed, free spreading.

Sandersonia. - Stem erect. Perianth tubular with short free tips.

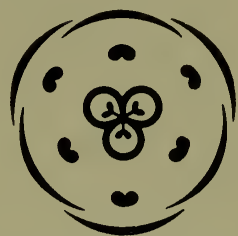

FIG. 23r.-Floral dia. gram of Aloe. (From Edmonds and Marloth's " Elementary Botany for South Africa".) Flowers solitary, hanging on slender pedicels from the axils of a few of the upper leaves.

Littonia. - Stem climbing by leaf tips.

Walleria.-Anthers opening by terminal pores.

Smilax.-Flowers diœcious, small, greenish, borne in umbels. Staminate flowers with 6 slender filaments and erect anthers. Pistillate flowers with 6 thread-like staminodia. Berry round, often only $\mathrm{I}$ - or $\mathbf{2}$-seeded.

A climbing shrub, supported by stipules, which are rarely found in monocotyledons. The many-ribbed stem is often armed with prickles, which help the stipules to support the plant. Leaves oval, glossy, netveined. In woods, usually on mountains.

Kalahari region: Transvaal, around Barberton. Eastern region: near Durban, Port Natal, Inanda. South Western region : about George and Bedford.

Asparagus.-Flower 3 perfect; stamens with versatile anthers. Berry round, seeds often solitary. Stem woody, erect or climbing, or spreading by means of spines produced from the base of papery scale-like leaves. Clusters of small green branches (Cladodia) take the place of foliage leaves. In some species a single flattened branch (Phylloclade) is borne in the axil of a leaf. These species are often called "Smilax". The thorny species are known as "Wacht een bietje".

Forty-four species of this large genus are found in South Africa. They do not favour one locality, but are found in all the five botanical regions. 
Kniphofia.-Perianth with a long tube. Stamens slightly curved toward the lower side of the flower (declinate), those opposite the petals longest. Ovary with a long style; ovaries many-seeded; seeds 3 -cornered.

A genus of handsome African plants with a short rootstock, long, narrow, radicle leaves and scapes bearing dense racemes of yellow or scarlet flowers. K. alooides, Moench, "The Red Hot Poker," is the most familiar. Many species are cultivated.

They occur from the Transvaal and Natal to the Cape Peninsula, and are also found in Tropical Africa and Natal.

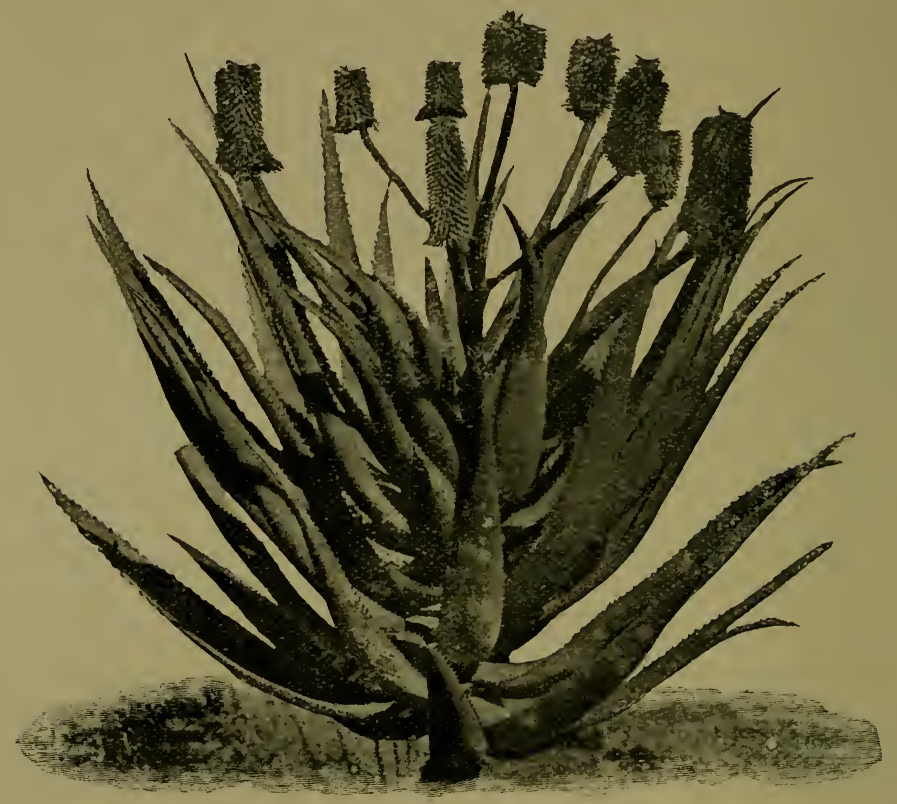

Fig. 232.-Aloe rupestris. (Photograph by Dr. Marloth.)

Aloe.-Perianth a short tube and long overlapping segments spreading only at the tips. Three outer lobes swollen at the base. Stamens equal to or longer than the perianth; filaments sometimes curved. Ovary somewhat 3 -angled. Seeds many, flattened or winged. 
Aloes are more numerous in the East, but $A$. rupestris, Baker, is found as far west as Port Nolloth. Aloes form a characteristic feature of the scenery in the Grahamstown region. They grow over the sun-burned hills, and cling along low broken sandstone ledges. Some have thick stems, shaggy below, with blackened remains of leaves, crowned with a bunch of spear-like leaves, above which rises a majestic stalk of flaming red or yellow flowers. $A$. arborescens, Mall., grows to a height of $\mathrm{I}_{5}$ feet. $A$. minima, Baker, which grows in grass, has a spike only 6 or 9 inches high, rising from a rosette of leaves.

The so-called American Aloe (Agave) belongs to the order Amaryllidaceae. It is native of Central America. In the dry climate of that country it has acquired similar habits of growth to the Aloes.

Agapanthus. - The large umbels of bright blue flowers (or rarely white) are subtended by two broad papery bracts, which fall early. Rootstock tuberous, with fleshy fibres. Leaves radical, fleshy, 6-8 scape; $3-4$ feet long.

Found in the Coast, Central, Kalahari, and Eastern regions. A handsome plant, frequently cultivated.

Bulbinella.-Perianth lobes I-nerved, remaining on after withering. Ovules 2 in a cell; seeds sometimes solitary. Leaves all radical; scape usually unbranched. Flower-stalks with a joint at the apex. Root of fleshy fibres. Chiefly Western.

Bulbine.-The bright yellow flowers may be known from Bulbinella by the pretty feathery stamens and numerous ovules. Some species have transparent leaf tips. White flowers also occur.

Stem sometimes branched and leafy.

A widely distributed genus, from near the sea-level to an altitude of 4000 feet.

Bowiea.-A peculiar plant with a large green tuber-like bulb on the surface of the soil. A slender wavy stem has many pinnate branches bearing slender Asparagus-like branchlets, which are subtended by scale leaves. Flowers small, $\frac{1}{2}$ to $\frac{1}{2}$ inch in diameter, borne from the main stem on long slender curved pedicels. One species, $B$. volubilis, Harv.

Found in the Eastern and Kalahari regions.

Albuca.-Outer perianth lobes spreading, inner shorter, having a hood-shaped process at the tip, and furnished with a 
large gland. Stamens all fertile, or the three anthers of the outer, small or wanting; filaments often winged at base. Leaves all radical. Flowers in racemes, large yellow or white, banded with green or brown, rarely quite green.

Found in the Coast, Central, Eastern.and Kalahari regions.

Eucomis may be easily recognized by its crown of leafy empty bracts. Perianth segments joined just at the base. Stamens adnate to the perianth : flowers greenish, marked with purple.

From the Malmesbury district to Natal.

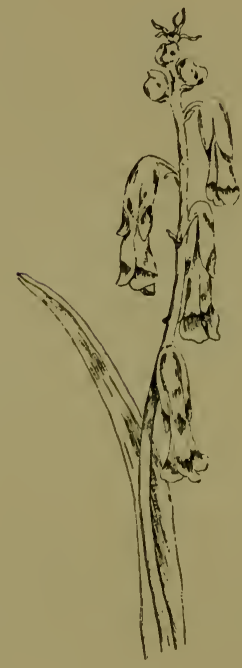

FIG. 233.-Lachenalia tricolor, Thunb.

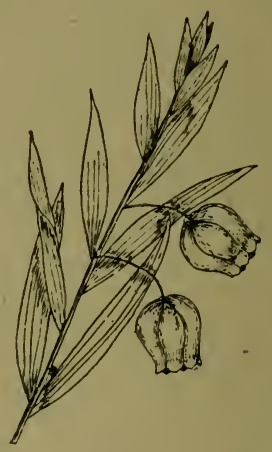

FIG. 234.-Sandersonia aurantiaca, Hook.

Ornithogalum (Chinkerinchee, Viooltje).-Perianth withering on the stalk. Stamens hypogynous. Style short. Leaves all radical. Flower in a raceme. The lower flower-stalks lengthen so as to make a flat-topped corymb, which elongates after flowering. 
About seventy species are found in South Africa. The large bulbs of some species store so imuch food that if the bulbs are gathered in early

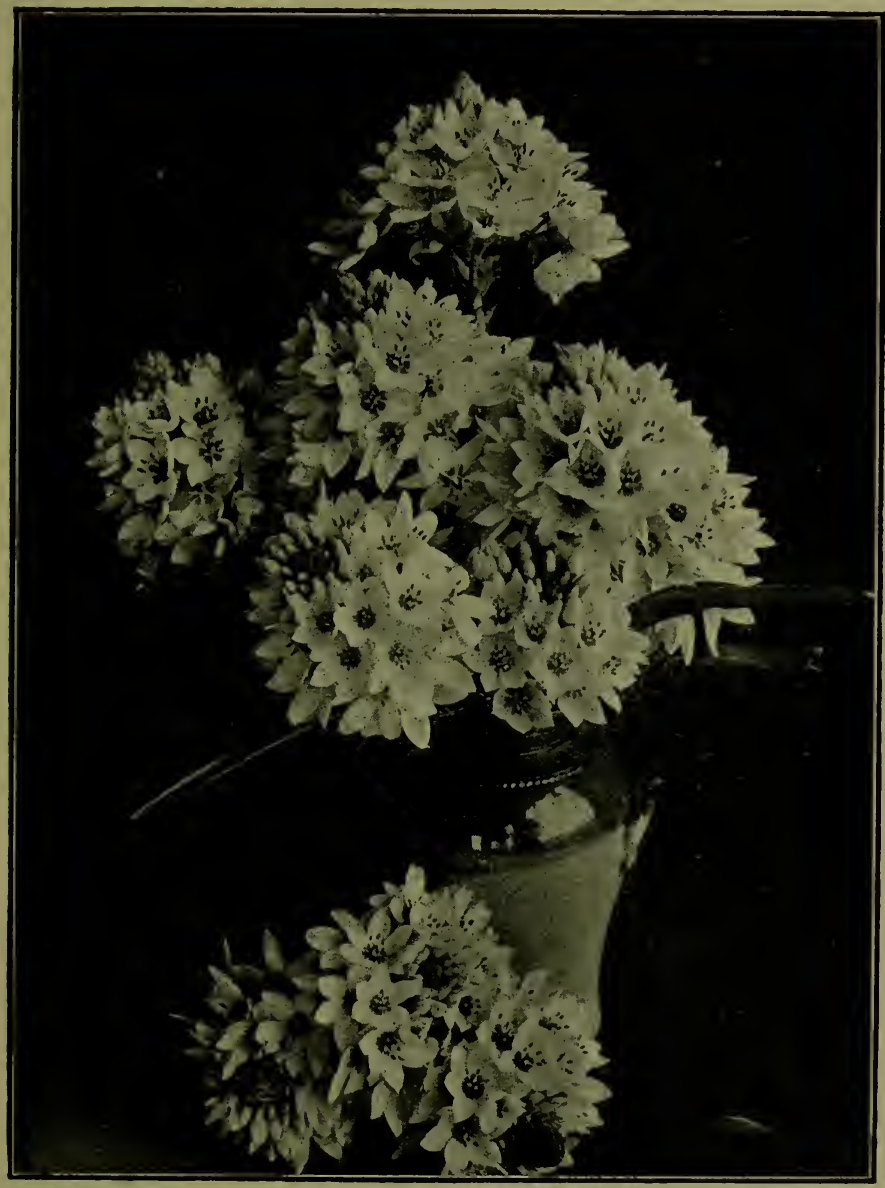

FIG. 235.-Ornithogalum thyrsoides, Jacq. (Photographed by E. J. Steer, Esq.)

flowering time and placed in the dark, the flower will continue to open for several months. These beautiful flowers so much in demand at 
Christmas time are a pest to farmers owing to the poisonous principle found in all parts of the plant.

Gloriosa.-Perianth segments clawed, spreading. Filaments slender; anthers versatile. Style long, sharply bent at

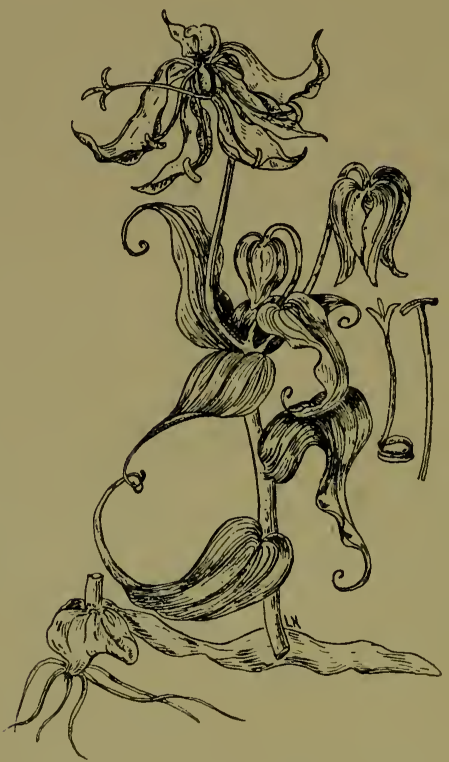

FIG. 236.-Giloriosa superba, Linn.

base; stigma 3-lobed. Seeds many, bright red. Flowers large and handsome. Rootstock tuberous; stem slender, climbing like Littonia by the curled leaf tips.

From Albany to Natal. Sandy hills.

Sandersonia.-Perianth tube tapering toward the throat, globose. Flowers bright yellow, hanging on slender stalks from the upper axils of the leaves. Leaves sessile alternate, 2 to 4 inches long, $\frac{1}{4}$ to $\frac{3}{4}$ inch broad. Stems I-2 feet high, leafy.

Found in the Eastern region. 


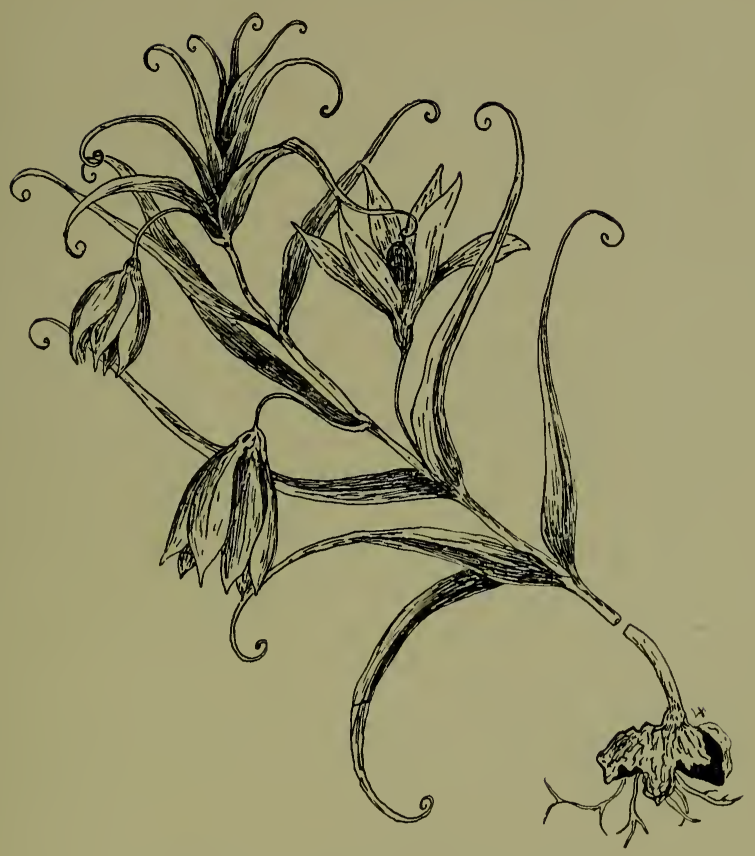

FIG. 237.-Littonia modesta, Hook.

Order AMARYLlidaceÆ.

Flowers perfect, regular, or nearly so. Outer segments of the perianth coloured. Stamens usually $3+3$, rarely 3 or many. Anthers introrse, long or short, basifixed or swinging. Ovary inferior, 3-celled; placentation axile ; stigmas three. Fruit usually a 3valved capsule, sometimes a berry. Capsule opening midway between the partitions (loculicidal), or splitting around at the centre. Seeds usually many.

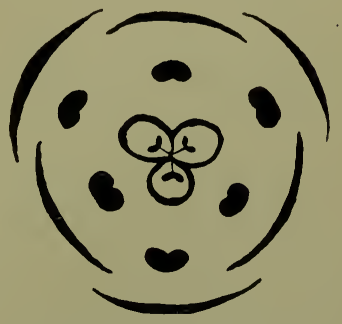

FIG. 238.-Floral diagram. A maryllidacee.

Usually stemless herbs with radical leaves. Mostly Xerophytes, leafing in the wet seascn. Rootstock a bulb or corm. Inflorescence 
always cymose. Flowers in umbels, corymbs, or single. Distinguished from the Lily family by the inferior ovary.

Tribe I. Hypoxide E.-Rootstock a corm. Flowers without a spathe below, usually yellow, and hairy outside.

Pauridia. - Stamens 3, opposite inner segments.

Curculigo.-Stamens 6. Fruit indehiscent, produced into a long beak beneath the perianth.

Hypoxis.-Stamens 6 . Capsule splitting around at the centre, not produced into a beak, or rarely beaked.

Tribe II. AmARyLLIDEe.-Rootstock a bulb. Leaves all radical. Flowers never hairy outside, usually in an umbel with a spathe below.

* Anthers basifixed.

Hessea.-Anthers small. Perianth cut down to the base.

Carpolyza.-Anthers small. Perianth with a tube.

Anoiganthus.-Anthers long, arrow-shaped. Flowers in umbels.

Gethyllis.-Flowers solitary, with a long tube and a flat spreading limb. Stamens in a single row; anthers linear.

Apodolirion.-Flowers solitary; perianth funnel-shaped. Stamens in two rows; anthers linear.

** Anthers attached at the back, swinging.

Fruit indehiscent, bursting regularly. Seeds one or few, bulb-like.

Crinum.-Segments of the perianth broad. Stamens declinate (filaments bending down toward the lower side of the flower, and then curving upward toward the anthers). Leaves persistent (with the flowers).

Amaryllis.-Lobes of the perianth broad. Stamens declinate. Leaves short-lived, withering before flowering.

Ammocharis. - Lobes of the perianth narrow. Stamens erect.

Fruit a 3-parted capsule. Seeds many, flattened.

Brunsvigia.-Perianth cut down to the ovary. Style not swollen at the base. Capsule turbinate (top-shaped), sharply angled.

Nerine.-Perianth cut down to the ovary. Style not swollen near the base. Capsule globose, obtusely angled.

Strumaria.-Perianth cut down to the base. Style swollen, and 3 -angled near the base.

Vallota. - Perianth with a tube rather shorter than the limb.

Cyrtanthus.-Perianth with a tube longer than the limb.

Fruit a berry or capsule. Ovules 2 or 3 , clustered at the middle of the placentas.

Clivia.-Bulb imperfect. Bracts below the umbel, several. Fruit a berry.

Hæmanthus. - Bulb large, with thick scale leaves in two ranks. Bracts under the umbel, several. Fruit a berry.

Buphane.-Fruit a capsule, Bracts 2. 
Tribe III. VELLOZIEÆ.-Rootstock not bulbous; leaves leathery, persistent. Flowers solitary.

Vellozia.-The only genus.

Pauridia.-Perianth with a short tube and spreading lobes. Stamens opposite the inner segments. P. hypoxidoides, Harv., is the only species. It has a corm $\frac{1}{4}$ inch in diameter, crowned with a rim of bristles. Leaves 6-12, sickle-shaped, I-2 inches long. Scapes several, about as long as the leaves. Perianth yellow, tipped with green.

This little plant, which is found about Cape Town on the hills and flats, has had difficulty in finding a habitation. Lacking the usual number of stamens, it was formerly placed among the Irideæ. Linnæus called it Ixia. It has since been known as Romulea, Galaxia, and Hypoxis.

Curculigo.--Perianth cut down to the ovary beak, filaments short, anthers long, basifixed, dehiscing extrorsely. The ovary is narrowed into a long beak resembling a perianth tube. Fruit fleshy, indehiscent, r-loculed, stigmas united. Rootstock a rhizome or corm, with fibrous tunics.

The flowers, yellow within and pale green without, resemble those of Hypoxis. Western (near Okiep), Coast, Central, and Eastern regions.

Hypoxis.-Perianth cut down to the ovary. Filaments short; anthers long, as in Curculigo; ovary rarely beaked, 3loculed; stigmas 3 , separate or united. Capsule usually with circumscissile dehiscence (splitting around near the middle). Corms in the Western species, $\frac{1}{4}$ to $\mathrm{I}$ inch in diameter; in the East some species have corms from 2 to 4 inches in diameter. Leaves plaited, found with the flowers.

Plants often growing in moist places. Flowers usually yellow. $H$. stellata, Linn., var. elegans, Pers., the most beautiful of the species, has large white star-like flowers, marked at the centre with a splash of iridessent colour.

Gethyllis (Kukumakranka).-Perianth white with a long slender tube, spreading limb. Stamens 6-20. Ovary hidden among the sheaths of the bulb, ripening partly underground. Fruit a yellowish, fragrant, edible berry, 2-3 inches long; leaves frequently spirally twisted, generally appearing after the flowers, with the fruit or later. 
Flowering in December. Fruit ripening about May. Coast, Central, and Western regions.

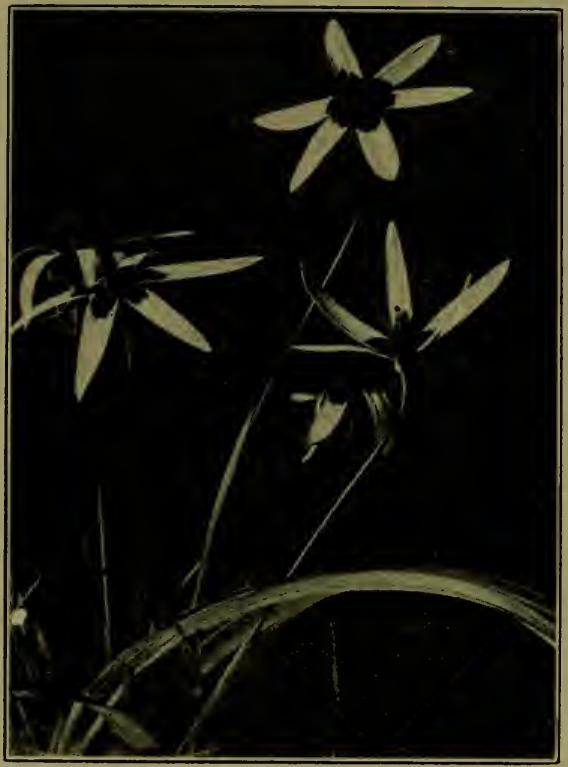

FIG. 239.-Hypoxis stellata, Linn., var. elegans, Pers.

Amaryllis.-This plant gave the name to the whole order, and its flowers are certainly beautiful enough to deserve the honour. Flowers 6-I 2 in an umbel. Pedicels $I-I \frac{1}{2}$ inch long. Ovules many; capsule large, round; seeds few. Leaves 7-9, growing after the flower, I foot long and $\frac{1}{2}$ to $\frac{3}{4}$ inch broad. The flowers are nearly regular, but the stamens curve upward. Coast region, flowering in March. A. belladonna, L., the only South African species, has a rose or whitish perianth $3-3 \frac{1}{2}$ inches long.

Nerine.-Tube cut down nearly to the ovary; lobes curved and frequently waved along the edges, bright red or pink, sometimes flecked with gold. Stamens of two lengths, slightly declinate. Bulbs near the surface; leaves produced with or after the flowers, Umbels 10-40 flowers. 
Vallota (Knysna Lily). Flowers with leaves, 6-9 to umbel, bright scarlet. Perianth tubular with equal spreading segments.

Western, Central, Eastern, and Kalahari regions.

Hæmanthus.- "The April Fool" merits its name, as we think when we find that what we took to be a single flower is really a dense umbel of many flowers surrounded by bright red bracts. After the bracts and flowers have withered and fallen, the bright red berries appear. Later come the leaves. They make enough food during the rainy season for the flowers and fruit of the next year, which is stored in the large bulbs. About thirty species are found, both Eastern and Western. Flowering in April.

Buphane is often confused with Brunsvigia, the flowers of each genus being in dense umbels on short stout scapes. The differences are so slight, and individuals of each genus are found having characters of the other, that they may well be grouped under the same genus.

Brunsvigia has a long ovary tapering down into the stalk. The flowers are slightly protandrous, but as in Buphane the stigma is bent and can, if necessary, brush out the pollen from its own or from neighbouring flowers.

Cyrtanthus may be known by its long perianth tube and hollow scape.

Its bright red, red and white, white, or yellow flowers are borne in many or few to I-flowered umbels. Seeds many ; ovary bursting irregularly. C. Sanguineus, Hook., has been crossed with Vallota purpurea, Herb.

\section{Order IRIDACEÆ.}

Besides the characters given in the key, the ovary of the Irideæ is 3 -celled with many ovules. The three stamens belong to the outer whorl, anthers extrorse.

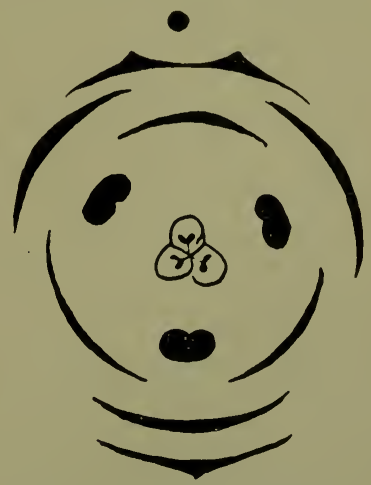

FIG. 240. -Floral diagram. Iridea. Fruit a 3 -celled capsule splitting down the centre of each carpel. 
The Iridaceæ are mostly perennial herbs with dry narrow leaves. Rootstock a corm, rarely a rhizome or fibrous. Leaves usually in two ranks.

The order Irideæ differs from Amaryllidaceæ in the absence of the inner circle of stamens, by the extrorse anthers, and in the inflorescence.

Sub-order I.-MORÆEÆ.-Flowers in corymbs; fading quickly, appearing one after the other from one bract. Stamens opposite the style-branches and pressed closely against them.

Moræa.-Style-branches of large petal-like crests with a horizontal stigma on the under side at the base of each crest.

Homeria.-Crests of style-branches small, spreading, shortly fringed around the edges.

Ferraria.-Crests of style small, petaloid, 2-lobed, deeply fringed around the edges.

Hexaglottis.-Style-branches long and slender, deeply forked.

Sub-order II. SisyrinchIEÆ. - Flowers in corymbs, fading quickly. Stamens alternate with the style-branches.

Tribe I. Galaxiece.-Bracts with one flower.

Galaxia.-Bracts down in the centre of a rosette of leaves. Stamens monadelphous. Stigma shield-like.

Syringodea.-As in Galaxia, but stamens free. Style with three wedge-shaped branches.

Romulea.-Bracts raised on a scape.

Tribe II. Aristea.-Bracts usually more than I-flowered.

Bobartia.-Style-branches long, awl-shaped.

Witsenia.-Style-branches shorter. Perianth lobes equal, shorter than the tube.

Cleanthe.-Style-branches short. Perianth without a tube, outer lobes 2-3 times smaller than the inner, black.

Aristea.-Style-branches short. Perianth lobes nearly equal, not narrowed into a claw.

Klattia.-Style-branches short. Perianth lobes nearly equal, longer than the tube, narrowed into a claw.

Sub-order III. IxIEÆ.-Flowers in spikes, not withering quickly, each one subtended by a pair of bracts.

* The three style-branches undivided. Flowers regular. Stamens not bending to one side of the flower-

Schizostylis. - Style short; branches long, awl-shaped. Root fibrous. Spathe valves green.

Hesperantha.-Like Schizostylis, but rootstock, a flattened corm.

Geissorhiza.-Style longer than Hesperantha, branches short, awl. shaped. Bracts green or membranous at the tip. 
Ixia.-Style long; branches short, awl-shaped. Outer bract short, brown, notched.

Streptanthera.--Style long ; branches short, wedge-shaped. Bracts both papery, lacerated. Leaves short.

Dierama.-Style long, branches short, wedge-shaped. Bracts both papery, not cut. Leaves long, rigid.

** Three style-branches, each bifid. Stamens curved towards one side of the flower-

Lapeyrousia.-Perianth tube slender, with the stamens borne at the throat. Ovules many.

Micranthus.-Perianth tube cylindrical. Stamens borne at the throat. Ovules 2, side by side.

Freesia.-Perianth tube broad. Stamens borne below the throat. Bracts small, green.

Watsonia.-Perianth tube widened at the middle where the stamens are borne. Bracts large, rigid, brown or green.

*** Three style-branches undivided. Stamens curved towards one side of the flower-

Babiana.-The genus may be known by its hairy accordion-pleated leaves.

Melasphœrula.-Perianth without a tube, lobes long, pointed.

Sparaxis.-Perianth regular, with a short funnel-shaped tube. Bracts papery, deeply fringed or lacerated.

Tritonia.-Perianth nearly regular, with a short tube. Bracts small, brown, notched.

Crocosma.-Perianth nearly regular, with a cylindrical tube. Bracts short, oblong. Capsule inflated, deeply 3-lobed.

Acidanthera.-Perianth nearly regular, with a long tube. Bracts long, green.

Synnotia.-Perianth irregular. Bracts papery, deeply cut.

Gladiolus.-Perianth irregular, with a funnel-shaped tube. Bracts large, green, lanceolate.

Antholyza.-Perianth irregular; tube swollen at the middle. Bracts oblong, lanceolate.

Moræa.-Flowers without a tube, regular, but the petals are much smaller than the sepals. Sepals showy, usually narrowed into a claw. Petals lanceolate, sometimes minute with a long, tapering point.

The genus is known from the other genera by the large petal-like stigmas. It is nearly like the Iris, "The fleur-de-lys," which is the flower of chivalry, the emblem of the Crusader, Louis VII.

The anthers are closely applied to the stigma but open away from it. The stigmas receive pollen from other flowers on a transverse ridge just above the stamens, 
Like other flowers of this group, their beauty is fleeting, as they wither quickly.

Homeria, formerly called Morcea, has a much smaller pistil, and the parts of the perianth are equal or nearly so. The flowers are pale yellow or pink occurring with the leaves.

$H$. collina, Vent., is the "Groot Tulp" which is poisonous to cattle. Dr. Pappe writes of a whole family being killed by eating the little bulbs

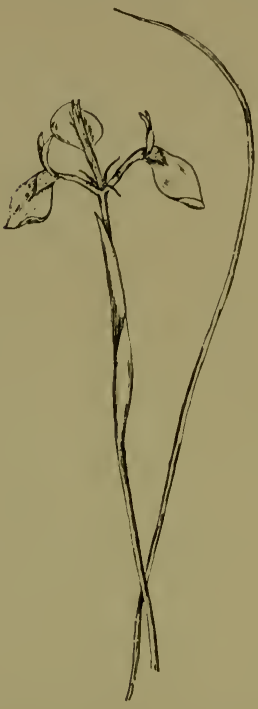

FIG. 24I.-Morca tripetala, Ker.

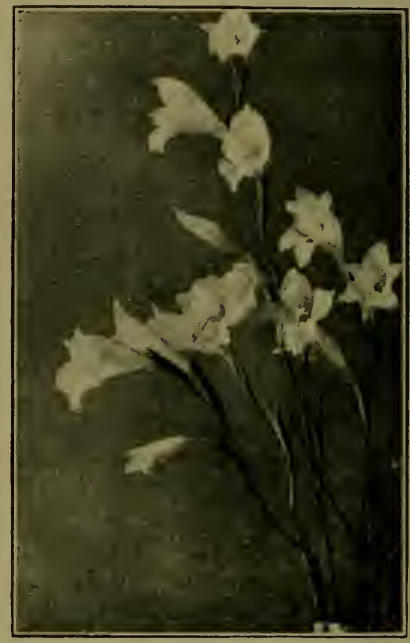

FIG. 242.-Gladiolus gracilis, Jacq.

which are produced in great abundance in the bulbs and axils of the leaves. Transport drivers use a decoction of the bark of the thorn tree (Acacia horrida, Willd.) as an antidote. This plant covers large areas in the western region.

Romulea ("Frutang ").-Flowers reddish-purple, lilac, or yellow. Leaves narrow, usually over-topping the flowers.

Aristea is a widely distributed genus, with bright blue flowers, which twist up in a spiral and become inky after flowering. The inner bract is papery, brown or white, and often deeply fringed. Rootstock of slender fibres or a rhizome, never bulbous. Leaves in a dense two-sided rosette. $A$. 
fruticosa, Pers., and $A$. corymbosa, Benth., have tall shrubby stems, rough below with the scars of fallen leaves.

Hesperantha ("Avond-bloemetjes").-Perianth with a tube and regular limb. Stamens borne on the throat of the tube. Style as long as the tube, with three long, slender, curved branches. Flowers white or yellow. The sepals frequently

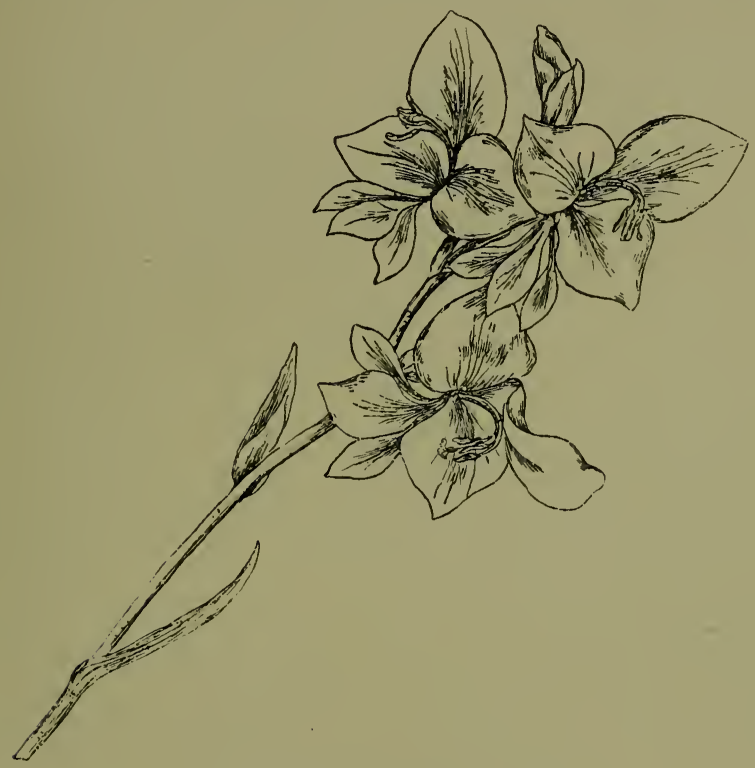

FIG. 243.-Gladiolus alatus, Linn.

red outside. The flowers are delightfully scented at evening when their insect guests are abroad.

Ixia.-Perianth tube long and slender, with a regular spreading limb. Stamens borne on the throat. Style longer than the perianth tube, with three short, spreading recurved branches.

Flowers in simple or panicled spikes of beautiful and varied colours. The Ixias are abundant in the West. I. viridiflora, Lam., has a pale green perianth with a purplish-black throat. One variety of this species has a pale lilac flower with a black centre; another has a pale blue perianth 
with a green centre. I. maculata, L., has orange or yellow flowers with a dark purple-black centre. Several species are found in the Transvaal and Natal.

Watsonia.-Perianth tube long, curved, widened towards the upper half. Flowers more or less regular. The stamen in front of the flower is bent backward in line with the other two, which are twisted halfway around on their filaments, so that all are placed in position to shed their pollen on the bees' hairy backs. ${ }^{1}$ The flowers often live in moist places. Water is necessary for making the honey, which sometimes half fills the long tube.

Rootstock a corm. Leaves ensiform (sword-shaped with their edge toward the stem). Flowers bright red, rose-pink, or white.

Babiana.-Flowers usually regular, frequently violet, sometimes milk-white or sulphur-yellow. $B$. ringens, Ker, is very irregular and bright red. B. plicata, Ker, has a delicate daytime odour. The genus may be known by its plaited hairy leaves, which are often on petioles.

Tritonia.-Flowers nearly regular, varying in colour, bright red or yellow, white, pale pink or green. Three lower lobes, sometimes marked with deep splashes of colour, sometimes furnished with conspicuous projections. Leaves few or in a fan-shaped rosette. Both Western and Eastern.

Gladiolus. - A great variety of colours is found in the flowers. Perianth tube curved, limb irregular, lobes often narrowed into a claw, the three lower often vividly marked. Seeds flattened, winged, numerous.

"Painted Ladies" and "Kalkoentjes" belong here. Eighty-one species of this large genus are found in South Africa.

Six species are known as "Painted Ladies". Of these the Christmas Painted Lady, G. tabularis, Ker, with white perianth tinged with pink, and leaves sheathing nearly their whole length, is confined to Table Mountain. G. debilis, Ker, has a very slender stem sheathed with three leaves with long slender points. Its flowers are lilac or claret-coloured. It extends from the Peninsula up to the Caledon and Worctster Divisions. G. cuspidatus, Jacq., may be known by the wavy points and the spadeshaped purple blotch on the three lower perianth segments.

1 This position of the stamens is assumed by the zygomorphic genera of the Order. 
Antholyza.-Perianth tube suddenly widening at the

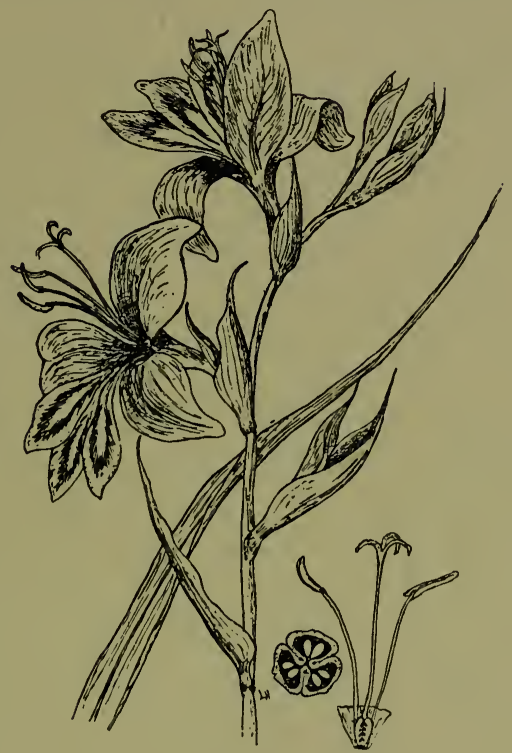

FIG. 244.-Gladiolus cardinalis, Curt.

middle, often twisted below. Seeds large, globose, not winged.

Order HæMODORACEÆ.

("The blood roots.")

Flowers perfect. Perianth regular or nearly so. Stamens 6 , or 3 opposite the petals. Ovary wholly or partly superior, or inferior. Fruit 3 -celled or becoming I-celled. Seeds one, few, or many. Herbs often covered with dense hairs. Never bulbous. Leaves often in two rows and firm. Roots often with a blood-red juice. Flowers in panicles. The order forms a connecting link between Liliaceæ and Iridaceæ, Amaryllidaceæ and Orchidaceæ. Herbs with panicled inflorescence.

Perianth remaining hairy, persistent.

Wachendorfia.-Stamens 3. Fruit free, 3-celled. Barberetta.-Stamens 3. Fruit free, I-celled. 
Dilatris.-Stamens 3. Fruit inferior, 3-celled.

Lanaria.-Stamens 6. Fruit inferior, I-celled.

Perianth not hairy, deciduous.

Sansevieria.-Perianth with a long tube. Fruit free.

Cyanella.-Stamens unequal. Ovary half inferior. Perianth deciduous.

Wachendorfia.-Perianth funnel-shaped; sepals hairy outside. Stamens opposite the sepals. Capsule r-seeded, splitting at the midrib of each carpel. Plants with yellow or brownish flowers, tuberous roots lance-like, plaited leaves and red juice. Malmesbury to Uitenhage.

Lanaria ("Cape Edelweiss").-L. plumosa, Ait., is a

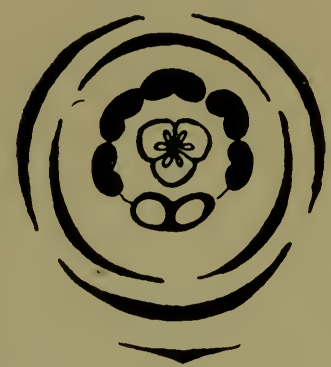

FIG. 245.-Floral diagram of plant densely coated with white, soft-spreading, plume-like hairs on branches and flowers. Flowers in a dense panicle. Rootstock of fleshy fibres. Leaves several, in a rosette at the base of the stem, together with the fibrous remains of old ones.

Found about Port Elizabeth, Riversdale, and in Bain's Kloof.

Cyanella has racemes or panicles of delicate blue or yellow flowers, and may be easily recognized by the peculiar hand-like centre composed of the-stamens, one of which is much larger than the others. Stamens opening by terminal pores. Leaves appearing before or with the flowers. Rootstock a corm, deeply sunk in the soil.

Order Musacex. (Included in Scitaminee, Bentham and Hooker).

Perianth 6-parted; both sepals and petals coloured. Stamens 5 or 1. Anthers 2-celled. Ovary 3-celled, inferior. Fruit a berry, or capsule. Large herbs with a rhizome and leaves rolled in the bud. The leaves are large, oval, with a stout midrib and parallel veins running from it to the edge. As they do not join as in Dicotyledons, they easily tear and 
become very ragged. The flower-stalk comes from the rhizome, and is surrounded at base by the leaves. The flowers are with large brightly coloured bracts.

Kæmpferia is a genus of low herbs. There is one perfect stamen and the staminodia, like those of the related genus Canna, are conspicuous. The flowers are large, rose-coloured with yellow markings. Fls. perfect or unisexual. Rhizome often aromatic.

Strelitzia has large elliptical leaves on long petioles arranged in two ranks. The flower-stalks push through the

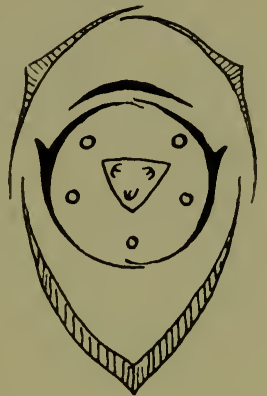

FIG. 246. - Floral diagram of Strelitzia. sheathing petioles. S. augusta, Th., is a tall banana-like species with a stem 18 or 20 feet high, the petals and sepals are white.

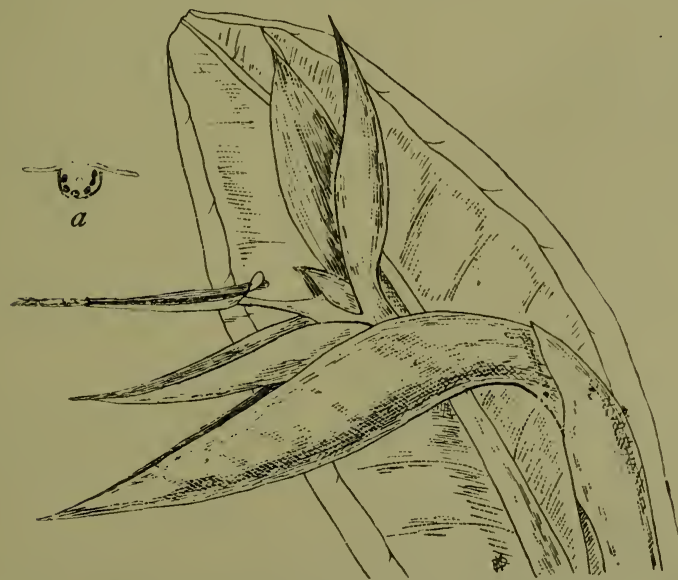

FIG. 247.-Strelitzia Regina, Banks. a, Cross-section of odd petal.

$S$. Regine, Banks, is a low species. The curious flower consists of three bright orange sepals, two standing erect. A small blue petal arches over the entrance to the nectar; the other two join, making a large arrow-shaped lip containing the five stamens on long filaments and the style, within a 
central groove. The flowers are in a cincinnus in the axil of a large spathe.

Nectarinia afra, one of the sun-birds, corresponding in colour to the flowers, probes for the honey with its long slender beak, and rubs first the stigma and then the anthers, which are exposed, by pressing down on the lip. The fruit is a capsule containing several black seeds with a bright orange feathery arillus. Eastern plants.

Musa (banana).-The sheaths of leaves, rolled around one another, give the appearance of long stems. The flowers are enclosed in brightly coloured bracts, and are also pollinated by birds. In the cultivated plants no seeds are developed from the ovules. Fruit a berry.

\section{Order ORCHIDACEÆ.}

Strange and grotesque as the orchids often are, by careful study the'same parts can be found as are present in the Iridaceæ. In the bud, three parts, the sepals overlap the petals. Two sepals are similar to each other, as are also two of the petals. The odd sepal may be, and the odd petal (the lip) is nearly always, peculiar in shape. These parts may be either very large and showy, or so reduced in size as almost to escape notice. As in the Iridacex, the inner circle of stamens is wanting in South African orchids. Of the outer circle, only one bears pollen. It is always opposite the odd sepal. The other two are peculiar staminodia. All three are joined with the style to form the column. ${ }^{1}$ A sticky substance formed by the disorganized walls of the parent and special parent cells of the pollen grains, holds the grains together in each pollen chamber, and merges to form a stalk. The mass of grains is called a pollinium and the stalk is known as the caudicle. Two of the stigmas are usually joined, forming a cushion-shaped body for receiving the pollen, while the third is enlarged and forms the rostellum. It furnishes a sticky fluid, forming small white glands. These unite with the caudicles and form the "labels" mentioned on p. 165 .

"The "style" may be a prolongation of the axis to which the stamens and stigma are attached. 
The rostellum is an interesting example of an organ which has lost its original use and has then acquired a new way of serving the plant. (Miss Duthie has found that the stigmatic surface in some species of Pterygodium extends some distance up on to the arms of the rostellum, which have not entirely lost their original function.)

The three carpels unite to form a single-chambered ovary, which is filled with an immense number of ovules. The fruit is an inferior capsule.

Dr. Bolus mentions that, with all the wonderful provisions for insect pollination, some orchids produce new plants entirely by tubers. This is possibly owing to the dying out of the insects which could effect pollination, owing to bush fires or other causes. The Western orchids are usually tuberous-rooted. Many in the East send up new shoots from creeping rhizomes, the food being sometimes stored in the lower swollen parts of stems.
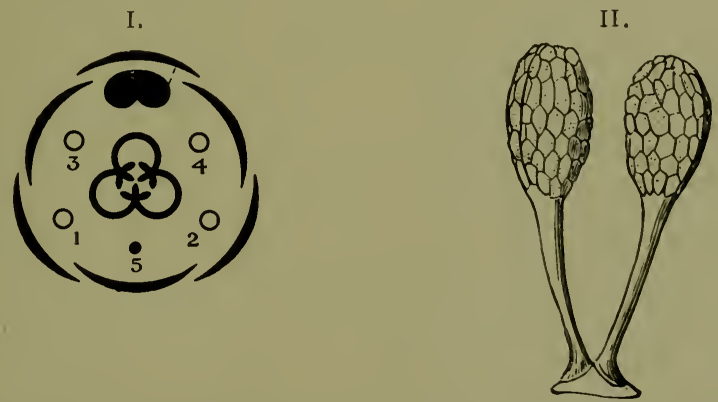

FIG. 248. - I. Floral Diagram of Disa. (From Edmonds and Marloth's "Elementary Botany for South Africa".) II. Pollen masses of an orchid joined with caudicles to a single gland. (From Thomé and Bennett's "Structural and Physiological Botany".)

Key to Some of the Larger Genera of Orchids.

A. Anthers lid-like.

B. Pollen masses 2-8, waxy. Not joined to a gland of the rostellum.

Petals linear; lip entire; terrestrial or epiphytic. Pollinia 4 . . . . LIPARIS.

BB. Pollen masses waxy, stalk united to a gland of the rostellum.

C. Lip not spurred; 3 -lobed; epiphytic . Polystachya. 
CC. Lip with a short sac or spur. Perianth lobes nearly equal . . . . Eulophia.

CCC. Lip with a long spur; epiphytic.

Pollen masses joined to one gland . . Angrecum.

Pollen masses with two glands . . Mystacidium.

AA. Anthers without a lid. Pollen masses granular, attached to a stalk.

B. Sepals and petals free from each other.

C. Sepals green, lip I-spurred.

Flowers solitary, lip deeply fringed. - BARTHOLINA.

Flowers spiked, lip not fringed . . HOLOTHRIX.

CC. Sepals petaloid.

Lip at the back, 2-spurred or saccate . Satyrium.

Lip in front, never spurred or saccate; stem straight. . . . . . Disa.

Lip in front in three distinct sections, base, middle, and apex; stem bent at the nodes Schizodium.

BB. Odd sepal and petals cohering together.

C. Side sepals free.

Side sepals spurred or saccate . . Disperis.

Side sepals not spurred or saccate.

Odd petal with a long spur . . . Habenaria.

Odd petal not spurred.

Hood erect ${ }^{-}$. . . . . . Pterygodium.

Hood nearly flat and horizontal . . CERTANDra.

CC. Side sepals joined to form a lower lip . Corycium.

Eulophia.-Sepals and petals nearly equal. Sometimes differently coloured. Lip saccate or with a short spur, smooth or crested or bearded on longitudinal furrows. Pollinia attached to one gland. Flowers small, yellow or dull coloured, shaded with purple, green, orange, or white. The base of the leaves often forms a bulb-like swelling above ground. Leaves in two ranks, usually plaited. Terrestrial.

Extending from Cape Town to Natal, but more common in the East.

Angraecium and Mystacidium are genera with much the same habit and appearance. They are epiphytes, often festooning the trees with beautiful showers of white blossoms.

The flowers are sometimes yellowish, and very small. Eastern districts and Natal.

Bartholina is one of the prettiest and daintiest of Orchids. It may be known at once by the peculiar lip, with its many long, slender projections. 
There are two species: in $B$.pectinata, $\mathrm{R}$. Br., the lashes are pointed and curve downward; in the rarer species, B. Ethalce, Bolus, they curve upward, adn each is tipped by a tiny knob. The solitary flowers are white,

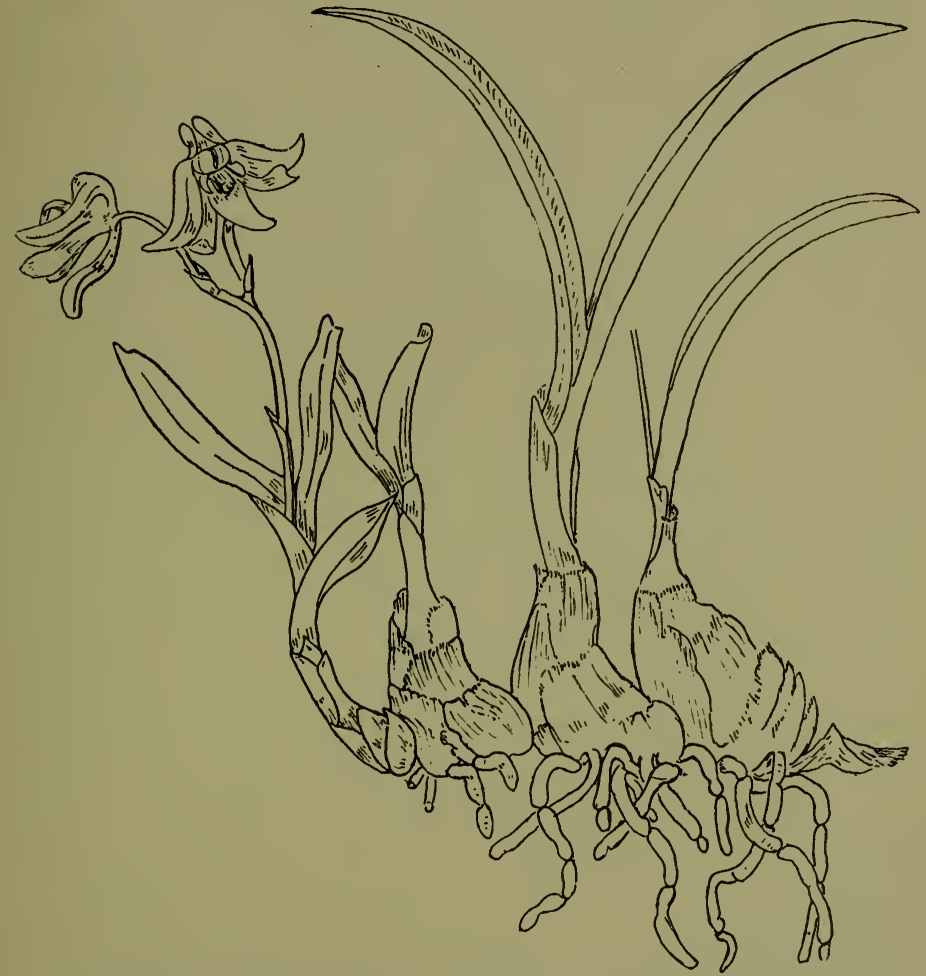

FIG. 249.-Polystachya Ottoniana, Reichb., an epiphytic genus with tuberiform stem bases. The flowers are yellow.

delicately tinged with purple. Leaf solitary, radical, flat on the soil. $B$. pectinata, R. Br., extends from the Cape peninsula to Grahamstown. Flowering in November and December.

Satyrium is distinguished from other Orchids by the two spurs of the hood-shaped lip at the back of the flower (i.e. next to the stalk). The sepals and two petals form the lower portion of the flower. The anther is in front, as the ovary is 
not twisted, and the glands of the pollinia lie in the notched rostellum.

Leaves two or one lying flat on the ground, or more than two erect. Flowers in dense spikes, white, brilliant yellow, orange, or a beautiful rose colour or dull brown. Different species may be found in flower from July to December. A widely distributed genus.

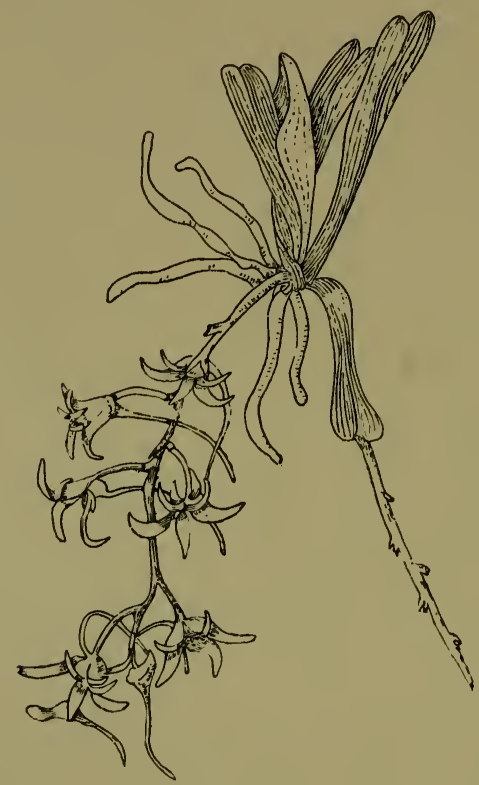

FIG. 250.-Mystacidium filicorne, Lindl. An epiphytic Orchid with aerial roots.

Satyridium is distinguished from Satyrium by the pollen masses being attached to a single gland. There is but one species, S. rostratum, Lind.

Disa.-Sepals nearly equal and separate; the odd one, which is at the back, and forms the conspicuous part of the flower, is helmet-shaped, I-spurred, or saccate. The lip in most species is small. In the blue Disa it is quite showy. Scapes leafy, or the leaves reduced to bracts. Roots tuberous. 
D. uniflora, Berg. (usually, called grandiflora) is the finest one, although others are quite beautiful if less showy.

In "Flora Capensis," the species of Disa with the lip posterior are separated to form the genus Orthopenthea.

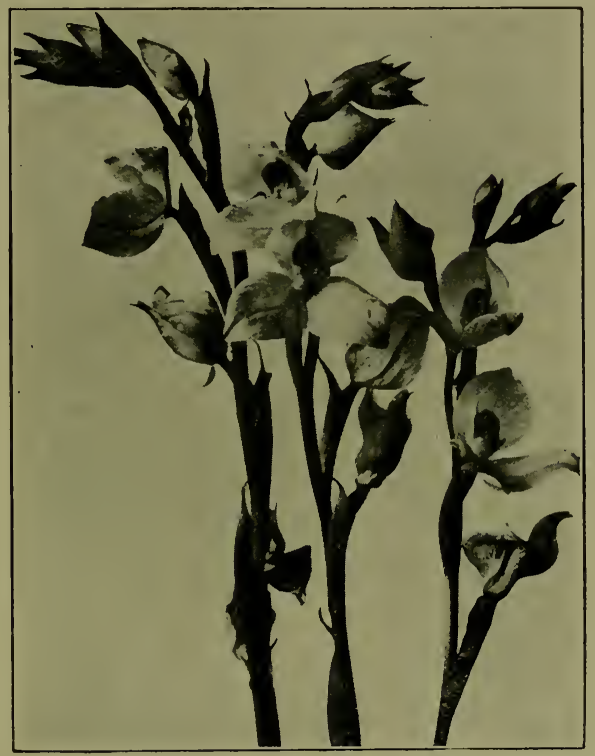

FIG. 251.-Disa racemosa, Linn.

Those with the glands of the pollinia united are placed in the genera Monadenia (odd sepal spurred), Amphigena (rostellum without appendage), Herschelia (rostellum 3-toothed).

Schizodium is similar to Disa, but the sharp angles at the nodes will tell this genus. Petals narrow, 2 -lobed at the tip, or twisted, and often eared at base. The lip is another distinguishing feature. It is as long as the sepals, narrowed above the base and often pointed, or the tip may be broad and waved, marking the lip into three distinct parts-a lower, upper, and middle.

Disperis, Pterygodium, and Ceratandra are nearly 
allied genera with the differences given in the key. In Disperis and Ceratandra the lip is clawed. Pterygodium has a

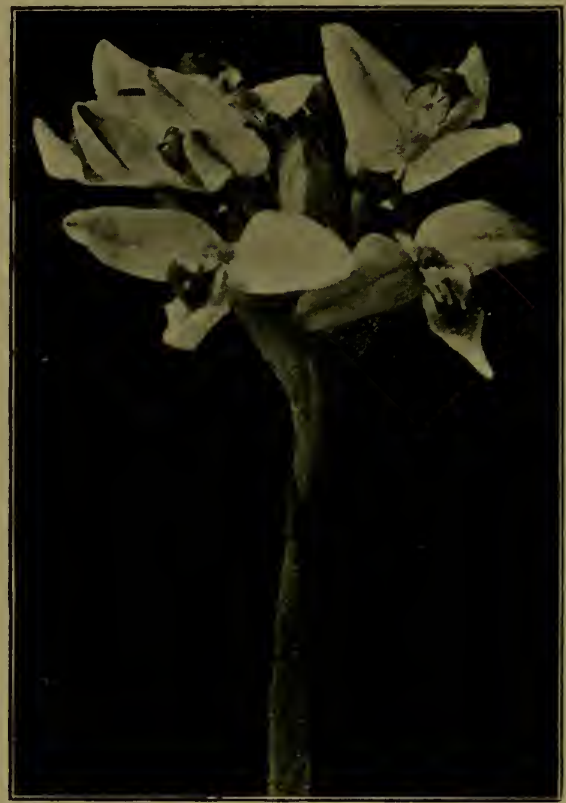

FIG. 252.-Disa melaleuca, Sw. Orthopenthea bivalvata (Rolfe).

sessile lip, and, like that of Disperis, it is often bent back over the column into the helmet.

Habenaria is a large genus found chiefly in the East. It may be recognized by the long spur of the three-parted lip and the usually 2 -parted petals. The lip is sometimes entire.

Stem either leafy at the base or the entire length. Flowers in spikes or racemes, large or small, sometimes quite beautiful, though not bright coloured. Found in February and March.

Corycium is nearly like Pterygodium, but the two sepals join in front to form a lower lip. The stigmas are two, separate, or one 2 -lobed. Capsule usually much narrowed toward the apex. Stem leafy. Leaves flat or crinkled. The genus merges into Pterygodium. 
Order Amentace※.

The orders Salicaceæ, Myricaceæ, Juglandaceæ,
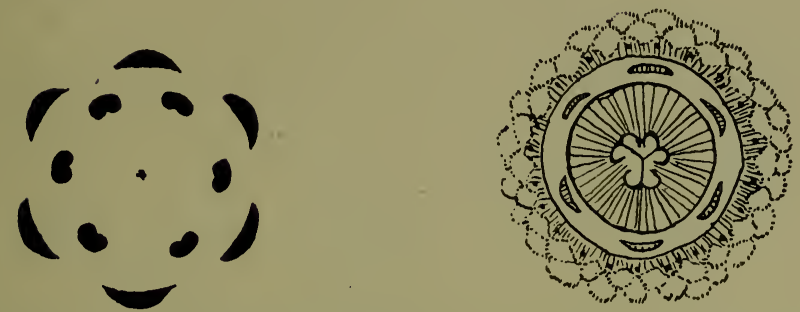
(Hooker).

FIG. 253.-Floral diagrams of Quercus. A, staminate; B, pistillate flower Betulaceæ, and Fagaceæ of cohorts 3, 4, 7, and 8 (Engler),

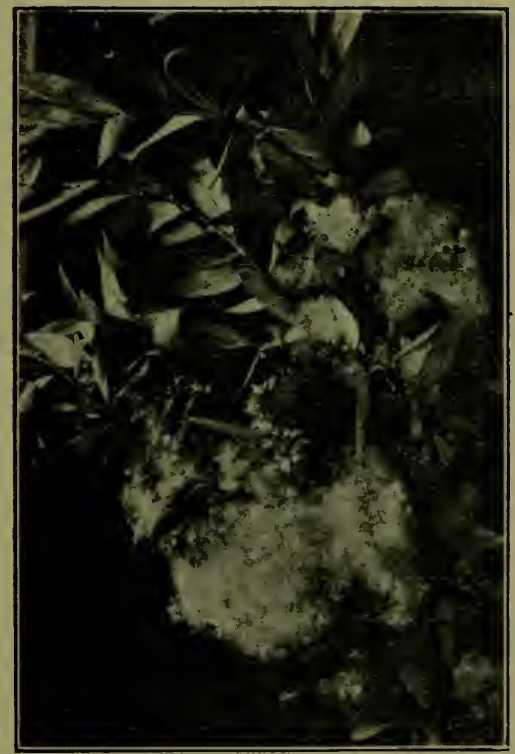

FIG. 254.-Willow seeds ready for flight.

may be united under the one order Amentaceæ. They are woody plants with alternate leaves. The staminate flowers hang 
in aments or catkins. The pistillate flowers form catkins as in Willow and Poplar, or they may occur in few-flowered heads. In the Oak the head is reduced to one flower. The fruit of Salicace is a many-seeded capsule, in the other orders it is a nut. The flowers are diœcious or monœcious. They are out in good season in the early spring, and are swinging their gold-and-silver tassels before the leaves get large enough to be in the way of the wind-scattered pollen.

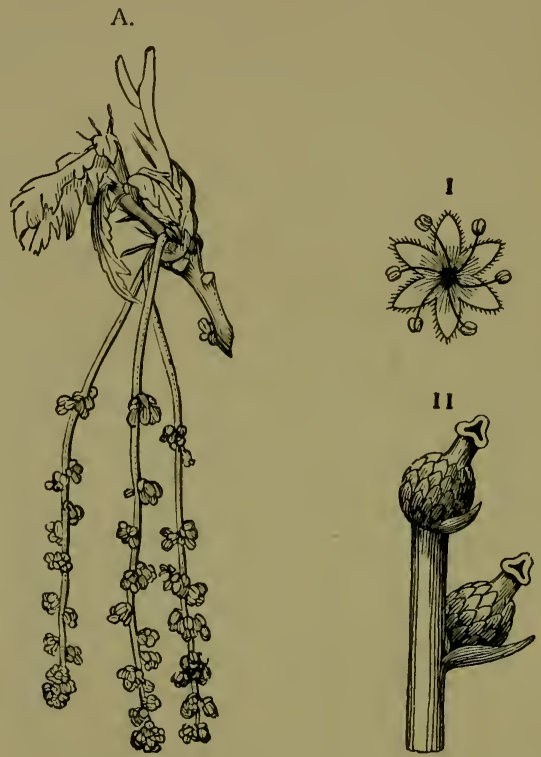

FIG. 255.-A, Catkin or amentum of the Oak. I. Flower of Oak. II. Female flowers. (Both $\times 3$.) (From Edmonds and Marloth's "Elementary Botany for South Africa".)

The flowers of Willows, Poplars, and Myrica (the Wax Bush) are subtended by a single bract. The staminate flowers of the Oak have a greenish 6-parted perianth. The few genera in each order, the simple flowers and fossil forms, indicate that these orders represent very old families of flowering plants.

SaliCaceæ.—Flowers diœcious. Capsules containing many minute seeds. The order contains two genera, Populus 
(Poplars), and Salix (the Willows). Both consist of deciduous trees, which border the streams in many parts of the country. They are introduced from the northern hemisphere. Salix capensis is a native of South Africa.

Myricace※.-Flowers diœcious or monœcious. Perianth wanting. Fruit indehiscent, dry, or covered with waxy scales.

I.

III.
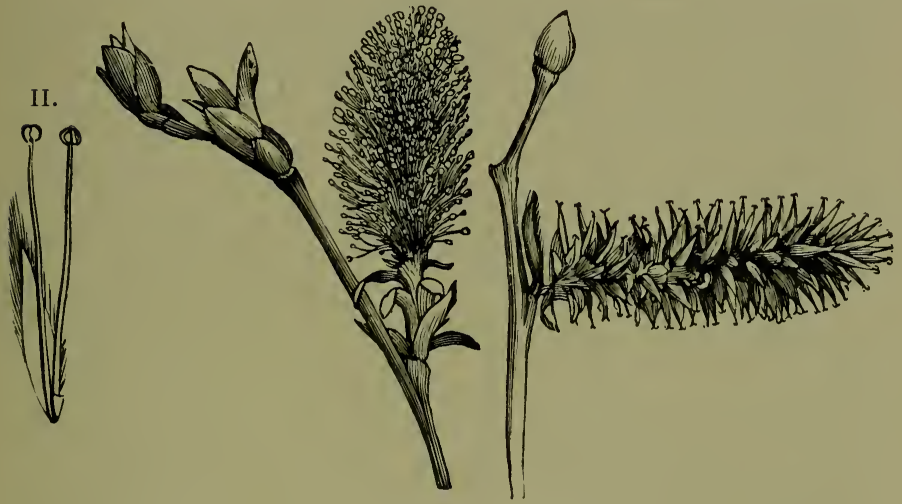

IV.

V.

VI.

VII.
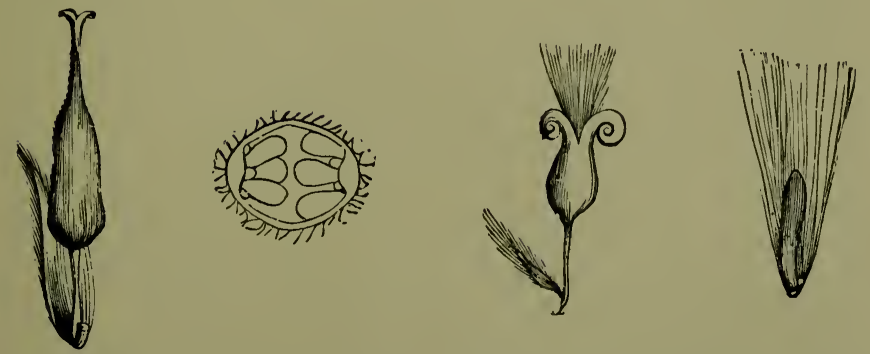

FIG. 256.-Sallow, Salix Caprea: I. male catkin (natural size); II. male flower (magnified); III. female catkin (natural size) ; IV. female flower (magnified); V. transverse section of ovary ; VI. fruit ; VII. ripe seed (magnified).

Myrica, the wax berry plant, referred to on p. 128 , is the only genus. Shrubs with exstipulate fascicule leaves.

FAGACE E.-The leaves of this order bear scale-like stipules, which drop off as the leaves unfold. Stamens often surrounded 
by perianth leaves. Fruit a nut surrounded by an involucre, the cup of the acorn and the burr, of chestnuts.

Pollination in the Oak occurs in September. At this time there are no ovules in the three-chambered ovary to be fertilized. Soon, however, two anatropous ovules appear in each chamber, only one of which is destined to become a seed; and after fertilization which occurs early in

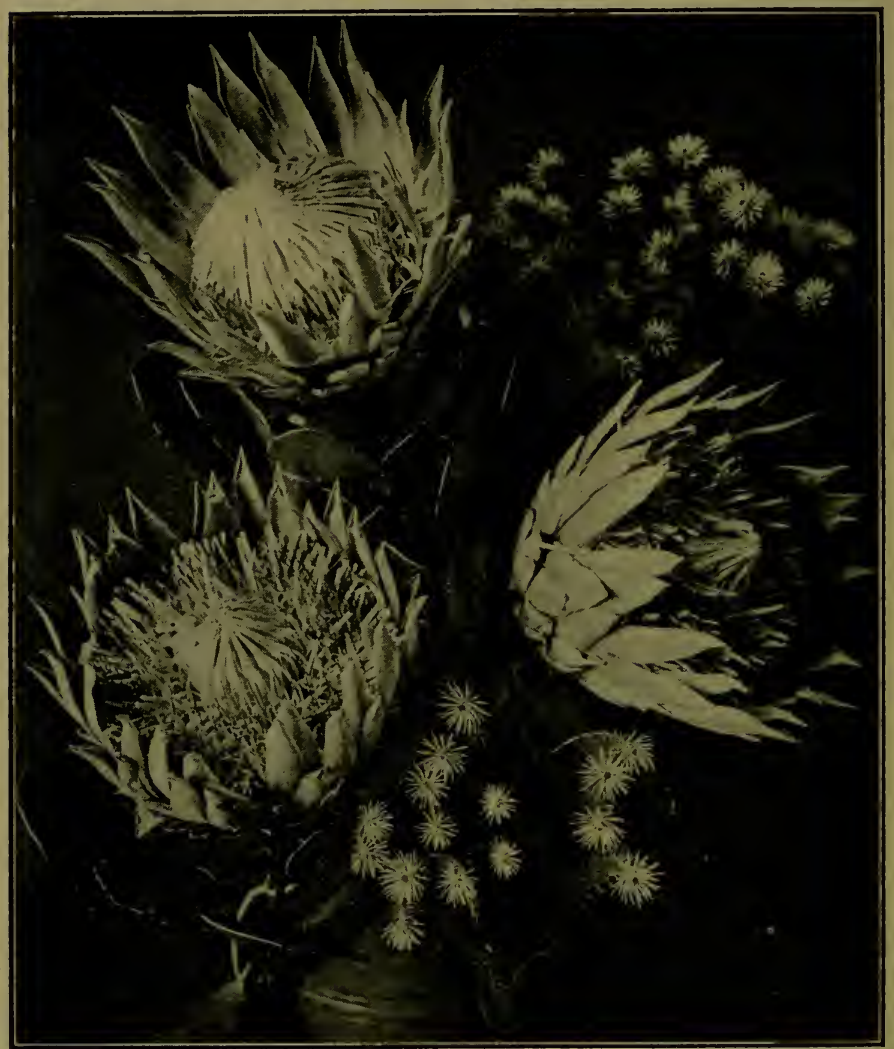

FIG. 257.-Protea cynaroides, L., with Staavia glutinosa, Th. (Photograph by E. J. Steer, Esq.)

November the other five disappear, the one seed filling the entire ovary which becomes the acorn. 
Quercus (the Oak) and Castanea (the Chestnut) represent the two genera of this order which have been introduced into South Africa.

\section{Order ProteaceÆ.}

The Proteacex, the glory of the Cape, are found also in Australia, New Zealand, Eastern Asia, the mountains of Tropical Africa, as well as in South America. Most of the plants of this order live in regions where there are long dry seasons alternating with rainy periods, and since they are neither succulent nor bulbous plants, their xerophytic habit is shown in

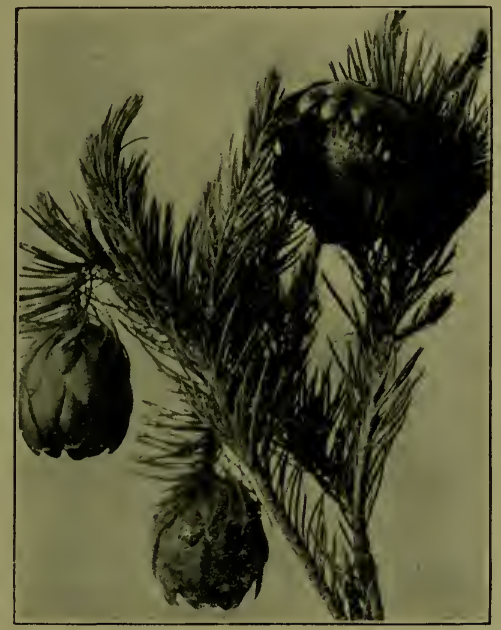

FIG. 258.-Protea rosacea, L.

their leaves. These meet their need of preventing transpiration in such a variety of ways that the order has received its name from the mythical sea-god Proteus, who delighted in a constant change of form.

A reduction of the leaf surface is a simple mode of preventing transpiration. Australian Hakea (used for hedges), Serruria, and Protea rosacea, Linn., adopt this plan. Protea cynaroides, Linn., has broad leaves, but they are protected by a thick leathery cuticle. The coating of hairs on the silver leaves have a similar use and, like all white surfaces, reflect the 
light-rays which would heat the plant. The sugar-bush leaves present their edges to the light by a twist at the base. The guard cells of the

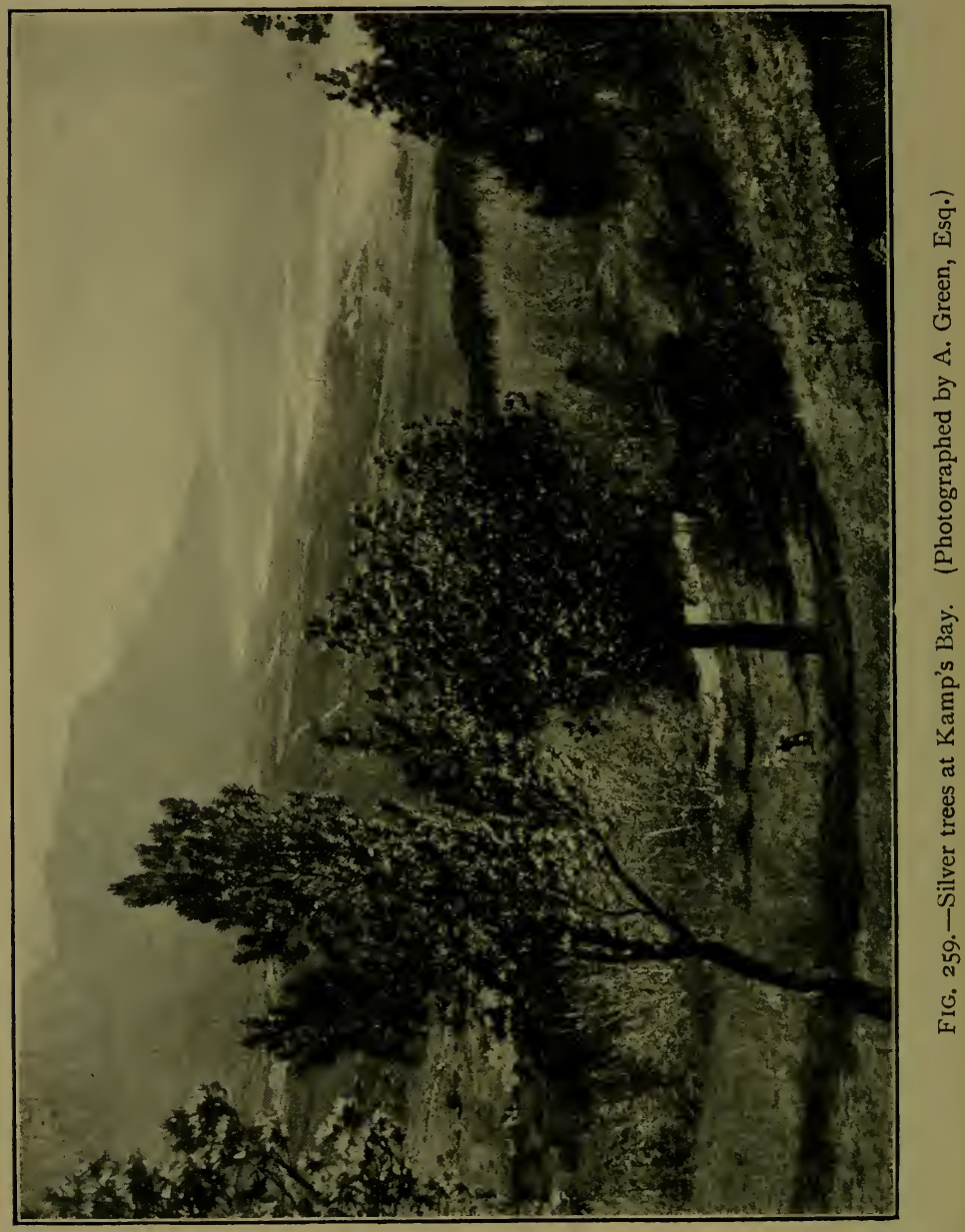

stoma are protected by over-arching cells. Flowers usually perfect. Sepals 4 , coloured; petals wanting. : Stamens 4 . Anthers sessile in the 
tips of the sepals (except Brabcium). Ovary superior, I-celled; style long. Fruit an achene in South African species.

Four small glands at the base of the ovary in some genera secrete honey which is sought by birds and beetles. The flowers are protandrous.

Of the 960 species there are, according to Engler, 59 I Australian, Eastern Asia 25, New Caledonia 27, New Zealand 2, Chili 7, Tropical South America 36, South-Western South Africa 300, Mountains of Tropical Africa 5, Madagascar 2, the greater number living in regions with long dry seasons.

The distribution recalls that of Restiacece and serves to confirm the evidence of a former land connexion between these distant countries.

The order is divided into two groups:-

I. Persoonioideæ.-Flowers single in the axils of bracts ; ovules seldom few or two. Drupe or nut $\mathrm{r}$-seeded.

II. Grevilloideæ.-Flowers in pairs ; ovules several or two ; fruit usually dehiscent.

South African representatives are found in the first group. Hakea and Grevillea are familiar representatives of Australian types which have been introduced belonging to Grevilloidece.

\section{Key to S.A. Genera.}

A. Flowers imperfect.

Staminate flowers in racemes . . Aulax.

Staminate flowers in heads . . LEUCADENDRON.

AA. Flowers perfect.

Flowers many in a head.

Calyx irregular, 2-lipped, 3-sepals or all, cohering.

Bracts showy, surrounding the head.

Fruit bearded, tailed by the style . Protea.

Bracts not showy, subtending each flower.

Fruit neither bearded nor tailed Leucospermum. Calyx regular, 4-parted.

Heads lateral.

Achene not on a stalk; leaves flat. Mimetes.

Heads terminal.

Achene on a short stalk; leaves pinnate parted, needle-shaped, rarely entire

Serruria. 
Leaves entire, small ; heads small .

Leaves large, expanded; heads large with large showy bracts .

Flowers in I-flowered or 2-6-flowered invol-

Diastella.

OROTHAMNUS. ucred heads, clustered in spikes or heads.

Calyx regular.

Achene not stalked; upper leaves entire or cut, lower pinnati parted Achene stalked; leaves linear entire, or some of the lower compound

Calyx irregular, I sepal larger
Flowers in spikes or racemes (not in heads)

Nivenia.

SoROCEPHALUS.

Spatalia.

Anthers sessile; nut bearded; spikes terminal ; leaves alternate, not

notched Anthers on short filaments; ovules 2 ; drupe velvety; racemes axillary; leaves whorled, serrate; fls. perfect and imperfect

Faurea.

According to Dr. Wiegand, hairy coverings are employed by plants in situations where, as on Table Mountain, a supply of water is available but where there is bright sunshine and frequent high winds. Hairs do not interfere with transpiration when mists hover over the mountain.

Cutin, on the other hand, is effective in places where a scarcity of water is constant.

Leucadendron.-Flowers diœcious, borne in cone-like heads. Involucre formed by the upper leaves, which give the delicate yellow colour to the veld in spring where these shrubs abound. In some species the involucre is reddish. The fruit may be flat, and distributed by wings or globose, as in the Silver Tree ( $L$. argenteum, R. Br.) (see pp. I55, I88). About sixty species chiefly in the Coast region.

Protea flowers are perfect; one perianth segment becomes separated from the other three. The genus may be distinguished by this character and by the showy involucres. The style remains on the hairy ovary. The involucres of $P$. mellifera, Thunb. (the Sugar Bush) are often half filled with honey in the early morning. The firm involucres in some species serve as a landing place for birds which aid in pollination. 
Erect or prostrate shrubs or trees. Mostly in the south-western

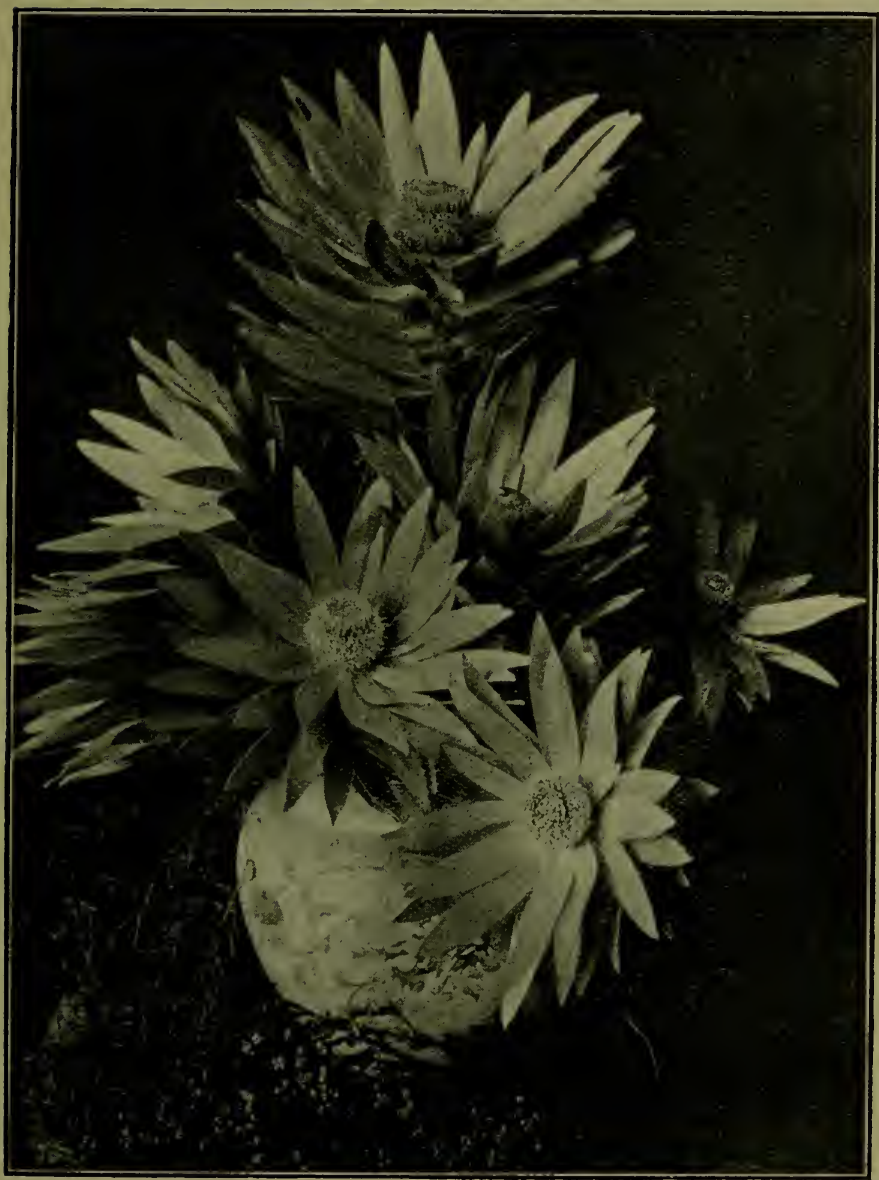

FIG. 26o.-Staminate cones of the Silver Tree, Leucadendron argenteum, R. Br. (Photograph by E. J. Steer, Esq.)

parts of Cape Province but also extending northwards. A few are found north of the Equator. About a hundred species. 
Leucospermum lacks the involucre that makes Protea conspicuous, but each flower is subtended by a well-developed

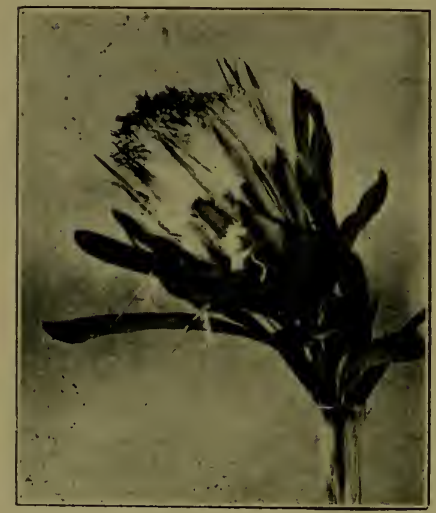

FIG. 26r.-Protea macrophylla, R. Br. bract. The claws of the perianth usually remain united or they may separate at the tips. The styles are deciduous and the fruit smooth. Trees or shrubs sometimes trailing. Flowers usually yellow (rarely red). About thirty species, mostly at the coast but extending to Rhodesia.

Mimetes has the habit of Leucospermum, but the flowers are reddish or purple, and the small axillary heads are arranged in a racemose inflorescence, each head being hooded by a bright bract subtending a head above.

Serruria may be known by the needle-shaped, usually divided leaves, and purplish silvery heads, frequently in clusters. Shrubs erect or trailing. Fifty species, chiefly Western.

Nivenia has 4-flowered heads in terminal spikes; involucres of four bracts, becoming hardened in fruit. Twiggy shrubs known usually by the two kinds of leaves, the lower pinnate, the upper simple, spathulate, flabellate, linear, or lanceolate. Some species have only slightly dimorphic leaves. About thirteen species.

Dr. Marloth in "The Flora of South Africa" retains the name Paranomus, Salisb. (1807), instead of Nivenia, the name given to the genus by Robert Brown (18 I0).

Faurea.-The calyx bursts below like that of the Silver Tree, but finally falls off. Nut bearded; style finally falling. Native of Natal and Rhodesia. The flowers are in terminal solitary spikes or racemes. Shrubs or trees with vertical leaves.

Brabeium (Kafir Chestnut or Wild Almond).—Staminate, 
pistillate, and perfect flowers are found on the same stalk. A shrub with whorled leaves, common along streams. The

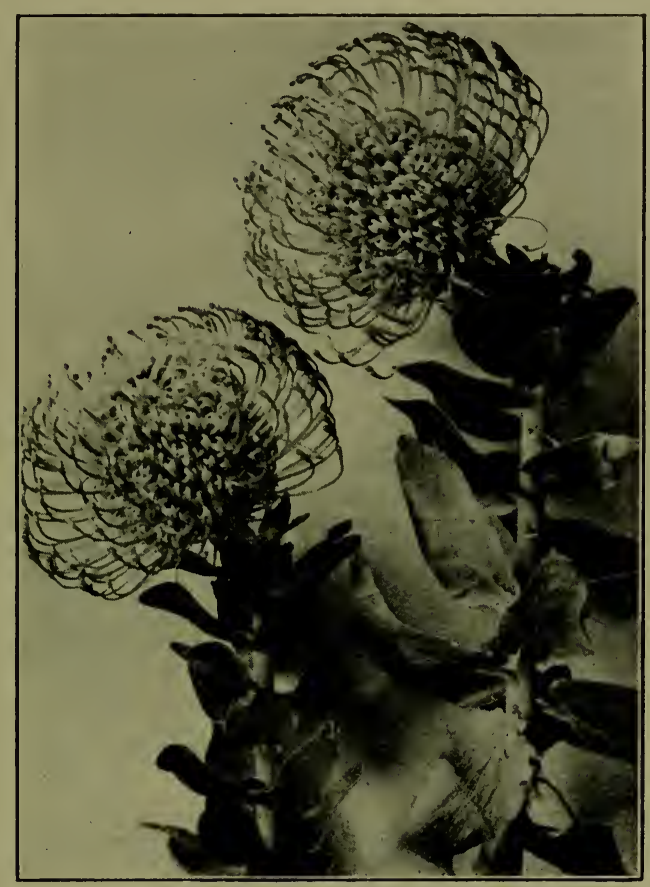

FIG. 262.-Leucospermum conocarpum, R. Br.

almond-like fruits, when roasted, make a good substitute for cocoa, though they are poisonous if eaten raw.

One species, $B$. stellatifolium, L., found in the western part of the Cape Province.

\section{Order LORANTHACEÆ.}

The order consists of partially parasitic plants, which attach themselves, by means of haustoria or modified roots, to other plants. The leaves (when present) and stems possess 
chlorophyll. Perianth either sepal-like or petaloid. Stamens

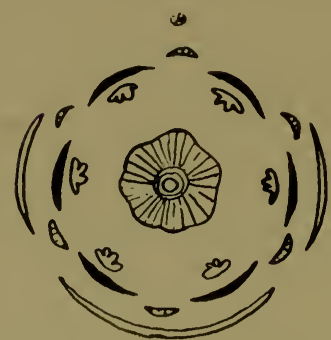

FIG. 263.-Floral diagram of Loranthus (Hooker). joined to the perianth, and as many as its lobes. Fruit a berry, sunk in the fleshy receptacle. Around the seed is a very sticky substance, which prevents it from being swallowed by birds. In freeing its bill from the seed the bird sows the seed on the tree.

Loranthus.-Flowers perfect; showy style long.

Viscum. - Flowers diœcious; style none, or very short.

Loranthus.-Shrubby plants, with opposite or alternate leaves. Flowers in umbels, axillary, orange, scarlet, or white with dark tips (see p. 16r). Parasitic on Acacia, Rhus, and other plants. It adapts itself not only to native plants but to introduced plants as well, such as oak, apple, etc. Eastern.

Viscum (Mistletoe).-Shrubs with forked, jointed green stems, leafy or leafless. Berries white or reddish. Parasitic on Euphorbia, Willow, Crassula, etc. Several species, both Eastern and Western. Dr. Marloth states that Viscum may grow on Loranthus, or the reverse may be seen.

\section{Order HydnoRaceÆ.}

Fleshy, scaly-coloured root parasites, becoming very woody. Calyx 3-parted. Fruit indehiscent, many-seeded. ${ }^{1}$

Hydnora is a parasite on the roots of Euphorbia. The bright red flowers are the colour of raw meat. A large glandular cushion on the inner surface of each of the three perianth lobes secretes an ill-scented fluid which induces insects to visit these striking plants. A fringe of hairs projects downwards from the top of the petals. These at first prevent the insect

${ }^{1}$ The distribution of this order shows a relation between the flora of the Old World and that of the New. It is placed by some in the order Rafflesiaceæ which is found in South America. (Engler retains the order Hydnoraceæ but places Cytinus in the South American order.) 
from escaping. The stigmas ripen before the anthers; by the time the latter are ripe the hairs are withered; the insect then escapes carrying some of the pollen with it. The flowers are borne along an underground rhizome which sends out haustoria into its host plant.

Cytinus has handsome scarlet flowers with a six-parted perianth.

The flowers are diœcious. The pollen grains from the numerous anther chambers remain in fours.

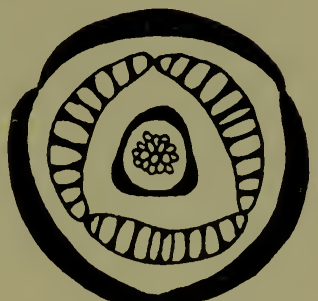

FIG. 264.-Floral diagram of Hydnora.

Found on Eriocephalus (Harvey), Agathosma (Dr. Bolus), Selago (Dr. Kolbe) and other hosts.
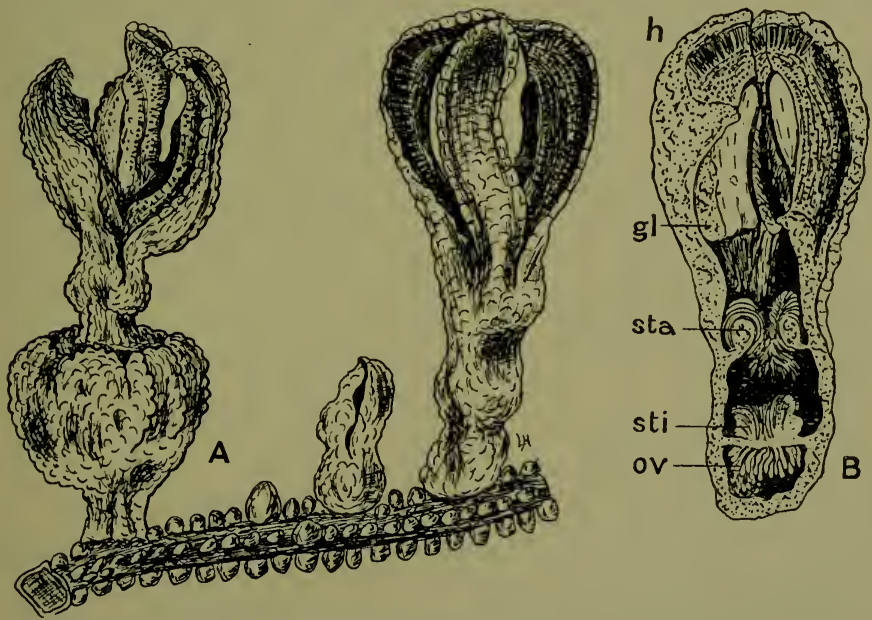

FIG. 265. - Hydnora africana, R. Br., parasite on the roots of Euphorbia, showing underground four-angled stem with tubercles in A, B. Section of flower showing the gland $(g l)$ which secretes an offensive substance attractive to certain carrion beetles; sta, monadelphous stamens ; sti, stigma ; $o v$, pendulous ovules.

\section{Order AIZOACE瓜 (FiCOID E).}

Herbs, usually succulent, with simple petaloid perianth. The ovary may be few- or many-seeded., superior or inferior. The most familiar genera are Mesembrianthemum and Tetragonia. 
The order has few well-defined characters and the genera approach the orders Phytolaccacea and Caryophyllacece. The order comprises spreading or prostrate herbs, half shrubs or shrubs.

Mesembrianthemum (Hottentot Fig genus).-The species of this genus are well fitted for their life on the hot, dry sands or sea coast, where they flourish. The leaves store an abundance of moisture, and standing erect, face to face, at the growing point, protect the bud. The leaves of $M$. crystallinum, L., are covered with globe-shaped hairs, that glisten in the sun. The fruit, unlike most capsules, opens and scatters in seeds only in moist weather, when the seeds can germinate. The parts may be made to open and close again and again by

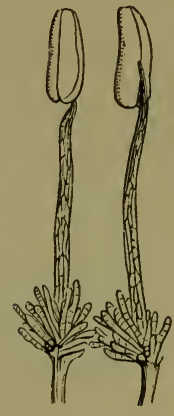

I.

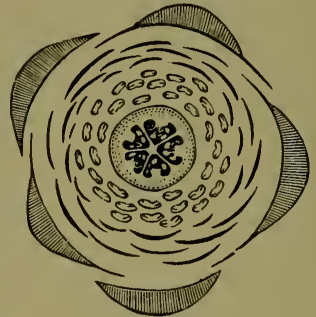

II.

FIG. 266.-Mesembrianthemum. I. Stamens. II. Diagram. (From Henslow's "South African Flowering Plants".)

placing them alternately in a glass of water, and then drying them in the sun. Dr. Marloth has called our attention to the similarity of the angular leaves to the rocks and pebbles among which they grow, which is a protection from grazing animals, as is also the astringent juice of the leaves. The showy part of the flower is made of stamens which have changed into petal-like bodies. The ovary is inferior, many-seeded, usually 5 (4-20-celled). The stamens and glandular receptacle secrete honey. Three hundred species. Abundant south of the Orange River and west of the Fish River.

'The placentation is peculiar in this genus. It is at first 
axile or nearly basal but by rapid growth of the tissue the seeds are carried out so that the placentation becomes parietal.

In this order are to be found some of the interesting types, first described by Dr. Marloth, of plants with "window leaves" which lie covered with earth except the upper end which is more or less flattened and transparent. Through this region the light penetrates to the underground part where the chlorophyll is formed. In the clear central cells of the leaves the light comes to a focus and is then diffused to the chlorophyll at the margin. When the sand washes off so as to expose the leaves above ground they become quite red, which serves to protect the exposed chlorophyll from the heat rays (see p. I 16$)$.

Tetragonia.-Calyx 4-parted, yellow within. Stamens varying in number. Ovary inferior, I-9-celled (usually 4celled). Fruit sharply 4-angled, winged or horned; cells Iseeded. Succulent herbs, spreading, or sometimes erect and shrubby. Fruit often ripening under the protection of the fleshy leaves close to the ground.

\section{Order CARYophyLLACEE.}

Flowers with both calyx and corolla or carolla wanting. Stamens 4-Io, free from the perianth, obdiplostemonous. Ovary superior, I-celled, or at the base 2-5-celled. Styles 2-5. Ovules 2-many.

Placentation is usually known as "free central" but it seems to be axile with the adjacent walls of the carpels broken down. Traces of the septa may be seen at the base of the ovary. Fruit usually a capsule dehiscing by apical teeth.

The inflorescence is definite form-

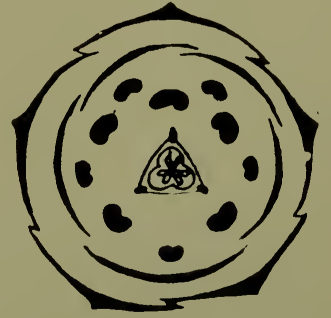

FIG. 267.-Floral diagram Silene venora. ing a dischasial cyme, but often one branch outgrows the other and at length one branch does not develop at all so that a cincinnus appears. In some a cincinnus appears from the start. 
Herbs with opposite, usually simple leaves, often stipulate. Stem often swollen at the nodes. Carnations belong to this order.

The order consists of honey-forming plants of two groups, one being polysepalous for short-tongued insects, the other having a gamosepalous calyx in which honey can be reached only by long-tongued butterflies and moths.

A. Calyx gamosepalous. Ovary raised on a stalk (gynophore).

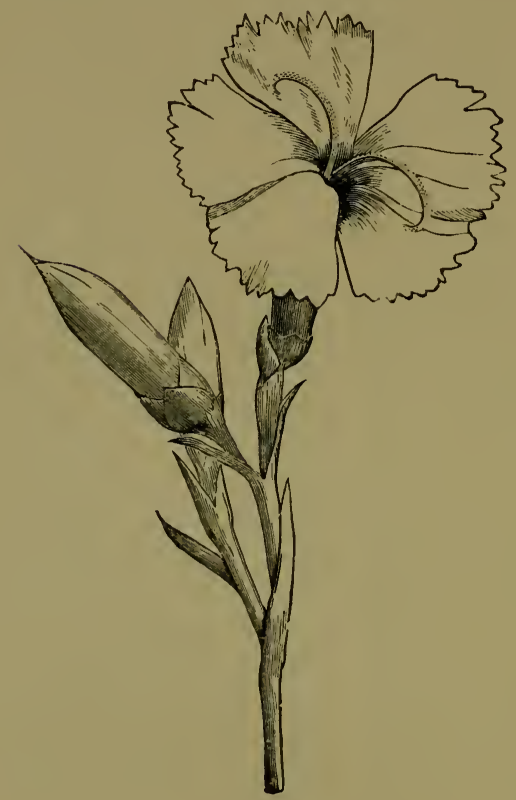

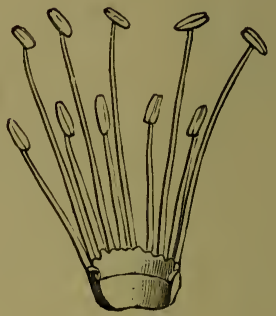

II.

I.

FIG. 268.-Dianthus caryophyllus. I. Portion of plant (natural size). II. Stamens (magnified). (From Thomé and Bennett's "Structural and Physiological Botany".)

Silene.-Calyx ribbed. Petals on long claws, the limb entire or divided. The flower-stalk is continued a node between the perianth and the other parts of the flower. Stamens ro, Styles 3 , corresponding to the number of carpels.

Small herbs often with sticky hairs, which guard the nectar from 
pilferers. On account of the small seeds, it is called the gunpowder plant. Children make pretty necklaces of the smooth shiny fruits.

Dianthus (the Carnation genus) differs from Silene in the smooth calyx tube, surrounded at base by several bracts. Styles 2. Herbs with generally grass-like leaves.

B. Calyx polysepalous. Ovary not raised.

Spergula, Stellaria, and Cerastium are common spreading weeds found in cultivated places. The flowers are small and often self-fertilized.

Stellaria media, V., has small white flowers with 2-parted petals. There is a double row of hairs at each internode, which may convey the water off in drying the plant, or they may absorb the water that runs down the stem.

\section{Order Ranunculace.}

Sepals 3-20, mostly 5, usually petaloid. Petals 5-I5 or wanting. Perianth usually deciduous. Stamens many, carpels many and apocarpous (in Nigella, a garden flower, they are 5 and syncarpous). The flower parts are placed spirally or the perianth (and carpels when united) may be cyclic. The flowers are usually regular. In the garden flowers Aconitum and Delphinium a single spur of the perianth makes the flowers zygomorphic.

Nectaries occur between the stamens and perianth; they are possibly suppressed stamens. The flowers are visited by various insects.

Leaves alternate except in Clematis, with broad sheathing bases.

Herbs or twining shrubs, mostly perennial with rhizomes. Each year's shoot ends in a definite inflorescence, a lateral bud continuing the rhizome.

A. Climbing shrubs with opposite leaves.

Clematis.-Sepals valvate, 4-8. Carpels with feathery tails.

B. Erect herbs with alternate or radical leaves.

* Sepals coloured. Petals none.

Thalictrum.-Sepals 4-5, shorter than stamens. Carpels without tails.

Anemone.-Sepals many, longer than the stamens. Carpels tailed. 
${ }^{*}$ Sepals green. Petals present.

Knowltonia.-Sepals 5. Petals many. Carpels juicy.

Ranunculus.-Sepals 3-5. Petals 5-10, each with a honey scale at the base.

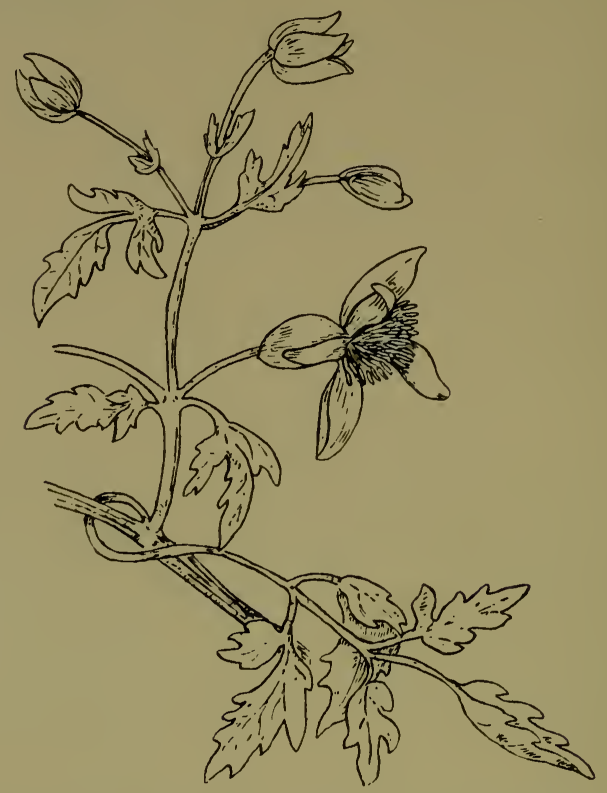
petals.

FIG. 269. - Flowering branch of Clematis. Two stamens have changed to

Clematis.-Flowers white or delicate green in definite

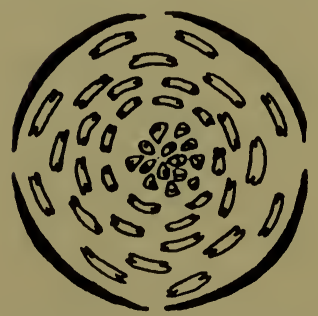

FIG. 270.-Floral diagram of Clematis (Hooker). clusters. No petals or honey secretion. Climbing by means of the sensitive petioles. "Klimop" or "Traveller's Joy".

Each indehiscent fruit is wafted by the feathery styles, carrying the seed to its final resting-place. Found east of Swellendam. The fleecy clusters of feathery fruits render as much joy to the "traveller" as do the flowers themselves.

Thalictrum.-Sepals soon falling, leaving the tufts of purplish stamens with slender filaments 
and large anthers. Carpels 4-8. Stem 2-3 feet high. Wind pollinated. Kafirland.

Anemone.-The large delicately tinted calyx makes this one of our most beautiful flowers. The Eastern species, $A$.

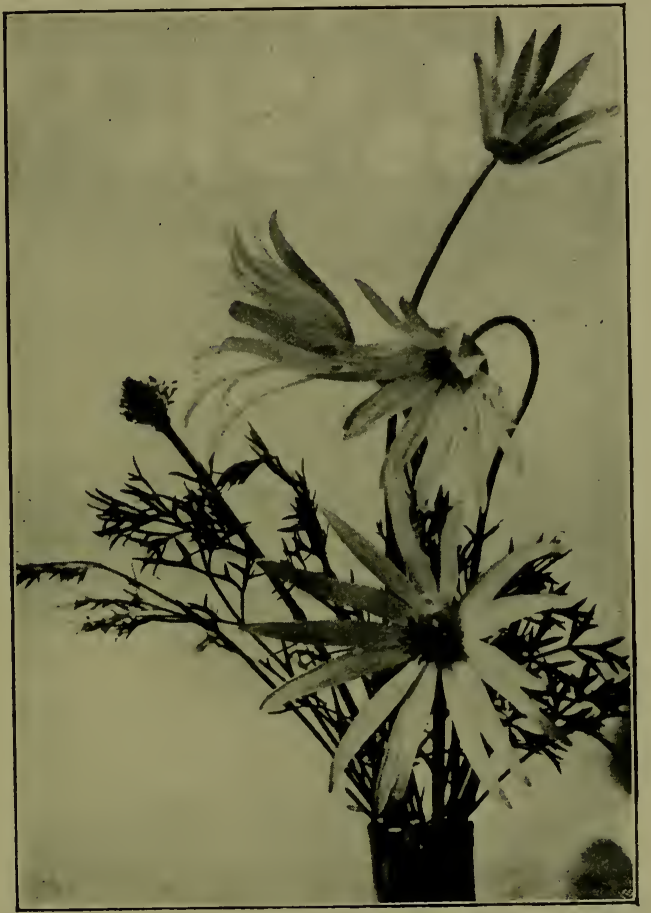

FIG. 27r.-Anemone capensis, L.

caffra, E. and Z., is stemless with lobed leaves. A. capensis, L. in the West has much-cut leaves.

Abundant on shady, grass-covered mountain lopes. From Groenkloof to Swellendam.

Knowltonia (Brand blaren).-Petals greenish. Herbs with radical compound leaves. Flowers in branching cymes or umbels. Throughout the Colony. 
Ranunculus.-Sepals falling. Petals bright yellow, each with a scale at the base.

Weeds with lobed or divided leaves growing in damp places, sending out rhizomes or runners. Cultivated species become double and varied in colour.

\section{Order CRUCIFERE.}

Sepals 4 , in two whorls. Petals spread in the form of a cross, often clawed. Stamens 6, in two whorls, the four inner ones longer (tetradynamous four in power). Carpels 2, with parietal placentation. A thin white partition grows up between the carpels. The carpels usually split up from the centre, leaving the placentas surrounding the partition. Fruit a siliqua, silicula, lomentum, or a schizocarp. The stamens have nectaries at the base which pour honey into the pouched bases of the inner sepals. The flowers are often borne in corymbs, which brings a number of flowers close together, so that a good many can be pollinated in a short time. As the flowers blossom the stalk lengthens, and so it forms a simple raceme. The flowers are not subtended by bracts, as is usually the case. Many garden vegetables belong to this order, as the Cabbage, Turnip, Mustard, and Cress.

Heliophila ("the sun-loving plant") is a familiar wild flower of this order. The flowers are bright blue, yellow, or white. The pods are straight edged, or sometimes constricted between the seeds, forming pretty bead-like siliquas. Delicate herbs or half shrubby plants. About sixty species are known, both Eastern and Western.

Capsella is a common weed with a heart-shaped silicula for a fruit.

Lepidium is another common weed differing from $\mathrm{Cap}$ sella in the smaller $\mathrm{I}$-seeded fruits. There are several species found in dry or shady waste places. The garden cress $(L$. sativum) is introduced.

Brachycarpea is a handsome Western genus with large purple or yellow flowers. The fruit is indehiscent, the carpels 
falling apart, each carries a single seed. A twiggy half shrub, 3 feet or more high.

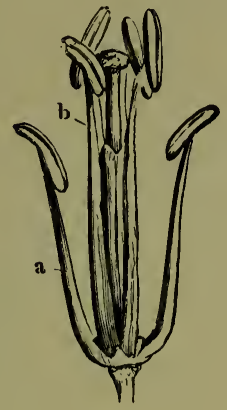

I.

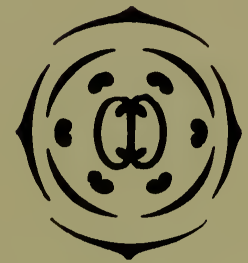

II.

FIG. 272.-I. Tetradynamous stamens and pistil of Brassica nigra: $a$, shorter, $b$, longer stamens. II. Floral diagram. (From Edmonds and Marloth's "Elementary Botany for South Africa".)

Brassica is a genus of common garden plants. They are interesting in showing how one group of plants can, when cultivated, develop along different lines; the Cabbage stores its food in the leaves; Brussels Sprouts in lateral branches, Cauliflower in the inflorescence. Mustard is cultivated for its seed.

\section{Order CAPPARIDEe.}

This order resembles the Cruciferæ in the 4 sepals in 2 whorls, 4 petals. The stamens are sometimes 6 as in Cruciferæ, but vary from 4 to many. The ovary is formed of 2 carpels meeting at their edges with parietal placentation, but there is no false partition or replum. The order may be recognized by the long stalk or gynophore which extends the ovary beyond the perianth. The stamens also may be raised on the stalk. Herbs, shrubs, or trees with simple or compound leaves, often with sticky hairs. Fruit a capsule or berry.

A. Fruit a capsule-

Gynandropsis.-Stamens 6. Capsule pod-like, r-celled, many-seeded. The stem axis is lengthened between the petals and stamens, and also between the stamens and ovary. Herbs with compound leaves, the upper sessile, the lower on long stalks. 
B. Fruit a berry-

Calyx persistent-

Niebuhria.-Berry roundish. Calyx funnel-shaped. Petals small or none. Trees or shrubs with simple or compound leaves.

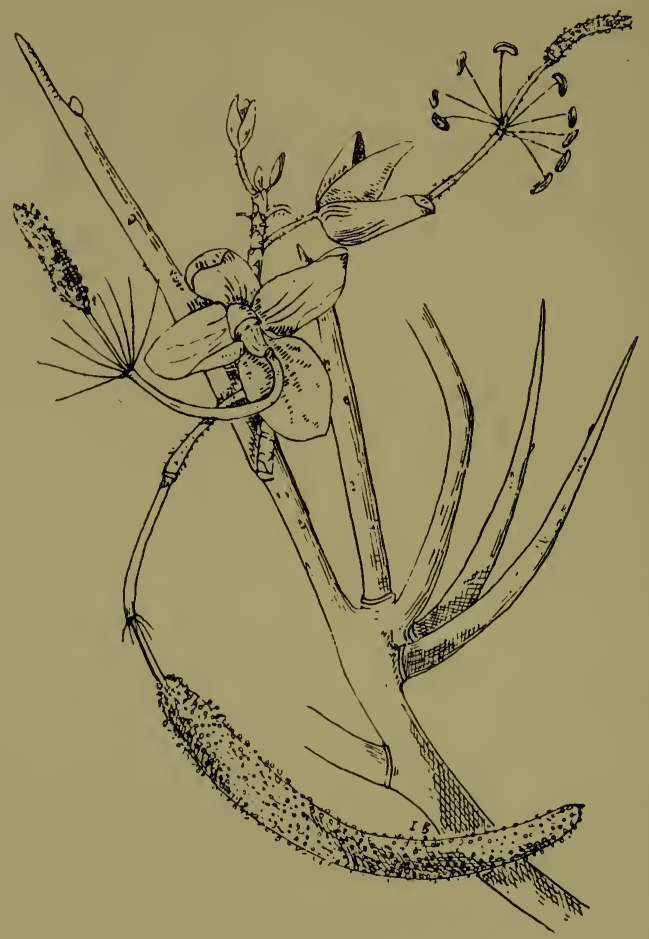

FIG. 273.-Cadaba juncea, Harv.

Mærua.-Berry long, cells I-seeded. Trees with simple leaves. Natal.

Calyx deciduous-

Cadaba.-Stamens $4-8$, raised with the ovary on a gynophore. Cadaba juncea, Harv., is shown in Fig. $27 \mathrm{I}$. It is a much-branched, twiggy, pale, leafless shrub about 2 feet high. 
Flowers yellow or purplish. Fruit a long berry with sticky hairs.

A Karroo plant formerly called Schepperia " in honour of some obscure botanist whose memory has otherwise passed away ".

Capparis (the Caper).-Stamens 8-many, on a slightly raised disk. Ovary on a long gynophore. Trees or shrubs

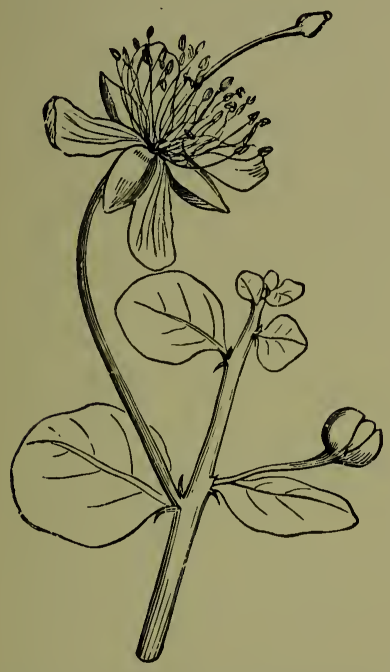

FIG. 274.-Flowering branch of $\mathrm{Cap}$ paris. (From Henslow's "South African Flowering Plants".)

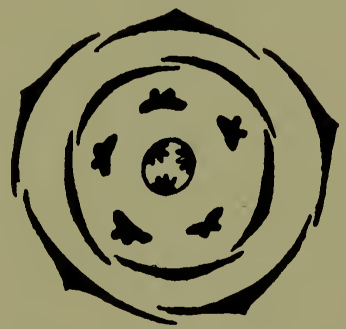

FIG. 275.-Floral diagran of Drosera.

with simple leaves, often climbing by means of thorny hooked stipules.

Order Droseraceæ (the Sundew Family).

Flowers regular, perfect. Sepals 5. Petals 5, very delicate. Stamens 5. Carpels 2, 3, 5. Ovary I-5-celled. Styles long; stigmas simple or branched. Fruit a capsule. Flowers in cymes. Herbaceous plants with a perennial rhizome. Of the six genera of this order, two are found in South Africa. 
A. Ovary I-locular; seeds many, parietal ; anthers opening by slits.

Drosera.-Delicate herbs with a rosette of leaves or a

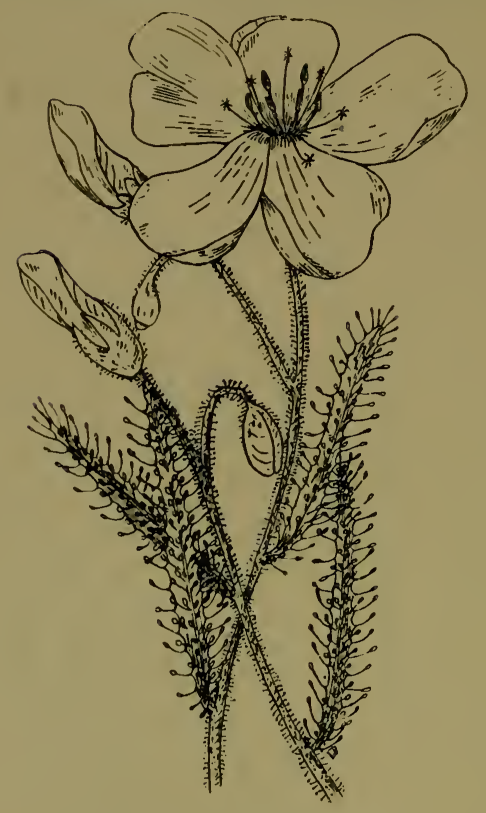

FIG. 276.-Drosera cistiflora, L. leafy stem; covered with curious " tentacles"; or stalks ending in swollen purple heads which glisten with a sticky fluid. Flies, mistaking this for honey, are caught fast. The tentacles are so sensitive to even a gentle pressure that they curve inward and smother their hapless victim. A fluid in the purple heads digests the food containing nitrogen in the insect's body. This is used by the plant especially in seed-making, although the plants can live without insect food. This is why sundews can live in very poor soil which will support nothing else. The genus is found in all parts of the world.

B. Ovary 3-locular; seed one, pendulous, anthers opening by pores, stamens with a sensitive gland.

Roridula is a branched shrubby plant. The tentacles do not curve over its victim as in Drosera.

Dr. Marloth has found that the sticky fluid which impales the insects does not digest them. This fact, together with the differences in habit and in floral structure, possibly entitles it to a position in a separate order.

A spider acts as a scavenger for the plants, removing the insects from the leaves, and is saved the trouble of making a web. Strangely enough the spider can run where the flies 
would fear to tread if they but knew the doom awaiting them. Another still smaller insect lives within the flower and pays for its food by setting off a little spring in the hinged stamen which flies up and scatters the pollen.

\section{Order CRAssulaceæ.}

Flowers perfect, regular. Sepals and petals 4-7. Petals separate or united. Stamens as many or twice as many as the petals. When more than one whorl, the outer are opposite the petals, obdiplostemonous. Carpels separate, as many as the petals, with a honey gland at the base of each. Fruit a group of follicles. Flowers in cymes. The plants are mostly herbs or half shrubs, living in hot, dry climates with the necessary adaptation for such situations. Water is stored in the stems and leaves. The leaves are often packed closely, as in Crassula pyramidalis, L. (p. ro6), and have a waxy, or a lime-encrusted surface. The lime attracts and retains moisture.

\section{A. Stamens as many as the petals.}

Grammanthes.-A small annual growing in sandy soil, with orange or cream - white flowers commonly marked with a V-shaped dark spot on each petal. Stems wiry, with distant pairs of leaves.

Rochea. - Corolla gamopetalous. A half shrub with handsome flowers, crimson, white, or yellow. Stamens borne on the corolla tube. Leaves opposite, sheathing or joined at base. Four species. Western.

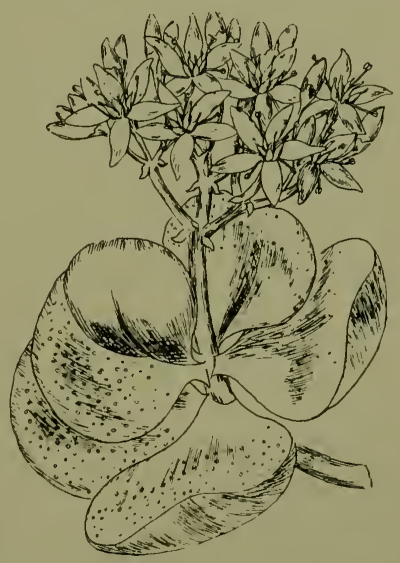

FIG. 277. - Crassula arborescens, Willd. (From "Botanical Magazine".)

Crassula.-Corolla polypetalous. Shrubby or herbaceous plants, with white, red, or yellow flowers. Flowers smaller than in Rochea, arranged in cymes. Leaves usually opposite 
and connate, often fringed with fleshy hairs. About a hundred species.

\section{AA. Stamens twice as many as the petals.}

Cotyledon.-Corolla gamopetalous, showy, with an eggshaped tube and spreading limb; either in cymes or racemes, hanging. Succulent plants with opposite or alternate fleshy leaves. Mostly Eastern. C. ventricosa, Burm. (C'Nenta) is poisonous to cattle (L. H. Walsh). Its flowers are greenish.

Kalanchoë.-Calyx 4-parted. Corolla with an urn-shaped tube and spreading limb; yellow, turning to red. Flowers in closely-branched cymes or loose panicles. Succulent halfshrubs with opposite leaves. Eastern.

Bryophyllum differs from Kalanchoe in the inflated calyx. $B$. proliferum, Bowe, has both simple and compound leaves on the same plant. B. tubiflorum, Harv., shows the lower pinnate of the first leaves of a branch reduced so that the leaves appear simple.

The name means "sprouting leaf". The fleshy leaves fall to the ground, and young plants sprout from the notched edges. These send out roots, and finally the entire plant takes root. See Fig. IIo, p. I22. Vegetative reproduction is quite frequent in the order.

\section{Order BRUNIACEÆ.}

This order of nine genera and forty-four species is peculiar

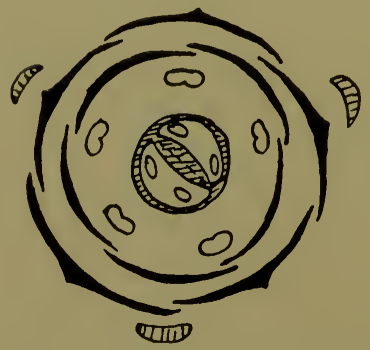

FIG. 278. -Floral diagram of Brunia. to South Africa. It is confined chiefly to the South-Western Cape Province. One of the two species of Thamnea extends to Grahamstown and one species of Berardia reaches to Natal.

They are heath-like shrubs, with flowers in dense globose or flattened heads or spikes or solitary. The flowers are perfect, usually regular, five parted, perigynous, protandrous. Stamens in one whorl, anthers arrow- or heart-shaped. Carpels $\left(3^{-2}\right)$, each with three to four ovules, or one, with one ovule. The carpels 
split apart when ripe, as in Saxifragacea to which the order

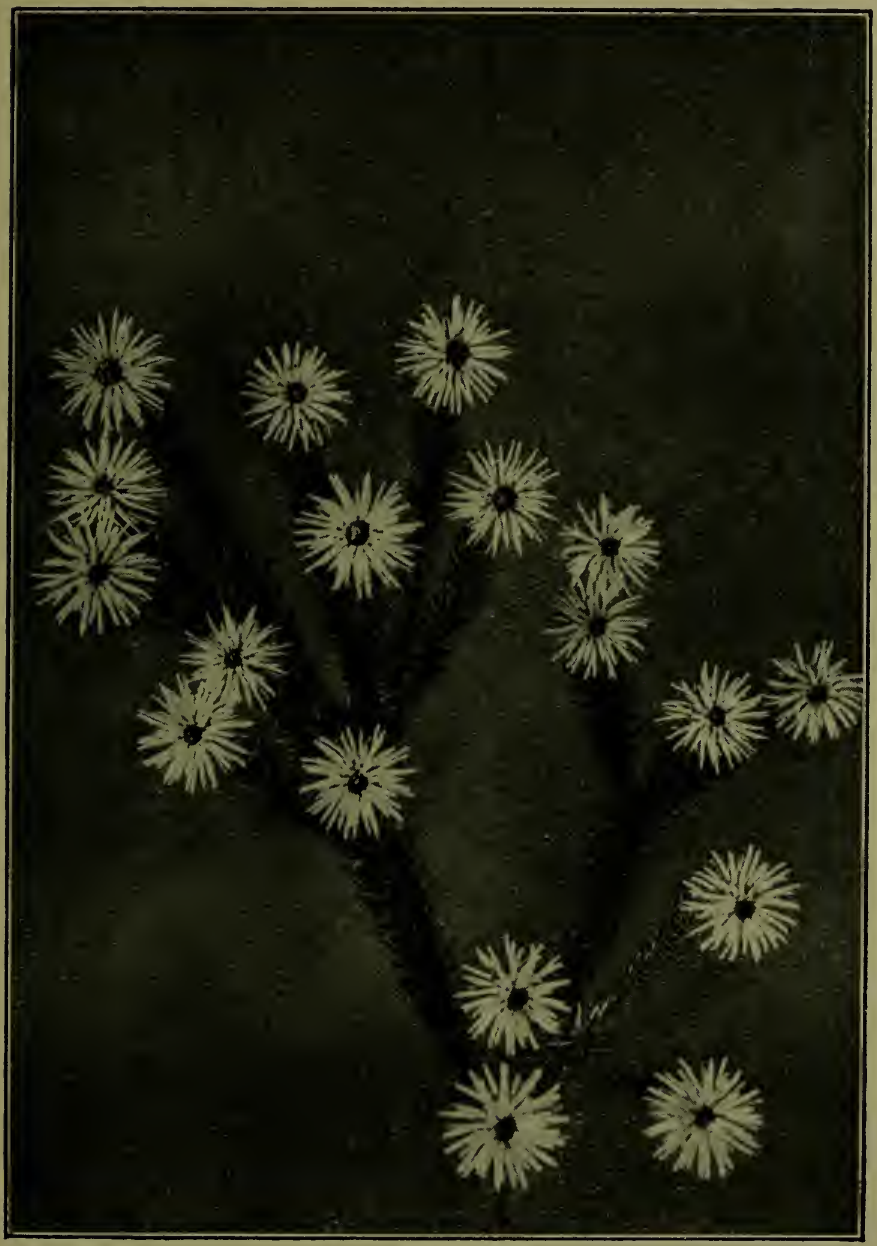

FIG. 279. - Staavia glutinosa, Th. (Photograph by E. J. Steer, Esq.) bears other points of resemblance. Seeds endospermous, arillate.

$$
20 *
$$




\section{Key to the Genera.}

Fruit I-seeded, mostly indehiscent.

Ovary I-locular, style

Ovary 2-locular.

Style $\mathrm{I}$; flowers axillary . . . . Tittmannia.

$$
\text { " I; " solitary, terminal . . Thitate or panicled . BRUnia. }
$$

Fruit a capsule.

Ovary 2-locular, 2-ovuled; flowers capitate.

Styles 2 ; petals free or slightly cohering .

Ovary 2-locular, 4-ovuled; flowers in leafy spikes.

Flowers sympetalous, 5-lobed . . . Lonchostoma.

Flowers choripetalous, 5-lobed; anthers apiculate

Ovary 3-loculate, 6-ovuled.

Flowers in spike-like terminal heads, red . Aunouinia.

\section{Order Rosace£.}

Like the Ranunculaceæ, the Rosaceæ have many free stamens and apocarpous ovaries; but in the Rosaceæ the receptacle is generally hollowed, and the flowers are perigynous

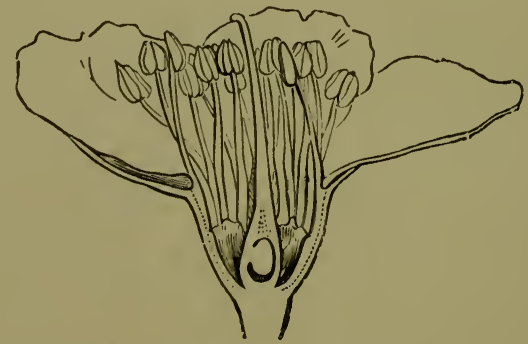

FIG. 280.-Flower of Peach with stamens around the ovary. (From Henslow's "South African Flowering Plants".)

or epigynous. The carpels are often borne on a raised portion of the receptacle, as in Ranunculacer. Sometimes the receptacle is free from the carpels, or it becomes joined to them, as in the apple (epigynous), so that hypogyny, perigyny, and epigyny occur. 
The plants of this order are usually trees or shrubs with simple or compound stipulate leaves. To this important order belong many of our fruits, as Apples, Pears, Peaches, Strawberries, Blackberries, as well as the Roses. The flowers are open, and expose their honey to bees and flies.

The order has a variety of fruits. The fruit is rarely a capsule. The single carpel may form a drupe or stone fruit, as in Apricot. Blackberry has a cluster of drupels. Strawberries have clusters of achenes on an enlarged receptacle. The hollow receptacle of the Apple forms most of the fruit.

The garden fruits belonging to this order and Roses have been introduced into South Africa.

Rubus (the Bramble) is a native of the Colony and of Natal. The fruit is a cluster of little drupes. Trailing shrubs armed with prickles.

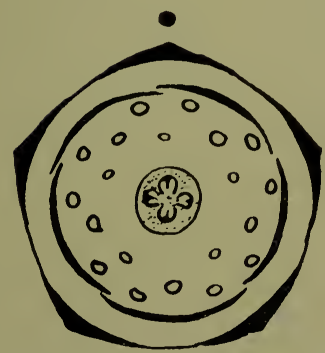

FIG. 28I.-Floral diagram of Pear.
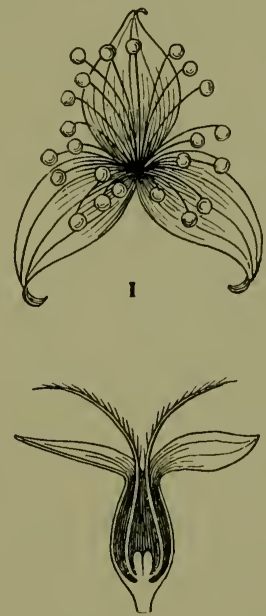

II

FIG. 282.-Cliffor'tia. I. Male flower. II. Vertical section of female flower.

Geum has handsome bright yellow flowers $\mathrm{I}-1 \frac{1}{2}$ inch across. The achenes are very hairy, tailed with the hooked or curved styles.

G. capense, Th., the only South African species, is a herbaceous plant $\mathrm{I}-2$ feet high, with large radical leaves and a few small stem leaves, From Grahamstown to Natal, 
Cliffortia.-Calyx 3-parted (sometimes 4). Corolla wanting. The flowers secrete no honey, but the stigmas are wind

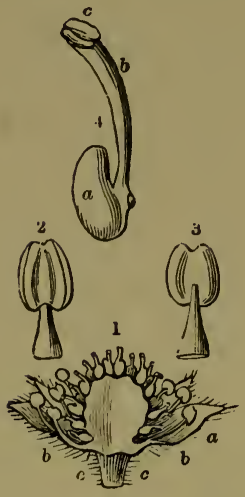

FIG. 283. - I, Flower of Strawberry cut through ; 2 , front : 3 , back of stamen; 4 , pistil ; $a$, ovary ; $b$, st yle ; $c$, stigma. (From Henslow's "South African Flowering Plants".) pollinated. The staminate flowers are often found a long distance from shrubs bearing pistillate flowers. Leaves trifoliate, or the three leaflets may be joined into one. Leaves sometimes opposite. Many have reduced leaves tipped with sharp points. A common bush in the Colony and Natal with small greenish axillary flowers.

Grielum is a trailing plant with hoary compound leaves, growing in sandy places and salt ground. Calyx joined with the 5 -parted succulent fruit. Corolla regular, 5 -parted, with the ro stamens borne at the throat of the calyx (receptacle), tube. Flowers are large and yellow.

Agrimonia, a north temperate genus has been introduced to this country. It is a pest to eastern wool growers on account of the hooked bristles of the persistent receptacle which surrounds the two achenes.

\section{Order Leguminose.}

This order, the second largest in the world, with about 440 genera and 7000 species, is found in every kind of soil, in any climate, and shows a corresponding variety in habit. Trees, shrubs, herbs, erect, climbing, or prostrate occur. Because of the bacteria which live in their roots, they can thrive in and enrich very poor soil. The plants climb by leaf tendrils, stem tendrils, by twining, and by hooks. Leaves alternate, stipulate, or sometimes opposite and ex-stipulate, and nearly always compound. Fruit usually a legume, sometimes a lomentum. Some pods explode and scatter their seeds. Sutherlandia has inflated pods which catch the wind. The pods of Medicago are furnished with hooks, which catch hold of the passer-by and so obtain free rides for the seeds, 
Inflorescence a raceme, panicle, or spike, apparently cymose in Dalbergia. The order is divided into three groups or suborders.

Mimoseæ.-Flowers regular. Corolla valvate. Stamens many or ro.

Cæsalpineæ.-Flowers zygomorphic or nearly regular, back petal folded within the side petals, which are overlapped by the front petals. Stamens ro or fewer.

Papilionaceæ. - Flowers irregular, back petal (standard) folding over the side petals (wings or alæ). The side petals overlap the two front petals, which join to form the keel. Stamens ro.

In some flowers of this group the stamens and pistil are held in the keel, and are released with an explosion, as in Indigofera, so that only one visit of the bee is invited. In the Sweet Pea a brush on the style sweeps the pollen out of the keel. The flowers are usually self-pollinated. In the Bean and Snail Creeper the stigma is forced out when the bee presses down upon the wings, and returns when it flies away, so that the bee is invited repeatedly.

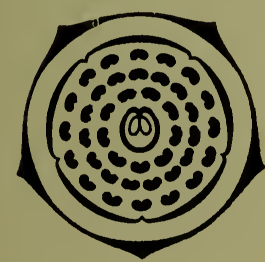

I.

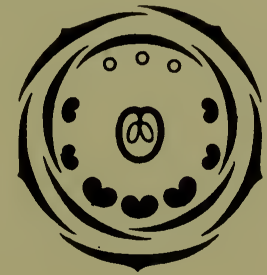

II.

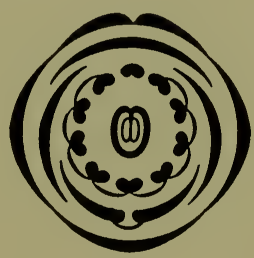

III.

FIG. 234.-Floral diagrams of Leguminosæ, showing folding of sepals and petals in I. Mimosere; II. Cesalpinea; III. Papilionacee.

\section{Sub-tribe Mrmoseæ.}

\section{A. Stamens indefinit ; pollen collected in masses. B. Stamens free.}

Acacia.-The minute flowers are clustered in golden heads or spikes. They are delightfully fragrant. The sepals form a short tube.

Trees with twice-pinnate leaves, except in the Australian wattles, which often develop the blade only in the first few leaves; the petiole then becomes flattened (Phyllode) with the edge turned toward the sun. 
A. horrida, W. (Karroo Thorn or Doornboom) has ivory-white thorns (stipules). A. giraffae, Bch., has strong brown thorns.

BB. Stamens connate.

Albizzia.-Petals united; stamens joined at base into a tube; leaves bipinnate with glands; unarmed. Flowers in heads or spikes with long white, rosy, or purple feathery clusters of stamens. Two South African species.

Zygia, found in Natal, has a longer staminal tube than Albizzia.

\section{AA. Stamens ro; pollen powdery.}

Entada has spicate flowers; the margined fruit breaks transversely into I-seeded parts. Shrubs, mostly climbing by tendrils (terminal pinnæ) or by hooked prickles.

Elephantorhiza (Eland's boontjes) is a small glabrous shrub with very large roots. Legume dehiscing by valves separating from the margins continuous. Leaves bi-pinnate ; flowers in dense spike-like racemes.

\section{Sub-tribe CæSALPINEÆ.}

Cassia.-Flowers nearly regular, yellow. Stamens ı, or the 3 upper wanting. In some the lower anthers are longer,

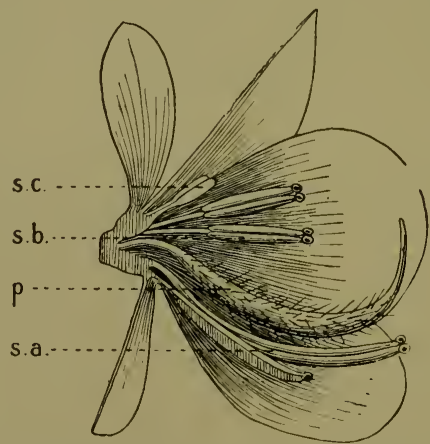

FIG. 285.-Cassia arachoides, Bur. Vertical section of flower: sa, large stamens ; $s b$, small stamens ; sc, staminodes. (From Edmonds and Marloth's " Elementary Botany for South Africa".)

and open by terminal pores. These brush against the insect's body while it is eating pollen from the upper ones. The 
ovaries bend to the right in some flowers, toward the left in others. Trees or shrubs. Eastern. Leaves pari-pinnate.

Schotia.-A handsome Eastern tree, with panicles of crimson or pink flowers. S. latifolia, Jacq. (Boerboon) has monadelphous stamens. Each seed has a yellow cup-like arillus. The pods are'roasted for food. Legume winged; leaves paripinnate.

Sub-tribe Papilionace

A. Stamens free.

Podalyria.-Legume rounded, woolly. Leaves simple or palmately compound.

Silvery-leaved shrubs with deciduous stipules. Flowers purple, rosy, or bluish white.

Virgilia.-Legume flattened, woolly, stuffed between the seeds. Calyx silky. Flowers rosy purple. Leaves ex-stipulate.

V. capensis, Lam., the Wilde Keureboom, is a tree found along riversides throughout the Colony. Leaves compound. Leaflets becoming smooth above, woolly, and rolled beneath.

AA. Stamens monadelphous, forming a split tube. Shrubs or herbs with simple or palmately compound leaves.

Crotalaria.-Legume swollen (not flat) keel sharply beaked. Style long, sharply bent. Legume turgid.

A large genus of shrubs with simple or compound leaves, and yellow, rarely purple flowers, in few-flowered racemes.

Aspalathus.-Calyx nearly regular. Flowers usually yellow.

Shrubby plants with heath-like tufted leaflets on a prominent cushion which is often spine-pointed. The stems are often pale with brown markings.

AAA. Stamens diadelphous. Ovary I-ovuled.

Psoralea.-Calyx concealing the pod, the lower lobe longer and broader than the others. Flowers purple, blue, or white.

A large genus of shrubs or herbs, with pinnate or trifoliate leaves, rarely one foliate, with stipules, and commonly marked with black resinous dots. Strongly scẹnted, Common, often along water-courses, 


\section{I 4 Plants and their Ways in South Africa}

AAAA. Stamens diadelphous. Ovary 2- to several-ovuled.

B. Small herbs, erect or trailing, but not climbing. Leaves 3-, rarely 5-foliate.

Trifolium.-Calyx showy after flowering, concealing the fruit. Keel joined to the wings. Flowers small, red, white, or yellow, in dense spikes or heads. Leaves usually 3 -foliate, stipules joined to the petiole. Herbaceous annual or perennial. The clovers belong to this genus.

Medicago.-Legume not hidden, spirally coiled, often provided with hooks. Keel free from the wings. Lucerne belongs to this genus.

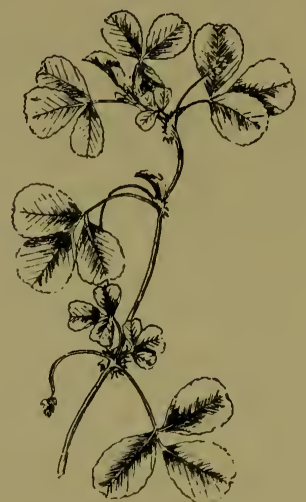

FIG. 286.-Branch of Medicago denticulata, Willd.

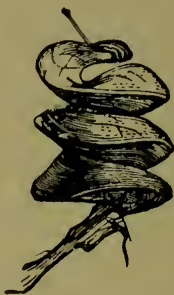

FIG. 287.-Twisted legume ot Lucerne (Medicago sativa, L.). (From Thomé and Bonnett's "Structural and Physiological Botany".)

Indigofera. - Flowers red, purple, or white. Standard bent back. Keel with a spur at each side. Anthers with a small point at the top. Pollen scattered by explosion. Leaves imparipinnate, or 3 to many palmately compound. Legume usually with partitions between the seed. Shrubs or annuals, erect or procumbent.

BB. Trees or shrubs.

Sutherlandia.-Standard shorter than the keel, wings very 
short. Stamens diadelphous. Legume inflated, papery, indehiscent. A fine shrub with scarlet or bright red flowers.

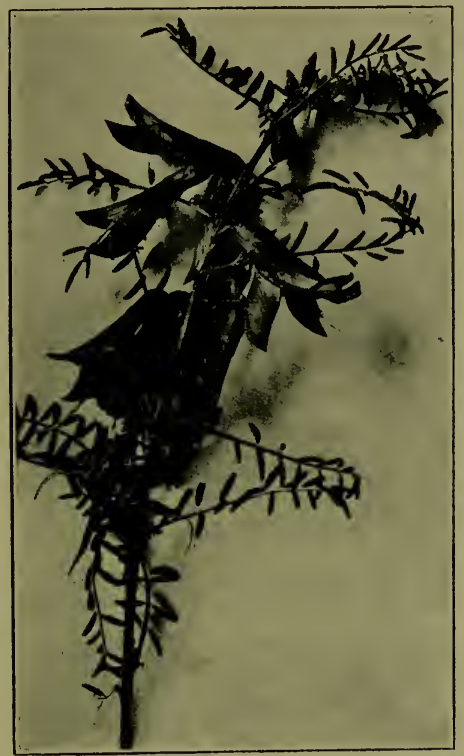

FIG. 289.-Sutherlandia fru'escens, R. Br.

S. frutescens, R. Br., the only species, is found throughout the Colony, uscially on dry hillsides, sometimes near water.

Erythrina.-Standard very much longer than the other petals. The petals forming the keel are not joined to form a support for visitors, as is usually the case, but the flowers are sometimes inverted, so that the standard can serve as a landing. Leaves pinnately trifoliate, the odd one removed from the other two.

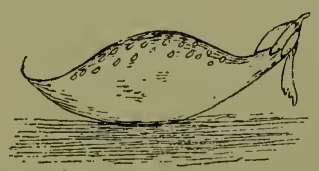

FIG. 289.-Inflated pod of Sutherlandia frutescens, R. Br.

Trees or shrubs with large handsome scarlet flowers. Stem and leaves often prickly. 


\section{Order GeRaniaceE.}

Flowers perfect, regular or zygomorphic, hypogynous. Sepals 5, imbricate, persistent. Petals usually 5, convolute, clawed. Stamens $5+5$, obdiplostemenous, or fifteen in groups of three, connate at base. When but one whorl of stamens is present, the outer antepetalous whorl forms staminodia. Carpels 5, opposite the petals, upon a disk which grows up between them. Stigmas 5 ; placentation axile, ovules 2

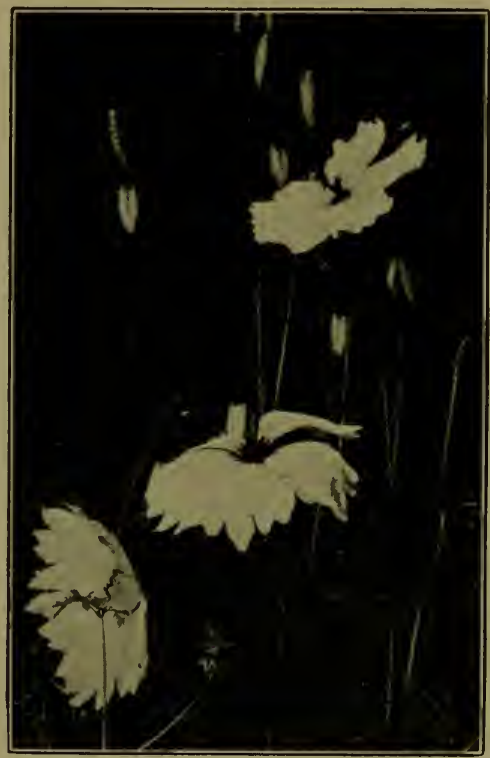

FIG. 290.-Monsonia speciosa, Linn. $f$.

or I in each carpel. The carpels separate when ripe and are indehiscent, forming a schizocarp, e.g. Erodium; or the segments dehisce and set free the seed, and the fruit is a schizocarpic capsule, e.g. Geranium.

Leaves alternate or opposite, stipulate. Herbs or shrubs, often hairy. Roots sometimes large tubers. 
Protandrous, but the stigmas in small flowers may roll back and effect self pollination.

\section{A. Flowers regular.}

Monsonia.-Stamens I 5, in groups of three. Annuals or perennials with usually deeply cut leaves. Peduncles with two bracts above the middle, and one, two, or several flowers in umbels. Flowers large and showy, usually pink or marked with pink. Rootstock often perennial.

Sarcocaulon.-Stamens I 5, monadelphous. Muchbranched, fleshy rigid shrubs, armed with spines, formed from old petioles. The stem is covered with a thick coating of wax

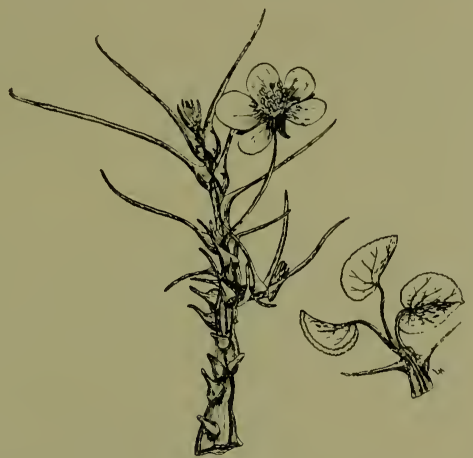
familien.

FIG. 291.-Sarcocaulon Marlothii, Eng., from Die Naturlichen Pfantzen-

and burns with a pleasant odour. Found in very dry places of Eastern and North-Eastern districts.

Geranium.--Stamens I 0 , the alternate longer, with honey glands at the base. Herbaceous plants, with alternate or opposite leaves, palmately lobed. A small genus from the Peninsula to Natal. Fruits explosive when splitting.

Erodium.-Flowers regular, outer whorl of stamens sterile, inner with anthers and a gland at the base of each. Flowers mostly in cymose umbels. Common weeds with simple, usually pinnate parted or cut leaves. The styles twist like a corkscrew on drying, and are caught fast in the weeds. When rain comes they uncoil, and as they lengthen push the 
seed into the soil. The downward pointing hairs help in scattering the seed.
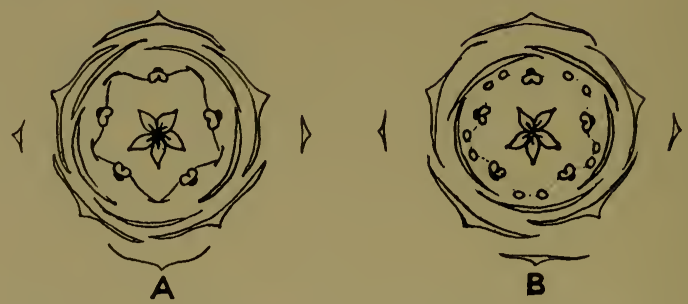

FIG. 292.-Floral diagrams. A, Erodium; B, Monsonia.

\section{AA. Flowers zygomorphic.}

Pelargonium.-Filaments 10 , unequal in length. From 2 to 7 of them bearing anthers. There is but one gland,

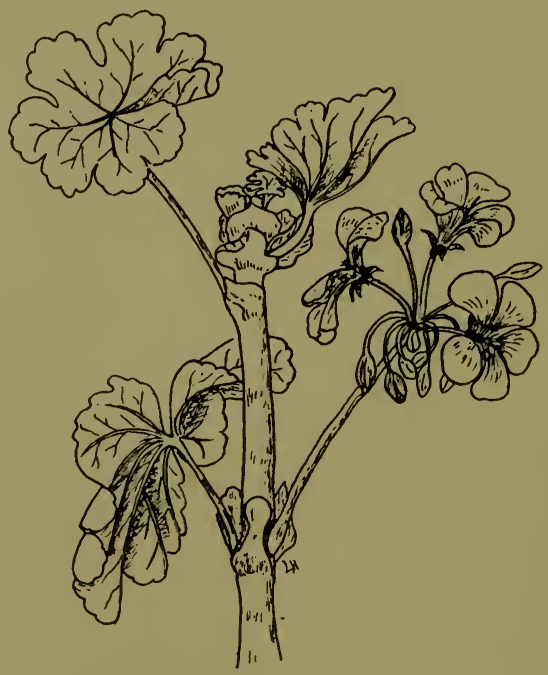

FiG. 293.-Garden Pelargonium.

found at the'base of the broad sepal. The honey is stored in a hollow spur of the calyx joined to the flower-stalk. 
A large genus, usually half shrubby, often with underground tubers in chains (moniliform). The flowers are often cultivated and are

I.

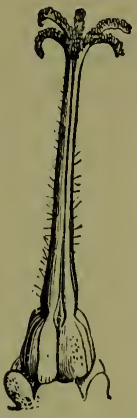

II,

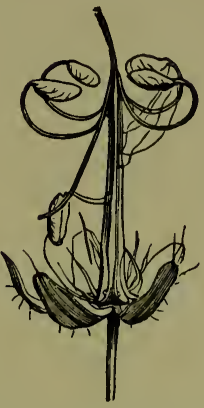

FIG. 294.-Geranium. I. Pistil with honey-glands below the ovary. II. Carpels splitting from the central column of coherent margins. (From Thomé and Bennett's "Structural and Physiological Botany".)

I.
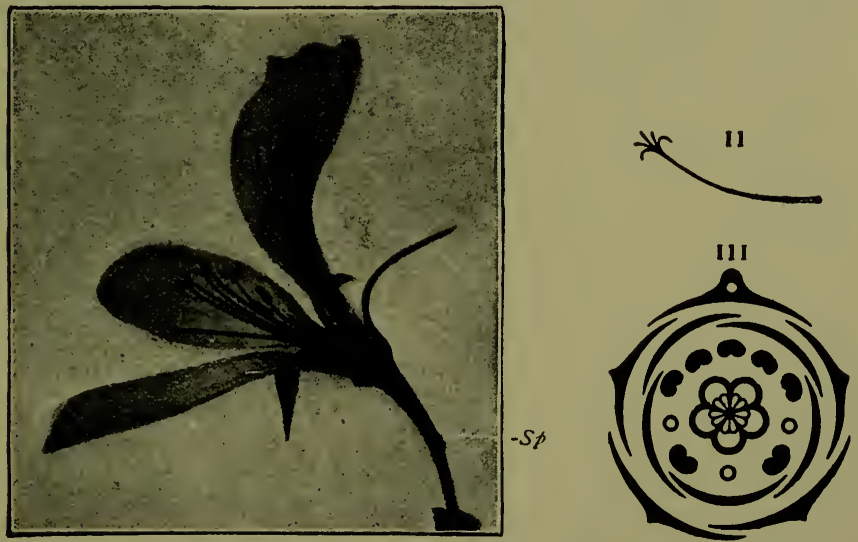

FIG. 295.-Pelargonium cucullatum, Ait. I. Section through flower, $2 \frac{1}{2}$ sepals and $2 \frac{1}{2}$ petals being removed; $S p$, hollow spur of upper sepal. II. Style with stigmas ready for pollination. III. Diagram of flower. (From Edmonds and Marloth's "Elementary Botany for South Africa".)

commonly called Geraniums, from which they differ in the irregular flowers, the stamens, and the one gland. The flowers often give forth a delightful odour at twilight. 


\section{Order OxalidaceÆ.}

Flowers regular, perfect. Calyx imbricate; petals twisted in the bud, clawed, deciduous. Stamens 10 , the 5 opposite the petals shorter. Ovary 5 -celled, with styles of different

I.

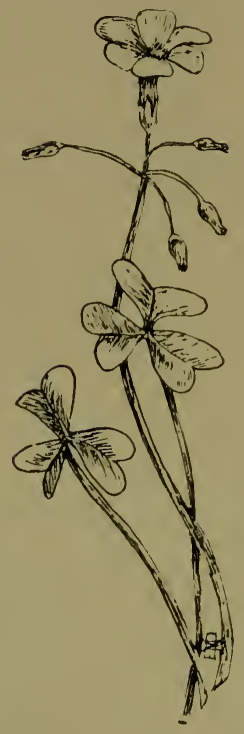

II.

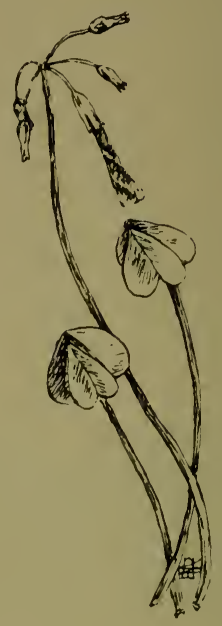

FIG. 296.-The Oxalis. I. Awake. II. Asleep.

lengths in different flowers. Fruit a fleshy, many-seeded capsule. The seed has a fleshy cup or aril at the base. When ripe, this turns suddenly inside out, and the seed is shot off some distance.

Oxalis.-Usually stemless herbs with compound ex-stipulate leaves of 3 to many leaflets. The leaves sleep at night and on very cold days, and the flowers on very bright days as well.

Many species have underground bulbs and fleshy stems. Oxalis is one of our brightest winter flowers. Early in April and May, they clothe the veld with masses of yellow, or stud it with white and red in many shades during July and August. 


\section{Order SAPINDACEÆ.}

Flowers regular, or often zygomorphic, with the ovary at one end of a boat-shaped flower, and a disk at one side of the ovary, between the stamens and petals. The flowers are perfect or diœcious. The staminodes in the pistillate flowers are often so well developed as to be taken for perfect stamens. Stamens 4 to ro, more or less united at the base. Ovary usually a few-seeded capsule. Leaves alternate, simple, or compound, frequently stipulate. Trees, shrubs, or half shrubs.

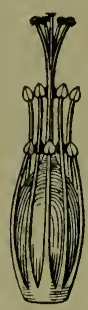

Aitonia.-Dear to the children's hearts is the FIG. 297."Christmas Tree" of the Oudtshoorn, Uitenhage, and Albany districts. Flowers more or less regular,

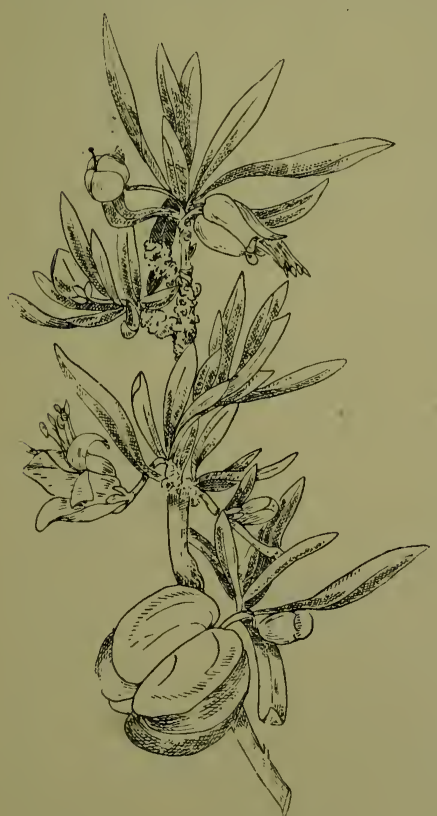

FIG. 298.-Aitonia capensis, L. $f$. (the with 8 monadelph-

ous stamens bending

toward one side of

the flower. The

scalloped disk is

surrounded by the

stamens. Flowers purple.

Of even more interest than the flowers are the gay clusters of balloon-like fruits, hanging purple and yellow and red among the narrow evergreen leaves. Such bright little lanterns are just the thing for lighting Christmas trees. The simple, entire leaves come from clusters of dwarf cushion-like branches.

Melianthus may be mistaken for Aitonia from the similarity of the inflated fruit, but the leaves are compound, the petiole usually winged 
between the pinnæ. The flower has from 4 to 5 stamens. A horseshoe-shaped disk lies between the stamens and petals.

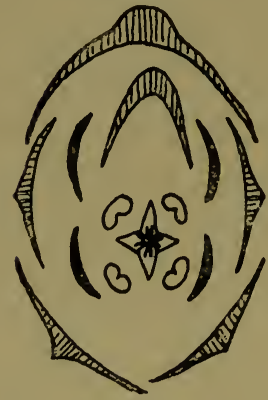

FIG. 299.-Floral diagram. Melianthus major, L. (Engler).
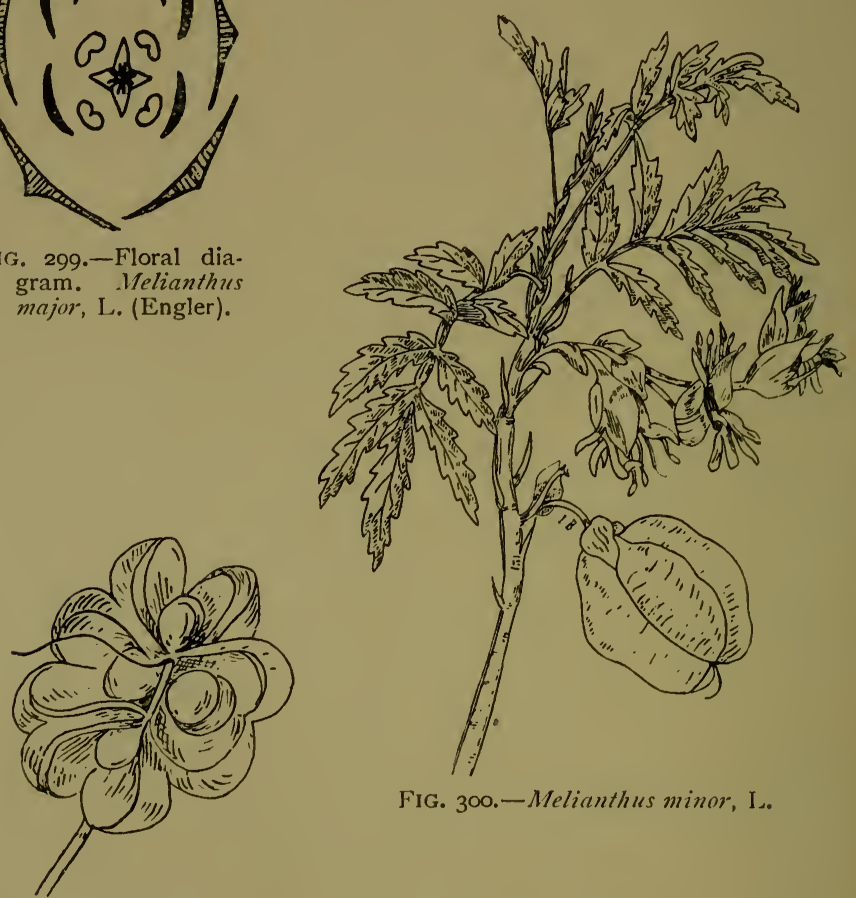

FIG. 300.-Melianthus minor, I..

FIG. 3or.-Woody capsule of Melianthus dregeana, Sond.

During flowering the flowers turn on their axis halfway around. M. dregeana, Sond., has a woody capsule.

Ptæroxylon (Sneezewood) and Sapindus (Wild Plum) belong to this order. Sneezewood furnishes beautiful wood, which takes a polish like mahogany. 


\section{Order RUTACE※.}

Flowers perfect, or unisexual, regular. Sepals 4 or 5 . Petals 4 or 5 , twisted or imbricate. Stamens as many, or twice as many, as the petals, mostly obdiplostemonous. Those opposite the petals may be without anthers. Honey is made in a ring or cup-shaped disk around the ovary. Handsome shrubs or trees known by their gland-dotted leaves, often heath-like. The dots are cavities containing a strongly scented oil. Leaves opposite or alternate, without stipules.

Some of the more familiar genera :-

A. Fruit a 5-r-celled capsule.

Leaves simple.

Staminodia absent.

Petals neither clawed nor bearded . . . Drosma. Staminodia 5.

Ovary raised on a stalk.

A handsome tree . . . . . . Calodendron. Ovary not raised.

Style short.

Petals not clawed, or but slightly clawed. - Adenandra.

Petals clawed, the claw bearded . . . Acmadenia. Styles as long as the petals.

Petals sessile; flowers axillary . . . BARosma.

Petals clawed; flowers terminal . . . Agathosma.

Leaves trifoliate

Leaves paripinnate ; flowers imperfect . . . ZANTHOxYLon.

Leaves imparipinnate . . . . . . Clausena.

AA. Fruit a many-celled berry.

Trees, often with axillary thorns . . . . Citrus.

The Orange and Lemon belong to the Citrus genus, which is not native to South Africa.

Diosma.-Petals and capsule longer than the calyx. Anthers tipped by a gland. Ovary sunk in the disk.

Small shrubs with alternate or opposite heath-like leaves. Flowers white or reddish.

Calodendron (Wilde Kastanien) is found in forests of the Eastern districts and Natal. Petals much longer than the calyx. Staminodia petaloid. Leaves opposite and decussate, evergreen. Flowers white or purplish, in showy panicles terminating the branches. C. capense, Thunb., is a handsome tree in Eastern forests. 
Adenandra ("Shepherd's Delight "). - Petals broad. Stamens and staminodia tipped with a gland. Capsule glanddotted. Small shrubs, with alternate or rarely opposite leaves, and pretty white flowers flushed with red at the back.

Barosma.-Petals much longer than the calyx. Stamens longer than the thread-like or petaloid staminodia, both bearing glands at the tip. Capsule eared at the tip. Small shrubs,
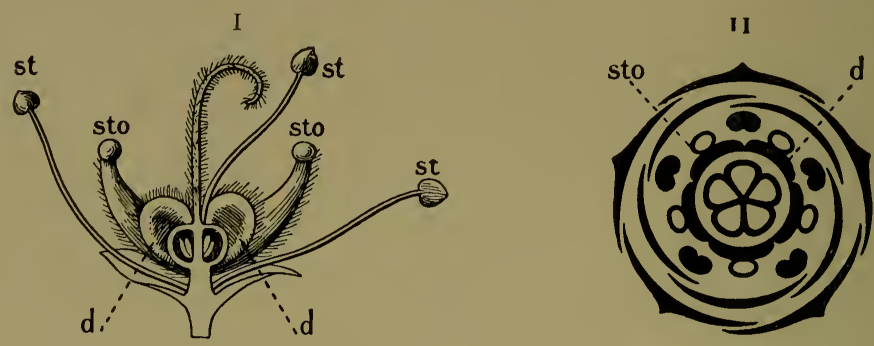

FIG. 302.-I. Section through flower of Barosma crenulata, Hook., after the removal of the petals (magnified): st, fertile stamens; sto, barren stainens (staminodes) $; d$, lobes of disc. II. Diagram of flower ; sto, staminodes $; d$, disc. (From Edmonds and Marloth's "Elementary Botany for South Africa.")

leaves mostly opposite, bordered with glands. B. crenulata, Hook., is the true "Buchu".

Agathosma.-Petals longer than the calyx. Staminodia, like slender clawed petals. Ovary 2-4 lobed. Small shrubs, with alternate or rarely opposite leaves. Flowers in heads or umbels (axillary in one species), white or reddish purple.

Zanthoxylon has flowers with calyx and corolla each of $4-(3-5)$ parts. Staminate flowers have stamens equal in number to the petals and a reduced ovary, which suggests that the flowers were in former times perfect. The pistillate flowers have 5-I carpels, separate or partially united; stamens none or much reduced; each carpel has 2 - I black shining seeds.

Eastern trees with paripinnate leaves, panicled flowers, and large strong thorns on stem and branches.

\section{Order Polygalace}

This order is often mistaken for Leguminosæ, as the flowers suggest a gay swarm of little butterflies ready for flight. A 
difference in the flowers will be brought out by comparing the floral diagrams. Instead of a large standard at the back, the Polygalaceæ have two small petals. One large one in front forms the keel. The two side petals are often absent, and the wings are formed by the two broad coloured side sepals. The stamens are usually 8 , monadelphous. The fruit a bilocular capsule, achene, or a $\mathrm{I}-2$-seeded drupe.

Sepals very unequal, the two side ones wing-like.

Polygala. - Fruit a 2-celled, heart-shaped capsule.

Mundtia.-Fruit a juicy drupe.

Securidaca.-Fruit a winged achene.

Sepals nearly equal similar.

Muraltia.-Capsule flattened, usually horned.

Polygala is a large genus of shrubs or herbs, with showy

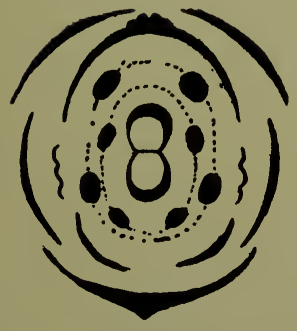

FIG. 303.-Floral diagram. Polygala vulgaris, L. (after Engler).

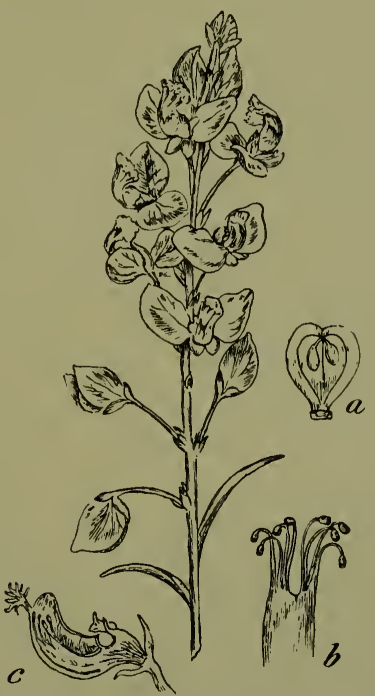

FIG. 304.-Polygala bracteolata, L. : $a$, section of fruit ; $b$, stamens; $c$, section of flower. (After "Botanical Magazine.")

mauve or white flowers in racemes, spikes, or heads. The stamens are concealed within the keel away from rain or 
marauder. As the bee lights on the fringe of the lower petal, its weight bears down upon the keel, so that the pollen, which has been caught in the spoon-tipped pistil, is pushed out and rubbed off on the bee's body. It is then carried to another flower and brushed off on the stigma, which is on the lower side opposite the spoon-tip : 450 species from New Zealand to Arctic Zone.

Mundtia is a stiff bush, with spine-tipped branches, 2 to 3 feet high. Flowers red or white. The berries are eaten by birds and children. Common in dry, rocky places and on the seashore. One species, $M$. spinosa, D.C.

Muraltia.-Usually small, rigid, twiggy shrubs. Leaves often ending in a sharp point. Capsule furnished with four horns or hornless. Flowers purple, or two petals white. Over fifty species.

The genus may be divided into two sub-genera :-

I. Eumuraltia.-Flowers nearly sessile, leaves usually fascicled; capsules long horned.

II. Psilocladus.-Flowers on pedicels ; leaves solitary ; capsules not horned.

\section{Order EuphorbiaceÆ.}

This large order is very prominent in South Africa. The plants, found in dry, rocky places, frequently resemble Cactus,

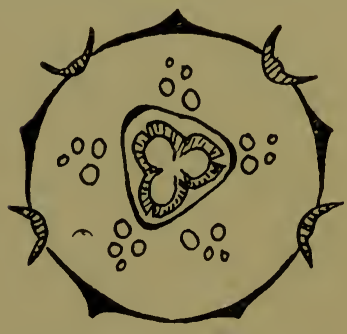

Fig. 305.-Diagrain o a Cya. thium of Euphorbia Peplus, L. (Eichler) containing one female and five male inflorescences. which is represented in the flora of this country only by one native genus Rhipsalis, and Opuntia which has become naturalized. Unless the plants are in flower, it is often difficult to distinguish the two orders. The flowers of the Euphorbia family are inconspicuous and always imperfect. Both corolla and calyx may be absent. The fruit is a 3 -celled capsule, which often bursts with an explosion and

scatters the seed.

Euphorbia is the most familiar genus of the order. Like 
the Cactus plant, the stem may be reduced to a roundish or club-shaped body, surrounded with cushions of leaf bases. Frequently a pair of stout thorns represent stipules of abortive leaves. An axillary thorn (reduced inflorescence) occur in some species. (Cactus has clustered thorns.) What at first

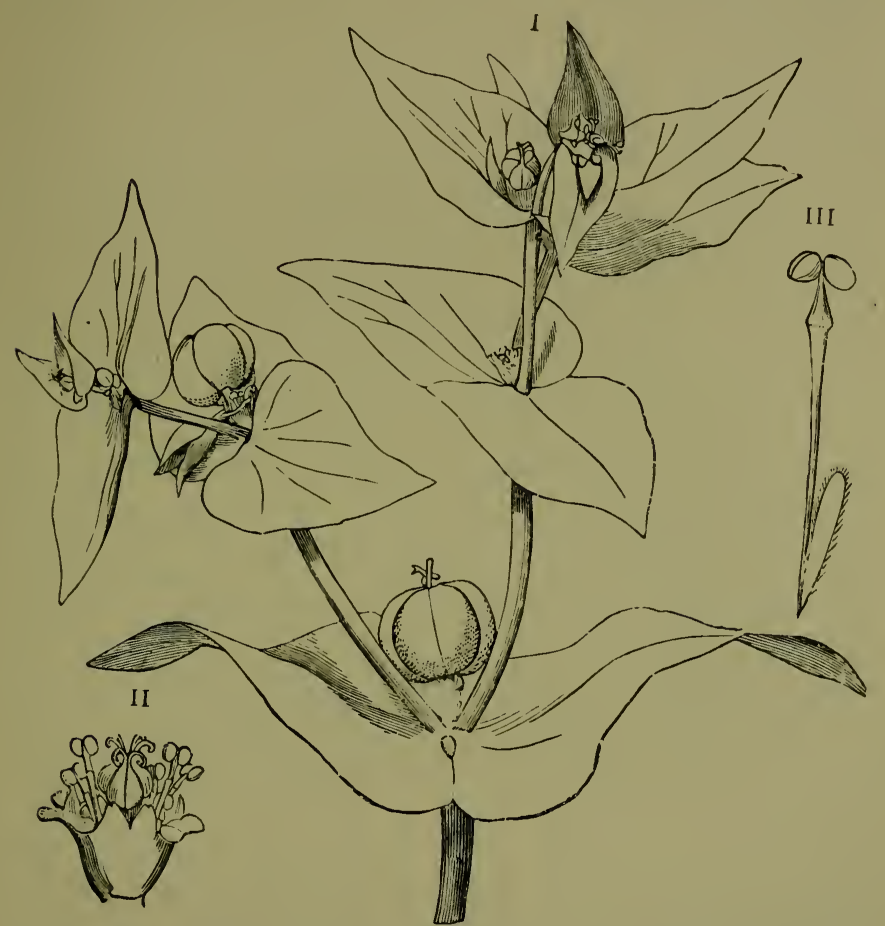

FIG. 306.-Euphorbia Lathyris, L. I. Part of a plant. II. Inflorescence. III. Male flower (magnified). (From Thomé and Bennett's "'Structural and Physiological Botany ".)

seems to be a single flower is an inflorescence consisting of a group of staminate flowers and a single pistillate flower. The pistillate flower is raised on a stalk, and is reduced to an ovary. Each staminate flower is also raised on a little stalk or pedicel, and consists of a single stamen. The central stamens ripen first. The whole inflorescence is surrounded by a cup-shaped 
involucre of 4 or 5 united bracts. The delicate green E. helioscopia, L., is a common weed. The Euphorbia often found in gardens (Poinsettia) is showy, with large bright red bracts underneath the inflorescences. The genus has a milky juice, by which, if not flowering, it may be distinguished from Cactus.

Cluytia is a diœcious shrub or half shrub; the flowers

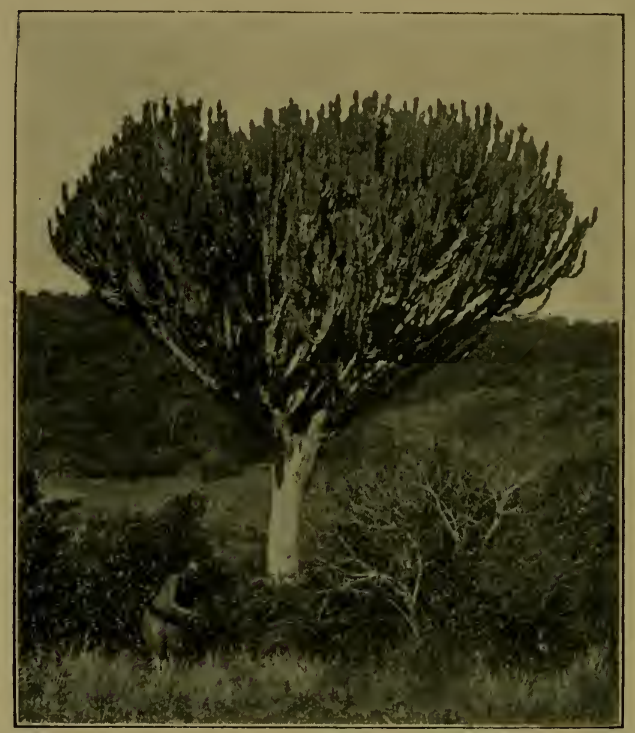

Fig. 307.-Euphorbia tree in Natal. (Wm. Laws Caney, Maritzburg.)

have a double perianth of a greenish colour. The abortive pistil in the staminate flowers suggest that these flowers have at one time been perfect.

Ricinus communis, L., the Castor-oil plant, is partly naturalized in the Colony. Flowers monœcious, calyx 5-parted; filaments much branched. Ovary trilocular, with one seed to each loculus.

\section{Order TILIACEæ.}

Flowers perfect. Sepals valvate. Stamens usually many, free or united in groups. Ovary superior. Fruit of I-4 hard- 
shelled drupes or a capsule with hooked bristles. Trees or herbs, mostly with star-like hairs and stipulate leaves. Flowers in cymose umbels. Anthers with two pollen sacs distinguish this order from Malvaceæ as well as the absence of a staminal tube.

Flowers 4-parted:-

Sparmannia is a handsome tree growing from George to Natal. The flowers are showy, with white or purple sepals and petals. The stamens are sensitive, and spring outward on being touched. The outer filaments are staminodia. In South Africa the stamens are yellow, the staminodia purple - tipped. Leaves on long petioles.

Flowers five-parted:-

Grewia. - Trees or shrubs with purple or yellow flowers and a 4 -lobed drupe, containing 2-4 hardshelled nuts.

Triumfetta.- Shrubs or herbs with small yellow or orange flowers. Capsule covered with long hooked or straight bristles.

Corchorus. - Herbs or shrubs. Leaves alternate, often bordered with long sharp points. Flowers

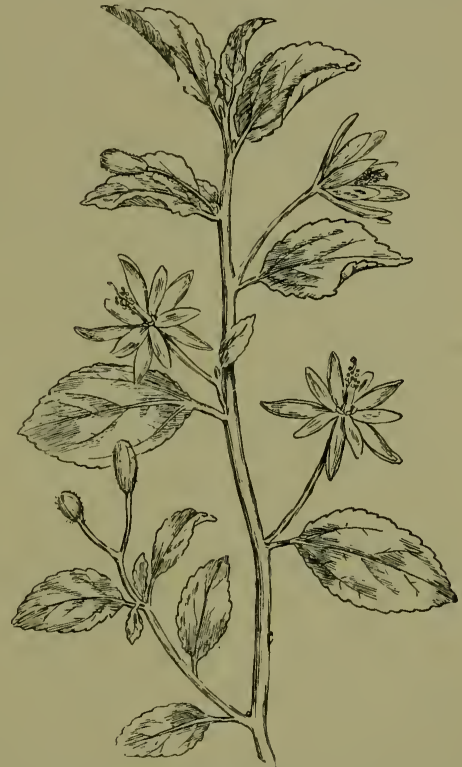

FIG. 308.-Grewia occidentalis, I.) (After "Botanical Magazine.") yellow, on simple or branched stalks. The plants are cultivated in India for their fibres, which are woven into coarse cloth for gunny sacks.

\section{Order Malvaceæ.}

Flowers perfect, regular. Sepals valvate, often surrounded by a circle of bracts (epicalyx). Petals 5 , twisted in the bud. 
The stamens are always joined to form a tube (monadelphous), and attached to the petals at the base, so that the corolla is slightly gamopetalous. The stamens branch at the top, so that a great many half anthers are present (anthers with but one cell). The fruit is a capsule or a schizocarp with several carpels; placentation axile. The flower-stalk is jointed below the flower. Seeds often hairy. The cotton plant (Gossypium) belongs to this order.

Herbs, shrubs, or trees, with alternate, stipulate leaves. Flowers solitary or in cincinni.

A. Fruit of separate carpels. Stamens bearing anthers at or to the very top.

B. Stigmas as many as the carpels.

C. Styles thread-like.

Althea.-Epicalyx 6-9-leaved

Malva.-Epicalyx 3-leaved.

CC. Stigmas cushion-like.

D. Epicalyx present, 3-parted.

Malvastrum.-Carpels with r ovule.

Sphæralcea.-Carpels with 2-3 ovules.

DD. Epicalyx wanting.

Sida.-Carpels r-seeded.

Abutilon.-Carpels 3-I2-seeded.

BB. Stigmas twice as many as the carpels.

Pavonia.-Epicalyx of 5-20 leaves.

AA. Fruit a capsule. Stamen tube 5-toothed at the apex. ${ }^{1}$ Stigmas cushion-shaped (capitate).

Hibiscus. -Ovary 5-celled. Epicalyx of 5-many bracts.

Malvastrum. - A shrub or herb with purple flowers (rosered or red and white), borne on short stalks in the axiles of the leaves, singly or in racemes. The leaves and stems are often sticky, softly downy, or covered with bristles.

Sida.-A low-growing shrubby plant with small white or yellow flowers (rarely purple). The flowers open for a short time about noon. The stigmas ripen at the same time as the anthers. (The stigmas reach out among the anthers and help themselves to pollen.) Flies sometimes visit the flowers.

Abutilon.-Shrubs or herbs, erect or prostrate, with soft

${ }^{1}$ The teeth are regarded by some as the remnant of the outer whorl of stamens. 
velvety stems and leaves. Pale yellow flowers an inch or more across. They are sometimes visited by birds.

Hibiscus.-Several species of this genus are cultivated in the garden. H. rosa sinensis, L., has large brilliant scarlet flowers.
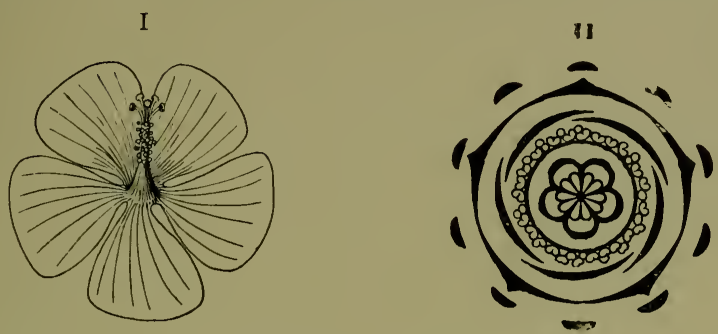

FIG. 309.-Hibiscus. I. Corolla, with petals adherent to monadelphous stamens. II. Diagram. (From Edmonds and Marloth's "Elementary Botany for South Africa ".)

H. calycinus, Willd., and $H$. Ludrvigii, E. and Z., are tall shrubs

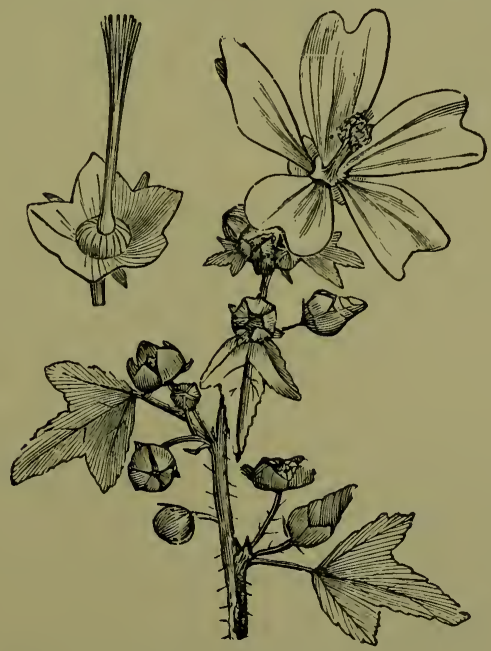

Fig. 3ro.-Malva. I. Portion of plant (reduced). II. Pistil. (From Thomé and Bennett's "Structural and Physiological Botany".)

with large yellow flowers and dark purple centres. Some species are low herbs with smaller flowers. Five pointed teeth 
crowning the staminal tube are considered to represent the outer whorl of stamens.

The larger flowers are much frequented by sugar-birds, which sip the honey on the wing. The fact that the birds seldom light on the flowers may account for the fact that these obliquely hanging flowers are so nearly regular. The smaller herbaceous flowers, like those of Sida, have short stamen tubes, and stigmas that can curve over and help themselves to the pollen which ripens with the stigmas (cf. Geraniaceæ and Compositæ).

\section{Order SterculiaceÆ.}

Flowers regular. Calyx lobes united, valvate. Petals 5, convolute. Stamens monadelphous (sometimes merely joined at the base). The outer whorl staminodial or absent. Ovary superior, of I, 2, or 5 carpels. Fruit capsule, or indehiscent. Flowers in cymes, with no epicalyx.

Trees, shrubs, or herbs with alternate stipulate leaves. The order is closely related to Malvaceæ, from which it may be known by the 2-celled anthers. Theobroma, from which chocolate is derived, belongs to this order.

\section{A. Flowers imperfect-petals none.}

Cola.-Staminate flowers with I0-1 2 sessile anthers in a ring. Pistillate with a five carpelled ovary and abortive stamens ; seeds numerous, ex-albuminous. Leaves entire.

C. Natalensis. - Kafir Umtenenenda, a tree in East Pondoland.) From trees on the West Coast seeds are used in preparing "Coco-Kola".

Sterculia.-Calyx coloured, downy on both sides; staminal column bearing many scattered extrorse anthers. Carpels 5 , seeds many, albuminous.

Trees with palmately compound leaves, found at Uitenhage and the Transvaal.

AA. Flowers perfect, petals present, staminodia alternating with the stamens.

Dombeya.-A 3-leaved, r-sided, deciduous involucre subtends the flowers. Calyx bending back as the flowers 
open. Petals twisted, unequal-sided. Stamens I0-I 5 , alternating in parcels of $2-3$ with 5 slender staminodia. Small

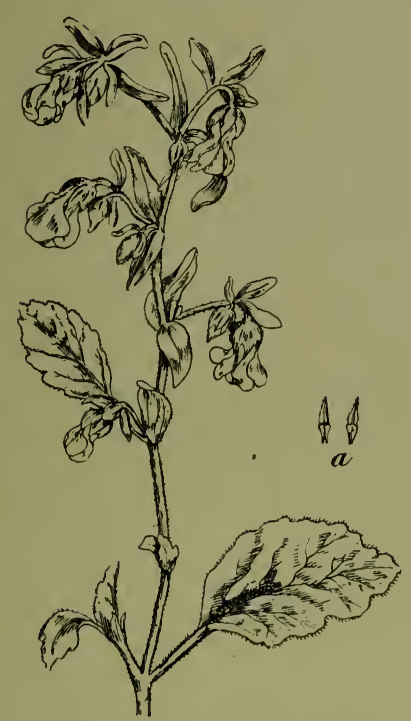

FIG. 3r.-Hermannia althafolia, I. : $a$, stamens. (After "Botanical Mágazine ".)

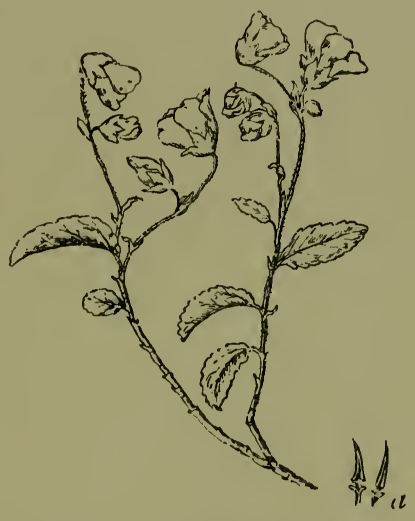

Fig. 3r2.-Hermannia (.Mahernia) ovalis, H. : $a$, stamens.

Eastern trees with an abundance of white or rosy flowers. The petals become papery and enlarged, remaining on.

AAA. Flowers perfect, no staminodia.

Hermannia is a very common, more or less prostrate, weed with the habit of a shrub or an under-shrub. The calyx is often inflated. The flowers red, orange, or creamy white. Stamens 5, opposite the petals, broad, narrowed toward the top or bottom. Leares entire or toothed, often plaited. The entire plant often

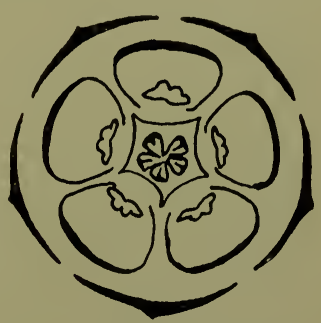

FIG. 3r3.-Floral diagram of Hermannia. covered with stellate hairs, woolly, velvety, or sticky. 
Mahernia, formerly regarded as a separate genus, is placed in a sub-section of Hermannia by Engler. In Mahernia there is a sudden cross-like broadening of the stamens above the middle.

\section{Order PenÆaCE}

This order is confined to the narrow limits of the southwestern region of the Cape Province. Its six genera, comprising twenty-two species, are all heath-like, xerophytic shrubs with opposite evergreen leaves.

Flowers regular, 4-parted; calyx coloured, persistent, valvate, enlarging; petals wanting. Stamens 4 , alternating with the sepals, borne at the throat of the tubular receptacle. Ovary free, 4 -locular, styles simple, ovules $4-2$ in each loculus, anatropous, ex-endospermous. Fruit a capsule. Flowers axillary, solitary, or in pairs, surrounded with showy bracts which are resinous in Sarcocolla.

Ovules 2 in each loculus, erect.

Styles 4 -angled or winged; stigmas 4 , placed crosswise.

Styles 4-winged . . . . . . Penea.

Styles 4 -angled, not winged . . . . . Stylapterus.

Styles terete; stigmas 4 -lobed capitate. .

Calyx tubes not longer than the lobes; stamens included

Calyx tube longer than lobes; stamens exserted; bracts resinous . . . . Sarcocolla.

Ovules 4 in each loculus, 2 ascending, 2 hanging.

Calyx tube 4-ribbed, scarcely longer than lobed. Flowers crowded in dense spikes . . . GLischrocolla.

Calyx tube long; flowers axillary scattered . EnDONEMA.

The few genera and species, their limited distribution and the development of the embryo sac which Miss Stephens has investigated, goes to confirm the belief that this endemic order is a very primitive one.

\section{Order Geissolomatace:}

This order, containing but one genus, was formerly included among the Penafacea but has been removed because of the following characters. 
In Geissoloma the calyx is imbricate, subtended by two

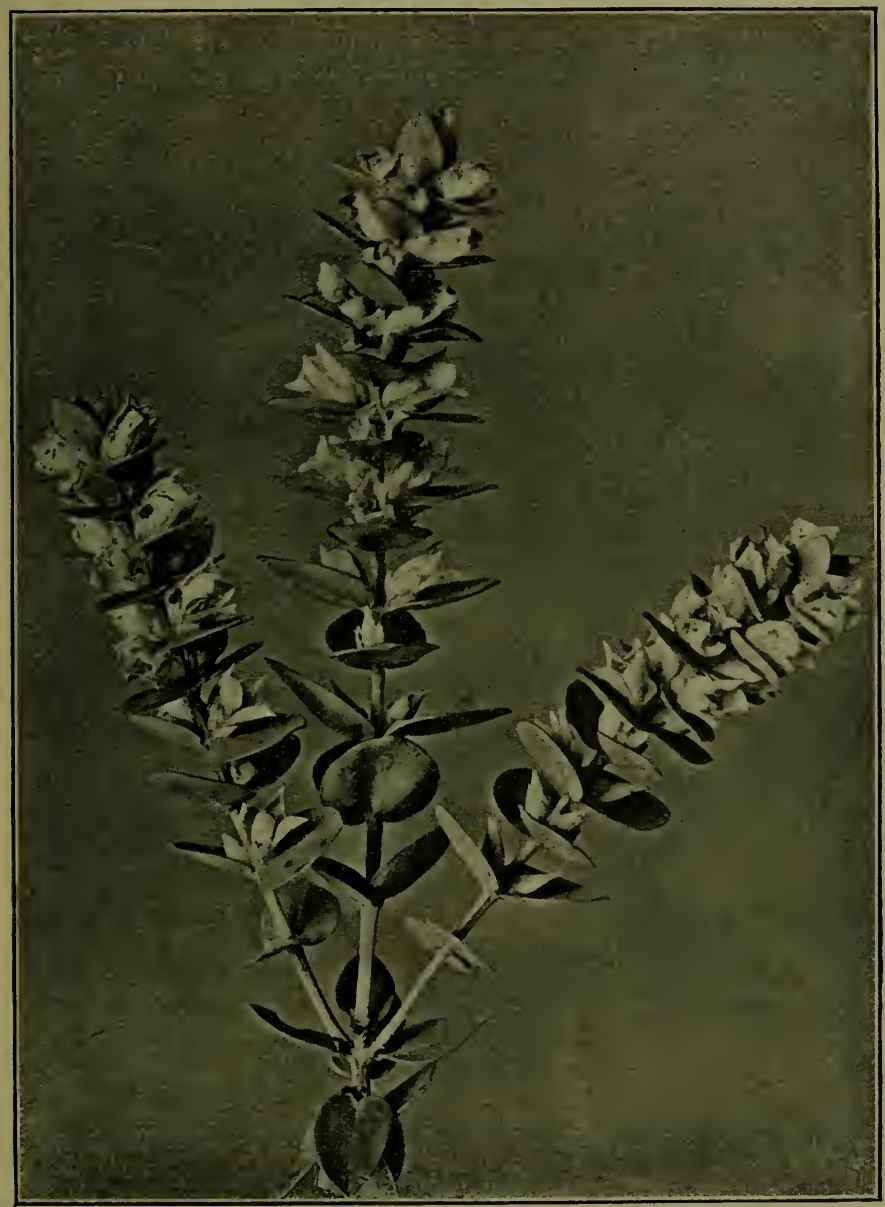

FIG. 314.-Geissoloma marginatum, A. Juss. (Photograph by E. J. Steer, Esq.) The oldest flowers are above.

ranked, imbricate scaly bracts. Stamens 8 in the base of the perianth, the four alternating with the lobes rather smaller, 
anthers versatile, seeds endospermous. Capsule loculicidal, seed solitary. Clanwilliam, Swellendam.

A shrub with opposite, ovate-cordate leaves and axillary solitary flowers. Perianth membranous. The photograph, Fig. 3 I4, shows the oldest flowers at the top, the younger below.

\section{Order ThyмeLÆACEÆ.}

Flowers perfect, with a long coloured tube and a 4-parted calyx (sometimes 5). The petals are wanting, or possibly represented by 2 or 8 scales at the throat of the long "calyx tube" or hollow receptacle. The fruit is an achene, or a berry
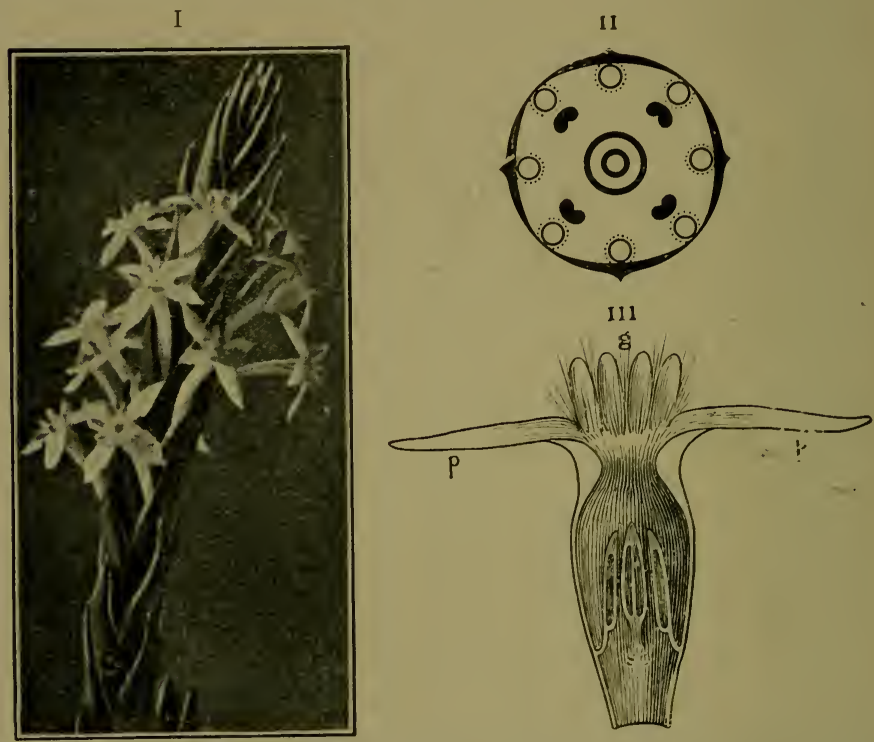

FIG. 315.-Struthiola. (From Edmonds and Marloth's "Elementary Botany for South Africa".)

which fits so closely within the hollow receptacle that it looks like an inferior ovary. The tube often breaks off just above the ovary. Stamens as many or twice as many as sepals, borne on the tube. 
Mostly slender shrubs with very tough bark and heath-like leaves. The flowers are arranged in heads, umbels, racemes, or leafy spikes. Honey may be found at the base of the tube by long-tongued insects. Phloem is formed internal to xylem.

A. Calyx without scales or glands.

B. Flowers in stalked umbels 4-5-parted. Anthers within the tube.

Peddiea.-A glabrous shrub with obovate shining leaves, found in Natal.

BB. Flowers in heads or spikes, or in the axils of the leaves.

C. Anthers concealed within the tube on short filaments.

Arthrosolen. ${ }^{1}-$ Flowers in heads or axillary. Leaves sessile.

CC. Anthers on slender filaments showing above the tube.

D. Stamens ro. Flowers in heads.

Dais.-Flower heads surrounded by a 4 -leaved involucre. Leaves large, flat. Eastern district and Natal.

DD. Stamens 8. Flowers in spikes within axils of leafy bracts.

Passerina.-Nut dry, with a hard shell. Leaves opposite and decussate.

Chymococca.-Berry fleshy, containing a hard seed, similar to Passerina. Fruit a fleshy drupe.

AA. Calyx having scales or glands in the throat, or more or less concealed in the tube.

Cryptadenia.-Stamens 8. Glands in the middle of the tube. Flowers purple or rosy, single or few. Leaves opposite. Western.

Lachnæa.-Stamens 8. Glands in the upper part of the tube, partly hidden among bristles. Flowers in heads. Scales 8 , below the stamens. Shrubs with slender branches and opposite or scattered leaves. Flowers in umbels with or without an involucre (sometimes solitary).

Struthiola.-Glands at the top of the tube, conspicuous. Filaments very short. Calyx 4-parted. Stamens 4. Heath-like shrubs with linear leaves.

Gnidia.-Stamens 8-1o. Glands petaloid or fleshy, 4 or ro. Heath-like shrubs, with rarely broad leaves. Flowers in spikes or solitary. A large genus. (Including Lasiosiphon.)

\section{Order Onagraceis.}

At first one would hardly suspect the members of this order found in South Africa to be the near relatives of the well-known Fuchsia. But the solitary flowers agree in an inferior ovary, usually 4 -celled, with axile placentation and

${ }^{1}$ Also placed in Gnidia. 
many seeds; a 4-parted valvate calyx, 4 petals usually twisted. Fruit usually a capsule. Perennial herbs or shrubs. Flowers adapted to bees or butterflies and moths. Those of Montinia to flies. Phloem internal to xylem.

Jussieua.-A genus of land or floating plants. Calyx persisting as a crown on the inferior ovary. Sepals 4-5. Petals 4-5. Stamens 8-10. Capsule 4-5-celled. Flowers yellow, white. Seeds small. Herbaceous or shrubby. Leaves alternate. Eastern.

CEnothera (O.biennis, L., Evening Primrose).-Naturalized near Cape Town. The flower has a very long axis tube, ad-

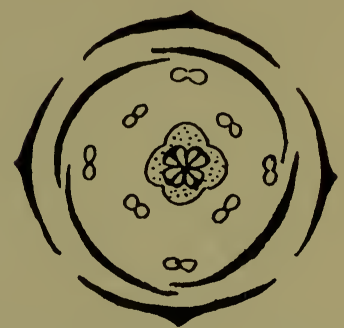

FIG. 316.-Floral diagram of Epilobium.

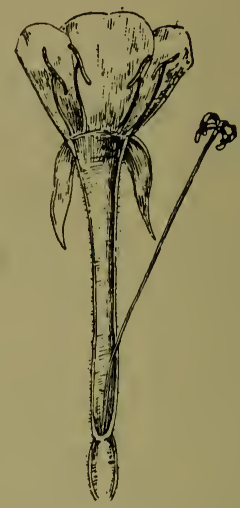

FIG. 317.-GEnothera biennis, L. Section of flower.

mitting only the long tongues of moths, which fly at night about the spikes of delicate yellow flowers, attracted by the evening scent. After a night of revelry the flower withers and falls, leaving the long green ovary, which looks like a flower-stalk. If the flower does not succeed in attracting the moths it stays open for a while the following day.

Epilobium can be distinguished from Enothera by the smaller rosy purple blossoms and hairy seeds which, after the capsule has burst, are sent adrift far and wide. In E. hirsutum, L., the stigmas and stamens ripen together. If put to it the stigmas can roll back and pollinate themselves. In other 
species the stigma is undivided, and since the stamens ripen first the flower cannot fertilize itself. It was Epilobium which led Conrad Sprengel to make the discovery of dichogamy, or the unequal ripening of stamen and pistil.

Montinia, which is described in Chapter XIV, also belongs to this order.

\section{Order UMBELLIFERæ.}

Plants of this order can usually be easily recognized. Many are herbs with stout stems hollow between the nodes. In
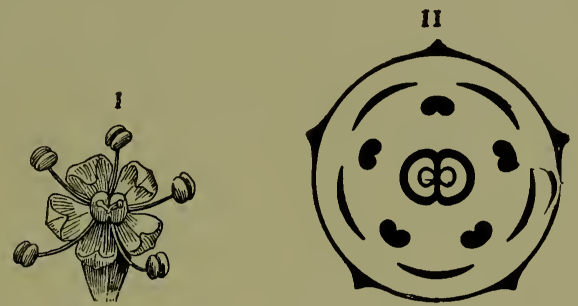

FIG. 318.-Bubon Galbanum, L. I. Flower. II. Floral diagram. (From Edmonds and Marloth's "Elementary Botany for South Africa".)

South Africa, as in the case of so many other plants, the flowering stalks often appear after the leaves, which have prepared food to be stored in underground reservoirs. They have alternate, exstipulate, much-divided leaves sheathing the stem. Or the leaves may be entire with narrowed petioles. The flowers are usually arranged in compound umbels with an involucre. Sepals 5, small. Petals 5 or none, usually regular, but the outer petals of the outer flowers are often longer, reminding us of the ray flowers of the Sunflower family. Stamens 5. Ovary inferior, 2-parted. On the top of the ovary is a disc where the honey is exposed to short-tongued flies, though bees visit the flowers also. When ripe, the dry schizocarp

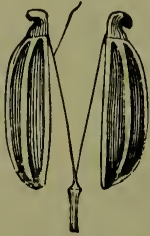

FIG. 319.-Fruit of the Fennel : a, carpophore. (From Thomé and Bennett's "structural and Physiological Botany".) splits apart; the two carpels are supported on a forked stalk which runs up between them. The fruit may be flattened on both sides or at the backs of the carpels. Carpels I-ovuled. 
A strongly scented oil is contained in cavities extending the length of the fruit.

The seeds have abundant endosperm; the fruit are adapted to wind distribution.

The plants show a sympodial growth and the umbels are frequently cymose.

The flowers are protandrous. Perfect, monœcious and diøcious forms occur.

Hydrocotyle has few flowered umbels of a cymose type. They are so reduced that the umbel may be mistaken for a single flower and the 4-6-parted involucre for a calyx. The fruits are flattened at the sides. Frequently but one flower bears fruit in the umbel, and one carpel is reduced.

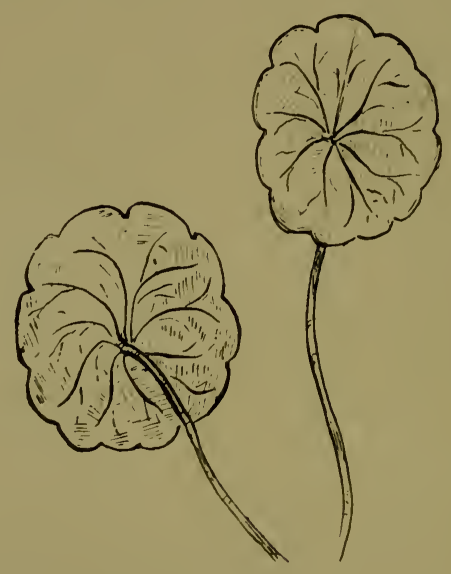

FIG. 320.-Peltate leaves of Hydrocutyle.

Slender herbs in moist places with peltate or reniform leaves or creeping shrubs showing a xerophytic nature in their welldeveloped underground system and rigid or hairy leaves.

$H$. verticillata, Th., is common by furrows with peltate leaves. $H$. solandra, L., is adapted to the sandy hillsides where it is found. It has white, woolly, wedge-shaped leaves, which come up in tufts from underground stems. Some species have linear leaves.

Bubon.-Umbels large, many rayed, yellowish-green. Involucre and involucel of many linear segments. Carpels flat- 
tened at the back, with narrow wings at the side. B. galbanum, L. (wild celery), is a common shrub with wedge-shaped leaflets. Some people are poisoned by touching the leaves.

Bupleurum has compound umbels of yellow flowers. Fruit flattened at the sides. First leaves divided, upper ones simple, linear. The petioles may become changed into phyllodes.

Arctopus is a common, low-growing plant with a rosette of leaves flat on the ground. The flowers are diœcious, but the two plants are not far apart. The staminate flowers have ovaries which are sterile. The involucre leaves are sometimes large and spine-tipped.

Hermas is a large almost shrubby plant, with entire leaves and large compound umbels of white or purple flowers. Some umbels contain only staminate flowers. The leaves are large, simple, clothed on one or both sides with white, woolly hairs. Hermas gigantea, L. f., is the "tondelboom".

Garden vegetables belonging to this order, are parsnip, carrot, celery, caraway.

\section{Order ERICACE}

While every South African knows in general what heaths are, it is difficult to give in a few terms the characteristics of the order. A so large and widely distributed order we should expect to vary in different ways from any genus which might be taken as a type.

That the flowers are perfect and the corolla regular are about the only unqualified statements that can be made of the floral characters. The glandular disc " usually" present beneath the ovary suggests that the order may be one derived from the Geranial group of Choripetalæ, a group that usually retains a double whorl of stamens and carpels equal in number to the petals. ${ }^{1}$

Calyx free 4-6 toothed, lobed or parted.

${ }^{1}$ In the orders belonging to the cohorts Contortæ and Tubifloræ the disc is also frequently evident. It is possible that they too have had a Geranial origin, an opinion held by Werner. ("New Phytologist," 1913.) 
Corolla hypogynous or (in Lagenocurpus) arising from the middle of the ovary, contorted or valvate in bud; sympetalous, of 2-5 (6-10) lobes or free, of 3-7 petals.

Stamens 3-10 (rarely more), obdiplostemonous, frequently horned or bearded at base, often dehiscing by terminal pores

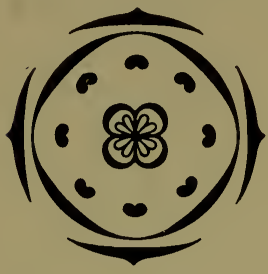

Fig. 321. - Floral dia. gram of Erica. (From Edmonds and Marloth's "Elementary Botany for South Africa".) or lateral slits. The anthers are included within the corolla or they may be exserted.

When bees visit the flower they touch the hanging stamens, or their horns, and are dusted from the pores. The stigma, being longer, is touched first. The horns also prevent the entrance into the flower of unwelcome visitors.

Nineteen of the fifty-six world's genera are described as belonging to South Africa. All are mentioned as "heath-like" (except Hexastemon which differs in being white, woolly). The heaths are usually shrubs rigid with reduced narrow rigid linear leaves alternate, opposite or whorled, with revolute margins, connate or free from the under side, forming a channel beneath.

Miss Ternitz has found that the fungi which grow on the roots of Ericaceæ forming mycorhiza, appropriate free nitrogen. It is difficult to transplant heaths successfully, which may be in part due to the fact that the appropriate fungus is lacking.

Azalea, Rhododendron and Laurel, northern representatives of this order, have broad leaves.

Stamens 8-rarely 6-7.

Erica.-Calyx equally 4-parted, usually much shorter than the corolla. Seeds light and usually very numerous rarely 2 in a cell. A large genus of over 400 species. The flowers are beautiful and of a great variety of shapes and colours. Inflorescence terminal or in upper axils; pedicels I-flowered; bracts 3 , rarely fewer or wanting.

The finest heaths are found at Riversdale and Caledon. A few are found as far east as Natal. Some are sticky on the outside of the flower, and so ward off ants. The stems, closely beset with small leaves, perform 
a similar service. The leaves are often bordered with hairs, which are always a severe trial to ants. Shrubs, from a few inches to Io feet high.

Eremia.-Seeds one in a cell. Cells 2-4. Flowers small, bell-shaped, in terminal umbels. Chiefly Western.

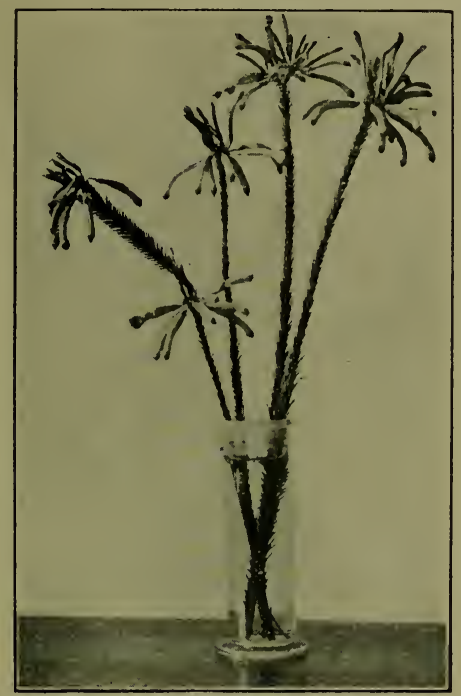

FIG. 322.-Erica Massoni, L.

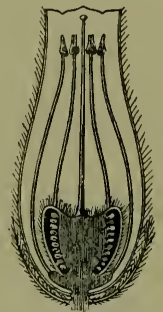

FIG. 323.-Erica cerinthoides, L. One-half of flower.

Stamens 3-4-sometimes 5-6.

Blæria.-Flowers 3-4 parted, bracts none Corolla small. Small shrubs resembling Erica. Western.

Grisebachia.-Small shrubs differing from Eremia in the number of stamens, and ovary 2 -celled.

\section{Order Plumbaginaceæ.}

Calyx remaining on. Corolla regular sympetalous. Stamens 5, opposite and adnate to the petals. Ovary I-celled, superior, with one pendulous ovule. Herbs or half shrubs, often growing near the sea.

Plumbago (Kafir, Um Ti wamadoda).-Calyx with sticky hairs along the ribs, which help to scatter the seed. Corolla 
tube much longer than the calyx, twisted in bud; limb spreading. Stamens free from the petals. Herbs or shrubs, often climbing, with alternate, stipulate leaves thickly encrusted with lime on the under surface. The spikes of pale blue flowers of $P$. capensis, Th., brighten the roadsides in the East. Often used for hedges. Two species. $P$. zeylanica, L., has white flowers. It occurs in Natal and Transvaal.

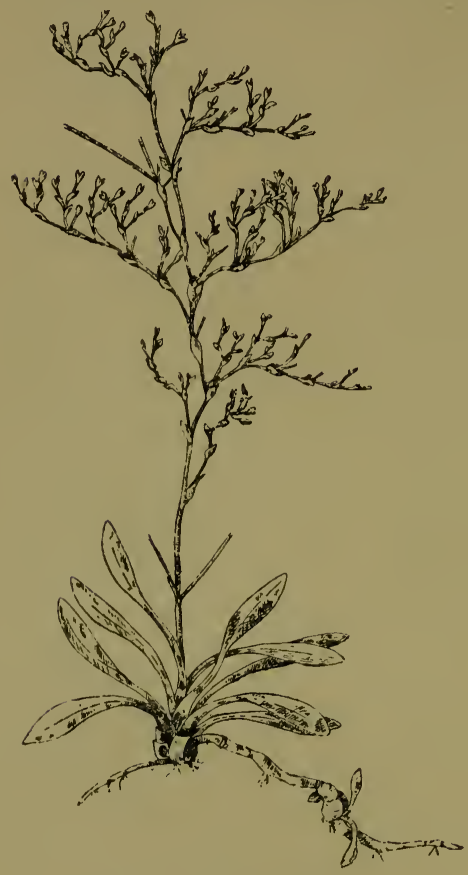

FIG. 324.-Statice.

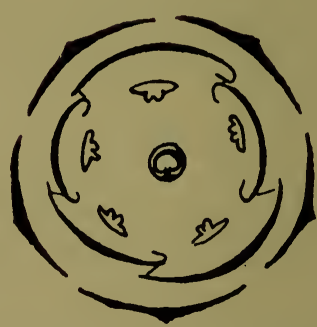

FIG. 325.-Floral diagram Plumbago.

Statice.-Corolla nearly polypetalous, bearing the stamens. Calyx coloured. Halophytes or plants growing in salt ground, by the sea. Since they cannot absorb much water without getting too much salt, such plants conserve water by the same means used by plants in dry situations. Statice has dense rosettes of leathery leaves and underground stems. 


\section{Order Gentianacei.}

Flowers usually regular, perfect. Calyx 5-lobed, persistent. Corolla 4-6 lobed, the limb twisted, remaining on and withering (marcescent). Stamens 5 on the corolla, alternate with the petals. Carpels 2. Ovary 2-I-celled, many-seeded. Placentation parietal or axile. Fruit a capsule or berry. Leaves opposite without stipules (alternate in water plants). Flowers arranged in cymes like those of Caryophyllaceæ. Herbs, rarely shrubs, with very bitter juice. Intraxylary phloem is found in the stem.

\section{A. Leaves opposite. Corolla treisted in the bud- \\ B. Flowers pink or purple, rarely white, ovary I-celled-}

Chironia.-Anthers straight, very large, yellow. Fruit a capsule. Flowers very handsome. Growing near the sea.

Orphium.-Anthers spirally twisted. Flowers handsome, rosy. A much-branched shrub with long narrow leaves. Common on the Cape Flats. When near the sea the growth is very compact and the leaves become thick and-fleshy.

BB. Flozerers yellowe or white, ovary 2-celled-

Sebæa.-Calyx and corolla segments 4-5; sepals acute or acuminate, keeled or winged. Corolla tube long or short, lobes convolute, spreading. Stamens 4-5 inserted at or below the throat, frequently with an apical gland and one or two at the base of the anthers, within the tube, or exserted.

Style filiform with an apical stigma and two stigmatic patches towards the base. Seeds many, minute or larger and ringed or frilled.

Annual, biennial or perennial herbs; stems erect or procumbent, simple or branched, with wings.

AA. Leaves alternate-

Corolla in the bud zeith incurved edges. Water or marsh plants, ovary I-celled-

Villarsia.-Erect marsh-growing plants with entire alternate leaves. Flowers yellow. Capsule I-celled, opening at the top. Common in the Colony.

Limnanthemum.-Floating plants with leaves on very long petioles, shield-shaped or heart-shaped. Flowers yellow, 
apparently springing from the upper end of the petiole, which is adnate to the inflorescence axis, so that as Goeble points out, the food materials passing from the leaves to the ripening seeds do not have to go down the length of the long petioles and up again as they do in many water plants. Cape Flats, Grahamstown, Uitenhage Div., Transkei.

\section{Order Apocynaceæ.}

Flowers perfect, regular. Calyx deeply 5-lobed. Corolla salver- or funnel-shaped. Petals twisted in the bud. Stamens 5, alternating with and upon the petals, with short filaments. Anthers more or less conniving. Disk usually present. Carpels 2, separate or united. Fruit a capsule, berry, or drupe. Shrubs with usually climbing, generally opposite leaves and usually poisonous, milky juice. Internal phloem is present.

The Oleander (Nerium) and Periwinkle (Vinca) belong to this genus.

A. Carpels united into a 2-celled berry or drupe.

Carissa.-Milky shrubs with forked spreading branches, opposite rigid leaves, and forked or twice-forked spines in the axils. Berry delicious. From Knysna district to Natal.

AA. Carpels separate; style single.

B. Not spiny or fleshy.

Strophanthus.-Glands at the base of the calyx. Corolla funnel-shaped. Petals with very long points. Throat furnished with a 2-parted scale between the petals. Stamens clusely surrounding the stigma, taper-pointed, and often bearded. Follicles with long hairy seeds. Flowers corymbose or solitary.

Climbing or erect shrubs with opposite or whorled leaves. Eastern. Furnishing the drug Stropanthin.

Acokanthera.-Shrubs or small trees with leathery leaves and corymbose dichasia. Flowers white or tinged with pink. $A$. venenata (Kafir gift boom) has sweet scented flowers and purple berries. The plant is very poisonous. The Zulus obtain poison for their arrows from the stem and root.

BB. Spiny shrubs with succulent stems. 
Pachypodium.-Corolla salver-shaped, lobes five, twisting to the right. Stamens inserted in the corolla tube. Anthers

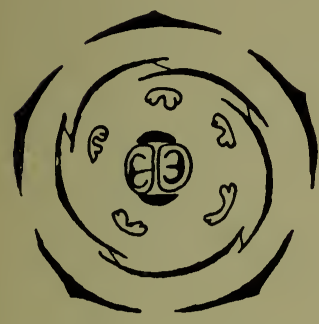

Fig. 326.-Floral diagram of Vinca. Two glands of the disc alternate with the carpels.

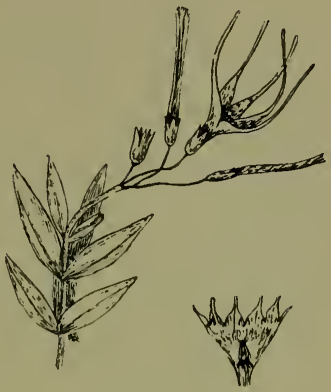

FIG. 327. - Strophanthus capensis, D.C. (speciosus, R.), and a corolla laid open showing scales at the throat.

conniving, tailed. Fruit of lanceolate follicles, many seeded ; seeds hairy at one end.

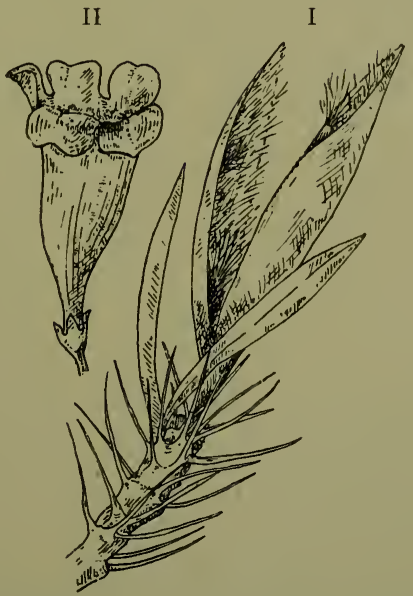

FIG. 328.-Pachypodium. I. Branch showing spinous stipules and follicles with hairy seeds. II. Flower.

Leaves in spirals, sometimes suppressed, with stipular spines. 
Small shrubs with tuberous roots. Flowers white, red, or yellow.

\section{Order AsclePiadaceÆ.}

Flowers perfect, regular, five parted; sepals imbricate, odd sepal at the back. Corolla sympetalous, valvate, or rarely convolute. Stamens five; carpels two, apocarpous below but sharing a single large five-angled stigma.

This order is like Apocynaceæ in general habit, latex, opposite leaves, follicles, and hairy seeds. But the stamens are united at base. ${ }^{1}$ In most flowers each stamen bears a petal-like or tongue-like process at the back, forming a crown.

The pollen is granular or united in masses as in Orchidaceæ. When granular (in the smaller group, Periplocæ), the pollen is shed into curious horny cornucopias or spoon-like pollen carriers (translators). These lie between the stamens, each translator receiving pollen from a half of two anthers. At the lower end of this remarkable structure is a sticky gland by which it becomes affixed to a visiting insect and then discharged of its pollen upon the stigma of the next flower visited. Six genera of this interesting group are described found in the Kalahari and Eastein regions. In most genera around the stigma five small dark brown pollen carriers may be seen to which pollinia are attached. The translator is the chief character separating the order from Apocynacex. In section Cynanchæ, the translator is $y$-shaped.

By placing a needle under the glands they may be withdrawn, as they are when an insect frees its foot from the slit between the anthers. The glands are between the stamens, and the pollen masses on either side come from the halves of two adjacent anthers.

The inflorescence is cymose or racemose. In some genera, e.g. Asclepias, the inflorescence is extra-axillary, as it is the main branch that turns aside to bear the flowers. 
Many are climbing, some are fleshy and leafless. A large order of which fifty-three genera are found in South Africa.

Internal phloem is found in the stems.

A. Pollen masses 20 , very small; anthers 4-celled.

Secamone, the "monkey-ropes" of the East. Loose climbing plants with leathery leaves. Flowers small. The genus is also found in Asia and Australia.

AA. Pollen masses ro, hanging, attached to an inverted $y$ shaped yoke (or translator).

B. Stamens without a crown.

Microloma.-Corolla urn-shaped, lobes twisted to the left. Tube furnished within with tufts of downward pointing hairs. Usually twining. Umbels of beautiful little waxy bells, scarlet, or pale red with green tips. Kalahari, Western, and Central.

BB. Stamens with a single crown.

Asclepias (Gomphocarpus). Crown of 5 petal-like bodies, the edges folded toward the stigma becoming erect or recurved, with or without a horn on its concave surface. Umbels at the nodes or tipping

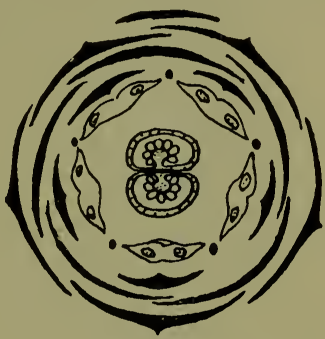

FIG. 329. - Floral diagram Asclepias. the stem, many flowered. Flowers greenish. Petals bending backward. Follicles single or rarely in pairs.

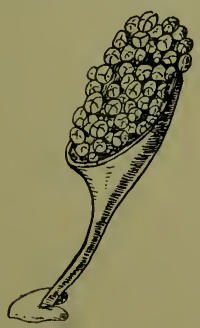

FIG. 330. - Translator of Phyllanthera carrying pollen. Gland at base. (After Delessert and Blume.)

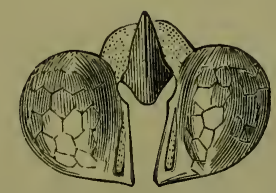

FIG. 331.-Pollen mass of Stapelia. (From Henslow's "South African Flowering Plants".)

Shrubby or herbaceous. A. fruticosa, Linn., with large spiny follicles and linear leaves, is common in the Karroo. Often tuberous. 
Pachycarpus has larger bell-shaped or globose flowers, and a corona of long flattened spreading lobes. Follicles winged. Mostly Kalahari and Eastern regions.

BBB. Stamens with a double crown.

Sarcostemma.-Corona of an outer fleshy ring and 5

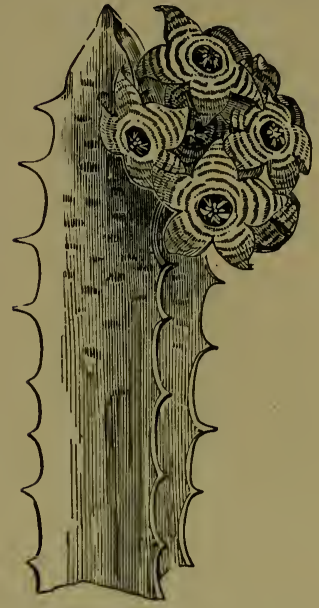

FIG. 332.-Stapelia. Stem and flowers. (From Henslow's "South African Flowering Plants".) inner leaves. Erect or climbing leafless shrubs, with fleshy jointed stems and wheel-shaped corollas.

AAA. Pollen masses Iо, erect, with the gland below. Corona double.

Riocreuxia. - Corolla bellshaped, swollen at the base, the slender tips meeting to form an arch.

Half shrubby graceful climbers, with heart-shaped petiolate leaves and greenish or dark purple flowers, and tuberous roots.

Stapelia.-Flowers large, starshaped, greenish purple, mottled. Their strong and disagreeable odour attracts carrion flies, which aid in fertilization. The tufted stems are leafless, 4-angled, and swollen. In the central portion water is stored.

Hoodia has large showy flowers over an inch in diameter; stem stout, cylindrical bushily branched, leafless; with many tubercled angles; tubercles spine or bristle tipped. The plant resembles Cactus or Euphorbia (fleshy species) in habit.

\section{Order Labiatæ.}

Calyx gamosepalous, 5-toothed, remaining on, and often showy after flowering. Corolla more or less zygomorphic, and 2 -lipped. Stamens 2 or 4 , of two lengths or nearly equal, borne on the petals. Ovary of 2 carpels, becoming 4 -celled each cell containing one basal, erect seed. The style comes from the base instead of the top of the carpels. When ripe the fruit separates into four nuts. The order may be re- 
cognized by the four nuts in the persistent calyx, the square stem, opposite and decussate, ex-stipulate leaves, and strong odour, due to oil secreted in hairs on the stem and leaves. The main stem continues growing, but the branches are tipped by a flower.

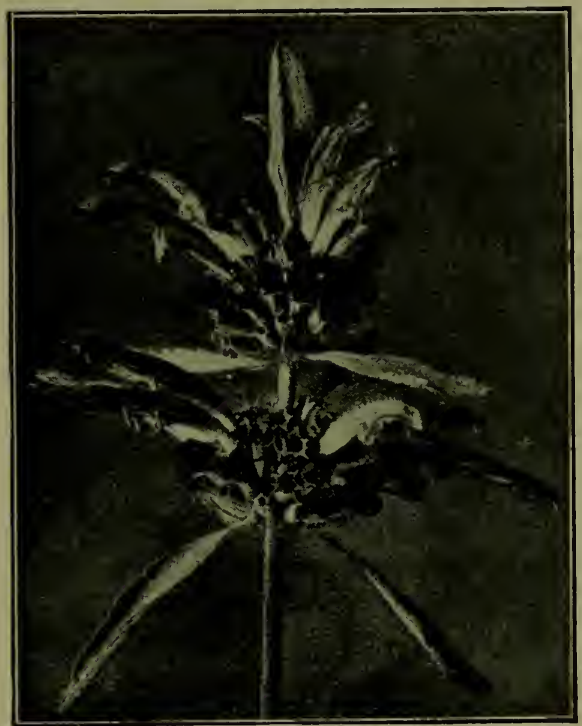

Fig. 333.-Leonotis Leonorus, R. Br. (From Edmonds and Marloth's "Elementary Botany for South Africa".)

There are 8 Eastern genera in which the filaments bend to the lower side of the flower. In the genera in which the lower lip serves for a landing-place for bees, which are their most frequent visitors, the filaments arch toward the upper petals. The upper lip shelters the essential organs.

In Mentha (the Mints) the corolla is nearly regular, and the four stamens spread equally around the flower.

Salvia.-Corolla large, the upper lip sheltering the stamens and stigma. Stamens 2, T-shaped, with short filaments and a long connective hinged to the filament near the centre. In South African Salvias, the half anther on the lower end of the connective bears no pollen (see p. r63). 
The Blue Sage (Salvia africana, L.) is common throughout the western part of the Colony.

Stachys.-Stamens 4 (the lower pair longer), anthers

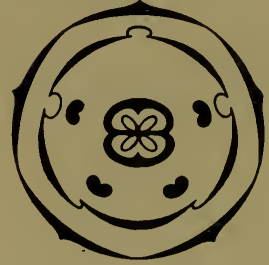

FIG. 334.-Floral diagram of Leonotis. (From Edmonds and Marloth's "Elementary Botany for South Africa".) by natives. Twelve species. 2-celled. Upper lip of the corolla spreading, lower longer. Herbs or shrubs with a disagreeable odour.

Leonotis. - Calyx ro - toothed, upper tooth larger. Corolla densely hairy, tube much longer than the calyx; upper lip long, curved, lower short, spreading, 3-lobed. Stamens 4 . Anthers in pairs, 2-celled. Herbs or half shrubs, with bright scarlet or orange flowers. L. Leonorus, R. Br. (Wild Dagga) leaves are smoked

\section{Order BORAGINACEÆ.}

The deeply 4-parted ovary and the more or less irregular flower, suggests the order Labiateæ. The flowers of this order are not so distinctly 2 -lipped. The leaves are usually alternate, the stem round, and often succulent, and the strong odour of the Labiateæ is lacking. Stamens 5, epipetalous. The flowers are arranged in a coiled cyme, which straightens as it lengthens. Stem and leaves frequently rough with hairs. Fruit of four separable nuts, or a berry. Seeds erect, basal as in Labiatæ, but radicle points upwards.

Calyx 5-parted, sepals lance-shaped.

Lobostemon.-Corolla more or less zygomorphic, funnelshaped. Stamens joined at about the middle of the corolla, each provided at base with a hairy bordered scale, which protects the honey from short-tongued insects. Fruit of four nuts. Herbs or shrubs with rough leaves and showy pink, purple, or blue flowers.

Echium is similar to Lobostemon. The stamens have no scale at base, but its bristly calyx would discourage ants.

Myosotis (Forget-me-not).-Corolla regular; tube closed 
with scales, serving as a honey-guard. Softly hairy herbs. Radical leaves tapering into petioles, stem leaves sessile. The colour changes as the flowers grow older, from white to rosy

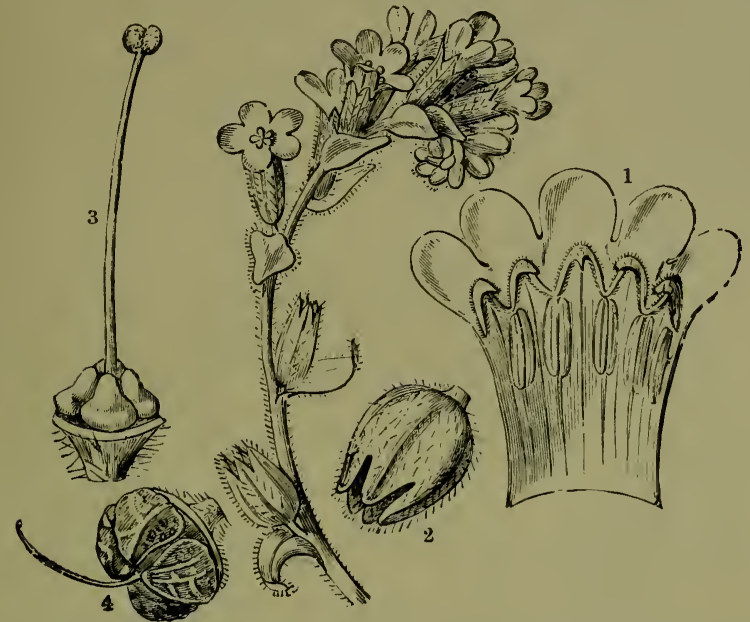

FIG. 335.-Anchusa (Alkanet). I, Corolla laid open showing corona and stamens ; 2, calyx ; 3 , pistil with 4-lobed ovary ; 4, fruit. (From Henslow's "South African Flowering Plants ".)

buds and blue flowers, or from yellow through bluish to violet. In Echium the change is from red through violet to blue. This, says Herman Muller, suggests that white, yellow, and red flowers were the ancestors of violet and blue flowers.

Heliotrope belongs to this order.

\section{Order SolanaceE.}

Calyx 5-parted, persistent (except Datura). Corolla convolute. Petals plaited in bud. Stamens 5, alternate with and upon the petals. Carpels 2, placed obliquely in the flower. Flowers solitary or in cymes. Herbs, shrubs, or small trees. Fruit a capsule or berry.

Leaves exstipulate, alternate (whorled in Retzia). In the flowering portions the leaves appear more or less opposite. This is due to a peculiarity of growth, A leaf remains adnate 
to its axillary branch and is carried up to its first node where it meets the lowest leaf of the branch which is usually smaller. It may be carried past the smaller leaf. The main branch on which the larger leaf was borne is turned aside and bears the inflorescence (as in Fig. 336).

A large order of herbs, climbing shrubs or, rarely, trees, unarmed or spinous, especially abundant in the Southern Hemisphere. Some, like the Potato, Tomato and Cape Gooseberry, are of economic importance, others are poisonous.

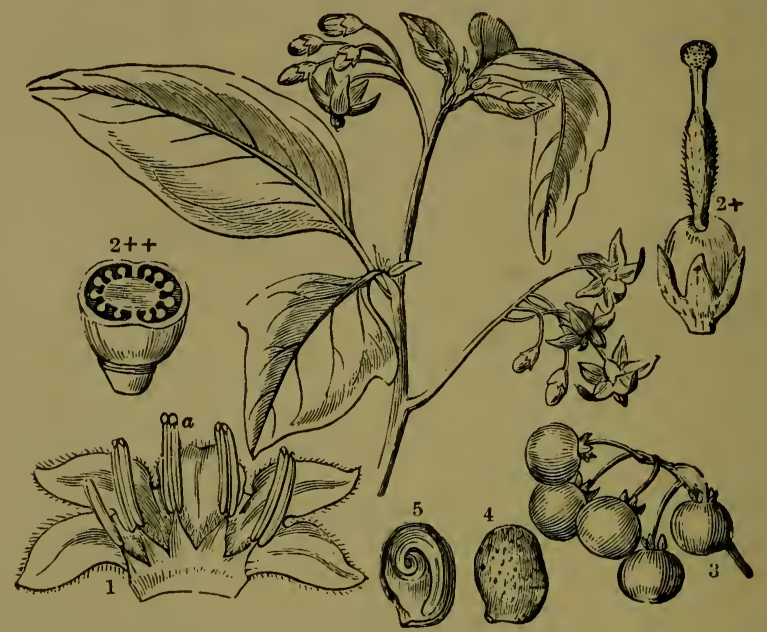

FIG. 336.-Solanum. Flowers, fruit, and seed. (From Henslow's "South African Flowering Plants"'.)

The order is related to Scrophulariaceæ and Boraginaceæ from which it may be distinguished by its internal phloem and the oblique ovary.

Fruit a many-seeded berry.

Solanum.-Anthers opening by terminal pores.

Physalis.-Anthers opening lengthwise. Calyx covering and much enlarged in fruit.

Lycium. - Anthers opening lengthwise. Calyx unaltered after flowering.

Fruit a capsule. 
Datura.-Calyx deciduous. Fruit a thorny 4 -celled capsule.

Nicotiana.-Calyx persistent, bell-shaped, 5-fid. Capsule 2-celled, many-seeded.

Retzia.-Calyx deeply lobed. Corolla tubular. Capsule fewseeded.

Solanum.-Corolla wheel-shaped, white, yellow, or purple. Anthers yellow, forming a cone, as in some of the Boraginaceæ.

A large genus of herbs, shrubs, or trees, often prickly or spiny. Often densely covered with star-shaped hairs. The potato and egg plant, natives of South America, belong to this genus. Engler also includes the tomato. The berries are showy, bright red, yellow, or blue. By cultivation, the number of carpels in the Tomato has been increased. By heaping earth around the stem more underground stems are developed in the Potato and so the crop is increased.

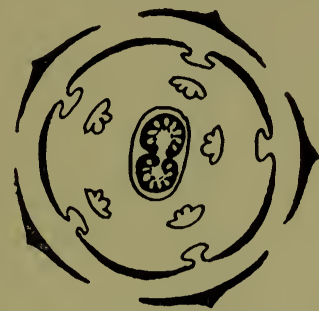

G. 337.-Floral diagram of Solanum showing obliquely placed ovary.

Physalis. - This genus may be recognized by the bladdery calyx. P. peruviana, L., is the "Cape Gooseberry". Other species of this genus are native.

Lycium.-Small trees, often with spiny thorns, funnelshaped. Reddish flowers, usually solitary. L. afrum, L. (Kaffir thorn) is used for hedges.

Datura.-The shrub in many gardens with large white hanging bells and thorny capsules belongs to this genus. Capsule 4 -locular by secondary divisions.

D. Stramonium, L.-The purple Stramonium grows in waste places. Bees are debarred from this flower by the inward turn of the stamens, but the long tongue of moths can reach the nectar. The plant is poisonous.

Nicotiana (Wild Tobacco) is found in many parts of the Cape. It is not a native of this country.

\section{Order SCROPHULARIACE.E.}

Flowers perfect in cymes or racemes. Calyx 4- or 5parted. Persistent. Corolla 5-parted, or 4 by the union of two back petals, often 2-lipped. Anthers 4 , of two lengths 
(didynamous, two in power), sometimes with one or two loculi. Ovary 2 -celled. Ovules many. Fruit a capsule, rarely a berry, with axile placentation. Below the ovary is a honey-making disc. The flowers are short-tubed and open for flies, or with a long tube for bees, with the stamens so placed as to brush the back of the insect; 160 genera, 46 South African, widely distributed in temperate zones.

Herbs, trees, or shrubs, found in all countries.

A. Back lobe of the corolla overlapping the front lobes in the bud.

B. Corolla saccate or spurred at base, tube short or none.

C. Corolla with two pouches or spurs-

Hemimeris.-Corolla 2-lipped. Stamens 2. Anthers I-celled. Two tooth-like bodies at the side of the throat clasp the stamens. Small annuals with opposite leaves and bright little yellow flowers. Western.

I.

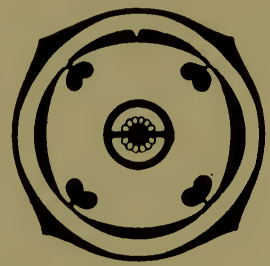

II.

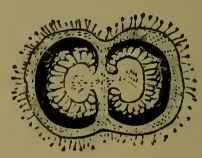

FIG. 338.-I. Floral diagram of Halleria flower. II. Bilocular ovary of Antirrhinum. (From Edmonds and Marloth's "Elementary Botany for South Africa ").

Diascia.-Corolla 2-lipped, but more regular than in Nemesia. Upper lip 2-parted, lower 3-parted. Middle lobe often notched. As in Nemesia the two longer (front) stamens curve round and clasp the upper pair.

Annuals or persistent herbs, often spreading, with dark wine-coloured or purplish flowers. Eastern and Western. In dry, sandy soil. Fortyseven species in South Africa.

CC. Corolla with a single pouch or spur at base.

Nemesia.-Upper lip 4-loped, lower entire. Stamens 4 , the lower filaments curved round at the base and clasping 
the upper, as in Diascia. Anther cells clinging together in pairs.

Herbs annual or perennial, bearing racemes of pretty flowers of many hues. Twenty-eight species, both Eastern and Western. Beautiful Nemesias in great abundance are found in the Malmesbury district.

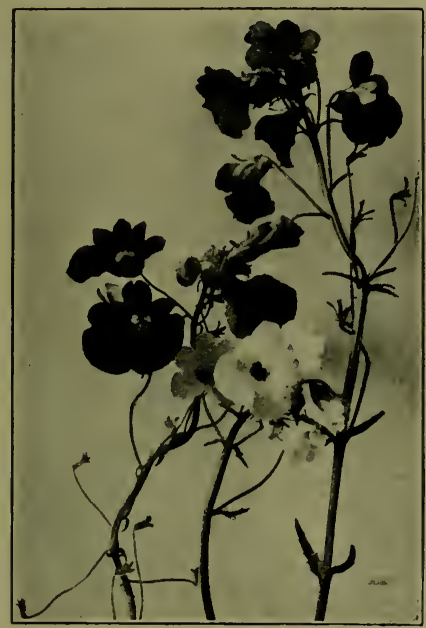

FIG. 339.-Nemesia.

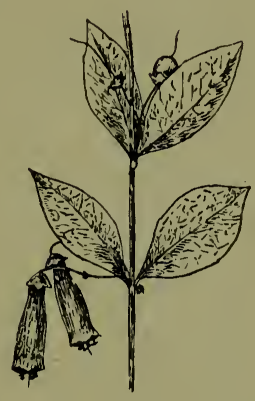

Fig. 340.-Halleria lucida, L.

BB. Corolla not saccate or spurred. Stamens 4-

Freylinia. - Calyx 5-parted. Corolla tubular, limb spreading. Shrubs with opposite (or upper alternate), shiny, entire leaves and panicles of orange or lilac flowers.

Halleria.-Calyx cup-like, 3-5-parted. Corolla tubular, widening upwards, and shortly lobed at the tip. Stamens 4 . Fruit fleshy, indehiscent. Shrubs with red flowers, hanging in clusters or single from the axils of dark glossy leaves.

Zaluzianskya (Nycterinia).-Corolla tube long, slender; limb 5-lobed, spreading; lobes often 2 -fid. Anthers of two upper stamens large, often two lower small or wanting.

Herbs, more or less viscid, turning black in drying. Flowers light inside, dark outside, opening in the evening.

Sutera (Lyperia).-Corolla with a long sticky tube, in- 
curved and swollen at the top. Anthers exserted, I-celled, kidney-shaped. S. atropurpurea, Hiern.-called "Cape Saffron" (Geele bloemetjes).

Herbs or small shrubs, often much branched. Lower leaves opposite ; upper alternate, entire, toothed, or much cut. Sometimes viscid; turning black in drying.

Manulea is similar to Sutera, but the tube is not swollen. Common little plants, often covered with woolly hairs. Corolla

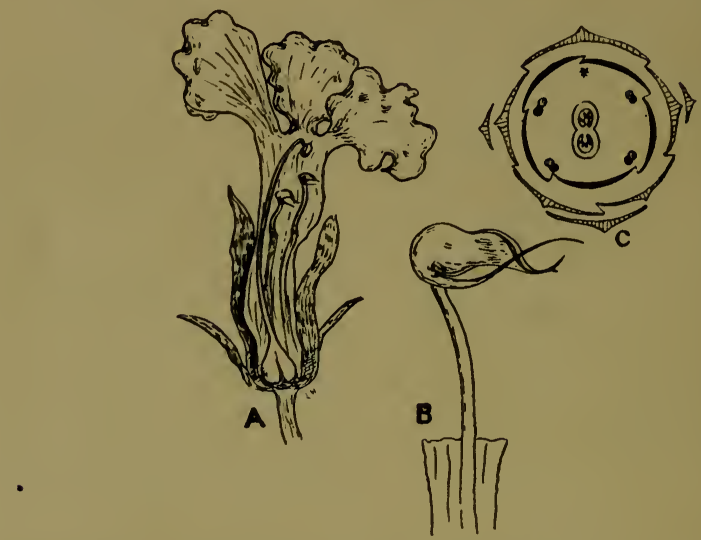

Fig. 341.-Harveya capensis, Hook. A, section of flower, B, stamen showing one long empty anther cell, $c$, floral diagram.

nearly regular, orange. Found in sandy soil. Herbs, rarely woody. Usually not drying black.

AA. Back lobes covered by the front lobes in bud. Root parasites-

B. Anthers I-celled-

Hyobanche.-Calyx deeply 5-parted. Corolla tubular, curved and hooded at the top, limb shortly 3 -lobed. Stamens of two lengths. Rose-red, thick stemmed. Parasites on the roots of Proteaceæ and other plants. Mr. v. d. Merwe, of Wellington, has found this parasite growing on roots, in an ant heap, 30 feet below the surface. 
BB. Anthers 2-celled -

Harveya. - Calyx campanulate or oblong, somewhat

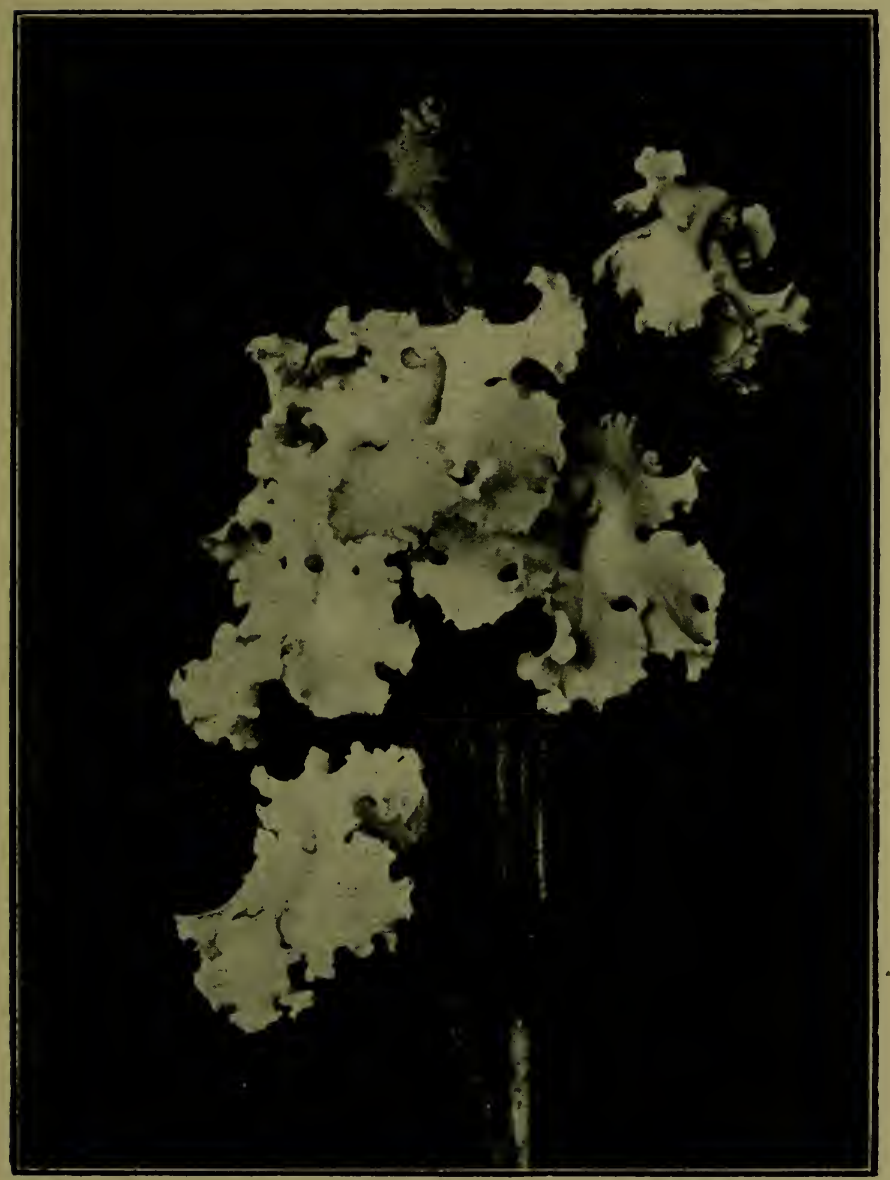

FIG. 342.-Harveya capensis, Hook. (Photograph by E. J. Steer, Esq.) inflated. Corolla with a long curved tube, spreading above. Stamens of two lengths, one cell of each anther containing 
pollen, ovate with long point, the other long and slender, empty. A parasite on roots of various plants, with handsome white, orange, rosy, or scarlet flowers.

Leaves scale-like, opposite or upper alternate.

\section{Order BignONIACE\&.}

Flowers perfect, zygomorphic. Calyx 5 ; corolla 5 , trumpet or bell-shaped, imbricate; stamens 5 , epipetalous, didynamous, or 4 , the staminode at the back always present; one anther lobe is usually above the other. Ovary raised on a disc, bicarpellary, with many anatropous ovules. Seeds without endosperm, with large membranous wings.

Inflorescence usually dichasial, passing into a cincinnus.

Trees or shrubs. Many are found in Brazil. Often tendril climbers, the tendrils taking the place of leaflets.

Stamens 4 with staminode.

Tecomaria is a handsome shrub with racemes of scarlet

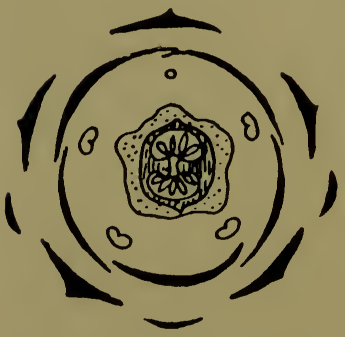

FIG. 343.-Floral diagram of Tecomaria (after Hooker).

flowers. Stamens are exserted. The walls of the capsule are flattened at right angles 'to the septum and dehiscence takes place loculicidally.

The opposite imparipinnate leaves are without stipules. Used as hedges in the West. Wild in the East.

Bignonia has the pod flattened parallel with the partition, the dehiscence is septifragal, and the compound leaves end in a tendril. Probably not native. B, capensis, Th., is placed in Tecomaria in "Flora Capensis."

\section{Stamens 5 .}

Cataphractes is a spiny shrub, with calyx tubular cleft on one side. Corolla white. Stamens 6 or 7 . Ovules.few, fruit warted. Found in Namaqualand. Leaves simple, tufted.

Rhigozum.-Calyx campanulate. Flowers yellow, borne singly in the axils of alternate leaves. A rigid shrub in the Eastern and Northern districts. Fruit warted. 
Kigelia.-A tree with panicles of pendulous flowers, on long peduncles, springing from dormant buds of old wood. Flowers claret-coloured. Ovary I-celled, fruit indehiscent.

"The sausage plant," named from the fruits, sometimes a

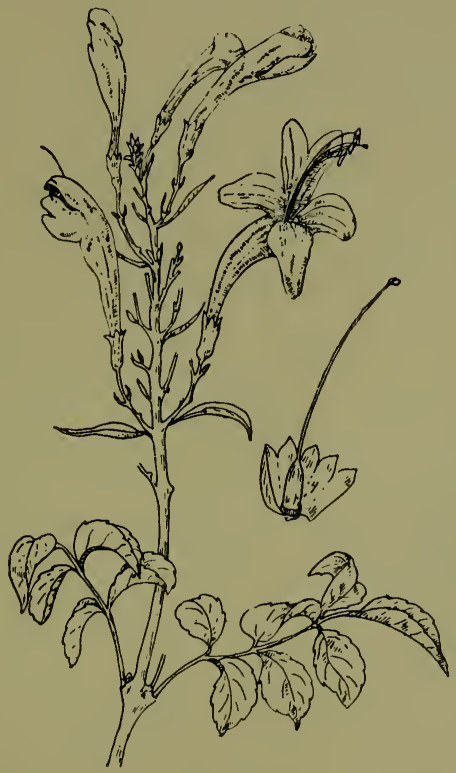

FIG. 344.-Tecomaria capensis, Spach. a, Pistil with disc below.

foot long, that hang from the long stalks. $K$. pinnuta, D.C., is found about Delagoa Bay, it has ternate leaves.

Jacaranda is a handsome tree with racemes of purple flowers frequently cultivated in gardens. It is from South America.

\section{Order RuBIACEא.}

Fiowers usually perfect, regular. Perianth epigynous. Sepals $4-5$, often very small, one frequently enlarged. Petals 4-9. Stamens $4-5$, borne on the corolla, alternate with the petals. Ovary I-2- or more celled, 2- or many-seeded. 
The order may be recognized by the opposite entire rarely toothed leaves and stipules. Sometimes the stipules are as large as the leaves, which gives the appearance of a whorl of leaves; but the presence of axillary buds will tell which are leaves. If the stipules are simple, six leaves appear to stand at a node. They may be fused in pairs on the same plant when four appear. Each stipule may be divided.

The inflorescence is cymose, it may be reduced to a solitary flower, umbellate or capitate.

One of the largest orders, 350 genera, of which about 24 are native to South Africa. Trees, shrubs or herbs of world-wide distribution. Most are tropical.

- Honey is usually secreted by a nectary upon the ovary, at the base of the styles (cf. Umbelliferæ).

\section{A. Fruit indehiscent, many-seeded. Shrubs or trees-}

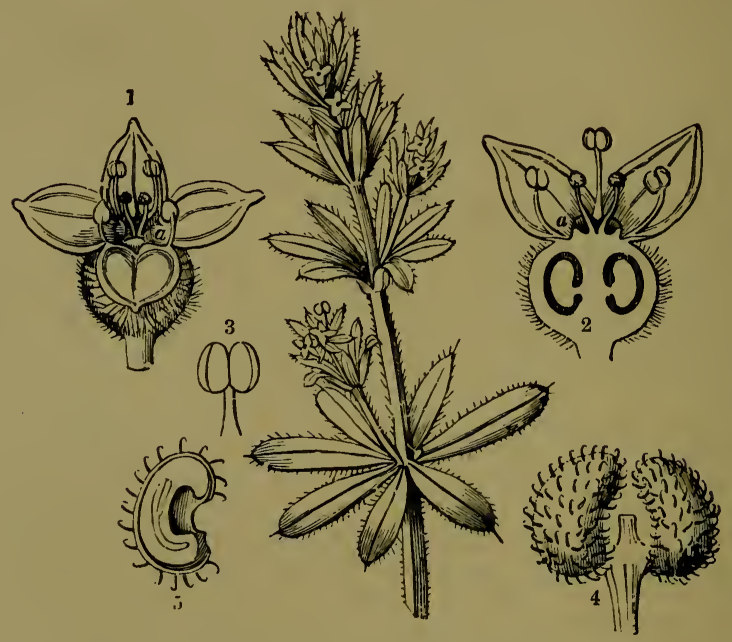

FiG. 345.-Galium (Cleavers). I, flower ; 2, section of flower ; 3, stamen ; 4 , fruit; 5 , section of 4 showing embryo. (From Henslow's "South African Flowering Plants".)

Burchellia.-Corolla funnel-shaped, with a very short limb. Anthers with the corolla. Berry nearly round, 2celled, crowned by the calyx.

B. capensis, R. Br. (Buffels doorn; Kafir, Tobankone), the only species, is a tree I2-14 feet high, with axillary corymbs of deep scarlet or 
orange flowers, and leaves $3-5$ inches long. Frequent in forests east of Swellendam.

Gardenia.-Corolla funnel- or salver-shaped. Anthers extending beyond the tube, 8 or 9 ; sessile in the throat of the corolla.

G. Thunbergia, L. $f$. (Wild Katjepiering: Kafir, Umkangaza.) Trees or shrubs with large, solitary, white flowers, or marked with red. Often sweetly scented. The berry is very hard.

AA. Fruit a 2-celled capsule, many seeded.

Hedyotis.-Corolla with a slender tube and spreading 4- or 5-parted limb. Capsule crowned with the calyx, dehiscing at the top. Small herbs with ovate lanceolate or linear leaves and bristle-like stipules.

AAA. Fruit nearly dry, of 2-6 nut-like parts-

Hydrophylax.-Glabrous, creeping fleshy herbs, growing by the sea, with stipules and leaves united, forming a cup.

AAAA. Fruit 2 -parted or 2 -celled, seeds one in each cell.

Galopina.-Flowers often diœcious or imperfect and perfect on the same plant. Perennial herbs with small flowers.

Anthospermum is frequently a shrub with long slender, rigid branches having an aspect of the narrow leaved Cliffortias for which it may be mistaken. The stipules are small, I-3 toothed. Flowers small, axillary, sessile, or rarely panicled, diœcious, polygamous or hermaphrodite. The fruit consists of two easily separable mericarps, distinguished from $U m$ belliferce by the erect seed in each.

Galium.-Corolla 4-parted. Fruit dry, separating into two I-seeded carpels. Branching, erect or spreading herbs, supported by hooks on the stem and leaves. Flowers white or greenish. Leaves 4 or many in a whorl. The enlarged stipules, united in pairs, make a whorl of 4 . If each stipule is divided there is a whorl of 10 . The ovary resembles that of Umbelliferce.

\section{Order Campanulaceæ.}

Flowers regular or zygomorphic. Sepals not meeting in the bud. Corolla valvate. Stamens 5, epigynous, free from 
the corolla. Anthers 5, free or united. Ovary inferior, or half inferior, 2-5-celled. Axile placentation and orules many. Style simple, stigmas as many as the carpels. Fruit a capsule or berry. Leaves alternate, exstipulate.

The flowers are very protandrous, and the style has the pollen shed upon it, where it is held by a ring of hairs just below the stigma. In many cases the stigmas turn back and touch the pollen of their own flowers, and so self-fertilization results. The flowers show interesting transitions to Composita, to which the order is related.

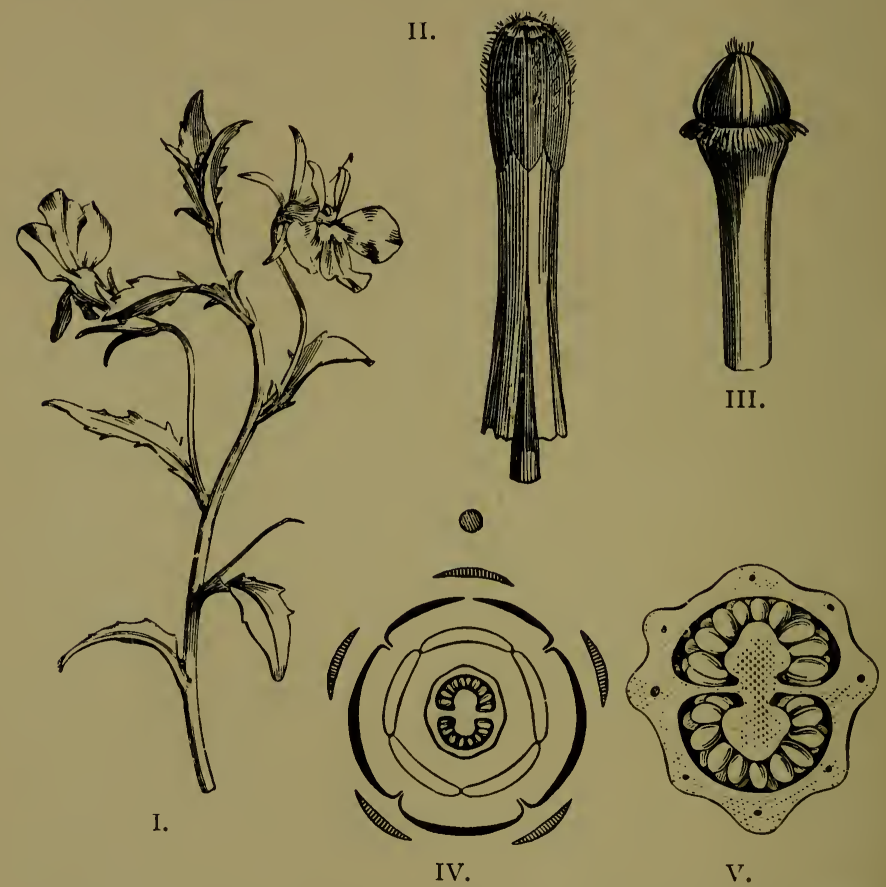

FIG. 346.-Lobelia. I. Flowering shoot. II. Stamens with syngenesious anthers closed over stigmas in bud. III. Style and addressed stigmas from II. IV. Diagram of flower. V. Transverse section of fruit. (From Henslow's "South African Flowering Plants".)

A. Corolla zygomorphic with a split tube; anthers unitedLobelia.-The flowers are twisted on their axis so that 
the odd sepal is at the back, and three petals form the lower lip. The two lower or all the anthers are bearded.

Weak herbs or small shrubs, with alternate toothed leaves and blue or violet flowers.

Parastranthus (Inverted flower) has the odd sepal in front and the upper lip of three petals, as there is no twist as in Lobelia. Herbs similar to Lobelia, with yellow, white or blue flowers.

AA. Corolla regular; anthers separate-

B. Capsule opening at the top by triangular lids-

Lightfootia. - Corolla open to the base, or nearly so. Filaments broad, fringed with soft hairs. Capsule half below the flower. Small shrubs or herbs. Leaves sometimes opposite. Flowers mostly in racemes, blue or white. Eastern and Western.

W a h lenbergia.Funnel-shaped or tubular. Filaments broad at base. Stigmas 5-3. Herbs with long forked flower-stalks, axillary or terminal. Flowers blue. The drooping flowers protect the pollen.

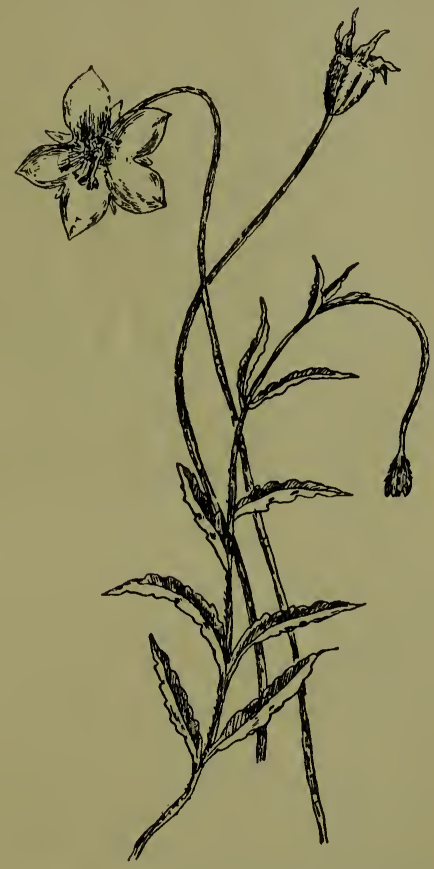

FiG. 347. - Wahlenbergia capensis, A.D.C. The fruit becomes erect on ripening.

The capsules after flowering stand erect, so that the seeds do not all fall out at once, but blow out a few at a time. Forty-six species.

Roella.-Corolla large, funnel-, tubular-, or bell-shaped. Ovary 2 -celled. Stigmas 2, thick. Capsule opening by a large pore at the top. 
Rigid undershrubs. Leaves narrow, crowded, often tufted in the axils. Flowers sessile, blue, white, or pale yellow with a dark centre. Eleven species.

AAA. Flowers more or less irregular. Anthers free-

Cyphia.-Petals 5, separate, or partly clinging by the

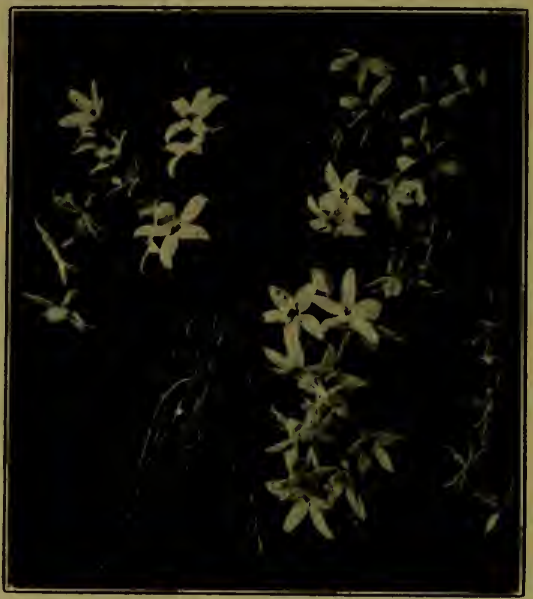

FIG. 348.-Cyphia Zeyheriana, Pr.

upper part of their claws. Capsule 2-celled, half superior opening at the top.

Erect or climbing herbs, mostly with succulent or tuberous edible roots. Flowers blue, white, or pink.

\section{Order Compositæ.}

This is the largest order of flowering plants. The flowers are massed together in heads, as in Protea, and surrounded by an involucre. In compensation the calyx is either wanting or very much reduced, or it is constructed so as to aid in distributing the seed. The calyx is known as the pappus. After flowering, it may enlarge into a parachute for carrying the seeds in the wind, or it is developed into bristles, which seize hold of animals and so distribute the seeds. The corolla is gamopetalous. All the flowers may be tubular and regular or all may be strap-shaped, or the central disc flowers may be 
tubular and surrounded by the strap-shaped (ligulate, "little tongue ") ray flowers. The ray flowers are usually developed at the expense of the stamens, and contain only pistils. Stamens 5, alternating with the petals, cohering by their anthers (syngenesious), as in Lobelia, forming a tube around the style. Ovary inferior, of two carpels with a simple style forking into two stigmas. The one-celled ovary contains one ovule, growing from the base of the ovary. The fruit is an achene.

Since the flowers are massed together, they may be very small, and yet form an attractive cluster for insects, especially when there are ray flowers. One insect may visit a great many flowers in a short time. The slender tube and united stamens protect the honey and pollen; if cross pollination fails, the divided stigmas may turn back and pollinate themselves from the pollen which the styles have brushed out of the anthers of the same flower. The flowers are so well equipped that they have been distributed, and flourish, in nearly every part of the globe.

Of the 81o genera, 153 are found in South Africa.

The genera are grouped according to the style branches, under six tribes, of which only a very few genera can be mentioned.

* Disc Flowers Tubular, Regular.

TRIBE I. VernoNiEe.-Style branches long, slender, pointed, hairy outside. Flowers not yellowe, all tubular. Stigmatic papilla all over the inner surface.

Vernonia.-Involucre of many overlapping scales, not spine-pointed. Pappus of many bristles in two or more rows. Achenes smooth or silky, ribbed. Erect or half-climbing shrubs and herbs with white or purple flowers. Heads single or in corymbs. Eastern.

Corymbium.-Heads I-flowered, involucre of two opposite scales, with two or three outer bracts at base. Achenes silky. Nearly stemless herbs; with linear parallel-veined leaves. The rootstock clothed with long, soft, silky hairs. Cape Town to Uitenhage.

Tribe II. Eupatoriee. - Style branches long, blunt or 
fattened at the tip. Flowers all tubular. Stigmatic papilla in marginal rowes.

Ageratum. - Heads many-flowers, roundish, clustered in corymbs. Pappus 5-10-toothed scales. Herbs with ovate or heart-shaped leaves on long petioles. Flowers mauve. Often cultivated; found in Natal.

TRIBE III. ASTEREÆ.-Style branches long, fattened, often crossing instead of curling backwards. Heads usually with ray flowers. Stigmatic papilla marginal, tips unreceptive.

Aster.-Heads many-flowered. Ray flowers, and usually disc flowers bearing fruit. Involucre of overlapping scales. Achenes flattened. Pappus of many saw-toothed bristles of equal length. Flowers with white, pink, or purple rays and yellow or purple discs. Herbs or shrubs with often small, rarely petioled leaves. A large genus.

Diplopappus.-Flowers as in Aster, except the pappus of two rows, the outer of short, the inner of long bristles. Much branched shrubs or rigid simple herbs.

Tribe IV. Senecionideæ.-Style branches linear, flattened at the top, bristly at the apex,

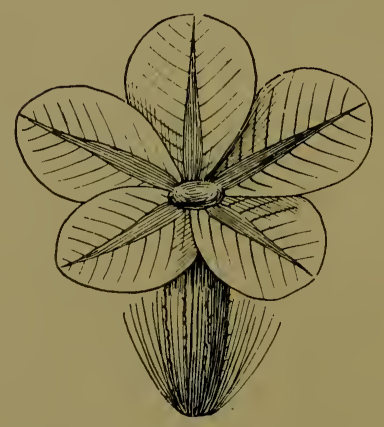

FIG. 349.-Sphenogyne anthem. oides, R. Br. Achene with scaly pappus. (From Edmonds and Marloth's "Elementary Botany for South Africa ".) or tipped with a bristly cone. Flowers all tubular or with ray and disc flowers.

A. Anthers without tails; pappus of large scales-

Sphenogyne.-Heads radiate, but the disc flowers bear the fruit. The receptacle bearing papery scales (paleæ) among the flowers. Involucre of overlapping scales, the inner larger with papery tips. Achenes surrounded at base with long silky hairs. Pappus of five broad scales, spirally rolled before the flower opens; much enlarged in fruit and milk-white.

Herbs or shrubs with simple or compound leaves, strongly scented. Flowers yellow, often copper-colour beneath. 
Ursinia differs from Sphenogyne in having within the pappus scales an inner row of slender bristles.

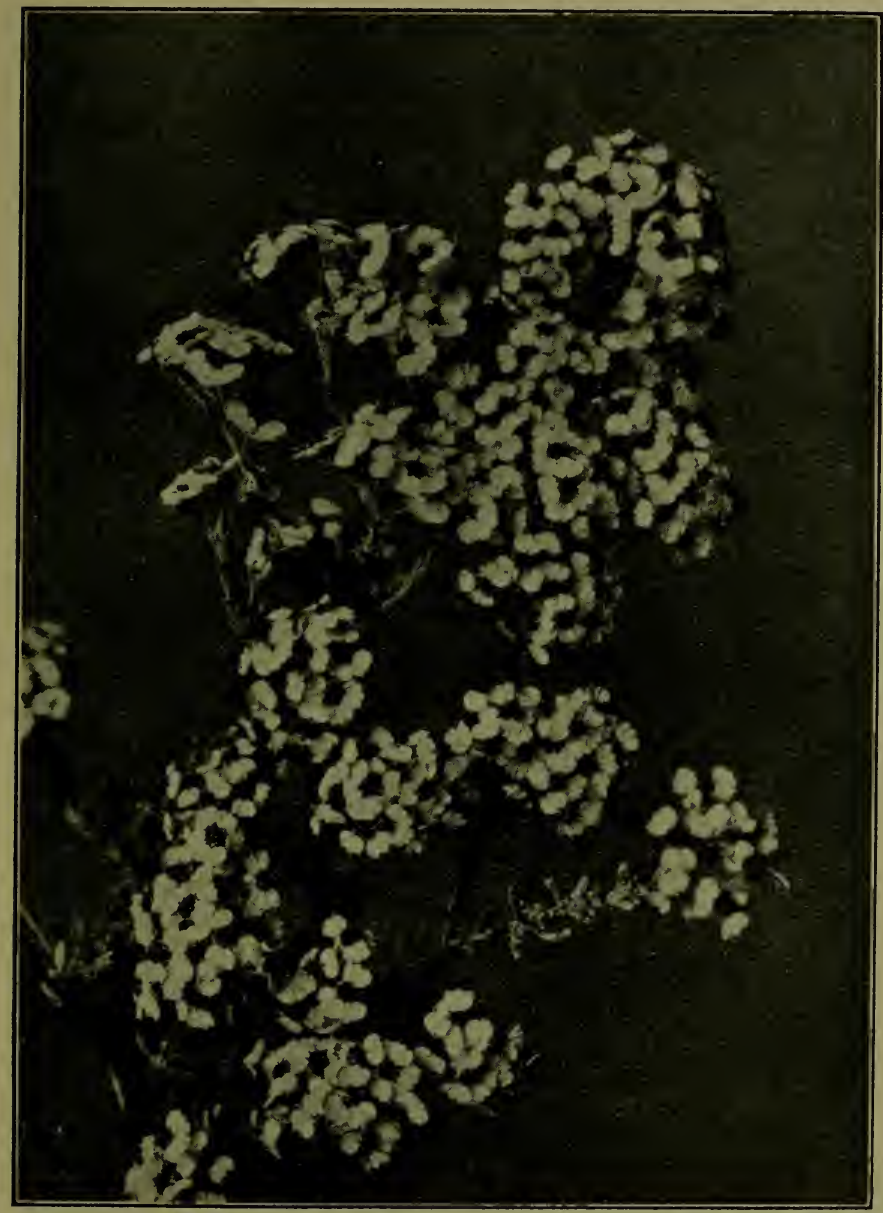

FIG. 350.-Eriocephalus umbellulatus, D.C. (Photograph by E. J. Steer, Esq.) AA. Anthers without tails. Pappus none. Eriocephalus (Woolly head), the "Capok-bosch".-- 
Heads small, the rays usually broad and heart-shaped, bearing fruit. Disc flowers bearing stamens. Involucre double, the outer of separate scales; the inner scales cohere to form a cup. The achenes are without pappus.

Much-branched rigid shrubs, silky or silvery. The flower heads become very woolly with age. These hairs are not pappus.

Athanasia.-Heads many-flowered, without rays. Involucre of dry, overlapping scales. Receptacle-bearing paleæ between the flowers. Achenes sharply five-angled or winged. Pappus of short, flat, unequal scales, or of short, woollen, jointed hairs or none.

Small shrubs or under-shrubs. Leaves entire, toothed or pinnateparted. Heads yellow, mostly in corymbs. Common. In flower nearly throughout the year.

AAA. Anthers tailed. Pappus plume-like. Involucre shining, not withering.

Elytropappus.-Heads 2-8-flowered. Involucre horny.
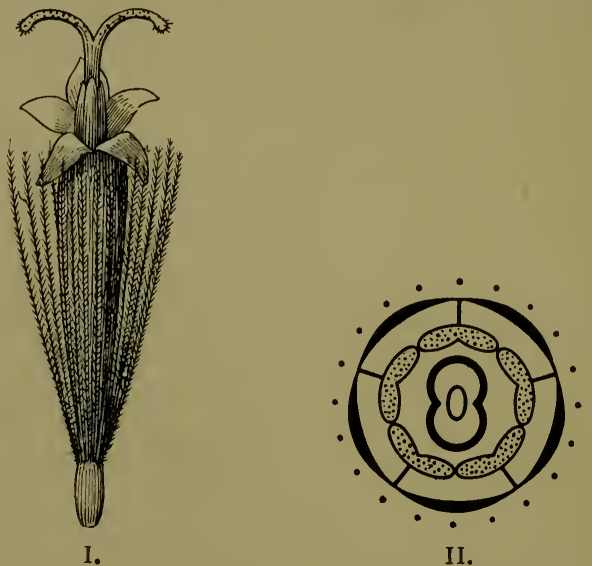

FIG. 351.-Helipterum canescens, D.C. I. Flower. II. Diagram of discflower. (From Edmonds and Marloth's "Elementary Botany for South Africa".)

Much-branched shrubs with heath-like, spirally twisted leaves. 
The Rhenoster bosch is the despair of farmers ; it is chiefly Western, but has spread as far as Grahamstown, crowding out other plants as it advances. Introduced from the Congo.

Helichrysum.-Heads many- or few-flowered, either all tubular or with ray flowers. Pappus of slender bristles. Involucre showy, rosy, yellow, or white. These and the next genus are the beautiful Everlastings, the Cape Flower.

Herbs and shrubs, mostly with woolly leaves and stems.

Helipterum differs from Helichrysum in having featherlike pappus.

AAAA. Anthers without tails. Pappus bristles abundant. Involucre in one row-

Senecio.-Heads with or without rays, rays pistillate, disc flowers perfect, purple or yellow. The genus may be known by the involucre of one row of scales with a few small bracts at the base. Herbs, shrubs, or small trees.

Othonna.-Rays yellow or purple, pistillate, disc flowers staminate. Involucre as in Senecio, but without bracts.

Shrubs or herbs with smooth shiny leaves. The herbs often have tuberous roots.

AAAAA. Anthers with short tails. Pappus none-

Dimorphotheca.-Heads with rays. Involucre in one row. The genus may be readily recognized by the two kinds of fruit. Those of the ray flowers are slender, three-cornered, tubercled; of the disc flowers, flattened, heart-shaped, with thick, wide wings.

Herbs or half shrubs, often sticky, with yellow or purple flowers, or white with purple underneath.

Osteospermum. - Heads yellow, many flowers with disc flowers staminate. Only the ray flowers bear fruits, which contain white, bony seeds. Involucre in few rows, its scales free.

Shrubs, rarely herbs, with alternate leaves, which may be cobwebby, or rough with sticky hairs, or smooth.

Tripteris. - Heads with ray flowers, which bear the fruit. Disc flowers perfect but sterile. Flowers yellow, white, or purplish. Fruits three-winged. Herbs or shrubs, mostly sticky, strongly scented. 
TRIBE V. CYNAREE.-Heads with rays (rarely all tubular). Anthers with short tails. Achenes swollen, with a flat disc at the top, often woolly. Pappus none, or of scales or bristles. Receptacle usually bristly.

Arctotis.-Ray flowers pistillate, disc flowers perfect. Pappus of two rows of scales. Achenes very silky near the base. Receptacle honeycombed, with bristles. Involucre of

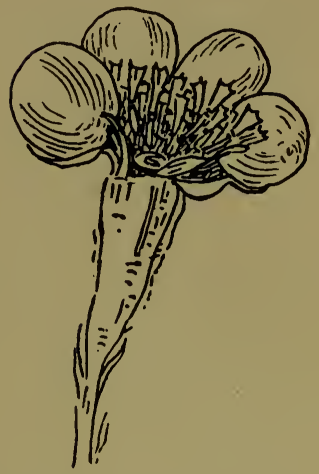

FIG. 352. - Osteospermum moniliferum $\mathrm{L}$. fruits; the ray flowers produce large achenes with bony seeds ; the disc-flowers are sterile.
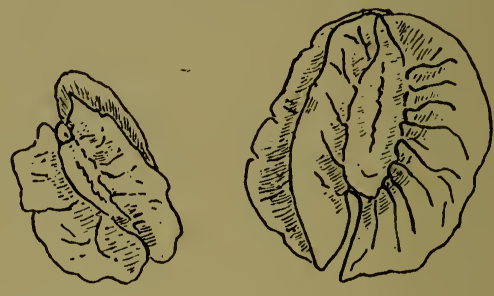

FIG. 353.-Three-winged fruits of Tripteris.

small outer scales, the inner with large, thin, papery tips, spirally twisted before flowering.

Herbs, often stemless. Flowers large, handsome, white, yellow, or orange, the rays usually purplish beneath.

Gazania.-Heads radiate, the disc flowers all forming fruit. Involucre in several rows, forming a cup at the base. Receptacle honeycombed. Pappus in two rows of toothed scales, often hidden in the wool of the achenes.

Herbs with or without stems. Leaves all radical or scattered, often white woolly beneath. Heads large, showy rays, yellow or orange, dark at base, reflecting peacock colours. 
** All the Flowers Strap-shaped and Perfect.

Tribe VI. LigulifLore.-Styles long. Plants with milky juice.

Urospermum.- - Heads many-flowered. Involucre in one row. Pappus one-rowed and feathery. Receptacle bristly.

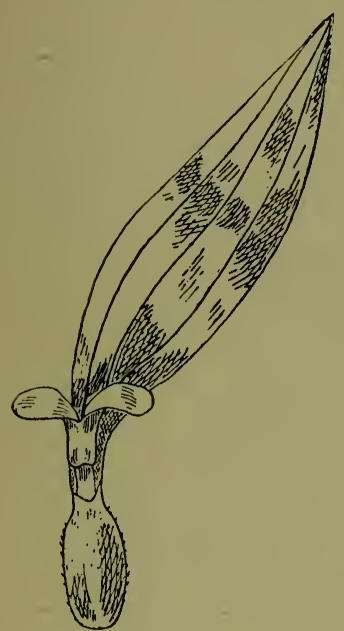

I.

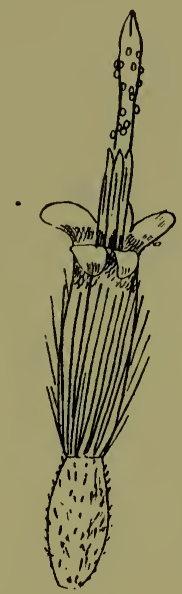

II.

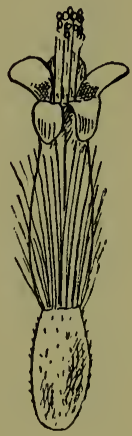

III.

FIG. 354.-Printzia. I. Ray flower. II. The stigma, pushing out, brushes the pollen from the stamens. III. The following day it draws back and leaves the pollen in a ring at the top of the stamens.

Achenes with long, sharp beaks, bladdery at base and rough with sharp points. Herbs with stem-clasping leaves.

Sonchus.-Heads many-flowered. Involucre in several rows. Pappus soft, very white slender hairs. Achenes not beaked.

Common weeds with yellow flowers, Leaves with a wavy margin, or pinnatisect. 


\section{CHAPTER XXIII.}

\section{THE BOTANICAL REGIONS OF SOUTH AFRICA.}

REFERENCE has been made to several orders which are found only in South Africa and which are confined wholly or largely to the southwestern portion. They probably represent very ancient types of plants of southern origin which have been confined in this restricted area by impassable climatic and geographical barriers farther north.

The origin of South African flora has greatly interested botanists since Sir Joseph Hooker published the results of his observations during the Antarctic expedition with Sir James Ross.

Certain orders of South Africa are abundantly represented in Australia; owing to the predominance of species in the latter country, it has apparently been the centre of distribution for several orders found in both South Africa and South America.

A South African tree Metrosideros belongs to the order Myrtaceæ which supplies us with Australian blue gums. This tree, found in the western mountains of Cape Province, has its centre of distribution in New $Z$ ealand. Besides the South African species, $M$. angustifolia, Sm., one species is found each in Chili, Java, and Madagascar.

Proteaceæ are especially interestıng as representing a southern distribution. Of the two main groups into which the order is divided (see p. 285) the first is found in Australia and South Africa, while the Grevilloideæ are largely represented in Australia and Chili, but none occurs native to South Africa. Many of the South American types thus associated are in the extreme south-western part of Chili.

A glance at the map will show that South America is much nearer to Africa than it is to Australia, it will therefore appear strange that its flora should be more closely related to Australia.

Among other orders representing a South African-Temperate Australian alliance may be mentioned Iridacea, Restiacea, Hamodor. acea, Compositce, Thymeliacea, and Rubiacea.

By referring to the chart, p. 375 , a partial similarity will be seen between the distribution of Proteaceæ and Cycadaceæ. Fossil forms of the latter order show that they were once widely distributed in the northern hemisphere. Well-grounded evidence for fossil Proteaceæ in the northern regions is wanting.

A distribution such as that of Proteaceæ, supports the belief that a former land connexion existed between South Africa and Australia. 


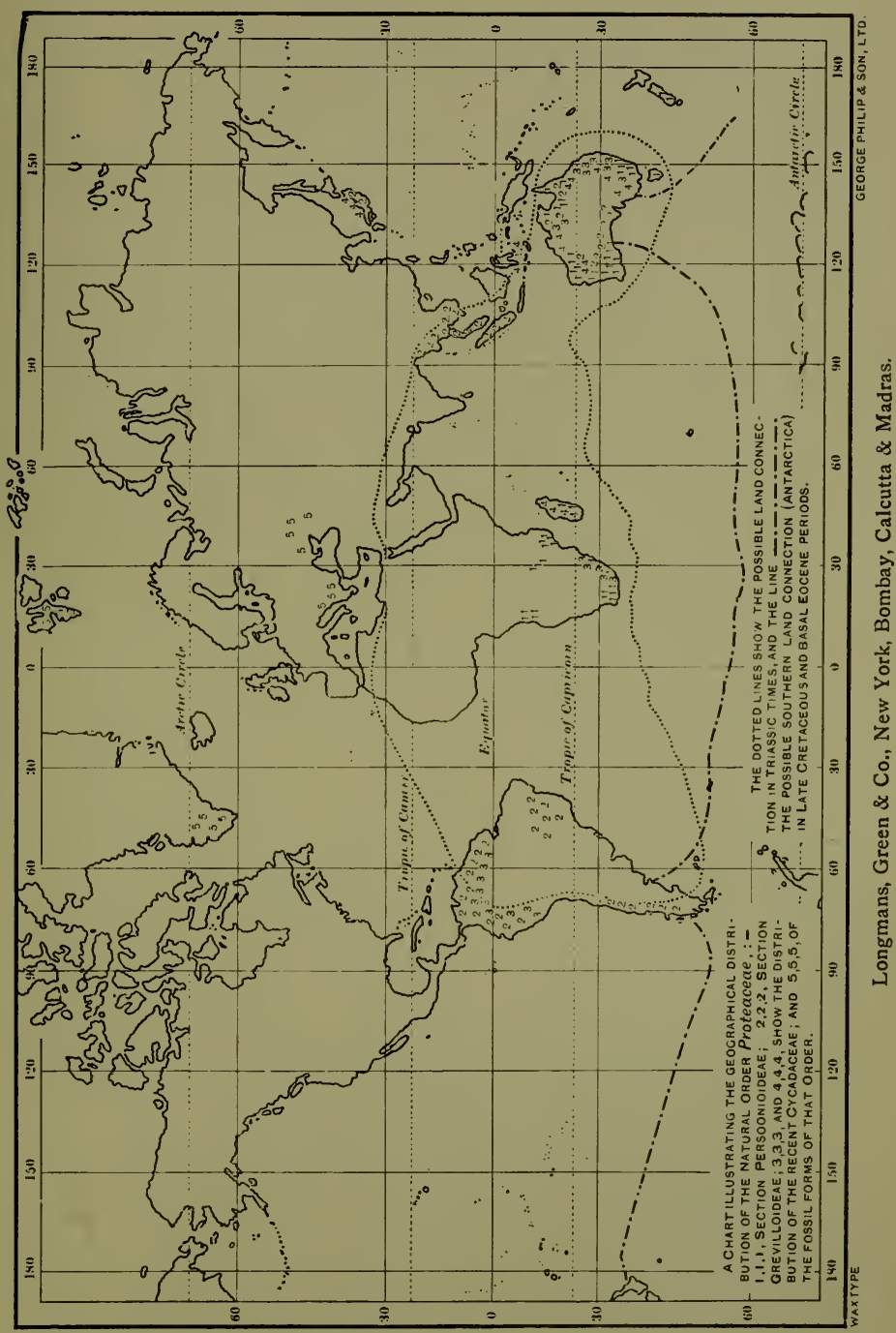

Index map of floral regions of South Africa, with approximate boundaries by $\mathrm{H}$. Bolus, rgo5.

(By the courtesy of Dr. H. Bolus.) 


\section{Plants and their Ways in South Africa}

That such a connexion existed until after the Antarctic glacial period in Permian times, is generally admitted by geologists. Types common to South Africa and to South America may have found their way to the latter country from Australia by a land connexion after that between South Africa and Australia had been severed. This supposition is strengthened by fossil land tortoises common to Australia and Patagonia and by the fossil remains in Patagonia of an animal which seems to have been identical with the present Tasmanian wolf. The discovery in recent times of a marsupial in South America belonging to a division (Diprodonts) hitherto known only in Australia may also tell of a long southern migration over this same land bridge, Antarctica, from Australia to South America. It is true that fossil marsupials are found in North America and Europe (division Polyprodonts), even earlier than any in South America. It may be that the northern division found their way south giving rise to the southern diprodonts, which then migrated to South America from Australia.

Amundsen and Scott in their expeditions to the South Pole secured interesting geological information bearing on this problem. The associations of rocks and the nature of the coal seams found in Antarctica serve to strengthen the view that the South Polar Regions are geologically a continuation of the Andes and of Tasmania and West Australia. However this may be, the similarity of the flora may be due in part to the plankton carried by ice-bergs and to the agency of winds. It is interesting to note in this connexion that Dr. Fritsch found the pollen of Podocarpus in material from the South Orkneys which he thinks must have been brought from South America, and Mr. Brown attributes to the agency of birds the presence of the Arctic mosses.

From geological evidence it is also thought that, after the land connexion between South Africa and Australia was severed, South Africa remained connected with India through Madagascar. (In Permo Carboniferous times, forming what is known as Gondwanaland.)

It is a much-disputed point as to whether there was a land bridge between South America and West Africa late enough, if at all, to account for an interchange of animals and plants between those two countries. How the South African Gloriosa (Liliaceæ) found its way to South America and the so-called Transvaal lily (Order Bromeliaceæ) found its place in Rhodesian mountains is as puzzling a question as to account for the Edentates and fresh-water / fish that are common to these two countries.

In the Eastern portion of South Africa the flora has gradually received forms from the southern migration of tropical plants while the southern forms were advancing north along the highlands. The northern forms have met the older flora of the south-western region and have partly driven them back. In the neighbourhood of Grahamstown, East London and Pondoland, signs of conflict between the old and the newer flora may be seen. Fossil forms show a meeting of the southern (Angiopteris) flora with the northern (Sigillaria) at Vereeniging. 
It is difficult in a small book for South African schools to give a satisfactory list of plants. A group of plants familiar in one district will be quite strange on the opposite side of a mountain range. The "South Easter" that parches one part of the country brings needed rains to another. Rainy winters of the Western Province produce a different flora from that of the dry winters and rainy summers of the East. Plants in a sandy soil will differ from those in a clayey soil. Dr. Bolus, in his "Sketch of the South African Flora," has given a vivid picture of the five botanical regions he has defined as follows:-

r. The South-Western Region is a strip from 40 to 80 miles wide, extending along the coast from near the mouth of Oliphant's River to the region of Port Elizabeth. It is bordered on the landward side by a range of mountains from 4000 to 8000 feet high. It is characterized by low-growing scattered shrubs, with small leaves of a sombre greyish-green, due to their waxy covering. Trees are chiefly confined to the seavard mountain slopes, and seldom exceed 50 feet in heigth. To the east, however, beautiful forests exist in this region. They are composed of Podocarpus (Yellow-wood), Ptaroxylon (Sneezewood), Grewia, Sideroxylon (Milkwood), Olives, and others, some of which furnish good timber.

Few flowers are found in summer except in the mountains. Disa uniflora can be found in January, and in March the flowers are at their best along the mountain streams of the Peninsula and about Wellington.

The Amaryllideæ have so much stored food that they need not wait for the rains, and Buphane and Brunsvigia fruits, chasing each other over the veld, remind us to be on guard. May is the beginning of the fall season. In a few weeks after the first rains the veld is aglow with Irideæ, Proteaceæ, Oxalis, Leguminosæ, and Ericaceæ.

2. South-Eastern Region.-From the Zitzikamma forests around the east coast, a broader strip of country than that on the south-east coast passes up to the Tropics. The vegetation changes. Trees are conspicuous with handsome green foliage. Palms and Encephalartos (Kaffir Bread) begin to appear, and the vegetation becomes tropical. Euphorbias and Aloes are typical; epiphytic orchids festoon the trees and tree ferns become more frequent.

3. The Karroo Region.-North of the South-West region, and extending somewhat farther east, there is a similarly curved region with the Nieuwveld mountains as a northern boundary. It is a large shallow basin surrounded by mountains. Violent rains have carried off the soil. Grazing flocks, by destroying vegetation and thereby loosening the soil, aid in the process, and year by year the rivers have carried away "the dust of continents yet to be". The climate is marked by dryness and extremes of heat and cold; the desert of the dry season becomes a garden after rain. Its plants are thorny and succulent, with underground storage systems. Acacia horrida (Karroo thorn), Portulacaria afra (Spekboom), Sarcocaulon (Candlebush), Testudinaria (Elephant's foot), serve as examples.

4. The Upper Karroo, or Region of Compositæ, a mountainous 
region lying north of the Karroo region, but not extending to the Orange River except at the extreme east and west, has a flora in some respects similar to that of the Lower Karroo region, but Composites abound, some of which furnish excellent food for stock.

5. The Kalahari Region is the name which Dr. Bolus gives to the large tract of land lying to the north of the Composite Region, west of the Natal Region and south of the Tropic of Capricorn. The western coast strip is a weird desert producing the curious Welwitschia on Istony ground among the sand dunes, and the Naras, or Acanthosicyos horrida. The latter is one of the Calabas family. It has roots as large as a man's arm and 50 feet or more in length. They push down until they find water below the sand of the desert. The rigid green stems have opposite thorns in the axils of reduced leaves. Growing in sandy places, the winds sweep over and often completely bury the stems. The stems push quickly up, and the sandhills are often built upon the plants, in the centre. A bitter juice protects all parts but the sweet juicy fruits, which are eaten by jackals and Hottentots.

To the east and north the region is largely a grass country. The tufts of grass grow to a great height. Between the months of November and February large tracts of grass look like fields of corn. Maize reaches a height of 8 to $\mathrm{r}_{3}$ feet, and it becomes necessary to cut down the stalks in order to get at the grain. 


\section{N D E X.}

ABUTILON, 330. Acacia, Ior, I13, II5, 3 II.

Acacia horrida, II5, 127, I42, 268, 312 .

Acanthacea, 220.

Achene, 175 .

Achlamydeous, 207, 209. Acidanthera, 267. Acmadenia, 323. Acokanthera, 346 . Aconitum, 297. Actinomorphic, 142. Adenandra, 323, 324. Adiantum, 230, 234. Aerial roots, 29. Estivation, 142. Agapanthus, 254, 257. Agathosma, 323, 324. Agave, 257.

Ageratum, 368 . Agrinonia, 3 ro. Aitonia, 321. Aizoacea, 203, 210, 293. Albizzia, 312.

Albuca, 185, 254, 257.

Algæ, 221.

Alkanet, 353.

Aloe, 254, 256.

Aloe ciliaris, 5 r.

Althea, 330.

Amanita, 224.

Amarantacea, 209.

Amaryllidacea, 205, 208, $257,26 \mathbf{r}$. Amaryllidea, 262. Amaryllis, 262, 264. Amentacea, 205, 28r. Amides, 67. Ammocharis, 262. Amphigena, 279.
Amphitropous, 132.

Anacampseros, II5, II7. Anacardiacea, 213. Anagallis, 137, 178 . Anatropous, 133 . Anchusa, 353 . Androcymbium, 255. Androcium, 140. Aneilema, 25I. Anemone, 297, 299. Angiospermae, 196, 202, 206, 220, 236, 243.

Angracum, 276 .

Annual, 25.

Annual rings, $3 \mathrm{I}$.

Annulus, 224.

Anoiganthus, 262.

Anonacea, 2 II.

Anther, 132.

Antheridia, 221, 226, 232. Antholyza, 166, 167, 169, $267,27 \mathrm{r}$.

Anthospermum, 363 .

Anthotaxy, I45.

Ants, I03.

Apocarpous, $\mathbf{1 3 4}_{34} \mathbf{1 7 8}$. A pocynacee, 204, $2 \mathrm{1} 8$, 346.

Apodolivion, 262.

Apogeotropic, 240.

Aponogeton, ro.

Aracea, 207.

Araliacea, 217.

Arancaria, 34 .

Arancariacea, 206.

Archegonia, 228, 232.

Archichlamydea, $\quad 3_{2}$, 199, 200, 209.

Arctopus, 34r.

Arctotis, 372 .

Aril, 174 .
Aristea, 266, 268.

Aristia, 266.

Aristotle, 195.

Arthrosolen, 337.

Arum, 157, 159.

Asclepiadacea, 204, 218, 348.

Asclepias, $164,186,348$, 349.

Aspalathus, 40, 313.

Asparagus, 42, 126, 254,

255.

Aspidium, I20, 233.

Assimilation, 92, 96 .

Aster, 368.

Asterea, 368 .

Athanasia, 370.

Audouinia, 308.

Aulax, 287.

Avena, 246, 247, 248 .

Avond-bloemetjes, 269 .

Axil of leaves, 25.

Azalea, $34^{2}$.

$B$ ABIANA, 267, 270.

Bacteria, 89, I0I, 223, 225.

Balanophoracea, 2 II.

Barberetta, 271 .

Barium hydroxide, 85 .

Bark, 3 I.

Barosma, 138, 139, 323 , 324.

Bartholina, 276.

Baryta-water, 85 .

Bast, 197.

Bauhin, 5 .

Baviaan's touw, I64.

Begoniacea, 2 r6.

Bentham, Ig8, 201, 202.

Berardia, 306, 308. 
Berry, I8I.

Berzelia, 308.

Betulacea, $28 \mathbf{r}$.

Bidens, 189 .

Biennial, 27.

Bignonia, 36 o.

Bignoniacea, 204, 219, 360.

Bisexual flowers, 135 .

Bixacece, 2II, 215.

Blade of leaves, 46 .

Blaria, 343.

Blastophaga glossorum, I83.

Blue gum, II2, I27, I28.

Bobartia, 266.

Boerboon, 3 ז3.

Bolus, Dr., 5, 126, 165, 275, 375, 377 .

Bolusiana, 5 .

Boraginacea, 204, 219, 352.

Botanical regions, 374 .

Bottle cell, 57.

Bowiea, II2, 254, 257.

Brabeium, 287, 288, 290.

Brachycarpea, 300 .

Brachysiphon, 334.

Bracts, I 49.

Brandblaren, 299.

Brassica, зог.

Briza maxima, 247.

Brunia, 306, 308.

Bruniacea, 215, 306.

Brunsvigia, 126, 189, $262,265$.

Bryophyllum, 123, 306.

Bryophyta, 220, 225.

Bryum, 232.

Bubon, 339, 340.

Buchu, 324.

Budding, I22.

Buds, 36 .

Bulb, 27.

Bulbine, 254, 257.

Bulbinella, 254, 257.

Buphane, 190, 262, 265.

Bupleurum, 53, 34I.

Burchellia, 362 .

Burmanniacea, 208.

Burr weed, I8g.

Burseracea, 2 r2.
CACTACEA, 216.

Cactus, 198 .

Cadaba, 302.

Caducous, I4I.

Casalpinea, 3 II, 312.

Calodendron, 323 .

Calyciflora, 201, 203.

Calyptrogen, 8r.

Calyx, I3I.

Cambium, 31, 74, 197.

Campanulacea, 204, 220, 363 .

Campylotropous, 133 .

Canna, 49.

Cape Edelweiss, 272.

Cape Flower, the, 37r.

Cape Lilac, 33.

Capitulum, I45.

Capok-bosch, $36 \mathrm{~g}$.

Capparidacea, 140, 202, 212, 301.

Capparis, 303.

Caprifig, 183 .

Capsella, 300.

Capsules, 177 .

Carbon dioxide, 85,95 ,

99

Carbonic acid gas, 92.

Carex, 244, 245.

Carissa, 346.

Carpels, I32.

Carpolyza, 262.

Carpophore, 339.

Carrot, 28, 79, 80, 34r.

Caryophyllacea, 202, 212, 294, 295.

Caryopsis, 176, 245.

Cassia, I16, 312 .

Cassytha, 98, 99.

Castanea, 285.

Casuarina, II 5 .

Cataphractes, 360 .

Catkin, 148.

Caudicle, 274.

Caustic potash, 86.

Celastiacea, 213.

Celastrinea, 203.

Celery, 34I.

Cells, $63,68$.

Cell sap, 64 .

Cell walls, 64 .

Cellulose, 65, 68.

Cerastium, 297.
Ceratandra, 276, 279.

Chalaza, r32.

Chenopodiacea, 209.

Chestnut, 285.

Chironia, 345 .

Chloral hydrate, 93 .

Chlorophyll, 94, 97, 99, 222.

Chloroplastids, 64,70 .

Choripetala, I4I, $34 \mathrm{I}$.

Christmas tree, $32 \mathrm{I}$.

Chromoplastids, 64,70 .

Chrysanthemums, I3I.

Chymococca, 337 .

Cilia, 226.

Citrus, 323.

Classification, 194 .

Clausena, 323 .

Cleanthe, 188, 266.

Cleistogamous, 168.

Clematis, 125, 126, 134,

135, 175, 297, 298.

Cliffortia, 155, 169, 3 1о.

Climbing plants, 124 .

Clivia, 262.

Club mosses, 229, 234 .

Cluytia, 328.

Cobalt chloride, 59 .

Coix, 247, 248.

Cola, 332.

Coleotrype, 251.

Combretacea, 217.

Combretum, 176 .

Commelina, 19, 20, 168, 25I, 252.

Commelinacea, 205, 209, $25 \mathrm{I}$.

Complete flowers, 134 .

Composita, 200, 203, 220, 366.

Compound leaf, 46 .

Cone, ${ }^{4} 8$.

Conifera, 238, $24 \mathrm{I}$.

Connaracea, 214 .

Connective, 138 .

Contorta, 34r.

Convolute æstivation, I 43 .

Convolvulacece, $2 \mathrm{rg}$.

Corchorus, 329.

Cork, 31 .

Corm, 27.

Cornacea, 217. 
Corolla, 132.

Cortex, $7 \mathrm{I}$.

Corycium, 276, 280.

Corymb, $\mathbf{1} 45$.

Corymbium, 367 .

Cotyledon, 3 о6.

Cotyledon reticulata, 108.

Cotyledons, 7.

Crassula, 106, 107, 108, I10, 134, 305.

Crassulacee, 203, 214, 305.

Crinum, 262.

Crocosma, 267.

Cross fertilized, 158.

Crotalaria, 3 I 3 .

Cruciferce, 202, 2II, 300.

Cryptadenia, 337.

Cryptogams, 196.

Cryptostemma, 16o.

Cucurbitacea, 220.

Cunonia, 130.

Curculigo, 262, 263.

Cuscuta, 98, 99.

Cutin, 65, 68, 288.

Cuttings, r2r.

Cyanella, 272.

Cyanotis, 251, 252.

Cyathea, 230.

Cycadacea, 206, 238.

Cycadales, 237.

Cyme, 146.

Cynancha, 348 .

Cynarea, 372.

Cyperacea, 205, 207, 243.

Cyperus, 245.

Cyphia, 124, 366.

Cypsella, I75.

Cyrtanthus, 262, 265.

Cystoliths, 67.

Cytinus, 292, 293.

Cytoplasm, 63,69 .

DAIS, 337.

Dalbergia, $3 \mathrm{II}$.

Darwin, $158,163,164$.

Datura, 132, 134, 353, 355.

Daucus, 79,80 , 149, $34 \mathrm{I}$.

Deciduous, $\mathrm{r} 4 \mathrm{I}$.

Decussate leaves, $5 \mathbf{I}$.

Defences of plants, ro3. Ensiform, i 12.
Delphinium, 297.

Dermatogen, $8 \mathrm{r}$.

Dianthus, 132, 296, 297.

Diascia, 356 .

Diastella, 288.

Diclinous flowers, 157 , 238.

Dicotyledons, 10, 196, 197, 202, 209.

Didynamous, 356 .

Dierama, 267.

Dilatris, 272.

Dimorphotheca, 37 I.

Diœcious, 238.

Dioscoriacea, 208.

Diosma, 323.

Diplopappus, 368.

Diplostemonous, r39.

Dipsacea, 203, 220.

Disa, 164, 275, 276, 278, 377.

Disciflora, 201, 203.

Disperis, 276, 279.

Dodonaa, 176.

Dombeya, 332.

Dovea, 249 .

Drosera, 102, 137, 304.

Droseracea, 202, 212 , 303.

Drupe, 180.

Duthie, Miss, 275.

EARTH Star, 225.

Ebenacea, 217.

Ebenales, 217.

Echium, 352.

Ecology, Ir7.

Ectoplasm, 69 .

Elatinacea, 214 .

Elegia, 249.

Elephantorhiza, $3 \mathbf{1 2 .}$

Elephant's foot, 377 .

Elytropappus, 370.

Embryo, 7, 234.

Encephalartos, 16, 237, 238, 239, 240.

Endocarp. I80.

Endodermis, $7 \mathbf{I}$.

Endonema, 334 .

Endoplasm, 69.

Endosperm, 8, 9, 197.

Engler, 199, 202, 206.
Entada, 312.

Enzymes, 68, 70.

Epicarp, 180.

Epidermis, 7I.

Epigynous, I4I, $20 \mathrm{r}$.

Epilobium, I85, 187 , 338.

47, Epipetalous, 139.

Epiphytes, 28.

Episepalous, 139 .

Equisetum, 229, 23 I.

Eremia, 343.

Erica, 194, 342.

Evicacea, 204, 218, 34I.

Eriocaulacea, 208.

Eriocephalus, 369.

Eriospermum, 254 .

Erodium, 189, 316, 317.

Erythrina, 315.

Essential organs, 135 .

Etærio, I75.

Eucalyptus, II2.

Eucomis, 254, 258.

Eulophia, 276.

Eumuraltia, 326.

Eupatoriea, 367.

Euphorbia, 176, 190, 198, 326.

Euphorbiacea, 205, 213, 326.

Euxyris, 253.

Everlastings, 37x.

Exstipulate, 46 .

$F_{A G A C E A E, 210,281,283 .}$

Faurea, 288, 290.

Fennel, 339.

Ferns, 229, 230.

Ferraria, 266.

Fertilization, I53, I59, 236.

Fibro-vascular bundles, $7 \mathrm{r}$.

Ficoidea, 203, 210, 293.

Fig, 182.

Filament, 132 .

Fir, 242.

Flagellaria, 126, I27.

Flagellariacea, 208.

Fleur-de-Lys, 267.

Flora Capensis, 192, 202,

279.

Floral clock, r65. 
Floscopa, $25 \mathrm{r}$.

Flowers, I3I.

Fly catcher, 164 .

Follicle, 177 .

Foreign immigration, 126.

Forget-me-not, 352.

Frankéniacea, 215.

Freesia, 267.

Freylinia, 357.

Frog spittle, 221.

Frond, 233 .

Fruit, definition, 174 .

Fruits, 174 .

Frutang, 268.

Fumariacea, $21 \mathrm{I}$.

Fungi, 98, 222.

Funicle, 132.

$G_{A L A X I A,} 266$.

Galaxiea, 266.

Galium, 363 .

Galls, 40 .

Galopina, 363 .

Gametophyte, 229, 235.

Gamopetalce, 203.

Gamopetalous, I4I.

Gamopetaly, 200.

Gamosepalous, I4 I.

Gardenia, 363 .

Gazania, 160, 372.

Geaster, 225.

Geele bloemetjes, 358 .

Geissoloma, 335 .

Geissolomacea, 215, 334 .

Geissorhiza, 266.

Gemmæ, 227.

Genera of South African

plants, 202.

Gentianacea, 204, 218, 345.

Genus, 194 .

Gevaniacea, 176, 203, 212, 316.

Geraniales, 212.

Geranium, 31ศ, 317.

Gerbera, 148 .

Germinate, 6 .

Germs, 2.

Gerrardanthus, 125 .

Gesneriacea, 219.

Gethyllis, 192, 262, 263.

Geum, 309.
Ginkgo, 237.

Ginkgoacea, 206.

Gladiolus, I7 I, 267, 270.

Gleichenia, 233.

Glischrocolla, 334 .

Gloriosa, 125, 255, 260.

Glumacea, 205.

Glumes, 149, 247.

Gnetacea, 206, 238, 243.

Gnetum, 243.

Gnidia, 337.

Gomphocarpus, 349.

Goodeniacea, 220.

Gossypitum, 330 .

Gratting, I22.

Graminacea, 206, 207, 245.

Grammanthes, 305.

Graphis, 4 .

Grappling plant, 189 .

Grasses, 245.

Grasshoppers, 3 .

Grenadilla, 125 .

Grevillea, 188, 287.

Grevilloidea, 287.

Grew, Nehemiah, 158 .

Grezeia, 329, 377.

Grielum, 3 1о.

Grisebachia, 343.

Groot Tulp, 268.

Growth curvatures, 20, 2 I.

Guttifera, 214.

Gymnosperma, 196, 206, $220,236,238$.

Gynandropsis, 139, 301.

Gynœcium, I40.

HABENARIA, 276, 280.

Hamanthus, 126, 262, 265.

Hamodoracea, 205, 208, $27 \mathrm{I}$.

Hakea, 188, 285, 287.

Halleria, 357.

Halophytes, 9I, I I I, 344 .

Haloragidacea, 217.

Hamamelidacea, 215.

Harpagophytum, 189.

Harveya, 99, 359 .

Hedyotis, 363 .

Helichrysum, $37 \mathbf{I}$.

Heliophila, 300.
Heliotrope, 353.

Helipterum, 370, 371.

Hemimeris, 356 .

Hemitelia, 230, 233.

Henslow, Rev. G., I7I.

Hermannia, 333 .

Hermaphrodite flowers, I 36.

Hermas, II I, 34I.

Herschelia, 279.

Hesperantha, 266, 269.

Hessea, 262.

Heterochlamydeous, 208, $2 \mathrm{II}$.

Hexagloltis, 266.

Hexastemon, 342 .

Hibiscus, 132, 134, 169, 330, 33I.

Hilum, 7,132 .

Holothrix, 276.

Homeria . 266, 268.

Homochlamydeous, 207.

Honey glands, $\mathrm{r}_{43}$.

Hoodia, 350.

Hooker, r98, 201, 202,

374.

Hook climbers, 126 .

Hottentot fig, I4I, 294.

Hybrids, 195 .

Hydnora, 99, 292.

Hydnoracea, 205, $2 \mathrm{II}$, 292.

Hydrocharitacea, 209.

Hydrocotyle, 340 .

Hydrogen, 90.

Hydrophylax, I Io, 363 .

Hydrophyllacea, 219.

Hymenophyllum, 233.

Hyobanche, 99, 358 .

Hyphæ, 98.

Hypodiscus, 249.

Hypogynous, I4I, $20 \mathrm{I}$.

Hypoxidice, 262.

Hypoxis, 178, 262, 263.

ILICACEAE, 213.

Imbricate æstivation,

I43.

Inperfect flowers, 135 .

Incompleta, 205.

Indian corn, 156.

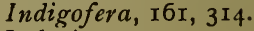

Indușium, 233. 
Inflorescence, 145 .

Insertion of flowers

Insolation, $\mathbf{1} 6$.

Internode, $\mathbf{x} 8$.

Inulin, 67, 92.

Involucre, I 49 .

Iodine, 92.

Iridacea , 205, 208, 265.

Irregular flowers, $\mathbf{1 4}_{42}$.

Ixia, 267, 269.

Ixiece, 266.

139.
265.
42.

ҰACARANDA, $36 \mathrm{r}$.

Job's Tears, 247, 248, 252.

Fuglanducea, $28 \mathrm{I}$.

Funcacea, 208, 249.

Fussieua, $33^{8}$.

KAEMPFERIA, 273.

Kaffir beer, 223.

Kalahari region, 378 .

Kalanchoe, $306 . \quad$ Ligule, 247

Lebeckia, 48.

Legume, I77.

Lycopodinea, 229, 234.

Leguminosa, 203, 214 , Lythracea, 2 I6. 3 Io.

Lemnacece, 207.

Lenticel, 33.

Lentibulariacea, 220.

Leonotis, $35 \mathrm{I}, 35^{2}$.

Lepidium, 300.

Leptocarpus, 249.

Leting, 223.

Leucadendron, I5.5, 185 , I86, I88, 286, 287, 288. 289 .

Leucoplastids, 64,70 .

MACOWANIANA, 5 .

Marua, 302.

Magnolia, 199.

Magnoliacece, 198.

Mahernia, 334 .

Maiden Hair, 230, 234.

Maizena, 92.

Malpighiacea, 2 13.

Malva, 330.

Malvacece, I76, 202, $2 \mathbf{I}_{4}$, I72, 287, 290, 29г. Manulea, $35^{8 .}$

Lichens, 4 , ror.

Lightfootia, 365 .

Lighting matches, r6r.

Lignin, 68.

Ligulate, 367 .

Ligule, 247.

Kalkoentjes, I4I, I42, Liguliflora, 373.

270.

Liliacea, 205, 208, 253.

Karroo region, I05, I Io, Limb, I 4 I.

377.

Karroo thorn, 312.

Kei apple, $4 \mathrm{I}$.

Kigelia, 204, 36r.

Kinoplasm, 69 .

Klattia, 266.

Kleinia, 121.

Klimop, 298.

Klis grass, $\mathbf{r} 89$.

Kniphopfia, 254, 256.

Knowltonia, 298, 299.

\section{Limnanthemum, 345 .}

Linacea, 212.

Linconia, 308.

Linnæus, I58, I65, I95, 25 I.

Liparis, 275.

Litmus paper, 58 .

Littonia, 255, 26r.

Liverworts, 225, 228.

Loasacea, 2 I6.

Lobelia, 364.

Kolbe, Dr., 5r, r 55, I7r. Lobostemon, 352.

Kukumakranka, I9I, Locules, r33. 263.

Loculicidal dehiscence, I78.

LABIATAE, 176, 204, 219 , 350.

Lachenalia, 254, 258.

Lachnea, 337.

Lagenaria, 125.

Lagenocarpus, 342 .

Lanaria, 272.

Lapeyrousia, 267.

Lauracea, 2 ro.

Laurus, 342.

Leaf scars, 37 .

Leaves, 45 .
Locusts, III.

Lodicules, 247.

Loganiacea, 218.

Lomaria, 233.

Lomentum, I78.

Lonchostoma, 308.

Loranthacea, 205, 2I I, $29 \mathrm{x}$.

Lovanthus, 99, 161, 162, 292.

Luffa, 125 .

Lycium, 354, 355 .
Marchantia, 226.

Marginal placentation, I37.

Marloth, Dr., II6, 29o, 294, 304.

Martyniacea, 2 I9.

Matjesgoed, 245.

Medicago, 189,3 Io, 3 I4.

Medulla, 72 .

Medullary rays, 72 .

Megaspores, 234 .

Melasphorula, 267.

Melastomacea, 2 г6.

Meliacea, 2 I3.

Melianthus, 322.

Mendel, r7o.

Menispermacea, $2 \mathrm{II}$.

Mentha, 351.

Meristem, 75 .

V. d. Merwe, Mr., $35^{8}$.

Mesembrianthemum, 9, rog, I ro, Ir6, I28, I4 I, I80, 293, 294.

Mesocarp, 180.

Metrosideros, 374 .

Micranthus, 267.

Microloma, I24, 125, 164 , 349.

Micropyle, 7, I96, 132.

Microsporangia, 138 .

Microspores, I32, I38, I96, 234, 236.

Migration of plants, 124 .

Milk bush, 164 .

Milkwood, 377 .

Mimetes, 287, 290. 
Mimosea, 3II.

Mistletoe, 99, roo.

Monadelphous, I 39 .

Monadenia, 279.

Monocotyledons, 10, 48 , 132, 196, I97, I98, 205, 207, 243 .

Monœrious, 238.

Monopetalous, r4I.

Monopetaly, 200.

Monsonia, 317 .

Montinia, I35, I53, I69, 339.

Moracee, 2 Iо.

Moraa, 266, 267.

Morcea, 266.

Mosses, 225, 227.

Motor zone, 20.

Moulds, 2, I0o, 222, 223.

Mucilage, 68.

Mucor, 223.

Mundtia, 325, 326 .

Muraltia, 325, 326 .

Musa, 274.

Musacea, 205, 208, 272.

Mushrooms, IOO, 224 .

Mycelium, 222, 225.

Mycorhiza, 222, 342.

Myosotis, 352.

Myrica, 128, 283.

Myricacea, 209, 283.

Myrsinacea, $2 \mathrm{I} 8$.

Myrtacea, 2 I6.

Myrtiflora, 216.

Mystacidium, 276, 278.

NAIADACEE, 207.

Nematopus, 253.

Nemesia, 356.

Nerine, 262, 264.

Nerium, 346.

Nicotiana, 355.

Niebuhria, 302.

Nigella, 297.

Nitrogen, IOI, 222.

Nivenia, 288, 290.

Node, 18 .

Nucellus, 132.

Nucleus, 63,69, r 59 .

Nyctaginacea, 2 ro.

Nycterinia, 357.

Nymphaacea, 2 ז.
OAks, growth of, 36, r28. Parsnips, 341.

Obdiplostemonous, I39.

Ochnacea, 213.

Enothera, 338.

Enotheracea, 203.

Olacacea, 213.

Oleacece, 219.

Oleander, 346.

Onagracea, 216, 337 .

Onagrariea, 203.

Onion, II 2.

Oogonia, 22r.

Opuntia, 326.

Orchidacea, 205, 208, 209, 274.

Orders, 194 .

Ornithogalum, 134, 254, 258.

Orobanchacea, 219.

Orothamnus, 288.

Orphium, 345.

Orthopenthea, 279.

Orthotropous, 132 .

Osmosis, 30.

Osmunda, 232.

Osteospermum, I75, 37I.

Othonna, 37I.

Outer bark, 32.

Ovary, 132, 134, 196.

Ovules, I32.

28I, Oxalidacea, 203, 212, 320.

Oxalis, Ir9, I59, I6o, I68, I90, 320.

Oxygen, $83,84,85,90$.

PACHYCARPUS, $35^{\circ}$.

Pachypodium, 204, 347 .

Painted Ladies, 270.

Palea, I49, 247.

Palma, 207, 208.

Palmate venation, 47 .

Palmiet, 249.

Panicle, I45.

Papaveracea, 2 II.

Papilionaceæ, 3I I, 3 I 3.

Pappe, Dr., 268.

Pappus, I88, 366.

Paranomus, 290.

Parasites, 98, 222.

Parastranthus, 365 .

Parenchyma, 65 .

Parietales, 215.
Passerina, 337.

Passifloracea, 215.

Patrijsjes, I4r, I42.

Pauridia, 262, 263.

Pavonia, 330.

Peddiea, 337.

Pelargonium, 188,318 .

Pellia, 227, 228, 230.

Pencea, 334.

Penceacea, 215, 334.

Penicillium, 222.

Perceptive zone, 20.

Perennial, 27.

Perfect flowers, 135 .

Perianth, 132.

Periblem, $8 \mathrm{I}$.

Pericycle, 74 .

Peridium, 225.

Perigynous, I40, 201.

Perisperm, ro.

Periwinkle, 346 .

Persistent, I4I.

Persoonioidea, 287.

Petaloidea, 205.

Petiole, 40.

Phanerogama, 196, 202.

Philippia, 194, I95.

Phloem, 72.

Phosphoric acid, 84 .

Phosphorus, 84 .

Phragmites, 248.

Phylloclades, 42 .

Phyllodes, II 4.

Phyllotaxy, 50, 5I, I45.

Phytolaccacea, 209, 294.

Physalis, 354, 355 .

Pileus, 225.

Pine seedling, 43 .

Pinnate venation, 47 .

Pinus pinaster, 242.

Pinus pinea, 235, 236, 242.

Pinus sylvestris, 137.

Piperacea, 209.

Pistil, 132, 136.

Pistillate flowers, I35 .

Pittosporacea, 2I4.

Placenta, I37, I75.

Placentation, 137 .

Plantaginacea, 2 rg.

Plastids, 64 .

Pleiostemonous, I39. 
Plerome, 8r.

Plumbago, 344 .

Plumbaginacea, 218, 343 .

Plumule, 7 .

Podalyria, 3 ז 3 .

Podocarpus, IOI, 24I, QUERCUS, 284, 285. 242, 377 .

Podostemacea, 214 .

Pods, 177.

Poinsettia, 328.

Pollen, I32, I58, I96, 236.

Pollination, 153 .

Pollinia, $164,274$.

Polygala, 325 .

Polygalacea, 202, 213, 324.

Polygonacea, 2 ro.

Polypetala, 202.

Polypetalous, I4r.

Polysepalous, I4r.

Polystachya, 275, 277.

Pome, I82.

Pomegranate, $4 \mathrm{I}$.

Pontederiacea, 208.

Poplars, 283 .

Populus, 283.

Portulacacea, 2 ro.

Portulacaria, 137, I76.

Prepotency, I59.

Primulacea, 218.

Primulales, 217.

Printzia, 373.

Prionum palmita, 249.

Pronuba moth, 165.

Prophyll, 197.

Prosenchyma, 65.

Protea, 134, I63, I75, I88, 284, 285, 287, 288.

Proteacea, 205, 210, 285 .

Proteids, 63, 67 .

Prothallia, 230.

Protophloem, 76 .

Protoplasm, 57, 58, 63 .

Protoxylem, 66.

Psalliota campestris, 224.

Psilocladus, 326.

Psoralea, 313 .

Ptcroxylon, 322, 377.

Pteridophyta, 220, 229.

Pteris, 233.
Pteris aquilina, 233.

Pterygodium, 92,275 , 276, 279.

Puff balls, 225 .

Pyrogallic acid, 86.

RACEME, I 45 .

Radicle, 7 .

Rafflesiacea, 292.

Raphe, I33.

Ranales, $2 \mathrm{II}$.

Ranunculacea, 198, 202, 210, 2 II, 297.

Ranunculus, 298, 300.

Receptacle, 137 .

Red rust, 98.

Regular flowers, I42.

Replum, r77, 30r.

Reproduction, methods of, II 9.

Resedacea, $2 \mathrm{rr}$.

Respiration, 83, 96.

Restiacea, I24, I55, 205, 208, 248.

Restio, 249, 250.

Retzia, 353, 355.

Rhamnacea, 213.

Rhenoster bush, 37x.

Rhigozum, 360.

Rhipsalis, 326 .

Rhizoids, 226, 230.

Rhizomes, 27, 120.

Rhizophoracea, 216.

Rhododendron, 342.

Rhoeadales, $2 \mathrm{II}$.

Rhus, 33.

Rice, 247.

Ricinus communis, 328.

Riocreuxia, 350.

Rochea, 305.

Roella, 14I, I58, I59, 365 .

Romulea, 266, 268.

Rooedblad, 176 .

Root cap, 30, 80.

Root hairs, I7, 29, 57 .

Root structure, 78 .

Roridula, 304.

Rosacea, 203, 214, 216, 308.

Rosales, 214.
Rostellum, 275.

Rotate, I4I.

Rubiacea, 204, 220, 36r.

Rubus, 309.

Rusts, 98, 223.

Rutacea, 203, 212, 323.

SACCHAROMYLES, 222.

Sage, I63, 35I.

Salicacea, 209, 28r, 282.

Salix, 283.

Salvadoracea, 218.

Salvia, 163, 35 .

Samara, 176.

Sandersonia, 255, 258, 260.

Sansevieria, 272.

Sap, 30.

Sapindacea, 203, 213, 321.

Sapindales, 213.

Sapindus, 322.

Sapotacea, 217.

Saprophytes, 98, гоo, 222.

Sarcocaulon, 3I 7 .

Sarcocolla, 334.

Sarcophyte, 99, 100.

Sarcostemma, 350.

Satyridium, 278.

Satyrium, Iro III, $\mathrm{I6}_{4}$, $276,277$.

Saxifragacea, 214.

Scape, I45.

Schepperia, 303 .

Schitaminea, 272.

Schizea pectinata, 232.

Schizocarp, I76.

Schizodium, 276, 279.

Schizostylis, 266.

Schotia, 313.

Scrophulariacea, 204, 219, 355.

Seaweeds, 221.

Sebæa, 345.

Secamone, 164, 349 .

Securidaca, 325 .

Seed, 6, I74.

Seed-bearing plants, 235 .

Seeds, distribution of, 185.

Selaginella, 234.

Senecio, 107, I6r, 37x. 
Senecionidea, 368.

Sepal, I3r.

Septicidal dehiscence, I78.

Serruria, 285, 287, 29o,

Sessile, 46 , I 45 .

Setaria, 189 .

Shrub, 29.

Sida, 330.

Sideroxylon, 377.

Silene, 295, 296.

Silicula, r77.

Siliqua, I77.

Silver tree, 103, 104, 135 , I 55, 288, 289 .

Sisyrinchia, 266.

Smilax, 254, 255.

Sneezewood, 322 .

Soil, 88.

Solanacea, 204, 219, 353.

Solanum, 354, 355 .

Sonchus, 373.

Sorocephalus, 288.

Sorus, 230.

Spadix, $\mathrm{I}_{4} 8$.

Sparaxis, 267.

Sparmannia, j29.

Spatalia, 288.

Spathe, 149.

Spawn, 224.

Species, 194.

Spekboom, 137, 176 .

Spergula, 297.

Spermaphyta, 196, 206, 235.

Spermatozoids, 22 I.

Sperm-cells, 226.

Spharalcea, 330.

Sphenogyne, 368.

Spike, 145.

Spirocyclic, I99.

Sporangium, I23, 227.

Spores, 222, 224, 230.

Sporogonium, 227.

Sporophyte, 229, 230, 235.

Sprengel, $\mathrm{x} 58$.

Staavia, 307, 308 .

Stachys, 352.

Stamens, 132, 138 .

Staminate flowers, 135 .

Staminodia, I39, $_{5}$ I. Stangeria, 238, 239, 240. Thalamus, 139.
Stapelia, r68, I86, 350.

Starch, 66, 92, 93 .

Statice, 344 .

Stele, $7 \mathrm{r}$.

Stellaria, 297.

Stem structure, $7 \mathrm{I}$.

Stem twiners, 124 .

Sterculea, 332.

Sterculiacea, 202, 214, 332.

Stigma, I33, r34.

Stipules, 46.

Stomata, 6r.

Strelitzia, 273.

Streptanthera, 267.

Streptocarpus, 189 .

Strophanthus, 346 .

Strumaria, 262.

Struthiola, 336, 337.

Stylapterus, 334 .

Style, r33, r34.

Suber, 68.

Sugar, 67, 92, 94, 246.

Sugar-bird, I7 7 , 172 .

Sugar-bush, I05, I06, 288.

Sundew, ro2.

Sutera, 357.

Sutherlandia, 3Io, 3 I 4 .

Symbionts, IOI, 222.

Sympetala, I32, I4 I, 200, 217.

Sympetaly, 200.

Synandrous, 139 .

Syncarpous, I34, I78.

Syngenesious, 139.

Synnotia, 267.

Synopsis of Orders, 202.

Syringoidea, 266.

TAMARICACE E, 215

Tannin, 32, 68, 70 .

Taxacea, 206.

Tecomaria, I4I, I72, 360.

Tendrils, 125.

Termites, I03.

Ternetz, Miss, 222, 342 .

Testudinaria, 377 .

Tetradynamous, 300.

Tetragonia, 293, 294-5.

T'gaukum, 9, 128 .

Thalamiflora, 201, 202.
Thalictrum, 297, 298.

Thallophyta, 220, 221.

Thallus, 226.

Thamnea, 306, 308 .

Thamnochortus, 249.

Theobroma, 332.

Thymelacea, 205, 215, 336.

Thymelaales, 215 .

Tiliacea, 202, 214, 328 .

Tittmannia, 308.

Toddalia, 323 .

Tondelboom -blaren), II2, 34I.

Tracheæ, 66.

Tradiscantia, 252.

Translator, 348 .

Transpiration, 30 .

Traveller's Joy, $134, \mathrm{I} 88$, 298.

Tree, 29.

Triaspis, 176.

Tricholana, 248.

Trichomanes, 233.

Trifolium, 3 I 4 .

Tripteris, 176, 37x.

Triumfetta, 329 .

Tritonia, 267, 270.

Tropæolum, 60.

Tuber, 27.

Tubiflora, 34r.

Tulbaghia, 254 .

Tunics, 27.

Turneracea, 2 I 5 .

Typha, 243, 244.

Typhacea, 207, 243.

UMBEL, I45.

Umbellifera, $\mathrm{176}, 203$, 217, 339.

Urospermum, 187,189 , 373.

Ursinia, 369.

Urticacea, 2 ro.

Utricularia, I02.

U-tube, 60 .

VALERIANACE E, 220.

Vallota, 262, 265 .

Valvate æstivation, I43.

Vascular bundles, 30 .

Vaucheria, $22 \mathrm{I}$.

Vellozia, 263. 
Velloziea, 263.

Venation, 46 .

Verbenacea, 219.

Vernonia, 367.

Vernoniea, 367 .

Villarsia, 345 .

Vinca, 346.

Violacece, 2 I5.

Viooltje, 258.

Virgilia, $3 \mathbf{1} 3$.

Viscum minimum, 189 , 292.

Vitacea, 213.

WACHENDORFIA, 27I, 272.

Wahlen bergia, 178,365 .

Walleria, 255.

Wallflower, 179 .
Water pressure, $5^{8}$.

Water uintjes, ro.

Waterways, 57 .

Watsonia, 267, 270.

Welwitschia, 243.

Werner, 34I.

Whorl, r3r.

Widdringtonia, 242.

Wiegand, Dr., 288.

Willow whistles, $3 \mathrm{I}$.

Window leaves, r r6, rr8.

Witsenia, 266.

Wonderboom, 5 .

Wool spider, 189 .

Wurmbea, 255.

X ANTHIUM, $\mathrm{r} 8 \mathrm{~g}$.

Xerophytic, IrI, 240.

Xylem, 7r.
$X_{y}$ vidacea $, 209,253$.

Xyris, 253.

YEAST, 3, 100, 222.

Yeast plant, Ir 5 .

Yellow wood, ror, 24r, 242.

Yucca, 165.

$Z_{A L U Z I A N S K Y A,} 357$.

Zantedeschia, 157 .

Zanthoxylon, 323, 324.

Zea mais, 9, 156, 246.

Zitzikamma forests, 377 .

Zonal development, r9g.

Zygia, $3 \mathbf{1 2 .}$

Zygomorphic, $\mathrm{r}_{42}$.

Zygomorphy, 200.

Zygophyllacea, 212. 



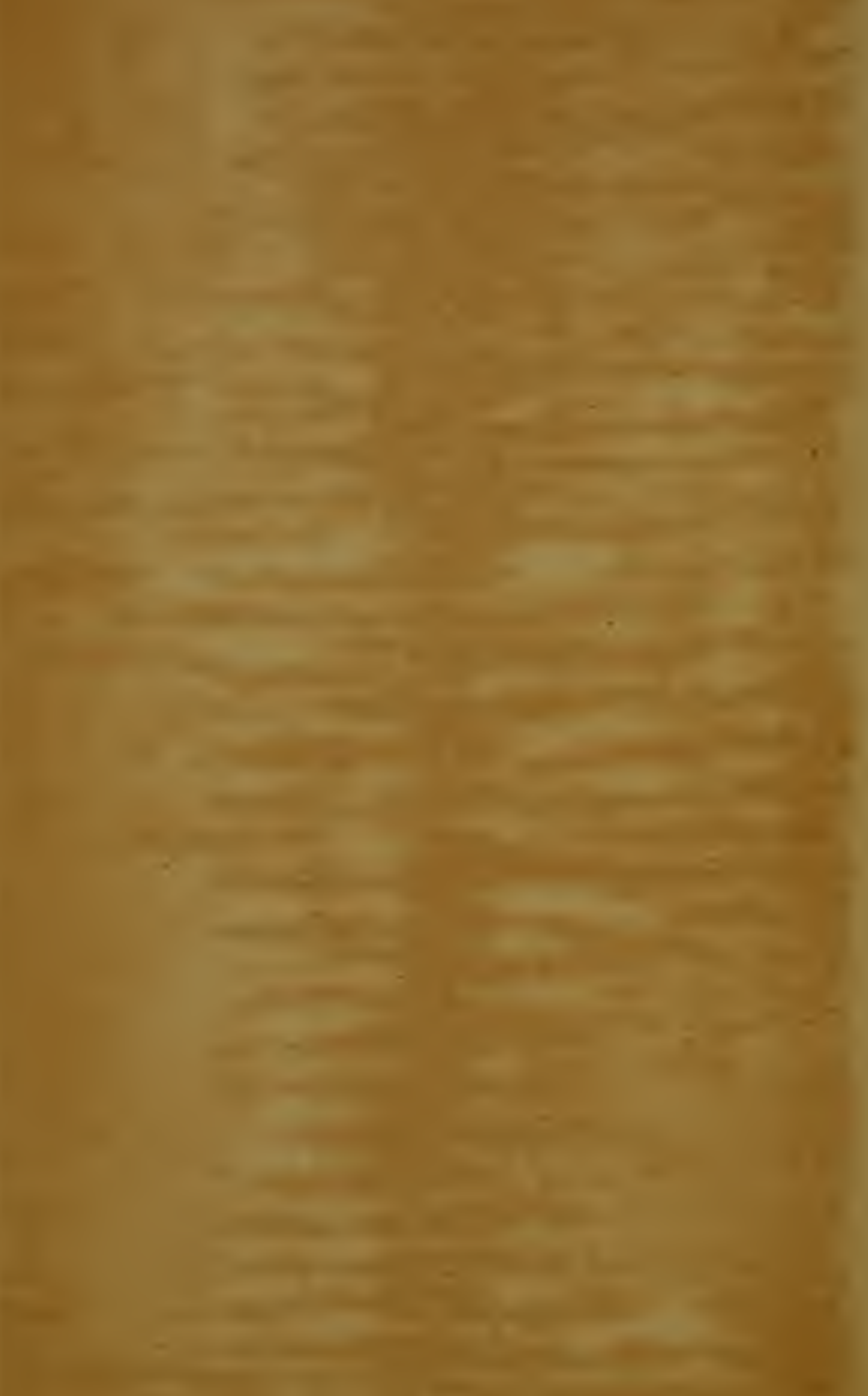


\section{OK 403 \\ QK 403.5751915}

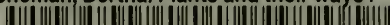

||||||||||||||||||||||||||||||||||||||||||||||||||||||||||

35185000624898 
